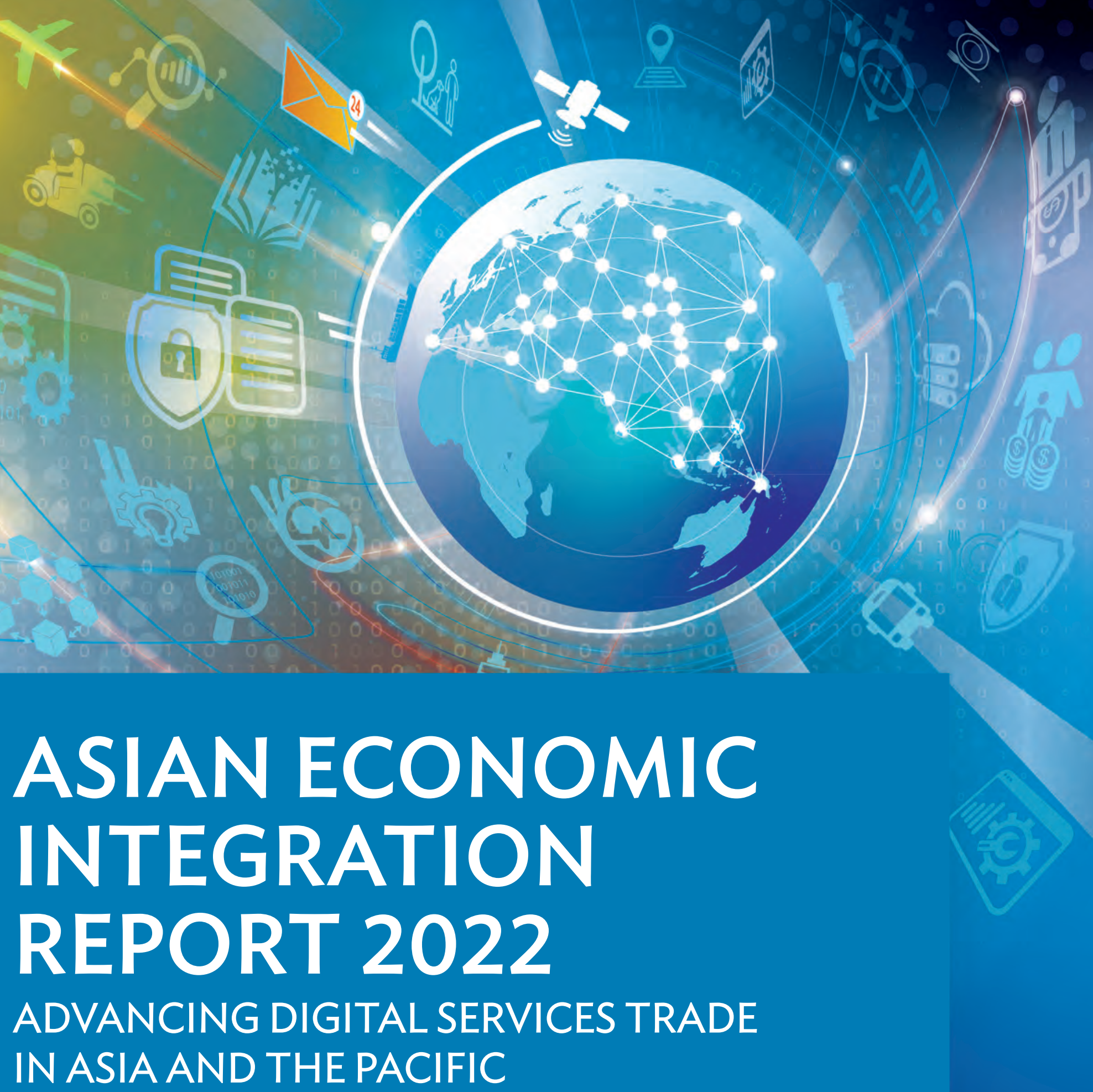

\title{
FEBRUARY 2022
}



ASIAN ECONOMIC INTEGRATION REPORT 2022 ADVANCING DIGITAL SERVICES TRADE IN ASIA AND THE PACIFIC

FEBRUARY 2022 
(C) 2022 Asian Development Bank 6 ADB Avenue, Mandaluyong City, 1550 Metro Manila, Philippines

Tel +632 8632 4444; Fax +63286362444

www.adb.org

Some rights reserved. Published in 2022.

ISBN 978-92-9269-361-9 (print); 978-92-9269-362-6 (electronic); 978-92-9269-363-3 (ebook)

Publication Stock No. TCS220041-2

DOI: http://dx.doi.org/10.22617/TCS220041-2

The views expressed in this publication are those of the authors and do not necessarily reflect the views and policies of the Asian Development Bank (ADB) or its Board of Governors or the governments they represent.

ADB does not guarantee the accuracy of the data included in this publication and accepts no responsibility for any consequence of their use. The mention of specific companies or products of manufacturers does not imply that they are endorsed or recommended by ADB in preference to others of a similar nature that are not mentioned.

By making any designation of or reference to a particular territory or geographic area, or by using the term "country" in this document, $A D B$ does not intend to make any judgments as to the legal or other status of any territory or area.

This work is available under the Creative Commons Attribution 3.0 IGO license (CC BY 3.0 IGO)

https://creativecommons.org/licenses/by/3.0/igo/. By using the content of this publication, you agree to be bound by the terms of this license. For attribution, translations, adaptations, and permissions, please read the provisions and terms of use at https://www.adb.org/terms-use\#openaccess.

This CC license does not apply to non-ADB copyright materials in this publication. If the material is attributed to another source, please contact the copyright owner or publisher of that source for permission to reproduce it. $\mathrm{ADB}$ cannot be held liable for any claims that arise as a result of your use of the material.

Please contact pubsmarketing@adb.org if you have questions or comments with respect to content, or if you wish to obtain copyright permission for your intended use that does not fall within these terms, or for permission to use the ADB logo.

Corrigenda to ADB publications may be found at http://www.adb.org/publications/corrigenda.

Notes:

In this publication, “\$” refers to United States dollars, unless otherwise stated.

ADB recognizes "Brunei" as Brunei Darussalam, "China" as the People's Republic of China, "Korea" and "South Korea" as the Republic of Korea, "Vietnam" as Viet Nam, and "Russia" as the Russian Federation.

On the cover: Fast-paced digitalization has been spurring the growth of services trade in recent years, with the COVID-19 pandemic accelerating this process. Digitally deliverable services are growing in importance, underscoring the need for enabling policies and regulations, especially in Asia and the Pacific.

Cover design by Erickson Mercado.

All masthead photos are from ADB. 


\section{CONTENTS}

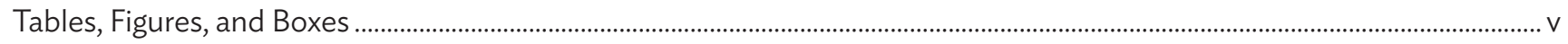

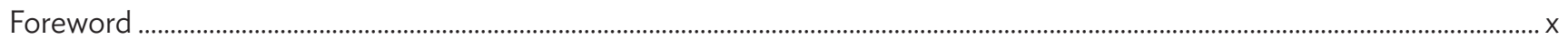

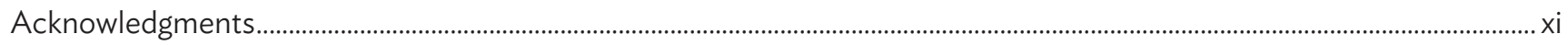

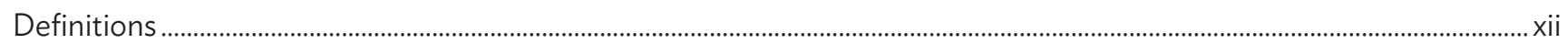

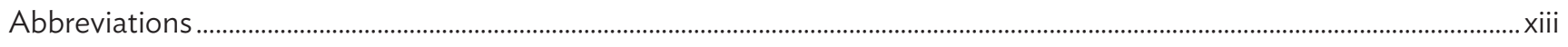

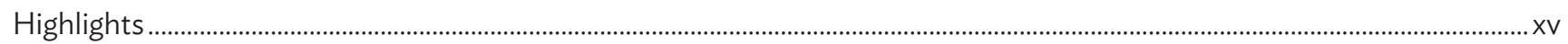

1. FRAGILE, UNEVEN RECOVERY AMID THE PANDEMIC

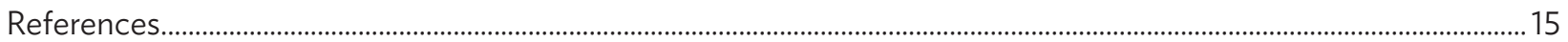

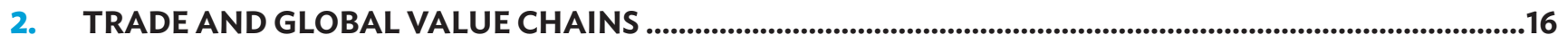

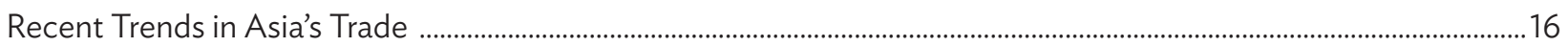

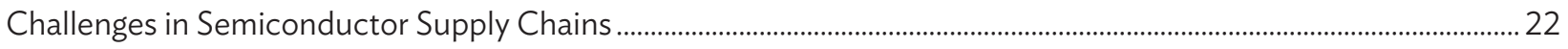

Progress of Global and Regional Value Chains .................................................................................................................................28

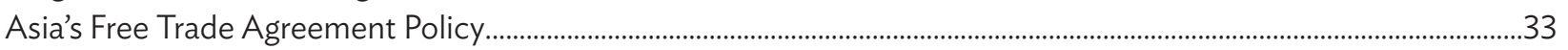

Way Forward for RCEP Implementation of Market Access Provisions.................................................................................... 36

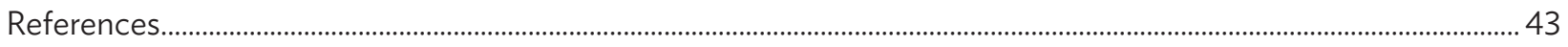

Annex 2a: Intraregional and Extraregional Trade Values Annual Growth Rate by Region ............................................. 45

Annex 2b: Analytical Framework of GVC and RVC........................................................................................................ 46

Annex 2c: Economy and Sectoral Coverage of the ADB Multi-Regional Input-Output Tables ................................... 47

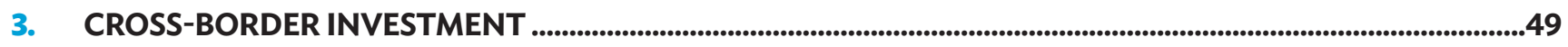

Recent Trends in Foreign Direct Investment ................................................................................................................ 49

Special Topic: Foreign Direct Investment in Digital Services .............................................................................................57

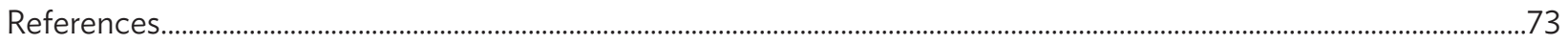

Annex 3a: Notes on Data Sources and Compilation ...........................................................................................................75

Annex 3b: Global Quarterly Inward FDI, by Mode of Entry ....................................................................................................76

Annex 3c: Most Affected Asian Destinations of Changes in FDI-Greenfield and M\&A, by Sector............................77

Annex 3d: Global Quarterly Outward FDI by Mode of Entry ................................................................................................. 78

Annex 3e: List of OECD Services Sectors Identified as Digitally Deliverable.................................................................... 79

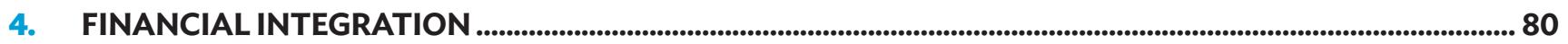

Recent Trends in Asia's Cross-Border Financial Assets and Liabilities ....................................................................... 88

Evolving Patterns of Capital Flows in Asia and the Pacific ............................................................................................. 92

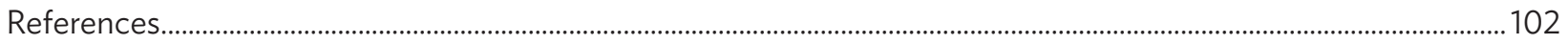

Annex 4a: Sectoral and Subregional Decomposition of Capital Flows ........................................................................106

Annex 4b: Identifying Capital Flow Surges and Stops ......................................................................................................... 108 


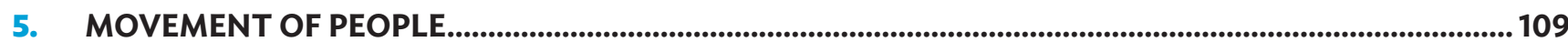

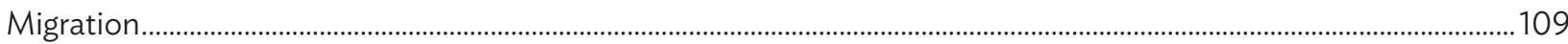

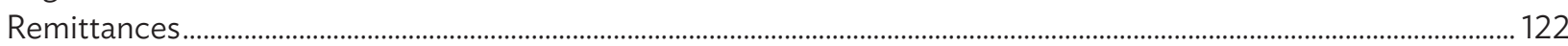

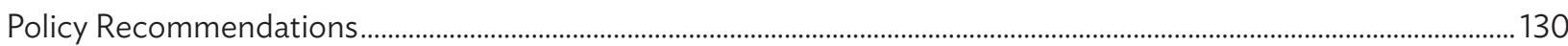

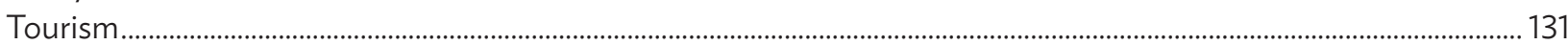

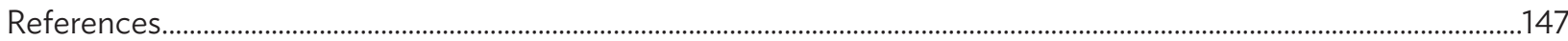

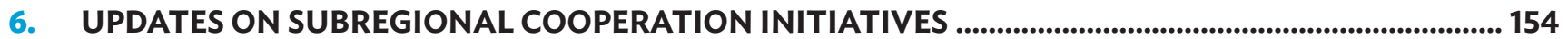

Central and West Asia: Central Asia Regional Economic Cooperation Program ................................................................. 154

Southeast Asia: Greater Mekong Subregion Program ............................................................................................................160

East Asia: Enhancing Regional Public Goods through Policy Dialogues under the CAREC ..........................................166

and GMS Subregional Programs and Knowledge-Sharing Initiatives

South Asia: South Asia Subregional Economic Cooperation ................................................................................................... 170

The Pacific: Leveraging Regional Reach for Broader COVID-19 Vaccine Coverage ......................................................174

Subregional Responses to COVID-19 and ADB's Support................................................................................................177

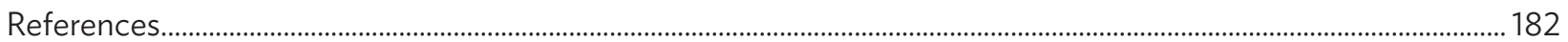

7. THEME CHAPTER: ADVANCING DIGITAL SERVICES TRADE IN ASIA AND THE PACIFIC .................. 184

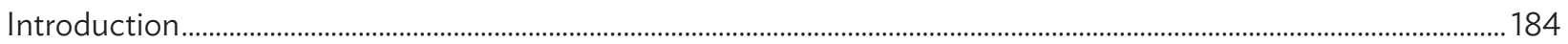

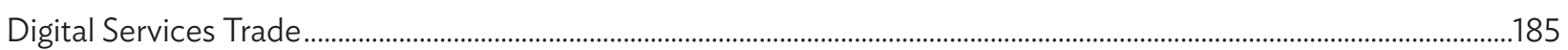

Digital Services Trade: Drivers and Impact ........................................................................................................................... 205

Economic Impact of Trade Liberalization and Deregulation ......................................................................................... 211

Trade Rules, Regulations, and Regional Cooperation ............................................................................................................225

Cybersecurity: Ensuring Safety of Digital Services Trade Transactions .................................................................................234

Digital Services Trade and Taxation .....................................................................................................................................238

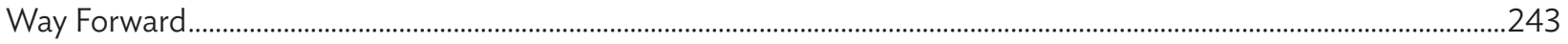

Background Papers ………………………………………………………………………………………………………... 250

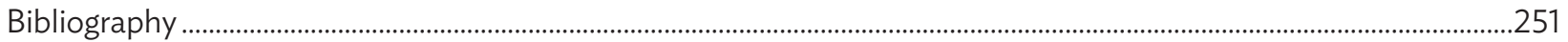

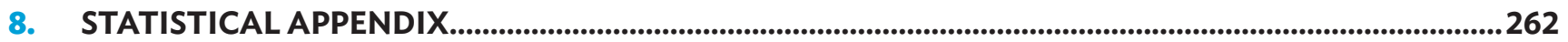

Regional Groupings.............................................................................................................................................................2.

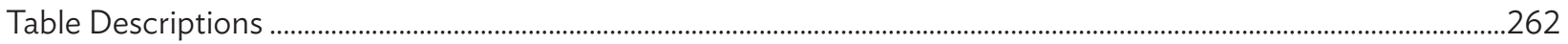




\section{TABLES, FIGURES, AND BOXES}

\section{TABLES}

1.1 Subregional Cooperation in Areas of Economic Management and Trade in Response to COVID-19 12

1.2 ASEAN, ASEAN+3 Health Cooperation Mechanisms for Epidemic Preparedness, 2003-2020 13

2.1 Recent Regional Trade Agreements in Asia and the Pacific 35

2.2 Comparison of Restrictiveness of Product-Specific Rules of Origin 39

3.1 Top 10 Destinations of Foreign Direct Investment-World and Asia and the Pacific 50

3.2 Average Project and Deal Size by Sector-Asia and the Pacific 52

3.3 Most Affected Asian Destinations of Changes in Total FDI 53

3.4 Top 10 Sources of Foreign Direct Investment-World and Asia and the Pacific 56

3.5 Bridge Table for EBOPS 2010 and ISIC Revision $4 \quad 59$

3.6 Digitally Deliverable Services-ISIC Revision 4, EBOPS 2010, NAICS 201760

3.7 Investment Policy Frameworks for Enhancing Digital Services FDI 72

5.1 Migrant Flows from Bangladesh, India, and Pakistan 115

5.2 Top 10 Economies Hosting Asian Migrants and COVID-19 Cases 118

5.3 Remittance Inflows by Recipient Region, 2020 and 2021

5.4 Remittance Inflows to Asian Subregions, 2020 and 2021

5.5 International Tourist Arrivals and Tourism Receipts in Asia and the Pacific by Subregion 134

5.6 Domestic Tourism in Selected Asian Economies 137

5.7 Key Responses to Revive Tourism in Selected Asian Economies 139

6.1 Selected Economic Indicators, 2020-CAREC 155

6.2 Selected Economic Indicators, 2020-Greater Mekong Subregion 161

6.3 Selected Economic Indicators, 2020-SASEC 171

7.1 Digitally Deliverable Services 188

7.2 Shares of Digitally Deliverable Services Trade, 2019

7.3 Counterfactual Changes in Total Intra-Asian Exports, by Sector 218

7.4 Counterfactual Changes in Real Income by Economy 220

7.5 Categories of Digital Trade Provisions in Trade Agreements 230

7.6 Recent Digital Services Tax Measures in Selected Asian Economies 240

\section{FIGURES}

1.1 COVID-19-Vaccinated People, by Region 1

1.2 COVID-19-Vaccinated People, by Subregion in Asia and the Pacific 1

1.3 COVID-19-Daily Vaccinations per Million People 2

1.4 Merchandise Trade Growth-Selected Asia and Pacific Economies 3

1.5 Inward Foreign Direct Investment-Selected Asia and Pacific Economies 3

1.6 Nonresident Portfolio Inflows-Selected Asia and Pacific Economies 4

1.7 Monthly Remittances Growth-January-October 2021

1.8 Trade in Services for Selected Asia and Pacific Economies $\quad 5$

1.9 International Tourist Arrivals $\quad 5$

$\begin{array}{ll}1.10 & \text { Output Difference and Vaccination }\end{array}$ 
1.11 Overall ARCII and Dimensional Index-Asia and the Pacific

1.12 Dimensional Indexes-Asia and the Pacific versus Other Regions, 2019

1.13 Dimensional Indexes by Subregions in Asia and the Pacific, $2019 \quad 8$

1.14 Difference between CPTPP and RCEP, 2020

1.15 Regional Trade 11

1.16 Intraregional Trade Intensity Index 11

1.17 Intraregional Investment-Greenfield FDI and M\&As 11

2.1 Monthly Merchandise Trade by Value and Volume-Asia and the Pacific 16

2.2 Monthly Trade Volume Growth-NIEs, the PRC, and Selected ASEAN Economies 17

2.3 Global Business Confidence versus Trade Volume Growth of Asia and the Pacific 18

2.4 Global Trade-Weekly Indicators 18

2.5 Intraregional Trade Shares by Region $\quad 20$

2.6 Regional Trade Partners Share-Asia-to-Asia and Asia-to-Other Economies 21

2.7 Intraregional Trade Shares by Asian Subregions 21

2.8 Share of Exports/Imports for Industries Spending at Least 1\% of Value-Added Production 22 on Semiconductor Chips

2.9 Global Semiconductor Demand by End-Use 23

2.10 World's Top Gaining/Losing Exports that Use Semiconductor Chips, 2020

2.11 Foundry Market Share Tree Map, 2020

2.12 Regional Breakdown of Semiconductor Value Chain Production, $2019 \quad 27$

2.13 GVC and RVC Participation Rates $\quad 28$

2.14 Asia's GVC and RVC Participation Rate 29

2.15 RVC-GVC Intensity by Region 29

2.16 RVC-GVC Intensity, by Major Sector-Asia and the Pacific 30

2.17 Overall RVC and GVC Participation-Selected Asia and Pacific Economies 33

2.18 Complex RVC and GVC Participation-Selected Asia and Pacific Economies 34

2.19 Newly Effective Free Trade Agreements-Asia and the Pacific 35

2.20 RCEP Intraregional Import Shares by Tariff Phasing Down Type and Economy Group, 2019

2.21 RCEP Intraregional Import Shares in 2019 and RCEP Tariff Phasing Down Over Years 38

2.22 RCEP Initial MFN Base Rate and Tariff Reduction 38

2.23 Product-Specific Rules of Origin by Harmonized System Chapter and Form of PSRO 40

3.1 Total Inward Foreign Direct Investment-Balance of Payments 49

3.2 Foreign Direct Investment by Mode of Entry (Firm-Level Activity) -Asia and the Pacific 51

3.3 Quarterly Inward FDI into Asia and the Pacific by Mode of Entry-Firm-Level Activity, Q1 2018-Q2 202152

3.4 Total Inward Foreign Direct Investment to Asia and the Pacific by Sector-Firm-level Activity 54

3.5 Inward Greenfield FDI Job Creation-Asia and the Pacific 55

3.6 Global Outward Foreign Direct Investment by Source-Balance of Payments 56

3.7 Quarterly Outward FDI from Asia and the Pacific by Mode of Entry-Firm-Level Activity, Q1 2018-Q2 202157

3.8 Inward FDI-Firm-Level Activity 62

3.9 Inward FDI in Digital Services by Subregion and Mode of Entry 63

3.10 Digitally and Non-Digitally Deliverable Services FDI by Asian Subregion and Mode of Entry 64

3.11 Inward FDI in Digitally Deliverable Services by Sector and Subregion 64

3.12 Top Digitally Deliverable Services FDI Subsectors, 2020 65

3.13 Digitally Deliverable Services in Asia and the Pacific_FDI versus Exports 66

3.14 FDI Regulatory Restrictiveness Index by Sector-Asia and the Pacific 69

3.15 FDI Regulatory Restrictiveness Index by Type of Restriction-Asia and the Pacific 70

3.16 FDI Regulatory Restrictiveness Index in Digitally Deliverable Services, 2020-All Types of Restrictions 70

3.17 Recent Foreign Investment Measures in Digitally Deliverable Services in Asia and the Pacific 71

4.1 Financial Stress Index $\quad 80$

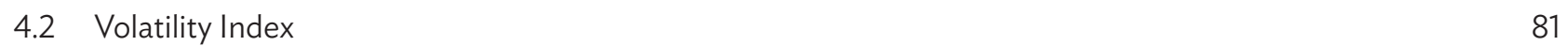


4.3 Credit Default Swaps-Selected Asian Economies 81

4.4 Cross-Currency Basis Swap Against the United States Dollar 81

4.5 Stock Price Index-Selected Asian Economies 82

4.6 Total Bond Return Index-Selected Asian Economies 82

4.7 Nonresident Capital Flows-Selected Asian Economies 83

4.8 Exchange Rate, \$/LCU—Selected Asian Currencies 83

4.9 Policy Rate-Selected Asian Economies $\quad 84$

4.10 Variance Decomposition-Equity Returns $\quad 85$

4.11 Variance Decomposition-Bond Returns $\quad 85$

4.12 Change in Sectoral Debt Ratio, 2019 versus Q3 2021-Selected Asian Economies 86

4.13 Corporate Financing-Emerging Asia 86

4.14 Bank NPL Ratio-Selected Asian Economies 87

4.15 Share Prices of Selected Property Developers in the PRC 87

4.16 Yield of the PRC's Junk Bonds $\quad 87$

4.17 Cross-Border Assets-Asia and the Pacific 88

4.18 Cross-Border Loan and Deposit Flows-Asia and the Pacific 89

4.19 Cross-Border Liabilities-Asia and the Pacific 90

4.20 Currency Composition of Asia's International Total Investments, 202091

4.21 Currency Composition of Asia’s International Debt Investments, 202091

4.22 Nonresident Capital Flows-Asia and the Pacific, by Investment Type 92

4.23 Resident Capital Flows-Asia and the Pacific, by Investment Type 93

4.24 Nonresident Capital Flows —-Asia and the Pacific, by Subregion 94

4.25 Nonresident Capital Flows-Selected Asian Economies, by Sector 94

4.26 Nonresident Capital Flows Volatility-Asia and the Pacific, 2001-2020 95

4.27 Regression Coefficients of Capital Flows Covariates-Selected Asian Economies 96

4.28 Frequency of Capital Inflows Stops and Surges 97

4.29 Selected Macroeconomic and Financial Variables-Asia and the Pacific 99

4.30 Policy Measures of Selected Asia and Pacific Economies 100

5.1 International Migrant Stock and Asia's Shares 109

$\begin{array}{lll}5.2 & \text { International Migrants by Origin and Destination } & 110\end{array}$

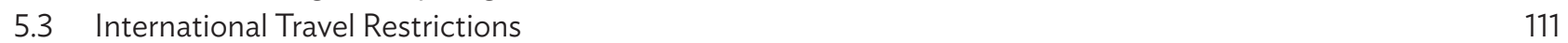

5.4 Out-migrants from Asian Subregions 114

5.5 Top 10 Sources of Migrants from Asia and the Pacific 114

5.6 Intraregional Migration in Asia and the Pacific 116

5.7 Worker Visas Issued to Asian Migrants by Selected Migrant Host Economies 117

5.8 Remittance Inflows to Asia and the Pacific and the World 122

5.9 Financial Flows to Asia and the Pacific, by Type 125

5.10 Trend of Remittance Inflows to Asia and the Pacific by Subregions 128

5.11 Top 10 Remittance-Recipient Economies in Asia and the Pacific, 2020129

5.12 Average Total Cost of Remitting \$200 130

$\begin{array}{ll}5.13 \text { Tourist Arrivals, January-October } & 131\end{array}$

$\begin{array}{ll}5.14 & \text { Daily COVID-19 Cases, 2021 } \\ 5.15 & 132\end{array}$

5.15 International Travel Restrictions 132

5.16 International Tourist Arrivals by Region of Destination 133

5.17 International Tourist Receipts by Region of Destination 133

5.18 Top 10 Recipients of International Tourism Receipts, 2019 and 2020135

5.19 COVID-19 Cases and People Vaccinated in Asia and the Pacific 142

6.1 CAREC Investments by Funding Source, as of 30 June 2021

6.2 CAREC Investments by Sector, as of 30 June 2021

6.3 SASEC Investment, by Sector, 2001-2021 171 
6.4 SASEC Projects by Sector, 2021

6.5 SASEC Investment by Volume and Financier, 2001-2021 172

6.6 GDP Growth in the Pacific 175

6.7 COVID-19 Vaccination Coverage 176

6.8 ADB's COVID-19 Response Package by Region, as of 7 February 2022

6.9 APVAX Committed Amount by Region, as of 7 February 2022

7.1 Conceptual Framework for Digital Trade 187

7.2 Measuring Trade in Digital Services: A Schematic View on Possible Proxies 189

7.3 Share of Digitally Deliverable Services Exports in Total Goods and Services Exports 190 and Income Per Capita by Region, 2019

7.4 Trade in Services by Region 192

7.5 Intraregional and Extraregional Trade in Services in Asia and the Pacific 193

7.6 Shares and Growth of Digitally and Non-Digitally Deliverable Services Trade 194

7.7 Average Annual Growth in Services Trade, 2005-2020 195

7.8 Trade in Services in Asia and the Pacific 195

7.9 Trade in Digitally Deliverable Services of Developing Asia, by Subregion 196

7.10 Digitally Deliverable Services Exports to Asia and the Pacific 196

7.11 Top Asian Exporters and Importers of Digitally Deliverable Services, 2020

7.12 Trade in Services in Asia and the Pacific, by Sector 197

7.13 Trade in Services in Asia and the Pacific, by Sector Breakdown 198

7.14 Trade in Digitally Deliverable Services in Asia and the Pacific, by Service Item 199

7.15 Digitally Deliverable Services Trade in Asian Subregions 199

7.16 Trade in Digitally Deliverable Services in Asia and the Pacific, by Mode of Supply 200

7.17 Asia's Largest Digitally Deliverable Services Subsectors, by Mode of Supply 201

7.18 Average Annual Growth of Services Trade by Region, 2005-2020 205

7.19 Revealed Comparative Advantage for Digitally Deliverable Services 206

7.20 Binned Scatterplots for Expected Years of Schooling, 2019

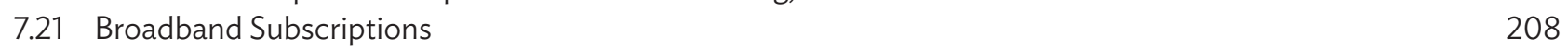

7.22 Binned Scatterplots for Mobile Broadband Subscriptions, 2019209

7.23 Binned Scatterplots for International Bandwidth per Internet User, 2019

7.24 Binned Scatterplots for Investments in Telecommunications, 2019

7.25 Binned Scatterplots for State Control Over Internet Access, 2019211

7.26 GVC Forward Linkages as a Percentage of Gross Exports for Digitally Delivered Services 212 Sectors-Asian Economies

7.27 GVC Backward Linkages as a Percentage of Gross Exports for Digitally Delivered Services 213 Sectors-Asian Economies

7.28 Digital Services Trade Restrictiveness Index-Selected Asia and Pacific Economies 214

7.29 Forward GVC Participation as a Percentage of Gross Exports by Sector-Intra-Asia and the Pacific 222

7.30 Backward GVC Participation as a Percentage of Gross Exports by Sector-Intra-Asia and the Pacific 223

7.31 Average Number of Digital Provisions Covered in New RTAs 231

7.32 FTAs with at Least One Provision in Each Category 231

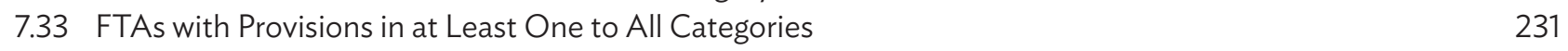




\section{BOXES}

1.1 An Enhanced Measure of Regional Cooperation and Integration 7

2.1 Rising Global Shipping Costs 19

2.2 Vertical Specialization in Electronic Products 26

2.3 Evolution of Economy-Level Contributions to Global and Regional Value Chains 31

3.1 The Reinforcing Role of Global Value Chain Participation and FDI_Prospects for Digital Services 67

4.1 International Investment Position

101

5.1 Return and Reintegration amid the 2020 COVID-19 Crisis-The Case of Overseas Filipino Workers 113

5.2 Pandemic-Induced Changes in Asian Migrant Flows to Other Major Host Economies 117

5.3 Share of Migrants as a Share of Population 120

5.4 Countercyclicality of Bilateral Remittance Inflows to Asia and the Pacific 124

5.5 Remittance Inflows during a Pandemic-Ridden 2020: The Case of Rural Households in Bangladesh 126

5.6 Thailand's Tourism Sector and Regional Economic Growth-A Global Value Chain Perspective 134

5.7 Reviving Tourism in the Pacific 136

5.8 Domestic Tourism in Post-COVID-19 Recovery-Reinventing Cruise Tourism 138

5.9 Tourist Inflows Amid a Pandemic Environment: The Case of Seoul, Republic of Korea 144

7.1 ADB Measurement of the Digital Economy 186

7.2 Digital Services Trade and Income Per Capita 190

7.3 Recent Developments in Digitally Deliverable Services in Developing Asia 201

7.4 Key Features of Digital Services Trade in Developing Asia 203

7.5 Impact of Data-Related Restrictions on Digital Services Trade 214

7.6 Impacts of Digital Services Trade on Household Welfare 221

7.7 Domestic Regulations in Asia-Pacific Economic Cooperation Economies 224

7.8 The Evolution of Digital Services in the World Trade Organization 226

7.9 The Case of the Republic of Korea 233

7.10 Defining Cybersecurity and Cybercrime 235

7.11 Mutual Recognition Agreements 246 


\section{FOREWORD}

Testing times in the first year of the coronavirus disease (COVID-19) pandemic continued through 2021, restricting life and livelihoods in Asia and the Pacific. While in some ways economic recovery has exceeded expectations, especially for merchandise trade and cross-border investment, its uneven pace amid varying progress of vaccine rollouts and the constant threat from virus mutations tempers prospects. Moreover, many hard-won gains in reducing poverty are still lost.

This double-edged reality gives greater reason to focus on the continuing achievements and potential of regional economic integration and cooperation to boost inclusive economic growth. Another year into the pandemic, the Asian Economic Integration Report (AEIR) 2022 describes a region that has more experience in tackling pandemic hardships, better data showing positive integration trends, and greater confidence in the power of cooperation to address shared concerns. Regional initiatives are navigating the health crisis and significant issues like climate change, while holding course for promoting inclusive economic growth through partnerships in trade, investment, finance, movement of people, and the benefits of digitalization. The updated Asia-Pacific Regional Cooperation and Integration Index also shows continued positive trends of regional cooperation efforts, including in areas of new technology and digital connectivity and environmental sustainability.

The report's theme chapter explores the implications for developing Asia from the acceleration of digital services during the pandemic, focusing on services delivered across borders and the promise of regional cooperation to boost participation in digital services trade and spread its benefits evenly. Mobility restrictions and physical distancing policies have jolted firms into leveraging digital technologies in ways that arguably are bringing more and faster changes to economies in Asia and the Pacific than other regions, and intensifying Asia's first-mover advantage in such sectors as business processing and outsourcing. With this, the cost of services trade is falling, opening the window of opportunity for disadvantaged groups to access affordable new services delivered digitally.

To maximize the economic gains from digital services trade, economies need to make their people better equipped with digital skills and knowledge, expand information and communication technology infrastructure, and nurture enabling environments through policy and regulatory reforms. Regional cooperation can bring together national efforts to reduce barriers to digital services trade by harmonizing rules and standards - with free trade agreements offering pivotal supportwhile strengthening consumer protection and cybersecurity, closing digital divides, and facilitating data flows.

An encouraging sign amid global economic slowdown is regional trade linkages and value chains holding strong, buoyed in part by the early recovery of the People's Republic of China and deepening industrial interlinkages in high and medium technology sectors.

Tourism, so vital for many economies, remains challenging amid the dearth of arrivals. Effective worldwide vaccination campaigns will be key to gradual reopening and tourism recovery. Health and safety protocols such as cross-border travel requirements will need to intensify to manage tourism flows safely, while regional cooperation is also a priority to ensure secure reopening of travel routes.

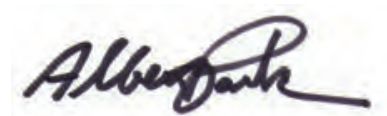

\section{Albert Francis Park}

Chief Economist and Director General

Economic Research and Regional Cooperation Department

Asian Development Bank 


\section{ACKNOWLEDGMENTS}

The Asian Economic Integration Report (AEIR) 2022 was prepared by the Regional Cooperation and Integration Division (ERCl) of the Economic Research and Regional Cooperation Department (ERCD), Asian Development Bank $(A D B)$, under the overall supervision of ERCI Director Cyn-Young Park. Jong Woo Kang coordinated overall production assisted by Mara Tayag. ERCI consultants under Technical Assistance 6753: Asian Economic Integration: Building Knowledge for Policy Dialogue, 2021-2022 (Subproject 2) contributed data compilation, research, and analysis.

Contributing authors include Rogelio Mercado Jr., Sanchita Basu Das, Rolando Avendano, and Josephine Duque-Comia, with data support from Pilar Dayag, Clarisa Joy Flaminiano, and Lovely Ann Tolin (Fragile, Uneven Recovery amid the Pandemic); Jong Woo Kang, Pramila Crivelli, Marife Lou Bacate, Joshua Anthony Gapay, Dorothea Ramizo, Patricia Georgina Gonzales, and Thi Hang Banh (Trade and the Global Value Chains); Rolando Avendano and Clemence Fatima Cruz, with data support from Lovely Ann Tolin (Cross-Border Investment); Rogelio Mercado Jr., Ana Kristel Lapid, and Dominique Hannah Sy (Financial Integration); and Kijin Kim, Sanchita Basu Das, Ma. Concepcion Latoja, and Aiko Kikkawa, with data support from Pilar Dayag and Zemma Ardaniel (Movement of People). The chapter "Updates on Subregional Cooperation Initiatives" was consolidated by Paulo Rodelio Halili and Josephine Duque-Comia, with data support from Pilar Dayag and based on contributions by regional departments of ADB: Saad Abdullah Paracha and Xinglan Hu (Central Asia Regional Economic Cooperation subsection); Greater Mekong Subregion (GMS) Secretariat (GMS subsection); Dorothea Lazaro and Loreli de Dios (East Asia subsection); Thiam Hee Ng, Tadateru Hayashi, Aileen Pangilinan, Esnerjames Fernandez, Jesusito Tranquilino, and Leticia de Leon (South Asia Subregional Economic Cooperation subsection); and Cara Tinio, Ki-Fung Kelvin Lam, Inez Mikkelsen-Lopez, Remrick Patagan, and Rommel Rabanal (Pacific subsection).

Jong Woo Kang, Rolando Avendano, and Pramila Crivelli coordinated and contributed to the production of the theme chapter, "Advancing Digital Services Trade in Asia and the Pacific," with support from Mara Tayag. Background papers were provided by Rolando Avendano, Rupa Chanda, Lennon Chang, Wonhee Cho, Pramila Crivelli, Bruno da Silva, Jane DrakeBrockman, Henry Gao, Jong Woo Kang, Minjung Kim, Antonella Liberatore, Han-Wei Liu, Guido Porto, Ben Shepherd, Dominique Hannah Sy, and Erik van der Marel. Contributions to the chapter were provided by Jane Drake-Brockman, Renata Fontana, Go Nagata, and Andre Wirjo. The team is grateful for the support on measurement and data in digital services trade provided by Antonella Liberatore from the Statistics and Data Directorate of the Organisation for Economic Co-operation and Development and Mahinthan J. Mariasingham from ERCD's Statistics and Data Innovation Unit. The theme chapter benefited from comments and suggestions provided by the participants of the following workshops and events: "ADB Virtual Inception Workshop on Digital Services Trade" held on 1-3 March 2021; "ADB-ADBI Virtual Conference: Digital Services Trade-Opportunities and Risks for Developing Asia” held on 30 June-2 July 2021; "ERCD Workshop: AEIR 2022 Theme Chapter on Digital Services Trade-Opportunities and Risks for Asia and the Pacific" held on 28 September 2021; and "Virtual Workshop: Asian Economic Integration Report 2022" held on 28 October 2021.

James Unwin and Eric van Zant edited the manuscript. Joseph Manglicmot typeset and produced the layout. Erickson Mercado created the cover design and assisted in typesetting. Tuesday Soriano proofread the report. Ana Kristel Lapid, Carol Ongchangco, Clemence Fatima Cruz, Joshua Anthony Gapay, and Dominique Hannah Sy assisted in proofreading. Support for AEIR 2022 printing and publishing was provided by the Printing Services Unit of ADB's Corporate Services Department and by the Publishing and Dissemination Unit of the Department of Communications. Pia Asuncion Tenchavez, Carol Ongchangco, Maria Criselda Aherrera, and Marilyn Parra provided administrative and secretarial support, and helped organize the AEIR workshops, launch events, and other AEIR-related webinars and briefings. Terje Langeland, with support from Lean Alfred Santos, of the Department of Communications coordinated the dissemination of AEIR 2022. 


\section{DEFINITIONS}

The economies covered in the Asian Economic Integration Report 2022 (AEIR 2022) are grouped by major analytic or geographic group.

- Asia and the Pacific refers to the 49 regional members of the Asian Development Bank. It includes Australia, Japan, and New Zealand, in addition to the 46 developing members.

- Subregional economic groupings are listed below:

- Central Asia comprises Armenia, Azerbaijan, Georgia, Kazakhstan, the Kyrgyz Republic, Tajikistan, Turkmenistan, and Uzbekistan.

- East Asia comprises Hong Kong, China; Japan; Mongolia; the People's Republic of China; the Republic of Korea; and Taipei,China.

- South Asia comprises Afghanistan, Bangladesh, Bhutan, India, Maldives, Nepal, Pakistan, and Sri Lanka.

- Southeast Asia comprises Brunei Darussalam, Cambodia, Indonesia, the Lao People's Democratic Republic, Malaysia, Myanmar, the Philippines, Singapore, Thailand, Timor-Leste, and Viet Nam.

- The Pacific comprises the Cook Islands, the Federated States of Micronesia, Fiji, Kiribati, the Marshall Islands, Nauru, Niue, Papua New Guinea, Palau, Samoa, Solomon Islands, Tonga, Tuvalu, and Vanuatu.

- Oceania includes Australia and New Zealand.

Unless otherwise specified, the symbol “\$” and the word "dollar" refer to the United States dollars, and percent changes are year-on-year. 


\section{ABBREVIATIONS}

\begin{tabular}{|c|c|}
\hline$A D B$ & Asian Development Bank \\
\hline AEIR & Asian Economic Integration Report \\
\hline $\mathrm{Al}$ & artificial intelligence \\
\hline APEC & Asia-Pacific Economic Cooperation \\
\hline APSI & Action Plan of SASEC Initiatives \\
\hline APVAX & Asia Pacific Vaccine Access Facility \\
\hline ARCII & Asia-Pacific Regional Cooperation and Integration Index \\
\hline ASEAN & $\begin{array}{l}\text { Association of Southeast Asian Nations (Brunei Darussalam, Cambodia, Indonesia, the Lao People's } \\
\text { Democratic Republic, Malaysia, Myanmar, the Philippines, Singapore, Thailand, and Viet Nam) }\end{array}$ \\
\hline ASEAN+3 & ASEAN plus Japan, the People's Republic of China, and the Republic of Korea \\
\hline ATIGA & ASEAN Trade in Goods Agreement \\
\hline BaTIS & Balanced Trade in Services \\
\hline BIS & Bank for International Settlements \\
\hline BOP & balance of payments \\
\hline CapEx & capital expenditure \\
\hline CAREC & Central Asia Regional Economic Cooperation \\
\hline CGE & computable general equilibrium \\
\hline CGFS & Committee on the Global Financial System \\
\hline COVAX & COVID-19 Vaccines Global Access \\
\hline COVID-19 & coronavirus disease \\
\hline CPIS & Coordinated Portfolio Investment Survey \\
\hline CPRO & Countercyclical Support Facility COVID-19 Pandemic Response Option \\
\hline СРTPP & Comprehensive and Progressive Agreement for Trans-Pacific Partnership \\
\hline CWRD & Central and West Asia Department \\
\hline DEA & Digital Economy Agreement \\
\hline DEPA & Digital Economy Partnership Agreement \\
\hline DST & digital services taxes \\
\hline DSTRI & Digital Services Trade Restrictiveness Index \\
\hline DVA & domestic value added \\
\hline EARD & East Asia Department \\
\hline ESCC & Energy Sector Coordinating Committee \\
\hline EU & $\begin{array}{l}\text { European Union (Austria, Belgium, Bulgaria, Croatia, Cyprus, Czech Republic, Denmark, Estonia, } \\
\text { Finland, France, Germany, Greece, Hungary, Ireland, Italy, Latvia, Lithuania, Luxembourg, Malta, the } \\
\text { Netherlands, Poland, Portugal, Romania, Slovakia, Slovenia, Spain, and Sweden) }\end{array}$ \\
\hline FDI & foreign direct investment \\
\hline FTA & free trade agreement \\
\hline GATS & General Agreement on Trade in Services \\
\hline GATT & General Agreement on Tariffs and Trade \\
\hline GDP & gross domestic product \\
\hline
\end{tabular}




\begin{tabular}{|c|c|}
\hline GDPR & General Data Protection Regulation \\
\hline GMRA & Greater Mekong Railway Association \\
\hline GMS & Greater Mekong Subregion \\
\hline GST & goods and services taxes \\
\hline GVC & global value chain \\
\hline HS & Harmonized System \\
\hline ICT & information and communication technology \\
\hline ILO & International Labour Organization \\
\hline IMF & International Monetary Fund \\
\hline IT & information technology \\
\hline KNOMAD & Global Knowledge Partnership on Migration and Development \\
\hline Lao PDR & Lao People's Democratic Republic \\
\hline$M \& A$ & merger and acquisition \\
\hline MFN & most-favored nation \\
\hline MRIOT & Multi-Regional Input-Output Tables \\
\hline NIE & newly industrialized Economy \\
\hline NPL & nonperforming loan \\
\hline OECD & Organisation for Economic Co-operation and Development \\
\hline PRC & People's Republic of China \\
\hline PSRO & product-specific rules of origin \\
\hline $\mathrm{RCA}$ & revealed comparative advantage \\
\hline$R \& D$ & research and development \\
\hline RCEP & Regional Cooperation Economic Partnership \\
\hline $\mathrm{RCl}$ & regional cooperation and integration \\
\hline RIF & regional investment framework \\
\hline $\mathrm{ROO}$ & rules of origin \\
\hline ROW & rest of the world \\
\hline RTA & regional trade agreement \\
\hline RVC & regional value chain \\
\hline SASEC & South Asia Subregional Economic Cooperation \\
\hline SDG & Sustainable Development Goal \\
\hline SPS & sanitary and phytosanitary \\
\hline TA & technical assistance \\
\hline TBT & technical barriers to trade \\
\hline TISMOS & Trade in Services data by Mode of Supply \\
\hline UK & United Kingdom \\
\hline UN & United Nations \\
\hline UNCTAD & United Nations Conference on Trade and Development \\
\hline UNWTO & United Nations World Tourism Organization \\
\hline US & United States \\
\hline USMCA & United States-Mexico-Canada Agreement \\
\hline VAT & value-added tax \\
\hline VIX & volatility index \\
\hline $\mathrm{WHO}$ & World Health Organization \\
\hline WTO & World Trade Organization \\
\hline
\end{tabular}




\section{HIGHLIGHTS}

\section{Fragile, Uneven Recovery amid the Pandemic}

- Asia and the Pacific saw fragile, uneven recovery in cross-border economic activities and movement of people in 2021, and the recovery momentum has weakened due to the Omicron variant. Merchandise trade, cross-border investment, capital flows, and international remittances have improved markedly since the latter half of 2020. But trade in services, particularly non-digital services, and movement of people are still sluggish due to the ongoing pandemic and emergence of new coronavirus disease (COVID-19) variants. Although ramped up across the region and elsewhere, the varying progress of vaccination underlies the uneven pace of recovery in cross-border transactions, investments, and movement of people. Sustained economic recovery post-COVID-19 requires stronger regional cooperation particularly through information sharing and other health control measures (such as cross-border travel requirements, and vaccinated travel lanes) to prevent flare-ups. Revamping social and economic infrastructure in such areas as health care, supply chains, and mitigation of climate change risks will be priority agendas for an inclusive and sustainable recovery.

\section{- The latest regional integration estimates suggest that regional integration trends in Asia and the Pacific} remain positive. The region reported a 7\% increase from 2006 to 2019 in the Asia-Pacific Regional Cooperation and Integration Index. In the new technology and digital connectivity dimension, Asia and the Pacific displays the highest performance among all regions, reflecting wider internet penetration, increased information and communication technology (ICT) goods trade and research collaboration. Asia's performance in environmental cooperation is comparable with other developing regions, with the estimated level now close to three-quarters of the European Union (EU) and North America, the top performing regions. In 2019, people and social integration, regional value chains, and infrastructure and connectivity dimensions were the main drivers of regional cooperation and integration ( $\mathrm{RCl}$ ) progress in Asia and the Pacific. The region's performance is similar to the EU in areas of regional trade, investment, and value chain participation, while gaps remain for money and finance. $\mathrm{RCl}$ performance continues to vary widely across the Asian subregions, with East Asia and Southeast Asia showing the highest integration. Subregional gaps in trade and investment, infrastructure and connectivity, and people and social integration remain high, while the divide in technology and digital connectivity within the region has narrowed.

\section{Trade and Global Value Chains}

- Asia's merchandise trade continued to grow rapidly in 2021, after demonstrating strong resilience amid the pandemic in 2020. After bottoming out in mid-2020 during the first wave of the pandemic, Asia's merchandise trade recovered faster than expected in 2021. Trade growth accelerated at double-digit rates, reaching $19.7 \%$ by June before settling down to $9.7 \%$ in September 2021. The steep rebound was underpinned by the release of pent-up demand supported by macroeconomic stimulus programs and economic recovery around the globe along with gradual progress in vaccine rollout in the region. The relatively early success of containing the pandemic in several major Asian economies also helped the region to become the supply hub of medical supplies and consumer 
goods and boosted its merchandise exports to the world. Yet, the uneven pace of vaccine rollout across the region and the spread of new virus variants remain a significant downside risk to continued trade recovery. Amid such persistent uncertainties, the region should intensify efforts to embrace liberal trade and investment regimes. The Regional Comprehensive Economic Partnership (RCEP), the largest mega trade agreement, is expected to help spur the region's trade growth. To magnify its trade creation effect, policy makers could also consider activating the built-in work plan of the agreement. This can cultivate RCEP's potential as a "living document" by deepening its commitment and expanding its coverage further in the future.

- The pandemic has not slowed the deepening of intraregional trade linkages and regional value chains. The region's intraregional trade share rose to $58.5 \%$ in 2020 from $57.5 \%$ in 2019 . This was driven mainly by the early recovery of the People's Republic of China (PRC) from the pandemic, which led to a surge in its exports and spilled over to other economies in the region with strong trade linkages with the PRC. Excluding the PRC, the region's intraregional share rather slipped to 38.2\% in 2020 from 38.4\% in 2019. At the subregional level, intraregional trade linkages strengthened for East Asia, South Asia, and the Pacific and Oceania, with South Asia demonstrating the largest increase in its intraregional trade share to $40.5 \%$ in 2020 from 38.9\% in 2019. Asia's global value chain (GVC) participation declined in 2020 in tandem with the similar decline of the world's GVC participation. Nevertheless, its regional value chain linkages strengthened further in 2020 during the pandemic thanks to its supply chain linkages with the PRC and deepening value chain linkages in high- and medium-technology sectors.

\section{- Supply chain bottlenecks associated with partial disruptions in production capacity and logistics logjams} during the pandemic continue to weigh on the global and regional trade outlook. Global shipping costs have risen sharply since mid-2020 due to excess demand for manufacturing goods, rising input costs, flawed performance of integrated logistics functions including inland trucking, and quarantine requirements for port workers. Proactive solutions such as operationalizing tracking technologies and the digitized trade and transport management system, expanding competition in port operations, and making systemwide investments throughout the logistics chain, from ports to warehouses to inland transport, can help ease the problems. While semiconductors are an essential component of electronic devices, enabling communications, computing, health care, transportation, clean energy, and countless other applications, their production capacities are highly specialized and geographically concentrated, exposing the sector to extreme vulnerabilities to potential supply chain disruptions. Further diversification of their supply chains and utilization of just-in-case inventory management are becoming increasingly popular among businesses. To meet ever growing demand for semiconductors, governments should nurture an enabling environment for the expansion of research and development (R\&D) and capital investments, and skills development for materials scientists and electronic engineers.

\section{Cross-Border Investment}

- Despite the pandemic's impact on global foreign direct investment (FDI), inward FDI to the region has been relatively resilient. Global FDI declined by $34.7 \%$ in 2020 based on balance of payments data-even lower than at the height of the global financial crisis. FDI into Asia and the Pacific, however, slipped by only $1.3 \%$ in 2020 . The region remains an attractive investment destination, accounting for $53.6 \%$ of global FDI. East Asia and Southeast Asia were the largest recipients in the region, attracting roughly $80 \%$ of Asia's inward FDI. Nevertheless, greenfield projects, which are typically aimed at input and labor-intensive activities such as in primary and manufacturing sectors, were hit hard by the pandemic. Greenfield FDI into Asia and the Pacific declined by 37.9\% in 2020, driven by a 75.8\% drop in the primary sector. In contrast, deal values for mergers and acquisitions (M\&As) in Asia posted $38.7 \%$ annual growth, boosted by M\&As in manufacturing and services which increased $51.0 \%$ and $31.2 \%$, 
respectively. The first half $(\mathrm{H} 1)$ of 2021 saw slow recovery in greenfield investment and a steady improvement in M\&As in the region. Meanwhile, Asia's outward FDI also dipped, falling 14.2\% in 2020 over the previous year. The recovery prospects for inward FDI remain uncertain as announced greenfield investments continue to decline. Supply chain disruptions due to recurrent pandemic waves and restrictive FDI measures may hamper FDI growth. As such, phasing out the restrictive investment policies enacted during the pandemic may allow the region to counter these challenges.

- FDI is increasingly important for fostering digital services trade in the region. Digitalization is fundamentally transforming how firms, in particular digitally intensive multinational enterprises, operate and invest overseas with less need for physical presence and faster speed of business transactions. Asia and the Pacific stands out as an important hub of digital services FDI, particularly for financial and insurance services; information, computer, and telecommunications; and other business services. The trend is increasingly driven by investments in fintech, digital payments, data processing and hosting, cloud computing, professional and technical services, among others. On average, 24\% of FDI into the region from 2003 to 2020 went into digital services, with East Asia and South Asia the main destinations. Greenfield FDI in Asia's digital services was particularly resilient during the pandemic, contracting by $9.7 \%$ in 2020 compared with the $57.9 \%$ plunge in $\mathrm{FDI}$ for non-digital services and $28.6 \%$ for manufacturing FDI. Restrictions on FDI in Asia's digital services sectors, such as legal and professional services, remain stricter than for non-digital services, mostly in the form of limitations on foreign equity and ownership. This, together with differences in FDI regulations across Asia and the Pacific, may hamper foreign firms' investment decisions in the region. To encourage FDI in digital services sectors, Asian economies should embed investment policy frameworks in national digital plans and services development strategies. Relevant investor criteria, such as digital infrastructure, digital regulatory barriers, ICT skills, and investment protection in regard to intellectual property rights, should be incorporated in FDI strategies for digital services. Investment promotion agencies, digital clusters, and digital special economic zones fit this purpose.

\section{Financial Integration}

- An accommodative macroeconomic policy environment and broadening vaccine rollouts buttressed the economic recovery and stable financial conditions in 2021, but considerable uncertainties remain. Financial markets were much calmer in $\mathrm{H} 12021$ than throughout 2020. Supportive fiscal and monetary policy measures and vaccination rollout lifted growth prospects for the region and kept financial conditions favorable. However, risks loom as high inflation will prompt advanced economies including the United States (US) to normalize monetary policy earlier than expected, which could tighten global liquidity conditions and trigger capital outflows from emerging and developing economies, including those in Asia and the Pacific. A sudden large capital flow reversal and weakening of the region's currencies could instigate financial instability. The ongoing financial woes of the PRC property and housing sector add to the concern given uncertainties over the risk of domestic and cross-border financial spillovers. The emergence of the Omicron variant and its possible impact on the global economy also poses a significant risk to financial stability.

- In 2020, Asian investors continued to invest more outside the region than inside. Around two-thirds of Asia's asset and liability holdings were placed in economies outside the region. In addition, almost half of Asia's international debt liabilities were denominated in US dollars as of the end of 2020, while 63\% of the region's debt assets are denominated in US dollars. The greenback's dominance in Asia's cross-border investment holdings and liabilities could lead to several risks including the impact of US monetary policy spillover effects on global liquidity, as well as balance sheet and welfare effects of large exchange rate fluctuations between the US dollar and local currency. 
- Foreign capital inflows in Asia and the Pacific continued to increase in 2021. Nonresident capital inflows in the region increased in 2020 to $\$ 1.6$ trillion from $\$ 1.2$ trillion in 2019 , mainly due to increases in other accounts payable, currency and deposits, as well as debt inflows including portfolio debt and loans. In contrast, equity inflows including $\mathrm{FDI}$ and portfolio equity decreased by $30 \%$ in 2020, compared with 2019. Extraordinary policy support in the region and elsewhere strengthened this rebound in nonresident capital inflows in 2020, following foreign capital outflows at the onset of the pandemic. However, the volatility of capital inflows inched higher in 2020 as volatilities for loans and portfolio inflows intensified. Nonresident capital inflows continued to increase in 2021, reaching around \$372 billion for selected Asia and Pacific economies in the second quarter (Q2) of 2021, a 175\% increase from Q2 2020. Nonetheless, volatility of nonresident capital inflows for selected economies in the region increased slightly in $\mathrm{H} 1$ 2021 compared with $\mathrm{H} 1$ 2020. Emerging trends and patterns of capital inflows and their compositions offer the key to assessing the likely impact of changes in capital flow drivers and forging policy responses.

\section{Movement of People}

- The COVID-19 pandemic continues to transform international migration and the mobility of people. The pandemic did not alter the upward trajectory of the global stock of migrants, which increased to 280.6 million in 2020 from 248.0 million in 2015-migrants from Asia and the Pacific reached 93.0 million. However, the economic repercussions of the pandemic curtailed the flow of migrant workers out of the region, especially from Central Asia and South Asia. Intraregional migration, accounting for one-third of total migrant movement in Asia and the Pacific, is especially prevalent for Asian migrants in East Asia, the Pacific and Oceania, and Southeast Asia. As economies reconfigure their approach to post-pandemic cross-border mobility, it is important to accelerate the pace of vaccination rollout, scale up disaster-preparedness initiatives, and leverage regional cooperation initiatives on migration facilitation through bilateral and regional labor agreements. These could help capitalize on migrants' contribution to global and regional economic recovery.

- Remittance inflows to Asia and the Pacific declined by only $\mathbf{2 . 0 \%}$ in 2020 and are estimated to grow by $\mathbf{2 . 5 \%}$ in 2021. Global remittance inflows reached $\$ 705.5$ billion in 2020, a 2.3\% decline from $\$ 722.2$ billion in 2019-Asia and the Pacific received $\$ 314.4$ billion in 2020. Remittance inflows to all subregions declined by varying degrees in 2020 , except the Pacific and South Asia which grew by $14.4 \%$ and $5.2 \%$, respectively. Along with altruism, factors including fiscal stimulus in migrant host economies, tax- and related incentives, increased use of digital channels, and local currency depreciation in home economies encouraged migrants to remit amid the pandemic. Facilitation of the use of formal channels also enhanced the capture of remittance data. In 2020, Bangladesh, India, Pakistan, the Philippines, and the PRC were among the top remittance recipients in Asia and the Pacific, and globally, accounting for $\$ 225.4$ billion or $32.0 \%$ of global and $71.7 \%$ of total regional remittance inflows when combined. Remittances as a share of gross domestic product (GDP) is significantly high in some economies in Central Asia and the Pacific such as Georgia, the Kyrgyz Republic, Tajikistan, Tonga, and Samoa. The average cost of remitting to Asia and the Pacific has been declining but remains higher than the Sustainable Development Goal of less than $3 \%$ to be reached by 2030 at 5.9\%. Data for $\mathrm{H} 12021$ showed continued recovery in remittance flows to the region. Remittances to all subregions except East Asia are expected to register a 2.5\% growth in 2021.

- The pandemic has hit tourism in Asia and the Pacific hard, and establishing recovery momentum remains challenging given the recurrent outbreaks. The last 2 years have seen the pandemic wreak havoc on global tourism. International tourism arrivals dropped by $72.6 \%$ globally in 2020 over 2019 , which snowballed into a $\$ 1.3$ trillion loss in tourism revenues and over $\$ 2$ trillion decline in global GDP. In Asia and the Pacific, international arrivals dropped 82.8\% and tourism revenues by 66.4\%, relative to the pre-pandemic average in 2015 through 2019. 
Major revenue losses due to low tourist arrivals were led by the Pacific, East Asia, and Southeast Asia, though other subregions were also badly hit. Tourism indicators in 2021 suggest that arrivals remain deeply stunted, but there are signs of optimism as vaccination programs pick up and economies cautiously reopen borders at a varying pace. Government support in particular, restoring travel confidence and use of technology to facilitate travel and follow health protocols could support the recovery of tourism. In some economies, government assistance focused on jump-starting the industry as the pandemic prolonged. Priority was therefore put on the resumption of domestic tourism prior to opening borders to international visitors. Restoring travel confidence among domestic tourists and potential international visitors with emphasis on hygienic health-care protocols is the new norm. Use of big data to formulate tourism policy and technological innovations for contactless tourism services are becoming popular to safely manage tourism flows in an economy. Regional cooperation across all these areas is important to overcome challenges in systematic planning and implementation toward recovery and greater resilience of the tourism sector.

\section{Theme Chapter: Advancing Digital Services Trade in Asia and the Pacific}

- Rapid digitalization is bringing down barriers to services trade. Globalization of the services sector in recent decades supported by the so-called third unbundling offers new opportunities for international division of labor with major implications for labor markets. Intensification of digitalization since the COVID-19 pandemic began has accelerated this phenomenon. Digital technology has also allowed access to a new range of products and services. This process may not be fully reversed post-pandemic and represents a structural shift in services transactions for the region and globally.

- Digital services trade has expanded thanks to the digitization of a wide range of services with the support of ICT applications and data-driven solutions. Digitally deliverable services are gaining traction compared with trade in services based on face-to-face interactions, with the help of rapidly developing digital technologies and the growing prevalence of "untact" transactions (without face-to-face encounters) in the provision of cross-border services.

- Asia and the Pacific is at the forefront of digital services trade with the highest regional growth. From $\$ 403.4$ billion worth of digitally deliverable services trade in 2005 , the region has witnessed its trade more than tripled, achieving over $\$ 1.4$ trillion in 2020 . The region is also a substantial and growing digital services partner with other regions. The region is also showing rapid growth in the relative share of digital services trade in total services trade. The data confirm a fast-growing share of digital services in Asia's total services export basket from 36\% to $48 \%$ and from 34\% to 39\% for imports between 2005 and 2019. An empirical analysis suggests digital services trade could contribute to the growth of both GDP and gross national income per capita.

- The region has yet to narrow the gap with respect to the global average. Cross-economy analysis reveals the region is still far behind other advanced economies such as the EU and North America in the share of digital services exports out of total goods and services exports, which translates into lower revealed comparative advantage for the region. While some economies in South Asia and Southeast Asia excel other regional peers for industrial competitiveness in such sectors as business process outsourcing and information technology (IT) and telecommunication services, many economies in the region are still at a nascent stage of developing financial, professional, and business services.

- In closing the gap with advanced economies in the competitiveness of digital services trade, the region needs to focus particularly on policy reforms. Among others, (i) human capital development, (ii) digital 
connectivity, (iii) ICT investment, and (iv) an enabling policy and regulatory environment all underpin the competitiveness of digital services. The length of education is associated with greater trade in digital services. The importance of upskilling and reskilling the workforce cannot be overstated, especially considering the skillcontingent barriers to the uptake of digital technology. Digital technologies are also the bedrock of fostering innovation among small and medium-sized enterprises to help them become competitive providers of digital services. Developing Asia's digital services exports hinge largely on the availability, accessibility, and affordability of high-quality broadband services. The region's rapid growth of mobile penetration bodes well on this front. Finally, supportive internet regulations could enable economies even with low digitalization to better reap the benefits of digital services trade.

\section{- Scenario (or policy) analysis points to clear positive impact on digital services trade from trade} liberalization and deregulation of digital services. Lowering trade barriers and deregulation lead to gains in both backward and forward GVC participation in manufacturing and services. More importantly, both policy moves could increase real incomes in regional economies, with deregulation generating much larger gains. From a welfare perspective, this implies the importance of considering nondiscriminatory regulatory reduction measures in addition to international trade policy reforms. Efforts to liberalize the policy environment should therefore embrace reforms in the domestic market.

- There are many potential synergies between digital services trade and other sectors of the economy. Growth in e-commerce for merchandise goods creates opportunities for digital services exports such as financial services and logistics. Manufacturing growth provides opportunities for embedding digital services and applications in manufacturing exports, enabling indirect exports of digital services. Given the prevalence of cross-border business-to-business (B2B) activity in digital services, access to digital services imports, including from foreign digital platforms, could still be a significant future facilitator of digital services exports, both directly and indirectly embedded in merchandise exports.

- Data-related policies could also have significant impact on digital services trade. Using a unique data set that traces the development of the policy measures in 64 economies, this chapter assesses which of the restrictions on (i) data localization policies, (ii) local storage requirements, and (iii) conditional flow regimes are driving the identified negative impact of trade in digital services for Asia and the Pacific and the rest of the world. The results show that data localization and local storage requirements cause negative trade results in digital services but that the role of conditional flow regimes is more complex. While many data flow restrictions are adopted and implemented from legitimate policy perspectives such as protection of privacy and personal data, and protection against the threat to cybersecurity, economies need to weigh their positive effects against their negative impact on digital trade flows.

\section{- Assessing the social and welfare impact of digital services trade requires examining impacts on household} incomes and prices. Expansion in digital services trade could help poverty reduction and welfare improvement given the overall positive impact on wages and cost reductions. Besides the potential replacement of traditional services jobs by technological solutions, worsening income inequality among those with different skill sets as well as potentially yawning divergence between urban and rural households remain concerns. This requires policy makers' continued attention to the sector, geographic, and gender distribution effects of the benefits from digital services trade.

- Global trade rules and provisions in bilateral and regional trade agreements provide an emerging international regulatory framework governing trading conditions. Although more and more digital-trade-specific trade agreements are expected to emerge, strengthened efforts are called for to come up with clearer guidelines for digital services trade and digital trade at large. World Trade Organization (WTO) negotiations also offer an opportunity for 
progress on digital services market access. WTO members in Asia and the Pacific should also consider joining the WTO plurilateral Joint Statement Initiative on Services Domestic Regulation as a commitment to adopt and ensure good regulatory practice that will help cut trade costs, including for digital services.

\section{- Regulatory cooperation can encourage interoperability of divergent digital regulatory approaches. By} adopting common standards, economies can reduce redundant efforts, minimize technical duplication, and promote a higher level of interoperability, which could help lower trade costs. By recognizing regulatory outcomes in trading partners voluntarily or through mutual arrangement, economies can support cross-border trade in services. Mutual recognition agreements need to be designed in an open and transparent manner and should offer due process that guarantees access to any party wishing to join. Digitalization brings more convenience but could entail greater vulnerabilities in security and pursuant economic and social costs. The importance of putting in place an appropriate risk management system against cybersecurity crimes cannot be overemphasized. The interoperability of cybersecurity frameworks should be enhanced while reducing the cost of regulatory frictions.

- Governments need to continue efforts to nurture the enabling environment for digital services trade.

- The ability to tap export opportunities for digital services depends on having capacity to leverage specific strengths and conditions. Partnership between government and industry is critical in this regard. Governments will need to keep pace with emerging needs in digital services sectors, investing in ICT infrastructure and specialized skills and updating regulatory regimes to fit the digital economy. Greater preparedness for experimentation, the embracing of opportunities to pilot and test applications, and adoption of a regulatory approach that encourages risk-taking can help economies to develop digital services sectors.

- Even if economies fall short in some areas of digital readiness, they can still succeed as digital services exporters. This requires leveraging strengths, for example, first mover advantage in such services as IT-business process outsourcing, a well-established and vibrant IT services industry, and domestic demand for apps and solutions to develop digital services exports. Economies can also convert disadvantages such as remoteness, geography, and a small domestic market into opportunity by targeting niche markets and using those as experimentation ground.

- Participation in digital services trade can be a building block for social and economic convergence within and across economies. This is attainable by creating jobs and increasing incomes, empowering less advantaged sections of society; by supporting financial inclusion; increasing access to health and education: by improving productivity; and lowering trade costs. To ensure that digital services trade makes such benefits possible, while avoiding aggravation of inequities during the process of digital transformation, it is vital that governments' overall approach to the digital economy includes dedicated focus on digital access and inclusiveness.

- Economy case studies highlight the scope for digital services trade to facilitate the integration of economies into global and regional markets. Bilateral and regional agreements need to focus more on digital services in their chapters and provisions on economic and regulatory cooperation, e-commerce, R\&D, investment, and mobility of people, as well as in their commitments under the General Agreement on Trade in Services (such as market access and national treatment) including in sectors such as financial and business services.

- Governments need to weigh carefully the pros and cons of data transfer restrictions. Greater cooperation on standards, interoperability, and dialogue with businesses and industry associations are needed to design policies to balance national security and sovereignty concerns without undermining commercial opportunities. 
As digital services trade has social and economic implications, restrictions on cross-border data transfers could have repercussions on the realization of development benefits, which needs to be properly gauged against other policy objectives.

- The new agreement on international tax rules could pave the way for fair taxation on digital services. Economies should consider the benefits and risks of digital services taxes and other unilateral measures, as they could trigger bilateral trade frictions and prompt compensatory measures and deter investment. In the meantime, rules to ensure effective collection of indirect taxes value-added tax or goods and services tax on imported digital services have gained traction. International cooperation will be essential to adapt and design domestic legislation, ensure the exchange of information for tax purposes, and develop mechanisms for dispute prevention on taxation for the implementation of new tax frameworks.

- The biggest challenge ahead for digital services trade is regulation which, though evolving, lacks transparency, predictability, and appropriate scope in many economies. Regular regulatory reviews, including in consultation with services industry stakeholders, and reforming domestic regulatory practices consistent with international benchmarks, principles, and frameworks should be undertaken. 


\section{Fragile, Uneven Recovery \\ amid the Pandemic}
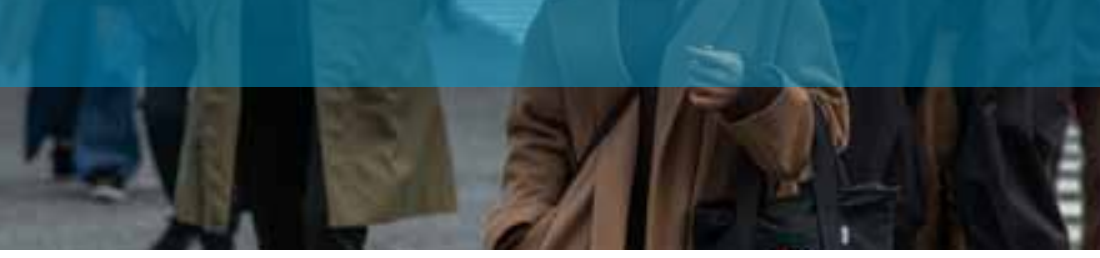

\section{Asia and Pacific economies ramped up COVID-19 vaccinations in 2021, but remain behind other regions.}

The surge in coronavirus disease (COVID-19) cases from the second half of 2021 as more transmissible COVID-19 variants spread underlines the importance of speeding and scaling up vaccination programs in the region. Immunization of a large proportion of the population remains the key policy priority for ending the ongoing health crisis and preventing the emergence of more virulent strains which may threaten the efficacy of existing vaccines. High immunization rate will allow gradual and steady reopening of economies, which will support strong and stable economic recovery. But the gradual reopening of economies and borders were stopped toward the end of 2021 as economies, including those in Asia and the Pacific, prevented the spread of the Omicron variant.

As of 31 December 2021, about 69\% of people in Asia and the Pacific were either fully or partially vaccinated. The region was behind North America at $74 \%$ and Latin America at $70 \%$, but was ahead of Europe, the Middle East, and Africa (Figure 1.1). Within Asia and the Pacific, the East Asia subregion recorded the highest vaccination rate at more than $86 \%$ (Figure 1.2), followed by Australia and New Zealand at $80 \%$, Southeast Asia at $61 \%$, South Asia at $57 \%$, and Central Asia at $48 \%$ of their total population fully or partially vaccinated. The Pacific subregion had vaccinated only $14 \%$ of its population as of third week of December 2021.
Figure 1.1: COVID-19-Vaccinated People, by Region (\% of population)

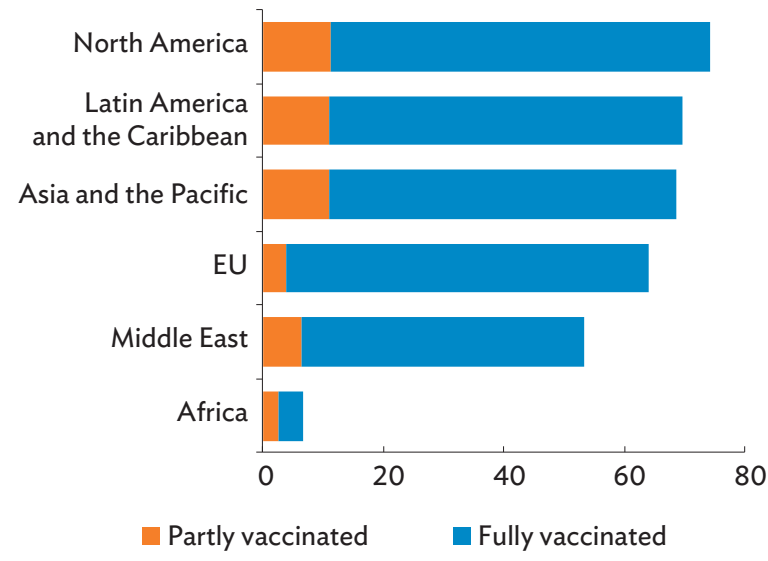

COVID-19 = coronavirus disease, EU = European Union (27 members).

Note: Data are as of the end of December 2021, except for the Pacific, which is as of the third week of December 2021.

Source: ADB calculations using data from Our World in Data and United Nations downloaded from CEIC Data Company.

Figure 1.2: COVID-19-Vaccinated People, by Subregion in Asia and the Pacific (\% of population)

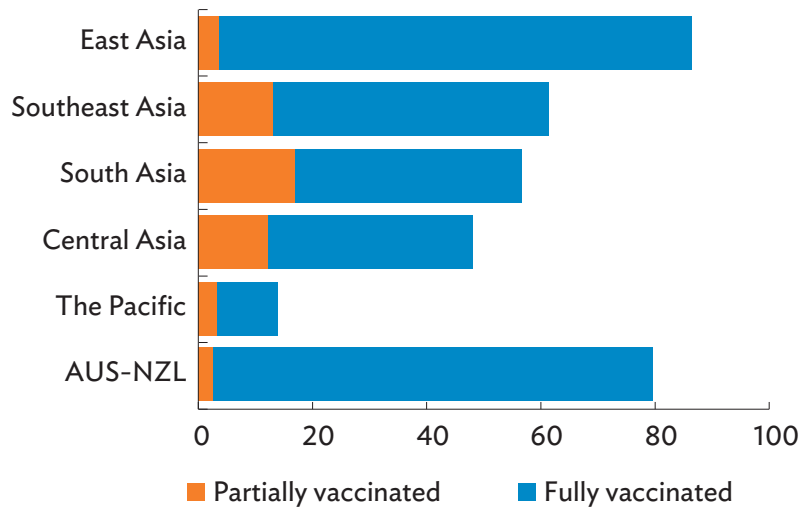

AUS = Australia, COVID-19 = coronavirus disease, NZL = New Zealand.

Note: Data are as of the end of December 2021, except for the Pacific, which is as of the third week of December 2021.

Source: ADB calculations using data from Our World in Data and United Nations downloaded from CEIC Data Company. 
The pace of COVID-19 inoculation had gained speed in the second half of 2021 (Figure 1.3). Thirteen of the top 50 economies with highest daily vaccinations per million people as of 31 December 2021 are in Asia and the Pacific. Nonetheless, some economies such as Bhutan, Kazakhstan, Nauru, Papua New Guinea, and Samoa have continued to lag. Continuous and increasing access to COVID-19 vaccines remains a priority for the region along with better information sharing among economies, use of granular or localized quarantine measures, and increasing the capacity of health-care systems, more so as new COVID-19 variants spread.

Figure 1.3: COVID-19-Daily Vaccinations per Million People (latest 7-day rolling average for December 2021)

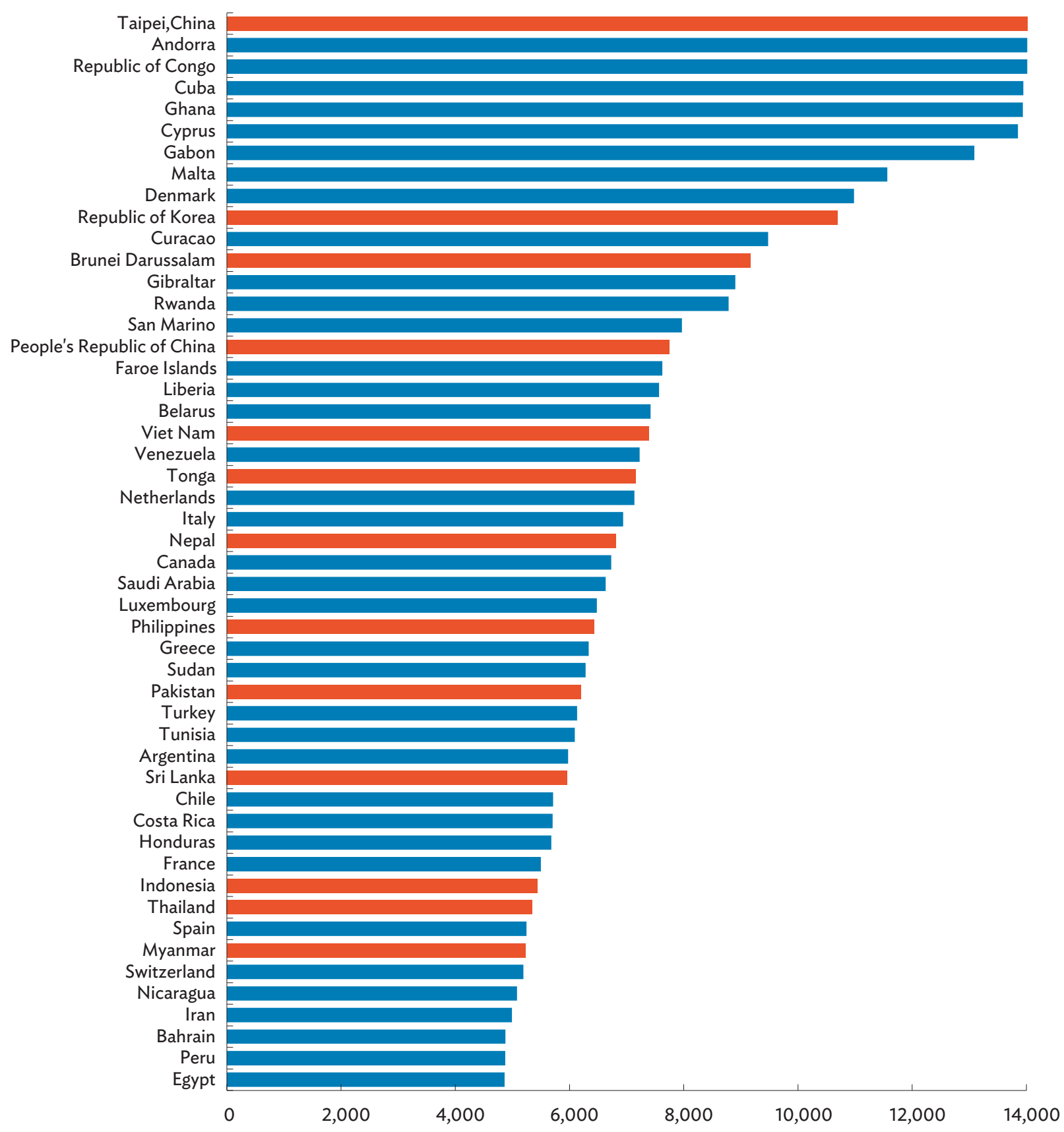

COVID-19 = coronavirus disease.

Notes: Red bars are Asia and Pacific economies. Data are as of the end of December 2021, except for Tonga, which is as of the third week of December 2021.

Source: Our World in Data downloaded from CEIC Data Company. 


\section{While merchandise trade and financial investment flows have improved, trade in services and cross-border movement of people remain sluggish.}

The region's total merchandise trade recovered in the first half of 2021, growing by around $31 \%$ compared with the same period in the previous year for selected Asia and Pacific economies (Figure 1.4). The strong recovery in merchandise trade reflects base effects from the trade decline due to strict lockdown measures in the prior year as well as improvement in external demand in the first half of 2021. However, merchandise trade growth slowed in the second half as regional economies imposed enhanced quarantine measures to suppress the rise of new COVID-19 variants and as global supply disruptions intensify. Merchandise trade in the third quarter of 2021 grew by $27.1 \%$ from the same quarter of 2020 .

Figure 1.4: Merchandise Trade Growth-Selected Asia and Pacific Economies (year-on-year, \%)

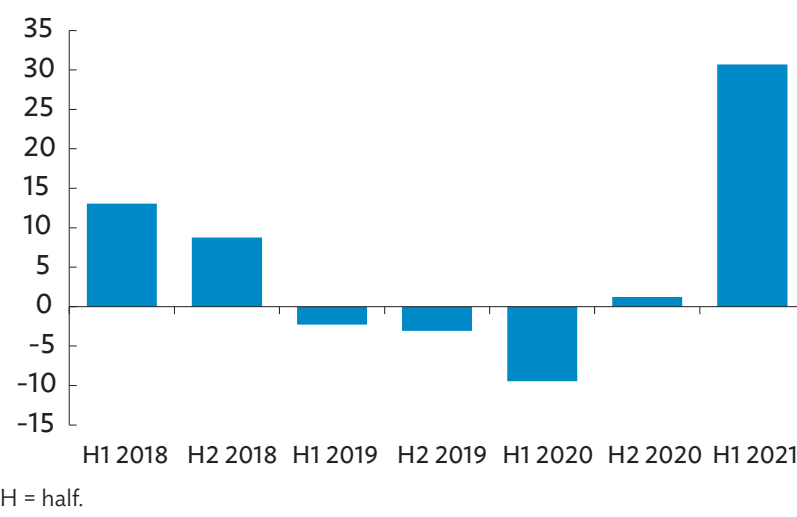

Notes: Merchandise trade is the sum of exports and imports. Asia and the Pacific includes Armenia; Australia; Azerbaijan; Bangladesh; Brunei Darussalam; Cambodia; Georgia; Hong Kong, China; India; Indonesia; Japan; Kazakhstan; the Kyrgyz Republic; Malaysia; Mongolia; Myanmar; Nepal; New Zealand; Pakistan; the People's Republic of China; the Philippines; the Republic of Korea; Singapore; Sri Lanka; Taipei,China; Tajikistan; Thailand; Uzbekistan, and Viet Nam.

Source: ADB calculations using data from CEIC Data Company.

Foreign direct investment (FDI) in the region continued to rise (Figure 1.5). In the first quarter of 2021, the region's FDI inflows reported in the Balance of Payments and
International Investment Position Statistics and national sources amounted to more than $\$ 212$ billion, a $60 \%$ increase from the same period in 2020.' The increase in FDI inflows reflected the high volume of mergers and acquisitions. The region's reported inward FDI growth was larger than for selected economies in other regions including North America and South America. FDI inflows slightly dipped to $\$ 182$ billion in the third quarter of 2021 , but still outpaced those in the same period of 2020 by $4 \%$. The resilience of FDI inflows to Asia and the Pacific mirrors the region's attractiveness as an investment destination and its stronger economic growth prospects compared with other regions.

\section{Figure 1.5: Inward Foreign Direct Investment-Selected} Asia and Pacific Economies (\$ billion)

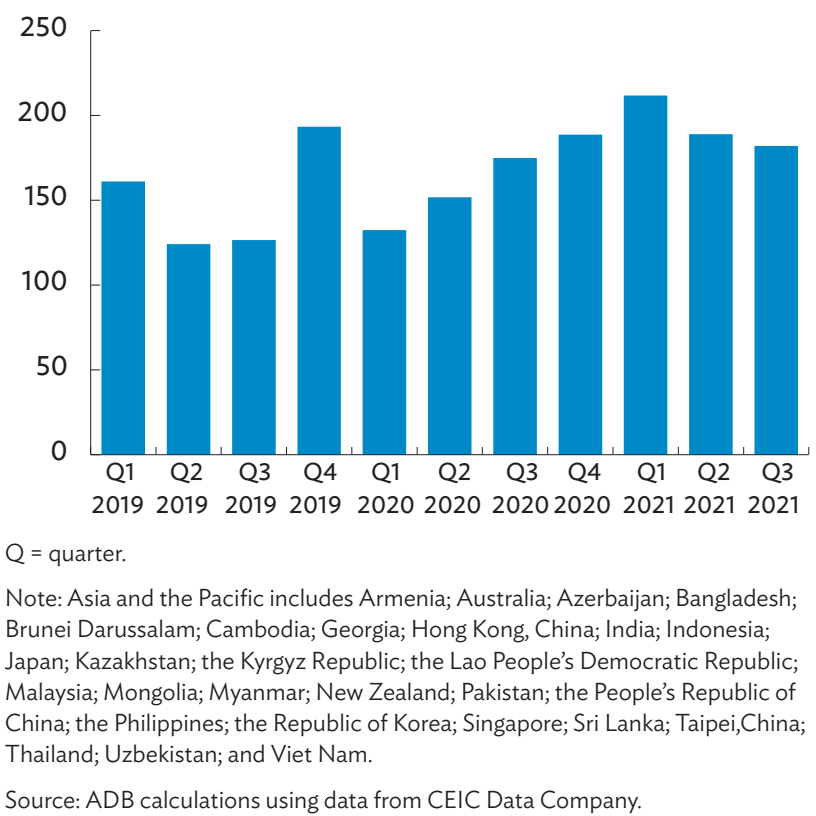

Nonresident portfolio inflows for selected Asia and Pacific economies continued to improve in the second quarter (Q2) of 2021 after reporting outflows in Q1 2020 (Figure 1.6). Nonresident debt securities or bond flows registered consecutive quarterly inflows from the second quarter of 2020 through the same quarter of 2021. Nonresident portfolio equity flows, likewise,

Data used in this chapter are quarterly FDI inflows from the Balance of Payments and International Investment Position Statistics of International Monetary Fund and national sources accessed through CEIC Data Company, while those in Chapter 3: Cross-Border Investment are bilateral annual FDI inflows from the United Nations Conference on Trade and Development, CEIC Data Company, and other regional organizations. Minor differences in estimates may be due to some methodological differences in data compilation, as well as in economy coverage. 
mostly reported inflows with the exception of the third quarter of 2020, when outflows were last recorded. Positive economic growth outlook and commodity price increases sustained nonresident portfolio inflows. Crossborder financial transactions, specifically remittances, also improved in 2021 (Figure 1.7). Remittances in the first 10 months of 2021 grew for most of the selected Asia and Pacific economies. But for some, remittances declined in the same period the year before. Other regions, such as Latin America and the Caribbean, also reported rising remittances. The expected rise in remittances for 2021 might be due to the economic recovery in host economies and the shift from cash to digital transfers as well as from informal to formal channels (Oxford Business Group 2021).

\section{Figure 1.6: Nonresident Portfolio Inflows-} Selected Asia and Pacific Economies (\$ billion)

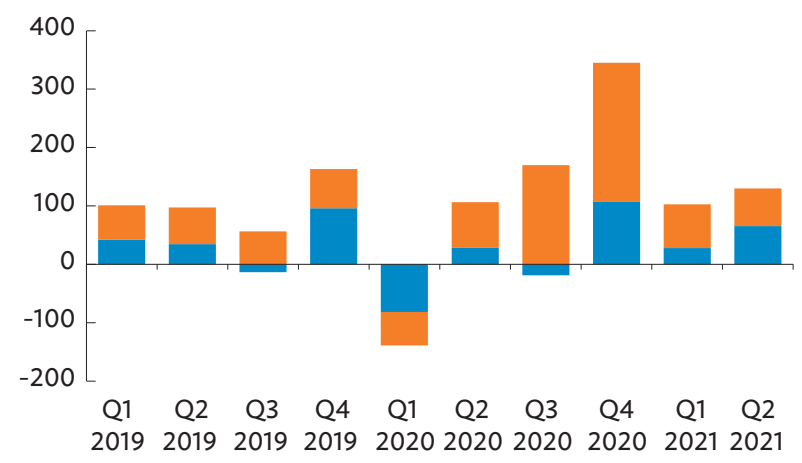

Equity Debt securities

\section{$Q=$ quarter}

Note: Asia and the Pacific includes Armenia; Australia; Azerbaijan; Bangladesh; Brunei Darussalam; Cambodia; Georgia; Hong Kong, China; India; Indonesia; Japan; Kazakhstan; the Kyrgyz Republic; the Lao People's Democratic Republic; Malaysia; Mongolia; Myanmar; New Zealand; Pakistan; the People's Republic of China; the Philippines; the Republic of Korea; Singapore; Sri Lanka; Taipei,China; Thailand; and Uzbekistan.

Source: ADB calculations using data from CEIC Data Company.

On the contrary, the region's trade in services continued to be weak in 2021 (Figure 1.8). Specifically, total trade in services for selected Asia and Pacific economies reached $\$ 624$ billion in the first quarter of 2021 and $\$ 655$ billion in the second quarter, both higher than $\$ 610$ billion recorded in the final quarter of 2020 . But these values were way below the pre-pandemic quarterly average value of about $\$ 754$ billion from 2018 to 2019. Among the categories of trade in services, cross-border travel continued to fall the most in 2021, reaching $\$ 57$ billion and $\$ 53$ billion in the first and second quarters of 2021, both significantly below the pre-pandemic quarterly average value of $\$ 221$ billion. In contrast, telecommunications, computer, and information trade services continued to rise during the pandemic up to 2021, from quarterly average value of about $\$ 67$ billion in 2018 to 2019 to about $\$ 80$ billion in 2020 to 2021.

Figure 1.7: Monthly Remittances GrowthJanuary-October 2021 (year-to-date, \%)

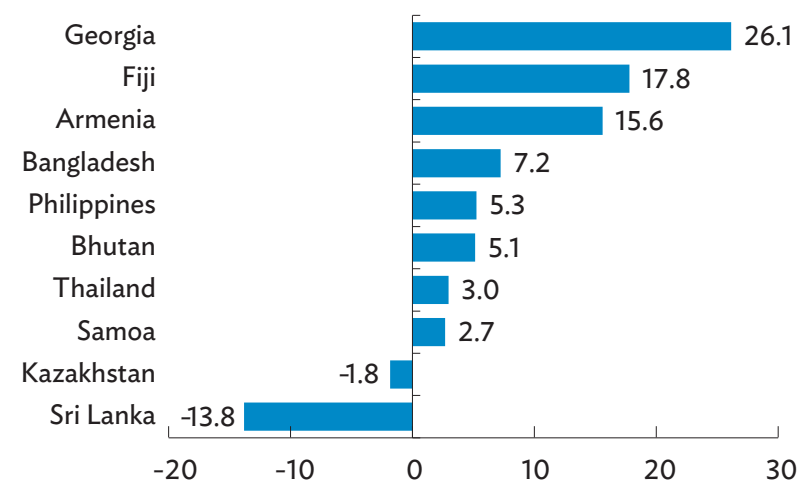

Note: Data for Bhutan and Kazakhstan cover the period until July and September, respectively.

Source: ADB calculations using data from national sources.

Among cross-border activities, tourist arrivals in Asia and the Pacific remained depressed in 2021. According to United Nations World Tourism Organization (UNWTO) November 2021 report, 30 destinations in the region stayed completely closed, 9 were partially closed, and 10 have compulsory testing and quarantine measures as the spread of COVID-19 variants prompted authorities to take a more cautious approach in opening their economies to foreign tourists (UNWTO 2021). Moreover, there was clear divergence in tourist arrivals within the region (Figure 1.9). In the second half of 2021, several destination economies, including Australia; Cambodia; New Zealand; and Taipei,China experienced continued declines in tourist arrivals compared with the first half of 2021; while improvements were seen in Georgia; Hong Kong, China; Japan; the Republic of Korea; and Singapore. 
Figure 1.8: Trade in Services for Selected Asia and Pacific Economies ( $\$$ billion)

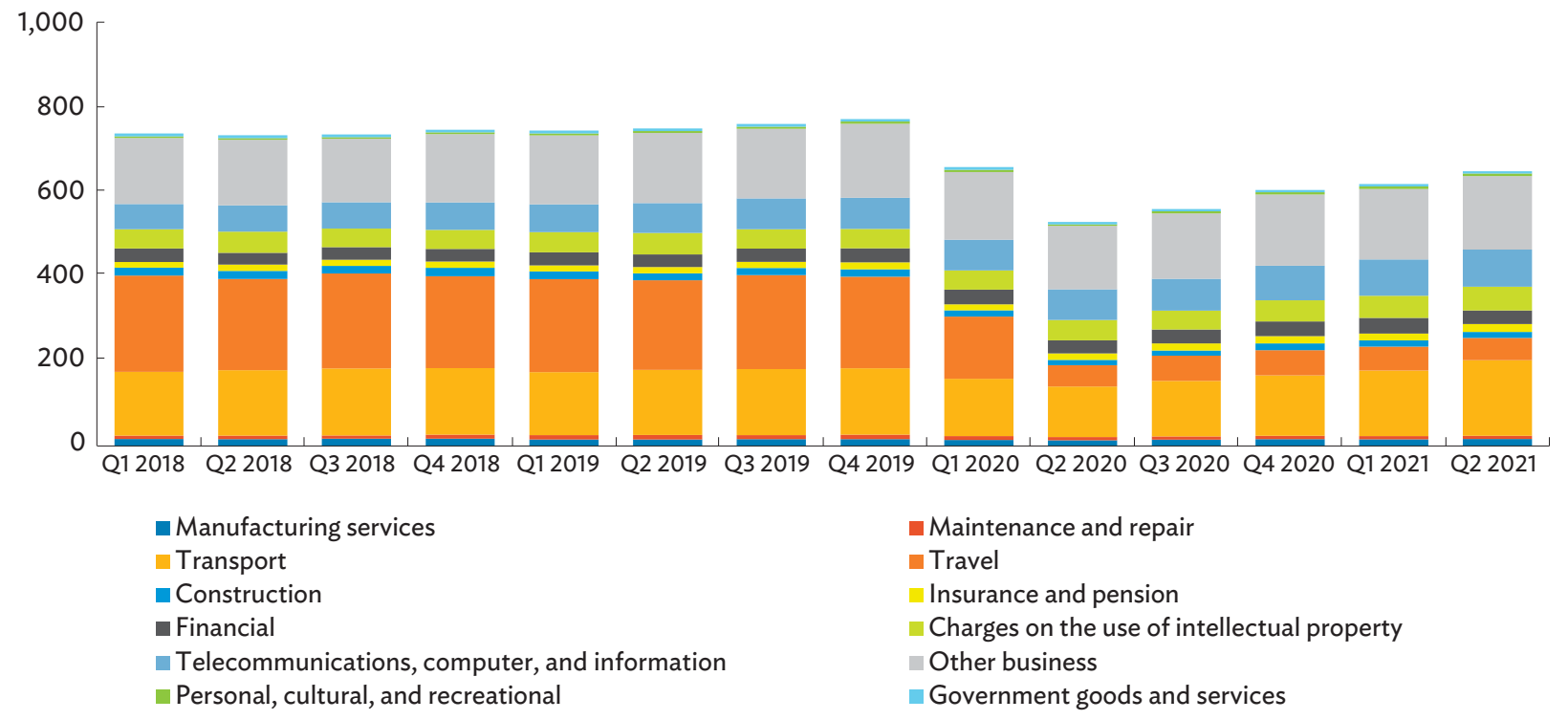

$Q=$ quarter

Notes: Trade in services is computed as trade in services credits plus debits. Asia and Pacific economies include Armenia; Australia, Cambodia; Fiji; Georgia; Hong Kong, China; India; Indonesia; Japan; Kazakhstan; Malaysia; Nepal; New Zealand; Pakistan; the People's Republic of China; the Philippines; the Republic of Korea; Singapore; Taipei,China; and Thailand.

Source: ADB calculations using data from International Monetary Fund. Balance of Payments and International Investment Position Statistics. https://data.imf.org/BOP (accessed January 2022).

Figure 1.9: International Tourist Arrivals (April $2020=100)$

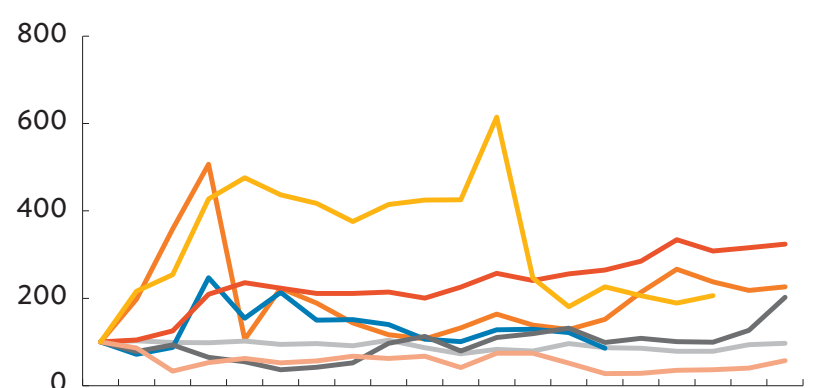

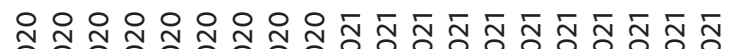

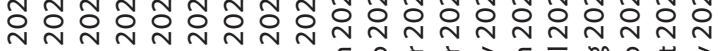

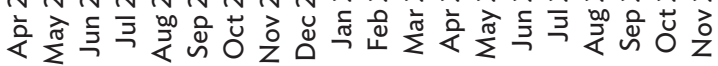

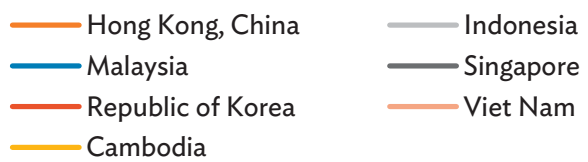

Source: ADB calculations using data from CEIC Data Company and national sources.

The overall weakness in tourist arrivals due to border closures and quarantine measures concurs with the global decrease in number of flights. Domestic and international flights have declined from pre-pandemic levels since

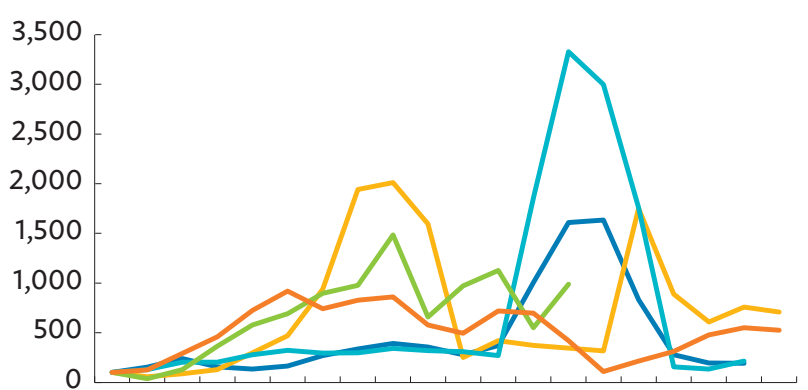

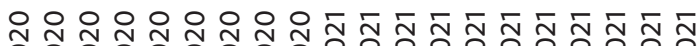

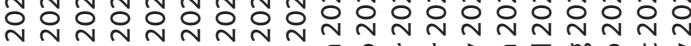

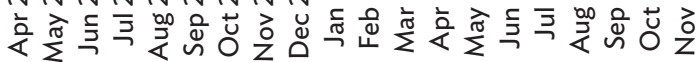

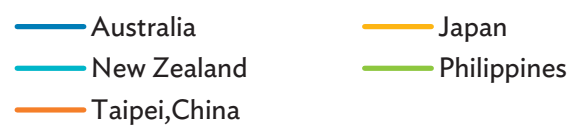

March 2020. However, domestic flights improved in the first half of 2021, particularly in the People's Republic of China (PRC), but numbers dropped again in the second half of 2021 as authorities implemented new restrictions to 
contain new COVID-19 variants. Meanwhile, international flights in the Asia and Pacific region lagged others as of September 2021 as the region remained mostly closed for passenger air travel (IATA 2021).

\section{Delays in vaccine rollout and new virus mutations continued to pose risks to economic recovery and full resumption of cross-border economic activities in Asia and the Pacific.}

In 2021, recovery in cross-border transactions were uneven, with merchandise trade, investment, capital flows, and remittances showing continued growth, while trade in services, particularly in non-digital services, and movement of people remained depressed. But as crossborder transactions and movement play a key role in the region's economic growth, full resumption of crossborder economic activities and synchronous recovery will depend on the speed and scale of COVID-19 inoculation. The longer the pandemic persists, the more chances new variants will emerge which risks the efficacy of existing vaccines and imposition of new containment measures and border closures. Although ramped up across the region and elsewhere, the varying progress of vaccination underlies the uneven pace of economic recovery in Asia and the Pacific (Figure 1.10).

\section{Figure 1.10: Output Difference and Vaccination}

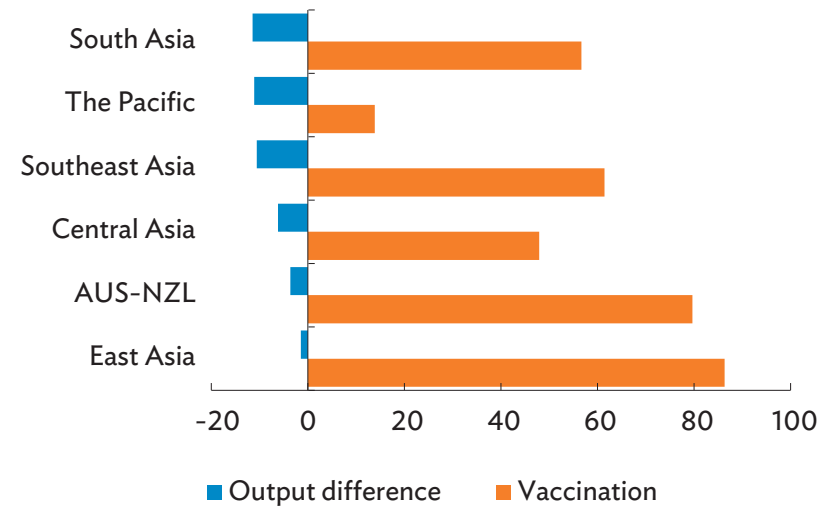

AUS = Australia, NZL = New Zealand

Notes: Output difference is the latest gross domestic product forecast index for 2021 minus the pre-pandemic forecast index for 2021. Vaccination is the fully and partially vaccinated people as percentage of population.

Sources: ADB calculations using data from ADB (2021b); and Our World in Data and United Nations downloaded from CEIC Data Company.

\section{Regional integration of Asia and the Pacific showed steady progress, especially in East Asia in 2019.}

Overall, regional cooperation and integration in Asia and the Pacific remained stable and displayed gradual progress in 2019 with a $7 \%$ improvement relative to 2006 (Figure 1.11). Regional integration estimates were high in people and social integration, regional value chain, and infrastructure and connectivity. Progress in a new measure for technology and digital connectivity has been important, registering a 2.8\% average annual increase for the same period. Innovations in the digital ecosystem contributed to the striking growth of technology and digital connectivity within the region, which features wider internet penetration, increased intraregional patent applications, and more trade in information and communication technology (ICT) goods. The rise of digital platforms is helping pave the way for digital transformation in Asia and the Pacific, which could support post-pandemic recovery efforts (ADB 2021a). Box 1.1 discusses the enhanced index of regional cooperation and integration.

Compared with other regions, Asia and the Pacific was next only to the European Union (EU) in terms of highest overall integration. Looking at indexes of the different dimensions of regional cooperation and integration in 2019, Asia and the Pacific performed equally well with the EU in trade, investment, and value chain participation, and exceeded all other regional groupings for technology and digital connectivity (Figure 1.12).

Asian subregions consistently showed divergent performance in most dimensions (Figure 1.13). East Asia and Southeast Asia maintained the highest levels of integration, while Central Asia showed upside potential. Southeast Asia's good performance in trade and investment, and people and social integration dimensions has been facilitated by members' participation in broader integration initiatives in Asia and the Pacific, such as the proposal for the Association of Southeast Asian Nations (ASEAN) to form an economic community. East Asia leads in five of the eight dimensions, with results comparable to Southeast Asia. As expected, digital connectivity across regions appears to be following a similar 
Box 1.1: An Enhanced Measure of Regional Cooperation and Integration

As channels of regional cooperation and integration evolve, ADB's Asia-Pacific Regional Cooperation and Integration Index (ARCII) needs to be reviewed and strengthened. Enhancements to the ARCII framework aim to ensure that the index adequately captures the drivers and mechanisms of regional cooperation and integration as well as improve the availability, quality, and consistency of data.

Two new dimensions, measuring the contributions of digital connectivity and environmental cooperation, were added to the ARCII, along with new indicators to better measure existing dimensions (box figure 1). The index coverage was expanded from a baseline of 158 to 173 economies and from 26 to 41 indicators. The two new dimensions facilitate better understanding of the role in regional cooperation and integration measures in technology, digital connectivity, and for environmental cooperation. Meanwhile, the new indicators in existing dimensions aim to improve the comparability and data coverage of the ARCII.

Estimates for Asian subregions remain consistent between the baseline and enhanced ARCII frameworks after new dimensions and other enhancements were introduced. As illustrated in box figure 2, East Asia and Southeast Asia continue to have the highest scores across dimensions, yet performance gaps remain pronounced in the trade and investment dimension.

Further innovations in the enhanced framework, such as index customization, improve the applicability of ARCII as a measure of regional cooperation and integration. A new feature is the flexibility to customize the index structure, which allows users to tailor the ARCII framework to fit

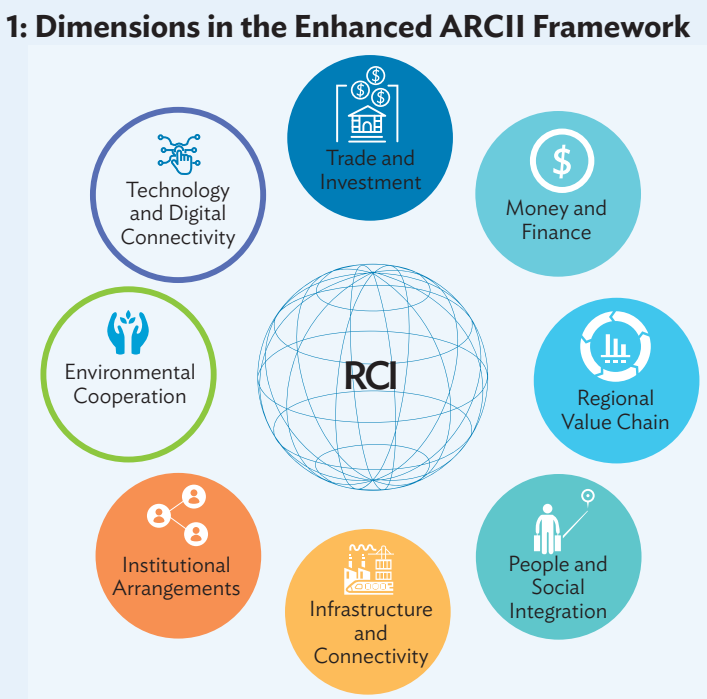

ARCII = Asia-Pacific Regional Cooperation and Integration Index, $\mathrm{RCI}=$ regional cooperation and integration.

Source: ADB (2021a).

their needs, include new specific indicators (e.g., tourism for the Pacific or health for Southeast Asia), and expand analysis to focus on specific areas. Examples on index customization for Eurasia and the Asia-Pacific Economic Cooperation (APEC) can be extended to other economy groupings. This tailored approach can also improve the accuracy of underlying data-for example, using national data sources in some indicator-and facilitate in-depth analysis on specific dimensions.

\section{2: Comparison of Baseline and Enhanced ARCII Estimates, 2019}

(a) Baseline (six-dimensional index)

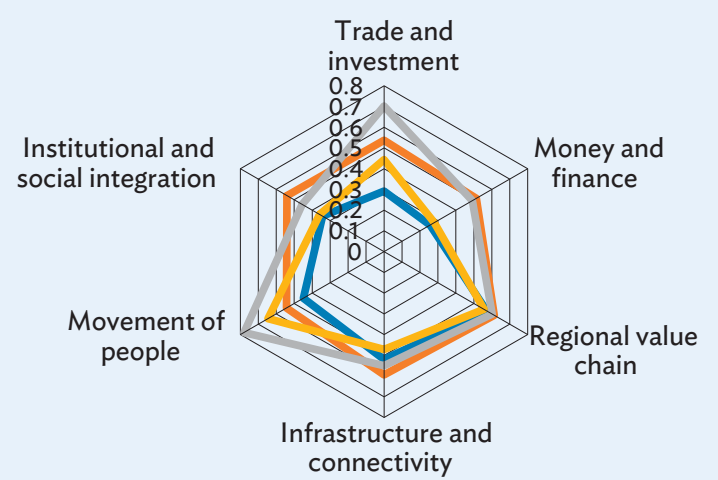

Central Asia $\quad$ East Asia (b) Enhanced (eight-dimensional index)

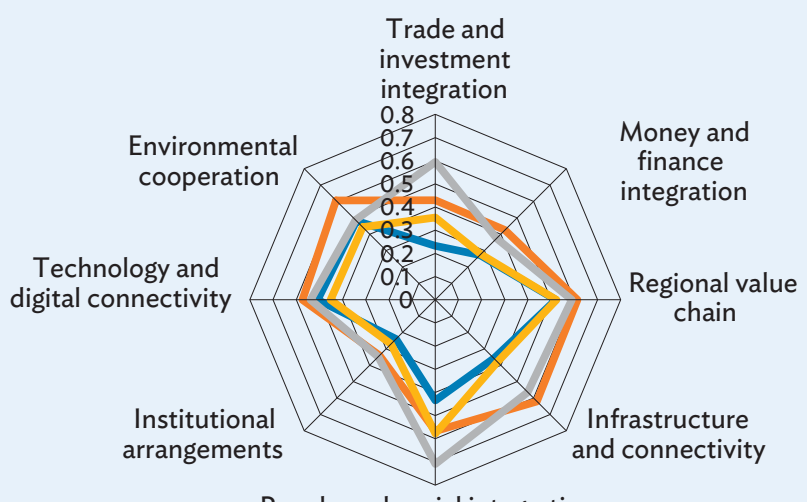

People and social integration

ARCII = Asia-Pacific Regional Cooperation and Integration Index

Source: ADB. Asia Regional Integration Center. Asia-Pacific Regional Cooperation and Integration Index Database. https://aric.adb.org/database/arcii (accessed October 2021). 
Figure 1.11: Overall ARCII and Dimensional Index-Asia and the Pacific

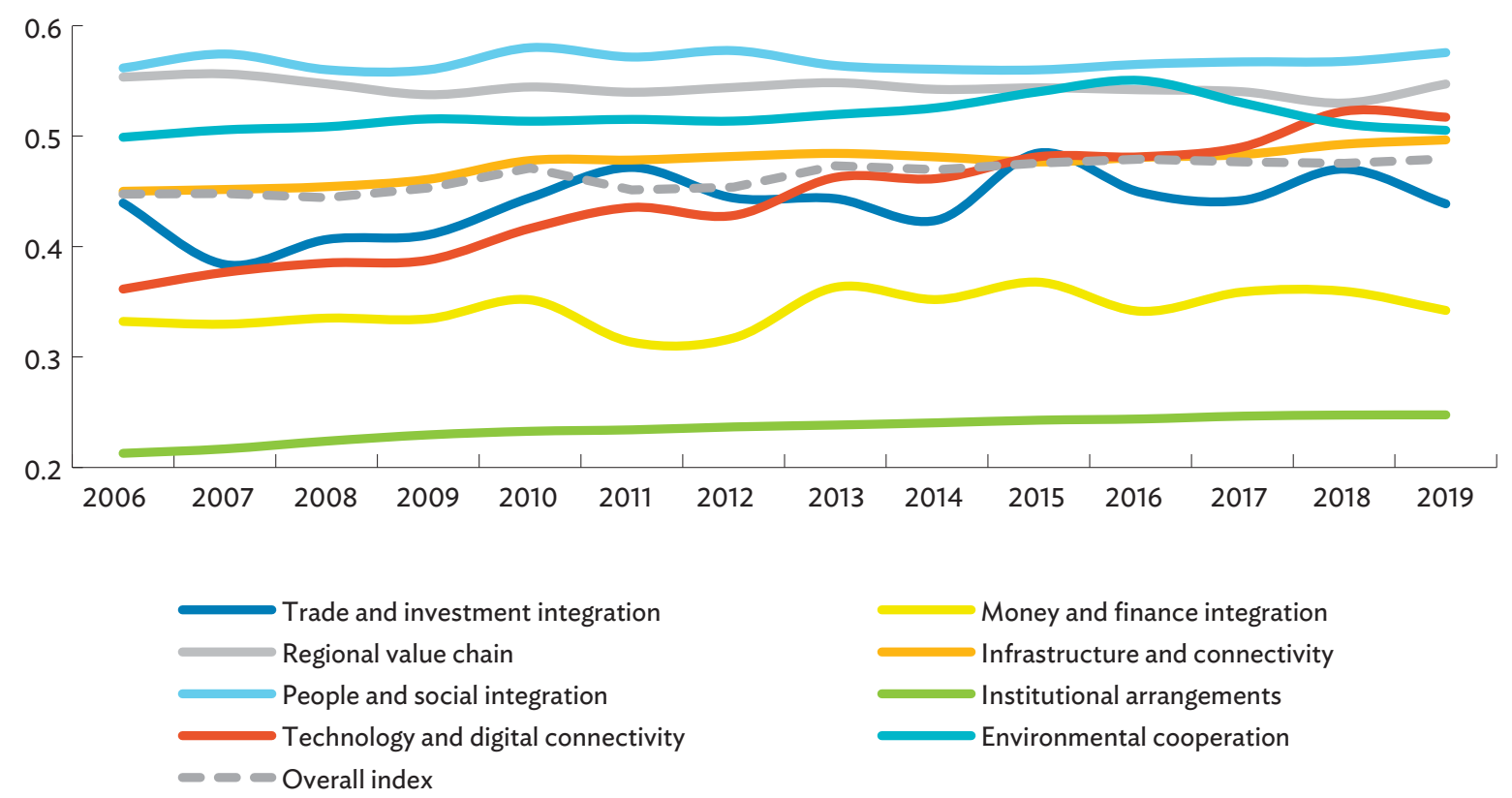

ARCII = Asia-Pacific Regional Cooperation and Integration Index.

Notes: Worldwide normalization is used for all estimations, where the indicators are normalized using global maximum and minimum values across all regions. Higher values denote greater regional integration.

Source: ADB. Asia Regional Integration Center. Asia-Pacific Regional Cooperation and Integration Index Database. https://aric.adb.org/database/arcii (accessed October 2021).

\section{Figure 1.12: Dimensional Indexes-Asia and the Pacific versus Other Regions, 2019}

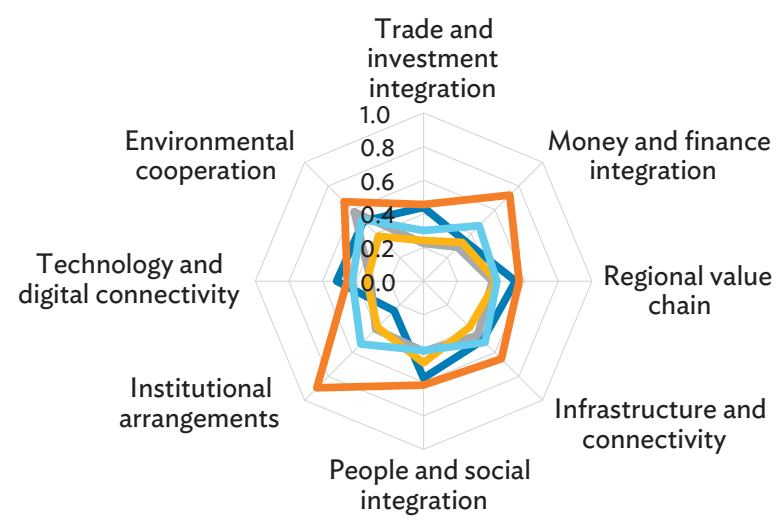

$$
\begin{array}{ll}
\text { - Asia and the Pacific } & \text { EU } \\
\text { - Africa } & \text { Middle East }
\end{array}
$$

ARCII = Asia-Pacific Regional Cooperation and Integration Index, $\mathrm{EU}=$ European Union .

Notes: Worldwide normalization is used for all estimations, where the indicators are normalized using global maximum and minimum values across all regions. Higher values denote greater regional integration.

Source: ADB. Asia Regional Integration Center. Asia-Pacific Regional Cooperation and Integration Index Database. https://aric.adb.org/database/arcii (accessed October 2021).
Figure 1.13: Dimensional Indexes by Subregions in Asia and the Pacific, 2019

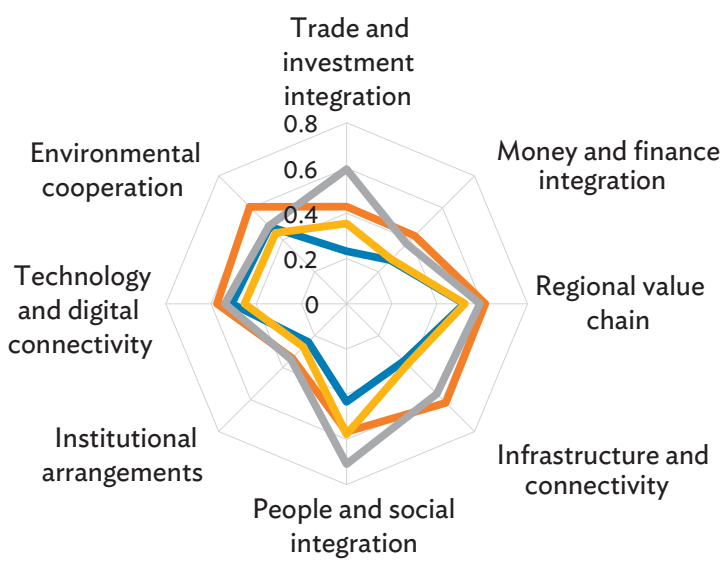

$$
\begin{array}{ll}
\text { - Central Asia } & \text { - East Asia } \\
\text { - South Asia } & \text { - Southeast Asia }
\end{array}
$$

ARCII = Asia-Pacific Regional Cooperation and Integration Index .

Notes: Worldwide normalization is used for all estimations, where the indicators are normalized using global maximum and minimum values across all regions. Higher values denote greater regional integration.

Source: ADB. Asia Regional Integration Center. Asia-Pacific Regional Cooperation and Integration Index Database. https://aric.adb.org/database/arcii (accessed October 2021). 
trend, while people and social integration remains at various levels of development. On environmental cooperation, Asia and the Pacific has remained stable among subregions, with its efforts now close to three-quarters of those in the EU and North America, the top performing regions. Overall, these indicators show willingness for regional cooperation and integration across Asia and the Pacific.

\section{Amid pandemic and economic uncertainties, Asia and the Pacific can take the opportunity to improve trade in digital services and deepen regional cooperation.}

Trade in digital services can offer new impetus for crossborder trade, which supports economic recovery, more so as the region has high technology and digital connectivity. Nonetheless, policy support and initiatives are needed to fully harness the benefits of trade in digital services. Deeper regional cooperation in data flow and regulations around data protection, consumer protection, e-signatures, and e-invoices will play a greater role in advancing new approaches to collaboration, enabling post-pandemic recovery, with inclusive, sustainable, and green outcomes. This will also reshape the future of globalization.

\section{Trade in digital services can offer impetus for post-pandemic economic recovery.}

Services have become the backbone of the world economy. In 2019, services accounted for about twothirds of both world gross domestic product (GDP) and FDI and provides majority employment (WTO 2020). The value of international trade in services is forecast to increase from $\$ 6.1$ trillion in 2019 to $\$ 8.0$ trillion by 2025 , equivalent to one-third of the value of global flows over this period (Oxford Economics and Western Union Business Solutions 2020). WTO (2019) projects that by 2040 the share of services in world trade will grow by $50 \%$. Developments in ICT, and digitalization in particular, have been responsible for the growing importance of trade in services. Digitalization dramatically cut costs and lowers barriers to entry, facilitating a wider range of services to be traded. Given social distancing and travel restrictions during the COVID-19 pandemic, adoption of digital technology was accelerated even more as companies expanded their online presence and consumers adopted new habits especially in the health, education, telecommunication, and audiovisual services sectors (WTO 2020).

This trend is also seen in Asia and the Pacific, where trade in digital services has been expanding more rapidly than trade in other services (Chapter 7: Theme Chapter-Advancing Digital Services Trade in Asia and the Pacific). ${ }^{2}$ The region is the second-largest trader of digital services, with this trading segment growing faster than in other parts of the world. In 2020, amid the COVID-19 pandemic, year-on-year growth of trade in digital services in Asia and the Pacific remained resilient (at a 1\% increase) while other services (global tourism, travel, and distribution sectors) plummeted 38\% (Liberatore, Avendano, and Cho 2021). In recent years, sectors contributing the most to Asia's growth in digital services trade are other business services and telecommunications, and computer and information services. The value of trade across the region is diverse, and so are the stages of development of the digital services trade sector. East Asia is by far the top trader, with the PRC; Singapore; the Republic of Korea; and Hong Kong, China as top traders not just for East Asia but for Asia and the Pacific as a whole. Similarly, India with its mature and diversified digital services sector dominates digital service exports across the whole of Asia and the Pacific. Some Southeast Asian economies have also been driving expansion in digital services trade by posting rapid growth in digital exports-as in Cambodia, the Lao People's Democratic Republic (Lao PDR), and the Philippines. Emerging areas of further growth include e-commerce, digital transactions, demand for automation, and the remote delivery of services (Chanda 2021). The theme chapter of this report extends the discussion.

A well-developed digital economy offers great opportunity for developing economies to catch up with developed economies through high-value service exports in areas such as artificial intelligence solutions and

2 Digital trade encompasses "cross-border, digitally-enabled transactions of goods and services, which involve consumers, firms, and governments as well as cross-border data flows that generate value for the domestic economy" (Chanda 2021). One component of digital trade is trade in digital services. 
predictive analytics; as well as skills-specific outsourcing (e.g., engineering and research and development services). This allows for diversification from resources and manufacturing and supports economic resilience as shown during the COVID-19 crisis. Moreover, the bold response of companies and governments to pandemic disruptions further accelerated adoption of digital and other technologies. Under certain conditions, these can increase productivity growth and support broadbased recovery. To tap and/or maximize these benefits, governments need to change domestic policies and collaborate on international policy reforms to further promote cross-border digital service flows (which again is discussed in the theme chapter).

\section{In the post-COVID-19 economic recovery, the mega trade agreements will sustain the region's momentum in cross-border trade, investment, and regional cooperation.}

The Regional Comprehensive Economic Partnership (RCEP) and the Comprehensive and Progressive
Agreement for Trans-Pacific Partnership (CPTPP) mark the importance of trade partnership to facilitate movement of goods and services and to forge closer economic cooperation. While RCEP encourages greater cooperation among the 10 ASEAN economies and its Free Trade Agreement (FTA) partners (Australia-New Zealand,the PRC, Japan, and the Republic of Korea), CPTPP strengthens the economic connectivity among 11 economies (Australia, Brunei Darussalam, Canada, Chile, Japan, Malaysia, Mexico, New Zealand, Peru, Singapore, and Viet Nam) (Figure 1.14). ${ }^{3}$

Both are comprehensive in nature and cover issues of market access and regulatory coherence. Although the scope of CPTPP is larger since it covers provisions for state-owned enterprises and labor and the environment, RCEP is more accommodative in its ambition because it gives more attention to the development differences of participating members. CPTPP entered into force on 30 December 2018, ${ }^{4}$ while RCEP became effective on 1 January 2022 after 60 days of ratification by six ASEAN members and four nonASEAN economies. ${ }^{5}$

Figure 1.14: Difference between CPTPP and RCEP, 2020

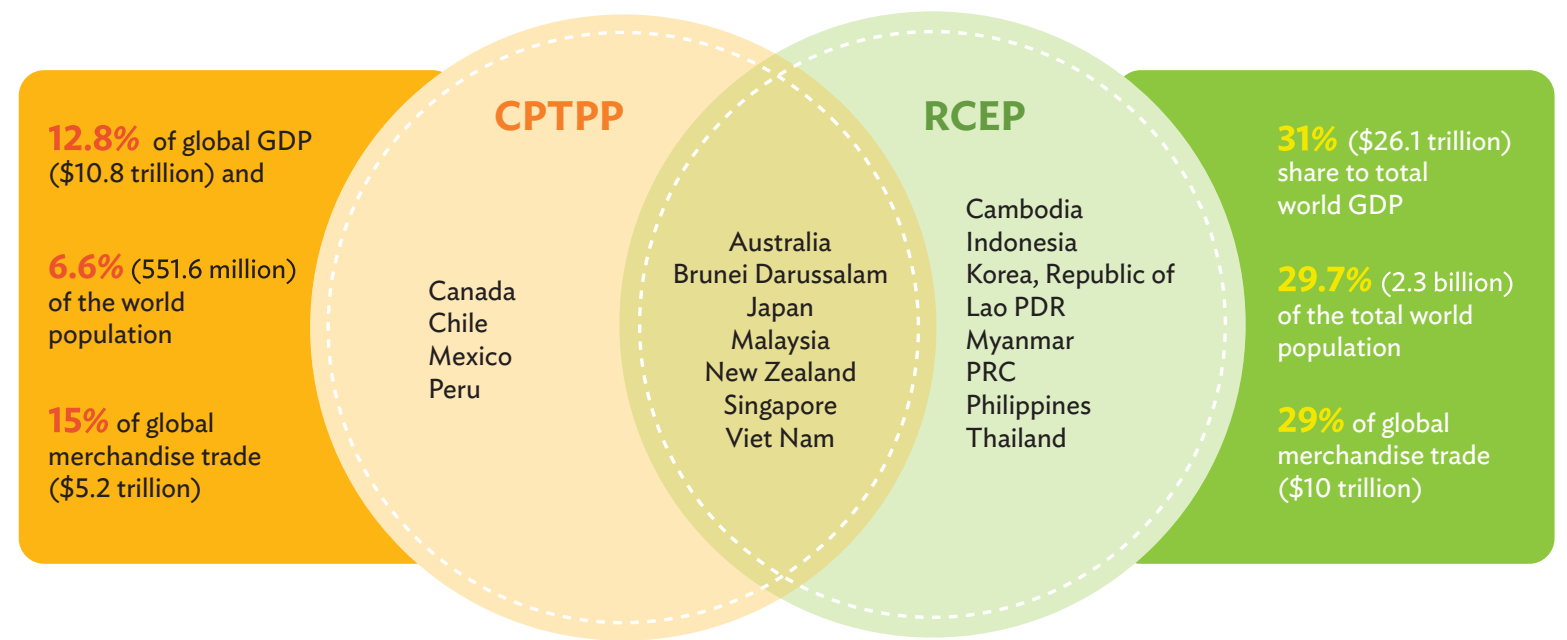

CPTPP $=$ Comprehensive and Progressive Agreement for Trans-Pacific Partnership, GDP = gross domestic product, Lao PDR = Lao People's Democratic Republic, PRC = People's Republic of China, RCEP = Regional Comprehensive Economic Partnership.

Sources: ADB calculations using data from International Monetary Fund (IMF). Direction of Trade Statistics. https://www.imf.org/dot (accessed July 2021); IMF. World Economic Outlook April 2021 Database. https://www.imf.org/en/Publications/WEO/weo-database/2021/April (accessed October 2021); and United Nations downloaded from CEIC Data Company.

ASEAN's FTA with Australia and New Zealand is a single trade agreement, known as ASEAN-Australia-New Zealand FTA.

4 CPTPP entered into force with seven economies on 30 December 2018. It is yet to be ratified by four other negotiating membersBrunei Darussalam, Chile, Peru, and Malaysia.

5 As of 2 November 2021, the six ASEAN economies that have ratified the agreement are Brunei Darussalam, Cambodia, the Lao PDR, Singapore, Thailand, and Viet Nam; while the four non-ASEAN economies are Australia, the PRC, Japan, and New Zealand. 
Both trade agreements are termed mega regionals as they account for a substantial part of global GDP and population. As of 2020, RCEP economies accounted for about 31\% ( $\$ 26.1$ trillion) of global GDP and around 29.7\% (2.3 billion) of the world's total population. These proportions are larger than CPTPP, which accounts for $12.8 \%$ of global GDP (\$10.8 trillion) and 6.6\% (551.6 million) of total population. RCEP also is larger in economic size compared with the European Union and the United States-Mexico-Canada Agreement (USMCA, formerly known as North American Free Trade Agreement or NAFTA). ${ }^{6}$

RCEP and CPTPP economies play a prominent role in global trade. In particular, the RCEP economies account for about $29 \%$ of global merchandise trade ( $\$ 10$ trillion), higher than the share of CPTPP (15\%) and USMCA (15.5\%). The share of RCEP economies in global trade has expanded in the last 2 decades, showing its growing significance in global trade (Figure 1.15). There is greater scope to increase the intraregional trade share of RCEP economies as the agreement comes into practice. While the intraregional trade intensity of RCEP economies in past years is greater than one, upside potential remains (Figure 1.16).

Figure 1.15: Regional Trade (\% share to global)

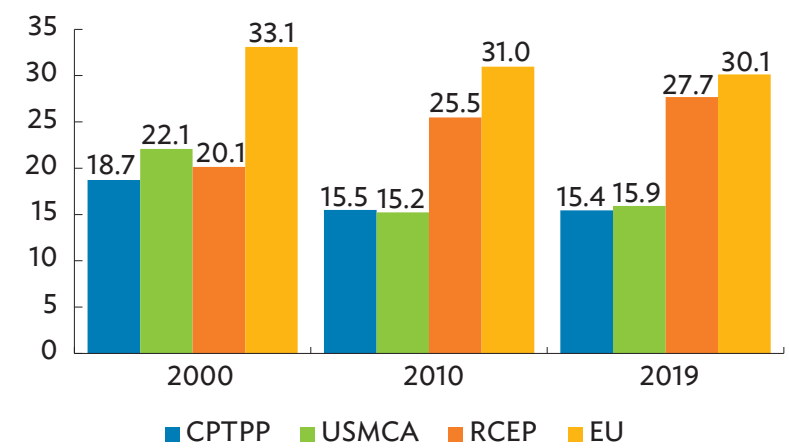

CPTPP $=$ Comprehensive and Progressive Agreement for Trans-Pacific Partnership, $\mathrm{EU}=$ European Union (27 members), RCEP = Regional Comprehensive Economic Partnership, USMCA = United States-Mexico-Canada Agreement.

Source: ADB calculations using data from International Monetary Fund. Direction of Trade Statistics. https://data.imf.org/dot (accessed July 2021).

The RCEP agreement is expected to promote investment in the region as the participating economies commit to remove some requirements on investors that intend to enter or expand in the RCEP economies (e.g., required percentage of domestic content) (Government of Singapore, Ministry of Trade and Industry. 2021). The value of intra-RCEP investment was $\$ 122$ billion in 2019, higher than in other regional cooperation blocs other than the EU, where investment between EU economies was $\$ 414$ billion over the same period (Figure 1.17). The diversity among RCEP members offer scope for complementarity generating opportunities for investment within the region.

Figure 1.16: Intraregional Trade Intensity Index (\%)

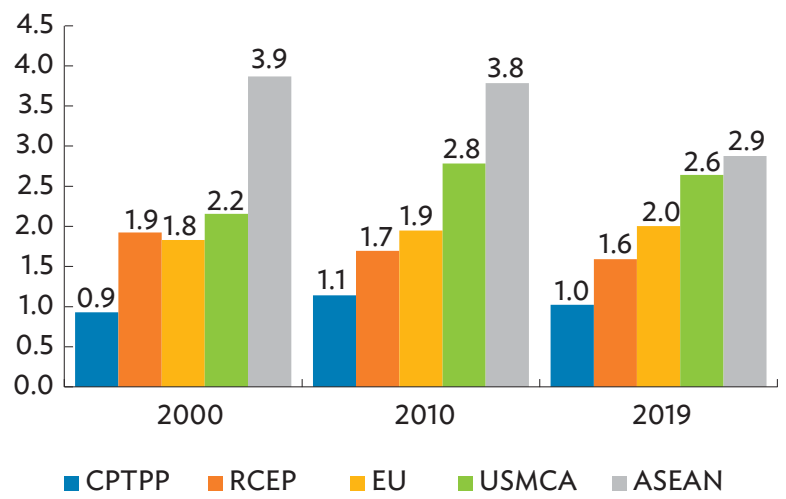

ASEAN = Association of Southeast Asian Nations, CPTPP = Comprehensive and Progressive Agreement for Trans-Pacific Partnership, EU = European Union (27 members), RCEP = Regional Comprehensive Economic Partnership, USMCA = United States-Mexico-Canada Agreement.

Source: ADB calculations using data from International Monetary Fund. Direction of Trade Statistics. https://data.imf.org/dot (accessed July 2021).

Figure 1.17: Intraregional Investment-Greenfield FDI and M\&As ( $\$$ billion)

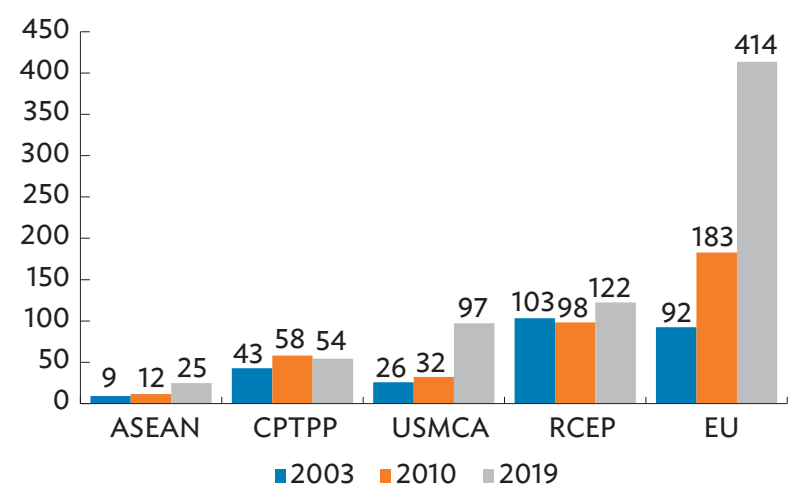

ASEAN = Association of Southeast Asian Nations, CPTPP $=$ Comprehensive and Progressive Agreement for Trans-Pacific Partnership, EU = European Union (27 members), $\mathrm{FDI}$ = foreign direct investment, $\mathrm{M} \& \mathrm{~A}$ = merger and acquisition, RCEP = Regional Comprehensive Economic Partnership, USMCA = United States-Mexico-Canada Agreement.

Sources: ADB calculations using data from Bureau van Dijk. Zephyr M\&A Database; and Financial Times. fDi Markets (both accessed September 2021).

6 The EU and USMCA constitute $5.7 \%$ and $6.4 \%$, respectively, of global population and $17.9 \%$ and $28 \%$, respectively, of global GDP. 
RCEP and CPTPP are expected to incentivize rebuilding of the supply chains in the region. Moreover, both RCEP and CPTPP dovetail well with the digital transformation agenda of the member economies following the COVID-19 pandemic (discussed in detail in Trade Rules, Regulations, and Regional Cooperation of the theme chapter). COVID-19 highlighted the importance of technology and digital trade. RCEP and CPTPP include commitments for a conducive digital trade environment in the region. They include provisions on cross-border data flows, digitization of trade documentation, use of electronic signature, and others to facilitate cross-border trade.

On the whole, both agreements have potential to make significant contributions to regional and national economies. The estimates are that by 2030 , RCEP will increase members' income by $0.6 \%$, and CPTPP by $0.3 \%$, while RCEP will add $\$ 245$ billion and CPTPP will add $\$ 113$ billion to regional income. RCEP is expected to add 2.8 million jobs to regional employment and CPTPP is expected to add 1.5 million. RCEP benefits are estimated to be greater than those of CPTPP - mainly because of RCEP's larger economic size, the higher degree of its prior integration, and new FTA partnerships, especially in East Asia (Park, Petri, and Plummer 2021).

\section{COVID-19 has highlighted the importance of global and regional cooperation to deal with challenges originating from health emergencies.}

Soon after the pandemic began, regional cooperation became important to keep global value chains functioning, particularly for essential goods (Table 1.1). The adoption of digital technology for customs reforms went well to address challenges in supply chain connectivity. Even cross-border e-commerce enabled many enterprises to maintain their business continuity. The disruptive effects of COVID-19 on many fronts - trade, logistics, mobility, health, finance, education - have amplified the need for economies to work together to promptly implement recovery initiatives and other measures.

In general, regional cooperation can take many forms across the spectrum, from informal collaboration to joint sectoral projects, to regional organization. In the past, these have worked to manage health emergencies. For example, during the 2003 SARS outbreak, ASEAN members along with Japan, the PRC, and the Republic of Korea decided to work together in areas of international travel, information sharing, and building alert and response capabilities. The regional response was commended by the World Health Organization (2003)

\section{Table 1.1: Subregional Cooperation in Areas of Economic Management and Trade in Response to COVID-19}

Areas of Collective Action Subregional/Economy-Led Initiatives

Keeping borders open, ensure flow of goods

Sustaining inclusive economic activity

Fiscal policy and macroeconomic management, strengthening disaster risk management
The Pacific Humanitarian Pathway on COVID-19 recognized needs to sustain trade-related economic activities of MSMEs and ensure gender equality; ASEAN established the COVID-19 response fund to procure medical supplies and equipment.

SASEC Customs Subgroup agreed to interagency and cross-border ASEAN during its special summit on COVID-19 agreed to preserve supply chain connectivity.

CAREC High-Level Virtual Panel on Countercyclical Fiscal Measures for Recovery and CAREC Economic and Financial Stability Forum foster coordinated policy solutions at regional and global levels. coordination, instituting special regimes for sensitive/critical goods;

ASEAN = Association of Southeast Asian Nations; CAREC = Central Asia Regional Economic Cooperation; COVID-19 = coronavirus disease; MSME = micro, small, and medium-sized enterprise; SASEC = South Asia Subregional Economic Cooperation.

Source: Adapted from Asian Development Bank. 
as an effective mode of cooperation against a common threat, leading to control of the spread of the disease. Similarly, during the COVID-19 pandemic, these economies used existing regional mechanisms or set up new ones to share daily updates, undertake risk assessments, exchange best practices, and disseminate knowledge on prevention and control (Fernando, De La Rosa, and Quiano-Castro 2020; and Table 1.2).

The regional cooperation mechanism can thus come up with several commitments and innovative tools and projects to overcome the challenges presented by the pandemic (discussed in detail in Chapter 6: Updates on Subregional Cooperation Initiatives).

\section{Enhancing regional cooperation is essential in post-COVID-19 socioeconomic agendas for an inclusive, resilient, and green recovery.}

COVID-19 offers a unique opportunity to rebuild economies through investment in social infrastructure while tackling pressing issues of poverty, inequality, and climate change. Health-care services have been worst hit during the pandemic. Even before, about 22\% of the global urban population and $56 \%$ of the rural population did not have health-care coverage. There was a need for 10 million health-care workers to ensure people's health security, including fighting infectious diseases (ILO 2017). The pandemic further highlighted the shortage of medical professionals. An estimated 18 million more health-care workers in low-income and lower-middle-income economies are now required to attain the comprehensive health coverage as stated in the 2030 Agenda for Sustainable Development (United Nations 2020). COVID-19 has pushed millions of people back into poverty, reversing much of the gain attained in the past. During 2010 and 2019, the share of population living in extreme poverty declined from $15 \%$ to $8.2 \%$. Given the prolonged nature of the pandemic, extreme poverty rose sharply in 2020 , the first increase since 1998. Around 70 million people fell into extreme poverty in 2020, according to UN estimates (United Nations 2020). These numbers are likely to rise further. COVID-19 is far from over as 2021 saw resurgence of the infection in many parts of the world.

Table 1.2: ASEAN, ASEAN+3 Health Cooperation Mechanisms for Epidemic Preparedness, 2003-2020

\section{3-2009 SARS and $\mathrm{H}_{1} \mathrm{~N}_{1}$}

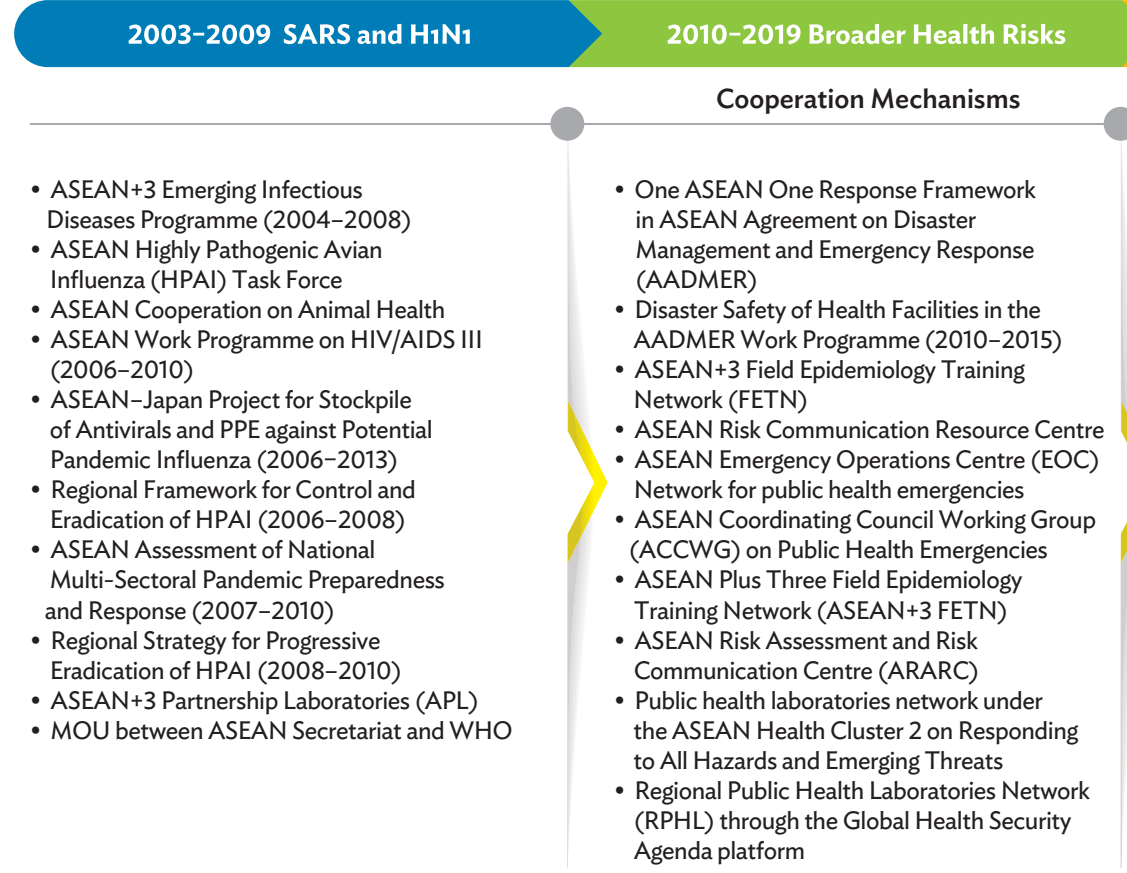

- ASEAN+3 Senior Officials' Meeting for Health Development (APT SOMHD) Mechanism Responding to COVID-19

- ASEAN Health Ministers and ASEAN+3 Health Ministers in Enhancing Cooperation on COVID-19

- ASEAN BioDiaspora Virtual Centre (ABVC) for Big Data Analytics and Visualization

ASEAN = Association of Southeast Asian Nations; ASEAN+3 = ASEAN plus Japan, the People's Republic of China, and the Republic of Korea; MOU = memorandum of understanding; PPE = personal protective equipment; SARS = severe acute respiratory syndrome; WHO = World Health Organization.

Source: Djalante et al. (2020). 
Rebuilding global and regional supply chains is a policy priority. Supply and demand shocks, along with temporary trade restrictions and shortages of critical goods exposed vulnerabilities in production strategies. Post-COVID-19, regional cooperation will become a necessity to increase supply chain resilience.

A multistakeholder approach involving the governments and businesses will need to be adopted to support information sharing and capacity building to learn from each other's experiences. Use of digital technology, efforts to solve behind-the-border challenges, and bilateral and regional trade agreements could help bring long-term efficiency gains. In addition, a resilient supply chain will require economies to invest in skills, minimize risks in inventory management, improve transport networks, strengthen trade logistics, and deploy digital means for cross-border paperless trade.

Finally, regional cooperation will have a greater role for a green recovery to ensure sustainable economic development. Before COVID-19, many Asia and Pacific economies had embarked on various climate change mitigating projects, including renewable energy, energy efficiency, and sustainable transport. They even decided to eliminate customs tariffs on environmental goods to promote usage in domestic economies, thus helping to strengthen environmental and climate protection. During 2006 and 2019, Asia and the Pacific witnessed an increase in the share of intraregional trade of environmental goods from $0.014 \%$ to $0.020 \%$ of total intraregional goods trade, with East Asia leading the way and Southeast Asia not far behind (ADB 2021a).

The pandemic, though applying the break, did not altogether reverse these initiatives. With progress in reopening, economic recovery plans will have to account for further investment in the green economy. The EU, Indonesia, the Republic of Korea, the Philippines, the United Kingdom, and others have announced recovery budgets that incorporates climate-related investments (ADB 2020). The ASEAN Catalytic Green Financing Facility, managed by ASEAN economies and ADB, have committed to support Southeast Asian economies in mobilizing finance for environment-sustainable infrastructure projects, and so contribute to climatechange commitments. Altogether, these efforts have potential to create sustainable jobs while protecting the environment and natural resources. Strong initiatives on climate change mitigating investments have potential to generate as much as $\$ 26$ trillion of net global economic benefits by 2030 , create 65 million new low-carbon jobs, and avoid 700,000 premature deaths from air pollution (The New Climate Economy 2018).

\section{Despite its limitations, globalization will retain its relevance and adapt to the changing environment post-pandemic.}

Seamless connectivity and a resilient supply chain will emerge as issues of greater importance. Concurrently, promoting cooperation for inclusive development that benefits people and small businesses will become crucial. The pandemic has already kick-started rapid digitalization. This will bring societal and economic transformation within nations and globally. International cooperation and policy adaptation will play a critical role in leveraging the benefits of digital transformation. Similarly, cooperation among economies will enhance greater resilience by managing vulnerability from climate change, disasters, and future pandemics. 


\section{References}

Asian Development Bank (ADB). 2020. Greening the Post-COVID-19 Recovery. Infographic. Manila.

- 2021a. Asia-Pacific Regional Cooperation and Integration Index: Enhanced Framework, Analysis, and Applications. Manila.

_. 2021b. Asian Development Outlook Supplement: Recovery Continues. Manila.

_- Asia Regional Integration Center. Asia-Pacific Regional Cooperation and Integration Index. https://aric.adb.org/arcii (accessed October 2021).

Chanda. R. 2021. Trade in Digital Services in Developing Asia. Background Paper for the Asian Economic Integration Report 2022 on "Digital Services Trade: Opportunities and Challenges for Developing Asia." Manuscript.

Djalante, R., L. Nurhidayah, H. V. Minh, N. T. N. Phuong, Y. Mahendradhata, A. Trias, J. Lassa, and M. A. Miller. 2020. COVID-19 and ASEAN Responses: Comparative Policy Analysis. Progress in Disaster Science. 8. 100129.

Fernando, F. M., J. F. E. De La Rosa, and M. K. QuianoCastro. 2020. COVID-19: A Collective Response in ASEAN. The ASEAN Magazine. 1. pp. 30-35.

Government of Singapore, Ministry of Trade and Industry. 2021. What You Need to Know About the Regional Comprehensive Economic Partnership Agreement. Press Release. 26 April.

International Air Transport Association (IATA). 2021. Air Passenger Market Analysis September 2021. Montreal.

International Labour Organization (ILO). 2017. World Social Protection Report 2017-19: Universal Social Protection to Achieve the Sustainable Development Goals. Geneva.

International Monetary Fund (IMF). Balance of Payments and International Investment Position Statistics. https://data.imf.org/bop (accessed January 2022).
—. Direction of Trade Statistics. https://data.imf.org/ dot (accessed July 2021).

Liberatore, A., R. Avendano, and W. Cho. 2021. Data on Trade in Digital Services Trade. Background Paper for the Asian Economic Integration Report 2022 on "Unlocking the Potential of Digital Services Trade in Asia and the Pacific." Manuscript.

The New Climate Economy. 2018. Unlocking the Inclusive Growth Story of the 21st Century: Accelerating Climate Action in Urgent Times. https://newclimateeconomy.report/2018/wpcontent/uploads/sites/6/2018/09/NCE_2018_ ExecutiveSummary_FINAL.pdf.

Oxford Business Group. 2021. Why Are Remittances to Emerging Markets Growing? London.

Oxford Economics and the Western Union Business Solutions. 2020. The Global Services Trade Revolutions: Fueling Post-Pandemic Economic Recovery and Growth. London: Western Union.

Park, C. Y., P. Petri, and M. Plummer. 2021. The Regional Comprehensive Economic Partnership and Recent Trade Policy Developments in Asia and the Pacific: Detailed Results. East Asian Economic Review. 25 (3). pp. 233-272.

United Nations (UN). 2020. The Sustainable Development Goals Report 2020. New York.

United Nations World Tourism Organization (UNWTO). 2021. COVID-19 Related Travel Restrictions: A Global Review for Tourism. Eleventh Report as of November 2021. Madrid.

World Health Organization (WHO). 2003. WHO Welcomes ASEAN Unity against SARS. Media Center. Geneva. 29 April.

World Trade Organization (WTO). 2019. World Trade Report 2019: The Future of Services Trade. Geneva.

2020. Trade in Services in the Context of COVID-19. Information Note. 28 May. 


\section{Trade and Global Value Chains}

\section{Recent Trends in Asia's Trade}

\section{Merchandise trade in Asia and the Pacific demonstrated strong resilience amid the pandemic in 2020 and continued its rapid growth in 2021.}

After bottoming out in mid-2020 during the first wave of the coronavirus disease (COVID-19) pandemic, the region's merchandise trade recovered faster than expected, especially over the first half of 2021 (Figure 2.1). When the first wave of the COVID-19 pandemic hit Asia and the Pacific, trade volumes declined rapidly beginning February 2020, hitting the lowest growth at $-6.0 \%$ in June 2020. The decline began to taper off in July 2020 and trade volumes were growing again by the third quarter of 2020, though plateaued at 3.8\% in November and 3.9\% in December 2020 before rising rapidly, to $10.2 \%$ in January 2021 . The recovery saw growth hit 19.1\% in June 2021 before settling to 12.7\% in August. The fluctuating trade growth partly reflects the patchy path of global economic recovery, which was affected by the phases of the pandemic and the containment measures taken by the governments.

Strong monetary and fiscal support by the governments, the arrival of vaccines, and the relative early success of most of the region's economies in getting the pandemic under control contributed greatly to this steep rebound (WTO 2021). Moreover, Asia and the Pacific became the supply hub for various consumer goods and medical supplies, which drove up its merchandise exports to the world. That said, with most of the region still struggling to secure enough effective vaccines and implement effective large-scale inoculation, resurgent waves due to new coronavirus variants such as Omicron pose a constant threat to the region's trade growth.

\section{Figure 2.1: Monthly Merchandise Trade by Value and Volume-Asia and the Pacific}

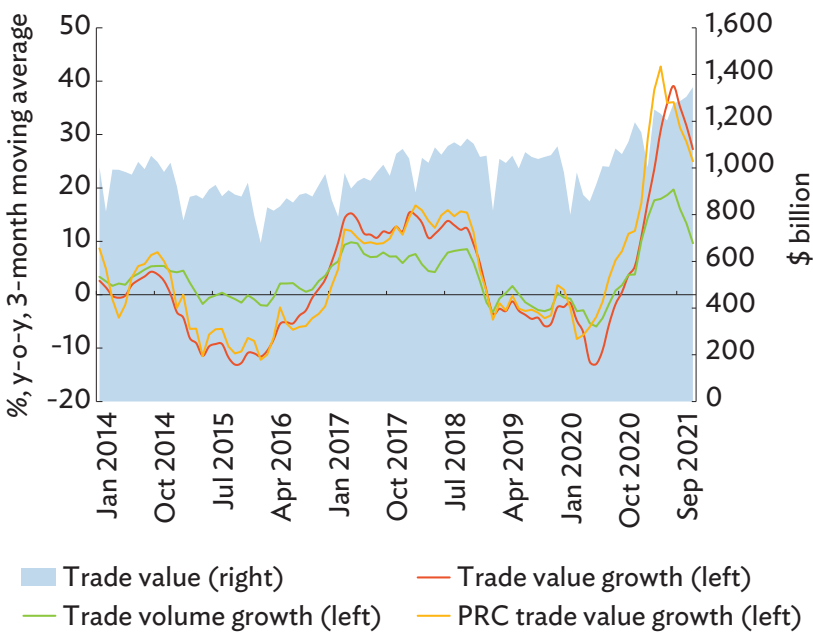

PRC = People's Republic of China, $y-0-y=$ year-on-year.

Notes: Trade volume growth rates were computed using volume indexes. For each period and trade flow type (i.e., imports and exports), available data include indexes for Japan, the PRC, and aggregate indexes for selected Asia and Pacific economies: (1) advanced economies excluding Japan (Hong Kong, China; the Republic of Korea; Singapore; and Taipei,China); and (ii) emerging economies excluding the PRC (India; Indonesia; Malaysia; Pakistan; the Philippines; Thailand; and Viet Nam). The aggregate index for Asia and the Pacific was computed using trade values as weights.

Sources: ADB calculations using data from CEIC Data Company; and CPB Netherlands Bureau for Economic Policy Analysis. World Trade Monitor. https:// www.cpb.nl/en/world-trade-monitor-october-2021 (accessed January 2022).

Figure 2.1 also highlights how the trade value growth of the People's Republic of China (PRC) recovered earlier and faster than in Asia and the Pacific overall, reaching doubledigit growth rates by November 2020 (11.4\%). The sustained rise peaked at $42.8 \%$ in April 2021 before moderating to 
$31.3 \%$ in July 2021. Figure 2.2 shows the PRC's export volume growth took a similar trend, peaking at $48.6 \%$ on March 2021 before moderating to $22.0 \%$ by June 2021 as external support waned (ADB 2021). However, the PRC's import volume grew more gradually, with positive rates beginning July 2020 at 4.8\% and reaching $17.4 \%$ in May 2021.

Merchandise export volumes in the newly industrialized economies (NIEs) showed a shallower contraction in mid-2020, followed by a return to growth during the second half of the year. Rapid rises in volume growth were observed for the Republic of Korea and Singapore in early 2021. Both economies gained from effective COVID-19 containment. In contrast, volume growth began to decelerate for Hong Kong, China in April 2021, although it demonstrated the fastest recovery in the early months of the year. Merchandise import volume growth also turned positive for the NIEs as early as the third quarter of 2020 although import volumes to Singapore shrank briefly in December 2020 and January 2021. Hong Kong, China's import volume growth, similar to its exports volume growth, increased faster than Taipei,China; Singapore; and the Republic of Korea, but slowed from March 2021.

\section{Figure 2.2: Monthly Trade Volume Growth-NIEs, the PRC, and Selected ASEAN Economies}

(\%, y-o-y, 3-month moving average)
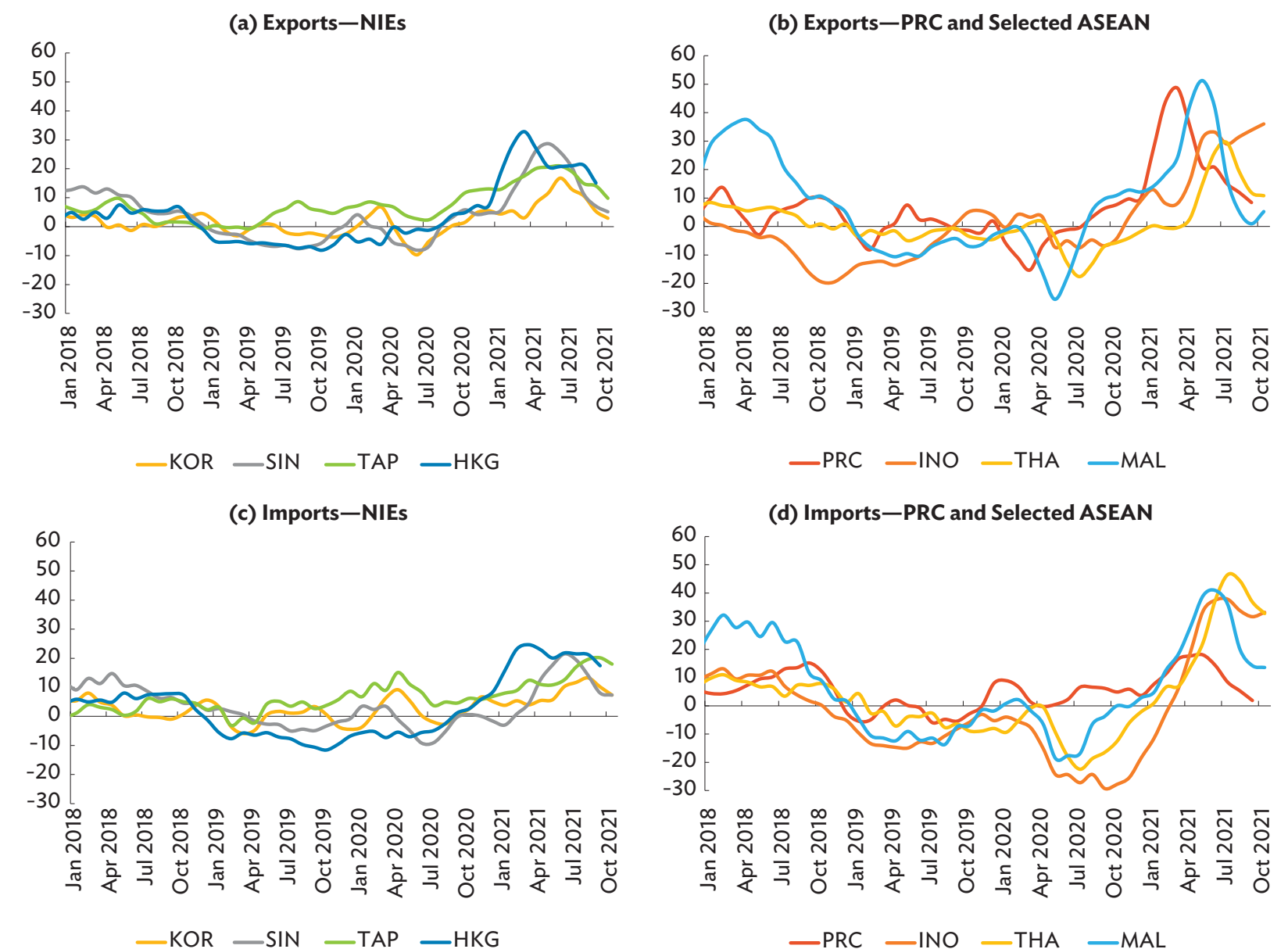

ASEAN = Association of Southeast Asian Nations; HKG = Hong Kong, China; INO = Indonesia; KOR = Republic of Korea; $M A L=$ Malaysia; NIE = newly industrialized economy; PRC = People's Republic of China; SIN = Singapore; TAP = Taipei,China; THA = Thailand; $y$-o-y = year-on-year.

Notes: Latest data are for October 2021 for all economies, except HKG and the PRC (September 2021). Data for the PRC refer to the export and import volume index from CPB Netherlands Bureau for Economic Policy Analysis. For the rest, export and import volumes are computed by deflating export and import values by their corresponding price indexes.

Sources: ADB calculations using data from CPB Netherlands Bureau for Economic Policy Analysis. World Trade Monitor. https://www.cpb.nl/en/world-trade-monitoroctober-2021 (accessed January 2022); and Haver Analytics. 
Merchandise import and export volumes for the three selected economies in the Association of Southeast Asian Nations (ASEAN) showed deeper and longer contractions in 2020 followed by bigger upswing trends than for the NIEs. They also differ on the timing of recovery. For instance, Malaysia's export volume shrank as much as $-25.6 \%$ in May 2020, but recorded earlier and higher recovery rates than Indonesia and Thailand. Export volumes for Thailand grew only from 2021. Recovery in imports was relatively slower or delayed, with Indonesia, for instance, only returning to positive import volume growth rates in March 2021. Gains from trade could falter, however, as some ASEAN economies are facing new waves of COVID-19 infection (ADB 2021).

Overall, global business confidence continues to improve as the world recovers from the pandemic and the vaccine rollouts progress gradually, even if unevenly, across the globe. Figure 2.3 shows that Asia's merchandise trade flow moves together with the business confidence index.

Standardized high frequency indicators-such as global shipping and packaging indexes suggest continuing global trade recovery (Figure 2.4). Nevertheless, the recent hikes in global shipping costs in particular for Asia and the Pacific to the United States (US), and Asia and the Pacific to Europe make it difficult to attribute this entirely to trade growth (Box 2.1).
Figure 2.3: Global Business Confidence versus Trade Volume Growth of Asia and the Pacific

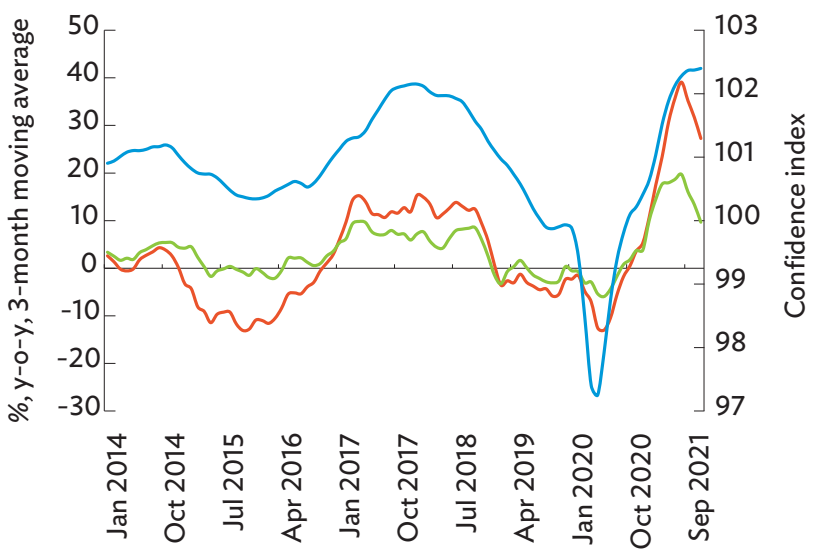

— Trade value growth (left) — Trade volume growth (left) —Global business confidence index (right)

$y-0-y=$ year-on-year.

Notes: Trade volume growth rates were computed using volume indexes. For each period and trade flow type (i.e., imports and exports), available data include indexes for Japan, the People's Republic of China (PRC), and aggregate indexes for selected Asia and Pacific economies: (i) advanced economies excluding Japan (Hong Kong, China; the Republic of Korea; Singapore; and Taipei,China); and (ii) emerging economies excluding the PRC (India; Indonesia; Malaysia; Pakistan; the Philippines; Thailand; and Viet Nam). The aggregate index for Asia and the Pacific was computed using trade values as weights. Global business confidence index represents Organisation for Economic Co-operation and Development (OECD) economies.

Sources: ADB calculations using data from CEIC Data Company; CPB Netherlands Bureau for Economic Policy Analysis. World Trade Monitor. https://www.cpb.nl/en/world-trade-monitor-october-2021; and OECD. Business Confidence Index (indicator). https://doi.org/10.1787/3092dc4f-en (both accessed January 2022)

\section{Figure 2.4: Global Trade-Weekly Indicators}

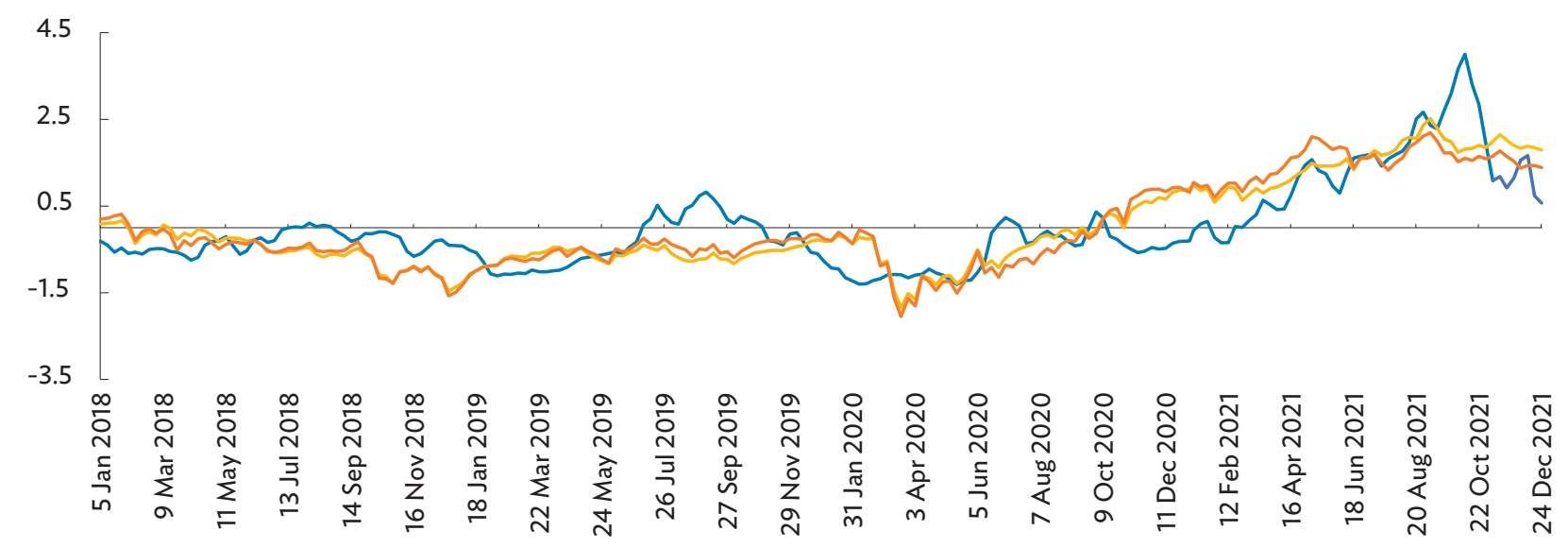

— Baltic Exchange Dry Index — Bloomberg World Packaging and Containers Index — MSCI World Containers and Packaging Index 


\section{Box 2.1: Rising Global Shipping Costs}

Not all the rising trajectory of high frequency data is accounted for by the strength of global trade recovery as it also reflects fast rising global shipping costs lately. Midway through the pandemic, from June 2020, dry bulk and container shipping rates began rising; then, from November 2020, surging at respective rates of $10 \%$ and $16 \%$ per month on average. In September 2021, the average freight rate for containerized goods was $\$ 10,839$, and for dry bulk $\$ 4,288$. During the same month in 2019 , these rates were $\$ 1,279$ and $\$ 2,255$.

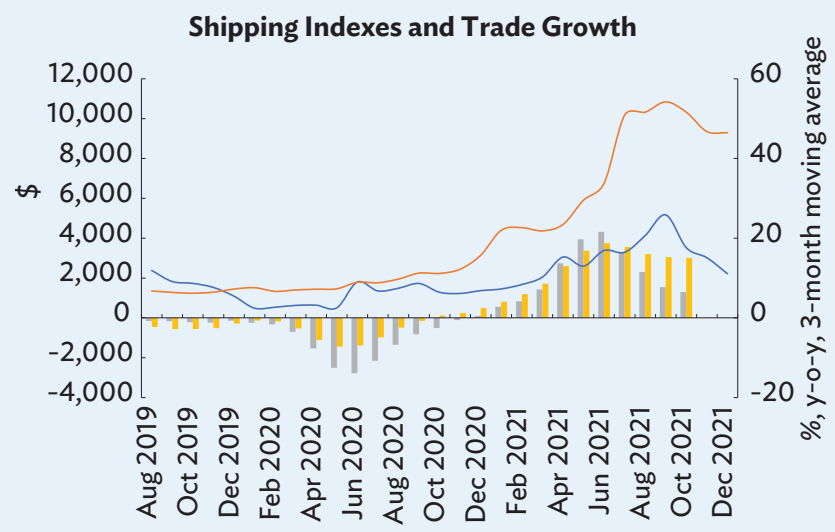

$\begin{array}{ll}\text {-Trade volume growth (right) } & \text { Trade unit value growth (right) } \\ \text { _Baltic Dry Index (left) } & \text { Freightos Baltic Global } \\ & \text { Container Index (left) }\end{array}$

$y-0-y=$ year-on-year

Notes: The Baltic Dry Index measures shipping costs for dry bulk commodities (including coal, grain, iron ore, finished steel, and other metals, minerals, and similar materials). The Freightos Baltic Global Container Index represents transport spot freight rates for a standard 40 -foot, unrefrigerated container, based on rolling tariffs and related surcharges reported by freight carriers, freight forwarders, and shippers

Sources: ADB calculations using data from CEIC Data Company; and Statista. Freightos Baltic Index. https://de.statista.com/statistik/daten/studie/1270630.

\section{Drivers of Rising Shipping Costs}

Shipping costs are determined by a myriad of factors which include (i) inputs for shipping transportation such as bunker fuel and labor; (ii) performance of integrated logistics functions such as ports, containers, storage, and inland transport; (iii) demand for shipping services and relative cost-efficiency of alternative modes of transport (e.g., air freight); (iv) production, consumption, trade flows, and overall economic integration (geography of value chains) (UNCTAD 2015); and (v) regulation in particular quarantine requirements for seafarers during the pandemic.
In light of this, the rise in oil prices, including bunker fuels, port congestions due to delayed manifestation of pent-up demand for manufacturing goods, sporadic lockdowns of ports in some Asian economies during the pandemic, and quarantine requirements for seafarers and port workers all contribute to the recent steep increase in shipping costs.

\section{Impacts}

Fast rising shipping costs add to the growing bottlenecks of supply chain disruptions amid the pandemic, slowing down trade flows and making the shipment of goods unable to meet overseas demand in a timely manner. Freightos estimates that average door-to-door shipping time for ocean freight has gone from 41 days a year ago to 70 days (The Economist 2021). This is especially consequential for containerized cargo where containers need to be returned and repositioned for succeeding trades. Rising shipping costs, on top of rising commodity prices and wages, are driving inflation to higher-than-expected levels. Affected producers could either squeeze their profit margins or pass the burden, though only partially, to more upstream producers or to consumers.

The direct financial strain from rising shipping costs could push producers to reshore productive activities and find domestic or regional partners increasingly attractive and strategic, especially in the medium to long terms. Incentives might also exist to consolidate parts of value chains to mitigate the risk of costly and inefficient transport. In the short term, however, firms may react by stockpiling inventories and pursue shifting from a "just-in-time" to a "just-in-case" inventory management philosophy (The Economist 2021) and building inventories to even higher-than-pre-pandemic levels to hedge against delays and shortages. This will entail higher costs and prompt a vicious inflationary cycle until consumer demand dampens or shipping bottlenecks are eased.

More fundamental and lasting solutions are needed to guard against unchecked increases in shipping costs. Tracking technologies such as the Automatic Identification System and digitized trade and transport records can be used to improve visibility of the global maritime network. This can provide an opportunity to optimize the transportation plan. Encouraging competition and making systemwide investments in the entire logistics chain, from ports to warehouses to inland transport, will also help grow capacity, level rates, and minimize the share of transport costs in total prices. 


\section{Asia's Intraregional Trade}

\section{Asia and the Pacific managed to strengthen intraregional trade linkages during the first wave of the COVID-19 pandemic in 2020.}

Asia and the Pacific sustained strong intraregional trade linkages amid the pandemic. The region's intraregional trade share even rose to $58.5 \%$ in 2020 from $57.5 \%$ in 2019, the highest since 1990 (Figure 2.5). This remains higher than for North America (39.3\%) and lower than the European Union plus the United Kingdom $(E U+U K)(63.8 \%) .^{7}$ The modest increase in the region's intraregional trade share during the pandemic is mainly due to the linkage with the PRC, which was first to ease off its mobility restrictions. Excluding the PRC, Figure 2.6 shows that the region's intraregional share declined marginally to $38.2 \%$ in 2020 from $38.4 \%$ in 2019. Intraregional trade values for all regions fell for 2 consecutive years in 2019 and 2020 (Annex 2a). The trade of Asia and the Pacific grew 29.6\% in the first 3 quarters of 2021, compared with global trade growth of $27.8 \%$. Trade within the region rebounded $31.2 \%$ during the same period, following a 3.1\% contraction in 2020. By comparison, the region's trade with non-regional trade partners fell $7.0 \%$ in 2020 before rebounding by $31.0 \%$ in the 9 -month period.

The role of the PRC as the region's major trading partner continues to grow-as shown by the increasing gap of intraregional trade share between Asian economies excluding the PRC, and Asia and the Pacific including the PRC (Figure 2.5).

\section{While intraregional trading within Asia and the Pacific (excluding the PRC) has remained relatively stable over the past 30 years, the dynamics of trade linkages with other regions have changed considerably.}

In 1990, North America was the most important trade partner of Asia and the Pacific (excluding the PRC)
Figure 2.5: Intraregional Trade Shares by Region (\%)

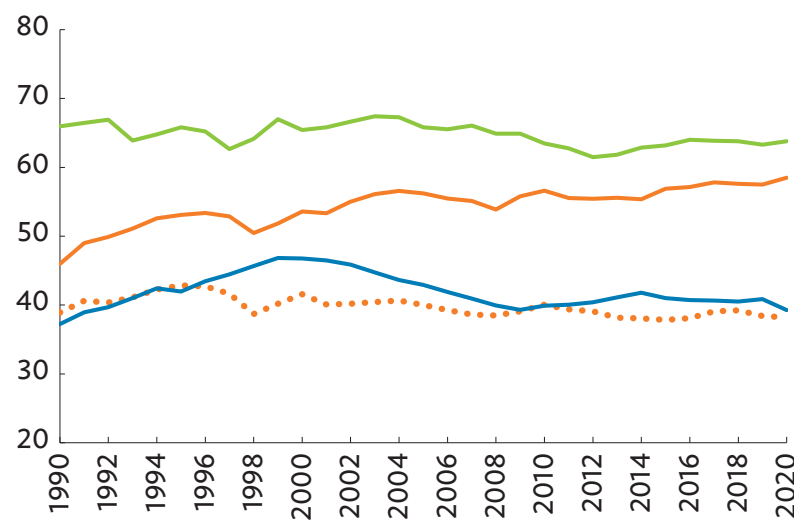

Asia and the Pacific $\cdots$ Asia and the Pacific ex-PRC EU+UK North America

EU = European Union (27 members), PRC = People's Republic of China, UK $=$ United Kingdom.

Notes: Values are expressed as percentage of the region's total merchandise trade (sum of exports and imports). North America covers Canada, Mexico, and the United States.

Source: ADB calculations using data from International Monetary Fund. Direction of Trade Statistics. https://data.imf.org/dot (accessed January 2022).

outside the region (with $24.8 \%$ of trade), followed by the EU+UK (17.6\%), as shown in Figure 2.6. In the past 3 decades, the share of Asia's (excluding the PRC) regional trade with North America and the EU+UK gradually fell by 2020 , to $12.6 \%$ and $10.7 \%$. In contrast, its share of regional trade with the PRC grew from $5.8 \%$ in 1990 to $26.6 \%$ in 2020. Intraregional trade, on the other hand, moved within the $38.0 \%$ to $43.0 \%$ band in the past 3 decades, peaking at $42.7 \%$ in 1996 and settling at 38.2\% in 2020. In terms of economies, Asia's (excluding the PRC) top 10 leading partners in 2020 are the PRC (26.6\%); the US (11.0\%); Japan (5.5\%); the Republic of Korea (4.2\%); Taipei,China (3.8\%); Singapore (3.6\%); Hong Kong, China (3.2\%); Malaysia (2.9\%); Viet Nam (2.9\%); and Thailand (2.5\%).

These strong trade linkages among Asian economies proved an effective buffer during the pandemic. In 2020, the distribution of trade share across major trade partners in Asia and the Pacific was relatively resilient against a black swan event such as the pandemic. For instance, during 2020, the first year of the pandemic,

The EU (27 members) plus the United Kingdom (UK) was used in the analysis. As of 1 February 2020, the UK has withdrawn from the EU. During the transition period that ended on 31 December 2020, the EU law remained applicable to and in the UK, with a few limited exceptions. Thus, for 2020 , the information on the EU, unless otherwise specified, continues to cover the UK. 
the bilateral trade flow share of Asia and the Pacific (excluding the PRC) with the PRC grew to $26.6 \%$ (from $24.4 \%$ in 2019) while the share of trade ties with North America remained relatively stable at $12.6 \%$. The share of trade flow with the other regions declined. Trade shares with the EU+UK dipped slightly from $11 \%$ to $10.7 \%$ while those with the rest of the world fell from $13.7 \%$ to $11.9 \%$.

Figure 2.6: Regional Trade Partners ShareAsia-to-Asia and Asia-to-Other Economies

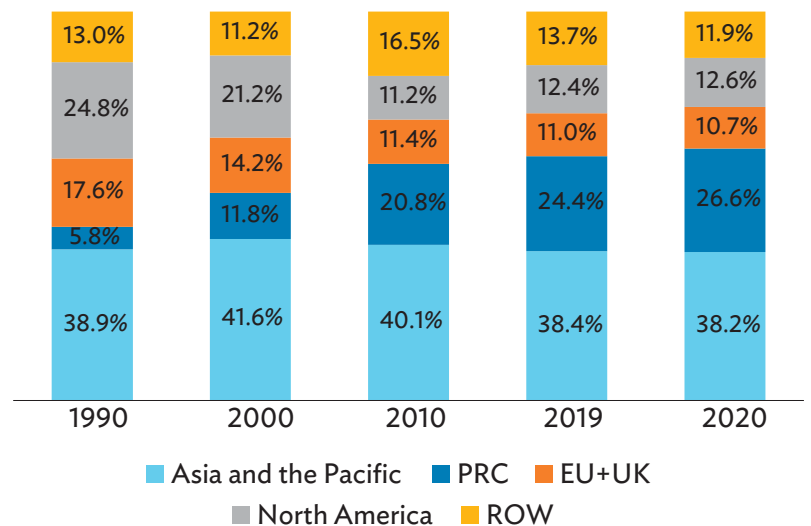

EU = European Union (27 members), PRC = People's Republic of China, ROW = rest of the world, UK = United Kingdom.

Notes: Values are expressed as percentage of the region's total merchandise trade (sum of exports and imports). North America covers Canada, Mexico, and the United States.

Source: ADB calculations using data from International Monetary Fund. Direction of Trade Statistics. https://data.imf.org/dot (accessed January 2022).

Optimizing regional trade linkages and strengthening regional trade integration could help the region's economies navigate the challenges to sustain trade growth. The region needs to embrace stronger trade liberalization and facilitation regimes, including engaging in regional and bilateral trade agreements and improving trade logistics to continue this momentum.

\section{Intraregional trade linkages further} strengthened across all subregions in Asia and the Pacific in 2020.

During the pandemic, intraregional trade linkages tightened the most for South Asia, showing the intraregional trade share's growth from 38.9\% in 2019 to $40.5 \%$ in 2020 (Figure 2.7). East Asian economies' trade ties with Asia and the Pacific also strengthened modestly, rising from a $55.7 \%$ in 2019 to $56.8 \%$ in 2020. Intraregional trade for the Pacific and Oceania region remained stable as it moved from $72.0 \%$ in 2019 to $72.6 \%$ in 2020. Intraregional ties for Central Asia expanded from $36.0 \%$ in 2019 to $36.8 \%$ in 2020 while that of Southeast Asia rose from $68.5 \%$ to $69.0 \%$.

By magnitude, the Pacific and Oceania continue to have the highest intraregional trade share in 2020 (72.6\%), followed by Southeast Asia (69.0\%) and East Asia (56.8\%) (Figure 2.7). Despite having increased the most over the past decade, the intraregional trade share for Central Asia and South Asia remained below 50\%.

Figure 2.7: Intraregional Trade Shares by Asian Subregions (\%)

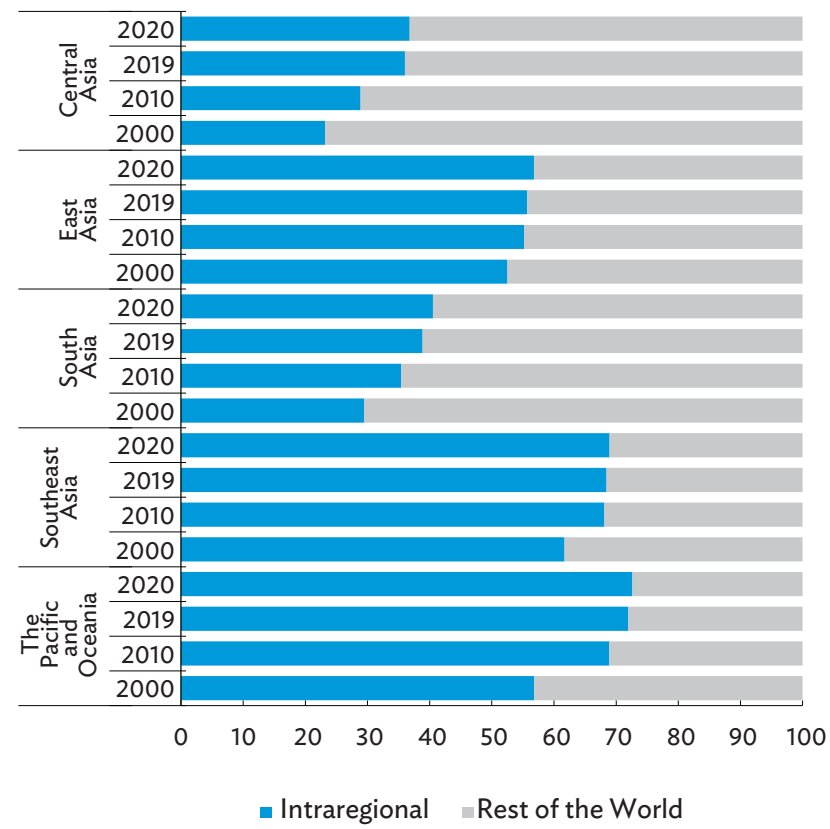

Note: Timor-Leste was recently classified under Southeast Asia. Until 2019, it was under the Pacific and Oceania.

Source: ADB calculations using data from International Monetary Fund. Direction of Trade Statistics. https://data.imf.org/dot (accessed January 2022).

Across subregions, East Asia continues to have the highest intrasubregional trade share (35.9\%), followed by Southeast Asia (21.1\%). The other subregions all recorded intrasubregional trade shares below 10\%Central Asia (8.8\%), the Pacific and Oceania (5.5\%), and South Asia (5.8\%). 


\section{Challenges in Semiconductor Supply Chains}

\section{Semiconductors are an essential component of electronic devices, enabling communications, computing, health care, transportation, clean energy, and countless other applications. ${ }^{8}$}

Goldman Sachs identified 169 industries that spend at least $1 \%$ of their value-added production on semiconductor chips. ${ }^{9}$ These include sectors that produce chip-dependent products such as cars, computers, and mobile phones. The list also includes industries making products that do not need chips, but whose machineries do-such as steel, ready-mix concrete, and soap manufacturing.
Using the United Nations Commodity Trade

Database 2020 data and the industrial list from Goldman Sachs, about $65 \%$ of the world's exports are estimated to depend on semiconductor chips directly and indirectly: $5 \%$ are semiconductor chips themselves (semiconductor devices and electronic integrated circuits) ${ }^{10}$ while $29 \%$ are chip-dependent products and $30 \%$ are products that do not have chips inside, but their production runs on them. Among the major regions, Asia's exports rely heaviest on chips, followed by the EU+UK and North America. Among Asian subregions, East Asia's exports rely the most on chips, followed by Southeast Asia. In the import side, all the regions have a fair share of imported goods that rely on chips and in most regions, the share continues to grow. East Asia and Southeast Asia's imports have the highest share of semiconductor chips (Figure 2.8).

Figure 2.8: Share of Exports/Imports for Industries Spending at Least 1\% of Value-Added Production on Semiconductor Chips (\%)

(a) Export Shares by Regions

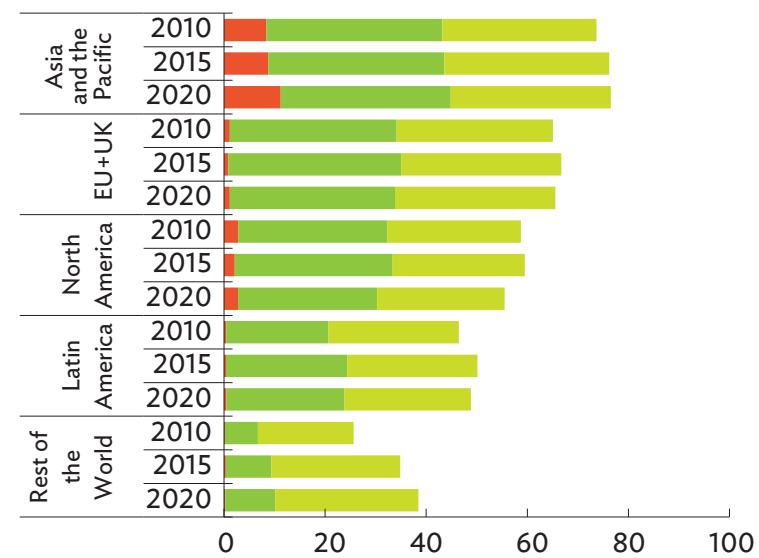

$\square$ Semiconductor chips $\quad \square$ Products with chips inside (b) Export Shares by Asian Subregions

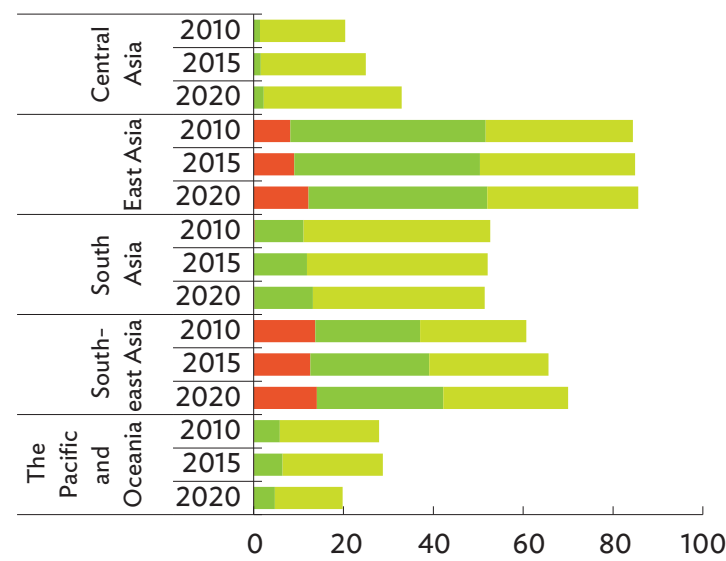

Products without chips, but their production relies on chips

8 Semiconductor Industry Association. What is a Semiconductor? https://www.semiconductors.org/semiconductors-101/what-is-a-semiconductor (accessed December 2021).

9 For reference, the automobile sector spends $4.7 \%$ of its GDP on semiconductor chips (Howley 2021).

10 Semiconductor devices cover all commodities under Harmonized System (HS) 8541, which includes diodes, transistors, photosensitive devices, and mounted piezo-electric crystals. Electronic integrated circuits cover all commodities under HS 8542, which include processors and controllers, memories, converters, logic circuits, amplifiers, clock and timing circuits, and others. 
Figure 2.8: continued

(c) Import Shares by Regions

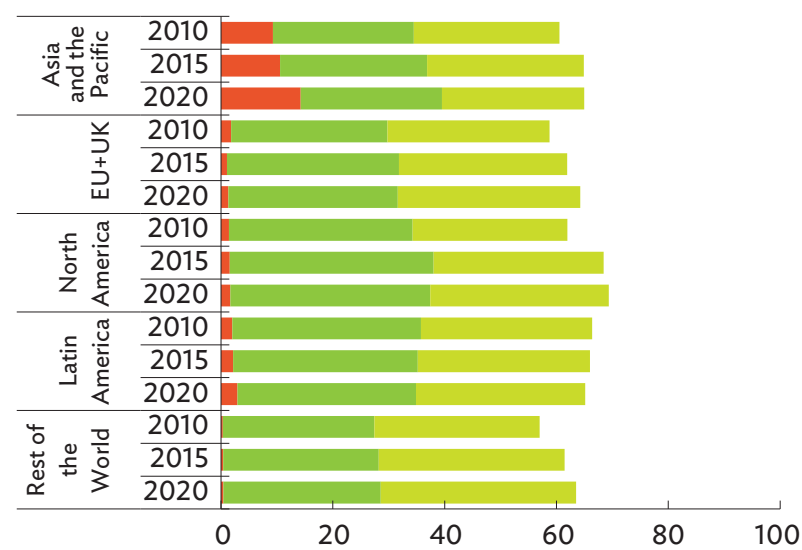

- Semiconductor chips $\quad$ Products with chips inside (d) Import Shares by Asian Subregions

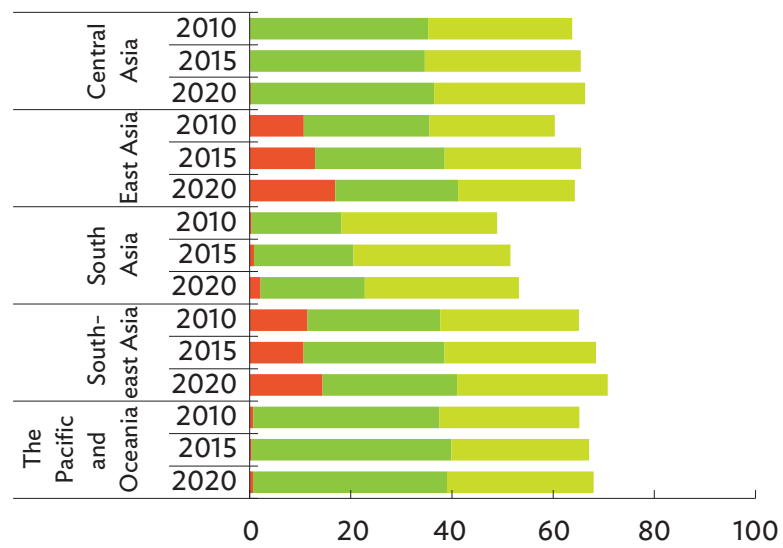

Products without chips, but their production relies on chips

$\mathrm{EU}=$ European Union, UK = United Kingdom .

Notes: Red bars represent the share of semiconductor devices and electronic integrated circuits in total exports or imports. Both light green and dark green bars represent the share of exported products under industries that spend at least $1 \%$ of their value-added production on semiconductor chips. These industries were classified by Goldman Sachs. The light green bars are exports that do not have chips inside their products, but production such as machineries relies on chips. The dark green bars are exports that have chips inside their products.

Source: ADB calculations using data from United Nations. Commodity Trade Database. https://comtrade.un.org (accessed December 2021).

Most of the semiconductor chips produced were used for computers in 2020 , followed by communications, and consumer products, as shown in Figure 2.9.

Figure 2.9: Global Semiconductor Demand by End-Use (\$ billion)

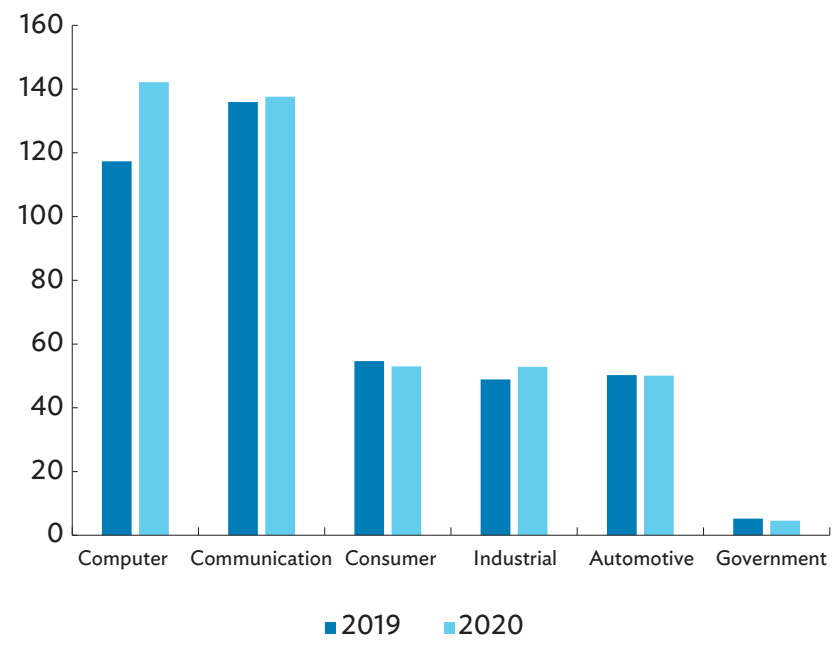

Source: Semiconductor Industry Association (2021a).

\section{Drivers of Demand for Semiconductors and Microchips}

Global exports of semiconductor devices grew by $8.7 \%$ in 2020 , while electronic integrated circuits grew by $19.6 \%$. However, despite the record high exports of semiconductor devices and electronic integrated circuits, especially in Asia and the Pacific, production was insufficient to meet demand. One hypothesis is that manufacturers failed to predict the impact of the pandemic on demand for their products. When the lockdowns were announced, car manufacturers anticipated the decrease in demand and cut production accordingly. Chip manufacturers then shifted their limited production of chips for vehicles to chips for computers and consumer electronics, as people began to work from home. This explains why the biggestgaining exports in 2020 were computers and laptops ( $\$ 28$ billion increase in exports from 2019 to 2020), while the exports that lost the most were motor vehicles ( $\$ 119$ billion decrease in exports). The pandemic has also increased the demand for mechano-therapy appliances such as artificial respiration (Figure 2.10). 
Figure 2.10: World's Top Gaining/Losing Exports that Use Semiconductor Chips, 2020 (\$ billion)

\section{(a) Top Five Gaining Products}

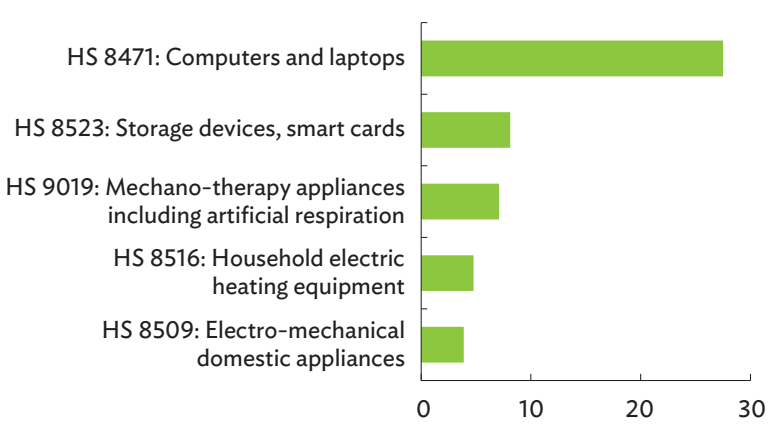

(b) Top Five Losing Products

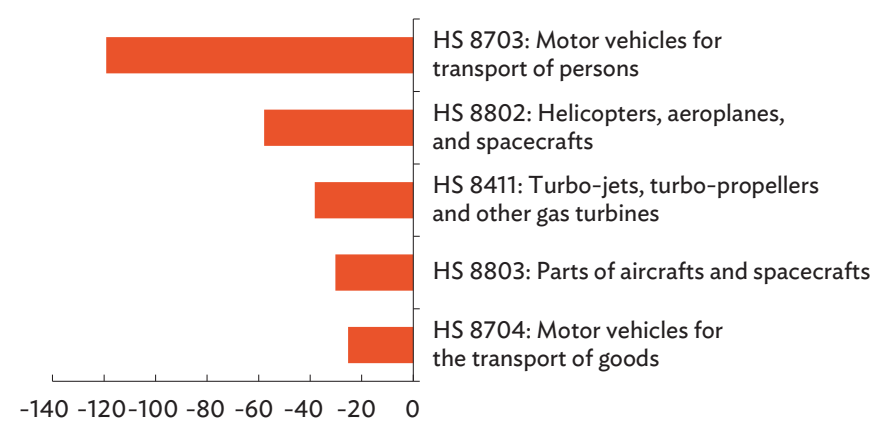

HS = Harmonized System .

Notes: The top five commodities that "gained" the most are the products at HS 4-digit commodity code, which increased the most by level of export value out of 186 products that depend on semiconductor chips. The top losers, on the other hand, decreased the most in export value.

Source: ADB calculations using data from United Nations. Commodity Trade Database. https://comtrade.un.org (accessed December 2021).

With the progress of COVID-19 vaccination programs and lifting of lockdown measures, demand for automobiles began to rise slowly. However, even though the chip manufacturers were running at almost full capacity (Semiconductor Industry Association 2021b), car manufacturers found it difficult to purchase semiconductor chips. The production of chips usually takes $2-3$ months and orders are usually made at least a year in advance (Jeong and Strumpf 2021). Some manufacturers also stockpiled chips, making chip shortages worse (Ludwikowski and Mjoberg 2021). As supply shortages of chips persist, car makers have experienced serious bottlenecks in rolling out production. This could have encouraged people to buy used cars, which seems to be the case in the US given that car production has declined while sales have increased. Demand for used cars eventually led to a sudden increase in used car prices in the US around May-June 2021.

\section{Expanding Semiconductor Production Capacity}

It is estimated that globally the semiconductor industry needs $\$ 3$ trillion of investments in research and development (R\&D) and capital expenditure
(CapEx) to double capacity by 2030. This is to keep up with the expected $4 \%$ to $5 \%$ average annual growth in semiconductor demand, according to the Semiconductor Industry Association (Varas et al. 2021). The cost of one lithography machine to produce chips ranges from $\$ 25$ million to $\$ 100$ million and it takes 12-15 months to install it, according to ASML Globalfoundries (Wall Street Journal 2021).

The huge investment on CapEx and R\&D in the semiconductor industry creates a natural barrier to entry for the new firms. The top five fabless firms invested $\$ 68$ billion in R\&D between 2015 and 2019, or an average of $\$ 2.8$ billion per firm per year, equivalent to $22 \%$ of their revenue." Moreover, the CapEx of the top five foundries (or semiconductor fabrication plants) over those 5 years amounted to about $\$ 75$ billion, or an average of $\$ 3$ billion per firm per year, equivalent to more than $35 \%$ of their annual revenue. To compensate for costs, firms must produce at a large scale, creating supply chains with high geographic concentration. For example, in 2019, Taipei,China had 63\% of the world's foundry market, with its biggest producer TSMC capturing a 54\% global market share (Figure 2.11).

11 Fabless firms design the hardware and semiconductor chips but do not manufacture the silicon wafers, or chips, used in their products; instead, they outsource the fabrication to a manufacturing plant or foundry. 
Figure 2.11: Foundry Market Share Tree Map, 2020

TSMC, $54 \%$
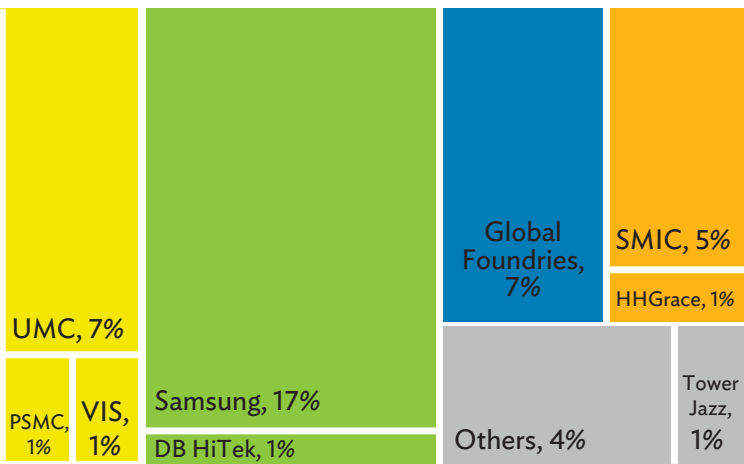

Taipei,China Republic of Korea People's Republic of China US Others

DB = Dongbu, HHGrace = Shanghai Huahong Grace Semiconductor Manufacturing Corp, PSMC = Powerchip Semiconductor Manufacturing Corporation, SMIC = Semiconductor Manufacturing International Corporation, UMC = United Microelectronics Corporation, US = United States, VIS = Vanguard International Semiconductor Corporation.

Note: TSMC is a semiconductor manufacturing company based in Taipei,China,

Source: Kuo (2021).

\section{Semiconductor Value Chain}

Semiconductor chip production has a highly complex value chain with each stage requiring specialization that only certain economies can offer. This results in a high geographic concentration in each stage. The whole process can be divided into eight steps (for vertical specialization analysis of electronic products, see Box 2.2). The first five steps are mostly R\&D intensive. These processes take up around $70 \%$ of the value chain. US firms contribute most in the first two stages: electronic design automation and core intellectual property. The next two stages-logic; discrete, analog, and optoelectronics and sensors; and memory-are done mostly by companies in East Asia. The fifth stage, manufacturing equipment, is done mostly by US companies (Figure 2.12).

The next two steps are relatively more CapEx intensive: materials and wafer fabrication. These take up $24 \%$ of the value chain and are done mostly by East Asian companies. The final step, of assembly, packaging, and testing, takes $6 \%$ of the value chain and is done mostly in the PRC and Taipei,China (Figure 2.12). Overall, the US contributes to $38 \%$ of the value chain while the four East Asia economies contribute $48 \%$. About half of the manufactured chips were sold in the US and the PRC in 2019.

\section{Risks and Vulnerabilities}

Economies of scale have helped decrease the cost of production for semiconductor chips. However, this also causes the high geographic concentration of activities in the supply chain which makes the whole system vulnerable. Single points of failure, especially in East Asian economies, where $75 \%$ of global installed capacity is concentrated, could cause large-scale supply interruptions. Moreover, $100 \%$ of the global capacity for highly advanced chips is located in Taipei,China and the Republic of Korea. ${ }^{12}$ Recent accidents and disasters triggered by natural hazards that have disrupted the semiconductor chip value chain include the following: (i) in December 2020, a power outage affected a memory fab in Taipei,China for just 1 hour, impacting $10 \%$ of global dynamic RAM supply; (ii) two fires at a package substrate plant in Taipei,China in October 2020 and February 2021 that affected the global capacity for assembly, packaging, and testing services; (iii) in early 2021, the polar vortex in Texas, US caused widespread power failures which hampered chip production (Williams 2021); and (iv) a fire in a Renesas fabrication plant in Japan in March 2021 exacerbated chip supply shortages, especially for the auto industry (Yamamitsu 2021).

12 Highly advanced chips are logic chips with 7- and 5-nanometer nodes. These are required for computer-intensive devices such as data center or artificial intelligence servers, personal computers, and smartphones (Varas et al. 2021). 


\section{Box 2.2: Vertical Specialization in Electronic Products}

The Asian economy's potential as a hub in semiconductor supply chain can be assessed by looking at its vertical specialization (VS) in electrical products. VS is a summary statistic used to measure international production sharing (Hummels, Ishii, and Yi 2001; Wang, Wei, and Zhu 2013). Over the past 2 decades, several developing economies increased their VS share to gross exports in electrical

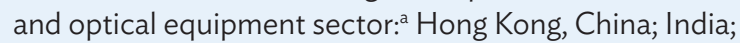
Indonesia; the Philippines; and Viet Nam. Meanwhile, some top exporters saw declining VS such as the People's Republic of China (PRC); the Republic of Korea; and Taipei,China. Their semiconductor exports fell because of increased reliance on domestically produced intermediate goods. Economies such as Malaysia and Thailand also saw declining VS (as described in the box figure).

One of the three components of VS is foreign valueadded in an economy's final goods exports (FVA_FIN). The increasing share of FVA_FIN suggests an economy is participating more in final assembling activities based on imported components-the low end of the global value chain. Economies such as Hong Kong, China; India; Singapore; and Thailand saw an increasing share of FVA_FIN in their VS (see box figure).
The second component of VS is foreign value-added share in an economy's intermediate exports (FVA_INT). An increasing FVA_INT may imply the economy is upgrading industry to start producing intermediate goods for other economies, especially when more and more of these goods are exported to third economies for production of final goods. This is a sign that the economy is climbing up the global value chain production ladder in the sector. Top exporters in the sector such as Japan; the Republic of Korea; Taipei,China; and smaller exporters such as Indonesia, Malaysia, the Philippines, and Thailand saw increasing shares of FVA_INT in their VS.

The third component of VS is pure double counting (PDC) terms in an economy's exports. An increasing share of PDC in VS indicates that the economy is deepening its cross-economy production sharing, where intermediate goods cross national borders multiple times before being used in final goods production. Economies such as the PRC; the Republic of Korea; and Taipei,China saw increasing PDC shares in VS in the past 2 decades (as shown in the box figure).

Vertical Specialization of Selected Asia and Pacific Economies in Electrical and Optical Equipment (\% share to vertical specialization)

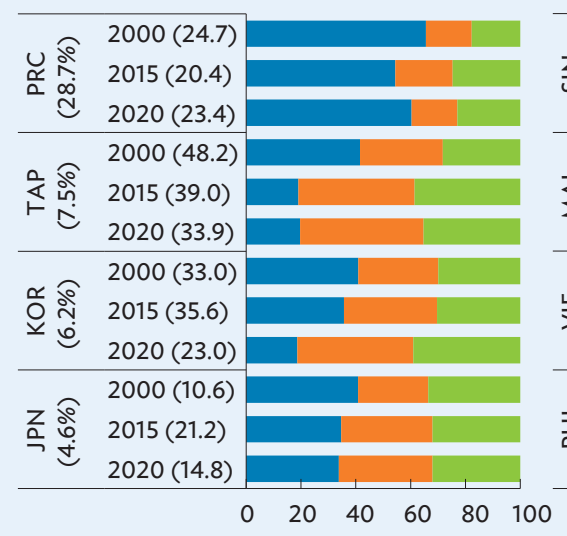

- foreign value-added in an economy's final goods exports (FVA_FIN)

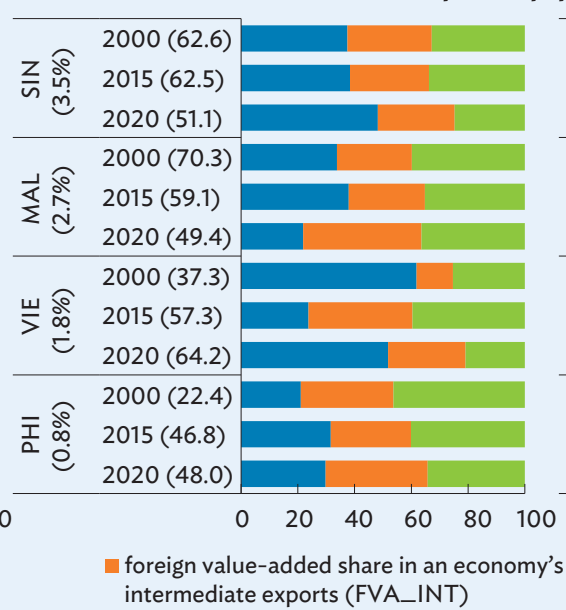

HKG = Hong Kong, China; IND = India; INO = Indonesia; JPN = Japan; KOR = Republic of Korea; MAL = Malaysia; PHI = Philippines; PRC = People's Republic of China; SIN = Singapore; TAP = Taipei,China; THA = Thailand; VIE = Viet Nam.

Notes: The economies chosen are the top 12 exporters in the electrical and optical equipment sector, of the 26 Asia and Pacific economies in the ADB Multi-Regional Input-Output Tables. Percentages next to the economies' three-letter codes are the share of the economy's gross export to global export of electrical and optical equipment in 2020. Values in parentheses beside the years are the share of vertical specialization to gross exports in the electrical and optical equipment sector.

Sources: ADB calculations using data from ADB. Multi-Regional Input-Output Tables; and methodology by Wang, Wei, and Zhu (2013, revised 2018).

a Among the 35 sectors in the ADB Multi-Regional Input-Output Tables, the electrical and optical equipment sector seems to be the most related to semiconductor industry.

Sources: ADB staff using ADB. Multi-Regional Input-Output Tables; Hummels, Ishii, and Yi (2001); and Wang, Wei, and Zhu (2013, revised 2018). 
Figure 2.12: Regional Breakdown of Semiconductor Value Chain Production, 2019 (\%)

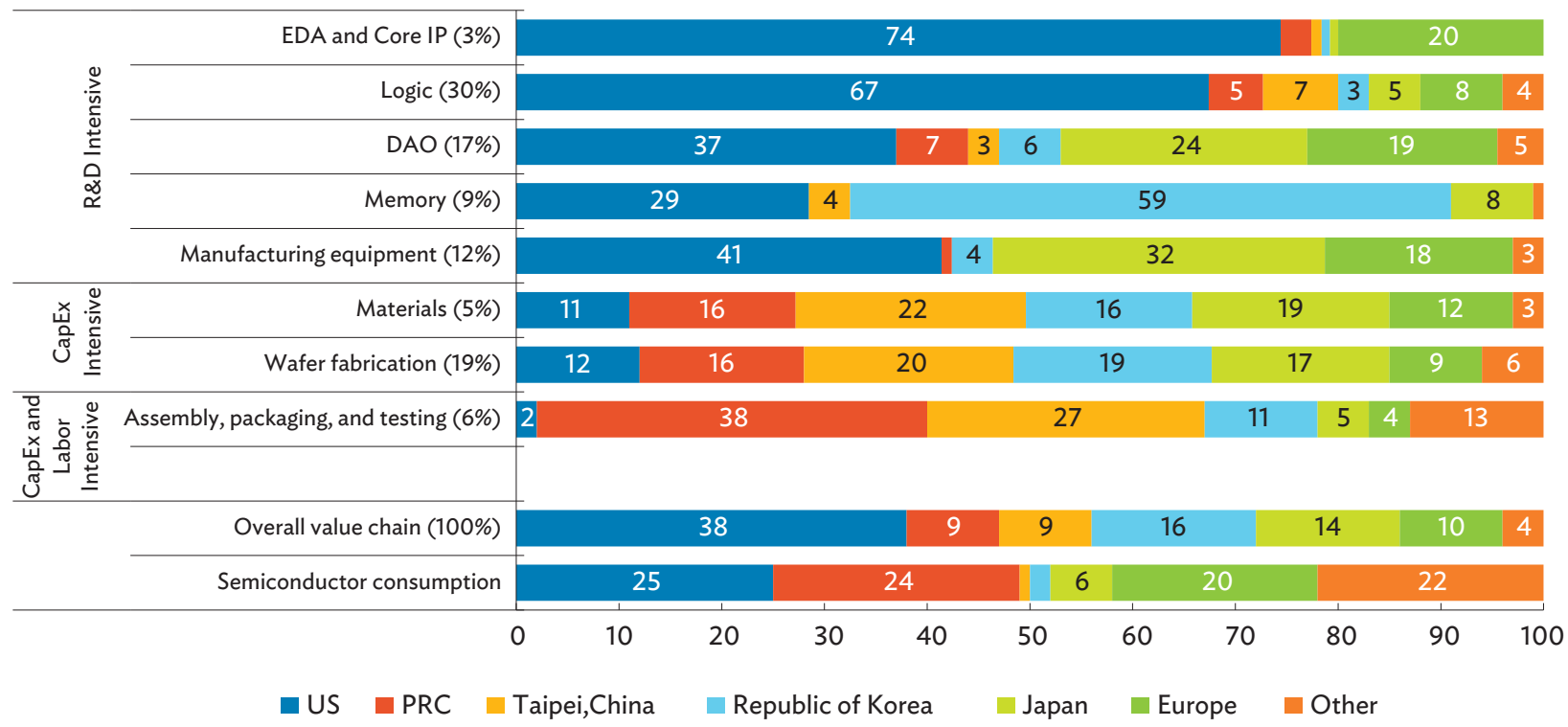

CapEx = capital expenditure; $\mathrm{DAO}=$ discrete, analog, and optoelectronics and sensors; $\mathrm{EDA}=$ electronic design automation; IP = intellectual property; PRC = People's Republic of China; R\&D = research and development; US = United States.

Notes: Regional breakdown on EDA, design, manufacturing equipment, and raw materials is based on company revenues and company headquarters location. Regional breakdown on wafer fabrication and assembly and testing is based on installed capacity and geographic location of the facilities.

Source: Varas et al. (2021).

Another risk for the semiconductor industry in the future is the shortage in skills and talent needed to sustain its highly technical activities. The industry has difficulty hiring workers since it needs graduates with a strong background in science, technology, engineering, and mathematics. In a 2017 survey of executives across different companies in the semiconductor supply chain, $77 \%$ believed the industry faced a critical talent shortage, while $14 \%$ expected a severe talent shortage in 2018-2020 (Richard, Ramachandran, and Pandoy 2017). In a 2018 survey, $64 \%$ of respondents named talent as one of the top threats to their firms' growth. The semiconductor firms also identified "talent development" among the top strategic priorities, next to "innovation" and "mergers and acquisitions" (Zanni et al. 2019). Moreover, in the next 10-15 years, the industry will have to cope with an aging workforce and the retirement of a significant number of employees in technical positions (Varas et al. 2021).

\section{Policy Responses to Global Chip Shortages}

Reshoring and self-sufficiency. Hypothetically, if all regions were to seek self-sufficiency, they would have to pay $\$ 900$ billion to $\$ 1,225$ billion in upfront investment and $\$ 45$ billion to $\$ 125$ billion in incremental recurrent annual operational costs. These could lead to a $35 \%$ to $65 \%$ increase in semiconductor prices and may result in higher prices of the electronic devices for end users (Varas et al. 2021). Complete self-sufficiency may not be feasible and is not an effective way to solve semiconductor shortages as it entails large-scale national industrial policies and huge costs.

Diversification. An alternative way to address the risk of major global supply disruptions is to achieve a more diversified geographic production of semiconductor products. The semiconductor industry could instead strengthen supply chain resilience by exploring potential economies that could be a part of or increase its participation in the value chain. Enactment of market- 
driven incentive programs could expand production in these sites and diversify sources of supply for some critical materials in the industry.

Just-in-case inventory management. Instead of a just-in-time inventory management for semiconductor chips, firms can adapt a "just-in-case" inventory management to reduce the risk of supply shocks. Manufacturers can find a right balance between the cost savings brought by "just-in-time" and the reduction of risk by using "just-in-case" inventory management.

Investment in R\&D. In parallel to diversification of the supply chain, policy makers need to step up efforts to stimulate R\&D. Asia's talent potential for R\&D has been increasing in the past years especially in terms of workers (Varas et al. 2021). To increase the potential for R\&D, the relatively high rate of graduates in science and engineering in Asia and the Pacific should be accompanied by an environment that fosters innovation. Governments could craft policies to strengthen protection for intellectual property rights, encourage foreign investment in $R \& D$, and support immigration policies that enable semiconductor hubs to attract talent.

Capital investment. To meet the demand in the next decade, production capacity needs to be increased significantly. However, the huge investment cost of building facilities for the semiconductor sector makes it challenging for firms to expand production. Moreover, this poses an immense barrier to entry for any entity or organization that wants to join the value chain. Policy makers can support the private sector's further investment through incentives within international norms.

Education and training for engineers. To support the expansion of the sector and diversification of the supply chain, policy makers will have to explore policies that will encourage more graduates in disciplines such as electrical and mechanical engineering, computer science and software engineering, physics, materials science and chemical engineering, and industrial engineering. The government may also partner with academic institutions and private firms to create additional semiconductor-related graduate programs, as well as help fund specialized training for those who will be joining the workforce.

\section{Progress of Global and Regional Value Chains}

\section{Asia's value chain linkage with the world shrank in 2020 in tandem with the world's global value chain linkages. Yet, its regional value chain linkages strengthened further during the pandemic.}

Global value chain (GVC) expansion has been in gradual decline since 2018 amid growing uncertainties surrounding trade policy environment in many parts of the world and sluggish world demand (Figure 2.13). When the COVID-19 pandemic struck in 2020, the world economy slowed down with lockdowns, constrained mobility, and disrupted supply chains pulling down GVC participation further to $70.7 \%$, lower than the $71.4 \%$ recorded in 2009 during the global financial crisis. Asia's GVC participation has also fallen over the same period, with Asia's value linkages with the world dipping to $65.7 \%$ in 2020.

Figure 2.13: GVC and RVC Participation Rates (\%)

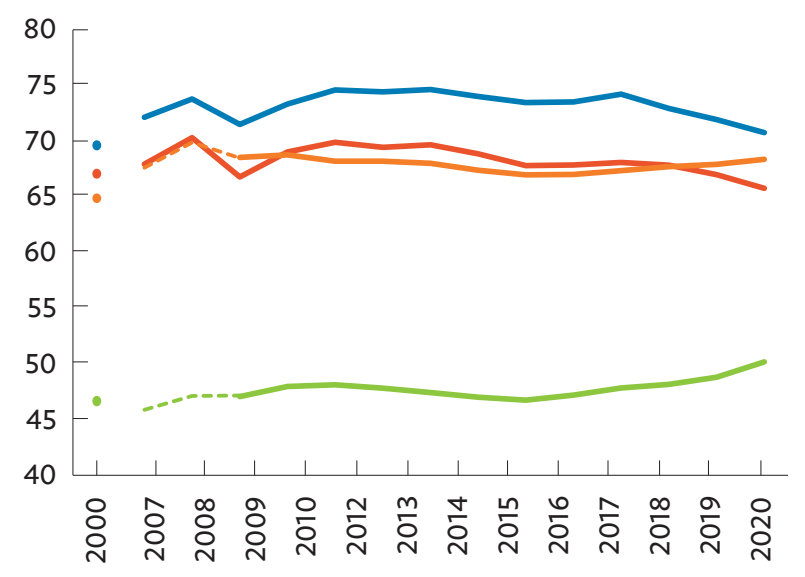

\footnotetext{
-World GVC (y-o-y) -Asia-to-World GVC (y-o-y) - Asia-to-Asia Gross RVC (3-yr-ma) - Asia-to-Asia Net RVC (3-yr-ma) --- Asia-to-Asia Gross RVC (y-o-y) -.- Asia-to-Asia Net RVC (y-o-y)

3-yr ma = 3-year moving average, GVC = global value chain, $\mathrm{RVC}=$ regional value chain, $y-0-y=$ year-on-year.

Notes: The GVC participation rate is the share of gross exports that involves production in at least two economies using cross-border production networks. The RVC participation rate, on the other hand, is the same as that of GVC, except that it only involves economies of the same region.

Sources: ADB calculations using data from ADB. Multi-Regional Input-Output Tables; and methodology by Wang, Wei, and Zhu (2013, revised 2018).
} 
This recent trend for both world and Asian GVCs is characterized particularly by a decline in complex GVCs, wherein intermediate exports cross borders at least twice (Figure 2.14a). ${ }^{13}$

Asia-to-Asia value chain participation, on the other hand, proved resilient as was also manifested by a higher intraregional trade share in 2020. Overall regional value chain (RVC) participation (3-year moving average) of economies in the region increased marginally to $68.9 \%$ in 2020 (from 68.4\% in 2019) while net participation rose from $50.5 \%$ in 2019 to $52.3 \%$ in 2020 , its highest rate since 2000.14 The continuing trend of deepening regional value chain seems to have been further strengthened during the pandemic. This is further characterized by rising participation in complex value chains and declining share of non-GVC exports and trading of single-bordercrossing intermediate exports (Figure 2.14b).
Figure 2.15: RVC-GVC Intensity by Region

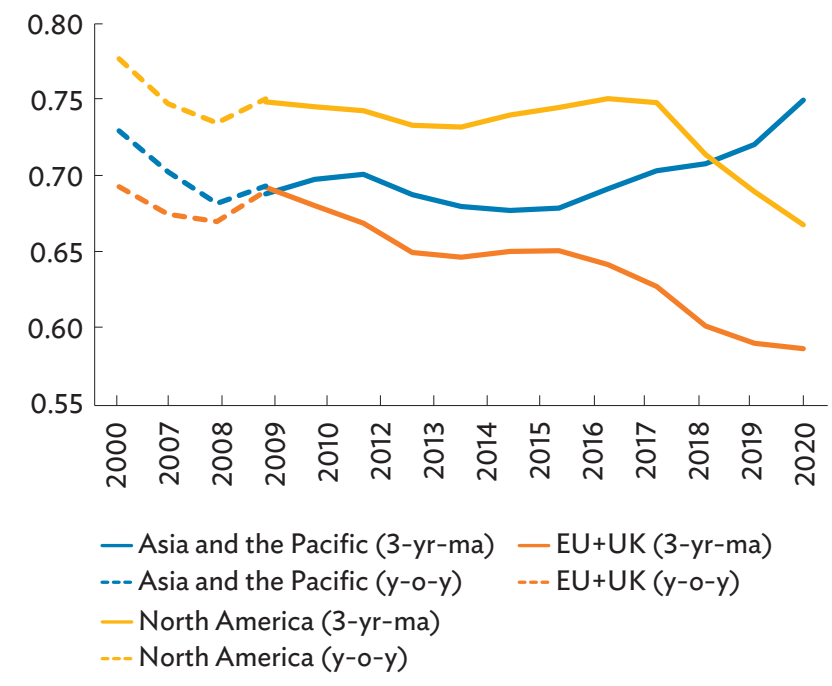

3-yr-ma = 3-year moving average, EU = European Union (27 members), $\mathrm{GVC}=$ global value chain, $\mathrm{RVC}=$ regional value chain, $\mathrm{UK}=$ United Kingdom, $\mathrm{y}-0-\mathrm{y}=$ year-on-year.

Notes: RVC-GVC intensity is the ratio of RVC participation and GVC participation rates. North America consists of the United States, Canada, and Mexico.

Sources: ADB calculations using data from ADB. Multi-Regional Input-Output Tables; and methodology by Wang, Wei, and Zhu (2013, revised 2018).

Figure 2.14: Asia's GVC and RVC Participation Rate (\%)

\section{(a) Asia-to-World GVC Participation Rate}

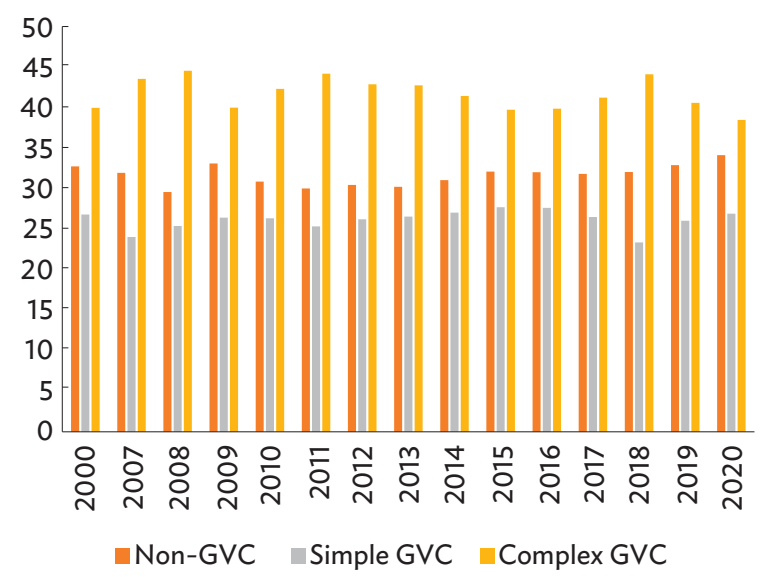

\section{(b) Asia-to-Asia Gross RVC Participation Rate}

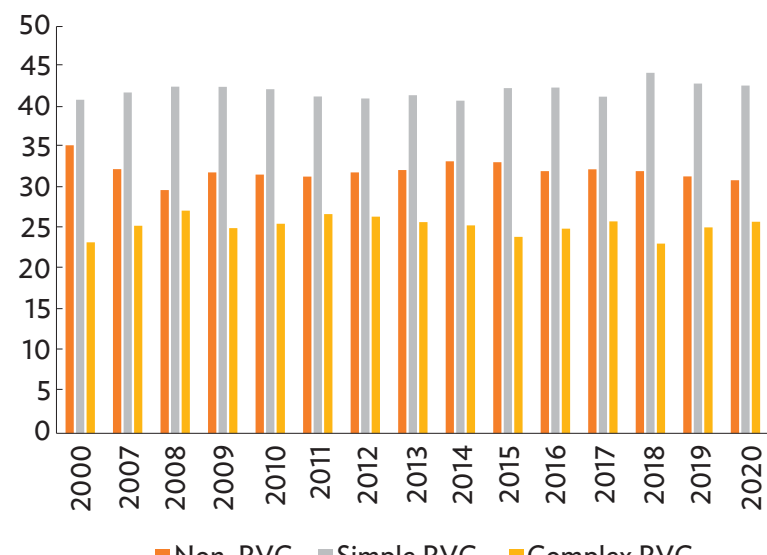

GVC = global value chain, $\mathrm{RVC}$ = regional value chain.

Notes: Gross RVC participation is the share of Asia's intraregional value chain exports to its intraregional gross exports, but excluding all non-Asian third economies in gross exports. Non-GVC refers to final goods exports. Simple GVCs are intermediate goods exports that cross borders only once or absorbed by the direct importer economy. Complex GVCs are intermediate exports that cross borders at least twice.

Sources: ADB calculations using data from ADB. Multi-Regional Input-Output Tables; and methodology by Wang, Wei, and Zhu (2013, revised 2018).

13 Complex GVCs include domestic value-added (DVAs) that are reexported by the direct importer to other economies except to the source economy, foreign value-added, returning DVA, and pure double counting of intermediate exports (Annex 2b).

14 Asia-to-Asia gross RVC is the ratio of Asia's intraregional value chains to its intraregional total gross exports, excluding non-Asian third economy partners. Asia-to-Asia net RVC is the same except that the denominator of total gross exports includes non-Asian third economy partners. 
By 2018, Asia's intensity of participation in RVCs in relation to GVCs at 0.70 is already above those of the $\mathrm{EU}+\mathrm{UK}$ at 0.65 and North America (Figure 2.15) at 0.56. All three regions saw declining RVC-GVC intensity in 2018, but those of the EU+UK and North America declined far more than in Asia and the Pacific. GVC participation has been on a downward trend for all three regions since 2018, while RVC participation fell more for the EU+UK and North America. This implies that the Asia and Pacific economies continue to strengthen value chain linkages within the region even during the pandemic.

\section{Regional value chain linkages relative to global linkages in Asia and the Pacific further intensified for all major sectors, especially in high and medium technology and business services.}

All sectors showed higher ratios of RVC participation to GVC participation in 2020 (Figure 2.16). This is partly due to the decline of integration to global production networks across all major sectors in 2020 except for the primary sector-comprising agriculture, mining, and quarrying. The biggest decline was exhibited by the low technology sector, which already has smallest participation rates in international production networks. Its integration with RVCs also slightly weakened in 2020, from $43.5 \%$ to $42.8 \%$. Given this is still less than the fall in its GVC participation rate, the sector showed a slight rise in RVC-GVC intensity in 2020.

Integration in regional value chains, on the other hand, expanded across the three other sectors: primary, high-medium technology, business services. ${ }^{15}$ The highest RVC expansion takes place in the high-medium technology sector, with intermediate exports trading comprising $51.1 \%$ of total gross regional exports in 2020 (from 48.8\% in 2019). Combined with a declining GVC participation, the high-medium technology sector has the highest increase in RVC-GVC intensity. The business services sector also showed increasing RVC integration, from $50.7 \%$ in 2019 to $52.8 \%$ in 2020, while GVC participation slightly declined. The primary sector's participation in RVCs increased more than its GVC participation.
Figure 2.16: RVC-GVC Intensity, by Major Sector-Asia and the Pacific

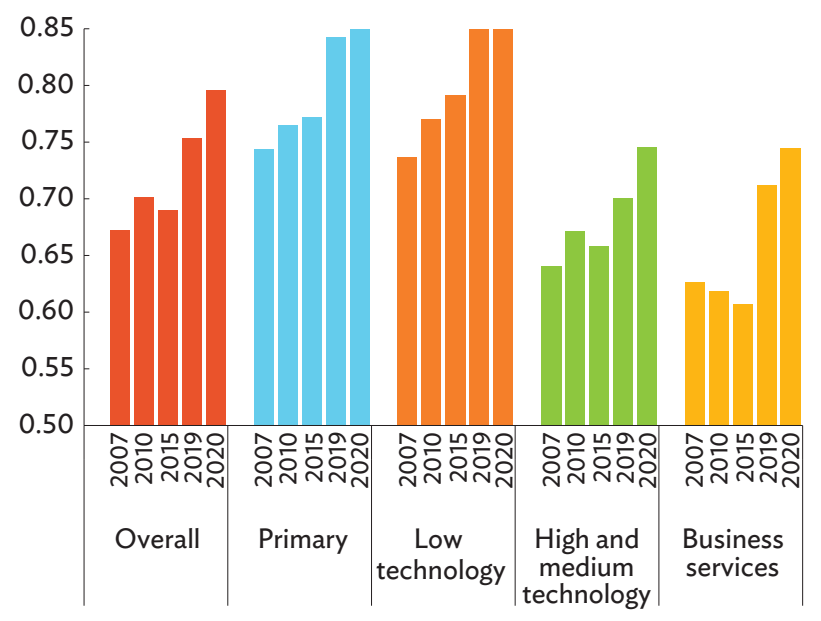

$\mathrm{GVC}=$ global value chain, $\mathrm{RVC}=$ regional value chain.

Notes: RVC-GVC intensity is the ratio of RVC participation and GVC participation rates. Sectoral classification is based on ADB (2015). Business services includes personal and public services.

Sources: ADB calculations using data from ADB. Multi-Regional Input-Output Tables; and methodology by Wang, Wei, and Zhu (2013, revised 2018).

Nevertheless, economy-level progress shows persistent heterogeneity depending upon an economy's relative position in regional and global production networks.

Of the 26 Asia and Pacific economies with data in the ADB Multi-Regional Input-Output Tables, 7 economies managed to increase GVC participation in 2020

(Figure 2.17). Cambodia experienced the highest GVC participation increase from $56.0 \%$ in 2019 to $69.6 \%$ in 2020. Other economies with big increases were the Lao People's Democratic Republic (Lao PDR) (from 69.3\% to $78.7 \%$ ), Kazakhstan (from $83.4 \%$ to $87.3 \%$ ), and Mongolia (from 79.8\% to 83.6\%). Australia and Malaysia, on the other hand, managed to maintain participation rates. Most of these economies are commodityexporting economies, with GVC participation rates highest in the primary sector. Moreover, except for Malaysia, their primary sectors comprise the highest share in total GVC trade value. Box 2.3 presents the historical trend of economy level contributions to GVC and RVC.

15 See Annex $2 c$ for the sectors these major groups comprise. Business services in this analysis includes personal and public services. 
Box 2.3: Evolution of Economy-Level Contributions to Global and Regional Value Chains

Charting the evolution of contributions of select economies to world global value chains (GVCs) and Asia-to-Asia regional value chains (RVCs) shows how much the value chain landscape has transformed over the past 2 decades.

\section{World GVC}

Box tables 1a and $1 \mathrm{~b}$ show that the contribution of the People's Republic of China (PRC) to world GVC has more than tripled in the past 20 years while it declined over time for Japan and the United States, among others. India's contribution also more than doubled. Other economies such as the newly industrialized economy of the Republic of Korea and the European Union plus the United Kingdom maintained their status of contribution to the world GVC over the same period. To a lesser extent, the same trend is observed with contributions to complex GVC.
Between 2019 and 2020, the PRC, which has dealt early on with the COVID-19 pandemic during the initial waves significantly expanded its role in world GVC.

\section{Asia-to-Asia RVC}

Within Asia and the Pacific, the PRC's rise and Japan's decline in terms of contribution to the region's value chain linkages follow a mirror image. While the PRC's contribution nearly doubled, that of Japan was almost halved from 2000 to 2020 (box tables 2a and 2b). India's contribution to the region also doubled while that of Malaysia and Indonesia declined and the Republic of Korea maintained its position over the same period. A similar pattern is observed for complex RVC. The PRC's contribution to Asian RVC further increased in 2020.

\section{1a: Contributions to World GVC (\%)}

\begin{tabular}{|c|c|c|c|c|c|c|c|c|c|}
\hline Year & PRC & Japan & $\begin{array}{l}\text { Republic } \\
\text { of Korea }\end{array}$ & $\begin{array}{l}\text { United } \\
\text { States }\end{array}$ & $\begin{array}{c}\text { European } \\
\text { Union + } \\
\text { UK }^{\mathrm{a}}\end{array}$ & Malaysia & Indonesia & Philippines & India \\
\hline 2000 & 4.7 & 10.2 & 4.6 & 21.2 & 35.0 & 3.2 & 1.7 & 0.6 & 1.4 \\
\hline 2010 & 12.5 & 7.3 & 5.0 & 14.5 & 33.7 & 2.4 & 1.9 & 0.5 & 3.0 \\
\hline 2015 & 14.9 & 6.0 & 5.9 & 15.5 & 33.5 & 2.0 & 1.7 & 0.6 & 2.5 \\
\hline 2019 & 14.3 & 5.8 & 5.2 & 16.3 & 35.4 & 1.9 & 1.5 & 0.6 & 3.7 \\
\hline 2020 & 16.6 & 5.6 & 5.3 & 15.6 & 35.4 & 1.9 & 1.5 & 0.6 & 3.6 \\
\hline
\end{tabular}

\section{1b: Contributions to World Complex GVC (\%)}

\begin{tabular}{lrccccccccc} 
Year & PRC & Japan & $\begin{array}{c}\text { Republic } \\
\text { of Korea }\end{array}$ & $\begin{array}{c}\text { United } \\
\text { States }\end{array}$ & $\begin{array}{c}\text { European } \\
\text { Union + } \\
\text { UK }\end{array}$ & Malaysia & Indonesia & Philippines & India \\
\hline 2000 & 4.9 & 10.3 & 5.7 & 21.1 & 41.6 & 5.0 & 1.8 & 0.8 & 1.2 \\
\hline 2010 & 13.1 & 7.4 & 6.4 & 13.3 & 41.2 & 3.5 & 1.9 & 0.6 & 2.7 \\
2015 & 14.4 & 6.2 & 7.6 & 14.7 & 42.9 & 2.7 & 1.6 & 0.6 & 2.3 \\
2019 & 12.4 & 5.3 & 5.9 & 15.0 & 45.2 & 2.3 & 1.3 & 0.7 & 2.9 & 2.3 \\
2020 & 14.7 & 5.0 & 6.0 & 14.3 & 45.8 & 2.4 & 1.3 & 0.7 & 2.8 \\
\hline
\end{tabular}

European Union = (27 members), GVC = global value chain, PRC = People's Republic of China, RVC = regional value chain, UK = United Kingdom.

a The UK withdrew from the EU on 1 February 2020, but during the transition period ending 31 December 2020, EU law remained applicable to and in the UK, with a few limited exceptions.

Note: Economy-level contributions are estimated by taking the difference of world GVC and Asian RVC between the world and a hypothetical world without that economy.

Sources: ADB calculations using data from ADB. Multi-Regional Input-Output Tables; and methodology by Wang, Wei, Zhu (2013, revised 2018). 
2a: Contributions to Asia-to-Asia RVC (\%)

\begin{tabular}{lccccccc} 
Year & PRC & Japan & $\begin{array}{c}\text { Republic } \\
\text { of Korea }\end{array}$ & Malaysia & Indonesia & Philippines & India \\
\hline 2000 & 29.4 & 52.5 & 23.8 & 15.6 & 12.2 & 3.7 & 4.3 \\
2010 & 48.7 & 37.1 & 22.7 & 5.6 & 11.8 & 3.1 & 9.6 \\
\hline 2015 & 55.3 & 31.6 & 25.8 & 4.6 & 10.8 & 3.5 & 8.2 \\
2019 & 56.0 & 26.8 & 22.0 & 10.2 & 10.1 & 3.5 & 10.5 \\
\hline 2020 & 57.3 & 24.7 & 22.0 & 9.8 & 9.0 & 2.8 & 9.4 \\
\hline
\end{tabular}

2b: Contributions to Asia-to-Asia Complex RVC (\%)

\begin{tabular}{lccccccc} 
Year & PRC & Japan & $\begin{array}{c}\text { Republic } \\
\text { of Korea }\end{array}$ & Malaysia & Indonesia & Philippines & India \\
\hline 2000 & 32.6 & 59.2 & 29.6 & 29.1 & 12.6 & 5.5 & 4.2 \\
2010 & 59.0 & 43.8 & 33.0 & 8.9 & 12.3 & 4.5 & 9.4 \\
2015 & 64.7 & 40.0 & 36.8 & 7.4 & 10.8 & 4.7 & 7.9 \\
2019 & 63.1 & 33.1 & 28.9 & 16.6 & 11.1 & 5.5 & 10.8 \\
2020 & 65.3 & 29.8 & 29.1 & 16.1 & 9.5 & 4.2 & 9.3 \\
\hline
\end{tabular}

GVC = global value chain, PRC = People's Republic of China, RVC = regional value chain.

Note: Economy-level contributions are estimated by taking the difference of world GVC and Asian RVC between the world and a hypothetical world without that economy.

Sources: ADB calculations using data from ADB. Multi-Regional Input-Output Tables; and methodology by Wang, Wei, Zhu (2013, revised 2018).

Source: ADB staff.

These same economies also deepened their gross RVC linkages with the region during the pandemic crisis, except for Malaysia: Australia increased gross RVC participation from 89\% in 2019 to $87.4 \%$ in 2020, Cambodia from $53.6 \%$ to $61.1 \%$, Kazakhstan from 94.4\% to $95.8 \%$, the Lao PDR from $77.6 \%$ to $82.8 \%$, and Mongolia from $94.4 \%$ to $95.9 \%$. Other economies that deepened gross RVCs in 2020 are Bangladesh, India, and Pakistan from South Asia; Indonesia from Southeast Asia; and all East Asian economies except Hong Kong, China and the PRC (i.e., Indonesia; Japan; the Republic of Korea; Singapore; and Taipei,China). Net RVC participation, on the other hand, grew in 20 of the 26 Asian economies. Only Bhutan; Hong Kong, China; Maldives; Nepal; the Philippines; and Sri Lanka saw net RVC decline from 2019 to 2020.
Complex regional and global value chains for the region show a different picture. Overall, East Asia and Southeast Asia comprising many manufacturing powerhouses demonstrate relatively higher regional and global value chain linakges. Participation of Asian economies in multi-border trading of intermediate goods declined from 47.2\% in 2019 to $39.3 \%$ in 2020 (Figure 2.18). Among the 26 Asia and Pacific economies, only Cambodia and Malaysia expanded complex GVCs between 2019 and 2020.

Nevertheless, the region strengthened regional linkages for trading complex RVCs wherein participation in gross complex RVC in the regions increased from $25.3 \%$ in 2019 to $26.0 \%$ in 2019 while participation in net complex RVC increased from $18.7 \%$ to $19.8 \%$ over the same period. 
Figure 2.17: Overall RVC and GVC Participation-Selected Asia and Pacific Economies

\section{(a) RVC Participation (\%)}

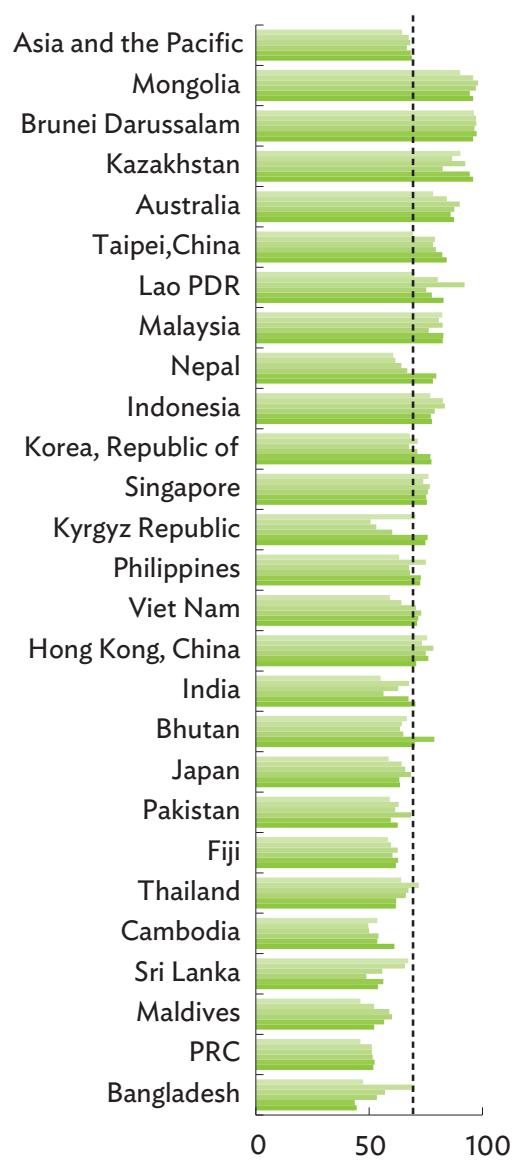

(b) GVC Participation (\%)

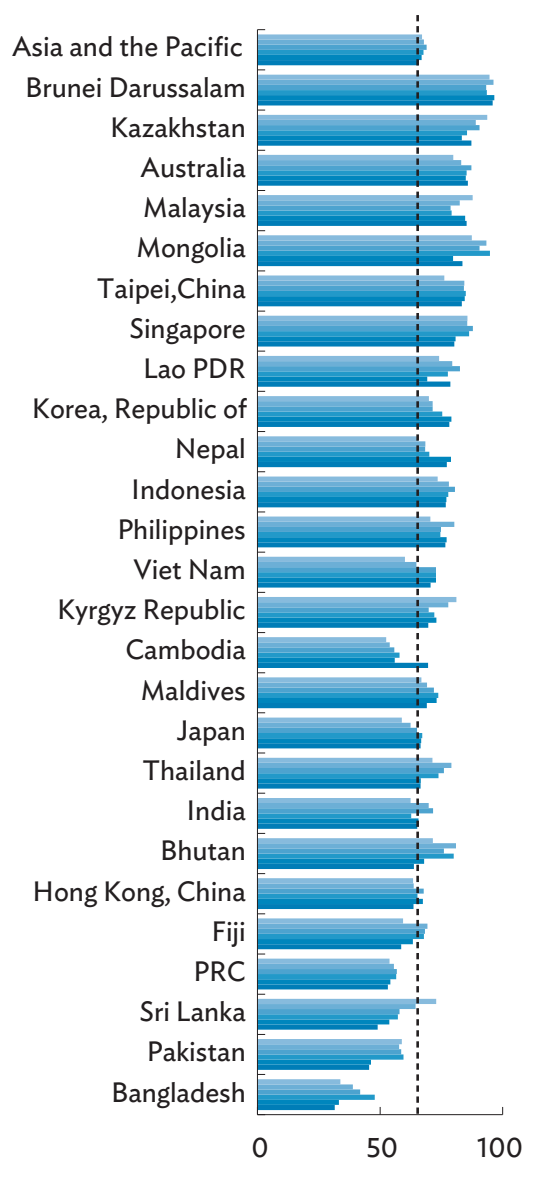

(c) RVC-GVC Intensity

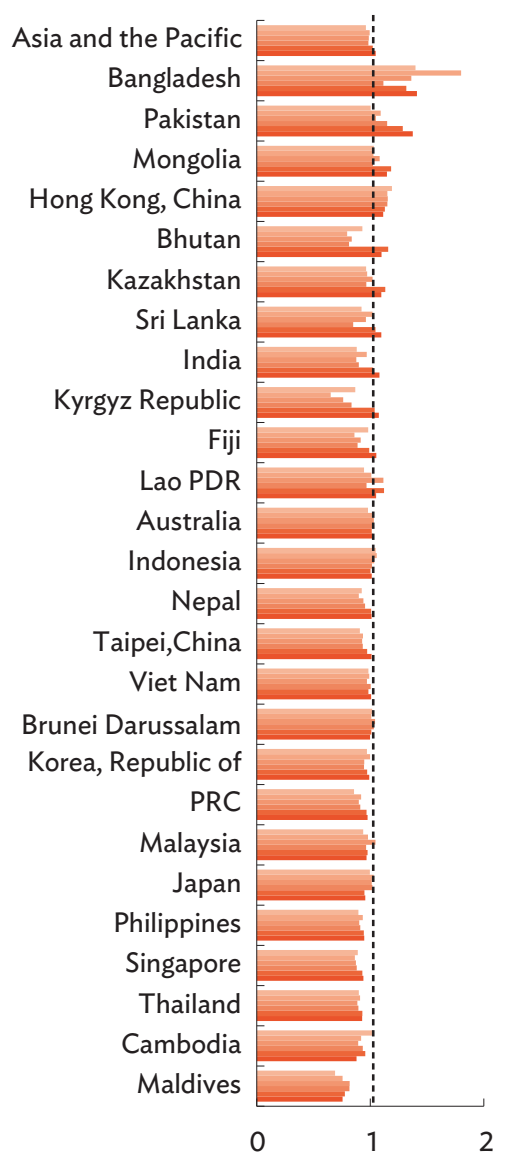

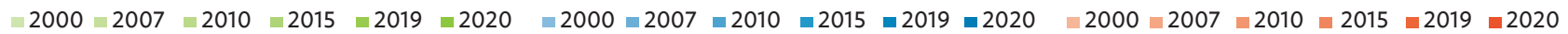

GVC = global value chain, Lao PDR = Lao People's Democratic Republic, PRC = People's Republic of China, RVC = regional value chain.

Notes: RVC-GVC intensity is the ratio of RVC participation and GVC participation rates. The overall GVC participation rate is the share of gross exports that involves production in at least two economies using cross-border production networks. The overall RVC participation rate is the same concept as that of GVC, except that it only involves economies of the same region. Economies are ordered by 2020 values from highest to lowest. The vertical dotted line represents the value for Asia and the Pacific for 2020 .

Sources: ADB calculations using data from ADB. Multi-Regional Input-Output Tables; and methodology by Wang, Wei, and Zhu (2013, revised 2018).

\section{Asia's Free Trade Agreement Policy}

\section{Interregional Asian free trade agreements (FTAs) are driving trade liberalization and will shape trade patterns in a post- COVID-19 world.}

The UK led the formation of 37 FTAs after leaving the EU on 1 January 2021. Five involved Asian economies: Georgia, Japan, the Republic of Korea, Singapore, and
Viet Nam. The proliferation of UK FTAs since Brexit has led to the unusually low share of Asian FTAs in the world's FTAs (Figure 2.21). All Asian FTAs that have entered into force in 2021 are interregional:

(1) Georgia-UK; (2) Japan-UK (January 2021);

(3) Republic of Korea-UK; (4) Singapore-UK (January 2021); (5) Viet Nam-UK (January 2021); (6) PRC-Mauritius (January 2021); (7) AzerbaijanTurkey Preferential Trade Agreement (March 2021); (8) India-Mauritius FTA (April 2021); (9) 
Figure 2.18: Complex RVC and GVC Participation-Selected Asia and Pacific Economies

(a) RVC Participation (\%)

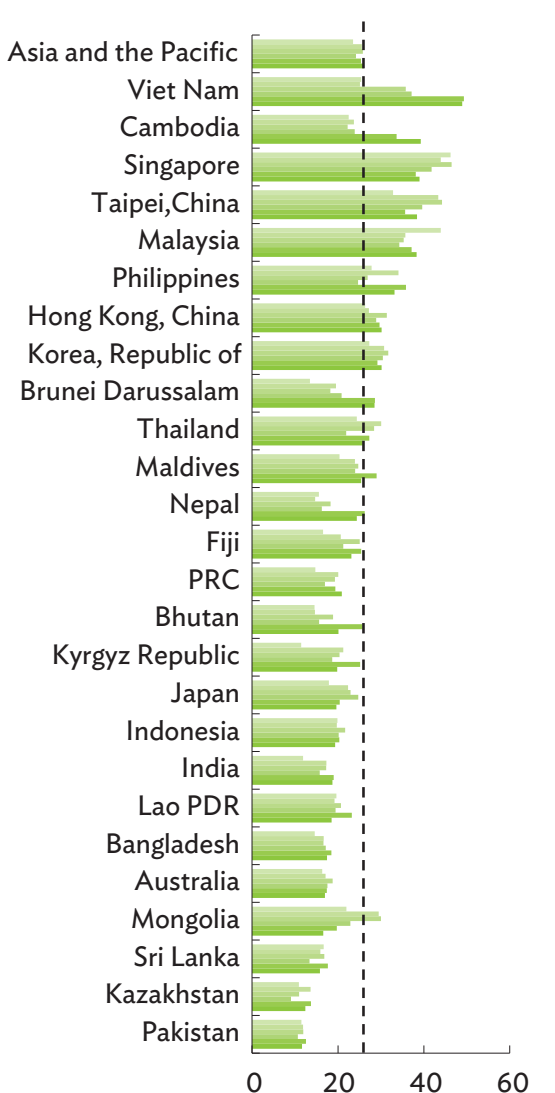

(b) GVC Participation (\%)

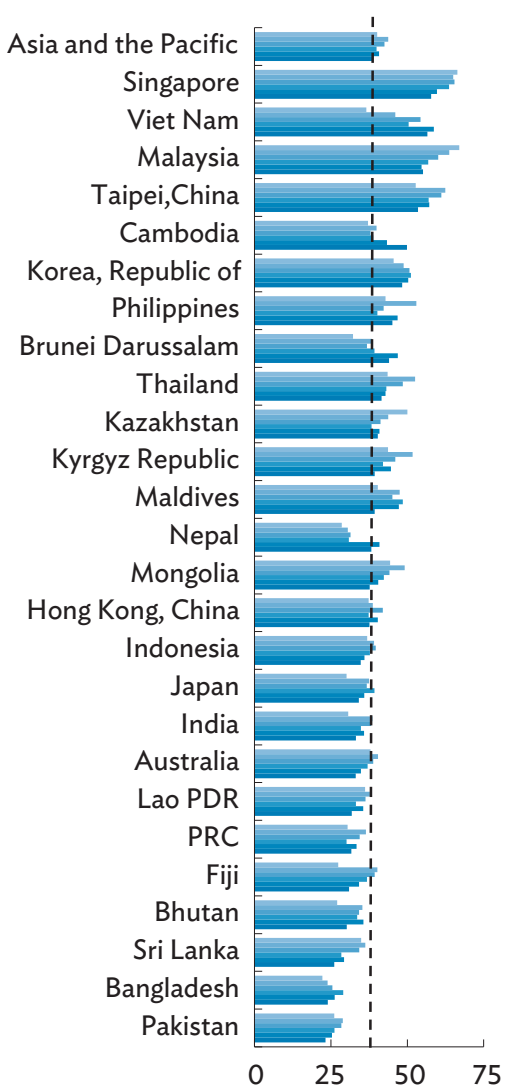

(c) RVC-GVC Intensity

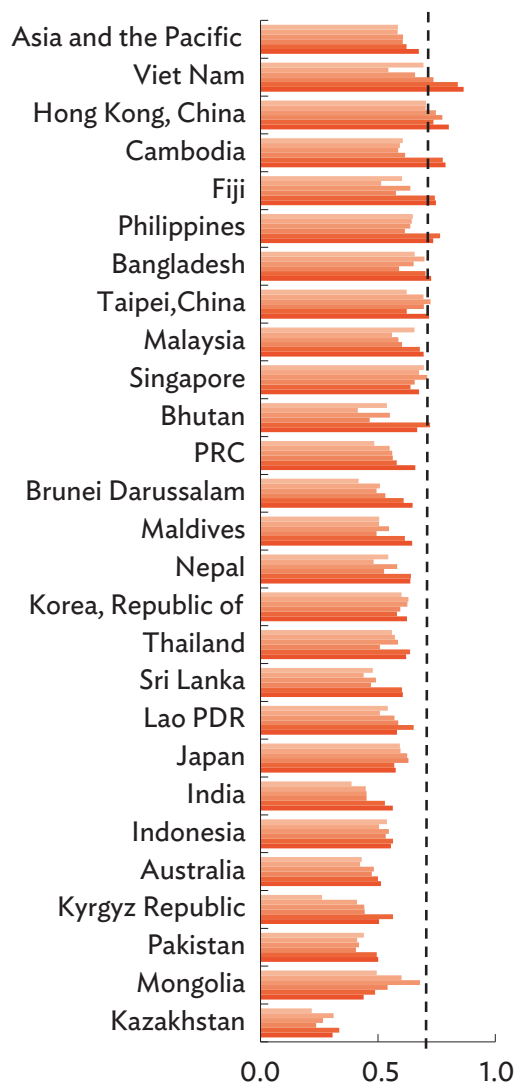

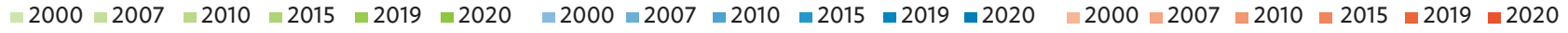

GVC = global value chain, Lao PDR = Lao People's Democratic Republic, PRC = People's Republic of China, RVC = regional value chain.

Notes: RVC-GVC intensity is the ratio of RVC participation and GVC participation rates. The complex GVC participation rate is the share of gross exports that involves production in at least two economies using cross-border production networks. The overall RVC participation rate, on the other hand, is the same concept as GVC, except that it only involves economies of the same. Both complex GVC and RVC participation includes only part of the gross exports for which the production entails bordercrossing twice or more. Economies are ordered by 2020 values from highest to lowest. The vertical dotted line represents the value for Asia and the Pacific for 2020.

Sources: ADB calculation using data from ADB. Multi-Regional Input-Output Tables; and methodology by Wang, Wei, and Zhu (2013, revised 2018).

Eurasian Economic Union-Serbia (July 2021); and (10) Indonesia-European Free Trade Association (November 2021). In December 2020, the AustraliaSingapore Digital Economy Agreement entered into force, marking a major advance in digital trade cooperation (more details are provided in Chapter 7: Theme Chapter-Advancing Digital Services Trade in Asia and the Pacific). The Regional Comprehensive Economic Partnership (RCEP) and the Cambodia-PRC FTA entered into force most recently on 1 January 2022.
Meanwhile, four FTAs were recently signed. Three of them are intraregional: (1) Bangladesh-Bhutan Preferential Trade Agreement (December 2020); (2) Indonesia-Republic of Korea FTA (December 2020); and (3) Cambodia-Republic of Korea FTA (October 2021). The Republic of Korea-Israel FTA was signed in May 2021. FTA negotiations between Australia and the UK were concluded on 15 June 2021, and between the Philippines and the Republic of Korea on 26 October 2021 (Table 2.1). The UK formally applied for membership of the Comprehensive and Progressive 
Figure 2.19: Newly Effective Free Trade AgreementsAsia and the Pacific

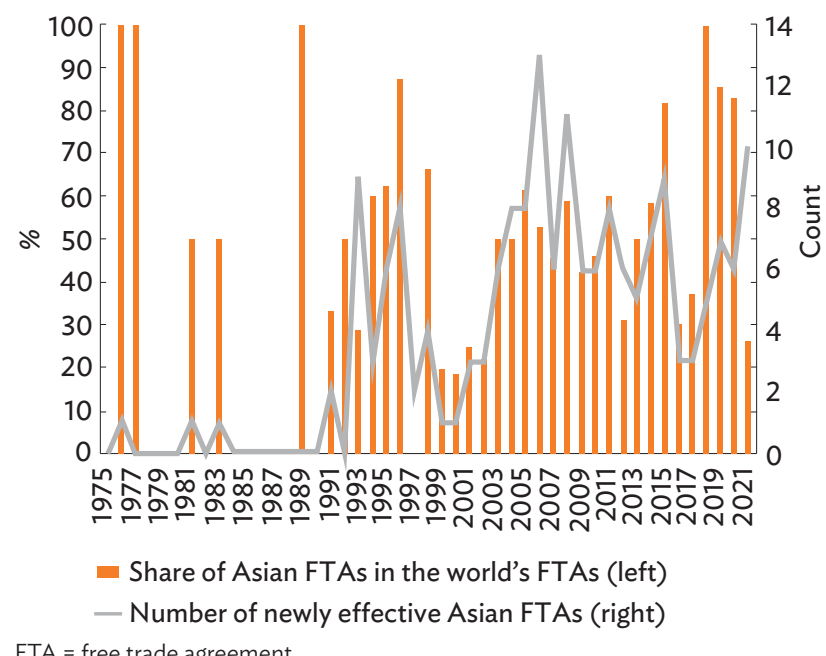

$\mathrm{FTA}=$ free trade agreement.

Sources: ADB calculations using data from ADB. Asia Regional Integration Center. FTA Database. https://aric.adb.org/fta; and World Trade Organization. Regional Trade Agreement Information System. http://rtais.wto.org (both accessed December 2021).
Agreement for Trans-Pacific Partnership (CPTPP) on 1 February 2021. Figure 2.19 shows the total number of FTAs in the region.

\section{Preference erosion resulting from graduation and the proliferation of new FTAs pose new trade policy challenges for developing Asia.}

The quest for increased market access is generating layers of bilateral FTAs that overlap with mega regionals such as the RCEP and CPTPP, and plurilateral FTAs such ASEAN +1 . Mega regionals can potentially contribute to reduce the complexity of the "spaghetti bowl" of overlapping FTAs that has progressively grown in Asia and the Pacific over the past few decades. However, this potential is conditional on (i) the additional market access provided by new agreements over the existing ones; (ii) their effective implementation; and (iii) their degree of utilization by the private sector.

Table 2.1: Recent Regional Trade Agreements in Asia and the Pacific

\begin{tabular}{|c|c|c|c|}
\hline Name & Coverage & Type & Status (Date) \\
\hline \multicolumn{4}{|c|}{ Intraregional } \\
\hline RCEP & Goods and services & FTA & In force (1 January 2022) \\
\hline Cambodia-PRC & Goods and services & FTA & In force (1 January 2022) \\
\hline Cambodia-Republic of Korea & Goods and services & FTA & Signed (26 October 2021) \\
\hline Indonesia-Republic of Korea & Goods and services & FTA & Signed (18 December 2020) \\
\hline Bangladesh-Bhutan & Goods & PTA & Signed (6 December 2020) \\
\hline Philippines-Republic of Korea & Goods and services ${ }^{\mathrm{a}}$ & FTA & Concluded (26 October 2021) \\
\hline \multicolumn{4}{|c|}{ Interregional } \\
\hline Indonesia-EFTA States & Goods and services & FTA & In force (1 November 2021) \\
\hline EAEU-Serbia & Goods & FTA & In force (10 July 2021) \\
\hline India-Mauritius & Goods and services & FTA and EIA & In force (1 April 2021) \\
\hline Azerbaijan-Turkey & Goods & PTA & In force (1 March 2021) \\
\hline PRC-Mauritius & Goods and services & FTA and EIA & In force (1 January 2021) \\
\hline Georgia-UK & Goods and services & FTA and EIA & In force (1 January 2021) \\
\hline Japan-UK & Goods and services & FTA and EIA & In force (1 January 2021) \\
\hline Republic of Korea-UK & Goods and services & FTA and EIA & In force (1 January 2021) \\
\hline Singapore-UK & Goods and services & FTA and EIA & In force (1 January 2021) \\
\hline Viet Nam-UK & Goods and services & FTA and EIA & In force (1 January 2021) \\
\hline Australia-Singapore & Digital trade & DEA & In force (8 December 2020) \\
\hline Republic of Korea-Israel & Goods and services & FTA & Signed (13 May 2021) \\
\hline Australia-UK & Goods and services & FTA & Concluded (15 June 2021) \\
\hline
\end{tabular}

$\mathrm{DEA}=$ digital economy agreement; EAEU = Eurasian Economic Union; EIA = economic integration agreement; EFTA States = European Free Trade Association which includes Iceland, Liechtenstein, Norway, and Switzerland; FTA = free trade agreement; PRC = People's Republic of China; PTA = preferential trade agreement; RCEP = Regional Comprehensive Economic Partnership; UK = United Kingdom.

${ }^{a}$ Trade in services and investment provisions to be further negotiated no later than 1 year after the deal enters into force.

Source: ADB compilation based on information available as of 14 December 2021. 
Least developed economies in Asia and the Pacific, such as Bangladesh, Cambodia, and Nepal, that have been relying on unilateral trade preferences such as Everything but Arms or other Duty-Free Quota-Free programs, are progressively exposed to preference erosion. This erosion stems not only from future graduation from least developed economy status, ${ }^{16}$ but also from the progressive entering into force of bilateral FTAs with large trading partners such as the $\mathrm{EU}$, and other preference-granting economies that are parties to FTAs in the region. While least developed economies are particularly vulnerable to preference erosion, the phenomenon also potentially concerns any developing economy.

A multiple track strategy is emerging in the region where different FTAs are entered into involving the same partners. As an example, Viet Nam has four FTAs with Japan: ASEAN-Japan, Viet Nam-Japan, CPTPP, and lately RCEP. The majority of FTAs in Asia and the Pacific lack provisions to build on the trade liberalization achieved in previous FTAs among partners. As a result, estimating the additional market access gain from each FTA remains challenging for businesses.

Evaluating the value of incremental trade liberalization with overlapping FTAs requires a detailed analysis of how firms make use of FTAs that are available at the time of exportation to a partner in the region. Such analysis with support and participation by the private sector could guide policy makers in formulating future FTA policies in an informed manner.

\section{Way Forward for RCEP Implementation of Market Access Provisions}

RCEP entered into force on 1 January $2022 . .^{17}$ It represents the most ambitious application of regional cooperation and integration in Asia and the Pacific. ${ }^{18}$ Like the CPTPP, RCEP is expected to strengthen the rules-based trading system, improve confidence in markets in Asia and the Pacific and support a more vibrant trade and investment environment in the region. Both agreements have potential to strengthen the region's manufacturing supply chains, raise productivity, and increase wages and employment. The resulting world income gains are estimated to be $\$ 188$ billion for CPTPP and $\$ 263$ billion for RCEP (Park, Petri, and Plummer 2021). While the degree of liberalization within RCEP may not be as deep as in CPTPP, and the coverage is less comprehensive, RCEP contains a built-in work plan to deepen its provisions and expand its coverage in the future. Therefore, RCEP policy makers and economic operators will have to work further on implementation to unlock the agreement's potential to create value beyond the network of existing FTAs in Asia and the Pacific. The next subsections examine the key market access provisions of RCEP: tariff reductions and rules of origin.

16 Bhutan is expected to graduate in 2023 and Solomon Islands in 2024. Bangladesh, the Lao PDR, and Nepal are scheduled to graduate in November 2026. Kiribati is recommended for graduation by the Committee for Development Policies (CDP) but the decision by the United Nations Economic and Social Council has been deferred to 2024. Cambodia is pre-eligible since 2021 and its full eligibility needs to be confirmed in 2024.

17 The 10 signatory states that have deposited their instruments of ratification, acceptance, or approval are Australia, Brunei Darussalam, Cambodia, Japan, the Lao PDR, New Zealand, the PRC, Singapore, Thailand, and Viet Nam. In the Republic of Korea, the RCEP agreement enters into force on 1 February 2022 (Government of Japan, Ministry of Economy, Trade and Industry 2021a, 2021b).

18 ASEAN plus Australia, the PRC, Japan, the Republic of Korea, and New Zealand. Kang et al. (2020) provides an overview of the RCEP agreement and its economic impact. 


\section{Tariff Reductions: An Initial Assessment}

Given the complex network of FTAs in the region, the major challenge of RCEP is to live up to expectations that the agreement will bring improvements in practice, creating impetus for trade liberalization through the most classical form of tariff reductions and streamlined rules of origin. Significant benefits are indeed expected. RCEP has potential to provide not only more market access than existing FTAs but also to create a preferential platform for economies that were not previously engaged in FTAs with each other (e.g., the PRC and Japan). The preliminary analysis of the tariff structure (38 tariff offers) and the phase-out periods (in some cases over 20 years) nevertheless provides sobering expectations (Crivelli and Inama 2022).

The absence of a most-favored nation (MFN) provision for the inclusion of previous tariff liberalizations existing in other FTAs indicates that RCEP will coexist with the ASEAN Trade in Goods Agreement (ATIGA), ASEAN+1 FTAs, and other bilateral FTAs. In addition, many RCEP economies have presented differentiated offers. Some ASEAN economies have made differentiated offers toward other ASEAN members while tariffs have been almost totally eliminated under ATIGA. ${ }^{19}$ This tariff structure brings another layer of complexity in implementing the tariff reduction with the introduction of tariff differentials and related provisions.

Most of RCEP intraregional imports (54\%) are already MFN-free, ranging between $43 \%$ for the Republic of Korea and $71 \%$ for Japan (Figure 2.20). Some tariff lines are excluded from the tariff offers, representing about $7 \%$ of intraregional imports with a maximum of $10 \%$ in the case of the Republic of Korea. Finally, out of the remaining $39 \%$ of intraregional imports expected to be liberalized under RCEP, $16 \%$ will be fully liberalized in year $1,16 \%$ between 10 and 16 years after entry into force, and 3\% only in year 20 or 21. Excluding duty-free tariff lines and focusing exclusively on the trade that could be liberalized though RCEP, (i.e., excluding dutyfree tariff lines [category O]), Figure 2.21 shows that $61 \%$ of intraregional trade could be fully liberalized after 10 years, $77 \%$ after 15 years, and $89 \%$ after 20 years. Such long phasing-out periods for many tariff lines and the complete exclusion from tariff liberalization for others, could cast doubt over the real value of such offers in terms of competitive market access.

\section{Figure 2.20: RCEP Intraregional Import Shares by Tariff Phasing Down Type and Economy Group, 2019 (\%)}

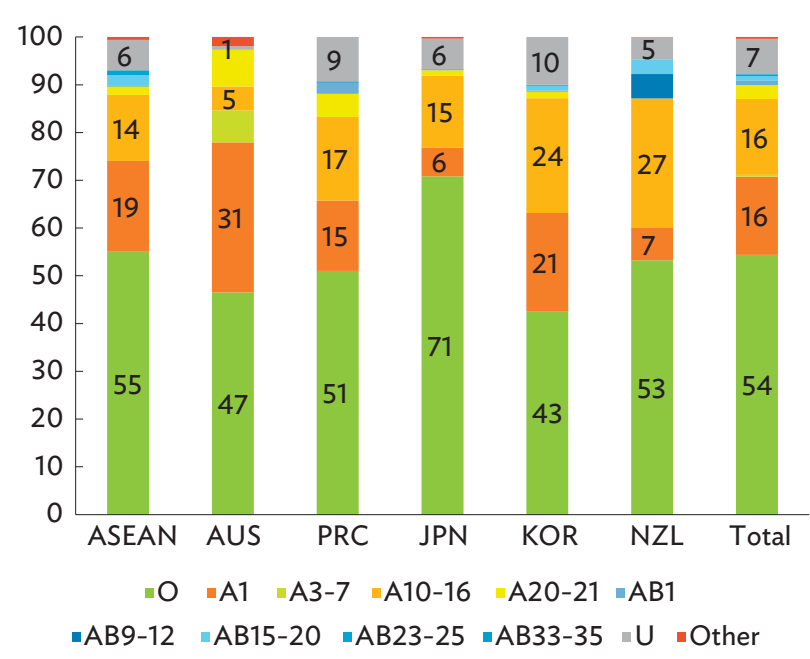

ASEAN = Association of Southeast Asian Nations, AUS = Australia, JPN = Japan, KOR = Republic of Korea, NZL = New Zealand, PRC = People's Republic of China, RCEP = Regional Comprehensive Economic Partnership.

$\mathrm{O}=$ non-dutiable goods; $\mathrm{AX}=$ ad-valorem tariff to be (gradually) reduced to zero in year $X$ after entry into force; $A B X=$ ad-valorem tariff to be (gradually) reduced to a lower but positive tariff in year $X$ after entry into force; $U$ = excluded from any tariff reduction or elimination.

Source: Crivelli and Inama (2022) based on official RCEP tariff commitments and United Nations. Commodity Trade Database. https://comtrade.un.org (accessed October 2021).

In addition, as shown in Figure 2.22, most of the excluded tariff lines had an initial MFN tariff (base rate) exceeding $10 \%$ and after the entry into force (excluding group A1), the next significant portion of liberalization (27\% of tariff lines on average) will take place between 9 and 15 years after entry into force.

19 Through ATIGA, Brunei Darussalam, Indonesia, Malaysia, the Philippines, Singapore, and Thailand have eliminated intra-ASEAN import duties on $99.65 \%$ of their tariff lines. Other ASEAN economies have reduced their import duties to $0 \%-5 \%$ on $98.86 \%$ of their tariff lines. 
Figure 2.21: RCEP Intraregional Import Shares in 2019 and RCEP Tariff Phasing Down Over Years

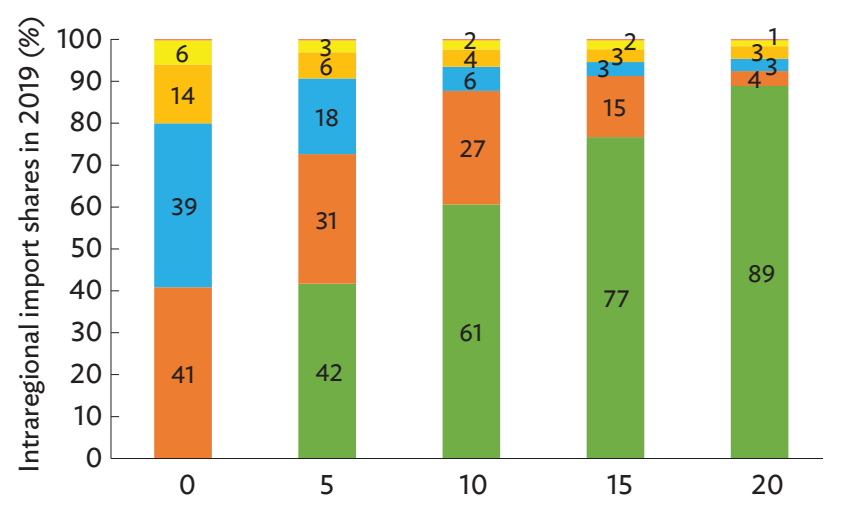

Number of years since RCEP enters into force

$$
\text { Itariff }=0 \% \quad \| \%<\text { tariff } \leq 5 \% \quad \square 5 \%<\text { tariff } \leq 10 \%
$$

$\| 10 \%<$ tariff $\leq 20 \% \quad 20 \%<$ tariff $\leq 50 \% \quad$ Itariff $>50 \%$

$\mathrm{HS}=$ harmonized system, $\mathrm{RCEP}=$ Regional Comprehensive Economic Partnership.

Notes: Tariff lines with a base rate of $0 \%$ and tariff lines subject to non-advalorem duties are excluded from total imports. Import at the national tariff line level is computed by using the share of tariff line in each HS6 category as a proxy for the proportion of trade of each tariff line within each HS6 category. The HS is an international nomenclature for the classification of products subdivided in chapters at 2-digits level (HS2), headings at 4-digits level (HS4), and subheadings at 6-digits level (HS6).

Source: Crivelli and Inama (2022) based on official RCEP tariff commitments and United Nations. Commodity Trade Database. https://comtrade.un.org (accessed October 2021).

\section{Product-Specific Rules of Origin: A Game Changer?}

RCEP has been welcomed as a game changer for Rules of Origin (ROO) thanks to (i) the possibility to cumulate inputs within the whole RCEP region to qualify as an RCEP-originating product, and (ii) bringing under a single FTA the thousands of product-specific rules of origin (PSROs) scattered in many ASEAN FTAs. Initial research points to several issues that temper these expectations (Crivelli and Inama 2021, 2022). A rational profit-maximizing firm uses the available FTA that provides the best combination of tariff offer and ROO advantages. Hence, if the preferential margin is better under a competing FTA with a favorable ROO, the firm might have no incentive to use RCEP and its cumulation provisions. Furthermore, the kind of cumulation provided under RCEP is limited to cumulation of inputs originating in other RCEP economies (diagonal cumulation) but not to working or processing carried out in other RCEP economies and subject to tariff differentials.

Figure 2.22: RCEP Initial MFN Base Rate and Tariff Reduction (\% of tariff lines by phasing down type)

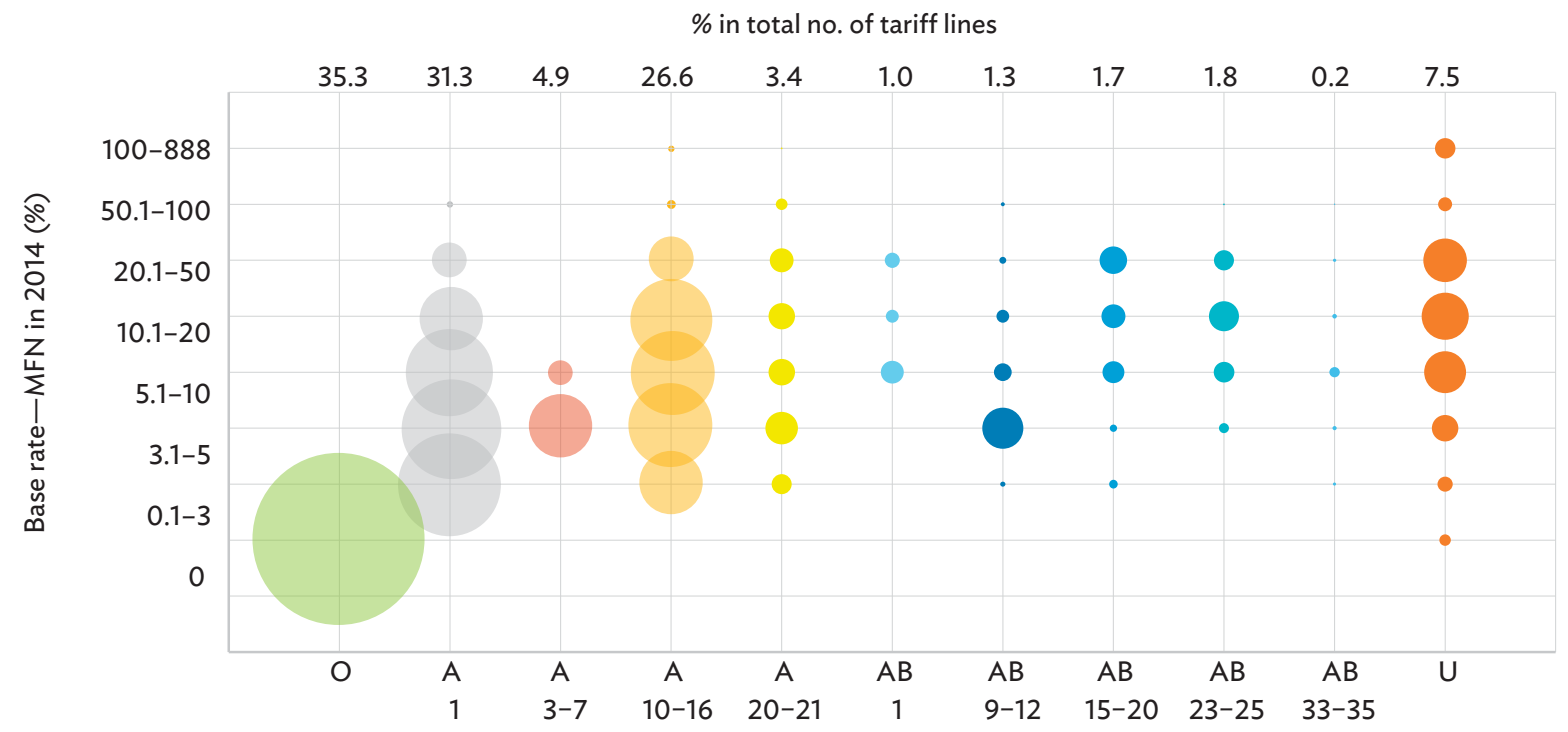

MFN = most-favored nation, $\mathrm{RCEP}=$ Regional Comprehensive Economic Partnership

$\mathrm{O}=$ non-dutiable goods, $\mathrm{AX}=\mathrm{ad}$-valorem tariff to be gradually reduced to zero in year $X$ after entry into force, $\mathrm{ABX}=\mathrm{ad}$-valorem tariff to be gradually reduced to a lower but positive tariff in the year(s) $X$ after entry into force, $U=$ goods excluded from any tariff reduction or elimination.

Note: The size of each bubble represents the average proportion of the number of national tariff lines within tariff group in the total number of national tariff lines.

Source: Crivelli and Inama (2022) based on official RCEP tariff commitments and United Nations. Commodity Trade Database. https://comtrade.un.org (both accessed October 2021). 
In simple words, a product manufactured in Cambodia using inputs from the PRC and exported to the Republic of Korea may be considered as originating from the PRC instead of Cambodia with the consequent application of a less generous tariff schedule unless the provisions for tariff differentials are met. In addition, the RCEP text on administration of the proof of origin (the so-called Certificate of Origin, or CO) does not provide for selfcertification but relies, albeit with some flexibility, on the use of COs stamped with the official seals and signatures of the certifying authorities. ${ }^{20}$ Finally, as mentioned earlier in this chapter, the new bilateral FTA between Cambodia and the PRC completed in 2021 may also offer competitive preferential margins and lenient PSRO.

Crivelli, Inama, and Pearson (forthcoming) conduct a comparison of the product-specific rules of origin contained in RCEP (Figure 2.23a), ATIGA (Figure 2.23b), and CPTPP (Figure 2.23c), showing the concentration of PSRO by chapters of the Harmonized System (HS) tariff nomenclature and form of PSRO most used in each FTA. Comparison of figures for RCEP and ATIGA show a high similarity on the use of the standard ASEAN PSRO: regional value content of $40 \%$ of the free-on-board price or change of tariff heading for many HS chapters. ${ }^{21}$ The similarity extends to the wide use of the more liberal PSRO (change of tariff subheading or RVC) in chapters 84 and 85 (machinery and electrical). RCEP makes more use than ATIGA of different forms of PSROs such as change of tariff chapter or RVC that feature in modern FTAs.
The striking difference between ATIGA and RCEP on the one hand and CPTPP on the other is the marked diffusion in CPTPP of different forms of PSROs that are widely used and spread among $\mathrm{HS}$ chapters, as depicted in Figure $2.25 \mathrm{c}$. The concentration of change of tariff subheading is noted in organic chemicals (HS Chapter 29) and product of machinery (HS Chapter 84), mirroring to a lesser extent the concentration noted in RCEP.

In terms of restrictiveness, Crivelli, Inama, and Pearson (forthcoming) developed a new methodology and a codification ranking from 1 to 3 ( 1 = least restrictive, 3 = most restrictive) for PSROs in ATIGA, RCEP, and CPTPP, which shows that ATIGA stands out, with 3,321 least restrictive PSROs (Table 2.2). ${ }^{22}$ Most importantly, CPTPP records 2,706 PSROs codified as least restrictive, which ranks better than RCEP (1,774 PSROs).

Leaving category 1 aside, RCEP appears to rank better under the second less restrictive PSRO ("intermediate" category), with 3,292 PSROs, while CPTPP has the higher number of most restrictive PSROs (at 1,111). However, many of the restrictive PSROs of CPTPP are essentially applicable in the textile and garment sector, which accounts for only $5 \%$ of intraregional RCEP trade. These initial results from the comparative analysis and coding need to be linked to volume of trade flows, preferential margins, and the RCEP tariff phasing down.

\section{Table 2.2: Comparison of Restrictiveness of Product-Specific Rules of Origin}

\begin{tabular}{lcc} 
& & Free Trade Agreement \\
\cline { 2 - 3 } Restrictiveness Code & ATIGA & RCEP \\
\cline { 2 - 3 } 1: Least restrictive & 3,321 & 1,774 \\
2: Intermediate & 1,807 & 3,292 \\
3: Most restrictive & 75 & 137 \\
\hline ATIGA = ASEAN Trade in Goods Agreement, CPTPP = Comprehensive and Progressive Agreement for Trans-Pacific Partnership, RCEP = Regional Comprehensive & 1,386 \\
Economic Partnership. & & \\
Source: Crivelli, Inama, and Pearson (forthcoming). & &
\end{tabular}

20 Some member states have introduced an approved exporters system, and a built-in agenda is contained in Article 3.16, para. 4.

21 The free-on-board price includes the cost of delivering the goods to the nearest port.

22 FTAs can have the same number on the same HS6 line if the rule is of the same stringency, and so the totals for 1, 2, and 3 will not add up to the total number of PSROs. This is expected. 
Figure 2.23: Product-Specific Rules of Origin by Harmonized System Chapter and Form of PSRO

(a) RCEP-2,075 Individual Rules as Applied to 5,203 Subheadings

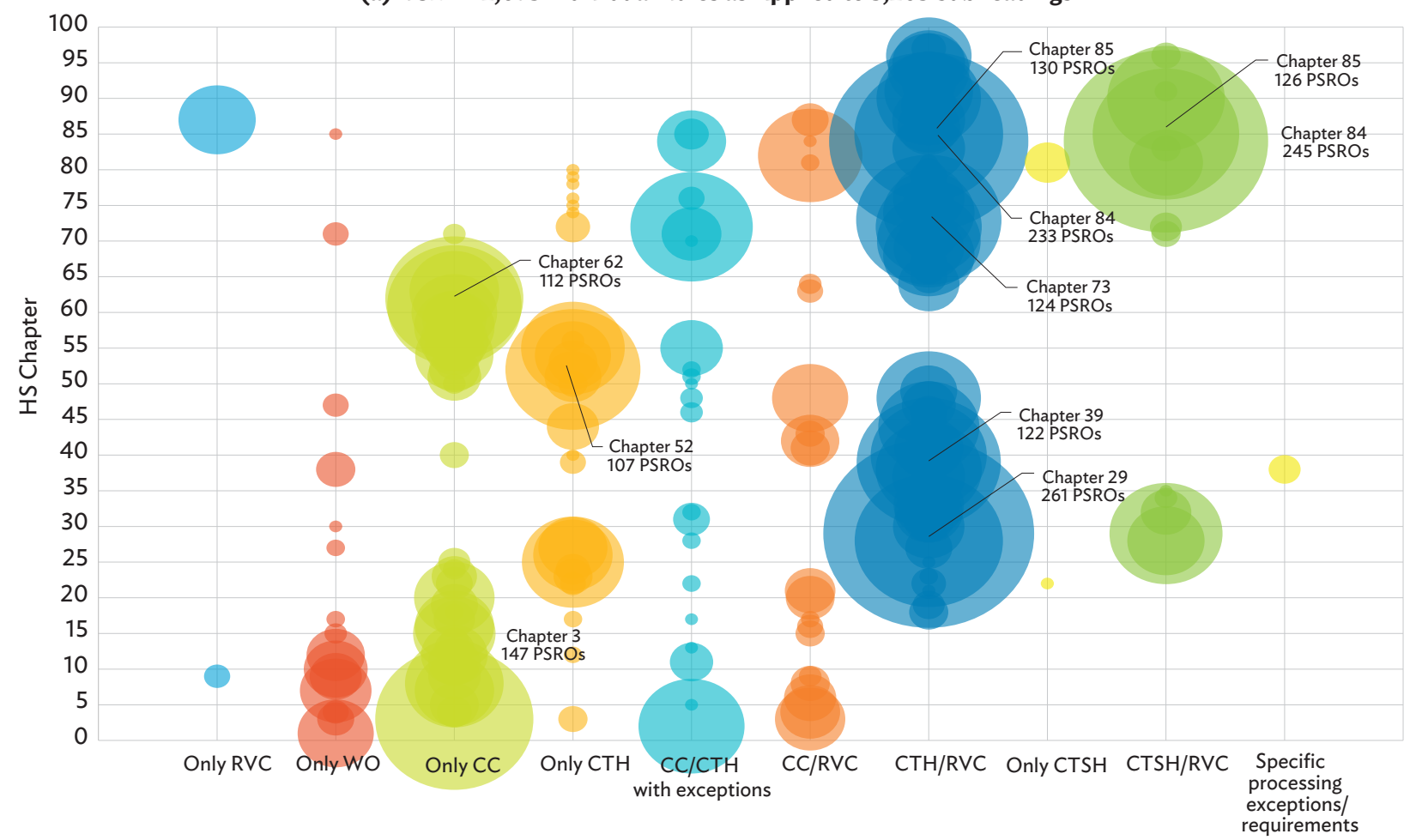

(b) ATIGA-2,735 Individual Rules as Applied to 5,203 Subheadings

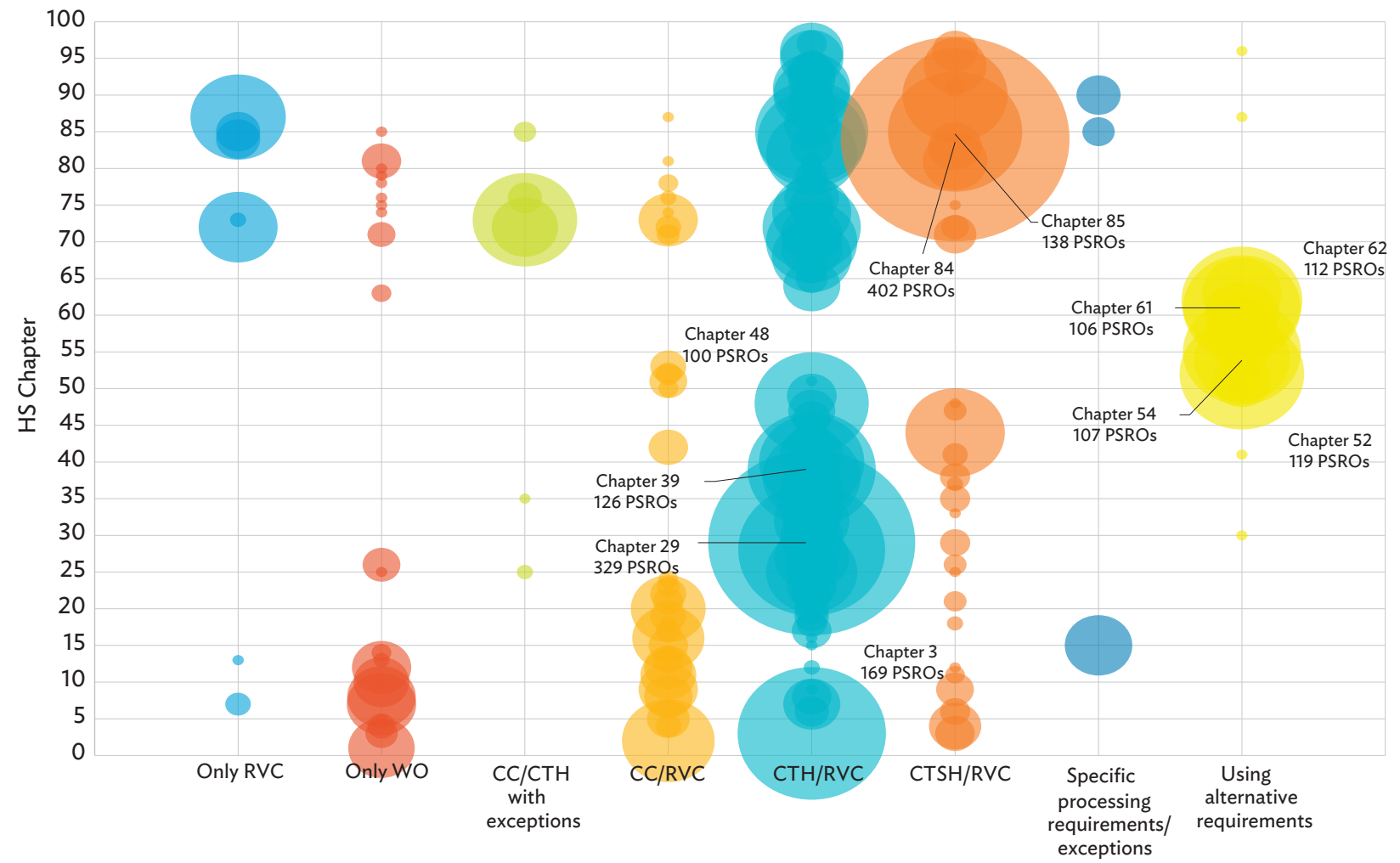


Figure 2.23: continued

(c) CPTPP-2,959 Individual Rules as Applied to 5,203 Subheadings

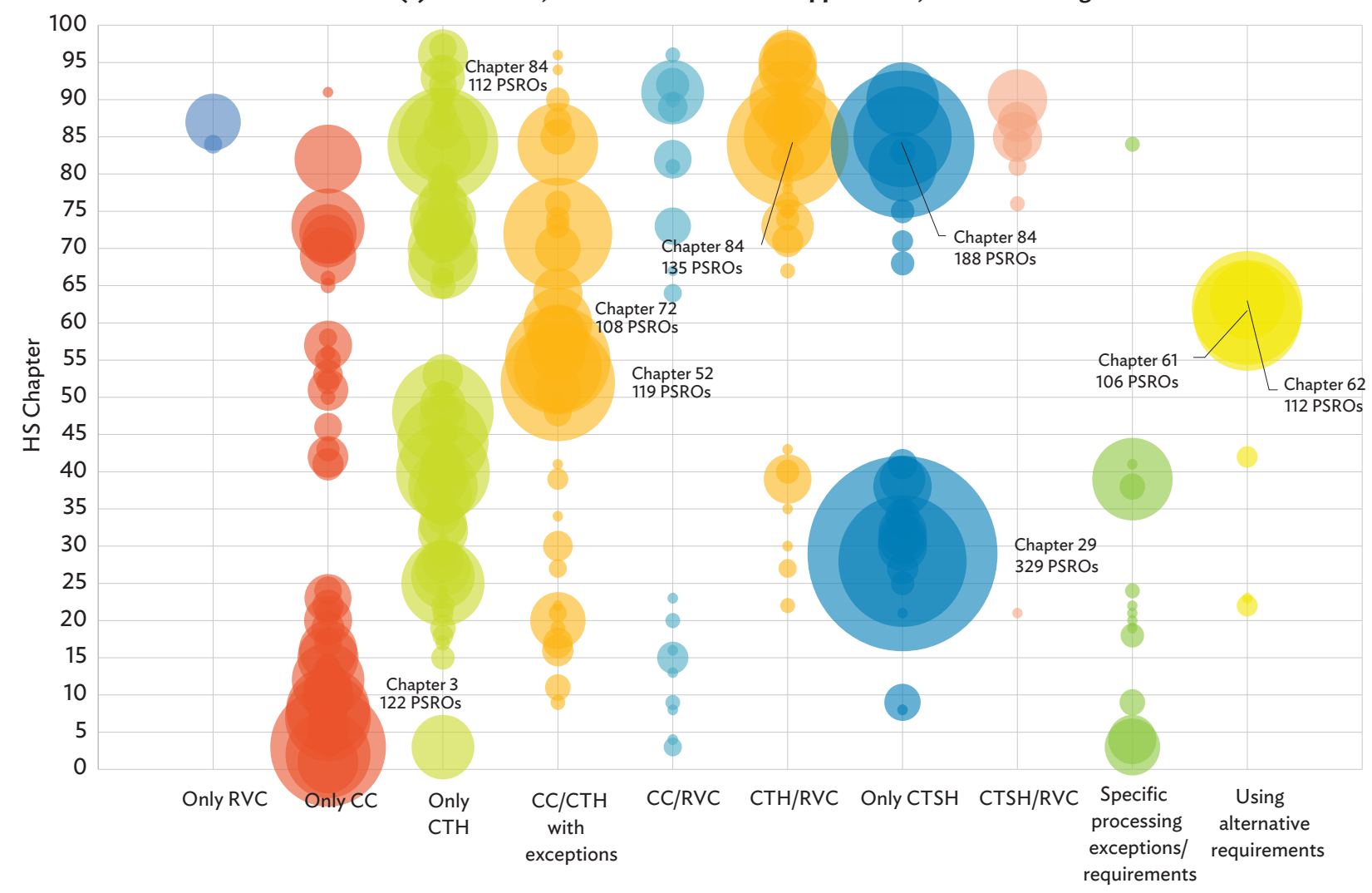

ATIGA = ASEAN Trade in Goods Agreement, CC = change of tariff chapter, CPTPP = Comprehensive and Progressive Agreement for Trans-Pacific Partnership, $\mathrm{CTH}=$ change of tariff heading, $\mathrm{CTSH}=$ change of tariff subheading, $\mathrm{HS}=$ Harmonized System, $\mathrm{PSRO}=$ product-specific rule of origin, RCEP = Regional Comprehensive Economic Partnership, RVC = regional value content, $\mathrm{WO}=$ wholly obtained.

Note: A total of 5,203 HS subheadings are included in the analysis.

Source: Crivelli, Inama, and Pearson (forthcoming).

The most interesting result from a policy agenda perspective is that the three FTAs have shown decisive scope for convergence and simplification of PSROs. Out of 5,203 PSROs comparatively analyzed among RCEP, CPTPP, and ATIGA, 769 PSROs are identical across the three FTAs and 2,340 have shown partial convergence, meaning that two FTAs have similar or identical PSROs while one FTA has a divergent PSRO. This brings the total of convergent PSROs showing great potential for simplification to 3,109.

RCEP can deepen integration by leveraging the built-in agenda on market access. RCEP has adopted a built-in agenda that accords with an ASEAN style of regional governance often defined the ASEAN Way of achieving integration by consensus. In order to effectively create a common umbrella that extends above the panoply of proliferating FTAs, policy makers need to quickly activate the built-in agenda so as to leverage the provisions of RCEP.

With regard to tariffs, government and development partners would benefit from further analysis to clearly identify areas and sectors where further negotiations are needed to make RCEP more competitive than the network of existing FTAs. These studies could trigger policy makers and negotiators to consider activating RCEP Article 2.5 on the acceleration of tariff commitments and the sectoral initiatives in Article 2.21 to achieve greater and faster tariff liberalization. ${ }^{23}$

23 Article 2.5 of the RCEP Agreement provides for the improvement of tariff commitments set out in Annex I, either unilaterally or mutually agreed between two or more parties. Under Article 2.21, the "parties may decide to initiate a work programme on sector-specific issues" (ASEAN Secretariat. RCEP Agreement Legal Text. https:// rcepsec.org/legal-text/ [accessed July 2021]). 
42 Asian Economic Integration Report 2022

Proof of origin and other discrepancies with administrative matters could pose challenges and add to the cost of compliance for businesses. As factual analysis of the text of the agreements shows a number of PSROs converging across FTAs, further convergence on best practices on proof of origin could act as a unifying factor to strengthen the ultimate goals of a regionwide FTA, not only in promoting deeper regional economic integration but in minimizing the administrative costs for ensuring compliance. 


\section{References}

ASEAN Secretariat. RCEP Agreement Legal Text. https://rcepsec.org/legal-text/ (accessed July 2021).

Asian Development Bank (ADB). 2015. Key Indicators for Asia and the Pacific 2015. Manila.

_2021. Asian Development Outlook Supplement July 2021: Renewed Outbreaks and Divergent Economies. Manila.

_- Asia Regional Integration Center. FTA Database. https://aric.adb.org/fta (accessed December 2021).

\section{- Multi-Regional Input-Output Tables.}

CPB Netherlands Bureau for Economic Policy Analysis. World Trade Monitor. https://www.cpb.nl/en/ world-trade-monitor-october-2021 (accessed January 2022).

Crivelli, P. and S. Inama. 2021. Making RCEP Successful through Business-Friendly Rules of Origin. Asian Development Blog. 12 February. https://blogs. adb.org/blog/making-rcep-successful-throughbusiness-friendly-rules-origin.

_. 2022. An Initial Assessment of Regional Comprehensive Economic Partnership Tariff Liberalization and Rules of Origin. ADB Briefs. No. 206. January. Manila: ADB.

Crivelli, P., S. Inama, and M. Pearson. Forthcoming. Product-Specific Rules of Origin of the Regional Comprehensive Economic Partnership-An Initial Assessment. Manila: ADB.

The Economist. 2021. A Perfect Storm for Container Shipping. 18 September. https://www.economist. com/finance-and-economics/a-perfect-stormfor-container-shipping/21804500.

Freightos. Freightos Baltic Index (FBX): Global Container Freight Index. https://fbx.freightos.com/ (accessed January 2022).
Government of Japan, Ministry of Economy, Trade and Industry. 2021a. The Regional Comprehensive Economic Partnership (RCEP) Agreement Will Enter into Force on January 1, 2022. News Release. 3 November. https://www.meti.go.jp/english/ press/2021/1103_001.html.

2021b. The Regional Comprehensive Economic Partnership (RCEP) Agreement Will Enter into Force in South Korea. 6 December. https://www.meti.go.jp/english/press/2021/1206_002. html.

Howley, D. 2021. These 169 Industries Are Being Hit by the Global Chip Shortage. Yahoo! News. 25 April. https://ph.news.yahoo.com/these-industriesare-hit-hardest-by-the-global-chipshortage-122854251.html.

Hummels, D., J.Ishii, and K.-M. Yi. 2001. The Nature and Growth of Vertical Specialization in World Trade. Journal of International Economics. 54(1). pp. 75-96.

International Monetary Fund (IMF). Direction of Trade Statistics. https://data.imf.org/dot (accessed January 2022).

Jeong, E. Y., and D. Strumpf. 2021. Why the Chip Shortage Is So Hard to Overcome. Wall Street Journal. 19 April. https://www.wsj.com/articles/ why-the-chip-shortage-is-so-hard-toovercome-11618844905.

Kang, J. W., P. Crivelli, M. C. Tayag, and D. Ramizo. 2020. Regional Economic Partnership: Overview and Economic Impact. ADB Briefs. No. 164. December. Manila: ADB.

Kuo, S. 2021. Progress in Importation of US Equipment Dispels Doubts on SMIC's Capacity Expansion for Mature Nodes for Now, Says TrendForce. Press Release. 5 March. https://www.trendforce.com/ presscenter/news/20210305-10693.html. 
Ludwikowski, M. and W. Mjoberg. 2021. Semiconductor Shortage and the US Auto Industry. Reuters. 22 June. https://www.reuters.com/legal/ legalindustry/semiconductor-shortage-us-autoindustry-2021-06-22/.

Organisation for Economic Co-operation and Development (OECD). Business Confidence Index (indicator) (accessed January 2022).

Park, C. Y., P. Petri, and M. Plummer. 2021. Economic Implications of the Regional Comprehensive Economic Partnership and Recent Trade Policy Developments in Asia and the Pacific. ADB Economics Working Papers. No. 639. Manila: ADB.

Richard, C., K. Ramachandran, and I. Pandoy. 2017. Workforce Development Survey: Looming Talent Gap Challenges Semiconductor Industry. Deloitte-Global Industry Association Serving the Electronics Manufacturing Supply Chain (SEMI). https:/www.semi.org/ko/workforce-development/ diversity-programs/deloitte-study\#_edn9.

Semiconductor Industry Association. 2021a. State of the US Semiconductor Industry. Washington, DC.

_. 2021b. Chipmakers Are Ramping Up Production to Address Semiconductor Shortage. Here's Why that Takes Time. Blog. 26 February. https://www.semiconductors.org/chipmakers-areramping-up-production-to-address-semiconductorshortage-heres-why-that-takes-time/.

-What Is a Semiconductor? https://www. semiconductors.org/semiconductors-101/what-isa-semiconductor.

. Freightos Baltic Index. https://de.statista.com/ statistik/daten/studie/1270630 (accessed January 2022).

United Nations (UN). Commodity Trade Database. https://comtrade.un.org (accessed October and December 2021).
United Nations Conference on Trade and Development (UNCTAD). 2015. Freight Rates and Maritime Transport Costs. In D. Barki and J. Rogers, eds. Review of Maritime Transport. Geneva.

Varas, A., R. Varadarajan, J. Goodrich, and F. Yinug. 2021. Strengthening the Global Semiconductor Supply Chain in an Uncertain Era. Washington, DC: Semiconductor Industry Association and Boston Consulting Group.

Wall Street Journal. 2021. Why the Global Chip Shortage Is Hard to Overcome. Video. youtube.com. 3 June. https://www.youtube.com/watch?v=FP_g-as29x0.

Wang, Z., S. J. Wei, and K. Zhu. 2013 (revised 2018). Quantifying International Production Sharing at the Bilateral and Sector Levels. NBER Working Paper. No. 19677. Cambridge, MA: National Bureau of Economic Research.

Williams, O. 2021. How the Polar Vortex Wreaked Havoc on the Automotive Industry. The New Statesman. 31 March. https://www.newstatesman. com/business/sustainability/2021/03/how-polarvortex-wreaked-havoc-automotive-industry.

World Trade Organization (WTO). 2021. Report of the TPRB from the Director-General on Trade-Related Developments (Mid-October 2020 to Mid-May 2021). Geneva.

- Regional Trade Agreement Information System. http://rtais.wto.org (accessed December 2021).

Yamamitsu, E. 2021. Renesas says Normal Production at Fire-Hit Chip Plant to Take 100-120 Days. Reuters. 30 March.

Zanni, T., L. Clark, C. Gentle, S. Jones, and S. Lohokare. 2019. Semiconductors: As the Backbone of the Connected World, the Industry's Future is BrightGlobal Semiconductor Industry Outlook 2019. Amstelveen: KPMG and Global Semiconductor Alliance. 


\section{Annex 2a: Intraregional and Extraregional Trade Values Annual Growth Rate by Region}

(a) Intraregional Trade

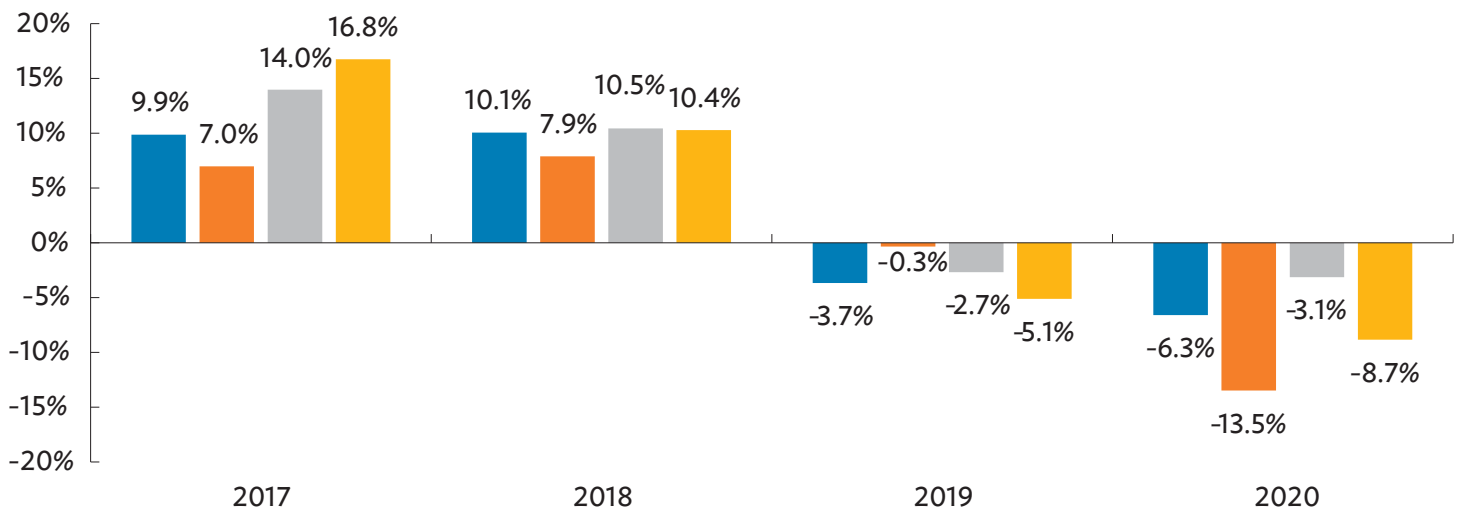

(b) Extraregional Trade

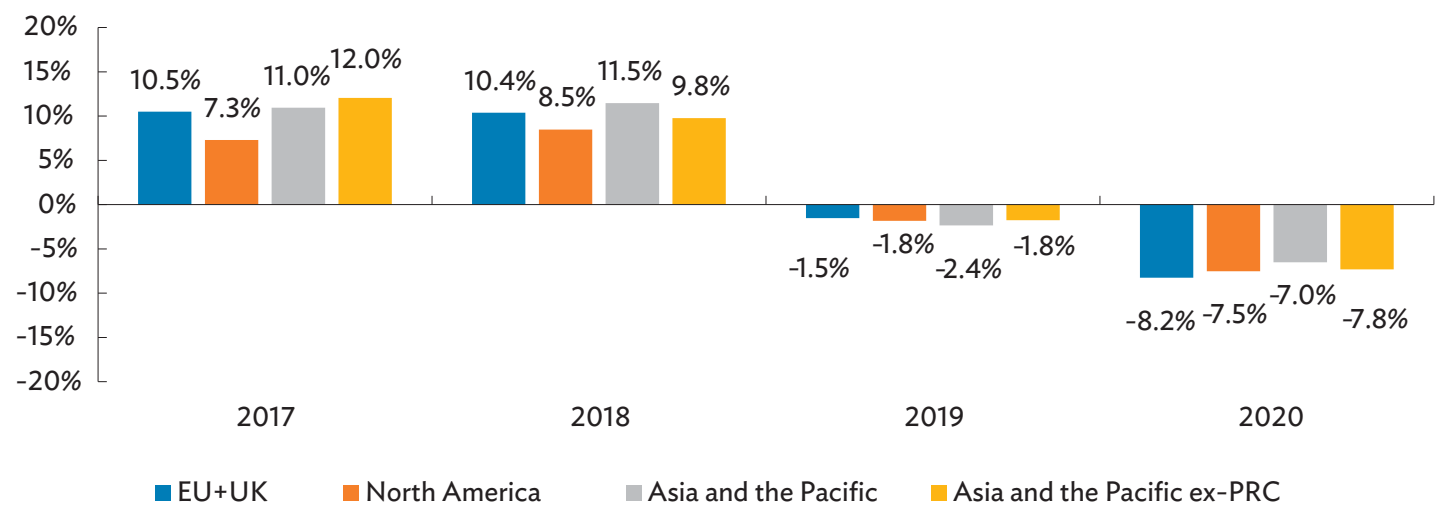

$\mathrm{EU}=$ European Union (27 members), PRC = People's Republic of China, UK = United Kingdom.

Notes: Values are expressed as percentage of the region's total merchandise trade (sum of exports and imports). North America covers Canada, Mexico, and the United States. Source: ADB calculations using data from International Monetary Fund. Direction of Trade Statistics. https://data.imf.org/dot (accessed January 2022). 


\section{Annex 2b: Analytical Framework of GVC and RVC}

A new framework for understanding participation in the global value chain (GVC) and regional value chain (RVC) is introduced to better track Asia and the Pacific's progress in global and regional trade linkages. The world's gross exports can be divided between (i) exports that cross a border once as final goods (represented by the blue area in the figure); and (ii) exports that go through two or more economies for further production (the yellow area). World-to-world GVC is the share of the world's total GVC terms to its gross exports. Asia-toworld GVC is the share of Asia's total GVC terms to its gross exports. Asia-to-Asia gross RVC is the share of Asia's intraregional GVC terms to its intraregional gross exports, excluding all non-Asian third economies.' Asiato-Asia net RVC is similar to gross RVC, except that its denominator, total intraregional exports, includes nonAsian third economies.

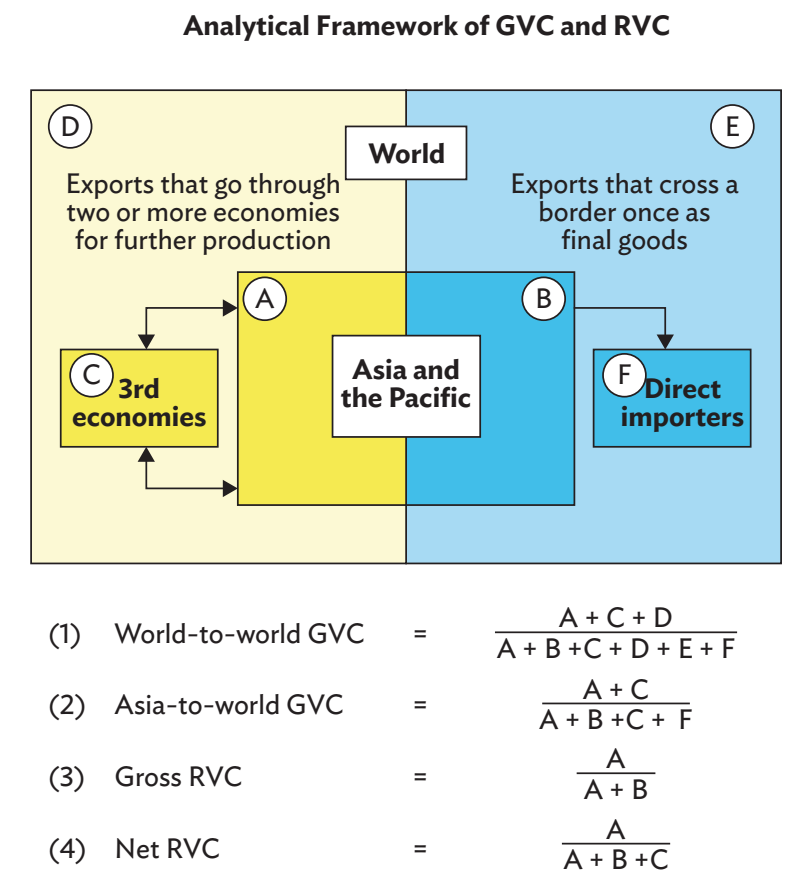

GVC = global value chain, $\mathrm{RVC}=$ regional value chain

Source: ADB based on Wang, Wei, and Zhu (2013, revised 2018). 


\section{Annex 2c: Economy and Sectoral Coverage of the ADB Multi-Regional Input-Output Tables}

\section{List of 62 Economies}

\begin{tabular}{|c|c|c|c|}
\hline Economy & Code & Economy & Code \\
\hline Australia & AUS & Lithuania & LTU \\
\hline Austria & AUT & Luxembourg & LUX \\
\hline Bangladesh & $B A N$ & Malaysia & $M A L$ \\
\hline Belgium & BEL & Maldives & $M L D$ \\
\hline Bhutan & $\mathrm{BHU}$ & Malta & MLT \\
\hline Brazil & BRA & Mexico & MEX \\
\hline Brunei Darussalam & $B R U$ & Mongolia & MON \\
\hline Bulgaria & $B G R$ & Nepal & NEP \\
\hline Cambodia & CAM & Netherlands & NET \\
\hline Canada & CAN & Norway & NOR \\
\hline Croatia & HRV & Pakistan & PAK \\
\hline Cyprus & CYP & People's Republic of China & $P R C$ \\
\hline Czechia & CZE & Philippines & $\mathrm{PHI}$ \\
\hline Denmark & DEN & Poland & POL \\
\hline Estonia & EST & Portugal & POR \\
\hline Fiji & FIJ & Republic of Korea & $K O R$ \\
\hline Finland & FIN & Romania & $\mathrm{ROM}$ \\
\hline France & FRA & Russian Federation & RUS \\
\hline Germany & GER & Singapore & SIN \\
\hline Greece & GRC & Slovakia & SVK \\
\hline Hong Kong, China & $H K G$ & Slovenia & SVN \\
\hline Hungary & HUN & Spain & SPA \\
\hline India & $I N D$ & Sri Lanka & SRI \\
\hline Indonesia & INO & Sweden & SWE \\
\hline Ireland & IRE & Switzerland & SWI \\
\hline Italy & ITA & Taipei,China & TAP \\
\hline Japan & $J P N$ & Thailand & THA \\
\hline Kazakhstan & $K A Z$ & Turkey & TUR \\
\hline Kyrgyz Republic & $K G Z$ & United Kingdom & UKG \\
\hline Lao People's Democratic Republic & LAO & United States & USA \\
\hline Latvia & LVA & Viet Nam & VIE \\
\hline
\end{tabular}

Note: The 26 economies from Asia and the Pacific are in italics.

Source: ADB. Multi-Regional Input-Output Tables. 


\section{List of 35 Sectors}

\begin{tabular}{|c|c|c|}
\hline $\begin{array}{l}1 \\
2\end{array}$ & $\begin{array}{l}\text { Agriculture, hunting, forestry, and fishing } \\
\text { Mining and quarrying }\end{array}$ & Primary \\
\hline 3 & Food, beverages, and tobacco & \multirow{5}{*}{ Low technology manufacturing } \\
\hline 4 & Textiles and textile products & \\
\hline 5 & Leather, leather products, and footwear & \\
\hline 6 & Wood and products of wood and cork & \\
\hline 7 & Pulp, paper, paper products, printing, and publishing & \\
\hline 8 & Coke, refined petroleum, and nuclear fuel & \multirow{2}{*}{ Medium-to-high technology manufacturing } \\
\hline 9 & Chemicals and chemical products & \\
\hline 10 & Rubber and plastics & Low technology manufacturing \\
\hline 11 & Other nonmetallic minerals & \multirow{5}{*}{ Medium-to-high technology manufacturing } \\
\hline 12 & Basic metals and fabricated metal & \\
\hline 13 & Machinery, not elsewhere classified (nec) & \\
\hline 14 & Electrical and optical equipment & \\
\hline 15 & Transport equipment & \\
\hline 16 & Manufacturing, nec; recycling & \multirow{3}{*}{ Low technology manufacturing } \\
\hline 17 & Electricity, gas, and water supply & \\
\hline 18 & Construction & \\
\hline 19 & Sale, maintenance, and repair of motor vehicles and motorcycles; retail sale of fuel & \multirow{12}{*}{ Business services } \\
\hline 20 & Wholesale trade and commission trade, except of motor vehicles and motorcycles & \\
\hline 21 & Retail trade, except of motor vehicles and motorcycles; repair of household goods & \\
\hline 22 & Hotels and restaurants & \\
\hline 23 & Inland transport & \\
\hline 24 & Water transport & \\
\hline 25 & Air transport & \\
\hline 26 & Other supporting and auxiliary transport activities; activities of travel agencies & \\
\hline 27 & Post and telecommunications & \\
\hline 28 & Financial intermediation & \\
\hline 29 & Real estate activities & \\
\hline 30 & Renting of machinery and equipment and other business activities & \\
\hline 31 & Public administration and defense; compulsory social security & \multirow{5}{*}{ Public and personal services } \\
\hline 32 & Education & \\
\hline 33 & Health and social work & \\
\hline 34 & Other community, social, and personal services & \\
\hline 35 & Private households with employed persons & \\
\hline
\end{tabular}

Note: Sectoral coverage of the ADB Multi-Regional Input-Output Tables database released in 2019.

Source: ADB. Multi-Regional Input-Output Tables. 


\section{Cross-Border Investment}

\section{Recent Trends in Foreign Direct Investment}

\section{Inward Foreign Direct Investment}

The COVID-19 pandemic continued to weigh on global inward investment activity in 2020; however, investment is expected to have picked back up in 2021 and to continue growing in 2022.

The ongoing global coronavirus disease (COVID-19) pandemic weighed down foreign direct investment (FDI) in $2020 .{ }^{24}$ From $\$ 1.5$ trillion in 2019, FDI slipped by over a third in 2020 to less than $\$ 1$ trillion based on balance of payments data from the United Nations Conference on Trade and Development (UNCTAD) ${ }^{25}$ This brings about a new trough for FDI, with 2020 estimates about 20\% lower than in 2009, in the wake of the global financial crisis. Developed economies felt most of the pinch in 2020 , as FDI in those economies fell by roughly $58 \%$. Meanwhile, FDI to developing economies inched up by $8 \%$. Despite the gloomy scenario for 2020 , preliminary estimates for 2021 show strong recovery in global FDI, while prospects for 2022 remain generally positive (Figure 3.1) (UNCTAD 2022).
Figure 3.1: Total Inward Foreign Direct Investment-Balance of Payments

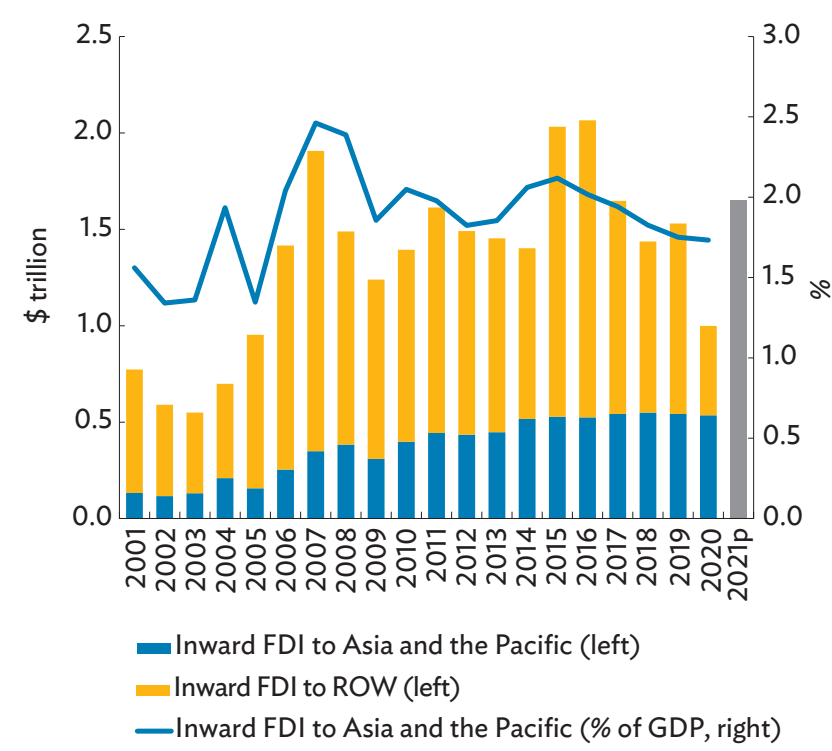

$\mathrm{FDI}=$ foreign direct investment, $\mathrm{GDP}=$ gross domestic product, $\mathrm{p}=$ preliminary, ROW = rest of the world

Note: The bar for 2021p plots preliminary estimates for global inward FDI from the United Nations Conference on Trade and Development's Global Investment Trend Monitor, No. 40

Sources: ADB calculations using data from ASEAN Secretariat. ASEANstats Data Portal. https://data.aseanstats.org (accessed July 2019); CEIC Data Company; Eurostat. Balance of Payments. https://ec.europa.eu/eurostat (accessed July 2021); International Monetary Fund. World Economic Outlook April 2021 database. https://www.imf.org/en/Publications/WEO/weo-database/2021/ April (accessed April 2021); and United Nations Conference on Trade and Development. World Investment Report 2021 Statistical Annex Tables. https://worldinvestmentreport.unctad.org/annex-tables/ (accessed July 2021).

24 For discussions on recent FDI trends, this chapter analyzes standard balance of payments data, as well as firm-level data by mode of entry (greenfield investment and mergers and acquisitions). For more information on the differences between the two and the data compilation methods used, please see Annex 3a.

25 The UNCTAD World Investment Report excludes the Caribbean financial centers from its total estimate. These include Anguilla, Antigua and Barbuda, Aruba, the Bahamas, Barbados, British Virgin Islands, the Cayman Islands, Curaçao, Dominica, Grenada, Montserrat, Saint Kitts and Nevis, Saint Lucia, Saint Vincent and the Grenadines, Saint Maarten, and the Turks and Caicos Islands. 
Globally, the United States (US) remained the largest recipient of FDI in 2020 (Table 3.1). However, foreign investment to this economy declined $40.2 \%$. The People's Republic of China (PRC), the second-largest recipient, received $\$ 149.3$ billion in FDI flows. Other Asian economies also proved to be attractive destinations for global foreign investment: Hong Kong, China (up 61.7\% from 2019); Singapore (down 20.7\% from 2019); and India (up 26.7\% from 2019) were among the top-five destinations for FDI globally.

Among Asia and Pacific economies, foreign investors also flocked to Australia (down 48.6\% from 2019); Indonesia (down 22.2\% from 2019); Viet Nam (down 2.0\% from 2019); Japan (down 29.5\% from 2019); the Republic of Korea (down 4.3\% from 2019); and Taipei,China (up 6.8\% from 2019).

East Asia and Southeast Asia remained top destinations of global FDI in 2020, accounting for over $80 \%$ of Asia's total inward FDI. East Asia remained the largest recipient of foreign investment in Asia and the Pacific, with 55.7\% of global FDI flowing into the region, while Southeast Asia received $25.4 \%$ of Asia's inward FDI. South Asia received 13.0\%; the Pacific and Oceania, 4.4\%; and Central Asia, 1.5\%.
Intraregional inflows amounted to $\$ 287.9$ billion in 2020 , down 2.9\% from 2019. Despite this, the intraregional share remained relatively high at $53.7 \%$. East Asia benefited most, with $61.3 \%$ of intraregional flows entering the subregion in 2020. Southeast Asia followed, with roughly one-fifth of intraregional investment flowing into the region that year.

\section{Despite strong recovery in global mergers and acquisitions (M\&As) in the third quarter of 2020, overall firm-level activity suffered as COVID-19 heavily affected greenfield investment. Meanwhile, the first half of 2021 hints at recovery in greenfield investment and stability in M\&A globally. ${ }^{26}$}

Global greenfield activity took a back seat in 2020. While third- and fourth-quarter estimates showed some signs of recovery, global flows for the whole of 2020 were still more than $\$ 200$ billion lower compared with 2019. The effects of the pandemic resulted in further decline, bringing total global greenfield investment to roughly half of that in 2018. Despite this, global greenfield activity showed signs of further revival in the first half of 2021, compared with 2020.

Table 3.1: Top 10 Destinations of Foreign Direct Investment-World and Asia and the Pacific (\$ billion)

\begin{tabular}{|c|c|c|c|c|c|}
\hline World & 2020 & 2019 & Asia and the Pacific & 2020 & 2019 \\
\hline United States & 156.3 & 261.4 & People's Republic of China & 149.3 & 141.2 \\
\hline People's Republic of China & 149.3 & 141.2 & Hong Kong, China & 119.2 & 73.7 \\
\hline Hong Kong, China & 119.2 & 73.7 & Singapore & 90.6 & 114.2 \\
\hline Singapore & 90.6 & 114.2 & India & 64.1 & 50.6 \\
\hline India & 64.1 & 50.6 & Australia & 20.1 & 39.2 \\
\hline Luxembourg & 62.1 & 14.8 & Indonesia & 18.6 & 23.9 \\
\hline British Virgin Islands & 39.6 & 39.1 & Viet Nam & 15.8 & 16.1 \\
\hline Germany & 35.7 & 54.1 & Japan & 10.3 & 14.6 \\
\hline Sweden & 26.1 & 10.1 & Republic of Korea & 9.2 & 9.6 \\
\hline Brazil & 24.8 & 65.4 & Taipei,China & 8.8 & 8.2 \\
\hline
\end{tabular}

Source: United Nations Conference on Trade and Development. World Investment Report 2021 Statistical Annex Tables. https://worldinvestmentreport.unctad.org/ annex-tables/ (accessed July 2021).

26 Firm-level estimates are computed using data from Bureau van Dijk. Zephyr M\&A Database; and Financial Times. fDi Markets. The firm-level data presented in this chapter capture information on the creation of new assets (new greenfield FDI) and the purchase of existing assets (M\&A). 
Much of the increase happened in North America and Latin America, cushioning declines in Asia and the Pacific and in the European Union plus the United Kingdom (EU+UK). In addition, stable M\&A activity continued in the first half of 2021. Global inward M\&A amounted to $\$ 688.0$ billion in the first half $(\mathrm{H} 1)$ of 2021 , slightly higher than total $M \& A$ value for $\mathrm{H} 1$ 2019. Large gains in M\&A deals in the EU+UK (up $\$ 87.8$ billion) were offset by losses in the Middle East (down $\$ 73.1$ billion), North America (down $\$ 69.8$ billion), and Asia and the Pacific (down $\$ 14.3$ billion) (Annex 3b).

FDI in Asia and the Pacific declined in 2020, with greenfield investment falling $37.9 \%$. Meanwhile, M\&A recovered after a crunch in 2019. While declines in 2020 were more moderate than in 2019, some economies in Asia and the Pacific were heavily affected.

FDI in Asia and the Pacific weakened 1.3\% in 2020, with noteworthy changes in composition (Figure 3.2). Greenfield FDI to Asia and the Pacific continued to drop, by $37.9 \%$ in 2020 after declining 35.4\% the previous year. Given the sizable economic gains greenfield investment could bring to host economies through job creation, technological spillovers, and transfer of managerial skills among others, the recent trend calls for renewed attention by policy makers in the region to identify and ease potential bottlenecks in attracting greenfield investments. In contrast, M\&A deal value recovered in 2020 after a crunch in 2019. The value of M\&A deals rose $38.7 \%$ to $\$ 277.0$ billion in 2020, compared with the $41.4 \%$ decline in 2019. Meanwhile, intraregional FDI dipped only slightly in 2020. Project and deal value declined $1.3 \%$ in 2020 , as a $74.1 \%$ increase in M\&A deal value cushioned the $43.6 \%$ decline in greenfield FDI.

Falling investments from the Cayman Islands, Indonesia, and Singapore were the largest sources of decline in FDI to Asia and the Pacific from 2019 to 2020. During that year, Indonesia's investment to Asia and the Pacific weakened by $\$ 13.5$ billion to $\$ 10.8$ billion, while Singapore's investment waned by $\$ 11.4$ billion to $\$ 17.4$ billion. The dip in total deal and project value is moderate in 2020 compared with 2019; however, some economies were still heavily affected. Viet Nam was most shaken by declining FDI to Asia and the Pacific in 2020, with foreign investment to the economy declining by $\$ 26.3$ billion. Sri Lanka was hit the next, as its inward FDI fell by $\$ 23.7$ billion in 2020 , followed by the PRC (down $\$ 17.7$ billion), Thailand (down $\$ 11.1$ billion), and the Philippines (down $\$ 10.8$ billion).

Figure 3.2: Foreign Direct Investment by Mode of Entry (Firm-Level Activity)-Asia and the Pacific (\$ billion)

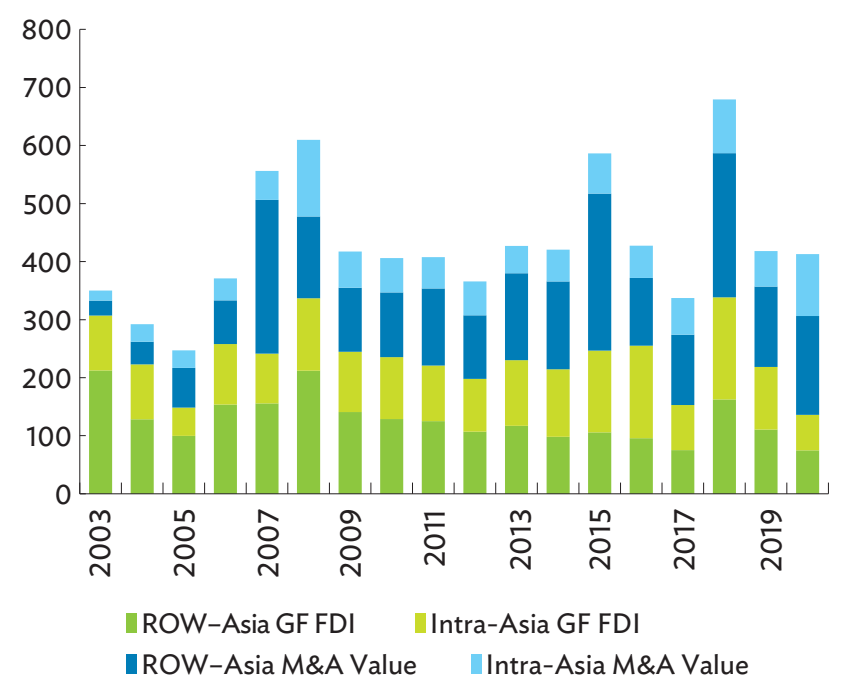

$\mathrm{FDI}=$ foreign direct investment, $\mathrm{GF}=$ greenfield, $M \& A=$ merger and acquisition, ROW $=$ rest of the world.

Sources: ADB calculations using data from Bureau van Dijk. Zephyr M\&A Database; and Financial Times. fDi Markets (both accessed May 2021).

A decrease in project and deal volumes in 2020, coupled with some recovery in value in the latter half of the year, resulted in an increase in average project and deal sizes in Asia and the Pacific.

FDI in Asia and the Pacific dipped slightly in 2020; however, the average size of deals and projects mostly increased that year (Table 3.2). Overall, average project and deal size increased by 4.0\%, from 2019 to 2020, while greenfield projects grew $2.4 \%$. M\&A deals were also larger in 2020 , as average deal size increased by $17.7 \%$ from $\$ 41.2$ million in 2019 to $\$ 48.5$ million in 2020. By industry, deals and projects in the primary sector were smaller in 2020, as the average size declined by $53.5 \%$ for greenfield projects, by $9.1 \%$ for M\&A deals, and by $69.4 \%$ in total. 
Table 3.2: Average Project and Deal Size by Sector-Asia and the Pacific (\$ million)

\begin{tabular}{|c|c|c|c|c|c|c|c|c|c|c|c|c|}
\hline \multirow[b]{2}{*}{ Year } & \multirow[b]{2}{*}{ GF } & \multirow[b]{2}{*}{$M \& A$} & \multirow[b]{2}{*}{ Total } & \multicolumn{3}{|c|}{ Greenfield FDI } & \multicolumn{3}{|c|}{ M\&A } & \multicolumn{3}{|c|}{ Total } \\
\hline & & & & MFG & PRI & SRV & MFG & PRI & SRV & MFG & PRI & SRV \\
\hline 2019 & 67.2 & 41.2 & 51.6 & 70.9 & $1,066.1$ & 34.2 & 45.1 & 52.3 & 38.6 & 57.6 & 312.2 & 37.1 \\
\hline 2020 & 68.8 & 48.5 & 53.7 & 91.6 & 495.5 & 41.5 & 64.4 & 47.5 & 41.3 & 73.4 & 95.4 & 41.3 \\
\hline
\end{tabular}

$\mathrm{FDI}=$ foreign direct investment, $\mathrm{GF}=$ greenfield, $M \& A=$ merger and acquisition, $M F G=$ manufacturing, $P R I=$ primary, $S R V=$ services.

Note: "Total" refers to the sum of greenfield capital expenditure and M\&A deal values. Average project and deal size equals greenfield project value and M\&A deal value in Asia and the Pacific divided by number of projects and deals.

Sources: ADB calculations using data from Bureau van Dijk. Zephyr M\&A Database; and Financial Times. fDi Markets (both accessed May 2021).

Like global trends, M\&A to Asia and the Pacific started to recover in the third quarter of 2020, while greenfield FDI inched back up in the fourth quarter. Meanwhile, the first half of 2021 showed stability in M\&A in the region.

Greenfield investment perked up in the second half of 2020, growing by $37.4 \%$ between the third and fourth quarters, due largely to gains in South Asia and Southeast Asia (Figure 3.3a). Despite this, greenfield investment into Asia and the Pacific was relatively modest in the first half of 2021 . After sliding by $14.7 \%$ in the first half of 2020 , greenfield FDI declined even further by $27.7 \%$ in the same period in 2021 . The $\$ 1.8$ billion increase in FDI to East Asia did little to cushion declines in the rest of the subregions, particularly substantial ones in South Asia (down $\$ 10.4$ billion) and the Pacific and Oceania (down $\$ 8.3$ billion). Economy-wise, Sri Lanka was most affected by decreased greenfield investment in Asia and the Pacific, with greenfield FDI into the economy declining by $95.6 \%$ in 2020 (Table 3.3a). Viet Nam (down 81.9\%) and the PRC (down 42.7\%) were also among those most affected.

M\&As in Asia and the Pacific, in contrast, performed better overall (Figure 3.3b). M\&A in the region increased by $18.4 \%$ in the third quarter and even further by $48.2 \%$ in the fourth quarter. East Asia benefited most from the increased deal activity. M\&A in Asia and the Pacific continued to be relatively stable in the first half of 2021.

Figure 3.3: Quarterly Inward FDI into Asia and the Pacific by Mode of Entry-Firm-Level Activity, Q1 $2018-Q 22021$ (\$ billion)

(a) Greenfield FDI

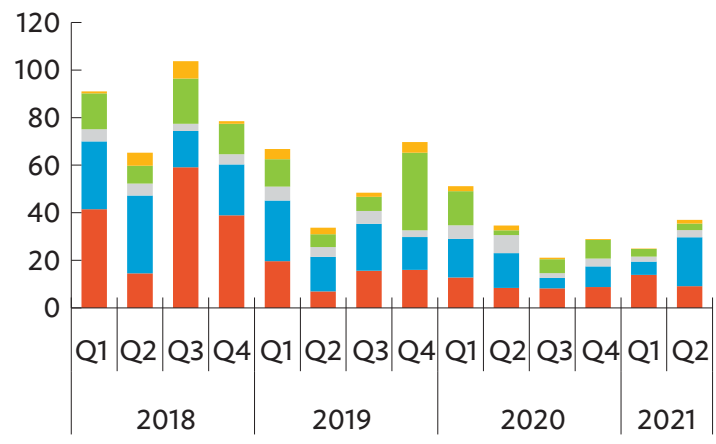

(b) $M \& A$

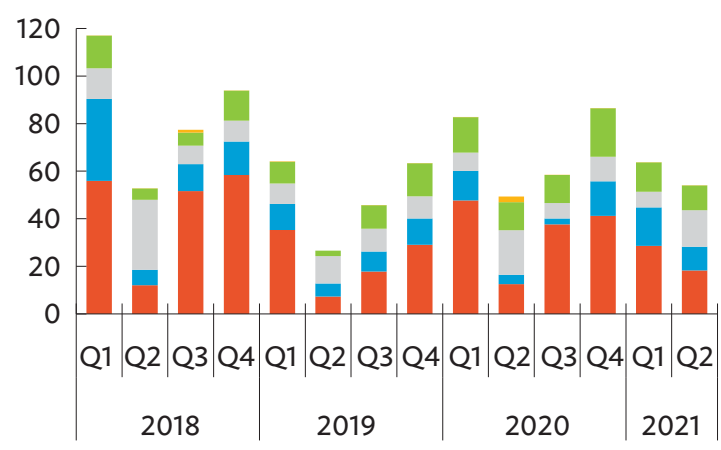

East Asia Southeast Asia The Pacific and Oceania $\quad$ South Asia Central Asia

$F D I=$ foreign direct investment, $M \& A=$ merger and acquisition, $Q=$ quarter.

Sources: ADB calculations using data from Bureau van Dijk. Zephyr M\&A Database; and Financial Times. fDi Markets (both accessed September 2021). 
Table 3.3: Most Affected Asian Destinations of Changes in Total FDI

\begin{tabular}{|c|c|c|c|c|c|}
\hline \multirow[b]{2}{*}{ Destination } & \multicolumn{5}{|c|}{ (a) Greenfield FDI } \\
\hline & $\begin{array}{c}2020 \\
(\$ \text { billion })\end{array}$ & $\begin{array}{c}2019 \\
\text { (\$ billion) }\end{array}$ & $\begin{array}{l}\text { Change } \\
\text { (\$ billion) }\end{array}$ & $\begin{array}{c}\text { Change } \\
(\%, 2019 \text { versus 2020) }\end{array}$ & $\begin{array}{l}\text { Share to Asia's Total } \\
\text { Decrease in FDI (\%) }\end{array}$ \\
\hline Sri Lanka & 1.1 & 24.9 & -23.8 & -95.6 & 28.7 \\
\hline Viet Nam & 5.1 & 28.0 & -23.0 & -81.9 & 27.7 \\
\hline People's Republic of China & 25.9 & 45.3 & -19.3 & -42.7 & 23.3 \\
\hline Philippines & 0.5 & 10.7 & -10.2 & -95.3 & 12.3 \\
\hline Bangladesh & 0.7 & 5.7 & -5.0 & -88.0 & 6.0 \\
\hline Kazakhstan & 0.8 & 5.4 & -4.6 & -85.0 & 5.6 \\
\hline Pakistan & 0.1 & 3.5 & -3.4 & -97.5 & 4.1 \\
\hline Malaysia & 6.4 & 8.9 & -2.5 & -28.0 & 3.0 \\
\hline Thailand & 1.3 & 3.4 & -2.1 & -61.0 & 2.5 \\
\hline Uzbekistan & 3.1 & 4.7 & -1.7 & -35.1 & 2.0 \\
\hline \multirow[b]{2}{*}{ Destination } & \multicolumn{5}{|c|}{ (b) M\&As } \\
\hline & $\begin{array}{c}2020 \\
(\$ \text { billion })\end{array}$ & $\begin{array}{c}2019 \\
\text { (\$ billion) }\end{array}$ & $\begin{array}{l}\text { Change } \\
\text { (\$ billion) }\end{array}$ & $\begin{array}{c}\text { Change } \\
(\%, 2019 \text { versus 2020) }\end{array}$ & $\begin{array}{l}\text { Share to Asia's Total } \\
\text { Increase in FDI (\%) }\end{array}$ \\
\hline Japan & 41.9 & 7.2 & 34.7 & 479.3 & 44.9 \\
\hline India & 58.3 & 34.7 & 23.6 & 68.2 & 30.6 \\
\hline Hong Kong, China & 31.6 & 14.1 & 17.5 & 124.0 & 22.6 \\
\hline Singapore & 20.8 & 9.3 & 11.5 & 123.3 & 14.9 \\
\hline Australia & 39.4 & 32.5 & 6.9 & 21.1 & 8.9 \\
\hline Azerbaijan & 2.4 & 0.0 & 2.4 & $\ldots$ & 3.0 \\
\hline People's Republic of China & 57.4 & 55.8 & 1.6 & 2.9 & 2.1 \\
\hline Malaysia & 3.1 & 2.7 & 0.4 & 16.1 & 0.6 \\
\hline Papua New Guinea & 0.5 & 0.2 & 0.3 & 183.5 & 0.4 \\
\hline Taipei,China & 3.3 & 3.2 & 0.1 & 2.2 & 0.1 \\
\hline
\end{tabular}

$\mathrm{FDI}=$ foreign direct investment, $M \& A=$ merger and acquisition

Notes: For shares to Asia's total increase or decrease in FDI, some values may be greater than 100 as economy-level changes may be largely positive or largely negative. When summed, all the economy-level changes would equal Asia's overall change, and percentages would total $100 \%$.

Sources: ADB calculations using data from Bureau van Dijk. Zephyr M\&A Database; and Financial Times. fDi Markets (both accessed May 2021).

Deals amounted to $\$ 117.8$ billion in that period andthough 11\% lower than deal values recorded in the first half of 2020-hints at continued recovery, with levels in that period almost $30.0 \%$ higher than that of the first half of 2019. Japan benefited most from the increased deals in Asia and the Pacific (Table 3.3b). The economy attracted $\$ 41.9$ billion in deals in 2020 , more than five times as much as it did in 2019. Meanwhile, India and Hong Kong, China also attracted more deals in 2020, with M\&As in India growing by $68.2 \%$ and those in Hong Kong, China doubling between 2019 and 2020.
Asia's primary sector was hit most in 2020, with a $75.8 \%$ decline in greenfield investments. On the flip side, M\&A in the manufacturing sector featured the strongest growth, increasing by $51.0 \%$. Overall, services and manufacturing showed more resilience in 2020.

Asia's sectoral data confirm global trends observed in FDI. On the one hand, greenfield investment, which is typically aimed at input and labor-intensive sectors, declined in all three economic sectors in 2020. 
The primary sector suffered the largest loss and decreased by $75.8 \%$, followed by a $28.6 \%$ loss in manufacturing, and a $20.2 \%$ decline in services (Figure $3.4 a$ ). On the other hand, M\&A deals recovered in all sectors in 2020, with manufacturing seeing the largest growth (51\%), followed by primary sector (36\%) and services (31\%). All modes of entry considered, total investment in Asia's primary sector amounted to $\$ 23.2$ billion, a 61.9\% decline between 2019 and 2020. In contrast, total FDI in manufacturing to the region grew by $3.6 \%$ in 2020, while total FDI in services rose by $14.4 \%$.

At the economy level, Sri Lanka was most affected by the decreased FDI in the primary sector (Annex 3c). Investment in the economy's primary sector slipped to only $\$ 145.2$ million in 2020 , a $99.4 \%$ decline from the previous year. Meanwhile, Japan benefited from strong investment into the manufacturing sector, reaching $\$ 35.7$ billion, four times larger than in 2019. In the services sector, FDI increased most in India, going from $\$ 25.6$ billion in 2019 to $\$ 59.7$ billion in 2020 .

Intraregional sectoral data paint a similar picture, with greenfield FDI declining and M\&A deal values recovering in all sectors. Intraregional greenfield FDI suffered most in the primary sector, where investment declined $89.5 \%$ compared with 2019. In contrast, intraregional M\&A in the primary sector totaled $\$ 4.6$ billion in 2020 , roughly 2.6 times the level observed in 2019.

\section{Jobs created by greenfield investment continued to decline in 2020, affecting the primary sector most.}

Apart from lower levels of greenfield FDI, the decline in greenfield projects also resulted in lower job creation in Asia and the Pacific (Figure 3.5a). After falling by 29.7\% in 2019, jobs created by greenfield FDI in the region continued to plunge in 2020 . This represents a $44.9 \%$ deterioration compared with the estimated 625,470 jobs created by greenfield projects in 2019 .

Greenfield projects from the US became the largest source of decreased job creation in Asia and the Pacific in 2020. After generating roughly 146,000 jobs in 2019 , US greenfield projects created 67,000 jobs less in 2020. Jobs created by greenfield projects from the PRC also declined significantly in 2020. On the recipient side, India, the PRC, and Viet Nam were most affected by the decreased greenfield job creation in Asia and the Pacific, with jobs generated by greenfield projects in those economies decreasing by 179,000 in 2020 .

Figure 3.4: Total Inward Foreign Direct Investment to Asia and the Pacific by Sector-Firm-Level Activity (\$ billion)

(a) Greenfield FDI

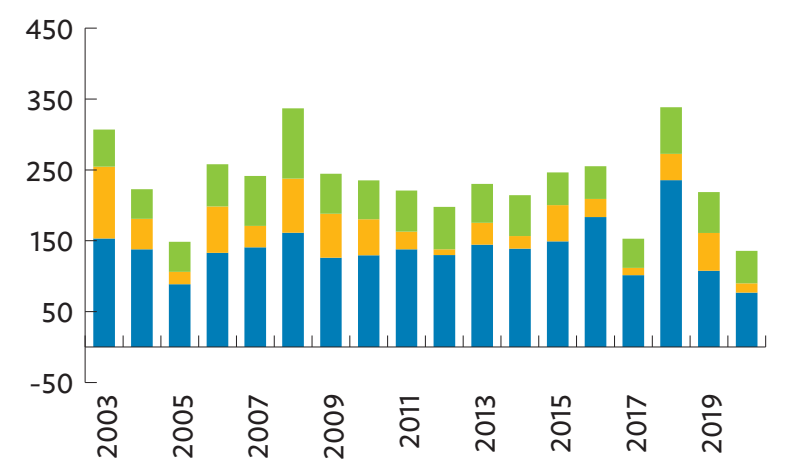

(b) M\&A

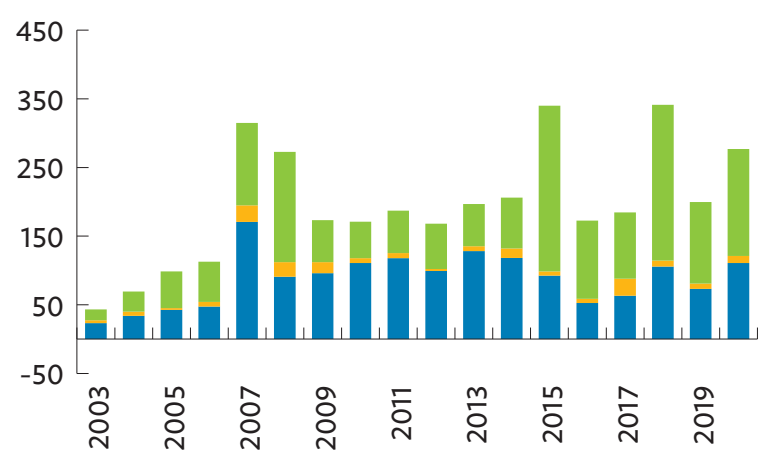

\footnotetext{
Manufacturing $\square$ Primary $\quad$ Services
}

$\mathrm{FDI}=$ foreign direct investment, $M \& A=$ merger and acquisition

Sources: ADB calculations using data from Bureau van Dijk. Zephyr M\&A Database; and Financial Times. fDi Markets (both accessed May 2021). 
Figure 3.5: Inward Greenfield FDI Job Creation-Asia and the Pacific (count, million)

(a) By Source

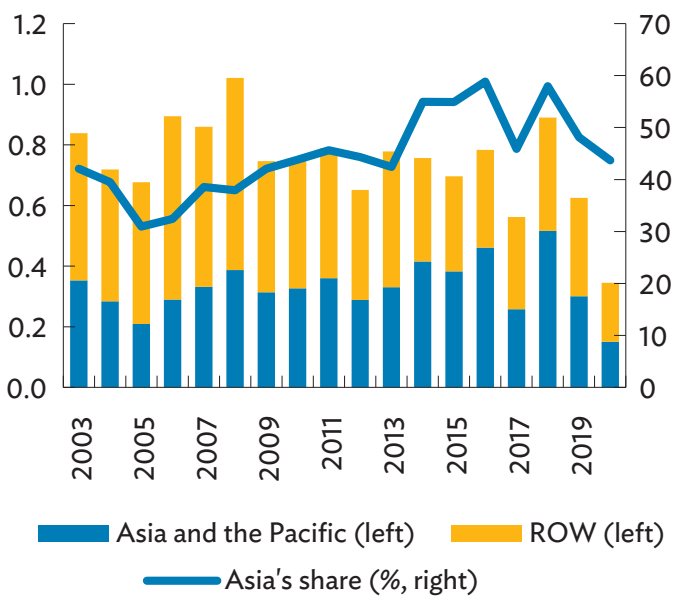

(b) By Sector

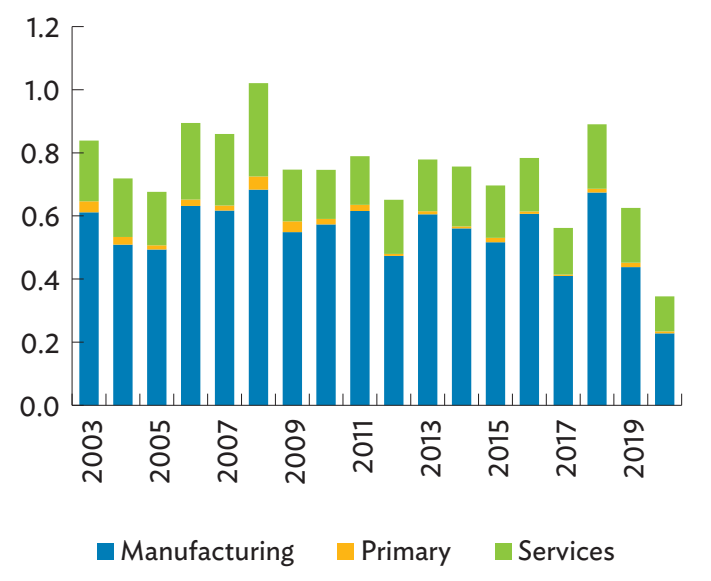

$\mathrm{FDI}=$ foreign direct investment, $\mathrm{ROW}=$ rest of the world.

Sources: ADB calculations using data from Bureau van Dijk. Zephyr M\&A Database; and Financial Times. fDi Markets (both accessed May 2021).

Together, these economies accounted for $63.7 \%$ of the total decline in Asia's job creation due to greenfield FDI.

Greenfield jobs in Asia and the Pacific declined across all economic sectors in 2020 (Figure 3.5b). While relatively small, Asia's primary sector was most affected, with jobs created by greenfield investment in that sector sliding by $53.6 \%$. Job creation in the manufacturing sector was also negatively impacted, falling by a further $48.0 \%$ in 2020 after declining by $35.1 \%$ in 2019.

\section{Outward foreign direct investment}

\section{As with global inflows, the persisting effects of the COVID-19 pandemic negatively affected global outward investment in 2020, based on balance of payments data.}

Global outward FDI also decreased in 2020, based on UNCTAD's balance of payments data. FDI outflows amounted to $\$ 739.9$ billion in 2020 globally, a $39.4 \%$ decline from the previous year's $\$ 1.2$ trillion (Figure 3.6). The dampened global economic activity due to
COVID-19 resulted in the gloomy outturn. Non-Asian investors seemed to take a more cautious stance, as foreign investment from these economies declined by 60.6\%. Meanwhile, investment from Asian economies slid by $14.2 \%$ from 2019. Globally, Asia and the Pacific emerged as the leading investing region worldwide, accounting for nearly $65 \%$ of global outward investment.

Both globally and in Asia and the Pacific, the PRC emerged as the largest investor in 2020, followed by Luxembourg and Japan (Table 3.4). Investment from these three economies accounted for half of the total outward investment in 2020. ${ }^{27}$ Among Asian economies, Hong Kong, China; the Republic of Korea; and Singapore were also among the top investors from the region. Together, the top-five Asian investors accounted for $86.7 \%$ of Asia's total outward investment.

Within the region, annual outward FDI from East Asian economies experienced the largest fall, notably from Japan. FDI from Southeast Asia also dipped in 2020, largely due to drops from Singapore and Malaysia. Both South Asia and Central Asia experienced moderate dips in outward FDI.

27 Investments from Luxembourg and Hong Kong, China, as well as similar financial centers, may be from another counterparty. 
Figure 3.6: Global Outward Foreign Direct Investment by Source-Balance of Payments

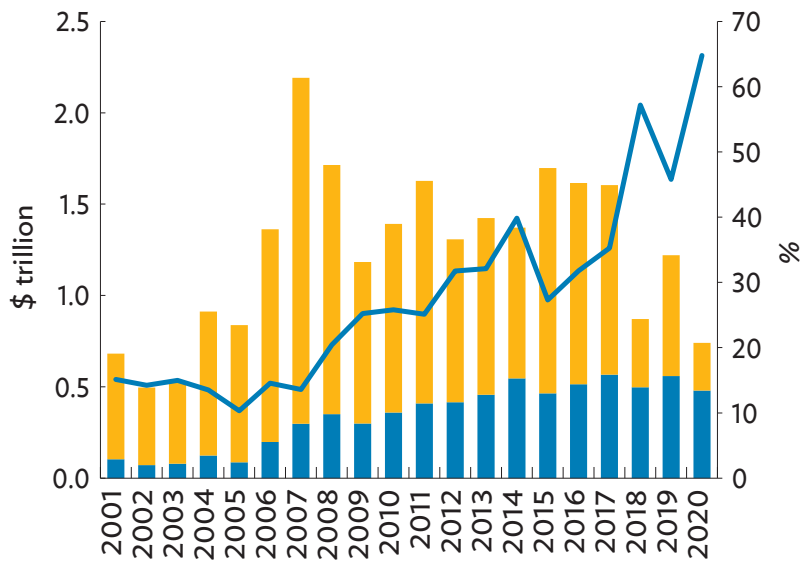

Outward FDI from Asia and the Pacific (left) Outward FDI from ROW (left)

- Asia's share (right)

$\mathrm{FDI}=$ foreign direct investment, $\mathrm{ROW}=$ rest of the world.

Source: United Nations Conference on Trade and Development. World Investment Report 2021 Statistical Annex Tables. https://worldinvestmentreport. unctad.org/annex-tables/ (accessed July 2021).

\section{Based on global firm-level data, outward} activity shows recovery in the third and fourth quarters of $\mathbf{2 0 2 0}$ for greenfield FDI and for $M \& A$.

Firm-level data show that global outward greenfield investment recovered in the third and fourth quarters of 2020, mainly through investments from North America,
Latin America, and the EU+UK. Increased outward greenfield investment ushered in the first half of 2021. Meanwhile, M\&A outflows saw stronger growth than greenfield projects during this period, outpacing levels recorded during the same quarters in the previous year. During the first half of 2021, a decline in deals from Asia and the Pacific by $\$ 119.3$ billion resulted in lower M\&A investments globally, but still close to the $\$ 391$ billion quarterly average for M\&A since 2018 (Annex 3d).

\section{Quarterly data show an uptick in greenfield investments and M\&A from Asia and the Pacific in the fourth quarter of 2020.}

Quarterly data suggest that greenfield investment from Asia and the Pacific dipped in the third quarter of 2020 and recovered in the fourth quarter (Figure 3.7a). A more stable trend in greenfield investment was observed between the first halves of 2020 and 2021. M\&As from Asia and the Pacific, on the other hand, peaked in the second and fourth quarters of 2020 (Figure 3.7b). Broad recovery in M\&A deals from Asia and the Pacific in 2020, particularly in the primary and services sectors, helped offset further losses in greenfield FDI. After strong M\&A outflows from Asia and the Pacific in 2020, deals from the region in the first half of 2021 were stable, yet below the levels observed the previous year.

Table 3.4: Top 10 Sources of Foreign Direct Investment-World and Asia and the Pacific (\$ billion)

\begin{tabular}{|c|c|c|c|c|c|}
\hline World & 2019 & 2020 & Asia and the Pacific & 2019 & 2020 \\
\hline People's Republic of China & 136.9 & 132.9 & People's Republic of China & 136.9 & 132.9 \\
\hline Luxembourg & 34.5 & 127.1 & Japan & 226.6 & 115.7 \\
\hline Japan & 226.6 & 115.7 & Hong Kong, China & 53.2 & 102.2 \\
\hline Hong Kong, China & 53.2 & 102.2 & Republic of Korea & 35.2 & 32.5 \\
\hline United States & 93.6 & 92.8 & Singapore & 50.6 & 32.4 \\
\hline Canada & 78.9 & 48.7 & Thailand & 8.4 & 16.7 \\
\hline France & 38.7 & 44.2 & Taipei,China & 11.8 & 14.3 \\
\hline British Virgin Islands & 44.2 & 42.3 & India & 13.1 & 11.6 \\
\hline Germany & 139.3 & 34.9 & Australia & 9.3 & 9.2 \\
\hline Republic of Korea & 35.2 & 32.5 & Indonesia & 3.4 & 4.5 \\
\hline
\end{tabular}

Source: United Nations Conference on Trade and Development. World Investment Report 2021 Statistical Annex Tables. https://worldinvestmentreport.unctad.org/ annex-tables/ (accessed July 2021). 
Figure 3.7: Quarterly Outward FDI from Asia and the Pacific by Mode of Entry-Firm-Level Activity, Q1 2018-Q2 2021 (\$ billion)

(a) Greenfield FDI

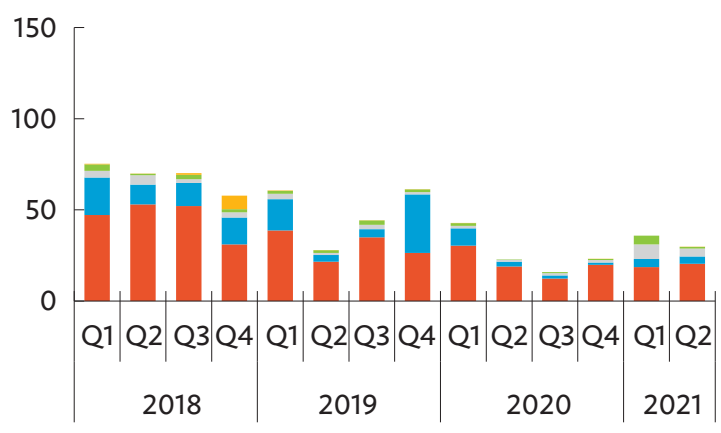

(b) $M \& A$

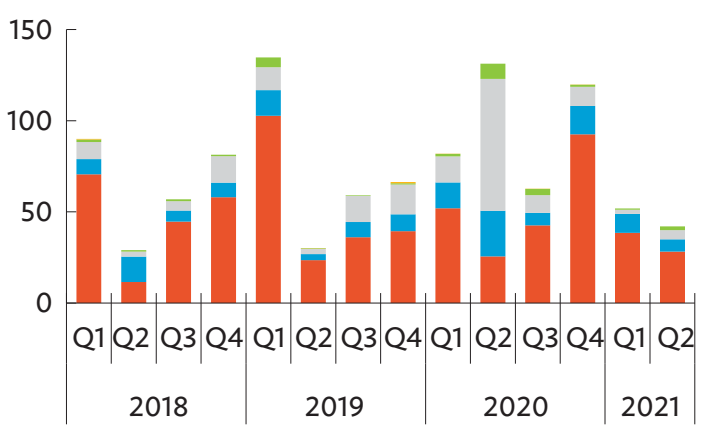

East Asia $\square$ Southeast Asia The Pacific and Oceania $\quad$ South Asia Central Asia

$\mathrm{FDI}=$ foreign direct investment, $M \& A=$ merger and acquisition, $Q=$ quarter.

Sources: ADB calculations using data from Bureau van Dijk. Zephyr M\&A Database; and Financial Times. fDi Markets (both accessed September 2021).

While global FDI rebounded in 2021 based on preliminary balance of payments estimates, some headwinds remain, especially with the moderate recovery of greenfield investment and M\&A in the first half of 2021. This is particularly important to developing economies, which tend to benefit more from greenfield investment projects. Other external factors may hamper global FDI growth in the short term, including potential pandemic flare ups, restrictive $\mathrm{FDI}$ measures, and disruptions to global value chains (GVCs). The entwined relationship between GVCs and FDI also underscores the importance of embedding an FDI perspective in policy measures to foster GVC participation (Qiang, Liu, and Steenbergen 2021; Box 3.1.)

For Asia and the Pacific, investment prospects were generally favorable in 2021 with some downside risks still on the horizon. FDI inflows to the region started to pick up steam in the first few months of 2021. M\&A in Asia and the Pacific, which showed signs of recovery as early as the third quarter of 2020, remained stable in the first half of 2021. FDI toward other sectors beyond manufacturing proved resilient in the wake of the COVID-19 pandemic (see this chapter's Special Topic). As such, investment in the region's digital sectorssuch as in information and communication technology (ICT) -is expected to remain robust in 2021 and support further inflows.
Continued investment in high-tech industries in East Asia and Southeast Asia, as well as India, may also support FDI growth in the region. However, Asia's prospects for 2021 are not without headwinds. Greenfield investment, which had been sensitive to the effects of the COVID-19 pandemic, remained weak in Asia and the Pacific in the first half of 2021. This is apparent in industries requiring intensive labor and equipment, such as coal, oil, and gas; chemicals; and renewable energy. Investment in these labor-intensive industries may remain weak in the medium term, as well as in international tourism, where the recovery remains fragile.

\section{Special Topic: Foreign Direct Investment in Digital Services}

\section{Introduction}

While foreign direct investment is driven by multinational enterprises to access new markets and tap new resources, digitalization is fundamentally transforming how some industries operate and invest overseas. The expansion of digital technologies is modifying the structure of GVCs and role of foreign affiliates in them. It is also prompting multinationals to revisit their business models and how they conduct their investments, affecting both the volume 
and direction of investment, and bringing a new range of investing actors. The impact of digitalization goes beyond companies' investment decisions. It also involves the type of goods or services they produce and the use of digital tools to improve production and distribution processes. As in the case of manufacturing, investment on services could be increasingly affected by the increasing adoption of digital technologies.

Digitally intensive multinationals are helping shape production networks and allocate investment.

Such companies have increased their presence worldwide, with 6 out of 20 of the largest global multinationals in 2020 and 7 out of the 20 largest Asian multinationals in digitally driven sectors. Many digital multinationals outpace traditional ones in total assets, sales, and number of employees. They also have a different profile in liquidity and intellectual property. More importantly, their drivers of investment and international footprint are different, as they do not aim at securing physical resources and can service customers from any location.

National investment policies are gradually adapting to these evolving business models. Attracting FDI to the digital economy, sometimes referred to as "digital FDI," has emerged as a strategy for increasing productivity, technology transfer, and job creation. Digital FDI is also deemed to help economies and companies boost their digital capabilities. Policies to attract digital FDI are usually associated with three main pillars: investment in new digital activities (e.g., software development), investment in the adoption of digital services (e.g., telemedicine), and investment in digital infrastructure. Digital services FDI refers mainly to this second subcomponent of digital FDI. While some national investment frameworks in Asia and the Pacific consider services FDI an important pillar, the perspective on digital services is relatively new. In general, digital development strategies and national digital plans do not take into account an investment dimension when designed.

This section examines the trends and policy framework for FDI in Asia's digital services sectors, based on the conceptual framework presented in the theme chapter of this report. The first part provides a synopsis on the distinctive features of digital multinationals. The second presents the main trends in digital services FDI in Asia and the Pacific. The third part compares Asia's foreign investment restrictions in digital services in relation to other sectors. The final part explores how Asia's investment policy frameworks can adapt to and seize the potential of digital services in the region.

\section{Digital multinational enterprises: What is different?}

To better understand the linkages between multinational enterprises and the digital economy, UNCTAD (2017) introduced a classification of companies based on the digital intensity of their activities. Two main categories are defined in this configuration: the first, digital multinational enterprises, includes digital platforms, digital solutions, and e-commerce to create markets and deliver digital products and services; and the second, ICT multinational enterprises, focuses on building and creating core telecommunications and digital connectivity. One salient characteristic of digital multinational enterprises is the higher proportion of foreign sales to foreign assets, compared with traditional multinational enterprises. These differences reflect how the operational nexus between multinational enterprise sales and physical presence is transformed by digitalization (Casella and Formenti 2018, Satyanand 2021). Foreign affiliates of digital multinational enterprises also tend to retain a large part of their revenues overseas in the form of cash or cash equivalents, often as unremitted foreign earnings. This makes digital multinational enterprises more prone to maximize from corporate tax structures in the jurisdictions where they locate. A third important feature of digital multinational enterprises is their relatively lower impact on job creation. Evidence in Asia and the Pacific suggests that FDI has higher spillovers on job creation in manufacturing, followed by primary industries, and last by service industries (ADB 2018a).

The modest footprint of digital multinationals in physical assets and employment underscores how their investment drivers may differ from other firms. Traditional FDI drivers such as access to natural resources, lower labor costs, or market size may not be necessarily relevant for investment allocation in the context of digital FDI and digitally deliverable services. 


\section{Trends in FDI in digitally deliverable services in Asia and the Pacific}

Over the past two decades, Asia's share of services FDI has remained relatively stable, accounting for $32 \%$ of total inward FDI to the region, and with nearly two-thirds of the investment entering through M\&A deals against greenfield projects. This allocation by sector and entry mode is comparable to other regions. As the digital content of services increases and digital multinational enterprises become major providers of digital products and services, this investment structure may have changed in recent years.

To estimate the trends and composition of Asia's FDI into digitally deliverable services, this section builds on the conceptual framework introduced in the theme chapter and proposes a concordance between sector classifications of services trade statistics with firm-level foreign investment data. A correspondence between the Extended Balance of Payments Services Classification and the International Standard Industrial Classification was used (Table 3.5). This allows assessment of firmlevel data from fDi Markets and Zephyr, which use classification based on the North American Industry Classification System.

North American Industry Classification System 2017International Standard Industrial Classification Rev. 4 concordance tables from Statistics Canada and the United States Census Bureau were then used to identify which services sectors would be tagged as digitally deliverable (Table 3.6). While the sectors identified as digitally deliverable services may not necessarily always be digitally delivered, estimates may provide an upper bound to the foreign investment directed to these sectors. In contrast to UNCTAD (2017), this exercise is done at the transaction level, matching information on deals and projects to an industry classification, rather than classifying multinational enterprises according to their digital content.

\section{Table 3.5: Bridge Table for EBOPS 2010 and ISIC Revision 4}

\begin{tabular}{|c|c|c|c|c|c|}
\hline $\begin{array}{l}\text { EBOPS } \\
\text { Code }\end{array}$ & Description & $\begin{array}{l}\text { TISMOS } \\
\text { Code }\end{array}$ & Description & $\begin{array}{l}\text { ISIC } \\
\text { Code }\end{array}$ & Description \\
\hline SA & $\begin{array}{l}\text { Manufacturing services on input } \\
\text { owned by others }\end{array}$ & SA & $\begin{array}{l}\text { Manufacturing services on physical } \\
\text { inputs owned by others }\end{array}$ & & \\
\hline SB & $\begin{array}{l}\text { Maintenance and repair services } \\
\text { not included elsewhere n.i.e. }\end{array}$ & SB & $\begin{array}{l}\text { Maintenance and repair services } \\
\text { n.i.e. }\end{array}$ & & \\
\hline SC & Transport services & SC & Transport & $\mathrm{H}$ & Transport and storage \\
\hline SD & Travel & SDASDB3 & Tourism and business travel & I & $\begin{array}{l}\text { Accommodation and food service } \\
\text { activities }\end{array}$ \\
\hline SE & Construction & SE & Construction & $\mathrm{F}$ & Construction \\
\hline $\begin{array}{l}\text { SF } \\
\text { SG }\end{array}$ & $\begin{array}{l}\text { Insurance and pension services } \\
\text { Financial services }\end{array}$ & SFSG & Insurance and financial services & K & $\begin{array}{l}\text { Financial and } \\
\text { insurance activities }\end{array}$ \\
\hline $\mathrm{SH}$ & $\begin{array}{l}\text { Charges for the use of intellectual } \\
\text { property n.i.e. }\end{array}$ & $\mathrm{SH}$ & $\begin{array}{l}\text { Charges for the use of intellectual } \\
\text { property n.i.e. }\end{array}$ & & \\
\hline SI1 & Telecommunications services & \multirow{3}{*}{ SISK1 } & \multirow{3}{*}{$\begin{array}{l}\text { Telecommunications, computer, } \\
\text { information, and audiovisual } \\
\text { services }\end{array}$} & \multirow{3}{*}{ J } & \multirow{3}{*}{ Information and communication } \\
\hline $\begin{array}{l}\mathrm{S} 12 \\
\mathrm{~S} 13\end{array}$ & $\begin{array}{l}\text { Computer services } \\
\text { Information services }\end{array}$ & & & & \\
\hline SK1 & Audiovisual and related services & & & & \\
\hline SJ1 & Research and development services & \multirow{3}{*}{ SJXSJ34 } & \multirow{3}{*}{$\begin{array}{l}\text { Other business services } \\
\text { (excluding trade-related) }\end{array}$} & \multirow{3}{*}{$L+M+N$} & \multirow{3}{*}{$\begin{array}{l}\text { Real estate; Professional, } \\
\text { scientific, and technical activities; } \\
\text { Administrative and support } \\
\text { service activities }\end{array}$} \\
\hline SJ2 & $\begin{array}{l}\text { Professional and management } \\
\text { consulting services }\end{array}$ & & & & \\
\hline SJ3 & $\begin{array}{l}\text { Technical, trade-related, and other } \\
\text { business services }\end{array}$ & & & & \\
\hline
\end{tabular}


Table 3.5: continued

\begin{tabular}{|c|c|c|c|c|c|}
\hline $\begin{array}{l}\text { EBOPS } \\
\text { Code }\end{array}$ & Description & $\begin{array}{l}\text { TISMOS } \\
\text { Code }\end{array}$ & Description & $\begin{array}{l}\text { ISIC } \\
\text { Code }\end{array}$ & Description \\
\hline \multirow{5}{*}{ SK2 } & \multirow{5}{*}{$\begin{array}{l}\text { Other personal, cultural, and } \\
\text { recreational services }\end{array}$} & SK23 & Heritage and recreational services & $\mathrm{R}$ & Arts, entertainment, and recreation \\
\hline & & SK24 & Other personal services & $S$ & Other service activities \\
\hline & & SDB1SK21 & Health services & Q & $\begin{array}{l}\text { Human health and social work } \\
\text { activities }\end{array}$ \\
\hline & & SDB2SK22 & Education services & $P$ & Education \\
\hline & & SWSJ34 & $\begin{array}{l}\text { Total trade-related services } \\
\text { (distribution) }\end{array}$ & G & $\begin{array}{l}\text { Wholesale and retail trade; repair } \\
\text { of motor vehicles and motorcycles }\end{array}$ \\
\hline SL & $\begin{array}{l}\text { Government goods and services } \\
\text { n.i.e. }\end{array}$ & & & & \\
\hline
\end{tabular}

EBOPS = Extended Balance of Payments Services, ISIC = International Standard Industrial Classification, TISMOS = Trade in Services Data by Mode of Supply. Sources: Organisation for Economic Co-operation and Development, World Trade Organization, and International Monetary Fund (2019); and Wettstein et al. (2019).

Table 3.6: Digitally Deliverable Services-ISIC Revision 4, EBOPS 2010, and NAICS 2017

\begin{tabular}{|c|c|c|c|c|c|c|}
\hline \multicolumn{2}{|c|}{ ISIC Revision 4} & \multicolumn{3}{|c|}{ EBOPS 2010} & \multicolumn{2}{|r|}{ NAICS 2017} \\
\hline Code & Description & & & Description & Code & Description \\
\hline \multirow[b]{2}{*}{ K } & \multirow[b]{2}{*}{$\begin{array}{l}\text { Financial and } \\
\text { insurance } \\
\text { activities }\end{array}$} & \multicolumn{3}{|c|}{ SF: Insurance and pension services } & 5241 & Insurance \\
\hline & & \multicolumn{3}{|c|}{ SG: Financial services } & $\begin{array}{c}52311 \\
523 \\
522 \\
52211\end{array}$ & $\begin{array}{l}\text { Corporate and investment banking } \\
\text { Investment management } \\
\text { Other (Financial services) } \\
\text { Retail banking }\end{array}$ \\
\hline $\mathrm{N}$ & $\begin{array}{l}\text { Admin. and } \\
\text { support service } \\
\text { activities }\end{array}$ & \multicolumn{3}{|c|}{$\begin{array}{l}\mathrm{SH} \text { : Charges for the use of intellectual property, not included } \\
\text { elsewhere }\end{array}$} & & - \\
\hline \multirow{15}{*}{ J } & \multirow{15}{*}{$\begin{array}{l}\text { Information and } \\
\text { communication }\end{array}$} & \multirow{14}{*}{$\begin{array}{l}\text { SI: Telecommu- } \\
\text { nications, } \\
\text { computer, and } \\
\text { information } \\
\text { services }\end{array}$} & \multirow{7}{*}{ SI1 } & \multirow{7}{*}{$\begin{array}{l}\text { Telecommu- } \\
\text { nications services }\end{array}$} & 5152 & $\begin{array}{l}\text { Cable and other subscription } \\
\text { programming }\end{array}$ \\
\hline & & & & & 5182 & $\begin{array}{l}\text { Data processing, hosting, and related } \\
\text { services }\end{array}$ \\
\hline & & & & & 5179 & Other telecommunications \\
\hline & & & & & 5151 & Radio and TV broadcasting \\
\hline & & & & & 5174 & Satellite telecommunications \\
\hline & & & & & 5171 & Wired telecommunication carriers \\
\hline & & & & & 5172 & Wireless telecommunication carriers \\
\hline & & & \multirow{6}{*}{$\mathrm{S} 12$} & \multirow{6}{*}{ Computer services } & $\begin{array}{l}541513 \\
541512 \\
541511\end{array}$ & $\begin{array}{l}\text { Computer facilities management services } \\
\text { Computer systems design services } \\
\text { Custom computer programming } \\
\text { services }\end{array}$ \\
\hline & & & & & 51913 & $\begin{array}{l}\text { Internet publishing and broadcasting } \\
\text { and web search }\end{array}$ \\
\hline & & & & & 5415 & Other (Software and IT services) \\
\hline & & & & & 541519 & Other computer related services \\
\hline & & & & & 5112 & Software publishers, except video games \\
\hline & & & & & 5112 & $\begin{array}{l}\text { Video games, applications and digital } \\
\text { content }\end{array}$ \\
\hline & & & $\mathrm{SI3}$ & $\begin{array}{l}\text { Information } \\
\text { services }\end{array}$ & 51919 & All other information services \\
\hline & & \multicolumn{3}{|c|}{ SK1: Audiovisual and related services } & 512 & $\begin{array}{l}\text { Motion picture and sound recording } \\
\text { industries }\end{array}$ \\
\hline
\end{tabular}


Table 3.6: continued

\begin{tabular}{|c|c|c|c|c|c|c|c|}
\hline \multicolumn{2}{|c|}{ ISIC Revision 4} & \multicolumn{4}{|c|}{ EBOPS 2010} & \multicolumn{2}{|r|}{ NAICS 2017} \\
\hline Code & Description & \multicolumn{3}{|c|}{ Code } & Description & Code & Description \\
\hline \multirow{14}{*}{$\begin{array}{l}\mathrm{L}, \mathrm{M} \\
\mathrm{N}\end{array}$} & \multirow{14}{*}{$\begin{array}{l}\text { Real estate } \\
\text { activities; } \\
\text { Professional, } \\
\text { scientific and } \\
\text { technical } \\
\text { activities; } \\
\text { Administrative } \\
\text { and support } \\
\text { service activities }\end{array}$} & \multicolumn{4}{|c|}{ SJ1: Research and development services } & & - \\
\hline & & \multirow{2}{*}{$\begin{array}{l}\text { SJ2:Professional } \\
\text { and management } \\
\text { consulting } \\
\text { services }\end{array}$} & \multicolumn{2}{|l|}{ SJ21 } & $\begin{array}{l}\text { Legal, accounting, } \\
\text { management, } \\
\text { consulting, and } \\
\text { public relations }\end{array}$ & $\begin{array}{c}5412 \\
5411 \\
54161\end{array}$ & $\begin{array}{l}\text { Accounting, tax preparation, } \\
\text { bookkeeping, and payroll services } \\
\text { Legal services } \\
\text { Management consulting services }\end{array}$ \\
\hline & & & \multicolumn{2}{|l|}{ SJ22 } & $\begin{array}{l}\text { Advertising, market } \\
\text { research, public } \\
\text { opinion polling }\end{array}$ & 5418 & Advertising and related services \\
\hline & & \multirow{11}{*}{$\begin{array}{l}\text { SJ3: Technical, } \\
\text { trade-related, and } \\
\text { other business } \\
\text { services }\end{array}$} & \multirow{7}{*}{$\begin{array}{l}\text { SJ31: } \\
\text { Architectural, } \\
\text { engineering, } \\
\text { scientific } \\
\text { and other } \\
\text { technical } \\
\text { services }\end{array}$} & SJ311 & $\begin{array}{l}\text { Architectural } \\
\text { services }\end{array}$ & \multirow[t]{2}{*}{5413} & \multirow{2}{*}{$\begin{array}{l}\text { Architectural, engineering, and related } \\
\text { services }\end{array}$} \\
\hline & & & & SJ312 & Engineering services & & \\
\hline & & & & \multirow{5}{*}{ SJ313 } & \multirow{5}{*}{$\begin{array}{l}\text { Scientific and other } \\
\text { technical services }\end{array}$} & 5614 & Business support services \\
\hline & & & & & & 5613 & Employment services \\
\hline & & & & & & 54162 & Environmental consulting services \\
\hline & & & & & & 54 & $\begin{array}{l}\text { Professional, scientific and technical } \\
\text { services }\end{array}$ \\
\hline & & & & & & 5414 & Specialized design services \\
\hline & & & \multicolumn{2}{|l|}{ SJ32 } & $\begin{array}{l}\text { Waste treatment } \\
\text { and de-pollution, } \\
\text { agricultural and } \\
\text { mining services }\end{array}$ & 562 & $\begin{array}{l}\text { Waste management and remediation } \\
\text { services }\end{array}$ \\
\hline & & & \multirow{3}{*}{\multicolumn{2}{|c|}{ SJ33 }} & \multirow{3}{*}{$\begin{array}{l}\text { Operating and } \\
\text { leasing services }\end{array}$} & 531 & Real estate services \\
\hline & & & & & & 532 & Rental and leasing services \\
\hline & & & & & & 5615 & $\begin{array}{l}\text { Travel arrangement and reservation } \\
\text { services }\end{array}$ \\
\hline \multirow{5}{*}{$\mathrm{R}$} & \multirow{5}{*}{$\begin{array}{l}\text { Arts, } \\
\text { entertainment, } \\
\text { and recreation }\end{array}$} & \multirow{6}{*}{\multicolumn{4}{|c|}{ SK2: Other personal, cultural, and recreational services }} & 71311 & Amusement and theme parks \\
\hline & & & & & & 7132 & Gambling industries \\
\hline & & & & & & 712 & Museums, historical sites, and similar \\
\hline & & & & & & 7139 & $\begin{array}{l}\text { Other amusement and recreation } \\
\text { industries }\end{array}$ \\
\hline & & & & & & 711 & $\begin{array}{l}\text { Performing arts, spectator sports, and } \\
\text { related }\end{array}$ \\
\hline$S$ & $\begin{array}{l}\text { Other service } \\
\text { activities }\end{array}$ & & & & & 812 & Personal services \\
\hline
\end{tabular}

- = unavailable, EBOPS = Extended Balance of Payments Services, ISIC = International Standard Industrial Classification, IT = information technology, NAICS = North American Industry Classification System.

Sources: Bureau van Dijk. Zephyr M\&A Database; Financial Times. fDi Markets (both accessed May 2021); Government of Canada, Statistics Canada. Industry classifications. https://www.statcan.gc.ca/en/concepts/industry; Government of the United States, United States Census Bureau. North American Industry Classification System. https://www.census.gov/naics/ (both accessed June 2021); and Wettstein et al. (2019).

\section{Asia and the Pacific remains an important destination of digitally deliverable services FDI globally, with M\&As as the preferred entry mode.}

While manufacturing has historically captured the lion's share of Asia's inward FDI, receiving on average $53 \%$ of investments between 2003 and 2020, the participation of services FDI has been important and increased in recent years. On average, FDI to digitally deliverable services in Asia and the Pacific, which includes financial and insurance services, accounted for nearly $24 \%$ of foreign investment during this period (Figure 3.8a). Worldwide, the bulk of foreign direct investment on digital services tends to go through M\&A as the main entry mode, with the EU+UK and North America capturing a significant proportion (Figure 3.8b). Between 2019 and 2020, and despite the significant impact of COVID-19 on delaying 
Figure 3.8: Inward FDI-Firm-Level Activity (\$ billion)

(a) Inward FDI to Asia and the Pacific by Sector

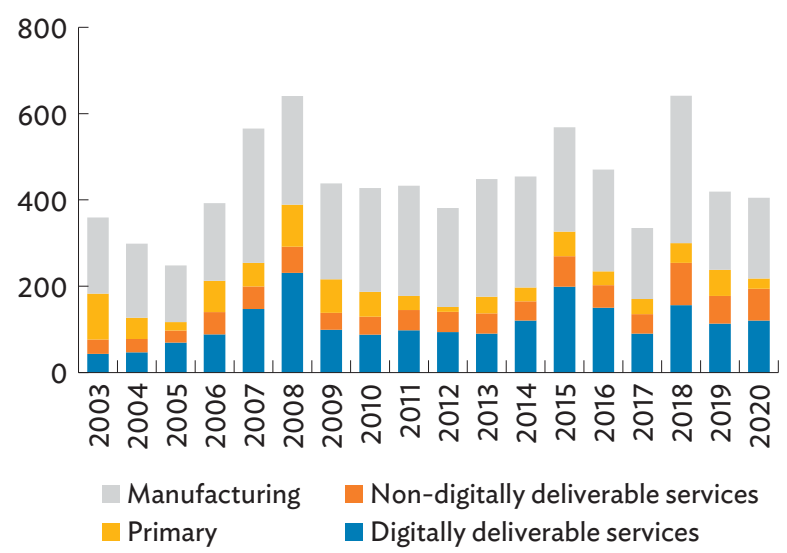

(b) Digitally Deliverable Services by Region, 2020

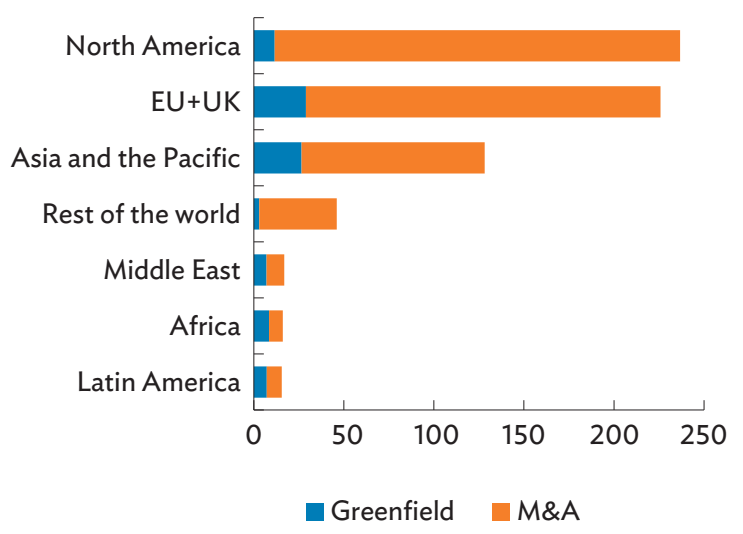

$\mathrm{EU}=$ European Union (27 members), $\mathrm{FDI}=$ foreign direct investment, M\&A = merger and acquisition, UK = United Kingdom.

Sources: ADB calculations using data from Bureau van Dijk. Zephyr M\&A Database; and Financial Times. fDi Markets (both accessed May 2021).

or dissuading investment decisions, digital services FDI in both greenfield and M\&A remained resilient. In 2020, Asia and the Pacific amassed $\$ 26.5$ billion in digital services greenfield investment, against $\$ 29.4$ billion the year before. Even more, M\&A investment in digitally deliverable services increased from $\$ 90.8$ billion to $\$ 101.7$ billion over the same period.

\section{East Asia and South Asia retained most of the foreign investment in digital services, both in greenfield and M\&A.}

East Asia and South Asia remain the main destinations of digital services FDI in the region, with $M \& A$ deals superseding greenfield investments in recent years (Figure 3.9). In 2020, South Asia accounted for $33.8 \%$ of greenfield investment in Asia's digitally deliverable services, followed by $29.4 \%$ for East Asia. The main targeted sectors in 2020 included data processing and hosting services, corporate and investment banking, and software publishers. Greenfield investment into digital services sectors has fallen $5 \%$ since 2011. In contrast, inward investment through M\&A is considerably larger and more volatile. Between 2019 and 2020, M\&A investment in digital services in Asia and the Pacific increased by $11.9 \%$, with East Asia receiving $\$ 43.7$ billion and South Asia \$29.4 billion in 2020.

\section{Mirroring the trend for exports, digital services FDI was more resilient to the COVID-19 shock than non-digital services FDI.}

Foreign investment in digital and non-digital services sectors in Asia and the Pacific evolved hand-in-hand for nearly a decade up to the COVID-19 crisis. While investment to digital and non-digital services sectors remained stable after the 2008 global financial crisis, the effect of COVID-19 on flows and mode of entry was different. Between 2019 and 2020, greenfield investment on digitally deliverable services decelerated by $9.7 \%$, while non-digitally deliverable services FDI contracted a drastic $57.9 \%$. In contrast, M\&A remained strong and increased in both digital and non-digital services sectors. The broad acceleration of M\&A in Asia and the Pacific has also benefited from external factors, including better growth opportunities, high profits, cheap credit, positive valuations, lower acquisition premiums and growing fintech demand, which has continued up to mid-2021.

Asian subregions experienced heterogenous impacts on digital services FDI since the beginning of the pandemic. While digital services FDI remained solid for most subregions in both greenfield and M\&A, investment in non-digital services FDI fluctuated heavily. A fall in greenfield investment was most felt in Southeast Asia 
Figure 3.9: Inward FDI in Digital Services by Subregion and Mode of Entry (\$ billion)

(a) Greenfield

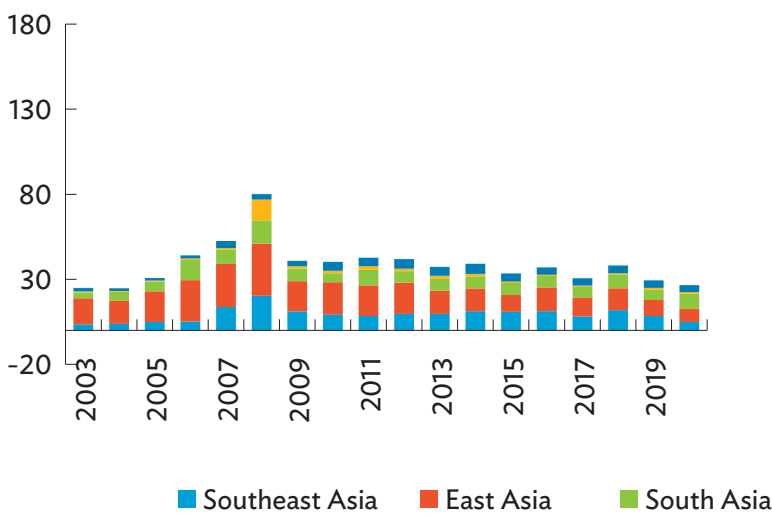

(b) M\&A

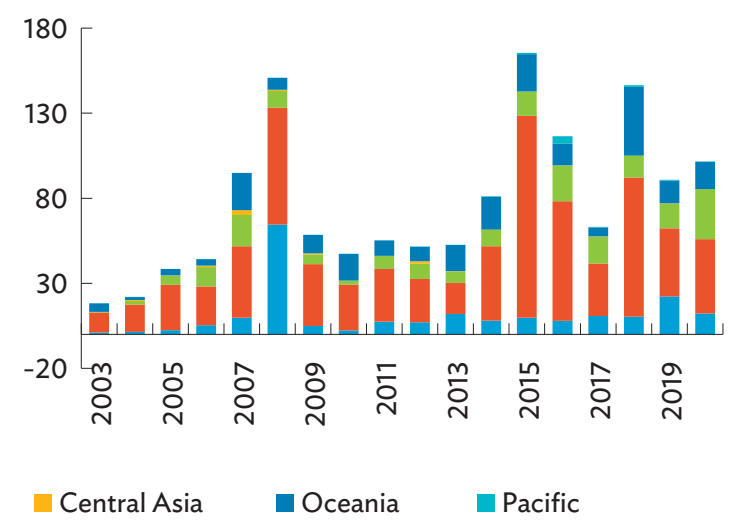

$\mathrm{FDI}=$ foreign direct investment, $M \& A=$ merger and acquisition

Sources: ADB calculations using data from Bureau van Dijk. Zephyr M\&A Database; and Financial Times. fDi Markets (both accessed May 2021).

(Figure 3.10a), whereas expansion in non-digital services via M\&A largely benefited East Asia and South Asia. In general, multinationals engaging in exporting activities are more likely to use the greenfield mode of entry, while $M \& A$ is more common when domestic markets are targeted. The recent expansion in $M \& A$ activity could also reflect this primary interest from investors to tap new markets.

\section{Inward FDI in digital services in Asia and the Pacific has been dominated by financial services; telecommunications, computer, and information services; and other business services.}

From the service items defined as digitally deliverable (insurance and pensions; financial; intellectual property; ICT; other business services; and personal, cultural, and recreational; see theme chapter), the core of investments in Asia and the Pacific have been targeted at financial, ICT, and other business services (Figure 3.11). The growth in demand and importance in financial technology and digital payment platforms, as well as the necessary infrastructure to support financial and other digital platforms, likely led to their large shares. Financial services and ICT services may also remain major components of digitally deliverable services, as work arrangements and the nature of transactions during the pandemic have underscored their importance.
The share in ICT services sectors in Asia and the Pacific stands out, averaging $31 \%$ of digital services FDI since 2003 , although it is lower than average shares in developed economies, including the EU+UK (38\%) and North America (41\%). Differences in FDI composition are also important among subregions. Financial services are predominant in Southeast Asia, East Asia, and the Pacific. South Asia and increasingly East Asia have attracted more FDI toward telecommunications, computer, and information services. FDI toward other business services sectors is more important for East Asia and Oceania. As one would expect, targeted FDI sectors by subregion reflect domestic needs and areas of specialization in digital services exports, notably large FDI volumes to ICT sectors in South Asia.

A small number of subsectors remained the main drivers of digital services FDI in 2020. Worldwide, companies in data processing, hosting, and related services were at the forefront of investment transactions for digitally deliverable services. Wired telecommunication carriers; investment management; and professional, scientific, and technical services were particularly important in North America, EU+UK, and Asia and the Pacific (Figure 3.12). Within Asia and the Pacific, the largest transactions went to South Asia, in the data processing, hosting, and related services. Retail banking, insurance, and software publishers (except video games) were the most active subsectors in East Asia. 
Figure 3.10: Digitally and Non-Digitally Deliverable Services FDI by Asian Subregion and Mode of Entry (\$ billion)

(a) Greenfield

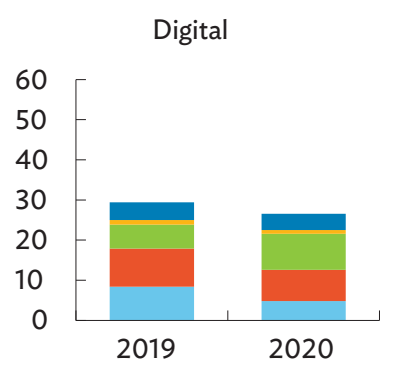

Southeast Asia

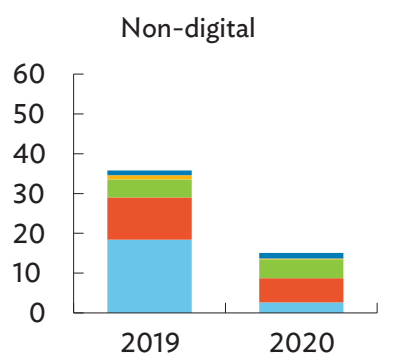

- Oceania $\quad$ Central Asia (b) M\&A
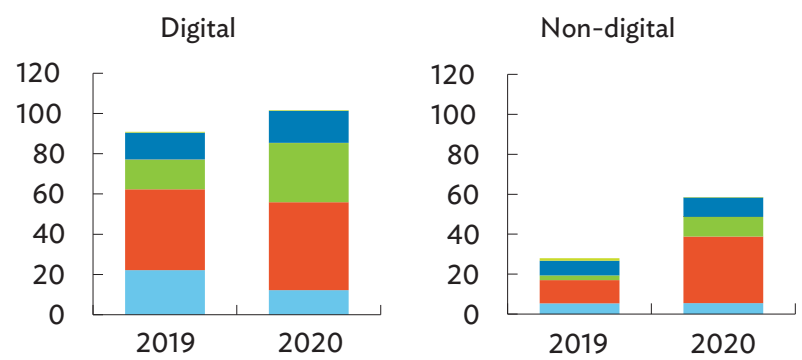

$\mathrm{FDI}=$ foreign direct investment, $M \& A=$ merger and acquisition

Sources: ADB calculations using data from Bureau van Dijk. Zephyr M\&A Database; and Financial Times. fDi Markets (both accessed May 2021).

Figure 3.11: Inward FDI in Digitally Deliverable Services by Sector and Subregion (\$ billion)

(a) Southeast Asia

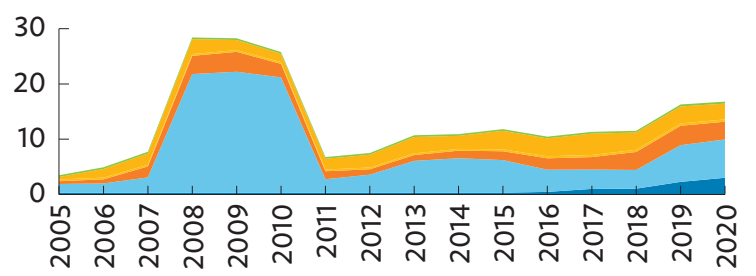

$\because \mathrm{SF} \backsim \mathrm{SG} \backsim \mathrm{SI} \backsim \mathrm{SK} 1 \backsim \mathrm{SJ} \backsim \mathrm{SK} 2$

(c) South Asia

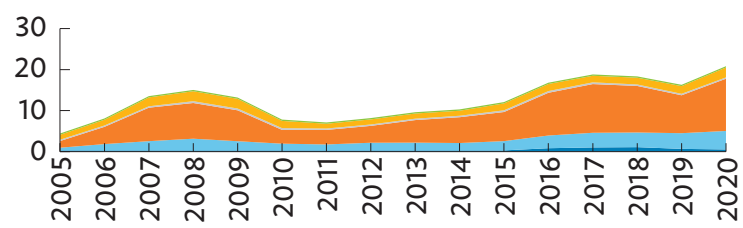

$\square \mathrm{SF} \backsim \mathrm{SG} \backsim \mathrm{SI} \square \mathrm{SK} 1 \backsim \mathrm{SJ} \backsim \mathrm{SK} 2$

(e) Oceania

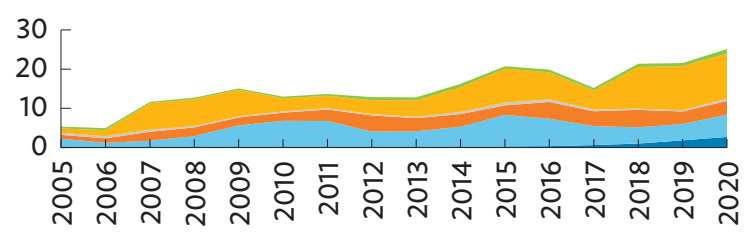

$\square \mathrm{SF} \backsim \mathrm{SG} \backsim \mathrm{SI} \backsim \mathrm{SK} 1 \quad \mathrm{SJ} \backsim \mathrm{SK} 2$ (b) East Asia

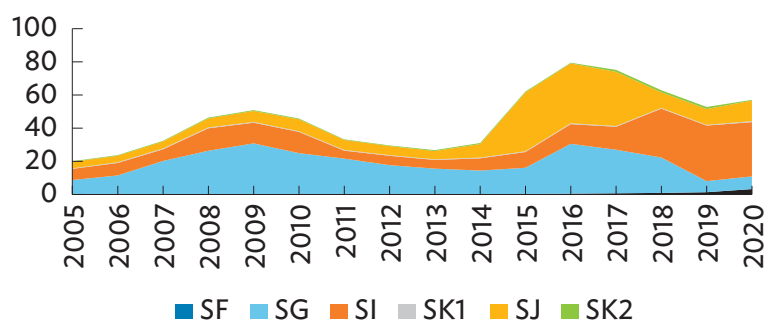

(d) Central Asia

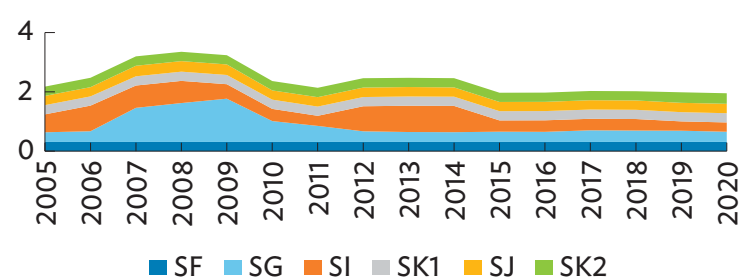

(f) The Pacific

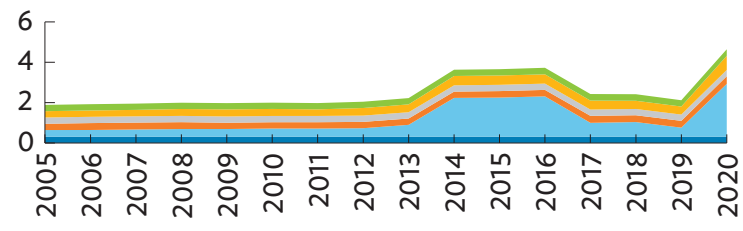

$\because \mathrm{SF} \backsim \mathrm{SG} \backsim \mathrm{SI} \backsim \mathrm{SK} 1 \quad \mathrm{SJ} \backsim \mathrm{SK} 2$

SF = insurance and pension services; SG = financial services; $\mathrm{SI}$ = telecommunications, computer, and information services; $\mathrm{SJ}=$ other business services (excluding traderelated services); SK1 = audio-visual and related services; and SK2 = other personal, cultural, and recreational services.

Notes: Series depicts combined greenfield and merger and acquisition investments (3-year moving averages) by subregion. Nomenclature following Extended Balance of Payments Services 2010 classification.

Sources: ADB calculations using data from Bureau van Dijk. Zephyr M\&A Database; and Financial Times. fDi Markets (both accessed May 2021). 
Figure 3.12: Top Digitally Deliverable Services FDI Subsectors, 2020 ( $\$$ million)

By World Region

(a) Greenfield

\begin{tabular}{|c|c|c|c|c|c|c|}
\hline Subsector & Africa & $\begin{array}{l}\text { Asia and } \\
\text { the Pacific }\end{array}$ & EU+UK & $\begin{array}{c}\text { Latin } \\
\text { America }\end{array}$ & $\begin{array}{c}\text { Middle } \\
\text { East }\end{array}$ & $\begin{array}{c}\text { North } \\
\text { America }\end{array}$ \\
\hline Data processing, hosting, and related services & 927 & 6,741 & 7,376 & 2,102 & 1,543 & 1,383 \\
\hline Wired telecommunication carriers & 4,193 & 310 & 7,296 & 1,371 & 723 & 465 \\
\hline Software publishers, except video games & 476 & 3,244 & 3,003 & 351 & 1,707 & 4,011 \\
\hline Wireless telecommunication carriers & 983 & 1,441 & 3,455 & 242 & 264 & 35 \\
\hline Retail banking & 160 & 4,217 & 886 & 278 & 633 & 416 \\
\hline Corporate and inves tment banking & 394 & 2,123 & 1,058 & 581 & 496 & 307 \\
\hline Custom computer programming services & 28 & 1,381 & 999 & 360 & 153 & 731 \\
\hline Inves tment management & 48 & 998 & 808 & 595 & 129 & 177 \\
\hline Insurance & 43 & 1,757 & 165 & 178 & 121 & 9 \\
\hline Internet publishing and broadcasting and web search & 188 & 463 & 623 & 54 & 27 & 163 \\
\hline
\end{tabular}

(b) M\&A

\begin{tabular}{|c|c|c|c|c|c|c|}
\hline Subsector & Africa & $\begin{array}{l}\text { Asia and } \\
\text { the Pacific }\end{array}$ & EU+UK & $\begin{array}{c}\text { Latin } \\
\text { America }\end{array}$ & $\begin{array}{c}\text { Middle } \\
\text { East }\end{array}$ & $\begin{array}{c}\text { North } \\
\text { America }\end{array}$ \\
\hline Data processing, hosting, and related services & 214 & 13,571 & 43,174 & 3,051 & 5,985 & 37,306 \\
\hline Wireless telecommunication carriers & 0 & 16,984 & 20,980 & 12 & 0 & 64,466 \\
\hline Investment management & 666 & 12,871 & 14,198 & 348 & 174 & 52,282 \\
\hline Professional, scientific, and technical services & 0 & 7,313 & 16,125 & 62 & 392 & 15,848 \\
\hline Insurance & 328 & 13,767 & 14,975 & 2,938 & 0 & 4,708 \\
\hline Other (Real estate) & 14 & 7,533 & 10,077 & 11 & 26 & 17,556 \\
\hline Software publishers, except video games & 31 & 6,803 & 14,068 & 333 & 295 & 6,835 \\
\hline Retail banking & 4,155 & 6,675 & 12,020 & 347 & 761 & 1,009 \\
\hline Custom computer programming services & 1 & 1,475 & 11,953 & 1 & 1,421 & 3,755 \\
\hline Business support services & 830 & 1,027 & 4,021 & 40 & 2 & 2,251 \\
\hline
\end{tabular}

By Asian Subregion

(c) Greenfield

\begin{tabular}{|c|c|c|c|c|c|c|}
\hline Subsector & $\begin{array}{c}\text { Central } \\
\text { Asia }\end{array}$ & $\begin{array}{l}\text { East } \\
\text { Asia }\end{array}$ & $\begin{array}{c}\text { Southeast } \\
\text { Asia }\end{array}$ & $\begin{array}{c}\text { South } \\
\text { Asia }\end{array}$ & Oceania & Pacific \\
\hline Data processing, hosting, and related services & 110 & 830 & 615 & 4,758 & 427 & 8 \\
\hline Retail banking & 0 & 3,506 & 515 & 61 & 136 & 274 \\
\hline Software publishers, except video games & 6 & 635 & 725 & 474 & 1,404 & \\
\hline Corporate and investment banking & 31 & 766 & 633 & 480 & 214 & 203 \\
\hline Insurance & 0 & 131 & 311 & 1,184 & 131 & 44 \\
\hline Wireless telecommunication carriers & 612 & 0 & 268 & 458 & 103 & 71 \\
\hline Custom computer programming services & 7 & 148 & 198 & 661 & 366 & 0 \\
\hline Investment management & 32 & 434 & 421 & 17 & 94 & 35 \\
\hline Internet publishing and broadcasting and web search & 0 & 25 & 128 & 30 & 279 & \\
\hline Professional, scientific, and technical services & 8 & 87 & 82 & 136 & 103 & 18 \\
\hline
\end{tabular}

(d) M\&A

\begin{tabular}{|c|c|c|c|c|c|c|}
\hline Subsector & $\begin{array}{c}\text { Central } \\
\text { Asia }\end{array}$ & $\begin{array}{l}\text { East } \\
\text { Asia } \\
\end{array}$ & $\begin{array}{c}\begin{array}{c}\text { Southeast } \\
\text { Asia }\end{array} \\
\end{array}$ & $\begin{array}{c}\text { South } \\
\text { Asia }\end{array}$ & Oceania & Pacific \\
\hline Investment management & 2 & 7,446 & 1,473 & 416 & 3,320 & 5,435 \\
\hline Wireless telecommunication carriers & 0 & 511 & 42 & 15,801 & 629 & 112 \\
\hline Insurance & 0 & 6,343 & 3,838 & 160 & 3,426 & 0 \\
\hline Data processing, hosting, and related services & 0 & 8,500 & 1,359 & 2,799 & 913 & 0 \\
\hline Other (Real estate) & 0 & 1,166 & 2,177 & 2,301 & 1,889 & 15 \\
\hline Professional, scientific and technical services & 18 & 7,091 & 15 & 22 & 166 & 4 \\
\hline Software publishers, except video games & 0 & 3,645 & 298 & 2,433 & 426 & \\
\hline Retail banking & 54 & 653 & 1,210 & 3,272 & 1,472 & 15 \\
\hline Other (Financial services) & 0 & 2,246 & 682 & 991 & 523 & 10 \\
\hline Business support services & 0 & 337 & 472 & 126 & 20 & 687 \\
\hline
\end{tabular}

$E U=$ European Union (27 members), FDI = foreign direct investment, $M \& A=$ merger and acquisition, UK = United Kingdom.

Sources: ADB calculations using data from Bureau van Dijk. Zephyr M\&A Database; and Financial Times. fDi Markets (both accessed May 2021). 


\section{Can FDI support digital services trade in Asia and the Pacific?}

Multinational enterprises can be central to creating trade and investment linkages where they operate, setting up affiliates to expand their markets, through so-called horizontal FDI, or to outsource part of their business operations, favoring the development of production networks through vertical or GVC-FDI. The latter has been a driver in the Asia and Pacific region, where a network of investments underlies the rapid development of GVCs.

Within manufacturing GVCs, services have also played an important role as they facilitate the movement of goods and information, induce innovation, and contribute to diversification (Lodefalk 2017; Avendano et al. 2019). "Cost" services including logistics, ICT, insurance, and financial services, improve the coordination and efficiency of production processes, while "value" services can contribute to product differentiation and strengthen customer loyalty. Services can also be important for firms to overcome barriers to foreign market entry. By establishing affiliates, multinational enterprises provide services including distribution, maintenance, marketing, and monitoring. They allow companies to gain knowledge of local markets and networks.

While still undeveloped in comparison to manufacturing, GVCs in services sectors have become more important
(Prakash and Shepherd 2021). However, the linkages through which FDI in services can support economies' exporting capacity in services need to be better understood. While services FDI can be seen as a substitute for services exports, more recent evidence suggests that services FDI is also associated with growth and tradability of goods and services exports.

The experience in Asia and the Pacific suggests that about $14 \%$ of multinational enterprises with foreign affiliates in business services engage in international trade (ADB 2016).

In the context of digitally deliverable services, some evidence underlines the possible link between digital services exports and digital services FDI in Asia and the Pacific, in particular for sectors such as telecommunications, computer and information services, and other business services (Figure 3.13). The role of foreign investment in digital services is more visible in industries that require a threshold of digital infrastructure to operate, telecommunications being the clearest example (Gestrin and Staudt 2018). Regional investments to build up capacity in data processing, hosting, and related services also reflect the focus in the adoption of digital services and digital infrastructure. With firms increasingly targeting investment in digital sectors to expand or digitize their operations, it is expected that FDI to digital services will increase in coming years.

Figure 3.13: Digitally Deliverable Services in Asia and the Pacific-FDI versus Exports (\$ billion)
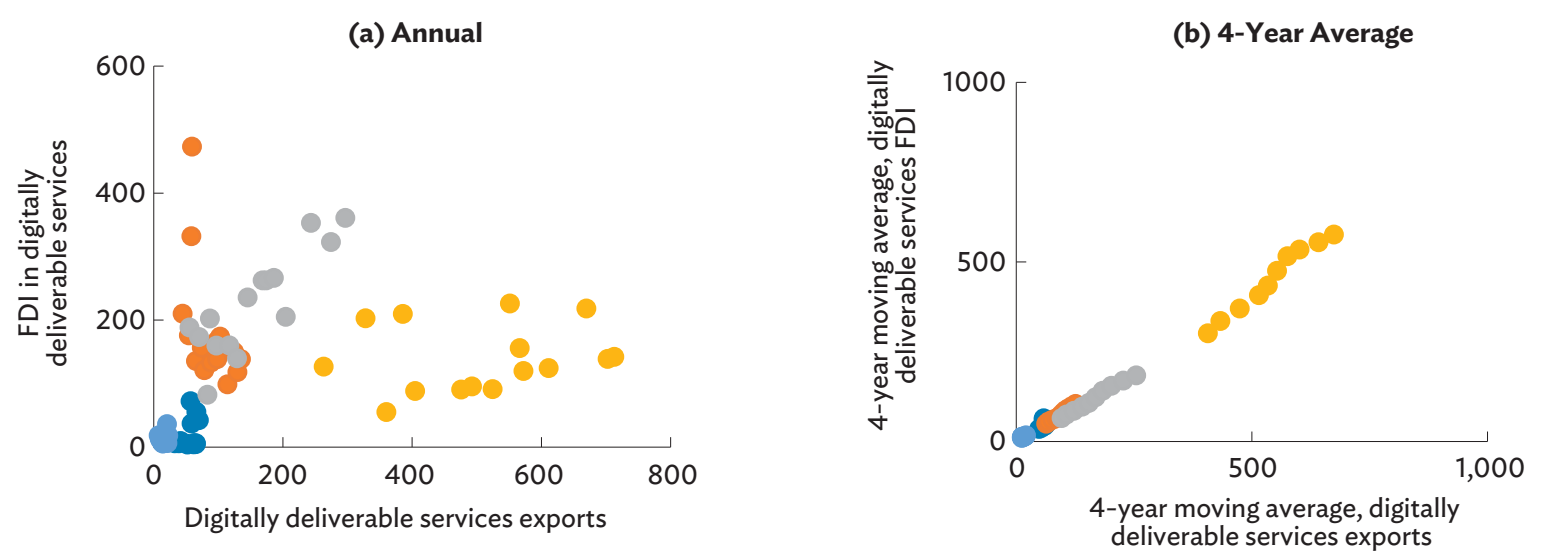

- SF: Insurance and pension services

SI: Telecommunications, computer, and information services - SG: Financial services

- SJ: Other business services

- SK: Personal, cultural, and recreational services

$\mathrm{FDI}=$ foreign direct investment

Sources: ADB calculations using data from Bureau van Dijk. Zephyr M\&A Database; and Financial Times. fDi Markets (both accessed May 2021). 
To maximize the potential of digital services FDI in the region, additional aspects need to be considered, in particular the degree of statutory restrictions to foreign investment in digital services and the existing investment policy frameworks. These aspects are explored below.

\section{Box 3.1: The Reinforcing Role of Global Value Chain Participation and FDI-Prospects for Digital Services}

Globalization and regional integration have enhanced the volume and nature of cross-border flows. Global value chains (GVCs) allow economies to specialize and participate in certain areas of production without having to wait for industries or industry segments to fully develop (Qiang, Liu, and Steenbergen 2021). GVC participation is also associated with inclusive growth, job creation, and poverty reduction (World Bank 2020). While GVCs generally flourish in industries in which production may easily be segmented (e.g., automotive, electronics, and garments), they have increasingly spread across other sectors, including services.

Efforts have been made to understand the drivers and mechanisms that affect GVC participation. Studies have shown that both economic factors (e.g., macroeconomic conditions, market size, industrialization) and structural characteristics (e.g., economy size, human capital development, trade and investment policies) affect participation in GVCs (Adarov 2021; Urata and Baek 2020). Foreign direct investment (FDI) is also associated with increasing GVC participation, with investment from multinationals playing an increasingly important role. Greenfield investment and mergers and acquisitions have become particularly important, as these involve initial FDI from lead firms looking to expand their market or inputs (ADB 2016; Andrenelli et al. 2019; Carril-Caccia and Pavlova 2018). Doing so may lower entry costs and entice these firms to involve their other GVC partners. Ultimately, the reinforcing nature of FDIs and GVCs has increased-as multinational enterprises tag in their partners, a fresh wave of investment also enters the economy (Qiang, Liu, and Steenbergen 2021).

Asia and the Pacific continues to be a major source and destination of global FDI. Relative to economic size, regional foreign investment represented $1.5 \%$ of gross domestic product (GDP) of inward FDI. The region is also a production hub, with its GVC participation rate standing at $65 \%$ in 2020 . The relative size of FDI has been posited to be linked with GVC performance. Economies with a larger FDI stock relative to GDP tend to have a higher participation in GVCs and domestic value added in trade. This is the case for Asian economies, where GVC participation and FDI presence suggest a positive correlation, particularly for outward FDI (box figure 1). Financial centers such as Singapore and Hong Kong, China are high in both GVC participation and FDI presence. In contrast, commodity exporters such as Brunei Darussalam and Kazakhstan have high GVC participation rates with stronger forward linkages regardless of FDI presence (ADB 2021b).

\section{1: Scatter Plots on GVC participation and FDI-Asia and the Pacific, 2020}
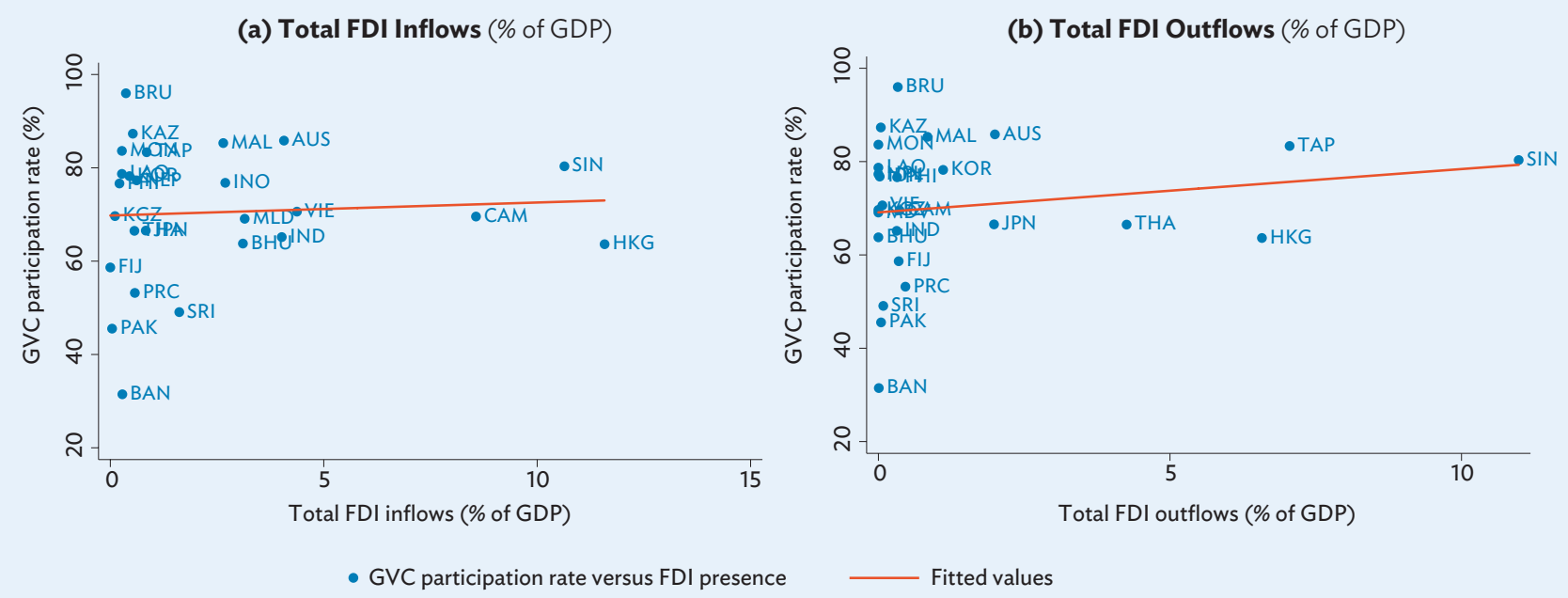

AUS = Australia; BAN = Bangladesh; BHU = Bhutan; BRU = Brunei Darussalam; CAM = Cambodia; FDI = foreign direct investment; FIJ = Fiji; GDP = gross domestic product; GVC = global value chain; HKG = Hong Kong, China; IND = India; INO = Indonesia; JPN = Japan; KAZ = Kazakhstan; KGZ = Kyrgyz Republic; KOR = Republic of Korea; LAO = Lao People's Democratic Republic; MAL = Malaysia; MLD = Maldives; MON = Mongolia; NEP = Nepal; PAK = Pakistan; PHI = Philippines; PRC = People's Republic of China; SIN = Singapore; SRI = Sri Lanka; TAP = Taipei,China; THA = Thailand; and VIE = Viet Nam.

Notes: GVC participation rate is calculated as the ratio of the sum of "terms 2 to 16 " to total gross exports based on the GVC decomposition methodology of Wang, Wei, Zhu (2013, revised 2018). Total FDI is calculated as the sum of greenfield FDI capital expenditure and merger and acquisition deal values.

Sources: ADB calculations using data from ADB. Multi-regional Input-Output Tables; Bureau van Dijk. Zephyr M\&A Database; Financial Times. fDi Markets (both accessed May 2021); and decomposition methodology of Wang, Wei, and Zhu (2013, revised 2018). 


\section{GVCs and Digital Services}

Recent years have seen a shift in employment, output, and trade from agriculture and manufacturing to service industries. GVCs have also seen a rise in service-related industries, which may positively impact employment and overall economic development (ADB 2021a). A similar trend is observed in Asia's foreign investment inflows, where the share of services to total FDI has risen from $19.3 \%$ in 2003 to almost $49.0 \%$ in 2020.

In Asia and the Pacific, digital services are an important component of total foreign investment. Even in Asia's digital services, the reinforcing relationship of GVC and FDI is apparent (box figure 2). Bhutan, Cambodia, Maldives, and Singapore featured both high FDI presence and high GVC participation in digital services sectors. Growing FDI in those sectors could improve the region's trade and integration to international production networks through various channels. Advancements in information and communication technologies and digital platforms have reduced distance-based barriers in goods and services trade and allowed firms and businesses to integrate to global supply networks (ADB 2021a).

As GVCs and FDI are intertwined and digitalization continues, international investment policies should be mindful of these interdependencies. Recent protectionist policies in some economies, as well as policy responses due to the COVID-19 pandemic exemplify this dependence. Investment policy frameworks can benefit from a more thorough assessment on the linkages with GVCs, for example, through the development of sectoral clusters, analyzing the consistency between investment and trade regulations, and exploring FDI measures more aligned with "light-handed" industrial policies.

\section{2: Scatter Plots on GVC Participation and FDI in Digital Services-Asia and the Pacific, 2020}

(a) FDI Inflows in Digital Services (\% of GDP)

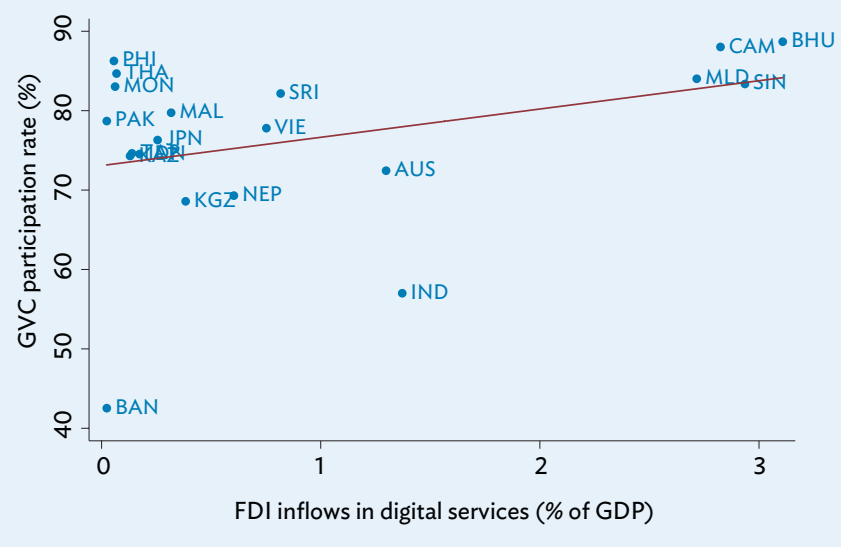

- GVC participation rate versus FDI presence (b) FDI Outflows in Digital Services (\% of GDP)

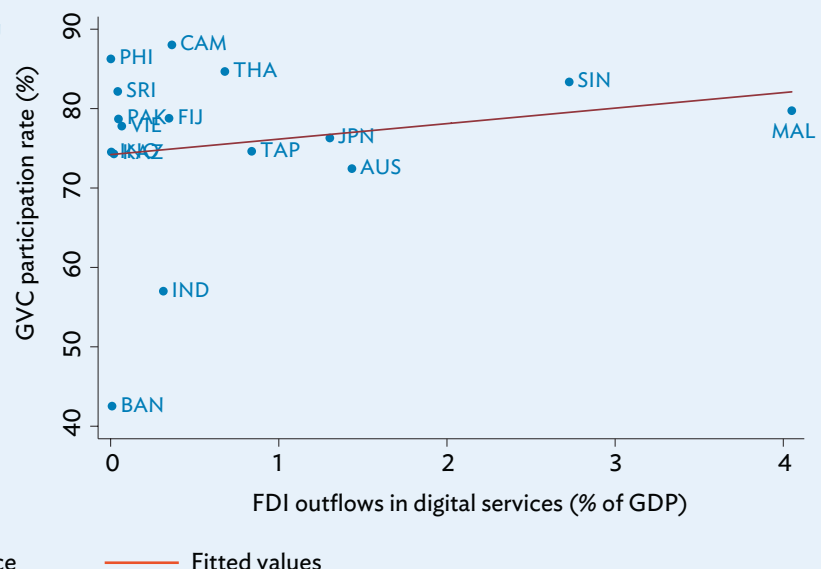

$\mathrm{AUS}=$ Australia; $\mathrm{BAN}=$ Bangladesh; $\mathrm{BHU}=$ Bhutan; $\mathrm{CAM}=\mathrm{Cambodia} ; \mathrm{FIJ}=\mathrm{Fiji} ; \mathrm{FDI}=$ foreign direct investment; $\mathrm{GDP}=$ gross domestic product GVC = global value chain; IND = India; INO = Indonesia; JPN = Japan; KAZ = Kazakhstan; $K G Z$ = Kyrgyz Republic; $M A L=$ Malaysia; $M L D=$ Maldives; $M O N=$ Mongolia; NEP = Nepal; PAK = Pakistan; PHI = Philippines; SIN = Singapore; SRI = Sri Lanka; TAP = Taipei,China; THA = Thailand; and VIE = Viet Nam.

Notes: GVC participation rate is calculated as the ratio of the sum of "terms 2 to 16 " to total gross exports based on the GVC decomposition methodology of Wang, Wei, Zhu (2013, revised 2018). Total FDI is calculated as the sum of greenfield FDI capital expenditure and mergers and acquisitions deal values. For GVC participation rate, sectors considered to be digitally deliverable were post and telecommunications; financial intermediation; real estate activities; renting of machinery and equipment and other business activities; and other community, social, and personal services. As a whole, these serve as an upper bound estimate. Sources: ADB calculations using data from ADB. Multi-Regional Input-Output Tables; Bureau van Dijk. Zephyr M\&A Database; Financial Times. fDi Markets (accessed May 2021); and decomposition methodology of Wang, Wei, and Zhu (2013, revised 2018). 


\section{FDI regulations in Asia and the Pacific tend to be most restrictive in the services sector.}

The potential of FDI to support the development of digital services sectors may have been hampered by regulatory restrictions to investment in these sectors, which have been dominant across the region. Discrimination against foreign investors in Asia and the Pacific remains high. The Organisation for Economic Co-operation and Development's (OECD) FDI Regulatory Restrictiveness Index, which covers statutory restrictions in 22 economic sectors, confirms that Asia's regulatory restrictiveness score on the services sector remains higher than OECD economies (Figure 3.14). While the pattern of restrictions between regions is similar, the extent of restrictiveness in Asia and the Pacific is considerably higher. Within economic sectors, regulatory environment in Asia and the Pacific is more welcoming to the manufacturing sector, against higher restrictions in services, with the possible hindering effects on market competition and higher service input costs. The decreasing trend in restrictions from 1997 to 2020 also reveals the pace of FDI facilitation reforms across many economies in the region, such as Indonesia, Malaysia, and Viet Nam.

\section{Figure 3.14: FDI Regulatory Restrictiveness Index by Sector-Asia and the Pacific}

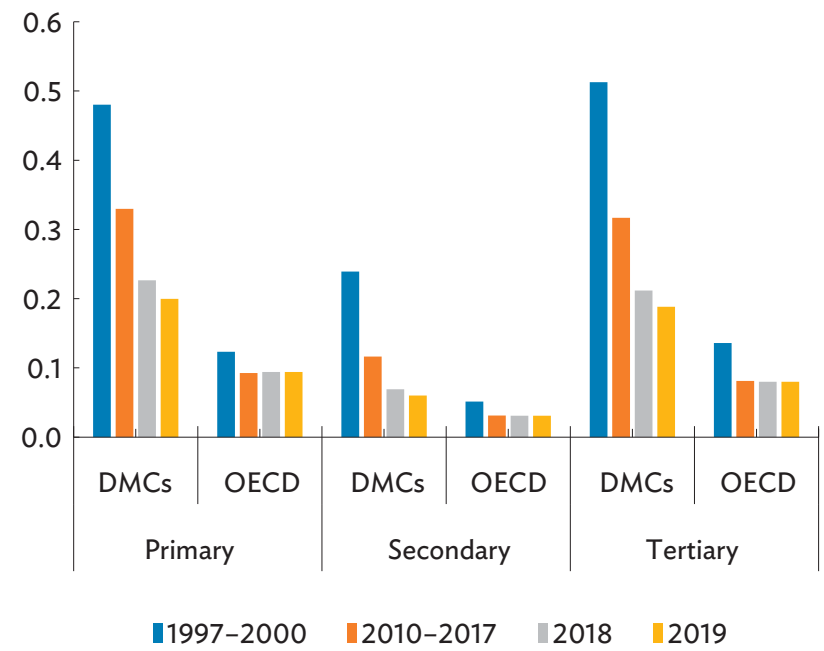

$\mathrm{DMC}=$ developing member country, $\mathrm{FDI}$ = foreign direct investment, $\mathrm{OECD}=$ Organisation for Economic Co-operation and Development.

Source: OECD. FDI Regulatory Restrictiveness Index Data Set. https://stats.oecd. org/Index.aspx?datasetcode=FDIINDEX\# (accessed September 2021).

\section{FDI restrictions in Asia's digital services sectors have decreased over time yet remain relatively higher than non-digital services.}

A glance at FDI restrictions in sectors associated to digitally deliverable services sectors in Asia and the Pacific suggests that, while decreasing, they remain high (Figure 3.15). ${ }^{28}$ Entry restrictions in services sectors are predominant in the region in the form of foreign equity limitations, which impose restrictions in the ownership share of nonresidents. Other restrictions, in particular on foreign personnel and screening and approval, remain relatively low. Together with high restrictiveness levels, the effect of regulatory heterogeneity on FDI in Asian economies can also affect firms' investment decisions. Reductions in regulatory divergence on control regulations, antitrust exemptions, and entry barriers in networks and services, for example, could be critical for attracting FDI.

\section{Within digitally deliverable services, radio and TV broadcasting, media, and legal services exhibit the highest level of FDI restrictions.}

Important gaps are observed on FDI restrictiveness scores between Asian and non-Asian economies across most digital services subsectors (Figure 3.16a). In general, radio and TV broadcasting, media, and legal services are more restrictive of FDI globally, whereas gaps with Asia and the Pacific are more pronounced in telecommunications and business services sectors. Economies in Southeast Asia (e.g., Indonesia, Malaysia, the Philippines, Thailand, Viet Nam) and the PRC, for example, had high scores on these sectors. Restrictions in accounting, insurance, and financial services remain higher in Asia and the Pacific, but are considerably lower in these sectors.

By economy, FDI restrictions in services sectors in Asia and the Pacific are wide-ranging, with digital services being more restrictive overall (Figure 3.16b). Across most Asian economies, FDI restrictions on digitally deliverable services are consistently higher.

28 For the purposes of this exercise, subsectors were identified based on classification and description available via the FDI Regulatory Restrictiveness Index from the OECD. See Annex 3e for the list of sectors identified as digitally deliverable. 
Figure 3.15: FDI Regulatory Restrictiveness Index by Type of Restriction-Asia and the Pacific

(a) Digitally Deliverable

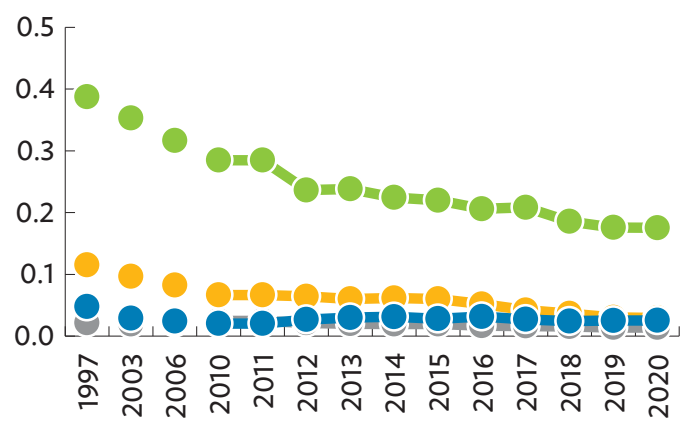

(b) Non-Digitally Deliverable

$$
\oiiint \text { Equity } \quad \text { Foreign personnel } \quad \text { Screening and approval } \quad \text { Other restrictions }
$$

$\mathrm{FDI}=$ foreign direct investment

Source: Organisation for Economic Co-operation and Development. FDI Regulatory Restrictiveness Index Data Set. https://www.oecd.org/investment/fdiindex.htm (accessed September 2021).

Figure 3.16: FDI Regulatory Restrictiveness Index in Digitally Deliverable Services, 2020-All Types of Restrictions

(a) By Digitally Deliverable Sector and Region
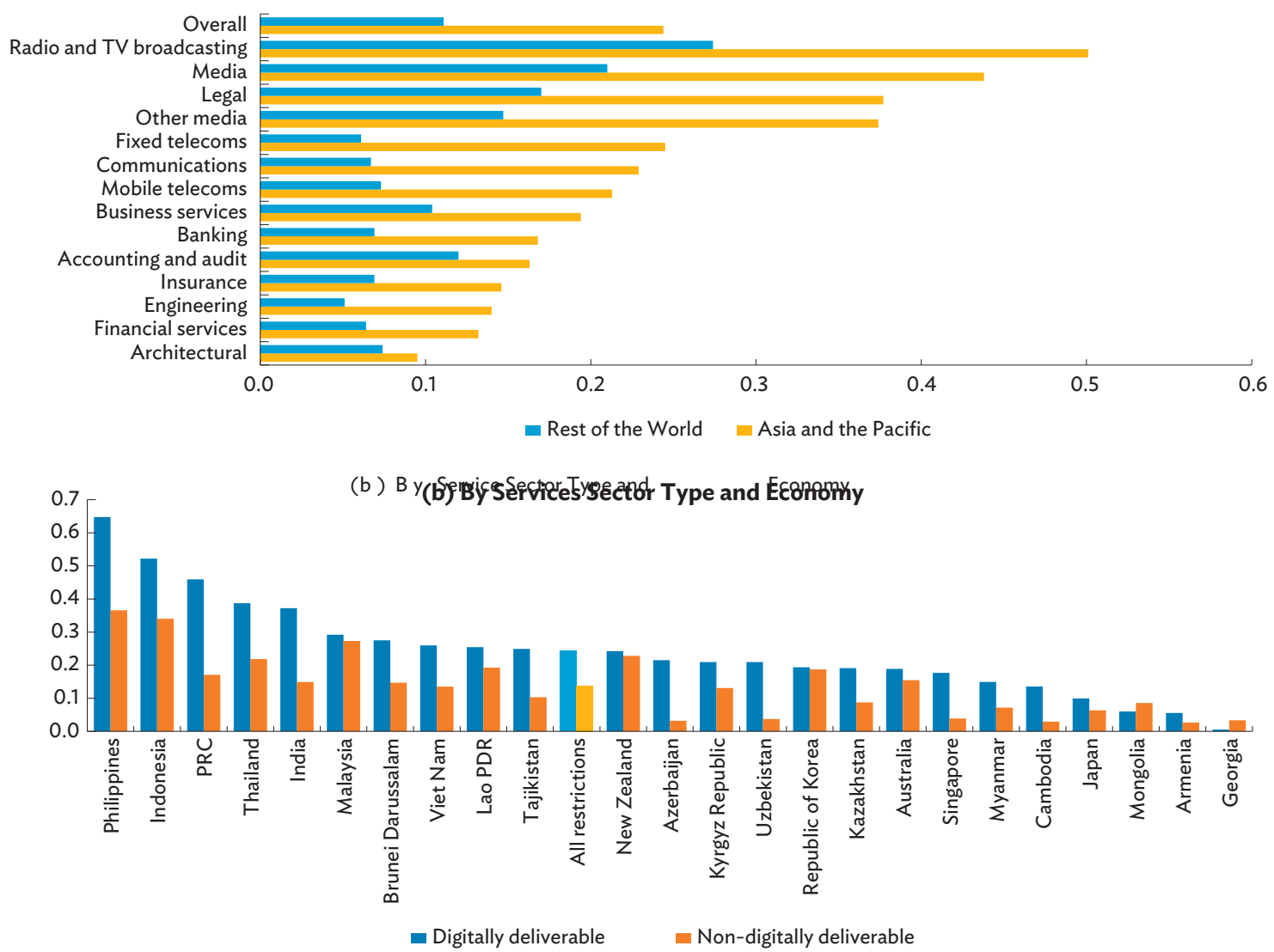

FDI = foreign direct investment, Lao PDR = Lao People's Democratic Republic, PRC = People's Republic of China.

Source: Organisation for Economic Co-operation and Development. FDI Regulatory Restrictiveness Index Data Set. https://www.oecd.org/investment/fdiindex.htm (accessed September 2021). 
Exceptions to this are Australia, Japan, New Zealand, and the Republic of Korea, more broadly aligned with OECD principles of non-discrimination of international investment. FDI restrictions in non-digital services sectors, such as transport and tourism (e.g., hotels and restaurants), are generally lower.

In recent years, several economies in the region have introduced measures to ease FDI restrictions involving digital services sectors. For example, Viet Nam in 2020 introduced new criteria and tax incentives for hightech investments in telecommunications, computer programming, and consultancy and related services. In 2021, India increased the FDI ceiling of insurance companies from $49 \%$ to $74 \%$ to direct investment toward the sector. The PRC has also abolished restrictions on foreign shareholding in joint venture life insurance companies. Indonesia, the Lao People's Democratic Republic, the Philippines, and Thailand have also introduced measures to facilitate FDI in strategically relevant sectors. Overall, the past few years showed more facilitative investment measures than restrictive ones implemented in Asia and the Pacific (Figure 3.17).

Figure 3.17: Recent Foreign Investment Measures in Digitally Deliverable Services in Asia and the Pacific

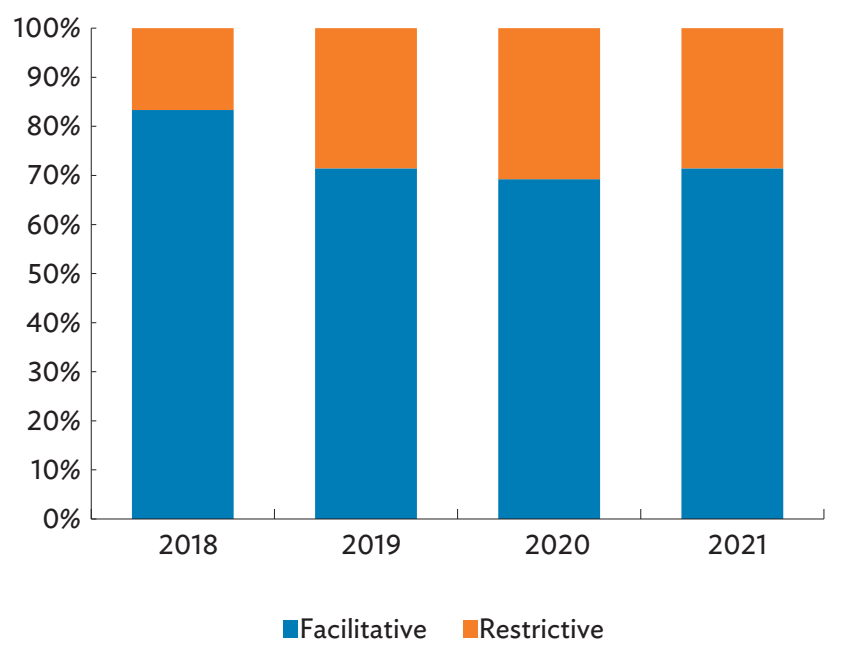

Note: Estimates for 2021 are based on information available as of 13 December 2021.

Source: ADB calculations based on data from Organisation for Economic Co-operation and Development. FDI Regulatory Restrictiveness Index. https://www.oecd.org/investment/fdiindex.htm (accessed September 2021); and United Nations Conference on Trade and Development. Investment Policy Hub: Investment Policy Monitor. https://investmentpolicy.unctad.org/investmentpolicy-monitor (accessed December 2021).

\section{Adapting Asia's investment policy frameworks for digital services}

The adoption of digital technologies and the gradual increase of cross-border provision of services may have implications for Asia and the Pacific and should be accompanied by active investment policies (Table 3.7). For economies in the region to leverage FDI into these sectors, investment policy frameworks must adapt and be embedded in development strategies of national digital plans and services. Factors influencing investment decisions such as physical infrastructure, regulatory frameworks, and ICT skills need to be taken into account in policies for the promotion and facilitation of investment (Eden et al. 2021). Some of these have been identified as limiting factors holding back FDI in digital services.

Improvements in the regulatory framework involve different areas of action. Many governments have defined digital development strategies with established cross-sectoral plans for developing digital infrastructure, strengthening e-government, and promoting ICT skills and competencies. However, often digital strategies in Asia and the Pacific and other developing regions do not systematically include an investment dimension with information on financing sources or policy instruments to facilitate investment (UNCTAD 2017). Information on investment needs should go beyond digital infrastructure. Also, policy measures for business development through FDI have been effectively used in the region for the promotion of digital services. These include digital clusters, targeted entrepreneurship programs, and digital special economic zones (Chapter 7: Theme Chapter-Advancing Digital Services Trade in Asia and the Pacific). Investment promotion agencies can be critical instruments to implement these models and align them with investors' expectations.

An increasingly important area for FDI, particularly for digital services, is intellectual property rights. Surveys among technology and digital firms show that, together with data security and data privacy, copyright laws to protect intellectual property remain a priority when investing in new digital activities (Kowalski et al. 2015; WEF 2020). Building strong intellectual property protection is increasingly needed in the region, while acknowledging the different 
Table 3.7: Investment Policy Frameworks for Enhancing Digital Services FDI

\begin{tabular}{|c|c|}
\hline Key Domain & Policy Recommendation \\
\hline \multirow{5}{*}{ Institutional and regulatory framework } & $\begin{array}{l}\text { Align investment policy with national digital strategies and national digital plans; investment } \\
\text { promotion planning should thus be fundamentally entwined with investment policy planning. }\end{array}$ \\
\hline & $\begin{array}{l}\text { Create an interministerial body involving services, digital economy, and other relevant agencies to } \\
\text { plan for and administer the digital services sector. }\end{array}$ \\
\hline & $\begin{array}{l}\text { Streamline regulatory barriers upholding digital services (e.g., phase out digital services taxes, } \\
\text { facilitate adoption of e-financial services and digital payments, improve standards for e-health and } \\
\text { remote education services). }\end{array}$ \\
\hline & $\begin{array}{l}\text { Implement sector regulations and independent supervision to ensure level playing field, competition, } \\
\text { and investor protection. }\end{array}$ \\
\hline & Strengthen intellectual property frameworks including legal framework for intellectual property rights. \\
\hline \multirow{3}{*}{ International investment agreements } & $\begin{array}{l}\text { Include digital provisions in new international investment agreements that reflect economy } \\
\text { commitments and regulations. }\end{array}$ \\
\hline & $\begin{array}{l}\text { Consider definition of investment provision in international investment agreements to cover } \\
\text { intangible assets and other relevant assets for digitally intensive firms. }\end{array}$ \\
\hline & $\begin{array}{l}\text { Ensure regulatory convergence with multilateral investment and trade commitments and General } \\
\text { Agreement on Trade in Services. }\end{array}$ \\
\hline \multirow{5}{*}{ Skills and competencies development } & $\begin{array}{l}\text { Collaborate across sectors to provide integrated solutions for small and medium-sized enterprises or } \\
\text { industries lacking trained workforce to lead transformations from the inside. }\end{array}$ \\
\hline & Enhance digital skills in curriculums (e.g., computer skills, basic coding, digital reading). \\
\hline & Talent and capability mapping to showcase specialized local capability for potential foreign direct investors. \\
\hline & Investment in large-scale reskilling programs, collaborating with private sector players. \\
\hline & Design online courses and flexible and affordable options for distance learning. \\
\hline \multirow{3}{*}{ Digital infrastructure } & Accelerate investments to improve international, national, and urban digital connectivity. \\
\hline & Improve regional coordination for digital infrastructure investment. \\
\hline & Digitize government services (e.g., online applications for permits, e-tax filing). \\
\hline \multirow{3}{*}{$\begin{array}{l}\text { Clusters for digital services } \\
\text { (innovation, financial instruments, } \\
\text { entrepreneurship programs) }\end{array}$} & $\begin{array}{l}\text { Enhance digital innovation hubs, incubators, and accelerators to promote business development } \\
\text { plans, offer technological expertise and experimentation facilities for digital service investors. }\end{array}$ \\
\hline & $\begin{array}{l}\text { Consider fiscal incentives and strategic support to digital services sectors, particularly those investing } \\
\text { in local innovation and job creation. }\end{array}$ \\
\hline & $\begin{array}{l}\text { In coordination with investment promotion agencies and other bodies, consider introduction of } \\
\text { digital technology parks, software parks, innovation districts, and a digital free trade zone. }\end{array}$ \\
\hline
\end{tabular}

FDI = foreign direct investment.

Source: ADB compilation based on UNCTAD (2017), Satyanand (2021), Stephenson (2020), and World Economic Forum (2020).

models and levels of progress in this area (ADB 2021a). Knowledge-intensive services that are digitally deliverable, such as cloud computing, data analytics, software development or management or organizational knowledge may be increasingly dependent on solid intellectual property regulations to attract foreign investors. An investment policy framework for digital services should take these aspects into consideration.
At the international level, most international investment agreements in Asia and the Pacific still do not tackle issues related to digitalization or contain digital provisions. Considerations on the scope and definition of investment, for instance, may not consider the coverage of intangible assets for digitally intensive firms. As economies modernize their current international investment agreements, these aspects and consistency of the agreements, notably with regional trade agreements and the General Agreement on Trade in Services, will be increasingly important. 


\section{References}

Adarov, A. 2021. Interactions Between Global Value Chains and Foreign Direct Investment: A Network Approach. The Vienna Institute for International Economic Studies Working Paper Series. No. 204. July. Vienna: The Vienna Institute for International Economic Studies.

Andrenelli, A., I. Lejarraga, S. Miroudot, and L. Montinari. 2019. Micro-Evidence on Corporate Relationships in Global Value Chains: The Role of Trade, FDI and Strategic Partnerships. OECD Trade Policy Papers. 227 (April). Paris: Organisation for Economic Co-operation and Development (OECD).

ASEAN Secretariat. ASEANstats Data Portal. https://data.aseanstats.org (accessed July 2019).

Asian Development Bank (ADB). 2016. Asian Economic Integration Report 2016: What Drives Foreign Direct Investment in Asia and the Pacific? Manila.

- 2018a. Asian Economic Integration Report 2018: Toward Optimal Provision of Regional Public Goods in Asia and the Pacific. Manila.

_.2018b. Online Annex: Foreign Direct Investment (Balance of Payments) and Firm-level Investment Activity by Mode of Entry-Data Description and Methodology. https://aric.adb.org/pdf/aeir2018_ onlineannex1.pdf.

- 2021a. Global Value Chain Development Report 2021: Beyond Production. Manila.

\section{_ 2021b. Asian Economic Integration Report: Making} Digital Platforms Work for Asia and the Pacific. Manila.

Avendano, R., F. Bontadini, N. Mulder, and D. Zaclicever. 2019. Latin America's Faltering Manufacturing Competitiveness: What Role for Intermediate Services? International Trade Series. No. 148 (LC) TS.2019/88). Santiago: Economic Commission for Latin America and the Caribbean.
Carril-Caccia, F. and E. Pavlova. 2018. Foreign Direct Investment \& Trade: A Global Value Chains Analysis. Paper prepared for the European Trade Study Group 12th Annual Conference. Warsaw. 13-15 September.

Casella, B. and L. Formenti. 2018. FDI in the Digital Economy: A Shift to Asset-Light International Footprints. Transnational Corporations. 25 (1). pp. 101-130.

Eden, L., M. Kende, F. Kimura, K. Sauvant, N. Srinivasan, M. Stephenson, L. Tajoli, and J. Zhan. 2021. Leveraging Digital FDI for Capacity and Competitiveness: How to Be SMART. September. G20 Insights Policy Brief. https://www.g20-insights.org/wp-content/ uploads/2021/09/TF3_LEVERAGINGDIGITAL-FDI-FOR-CAPACITY-ANDCOMPETITIVENESS-HOW-TO-BE-SMART.pdf.

Eurostat. Balance of Payments. https://ec.europa.eu/ eurostat (accessed July 2021).

Gestrin, M. and J. Staudt. 2018. The Digital Economy, Multinational Enterprises and International Investment Policy. Paris: OECD.

Government of Canada, Statistics Canada. Industry classifications. https://www.statcan.gc.ca/en/ concepts/industry (accessed June 2021).

Government of the United States, United States Census Bureau. North American Industry Classification System. https://www.census.gov/naics/ (accessed June 2021).

International Monetary Fund. World Economic Outlook April 2021 Database. https://www.imf.org/en/ Publications/WEO/weo-database/2021/April (accessed April 2021). 
Kowalski, P., J. Gonzalez, A. Ragoussis, and C. Ugarte. 2015. Participation of Developing Countries in Global Value Chains: Implications for Trade and Trade-Related Policies. OECD Trade Policy Papers. April. Paris: OECD.

Lodefalk, M. 2017. Servicification of Firms and Trade Policy Implications. World Trade Review. 16 (1). pp. 59-83.

Organisation for Economic Co-operation and Development, World Trade Organization, and International Monetary Fund. 2019. Handbook on Measuring Digital Trade, Version 1. Paris; Geneva; and Washington, DC.

. FDI Regulatory Restrictiveness Index. https://www.oecd.org/investment/fdiindex.htm (accessed September 2021).

Prakash, A. and B. Shepherd, eds. 2021. Global Value Chains and Investment: Changing Dynamics in Asia. Jakarta: Economic Research Institute for ASEAN and East Asia.

Qiang, C., Y. Liu, and V. Steenbergen. 2021. An Investment Perspective on Global Value Chains. Washington, DC: World Bank.

Satyanand, P. N. 2021. Foreign Direct Investment and the Digital Economy. ARTNeT on FDI Working Paper Series. No. 2 (July). Bangkok: United Nations Economic and Social Commission for Asia and the Pacific.

Stephenson, M. 2020. Digital FDI: Policies, Regulations and Measures to Attract FDI in the Digital Economy. World Economic Forum White Paper. September. Cologny: World Economic Forum.

United Nations Conference on Trade and Development (UNCTAD). 2009. UNCTAD Training Manual on Statistics for FDI and the Operations of TNCs: Volume I-FDI Flows and Stocks. New York and Geneva.
_. 2017. World Investment Report 2017: Investment and the Digital Economy. Geneva.

_. 2022. Global Investment Trend Monitor, No. 40. https://unctad.org/system/files/official-document/ diaeiainf2021d3_en.pdf.

_ Investment Policy Hub: Investment Policy Monitor. https://investmentpolicy.unctad.org/ investment-policy-monitor (accessed December 2021).

- World Investment Report 2021 Statistical Annex Tables. https://worldinvestmentreport.unctad.org/ annex-tables (accessed July 2021).

Urata, S. and Y. Baek. 2020. Determinants of Participation in Global Value Chains: A CrossCountry, Firm-Level Analysis. ADBI Working Paper Series. No. 1116 (April). Tokyo: ADB Institute.

Wang, Z., S. J. Wei, and K. Zhu. 2013 (revised 2018). Quantifying International Production Sharing at the Bilateral and Sector Levels. NBER Working Paper. No. 19677. Cambridge, MA: National Bureau of Economic Research.

Wettstein, S., A. Liberatore, J. Magdeleine, and A. Maurer. 2019. A Global Trade in Services Data Set by Sector and by Mode of Supply (TISMOS). Geneva: World Trade Organization.

World Bank. 2020. World Development Report 2020: Trading for Development in the Age of Global Value Chains. Washington, DC.

World Economic Forum. 2020. Accelerating Digital Inclusion in the New Normal. Geneva. 


\section{Annex 3a: Notes on Data Sources and Compilation}

Discussions of recent trends in this chapter use data on (i) foreign direct investment (FDI) based on standard balance of payments (BOP) data, and (ii) investment data based on firm-level activity. While both illustrate economy-level foreign investment and global trends, BOP data are supplemented by firm-level data as they help trace the mode of entry and the global ultimate ownership of the investment.

\section{Balance of payments}

Bilateral data on FDI based on the standard BOP definition are compiled from various sources. Data on net inflows are primarily obtained from national sources via the CEIC Data Company and, when unavailable, complemented by data from international or regional organizations such as the Association of Southeast Asian Nations, EuroStat, and the United Nations Conference on Trade and Development (UNCTAD). Missing data for some years are estimated using a gravity model. When combining data from these sources, first preference is given to data from national sources.

\section{Firm-level activity}

Data on firm-level activity is used to complement information supplied by the standard BOP data. Firmlevel activity enables analysis by mode of entry, which can either be via greenfield investment-the creation of new assets - or via mergers and acquisitions (M\&As) - the purchase of existing assets. Apart from differentiating between modes of entry, firm-level data also offers information on global ultimate ownership, shedding more light on the origins of the investment. Moreover, firm-level data also provides additional insight on the "economic activities of foreign affiliates and their importance to the host economy," as analyses of firm-level data allow host economies to assess the impact of investment from multination corporations (UNCTAD 2009).

This chapter uses data on greenfield investment from Financial Times' fDi Markets and M\&A deals from Bureau van Dijk's Zephyr M\&A Database. Data obtained from fDi Markets consists of announced new greenfield projects and excludes rumored projects. This data covers information on destination and source economies, project date, sectors, capital investment, project counts, and jobs generated. In case of data unavailability for capital expenditure or job creation, fDi Markets employs a proprietary algorithm to estimate those based on similarly sized projects.

Meanwhile, data sourced from the Zephyr M\&A database covers completed M\&A deals and covers information on the acquiror and its ultimate owner, the target company, sector classification code (using the North American Industry Classification System), deal type, completed date, and deal value. Similar to data from fDi Markets, Zephyr estimates unavailable deal values based on similarly sized deals. In addition, missing information on the economy of a target company or an acquiror's global ultimate owner is supplied via a reverse search using Bureau van Dijk's Orbis. Data from fDi Markets and Zephyr M\&A database are then matched by economy, year, and subsector following the North American Industry Classification System.

More detailed information on estimation of missing data for BOP-based FDI, as well as for sector matching for greenfield investment and M\&A, is available through the Asian Economic Integration Report 2018: Toward Optimal Provision of Regional Public Goods in Asia and the Pacific online annex on BOP-based FDI and firm-level activity (ADB 2018b). 


\section{Annex 3b: Global Quarterly Inward FDI, by Mode of Entry ( $\$$ billion)}

(a) Greenfield FDI

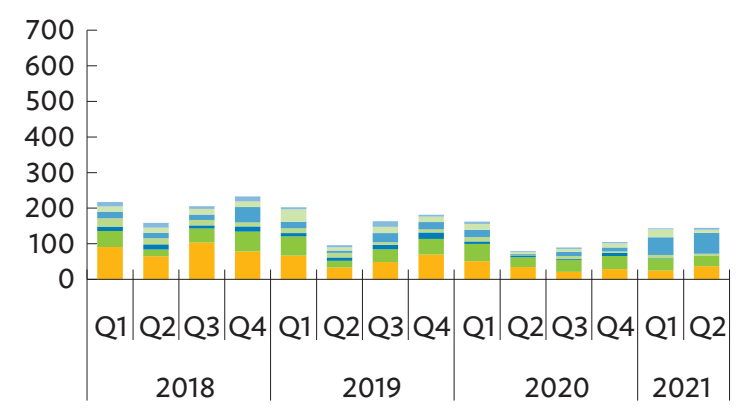

(b) M\&As

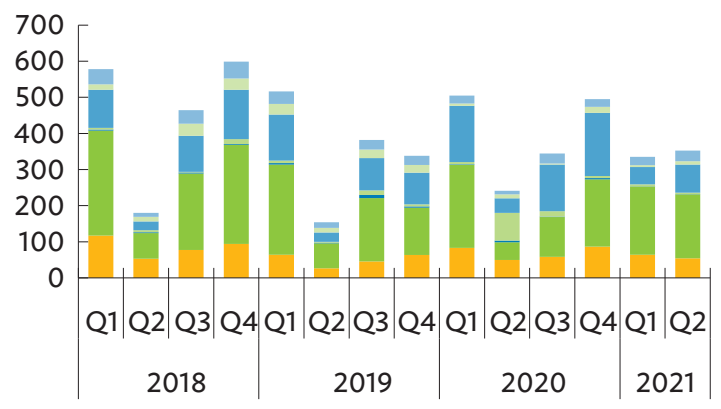

$\square$ Asia and the Pacific $\quad$ Africa $\quad$ North America $\quad$ Rest of the World $\square$ EU+UK $\square$ Middle East $\quad$ Latin America

$\mathrm{EU}=$ European Union (27 members), FDI = foreign direct investment, M\&A = merger and acquisition, $\mathrm{Q}=$ quarter, $\mathrm{UK}=\mathrm{United}$ Kingdom .

Sources: ADB calculations using data from Bureau van Dijk. Zephyr M\&A Database; and Financial Times. fDi Markets (both accessed September 2021). 


\section{Annex 3c: Most Affected Asian Destinations of Changes in $\mathrm{FDI}-$ Greenfield and M\&A, by Sector}

\begin{tabular}{|c|c|c|c|c|c|}
\hline \multicolumn{6}{|c|}{ Manufacturing } \\
\hline Destination & $\begin{array}{c}2020 \\
(\$ \text { billion })\end{array}$ & $\begin{array}{c}2019 \\
\text { (\$ billion) }\end{array}$ & $\begin{array}{l}\text { Change } \\
\text { ( } \$ \text { billion) }\end{array}$ & $\begin{array}{c}\text { Change } \\
\%(2019 \text { versus 2020) }\end{array}$ & $\begin{array}{l}\text { Share to Asia's } \\
\text { total increase in } \\
\text { FDI }(\%)\end{array}$ \\
\hline Japan & 35.7 & 8.5 & 27.2 & 319.8 & 412.8 \\
\hline Indonesia & 20.1 & 7.6 & 12.5 & 165.7 & 189.9 \\
\hline Singapore & 17.6 & 5.4 & 12.2 & 228.1 & 185.6 \\
\hline Republic of Korea & 3.8 & 2.4 & 1.4 & 58.9 & 21.2 \\
\hline Cambodia & 1.5 & 0.5 & 0.9 & 166.2 & 13.8 \\
\hline \multicolumn{6}{|c|}{ Primary } \\
\hline Destination & $\begin{array}{c}2020 \\
(\$ \text { billion })\end{array}$ & $\begin{array}{c}2019 \\
\text { (\$ billion) }\end{array}$ & $\begin{array}{l}\text { Change } \\
\text { ( } \$ \text { billion) }\end{array}$ & $\begin{array}{c}\text { Change } \\
\%(2019 \text { versus 2020) }\end{array}$ & $\begin{array}{l}\text { Share to Asia's } \\
\text { total decrease in } \\
\text { FDI }(\%)\end{array}$ \\
\hline Sri Lanka & 0.1 & 23.9 & -23.8 & -99.4 & 63.1 \\
\hline Viet Nam & 0.0 & 14.3 & -14.3 & -100.0 & 37.9 \\
\hline Bangladesh & 0.2 & 5.2 & -5.0 & -97.0 & 13.3 \\
\hline Philippines & 0.0 & 2.2 & -2.2 & -100.0 & 5.7 \\
\hline Republic of Korea & 0.0 & 2.0 & -1.9 & -97.5 & 5.2 \\
\hline \multicolumn{6}{|c|}{ Services } \\
\hline Destination & $\begin{array}{c}2020 \\
(\$ \text { billion })\end{array}$ & $\begin{array}{c}2019 \\
\text { (\$ billion) }\end{array}$ & $\begin{array}{l}\text { Change } \\
\text { (\$ billion) }\end{array}$ & $\begin{array}{c}\text { Change } \\
\%(2019 \text { versus 2020) }\end{array}$ & $\begin{array}{c}\text { Share to Asia's } \\
\text { total increase in } \\
\text { FDI }(\%)\end{array}$ \\
\hline India & 59.7 & 25.6 & 34.0 & 132.8 & 133.6 \\
\hline Hong Kong, China & 29.4 & 13.0 & 16.5 & 126.9 & 64.6 \\
\hline Japan & 11.7 & 3.8 & 8.0 & 212.7 & 31.3 \\
\hline Australia & 22.8 & 18.3 & 4.5 & 24.6 & 17.6 \\
\hline Malaysia & 3.6 & 2.6 & 0.9 & 35.8 & 3.7 \\
\hline
\end{tabular}

$\mathrm{FDI}=$ foreign direct investment, $M \& A=$ merger and acquisition.

Notes: For shares to Asia's total increase or decrease in FDI, some values may be greater than 100 as economy-level changes may be largely positive or largely negative. When summed, all the economy-level changes would equal Asia's overall change, and percentages would total $100 \%$.

Sources: ADB calculations using data from Bureau van Dijk. Zephyr M\&A Database; and Financial Times. fDi Markets (both accessed May 2021). 


\section{Annex 3d: Global Quarterly Outward FDI by Mode of Entry (\$ billion)}

(a) Greenfield FDI

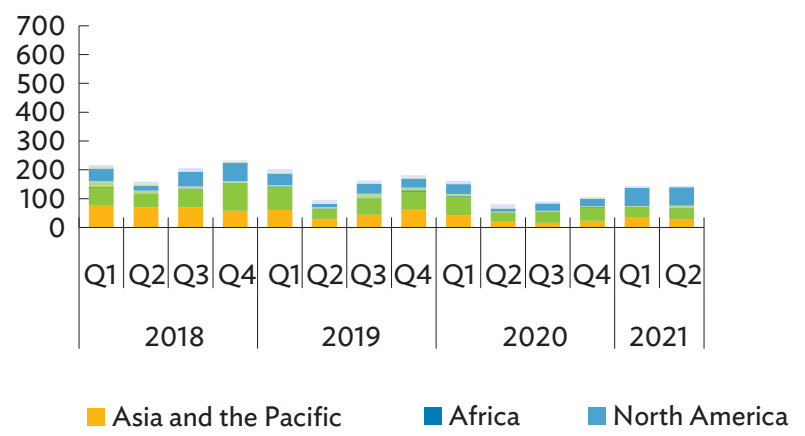

(b) M\&As

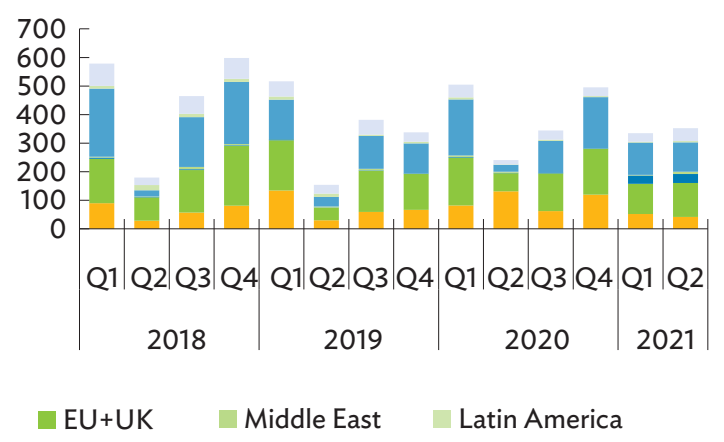

$\mathrm{EU}+\mathrm{UK}=$ European Union including the United Kingdom, $\mathrm{FDI}=$ foreign direct investment, $M \& A=$ merger and acquisition, $\mathrm{Q}=$ quarter.

Sources: ADB calculations using data from Bureau van Dijk. Zephyr M\&A Database; and Financial Times. fDi Markets (both accessed September 2021). 


\section{Annex 3e: List of OECD Services Sectors Identified as Digitally Deliverable}

\begin{tabular}{|c|c|c|}
\hline ISIC Rev. 4 & EBOPS 2010 & OECD FDI RRI Sectors \\
\hline \multirow[b]{2}{*}{ K: Financial and insurance activities } & SF: Insurance and pension services & Insurance \\
\hline & SG: Financial services & $\begin{array}{l}\text { Financial services } \\
\text { Banking }\end{array}$ \\
\hline $\mathrm{N}$ : Administrative and support service activities & $\begin{array}{l}\text { SH: Charges for the use of intellectual property, } \\
\text { not identified elsewhere }\end{array}$ & Data unavailable. \\
\hline J: Information and communication & $\begin{array}{l}\text { SISK1: Telecommunications, computer, } \\
\text { information, and audiovisual services }\end{array}$ & $\begin{array}{l}\text { Communications } \\
\text { Fixed telecommunications } \\
\text { Media } \\
\text { Mobile telecoms } \\
\text { Radio and television broadcasting } \\
\text { Other media }\end{array}$ \\
\hline $\begin{array}{l}\text { L, M, N: Real estate activities; Professional, } \\
\text { scientific, and technical activities; } \\
\text { Administrative and support service activities }\end{array}$ & $\begin{array}{l}\text { SJXSJ34: Other business services } \\
\text { (excluding trade-related) }\end{array}$ & $\begin{array}{l}\text { Accounting and audit } \\
\text { Legal } \\
\text { Architectural } \\
\text { Engineering } \\
\text { Business services }\end{array}$ \\
\hline $\begin{array}{l}\text { R: Arts, entertainment, and recreation } \\
\text { S: Other service activities }\end{array}$ & $\begin{array}{l}\text { SK2: Other personal, cultural, and recreational } \\
\text { services. }\end{array}$ & Data unavailable. \\
\hline
\end{tabular}

EBOPS $=$ Extended Balance of Payments Services, FDI = foreign direct investment, ISIC = International Standard Industrial Classification, OECD = Organisation for Economic Co-operation and Development, RRI = regulatory restrictiveness index.

Sources: Bureau van Dijk. Zephyr M\&A Database; Financial Times. fDi Markets (both accessed May 2021); Government of Canada, Statistics Canada. Industry classifications. https://www.statcan.gc.ca/en/concepts/industry; Government of the United States, United States Census Bureau. North American Industry Classification System. https://www.census.gov/naics/ (both accessed June 2021); OECD. FDI Regulatory Restrictiveness Index Data Set. https://stats.oecd.org/Index. aspx?datasetcode=FDIINDEX\# (accessed September 2021); and Wettstein et al. (2019). 


\section{Financial Integration}

Continued accommodative policy and stronger growth prospects due to vaccine rollout in Asia and the Pacific and elsewhere buoyed financial conditions in the first half of 2021, but financial uncertainties emerged in the latter part of the year.

Despite uncertainties about the coronavirus disease (COVID-19) pandemic, financial markets remained relatively calm in the first half $(\mathrm{H} 1)$ of 2021 , compared with 2020. Supportive fiscal and monetary policy measures and vaccination rollout lifted growth prospects and sustained favorable financial conditions in Asia and the Pacific and elsewhere. Global financial stress has trended downward since the second quarter (Q2) of 2020. And financial stress indexes in advanced and selected Asia and Pacific economies have declined since early 2021 as investor sentiment improved and accommodative policy measures remained. The financial stress indexes in the euro area, the United Kingdom, and the United States (US) and selected Asia and Pacific economies, including Hong Kong, China; India; Indonesia; Japan; the People's Republic of China (PRC); the Philippines; Singapore; and Thailand-showed no signs of stress in financial markets during March to July 2021 (Figure 4.1). Investor risk appetite also improved. The Chicago Board Options Exchange's volatility index (VIX), a measure of risk aversion, has likewise continued to trend downward, approaching its pre-pandemic level (Figure 4.2).

\section{Figure 4.1: Financial Stress Index}

(a) Euro Area, United Kingdom, and United States

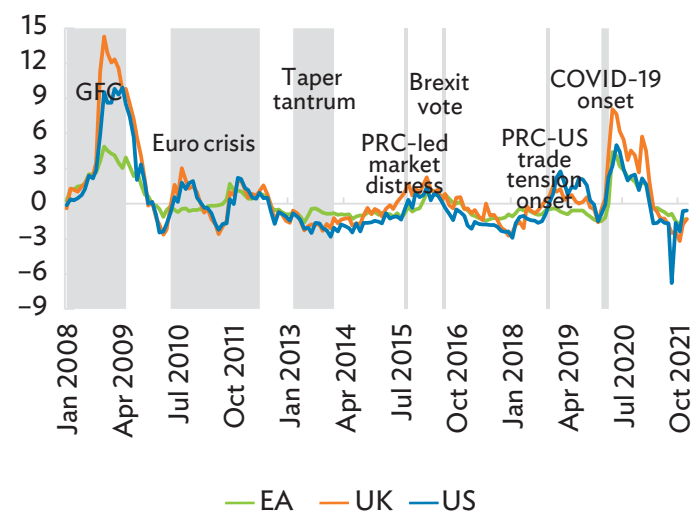

(b) Selected Asian Economies

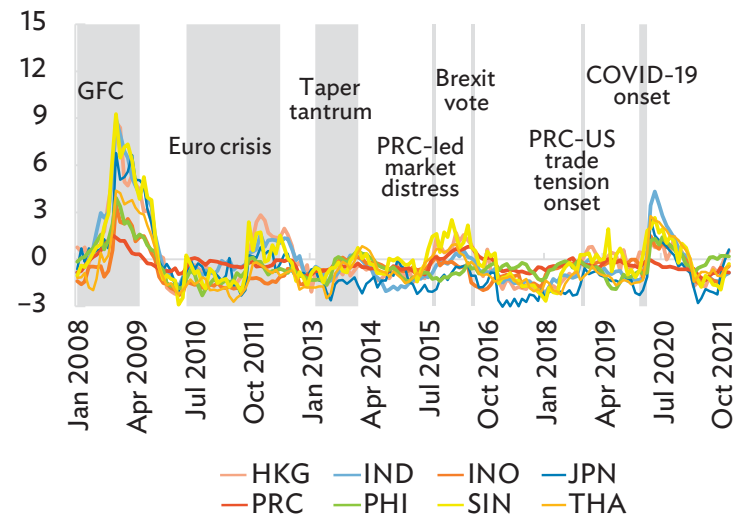

COVID-19 = coronavirus disease; EA = euro area; GFC = global financial crisis; HKG = Hong Kong, China; IND = India; INO = Indonesia; JPN = Japan; PHI = Philippines; PRC = People's Republic of China; SIN = Singapore; THA = Thailand; UK = United Kingdom; US = United States.

Notes:

(i) Based on principal components analysis on data from four major finance sectors: banking, debt, equity, and foreign exchange markets.

(ii) Principal components are based on the banking sector price index, sovereign yield spreads, stock market volatility, stock price index return, and exchange market pressure index.

Sources: ADB calculations using data from Bloomberg; CEIC Data Company; Haver Analytics; and International Monetary Fund. International Financial Statistics. http://data.imf.org/IFS (accessed October 2021); and methodology by Park and Mercado (2014). 
Figure 4.2: Volatility Index

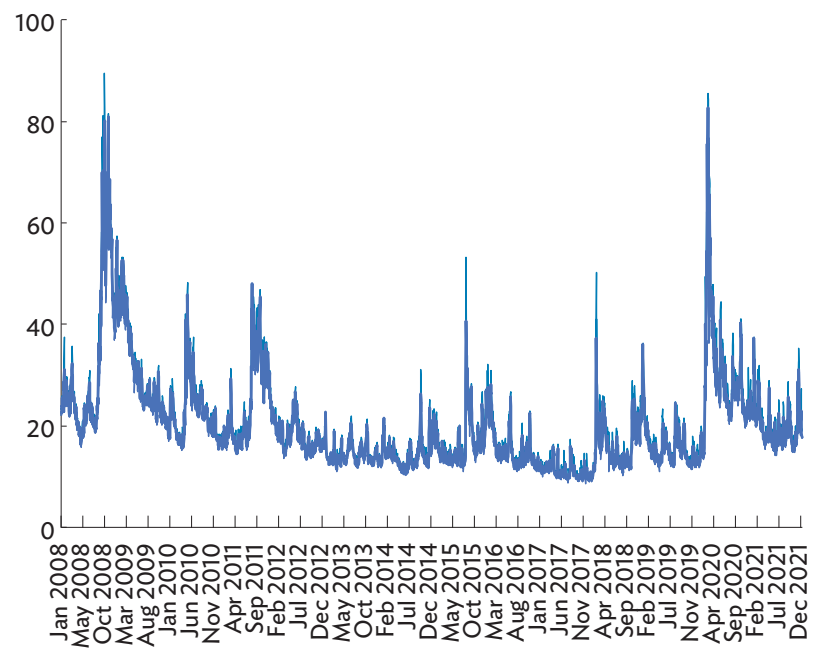

Notes: Volatility index (VIX) refers to the Chicago Board Options Exchange VIX Index's close value. High and low positions are plotted as confidence bands.

Source: Bloomberg.

Sovereign credit default swaps of selected Asian economies have also declined from peaks in March-May of 2020 (Figure 4.3). As of July 2021, sovereign credit default swaps have dropped below pre-pandemic levels for Japan and the Republic of Korea, and stayed above pre-pandemic levels for others. In addition, short-term US dollar funding markets have returned to pre-pandemic levels for most of 2021, along with offshore US dollar funding costs as measured by foreign currency basis swaps versus the US dollar (Figure 4.4). Consequently, these measures indicate favorable financial market conditions in the first 7 months of 2021.

However, financial uncertainties emerged in the second half of 2021. Strong growth in advanced economies, such as the US, and inflation concerns signaled earlier monetary policy normalization than in emerging and developing economies (Knightley and Garvey 2022). Such a scenario could lead to tighter liquidity conditions in emerging and developing economies, including those in Asia and the Pacific, and could result in lower capital inflows or capital flow reversals and further weakening of the region's currencies. In addition, the ongoing financial woes of Evergrande in the PRC property and housing sector adds to uncertainties over its domestic and cross-border financial spillovers. Consequently, the regional financial stress indexes, global risk aversion, sovereign credit default swaps, and offshore dollar funding costs trended upward beginning October 2021 (Figures 4.1, 4.2, 4.3, and 4.4).

Figure 4.3: Credit Default Swaps-Selected Asian Economies (2 January $2020=100$ )

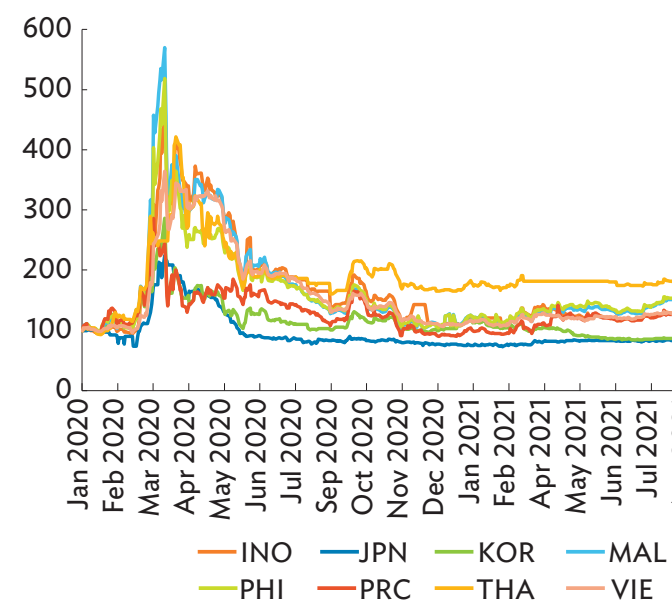

INO = Indonesia, JPN = Japan, $\mathrm{KOR}=$ Republic of Korea, $\mathrm{MAL}=$ Malaysia PRC $=$ People's Republic of China, $\mathrm{PHI}=$ Philippines, $\mathrm{THA}=$ Thailand, $\mathrm{VIE}=$ Viet Nam

Notes: A credit default swap is a financial derivative that insures against the risk of default by one party. A higher index value reflects a higher spread, which is associated with higher default risk.

Source: ADB calculations using data from Bloomberg.

Figure 4.4: Cross-Currency Basis Swap Against the United States Dollar (basis points)

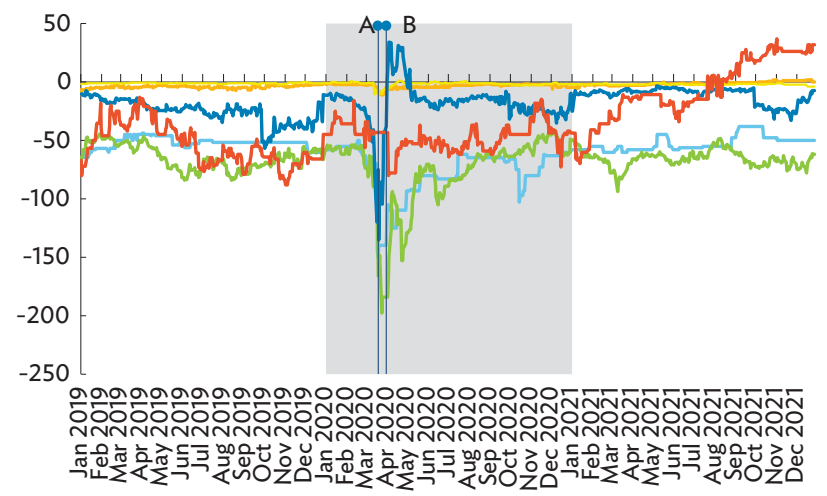

- baht - ringgit - Singapore dollar - won - yen - yuan

- - - A (19 March 2020): US Federal Reserve established nine temporary dollar liquidity swap lines

- - - B (30 March 2020): US Federal Reserve introduced temporary foreign and international monetary authorities repo facility

Note: 3-month cross-currency basis swap for the yen, ringgit, and yuan; 6 months for baht; and 3 months won versus 6 months US dollar.

Source: Bloomberg. 
Prices of financial assets in the region have diverged in 2021 but the region's total nonresident capital inflows remained robust, while its currencies weakened.

Stock prices in the region have recovered from their lowest point in 2020. However, equity prices have diverged across the region in 2021. Benchmark stock price indexes in Australia; India; Kazakhstan; Sri Lanka; Taipei,China;

Figure 4.5: Stock Price Index-Selected Asian Economies

(a) Index (2 January $2020=100$ )
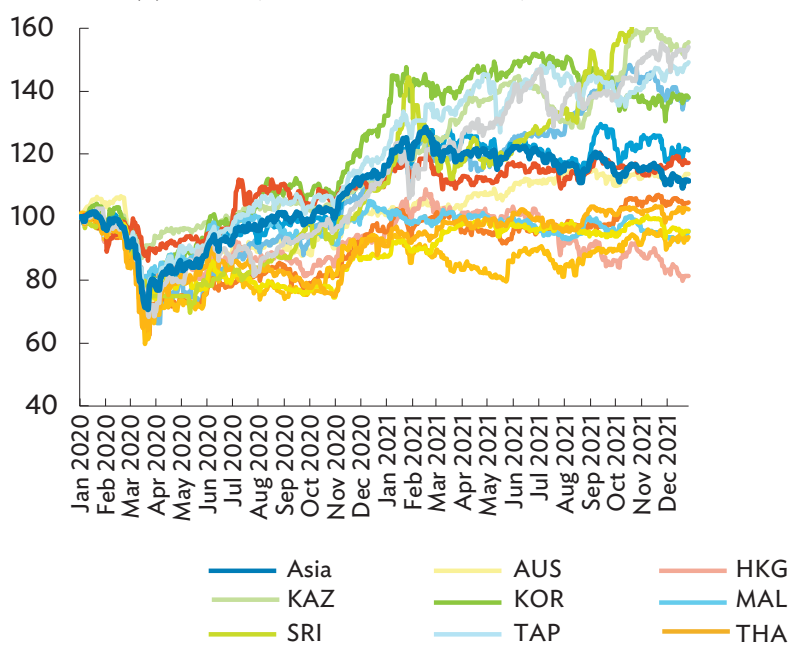

Thailand; and Viet Nam have grown by more than 10\% since the start of 2021 up to 10 December 2021. Those in Indonesia, Japan, the Philippines, the PRC, the Republic of Korea, and Singapore have grown less than $10 \%$; while share prices in Malaysia and Hong Kong, China have declined in value since the start of 2021 (Figure 4.5). The prices of sovereign bonds of selected Asia and Pacific economies also diverged in 2021, following their recovery in late 2020 from a slight drop in March 2020 (Figure 4.6).

(b) Year-to-Date Change (\%, as of 27 December 2021)

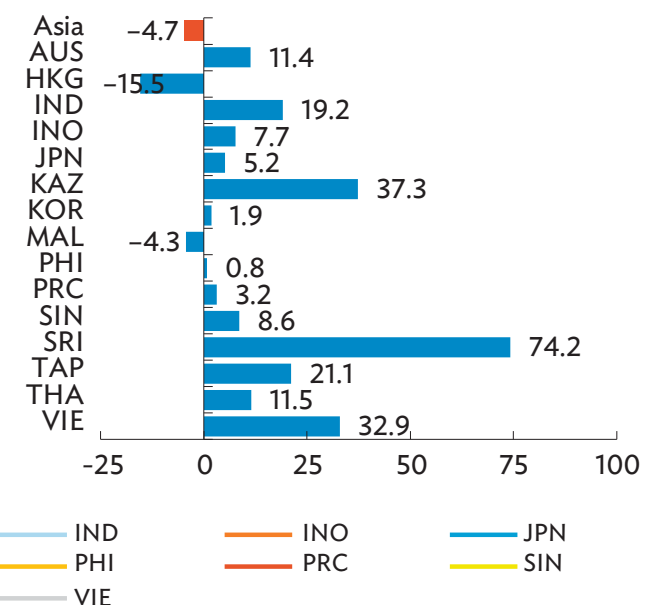

AUS = Australia; HKG = Hong Kong, China; IND = India; INO = Indonesia; JPN = Japan; KAZ = Kazakhstan; KOR = Republic of Korea; MAL = Malaysia; PHI = Philippines; PRC = People's Republic of China; SIN = Singapore; SRI = Sri Lanka; TAP = Taipei,China; THA = Thailand; and VIE = Viet Nam.

Note: Asia refers to the MSCI Asia Index.

Source: ADB calculations using data from Bloomberg.

Figure 4.6: Total Bond Return Index-Selected Asian Economies

(a) Index (2 January $2020=100)$

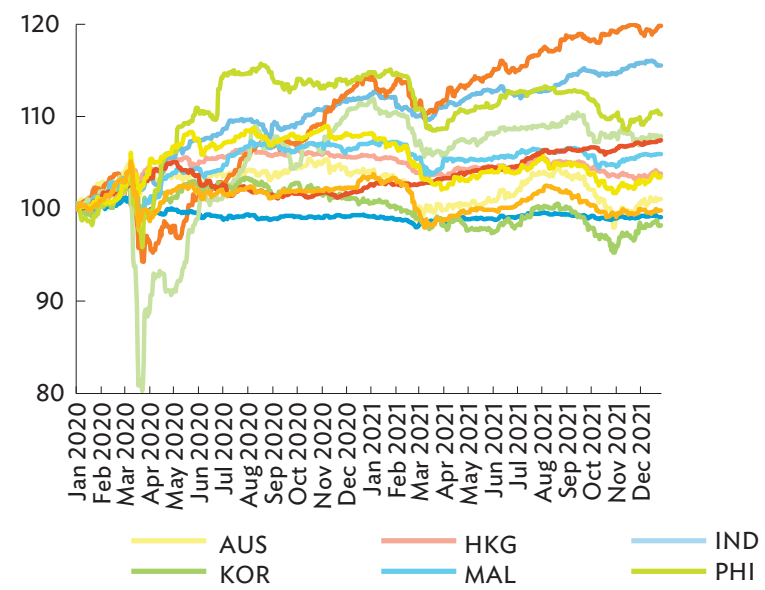

(b) Year-to-Date Change (\%, as of 27 December 2021)

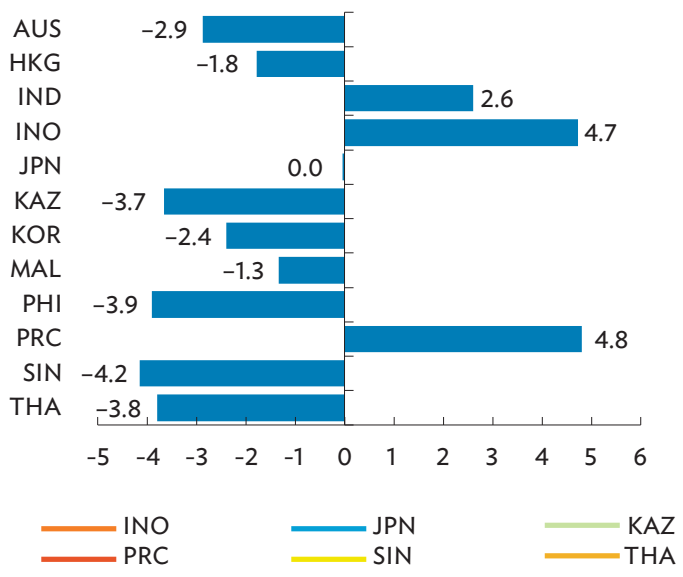

AUS = Australia; HKG = Hong Kong, China; IND = India; INO = Indonesia; JPN = Japan; KAZ = Kazakhstan; KOR = Republic of Korea; MAL = Malaysia; $P H I=$ Philippines; PRC = People's Republic of China; SIN = Singapore; SRI = Sri Lanka; and THA = Thailand .

Source: ADB calculations using data from Bloomberg. 
In particular, the values of sovereign bonds of Australia; Hong Kong, China; Kazakhstan; Malaysia; the Philippines; the Republic of Korea; Singapore; and Thailand slightly dipped in 2021, while those for India, Indonesia, Japan, and the PRC slightly increased, suggesting diverging bond price movements due to various economic factors associated with uneven economic recoveries, varying pace of vaccine rollout, and differences in policy support measures.

\section{Figure 4.7: Nonresident Capital Flows-Selected Asian Economies ( $\$$ billion)}

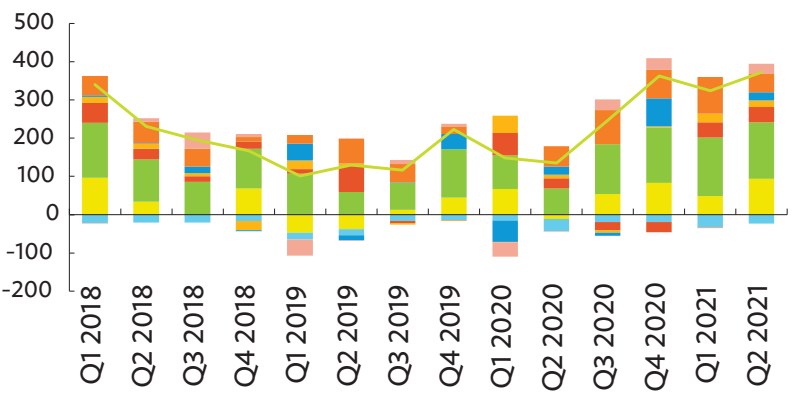

Currency and deposits FDI

Financial derivatives

Portfolio debt - Portfolio equity Other investments Trade credit and advances Loans_Nonresident capital flows

$\mathrm{FDI}=$ foreign direct investment, $\mathrm{Q}=$ quarter

Notes:

(i) Selected Asian economies include Bangladesh; Cambodia; Hong Kong, China; India; Indonesia; Kazakhstan; Mongolia; Nepal; the People's Republic of China; the Philippines; the Republic of Korea; Taipei,China; and Thailand.

(ii) Other investments category includes insurance, pension, and standardized guaranteed schemes; other accounts payable; other equity; and special drawing rights.

Source: ADB calculations using data from International Monetary Fund. Balance of Payments and International Investment Position Statistics. Accessed from CEIC Data Company.
The region's nonresident capital inflows continued to increase in 2021, reaching around $\$ 372$ billion for select Asia and Pacific economies in Q2 2021, a 175\% increase from Q2 2020 (Figure 4.7). Nonetheless, the volatility of nonresident capital inflows for select economies in the region increased slightly in $\mathrm{H} 12021$ compared with H1 2020. The sustained increase in nonresident capital inflows in 2021, follows the increase of capital inflows in 2020 to $\$ 1.6$ trillion from $\$ 1.2$ trillion in 2019, mainly due to increases in other accounts payable, currency and deposits, as well as debt inflows including portfolio debt and loans. In contrast, equity inflows including foreign direct investment (FDI) and portfolio equity decreased by $30 \%$ in 2020, compared with 2019. Moreover, the volatility of capital inflows inched higher in 2020 compared with 2019 as volatilities for loans and portfolio inflows have gone up.

Regional currencies have mostly weakened against the US dollar in 2021 on expectations of stronger recovery in the US compared with other economies and softening regional growth prospects in the second half of 2021 (Figure 4.8). Regional currencies have weakened against the US dollar on a year-to-date basis in 2021, with the Australian dollar, baht, Sri Lankan rupee, yen, and won dropping by more than 5\%; while the Hong Kong dollar, the Indian rupee, peso, ringgit, rupiah, Singapore dollar, som, and tenge have declined by less than $5 \%$ since the start of 2021.

\section{Figure 4.8: Exchange Rate, \$/LCU-Selected Asian Currencies}

(a) Index (2 January $2020=100)$

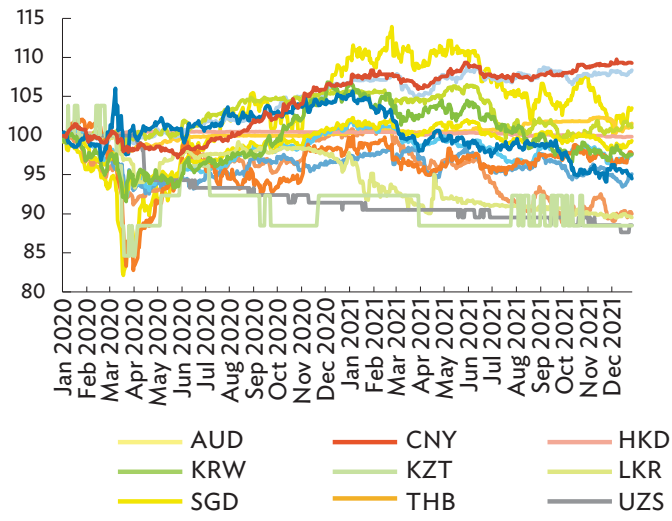

(b) Year-to-Date Change (\%, as of 27 December 2021)

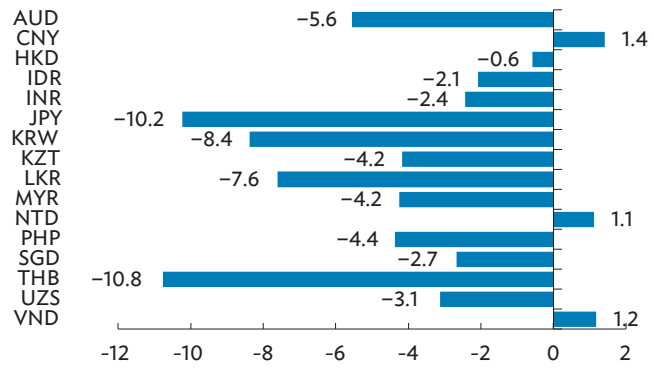

IDR
MYR
VND

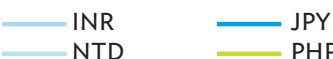

AUD = Australian dollar, CNY = yuan, HKD = Hong Kong dollar, IDR = rupiah, INR = Indian rupee, JPY = yen, KRW = won, $K Z T=$ tenge, LCU = local currency unit, $L K R=$ Sri Lanka rupee, $M Y R=$ ringgit, NTD = NT dollar, $P H P=$ peso, $S G D=$ Singapore dollar, $T H B=$ baht, UZS = som, VND = dong. 


\section{Monetary policy in the region was mostly accommodative in 2021 as economies weathered the uncertainties of the ongoing pandemic.}

Despite continuous efforts to curb the pandemic through containment measures and improved vaccine rollouts in 2021, Asia and Pacific economies and elsewhere continued to face uncertainties over the outcome of the pandemic as novel variants of the COVID-19 virus emerged, including the highly transmissible Delta and Omicron variants. To keep economies afloat and ease investor concerns, central banks in Asia kept policy rates low. With the exception of Taipei,China, policy rates in selected Asian economies in mid-2021 were mostly lower compared with March 2020. Taipei,China held its policy rate at $1.1 \%$ (Figure 4.9). But rising inflation concerns in the second half of 2021 prompted some regional central banks to raise policy rates. The Bank of Korea raised its policy rate from $0.5 \%$ to $0.75 \%$ in August 2021, then to $1.0 \%$ in November 2021, while the Central Bank of Sri Lanka raised its policy rate from $4.5 \%$ to $5.0 \%$ in the same period. The Reserve Bank of New Zealand also raised its policy rate to $0.5 \%$ in October 2021, after keeping it at 0.25\% since March 2020.

To further curb exchange rate pressures and volatility, and to keep supporting foreign exchange rate liquidity, the US Federal Reserve extended its temporary US dollar swap lines, established in March 2020, up to December 2021. ${ }^{29}$ In the region, some bilateral currency swap arrangements were renewed in 2021, notably, between those of the PRC and Thailand; Canada and the PRC; as well as between the Republic of Korea and Switzerland (Cantú et al. 2021).
Figure 4.9: Policy Rate-Selected Asian Economies (\%)

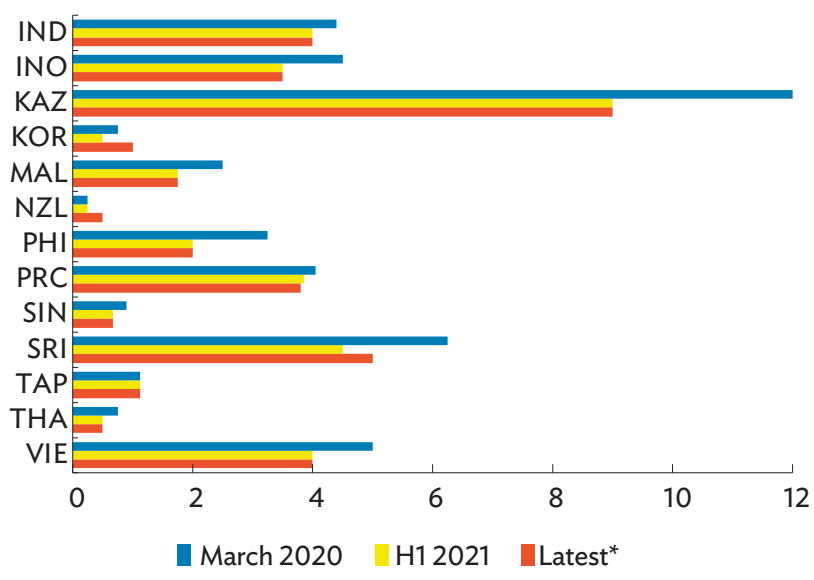

$\mathrm{H} 1$ = first half; IND = India; INO = Indonesia; $K A Z=$ Kazakhstan; $K O R=$ Republic of Korea; MAL = Malaysia; NZL = New Zealand; PHI = Philippines; PRC = People's Republic of China; SIN = Singapore; SRI = Sri Lanka; TAP = Taipei,China; THA = Thailand; VIE = Viet Nam .

*As of July 2021 for SIN; as of September 2021 for KAZ; as of October 2021 for NZL and THA; as of November 2021 for IND, INO, KOR, MAL, PHI, SRI, TAP, and VIE; and as of December 2021 for PRC.

Source: CEIC Data Company.

\section{The global nature of the ongoing COVID-19 pandemic was reflected in the increase in the share of global shocks in the variation of Asian financial asset price returns.}

The share of global shocks that explains the variation of equity returns in Asia increased from $19.8 \%$ at the onset of the COVID-19 pandemic in the first quarter of 2020 to around $20.4 \%$ during the pandemic from April 2020 to December 2021 (Figure 4.10). The share of regional shocks during the pandemic, likewise, grew from $7.2 \%$ at the onset of the pandemic to $9.2 \%$. Across subregions, South Asia's equity markets witnessed a large increase in sensitivity to global and regional shocks between both periods. In contrast, responsiveness to global and regional shocks dropped noticeably in the East Asia subregion. Meanwhile, the share of domestic shocks explaining the variation of equity returns dropped from $73.0 \%$ in the COVID-19 onset period to around $70.4 \%$

29 The temporary US dollar liquidity swap lines were extended up to 31 December 2021 (Board of Governors of the Federal Reserve System 2021a, 2021b). 
during the pandemic, suggesting the importance of global and regional shocks over domestic shocks during the pandemic period.

Figure 4.10: Variance Decomposition-Equity Returns

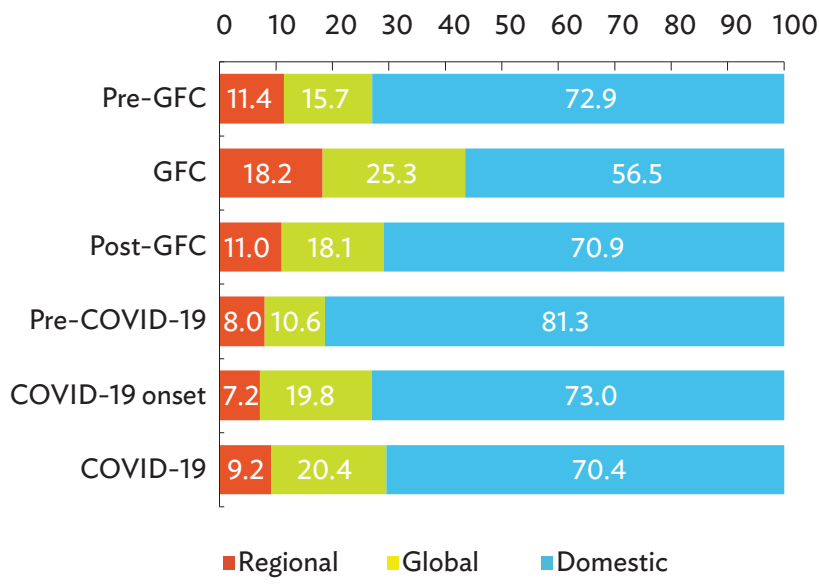

COVID-19 = coronavirus disease, $\mathrm{GFC}=$ global financial crisis.

Pre-GFC = January 1999 to September 2007, GFC = October 2007 to June 2009, Post-GFC = July 2009 to December 2015, Pre-COVID-19 = September to December 2019, COVID-19 onset = January to March 2020, COVID-19 = April 2020 to December 2021

Note: Asia and the Pacific includes Australia; Bangladesh; Cambodia; Georgia; Hong Kong, China; India; Indonesia; Japan; Kazakhstan; the Kyrgyz Republic; the Lao People's Democratic Republic; Malaysia; Mongolia; Nepal; New Zealand; Pakistan; the People's Republic of China; the Philippines; the Republic of Korea; Singapore; Sri Lanka; Taipei,China; Thailand; Uzbekistan; and Viet Nam.

Sources: ADB calculations using data from Bloomberg; CEIC Data Company; and methodology by Lee and Park (2011).

Similarly, the proportion of global shocks that explain the variation of bond returns increased to $14.7 \%$ during the COVID-19 period (April 2020-December 2021) from $10.8 \%$ at the onset of COVID-19 period. Similarly, the proportion of regional shocks that explain the variation of bond returns also increased from $7.7 \%$ during the COVID-19 onset to $7.9 \%$ during the COVID-19 period (Figure 4.11). Across subregions, the increase in the share of global shocks between the COVID-19 onset and pandemic periods was highest for Southeast Asia, while the decrease in the proportion of regional shocks was largest for India. Similar to equity returns, the share of domestic shocks explaining the variation of bond returns dropped from $81.4 \%$ in the COVID-19 onset period to around $77.3 \%$ during the pandemic period.
Figure 4.11: Variance Decomposition-Bond Returns

$$
\begin{array}{lllllllllll}
0 & 10 & 20 & 30 & 40 & 50 & 60 & 70 & 80 & 90 & 100
\end{array}
$$
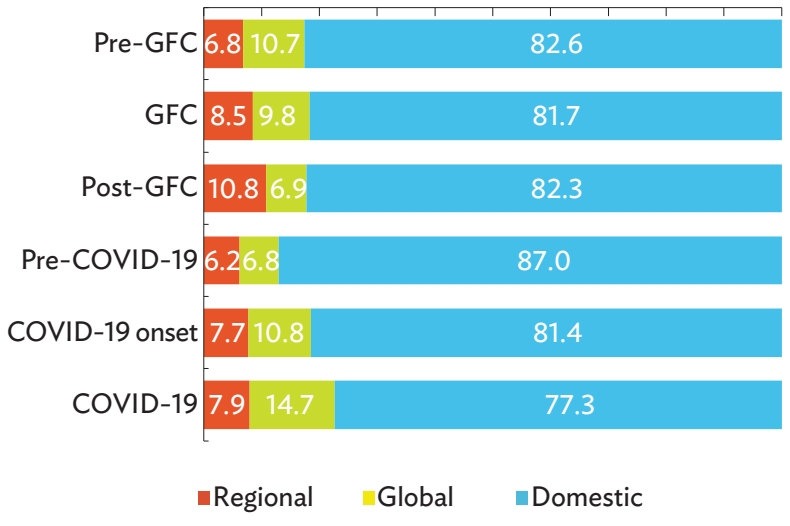

COVID-19 = coronavirus disease, $\mathrm{GFC}=$ global financial crisis.

Pre-GFC = January 2005 to September 2007, GFC = October 2007 to June 2009, Post-GFC = July 2009 to December 2015, Pre-COVID-19 = September to December 2019, COVID-19 onset = January to March 2020, COVID-19 = April 2020 to December 2021.

Note: Asia and the Pacific includes Australia; Hong Kong, China; India; Indonesia; Japan; Kazakhstan; Malaysia; the People's Republic of China; the Philippines; the Republic of Korea; Singapore; Thailand; and Viet Nam.

Sources: ADB calculations using data from Bloomberg; CEIC Data Company; and methodology by Lee and Park (2011).

Compared with the 2008-2009 global financial crisis, the share of external shocks that account for the variations in equity returns was considerably lower during the COVID-19 pandemic, while the share of domestic shock was higher (Figure 4.10). In contrast, the proportions of global and regional shocks that account for the variations in bond returns were higher in the ongoing COVID-19 pandemic, while the proportion of domestic shocks was smaller (Figure 4.11). These imply the varying sensitivity of financial asset price returns to external shocks across these two different episodes.

\section{While stable at the moment, Asia and the Pacific is not immune to risks of capital flow reversals, and financial vulnerabilities and uncertainties.}

Diverging economic growth paths, due to uneven vaccine rollout, as well as differences in policy support and containment measures, could lead some large 
and advanced economies, such as the US, to pursue policy normalization ahead of emerging and developing economies, including those in Asia and the Pacific. The expected economic recovery in the US-5.5\% for 2021 and 3.9\% by 2022-as projected by ADB's Asian Development Outlook Supplement (ADB 2021), along with rising inflation, partly due to commodity price increases and supply chain bottlenecks, could signal winding down of policy support measures while other emerging and developing economies are still addressing and containing the ongoing COVID-19 pandemic, given the spread of Omicron variant in the final months of 2021. Such a scenario may lead to tighter liquidity conditions in emerging and developing economies and could potentially result in lower capital inflows or capital flow reversals.

Economies with slower inoculation and higher infections of new COVID-19 variants may turn to renewed and/or continued containment measures. This will slow economic recovery momentum by limiting economic reopening, resulting in weaker economic growth. Such weak recovery coupled with higher corporate debt levels may result in debt servicing difficulties. As governments and corporations borrowed to weather the pandemic, economies in the region reported increases in corporate debt ratios, between 2019 and the third quarter of 2021 (Figure 4.12). For example, the changes in the corporate debt ratios of Hong Kong, China; Japan; and the Republic of Korea were greater than $20 \%$ of gross domestic product (GDP); while the increase in government debt ratios for the Philippines and Singapore were above 20\% of GDP. Increasing interest rates, coupled with high debt levels, may lead to higher borrowing costs; and will make debt with variable interest rates more costly. Should that happen, debtors may face debt payment difficulties, particularly when growth remains fragile, and could result in higher debt premiums and lower credit ratings.

As economies in the region rely heavily on bank credit for corporate financing, this adds more reason to be concerned with looming rising interest rates (Figure 4.13). Should corporations be unable to make their debt payments on time, banks' debt quality could erode. As it is, some economies in the region have already experienced increased banking sector nonperforming loan (NPL) ratio in 2020 (Figure 4.14).
Figure 4.12: Change in Sectoral Debt Ratio, 2019 versus Q3 2021-Selected Asian Economies (\% of GDP)

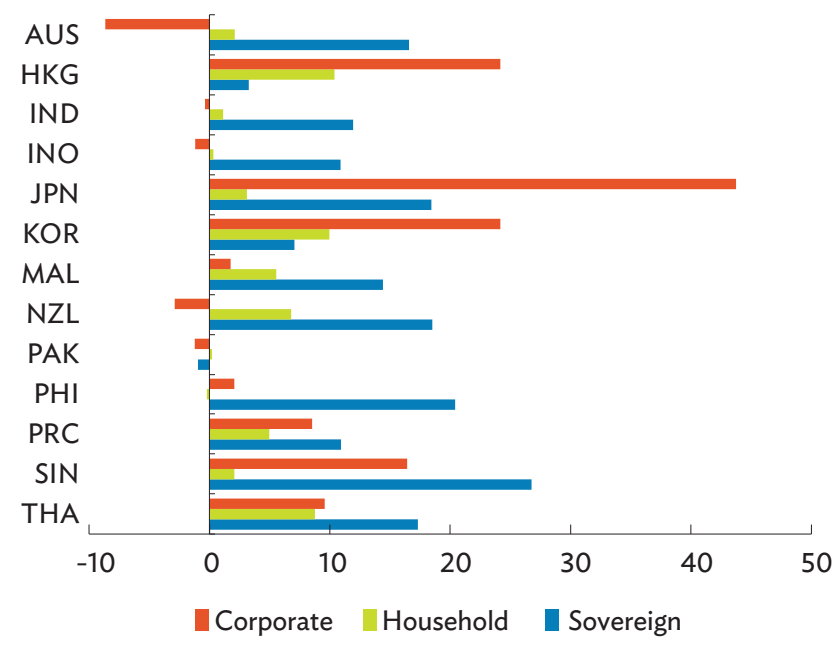

AUS = Australia; GDP = gross domestic product; HKG = Hong Kong, China; IND = India; INO = Indonesia; JPN = Japan, KOR = Republic of Korea; NZL = New Zealand; PAK = Pakistan; PHI = Philippines; PRC = People's Republic of China; Q3 = third quarter, SIN = Singapore; and THA = Thailand.

Source: ADB calculations using data from Institute of International Finance. Global Debt Monitor November 2021. https://www.iif.com/Research/CapitalFlows-and-Debt/Global-Debt-Monitor (accessed December 2021).

\section{Figure 4.13: Corporate Financing-Emerging Asia} (\% of GDP)

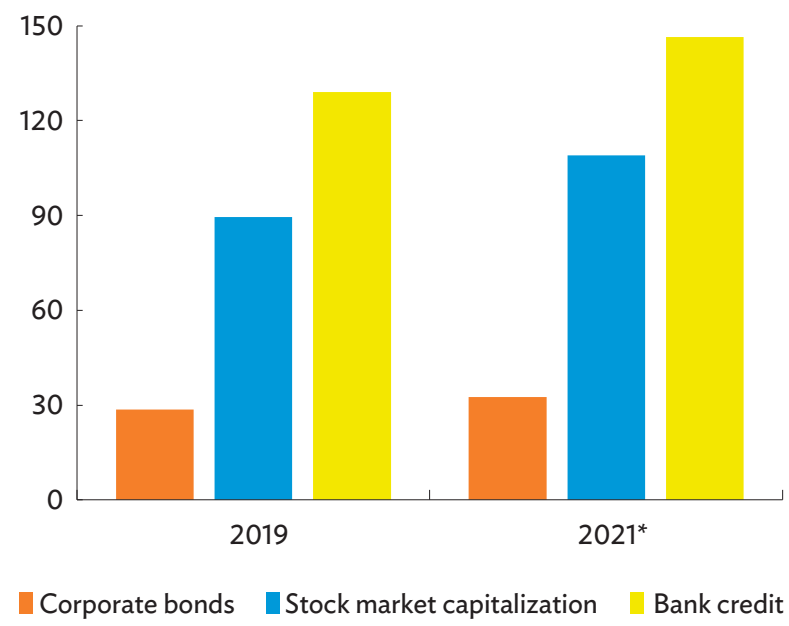

GDP = gross domestic product.

*As of second quarter of 2021 for bank credit, and as of third quarter of 2021 for corporate bonds and stock market capitalization.

Note: Emerging Asia includes Hong Kong, China; India; Indonesia; Malaysia; the People's Republic of China; the Philippines; the Republic of Korea; Singapore; and Thailand.

Sources: ADB calculations using data from ADB. AsianBondsOnline. https://asianbondsonline.adb.org (accessed December 2021); and CEIC Data Company. 
Figure 4.14: Bank NPL Ratio-Selected Asian Economies (\% of total loans)

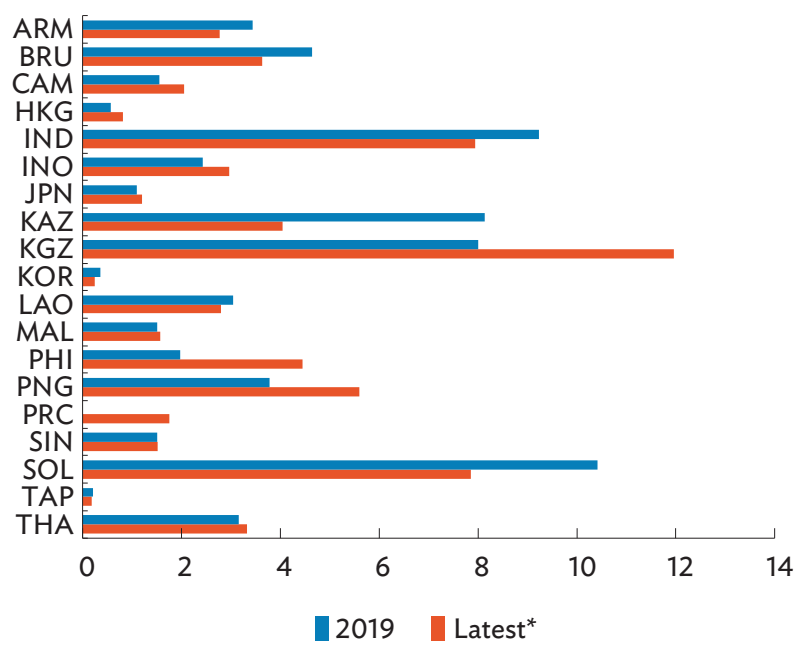

$\mathrm{ARM}=$ Armenia; $\mathrm{BRU}=$ Brunei Darussalam; $\mathrm{CAM}=$ Cambodia $; \mathrm{HKG}=$ Hong Kong, China; IND = India; INO = Indonesia; JPN = Japan; KAZ = Kazakhstan; KGZ = Kyrgyz Republic; KOR = Republic of Korea; LAO = Lao People's Democratic Republic; MAL = Malaysia; NPL = nonperforming loan; PHI = Philippines; PNG = Papua New Guinea; PRC = People's Republic of China; SIN = Singapore; SOL = Solomon Islands; TAP = Taipei,China; THA = Thailand

* = As of December 2020 for IND; as of March 2021 for JPN and SOL; as of June 2021 for PHI, PRC, and SIN; as of September 2021 for BRU, CAM, HKG, INO, LAO MAL, PNG, and THA; and as of October 2021 for ARM, KAZ, KOR, KGZ, and TAP. Sources: ADB calculations using data from CEIC Data Company.

For instance, Papua New Guinea's NPL ratio increased from $3.8 \%$ in 2019 to $5.9 \%$ in June 2021 ; that of the Philippines increased from $2.0 \%$ in 2019 to $4.4 \%$ in June 2021; and the Kyrgyz Republic's NPL ratio increased from $7.7 \%$ in 2019 to $11.8 \%$ in October 2021. Uncertain recovery, higher interest rates, and rising NPL ratios may prompt banks to be more cautious in lending, which could undermine prospects of stronger recovery.

The Asia and Pacific region also faced potential cross-border financial risk spillovers emanating from Evergrande's debt woes and its impact on the PRC's property sector and the broader economy in the second half of 2021. The Evergrande group, with debts exceeding $\$ 300$ billion, is the PRC's most indebted property developer. In Q4 2021, the company delayed its offshore bond payments amounting to $\$ 83.5$ million, indicating its difficulties in repaying its debt obligations (Wilkins et al. 2021); its share price lost about $90 \%$ of its value and its market capitalization $89 \%$ of its value from early January 2021 to the end of 2021. Several property developers in the PRC, including China Properties Group, Fantasia Holdings Group, and Sinic Holdings Group also faced debt repayment difficulties in the latter part of 2021 (Nikkei Asia 2021, The Straits Times 2021). Rating agencies, including Moody's and Fitch, downgraded the credit ratings of several PRC property bond issuers (Toh 2021). As Evergrande and other property developers delayed their debt payments, concerns grew over their impact on the PRC's property sector, which accounts for almost $30 \%$ of its economy. Share prices of property developers plunged and the PRC's junk bond yields peaked in November 2021 (Figures 4.15 and 4.16).

\section{Figure 4.15: Share Prices of Selected Property Developers} in the PRC (1 January $2021=100)$

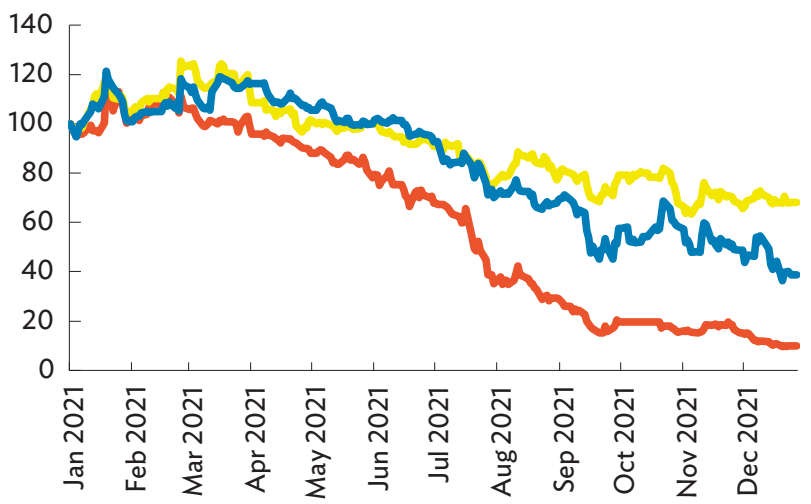

- China Evergrande Group - China Vanke Country Garden Holdings - Sunac China Holdings

PRC = People's Republic of China.

Source: ADB calculations using data from Bloomberg.

Figure 4.16: Yield of the PRC's Junk Bonds (\%)

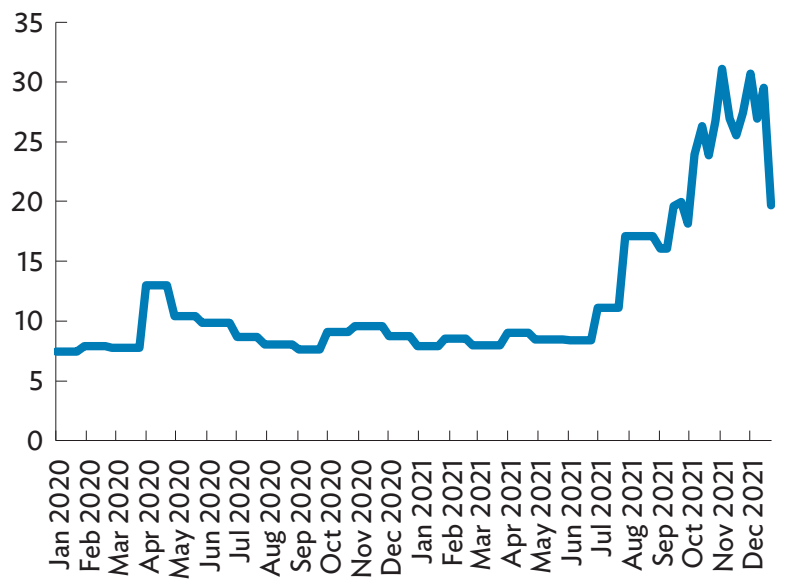

PRC = People's Republic of China.

Source: Bloomberg. 
Although the PRC's property sector debt problems remained contained within the sector as of final quarter of 2021, risks of wider impact on the economy and potential cross-border spillovers persisted (Magnus 2021, Tan 2021).

To mitigate potential risks in the finance sector, economies in the region need to continue to strengthen economic fundamentals. Speeding and scaling up the inoculation drive to contain the spread and emergence of new COVID-19 variants remains paramount in supporting economic recovery and reopening economies, particularly for emerging and developing economies. Sustained and stable growth momentum will help ease risks of rising corporate and government debt levels. Policy support must also be calibrated depending on domestic financial conditions and circumstances and the viability of recipients. Addressing rising NPLs will help improve debt quality and bank balance sheets.

\section{Recent Trends in Asia's Cross-Border Financial Assets and Liabilities}

\section{In 2020, Asian investors continued to invest more outside the region than inside. ${ }^{30}$}

\begin{abstract}
Asia's total cross-border financial asset holdings reached $\$ 25.4$ trillion in 2020 , up significantly from $\$ 16.3$ trillion at the end of 2016 (Figure 4.17). ${ }^{31}$ Most of the region's investment holdings in 2020 were FDI assets ( $\$ 9.2$ trillion), followed by portfolio equity ( $\$ 6.5$ trillion), portfolio debt ( $\$ 5.5$ trillion), and banking sector loan and deposit holdings ( $\$ 4.2$ trillion). Around two-thirds of Asia's asset holdings were placed in non-regional economies, and only one-third in regional economies. This proportion was roughly unchanged between 2016 and 2020, despite Asia's growing share of world output. Nonetheless, this proportion suggests the region's diversified investment position. Of Asia's intraregional
\end{abstract}

\section{Figure 4.17: Cross-Border Assets-Asia and the Pacific}

\section{(a) 2016}

\begin{tabular}{l|r|}
$\begin{array}{l}\text { Bank: } \\
\$ 3.5 \text { trillion } \\
(21.3 \%)\end{array}$ & $\begin{array}{r}\text { Portfolio debt: } \\
\$ 4.1 \text { trillion } \\
(25.1 \%)\end{array}$ \\
$\begin{array}{l}\text { Asia's intraregional } \\
\text { share: } 40.3 \%\end{array}$ & $\begin{array}{r}\text { Asia's intraregional } \\
\text { share: } 15.7 \%\end{array}$ \\
& $\begin{array}{r}\$ 16.3 \\
\text { trillion }\end{array}$ \\
\hline $\begin{array}{l}\text { FDI: } \\
(30.6 \%)\end{array}$ & Portfolio equity: \\
\$3.7 trillion & (23.1\%) \\
share: $49.0 \%$ & Asia's intraregional \\
& share: $20.2 \%$
\end{tabular}

\section{(b) 2020}

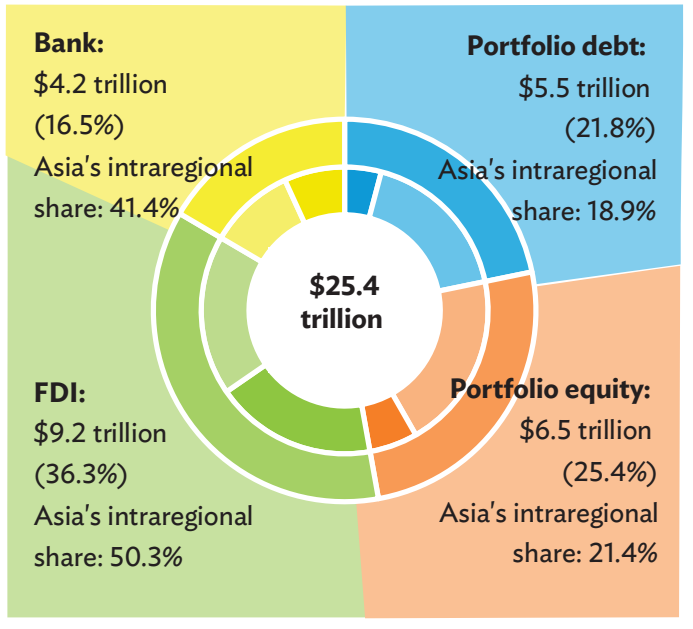

FDI = foreign direct investment.

Notes: FDI assets refer to outward FDI holdings. Bank assets (claims) are limited to loans and deposits. Values may not add up due to rounding off.

Sources: ADB calculations using data from the Bank for International Settlements. Locational Banking Statistics. https://www.bis.org/statistics/bankstats.htm; International Monetary Fund (IMF). Coordinated Direct Investment Survey. https://data.imf.org/cdis (both accessed December 2021); and IMF. Coordinated Portfolio Investment Survey. https://data.imf.org/cpis (accessed September 2021).

30 The Asia and Pacific reporting economies include Australia; Bangladesh; the People's Republic of China; Hong Kong, China; India; Indonesia; Japan; Kazakhstan; Malaysia; Mongolia; New Zealand; Pakistan; Palau; the Philippines; the Republic of Korea; Singapore; and Thailand.

31 The values reported for total cross-border assets, liabilities, and net position do not reflect total values in the International Investment Position. This is because reported values include only those with available bilateral breakdown to decompose regional and non-regional holdings and liabilities. Refer to Box 4.1 for discussion on the uses of the International Investment Position data set. Throughout this chapter, cross-border investment holdings include banking sector loan and deposit assets (claims) and liabilities, FDI, portfolio debt, and portfolio equity. 
holdings, much of its portfolio assets in 2020 were East Asian assets (68.7\%). East Asia and Southeast Asia mostly held East Asian portfolio assets in 2020, at 67.1\%, and $24.9 \%$, respectively, suggesting the attractiveness of East Asian portfolio debt and equity assets.

Asia's portfolio debt holdings increased from $\$ 5.0$ trillion in 2019 to $\$ 5.5$ trillion in 2020, reporting a 11.1\% increase and continuing a rising trend over the past 6 years. ${ }^{32}$ Asian investors' portfolio equity holdings increased $19.4 \%$ from $\$ 5.4$ trillion in 2019 to $\$ 6.4$ trillion in 2020 . Asia's crossborder loan and deposit claims, meanwhile, continued to rise in 2020 , to $\$ 4.2$ trillion from $\$ 3.9$ trillion in 2019 . For cross-border banking flows, loan and deposit asset flows decreased from $\$ 79.9$ billion in 2019 to $\$ 51.4$ billion in 2020, much of the decrease was attributable to the decline in banking flows to the rest of the world (Figure 4.18a).

The region's total external financial liabilities also inched higher, to $\$ 25.4$ trillion in 2020 , up from $\$ 18.0$ trillion in 2016 (Figure 4.19). Much of the region's liabilities were FDI ( $\$ 10.1$ trillion), followed by portfolio equity ( $\$ 6.8$ trillion), banking sector loan and deposit liabilities (\$4.9 trillion), then portfolio debt ( $\$ 3.7$ trillion). As in previous years, around two-thirds of the region's external investment liabilities were held by non-regional economies, and one-third by regional economies. Inward debt portfolio investment increased $16.4 \%$ to $\$ 3.7$ trillion in 2020 from $\$ 3.2$ trillion in 2019, while the value of inward equity portfolio investment rose $21.1 \%$ to $\$ 6.8$ trillion in 2020 from $\$ 5.6$ trillion in 2019 . The intraregional share of inward portfolio debt edged down from $28.6 \%$ in 2019 to $28.5 \%$ in 2020; the intraregional share of inward portfolio equity increased from $19.1 \%$ to $20.3 \%$ in the same period. Asia's cross-border loan and deposit liabilities increased in 2020 to $\$ 4.9$ trillion from $\$ 4.6$ trillion in 2019 .

For cross-border banking flows, Asia's loan and deposit inflows reversed from $\$ 28.7$ billion in 2019 to -\$32.6 billion in 2020 as the region's loan and deposit liabilities with the rest of world registered a large reversal, amounting to $\$ 90.1$ billion, while liabilities with Asia increased from $\$ 23.1$ billion in 2019 to $\$ 24.9$ billion in 2020 (Figure 4.18b).

Figure 4.18: Cross-Border Loan and Deposit Flows-Asia and the Pacific (\$ billion)

(a) Bank Claims

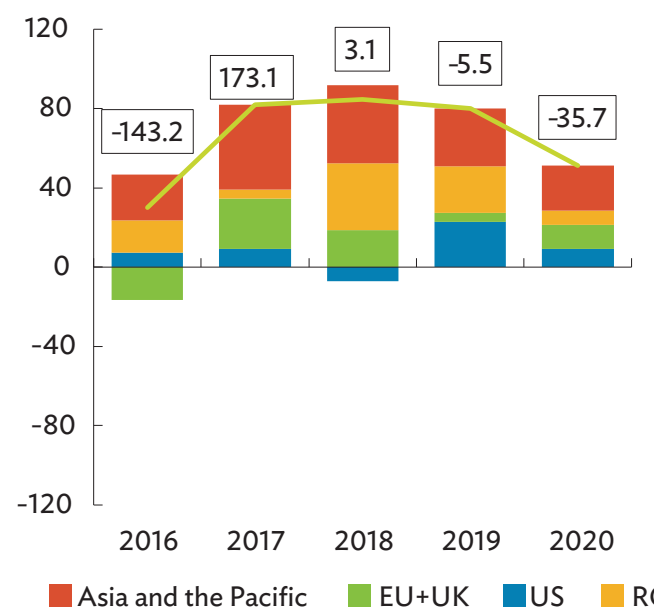

(b) Bank Liabilities

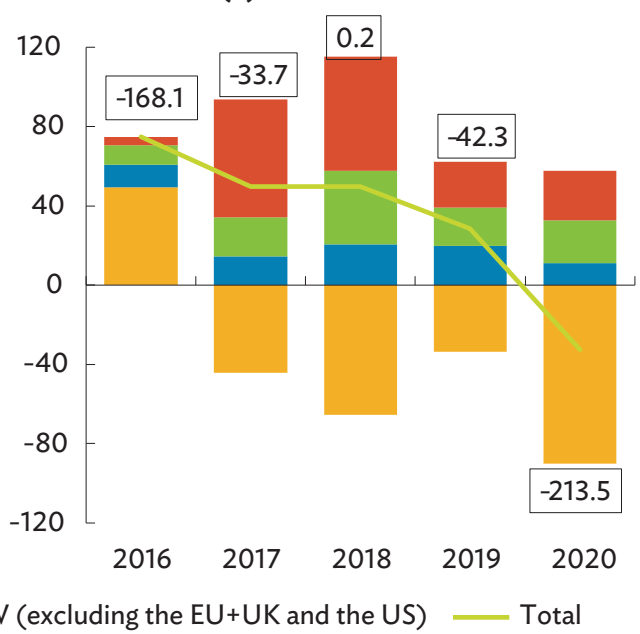

EU = European Union (27 members), ROW = rest of the world, UK = United Kingdom, US = United States.

Note: Labels refer to year-on-year percentage change.

Source: ADB calculations using data from the Bank for International Settlements. Locational Banking Statistics. https://www.bis.org/statistics/bankstats.htm (accessed December 2021).

32 The overall increase or decrease in stock portfolio holdings and liabilities is attributed to changes in flows and valuation changes of existing portfolio assets and liabilities. 
Figure 4.19: Cross-Border Liabilities-Asia and the Pacific

(a) 2016

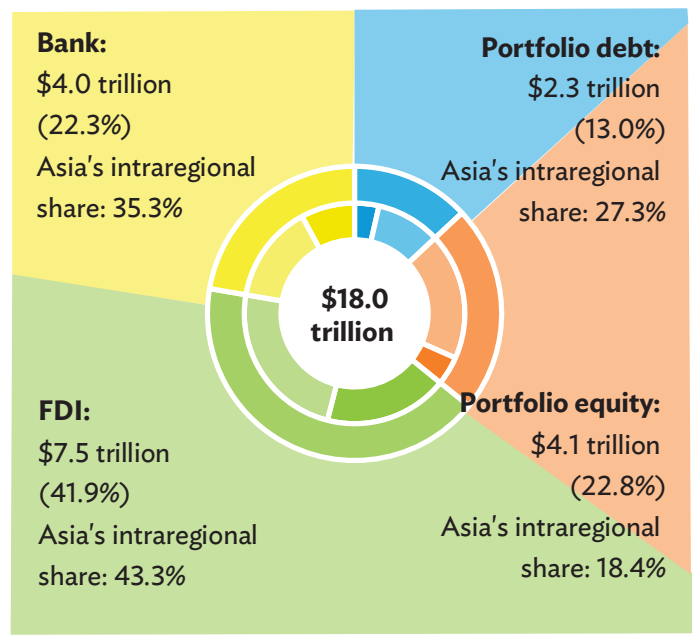

FDI = foreign direct investment

Notes: FDI liabilities refer to inward FDI holdings. Bank liabilities are limited to loans and deposits. Values may not add up due to rounding off.

Sources: ADB calculations using data from Bank for International Settlements. Locational Banking Statistics. https://www.bis.org/statistics/bankstats.htm; International Monetary Fund (IMF). Coordinated Direct Investment Survey. https://data.imf.org/cdis (both accessed December 2021); and IMF. Coordinated Portfolio Investment Survey. https://data.imf.org/cpis (accessed September 2021).

As the region held more debt assets than debt liabilities, but more equity liabilities than equity assets, it retained its long debt, short equity position as of the end of 2020. The net debt positions in 2016 and 2020 were the same, at $\$ 1.2$ trillion, while the net equity position improved from $-\$ 2.9$ trillion in 2016 to $-\$ 1.2$ trillion in 2020. As of the end of 2020, the largest share of its long debt and short equity positions were with non-regional economies, mirroring the regional breakdown of its international investment assets and liabilities.

\section{The currency compositions of Asia's international investment assets and liabilities indicate the dominance of the US dollar. ${ }^{33}$}

Almost half of Asia's international asset holdings were denominated in US dollars as of the end of 2020 , followed by other currencies, at $17 \%$ and then euros, at $11 \%$. In contrast, around $64 \%$ of the region's external liabilities were dominated in local currencies, followed by US dollars, at 25\% (Figure 4.20). Across types of international investments, equity-type assets, which include FDI and portfolio equity, were mostly denominated in other currencies, as it is assumed that the currency composition of these investments closely tracks geographic positions. Equity-type liabilities were denominated in local currency as FDI and portfolio equity ownerships were mostly denominated in the host economy's currency. The currency compositions of debt-type international investments indicated the dominance of the US dollar. For debt assets, which include portfolio debt, other investments, and official reserves, about $63 \%$ were denominated in the US dollar, followed by the euro (13\%), and other currencies (9\%). In contrast, half of debt liabilities, including portfolio debt and other investments, were denominated in US dollars, followed by local currency (28\%), and other currencies (10\%) (Figure 4.21). The dollar dominance in Asia's cross-border investment holdings can lead to several risks, including US monetary policy spillovers and their impact on global liquidity and the balance sheet and welfare effects of large exchange rate fluctuations between the US dollar and local currency.

33 This analysis uses the estimated Bénétrix et al. (2019) data set on currency composition weights for 2017 and applied those weights to the 2020 values of the International Investment Position, which reports the total external assets and liabilities across all types of instruments, for selected Asia and Pacific economies. 
Figure 4.20: Currency Composition of Asia's International Total Investments, 2020 (\%)

(a) Total Assets

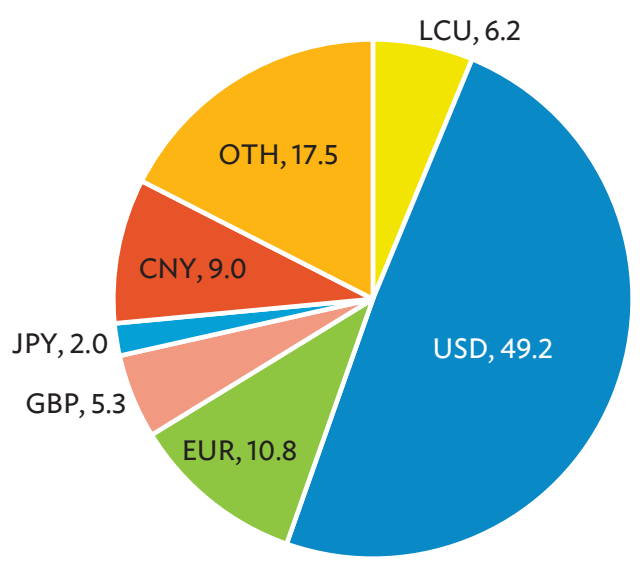

(b) Total Liabilities

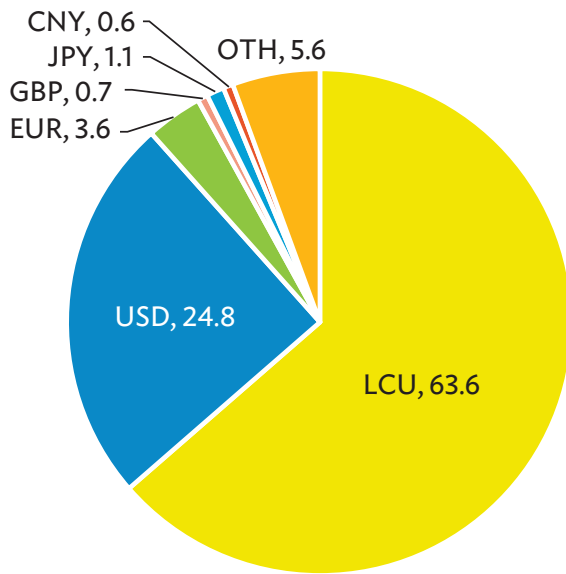

$\mathrm{CNY}=$ yuan, $\mathrm{EUR}=$ euro, $\mathrm{GBP}=$ pound, $\mathrm{JPY}=$ yen, $\mathrm{LCU}=$ local currency unit, $\mathrm{OTH}=$ other currencies, $U S D=$ United States dollar.

Notes:

(i) CNY and JPY are classified as LCU for the People's Republic of China and Japan, respectively.

(ii) Values were estimated using currency weights for 2017 based on latest available data set from Benetrix et al. (2019) and International Investment Positions for 2020 . The values shown are in percentages of total.

(iii) OTH shares were derived as residual values.

(iv) Asia and the Pacific includes Australia; Hong Kong, China; India; Indonesia; Japan; Malaysia; New Zealand; Pakistan; the People's Republic of China; the Philippines; the Republic of Korea; Singapore; Sri Lanka; and Thailand.

Source: ADB calculations using data from International Monetary Fund. Balance of Payments and International Investment Position Statistics. http://data.imf.org/IIP (accessed September 2021); and Benetrix et al. (2019).

Figure 4.21: Currency Composition of Asia's International Debt Investments, 2020 (\%)

(a) Debt Assets

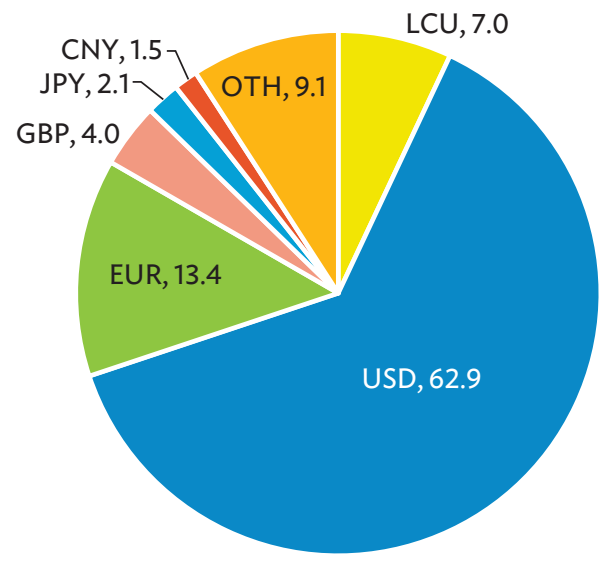

(b) Debt Liabilities

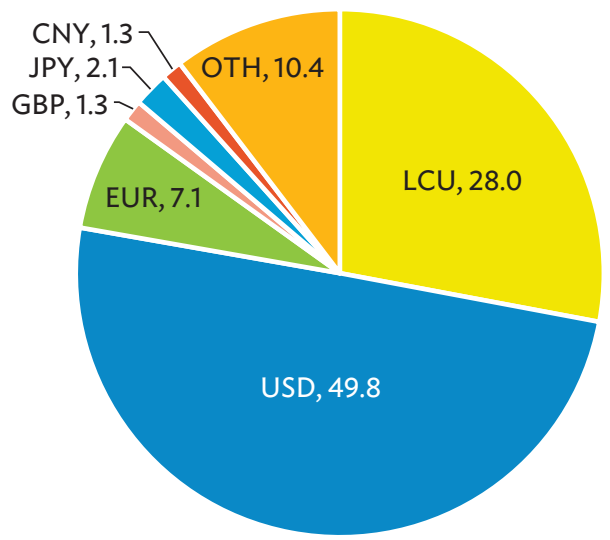

$\mathrm{CNY}=$ yuan, $\mathrm{EUR}=$ euro, $\mathrm{GBP}=$ pound, $\mathrm{JPY}=$ yen, $\mathrm{LCU}=$ local currency unit, $\mathrm{OTH}=$ other currencies, $\mathrm{USD}=$ United States dollar.

Notes:

(i) CNY and JPY are classified as LCU for the People's Republic of China and Japan, respectively.

(ii) Values were estimated using currency weights for 2017 based on latest available data set from Benetrix et al. (2019) and International Investment Positions for 2020. The values shown are in percentages of total.

(iii) OTH shares were derived as residual values.

(iv) Asia and the Pacific includes Australia; Hong Kong, China; India; Indonesia; Japan; Malaysia; New Zealand; Pakistan; the People's Republic of China; the Philippines; the Republic of Korea; Singapore; Sri Lanka; and Thailand.

Source: ADB calculations using data from International Monetary Fund. Balance of Payments and International Investment Position Statistics. http://data.imf.org/IIP (accessed September 2021); and Benetrix et al. (2019) 


\section{Evolving Patterns of Capital Flows in Asia and the Pacific}

An earlier monetary policy normalization in large and advanced economies, such as the US, has raised concerns about the impacts on emerging and developing economies. Specifically, higher interest rates in advanced economies are often associated with capital inflow decreases or reversals in emerging and developing economies (Bryne and Fiess 2016; Ghosh et al. 2014; Giordani et al. 2017; Li, de Haan, and Scholtens 2018; and Mercado 2018a). As the divergence of economic recovery becomes more apparent in 2021, assessing the evolution of nonresident capital flows is warranted to better understand the likely impacts of large capital flow reversals, in the light of uncertain pandemic outcomes. This subsection discusses the patterns of nonresident capital flows over the past 2 decades for Asia and the Pacific. It also considers policy tools used to address the adverse effects of volatile capital flows.

\section{Nonresident capital inflows in Asia and the Pacific have doubled in the last decade, with notable changes in the composition and patterns of capital flows.}

Total gross capital inflows in Asia and the Pacific roughly doubled over the last 2 decades, from average annual inflows of around $\$ 0.7$ trillion in 2001-2010 to over $\$ 1.4$ trillion in 2011-2020 (Figure 4.22). ${ }^{34}$ The doubling of gross flows in Asia and the Pacific contrasted starkly to the decline of capital inflows to advanced economies, from an annual average of $\$ 4.3$ trillion in 2001-2010 to $\$ 3.0$ trillion in 2011-2020, in line with subdued crossborder banking flows following the global financial crisis of 2008-2009 (McQuade and Schmitz 2017), as well as the moderate increase in capital inflows to other emerging and developing economies from an annual average of around $\$ 0.4$ trillion in 2001-2010 to around
\$0.6 trillion in 2011-2020. On the one hand, the doubling of gross flows to Asia reflects its attractiveness as a main destination of foreign investments. Specifically, compared with other emerging and developing economies, Asia and the Pacific received twice the FDIs in 2011-2020. But the doubling of gross capital inflows to the region implies greater potential adverse impact of capital flow reversals.

\section{Figure 4.22: Nonresident Capital Flows-Asia and the Pacific, by Investment Type (\$ billion)}

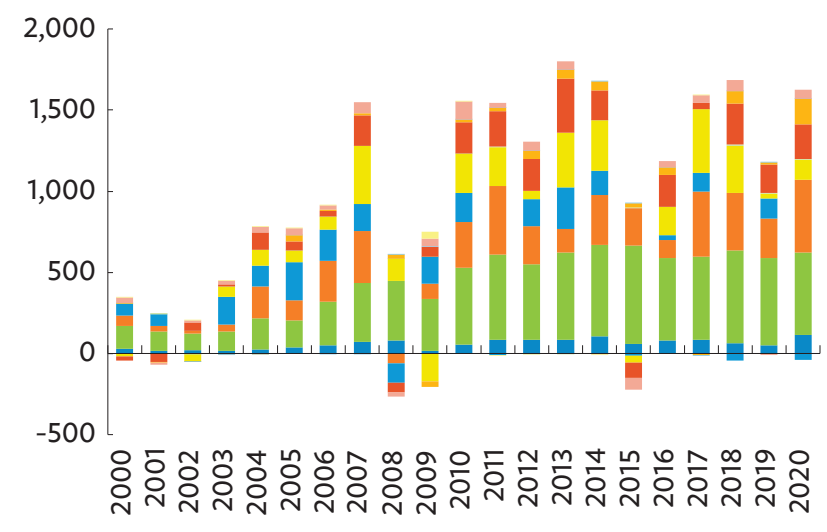

\begin{tabular}{|c|c|c|}
\hline Currency and deposits & FDI debt & LIPS Loans \\
\hline Other AP & Other equity & Portfolio debt \\
\hline Portfolio equity & SDR & Trade credit and advances \\
\hline
\end{tabular}

$A P=$ accounts payable; $F D I$ = foreign direct investment; LIPS = loans, insurance, pension, and guaranteed investment schemes; SDR = special drawing rights.

Note: Asia and the Pacific includes Afghanistan (beginning 2008); Armenia; Australia; Azerbaijan (beginning 2002); Bangladesh; Bhutan (beginning 2006); Cambodia; Fiji; Georgia; Hong Kong, China; India; Indonesia; Japan; Kazakhstan; Kiribati (beginning 2006); the Kyrgyz Republic; the Lao People's Democratic Republic; Malaysia (beginning 2002); Maldives; Mongolia; Nepal; New Zealand; Pakistan; the People's Republic of China; the Philippines; the Republic of Korea; Samoa (beginning 2004); Singapore; Solomon Islands; Sri Lanka; Taipei,China; Tajikistan (beginning 2002); Thailand; Timor-Leste (beginning 2006); Tonga (beginning 2003); Tuvalu; Uzbekistan (beginning 2010); and Vanuatu.

Sources: ADB calculations using data from CEIC Data Company; International Monetary Fund. Balance of Payments and International Investment Position Statistics. http://data.imf.org/IIP (accessed October 2021); and national sources.

Nonetheless, as a percentage of GDP, the magnitude of gross capital inflows to the region remained roughly the same, at an average of 5.5\% for both periods. In addition,

34 The focus of analysis in this subsection is on nonresident capital inflows (gross capital inflows), instead of net nonresident capital inflows (net capital inflows) or resident capital outflows. Net capital inflows are usually more stable than nonresident capital inflows, which exhibit volatilities. Moreover, focusing on nonresident capital inflows will identify nonresident capital flow reversals, instead of net capital inflow reversals, which may either be attributed to residents or nonresidents. Nonresident capital flows include direct investment abroad, portfolio equity, portfolio debt, and other investments as defined by Balance of Payments Manual 6 (BPM6). Resident capital flows include foreign direct investment, portfolio equity, portfolio debt, other investment, and reserve assets as defined by BPM6. 
resident capital outflows have grown, from an annual average of $\$ 0.8$ trillion in 2001-2010 to $\$ 1.6$ trillion in 2011 to 2020 (Figure 4.23). Hence, net resident capital outflows have mostly been positive in the last 2 decades, indicating that Asia and the Pacific had been a net capital exporter.

Figure 4.23: Resident Capital Flows-Asia and the Pacific, by Investment Type (\$ billion)

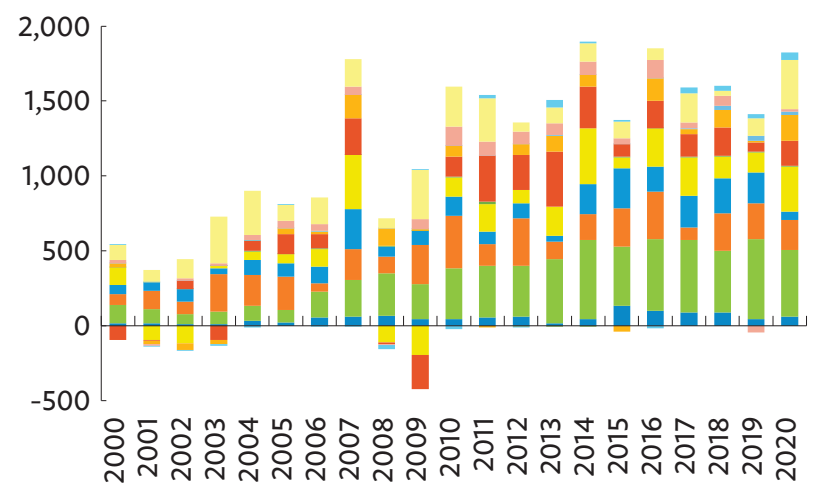

Currency and deposits Financial derivatives
LIPS LDI debt FDI equity

Portfolio equity Reserve assets Trade credit and advances

$A R=$ accounts receivable $; \mathrm{FDI}=$ foreign direct investment;

LIPS = loans, insurance, pension, and guaranteed investment schemes.

Note: Asia and the Pacific includes Afghanistan (beginning 2008); Armenia; Australia; Azerbaijan (beginning 2002); Bangladesh; Bhutan (beginning

2006); Cambodia; Fiji; Georgia; Hong Kong, China; India; Indonesia; Japan; Kazakhstan; Kiribati (beginning 2006); the Kyrgyz Republic;

the Lao People's Democratic Republic; Malaysia (beginning 2002); Maldives; Mongolia; Nepal; New Zealand; Pakistan; the People's Republic of China; the Philippines; the Republic of Korea; Samoa (beginning 2004); Singapore; Solomon Islands; Sri Lanka; Taipei,China; Tajikistan (beginning 2002); Thailand; Timor-Leste (beginning 2006); Tonga (beginning 2003); Tuvalu; Uzbekistan (beginning 2010); and Vanuatu.

Sources: ADB calculations using data from CEIC Data Company; International Monetary Fund. Balance of Payments and International Investment Position Statistics. http://data.imf.org/IIP (accessed October 2021); and national sources.

As nonresident capital inflows increased in the region, there are noticeable changes in their composition and patterns. First, multinational enterprises, including those in the region, have significantly shaped nonresident capital flows in the past decade, given the complexity of their cross-border financial investments (Avdjiev, Chui, and Shin 2014). Nonfinancial multinational enterprises can provide within-company credit to their parent company or subsidiaries located elsewhere. This transaction appears as "FDI debt" in the balance of payments statistics. In Asia and the Pacific, FDI debt has more than doubled from an average annual value of $\$ 39$ billion in 2001-2010 to $\$ 82$ billion in 2011-2020. Nonfinancial multinational enterprises also provide trade credits and loans to other companies, and can make cross-border bank deposits. These partly explain the rise in cross-border currency and deposits and loans, which have increased from an average annual value of $\$ 84$ billion and $\$ 60$ billion in 2001-2010 to $\$ 190$ billion and $\$ 170$ billion in $2011-2020$, respectively. These transactions may understate the true cross-border exposures of nonfinancial multinational enterprises that have borrowed abroad through their affiliates.

Second, in 2011-2020 nonresident portfolio debt inflows rose, coinciding with the rise in debt issuance in Asia and the Pacific. In the same period, total bond issuance in the region increased from $\$ 2.3$ trillion to $\$ 7.2$ trillion, representing a compounded annual growth rate of $13.2 \% .^{35}$ Average annual portfolio debt inflows more than doubled from $\$ 131$ billion in 2001-2010 to $\$ 290$ billion in 2011-2020. The increase in portfolio debt inflows reflects the shift from bank-intermediated financing to market-based financing centering on emerging market debt securities over the last decade (Shin 2013).

Third, subregionally, "other advanced Asia," which includes Australia, Japan, and New Zealand, remains the top destination of nonresident capital flows in the last decade, with an average annual capital flow amounting to $\$ 424$ billion in 2011-2020, significantly up from $\$ 222$ billion in 2001-2010 (Figure 4.24). Newly industrialized economies (NIEs) remained the secondbiggest recipient of foreign capital inflows in 2011-2020, followed by the PRC, India, ASEAN4, and other Asia emerging/developing economies, respectively. ${ }^{36}$ But there are also noticeable differences in the composition

35 Asian economies with data include Indonesia, Malaysia, the People's Republic of China, the Philippines, the Republic of Korea, Thailand, and Viet Nam. see ADB. AsianBondsOnline. https://asianbondsonline.adb.org (accessed October 2021).

36 Other advanced Asia refers to Australia, Japan, and New Zealand. NIEs refer to Hong Kong, China; the Republic of Korea; Singapore; and Taipei,China. ASEAN4 refers to Indonesia, Malaysia, the Philippines, and Thailand. 
of capital inflows across economies and subregions, as shown in figures in Annex 4a.1. The PRC received a large share of FDI equity in both periods, and there was a marked shift from loan inflows to portfolio debt (bond) inflows in 2011-2020. For India and the NIEs, aside from FDI equity inflows, both subregions received large amounts of nonresident currency and deposit inflows in 2011-2020. ASEAN4 received large FDI equity inflows as well as portfolio debt inflows, while other emerging and developing Asia economies received large FDI equity inflows and loan inflows in 2011-2020.

\section{Figure 4.24: Nonresident Capital Flows-Asia and the Pacific, by Subregion ( $\$$ billion)}

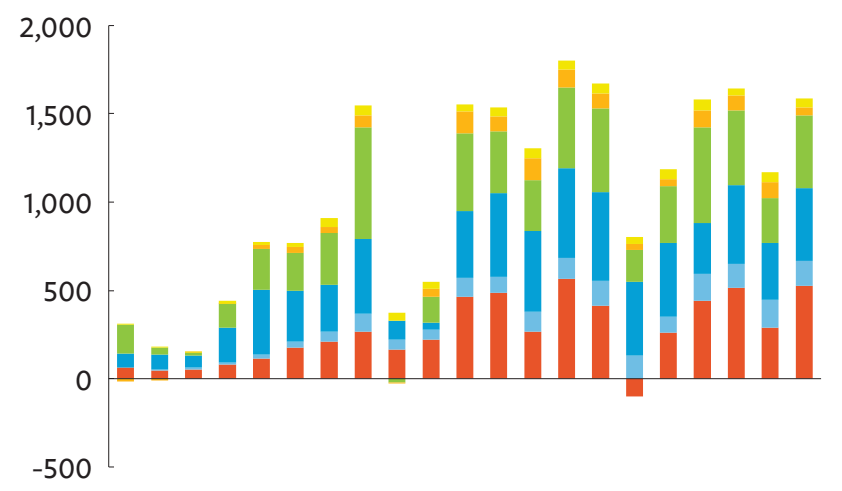

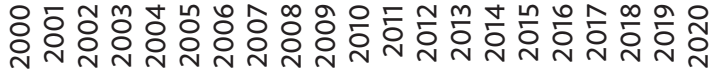

ASEAN4 India NIEs Other advanced Asia

Other emerging and developing Asia IPRC

ASEAN = Association of Southeast Asian Nations, NIE = newly industrialized economy, PRC = People's Republic of China.

Note: ASEAN4 includes Indonesia, Malaysia (beginning 2002), the Philippines, and Thailand. NIEs include Hong Kong, China; the Republic of Korea; Singapore; and Taipei,China. Other advanced Asia includes Australia, Japan, and New Zealand. Other emerging and developing Asia includes Afghanistan (beginning 2008), Armenia, Azerbaijan (beginning 2002), Bangladesh, Bhutan (beginning 2006), Cambodia, Fiji, Georgia, Kazakhstan, Kiribati (beginning 2006), the Kyrgyz Republic, the Lao People's Democratic Republic, Maldives, Mongolia, Nepal, Pakistan, Samoa (beginning 2004), Solomon Islands, Sri Lanka,

Tajikistan (beginning 2002), Timor-Leste (beginning 2006), Tonga (beginning 2003), Tuvalu, Uzbekistan (beginning 2010), and Vanuatu.

Sources: ADB calculations using data from CEIC Data Company; International Monetary Fund. Balance of Payments and International Investment Position Statistics. http://data.imf.org/IIP (accessed October 2021); and national sources.

Fourth, nonresident capital inflows to Asia and Pacific economies mostly went to nonfinancial corporates (Figure 4.25). This pattern is unsurprising given that the region attracts a large share of global FDI and that nonfinancial multinational enterprises are increasing their cross-border financial transactions. Such patterns may give rise to financial stability concerns if these flows lead to more financial operations rather than real economic activities (Avdjiev, Chui, and Shin 2014). The banking sector was the second-largest recipient of nonresident capital flows. But for some years, including 2020, the government sector received more nonresident capital flows than the banking sector, suggesting the rising importance of the public sector as borrower, as also noted by the Committee on Global Financial System report (CGFS 2021). The capital inflow surges and reversals before and during the global financial crisis of 2008-2009; as well as the moderate levels of nonresident capital inflows in post-global financial crisis were largely explained by banking sector flows (Milesi-Ferretti and Tille 2011; McCauley et al. 2019; and McQuade and Schmitz 2017). In contrast, the sudden stops experienced by some economies at the onset of the COVID-19 pandemic appeared mainly to be driven by investment funds from advanced economies (Lane 2020). These evolving patterns of sectoral nonresident capital inflows into the region and elsewhere highlight sectoral differences in sensitivity to drivers as well as to policy measures (Lepers and Mercado 2021).

\section{Figure 4.25: Nonresident Capital Flows-Selected Asian Economies, by Sector ( $\$$ billion)}

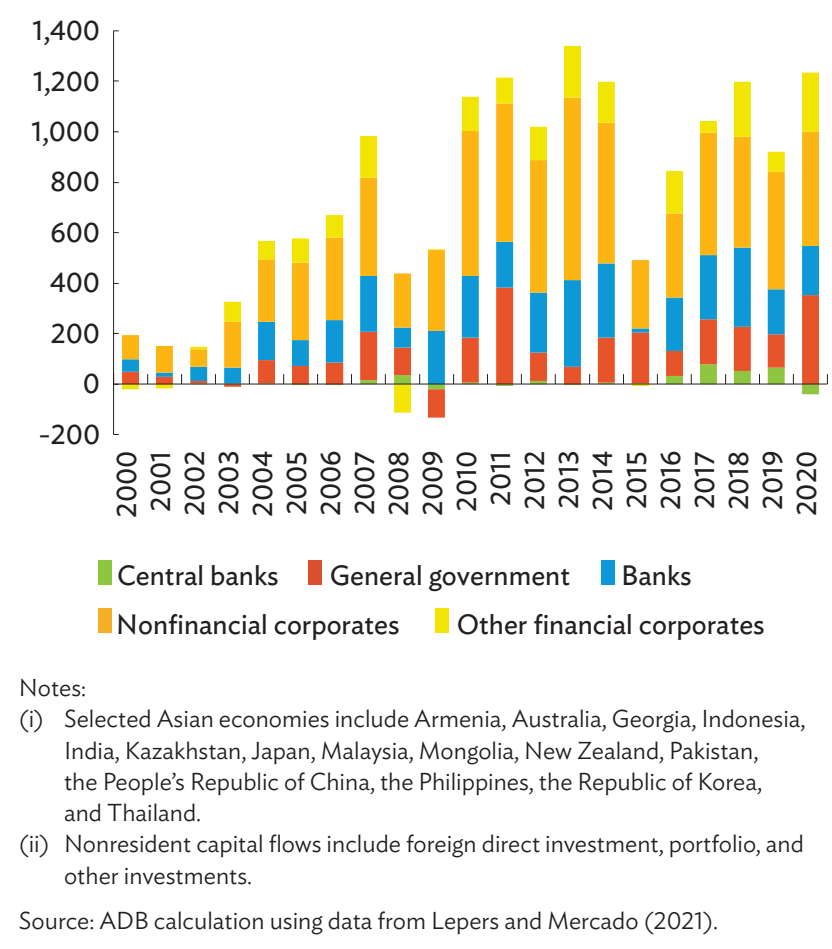


Across types of investments, most FDI and portfolio equity inflows in selected Asia and the Pacific economies went to nonfinancial corporates (The SEACEN Centre 2020). But there are differences for sectoral debt inflows, which includes bond and loan inflows, as shown in the figures in Annex 4a.2. For instance, in the PRC, bank debt inflows in 2011-2020 were dominantly in the form of bonds, in contrast to the 2001-2010 period when most bank debt inflows were in the form of loans. For ASEAN4, there was also a marked shift in government debt inflows from loans to bonds in 2011-2020, but for other emerging and developing Asia and Pacific economies, most government debt inflows were loans.

Fifth, volatilities of nonresident capital inflows in Asia and the Pacific have gone down in 2011-2020, compared with 2001-2010, which is partly explained by the "great moderation" of capital flows, particularly from advanced economies in the post-global financial crisis period (McQuade and Schmitz 2017). Moreover, policy measures that address capital flow volatility may have also contributed to its decline in 2011-2020 (CGFS 2021). The relative volatilities of gross capital inflows across types of investments remained consistent over the last 2 decades (Figure 4.26a). Other investment inflows, which include loans, currency and deposits, and trade credits, remained the most volatile capital flows, followed by portfolio flows and then FDI flows. The same patterns were previously noted by Mercado and Park (2011) for developing Asia economies from 1980 to 2009. Across the Asia and Pacific subregions, the PRC had the most volatile nonresident capital inflows in 2011-2020, followed by ASEAN4 and NIEs (Figure 4.26b). Among sectors, public sector inflows (central bank and general government) as well as other financial corporate inflows were more volatile in both periods, compared with banks and nonfinancial corporates

(Figure 4.26c).

Figure 4.26: Nonresident Capital Flows Volatility-Asia and the Pacific, 2001-2020 (\% GDP, coefficient of variation)

(a) By Investment Type

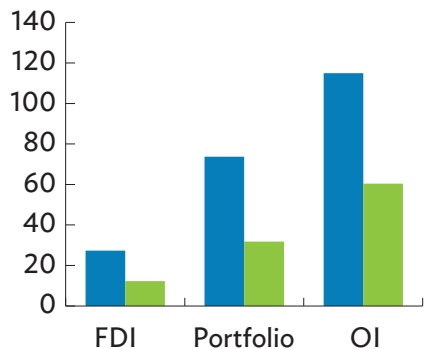

(b) By Subregion

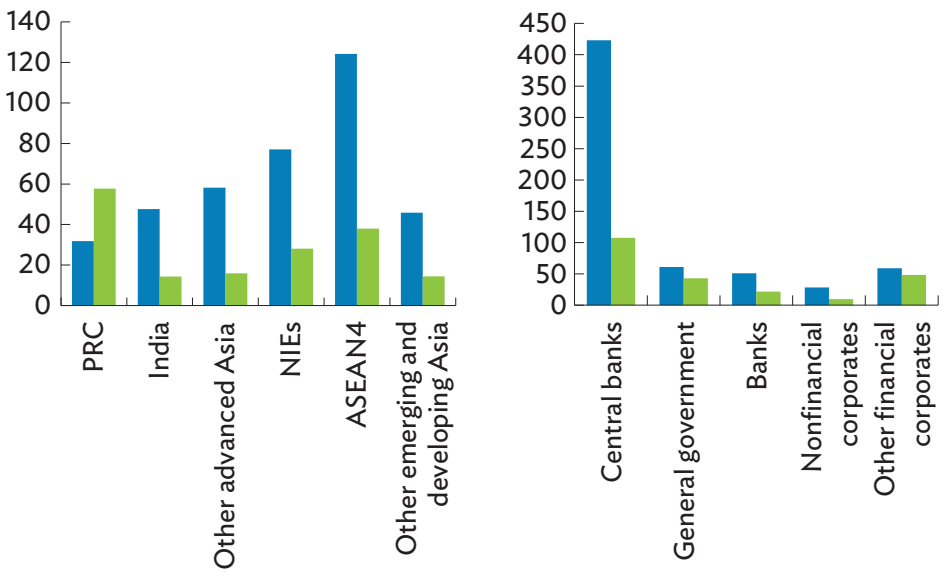

2001-2010 2011-2020

ASEAN = Association of Southeast Asian Nations, FDI = foreign direct investment, GDP = gross domestic product, NIE = newly industrialized economy, $\mathrm{OI}=$ other investment, $\mathrm{PRC}=$ People's Republic of China

Notes:

(i) ASEAN4 includes Indonesia, Malaysia (beginning 2002), the Philippines and Thailand. NIEs include Hong Kong, China; the Republic of Korea; Singapore; and Taipei,China. Other advanced Asia includes Australia, Japan, and New Zealand. Other emerging and developing Asia includes Afghanistan (beginning 2008), Armenia, Azerbaijan (beginning 2002), Bangladesh, Bhutan (beginning 2006), Cambodia, Fiji, Georgia, Kazakhstan, Kiribati (beginning 2006), the Kyrgyz Republic, the Lao People's Democratic Republic, Maldives, Mongolia, Nepal, Pakistan, Samoa (beginning 2004), Solomon Islands, Sri Lanka, Tajikistan (beginning 2002), Timor-Leste (beginning 2006), Tonga (beginning 2003), Tuvalu, Uzbekistan (beginning 2010), and Vanuatu.

(ii) Figure 4.26a includes ASEAN4, India, NIEs, other advanced Asia, other emerging and developing Asia, and the PRC.

(iii) Figure 4.26c includes Armenia, Australia, Georgia, Indonesia, India, Kazakhstan, Japan, Malaysia, Mongolia, New Zealand, Pakistan, the People's Republic of China, the Philippines, the Republic of Korea, and Thailand.

(iv) The coefficient of variation is the ratio of the standard deviation to the mean, multiplied by 100

Sources: ADB calculations using data from CEIC Data Company; International Monetary Fund (IMF). Balance of Payments and International Investment Position Statistics. http://data.imf.org/IIP; IMF. World Economic Outlook October 2021 Database. https://www.imf.org/en/Publications/WEO/weo-database/2021/October (both accessed October 2021); Lepers and Mercado (2021); and national sources. 


\section{The changing patterns of foreign capital inflows into Asia and the Pacific reflect the varying relevance of global and domestic factors.}

More recent studies show that global and domestic economic growth, investor risk appetite, domestic macroeconomic risks, trade and financial openness, quality of governance, and domestic financial depth are the relevant drivers of foreign capital inflows (Ahmed and Zlate 2014; Byrne and Fiess 2016; Fratzscher 2012; Ghosh et al. 2014; Giordani et al. 2017; Li, de Haan, and Scholtens 2018; Mercado 2018a; and Mercado and Park 2011). Other drivers have also been identified. CGFS (2021) highlighted the significance of the institutional infrastructure of the global financial system through which capital flows ultimately move, known as "pipes" as an important determinant of the magnitude of capital inflows; while Mercado (2018b and 2020) found that gravity factors such as bilateral trade and distance drive bilateral capital flows. But the significance of these drivers change over time. For example, CGFS (2021) stressed that the changes in capital flow pipes have become the most important driver of capital flow patterns in the post-global financial crisis period.

Focusing on a sample of Asia and Pacific economies between 2001-2010 and 2011-2020, the conditional correlations between various types of gross capital inflows and global and domestic factors show that the significant negative correlation between portfolio equity flows and VIX have declined between the two periods (Figure 4.27), while the positive conditional correlation between portfolio debt inflows and domestic GDP growth has increased and became significant in 2011-2020, compared with the previous period. This implies that foreign investors have become responsive to domestic economic growth in deciding whether to hold Asia and Pacific portfolio debt. These findings remain the same when additional domestic covariates are considered. In addition, the positive and significant correlation between domestic capital account openness and domestic financial depth with FDI inflows have increased in the second period; while the positive and significant correlation between domestic governance quality and other investment inflows likewise increased in 2011-2020, compared with 2001-2010. Again, these results suggest that foreign investors have become more responsive to domestic factors in Asia and the Pacific in deciding whether to invest in the region.

\section{Figure 4.27: Regression Coefficients of Capital Flows Covariates-Selected Asian Economies}

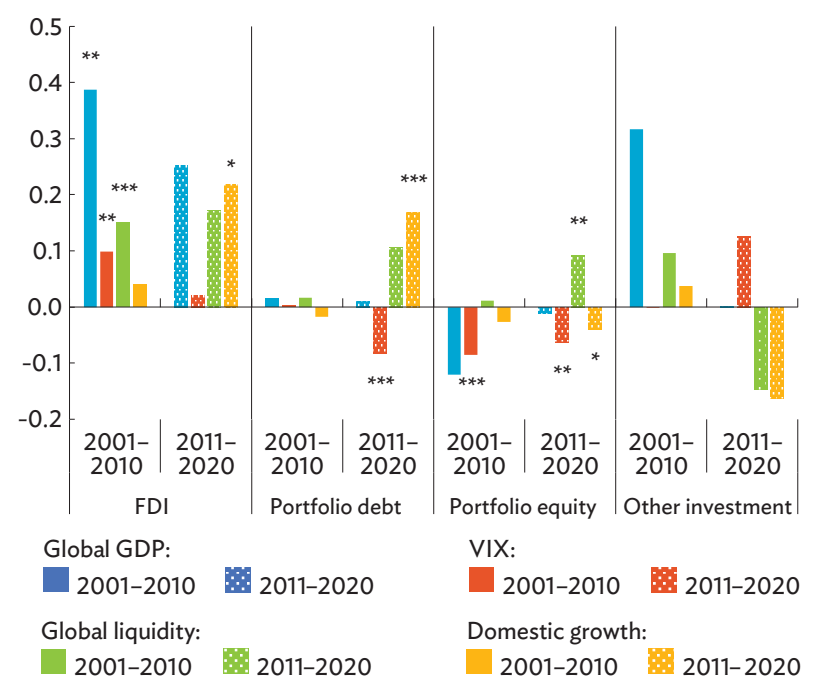

$\mathrm{FDI}=$ foreign direct investment, GDP = global domestic product, $\mathrm{VIX}=$ volatility index.

Notes:

(i) The change in the effect of push and pull factors, between 2001-2010 and 2011-2020 was analyzed by using a panel regression with economy fixed effects. The analysis highlights basic correlations (not causal relationships).

(ii) The dependent variables are gross capital inflows to economy $\mathrm{i}$ in year $\mathrm{t}$ scaled by GDP.

(iii) Global liquidity refers to total international banks' claims on all sectors as \% of GDP. Domestic growth refers to the year-on-year growth of each economy's annual GDP.

(iv) The asterisks denote significance levels. ${ }^{* *}$ at $1 \%,{ }^{* *}$ at $5 \%$, and ${ }^{*}$ at $10 \%$.

Sources: ADB calculations using data from Bank for International Settlements Global Liquidity Indicators. https://www.bis.org/statistics/gli.htm (accessed August 2021); Bloomberg; International Monetary Fund (IMF). Balance of Payments and International Investment Position Statistics. http://data.imf. org/IIP; and IMF. World Economic Outlook Database. https://www.imf.org/en/ Publications/WEO/weo-database/2021/October (both accessed October 2021); and methodology by Committee on Global Financial System (2021).

\section{Asia and Pacific economies experienced marked periods of large nonresident capital inflows and outflows over the last 2 decades.}

Foreign capital inflows peaked in 2007 for most economies in the region before capital flow reversals during the global financial crisis of 2008-2009. Nonresident capital flows in the region also peaked around 2013-2014, before reversals in 2015. Such 
episodes of large nonresident capital inflows or "surges" and outflows (reversals) or "stops" are caused by various domestic and global factors, such as investor risk appetite, contagion effects, among others (Caballero 2016; Calderon and Kubota 2013; Calvo 1998; Calvo, Leiderman, and Reinhart 1993 and 1996; Calvo, Izquierdo, and Mejia 2008; Cavallo and Frankel 2008; Forbes and Warnock 2012a and 2012b; Ghosh et al. 2014; Levchenko and Mauro 2007; Magud, Reinhart, and Vesperoni 2014; Mercado 2018a and 2019; MilesiFerretti and Tille 2011; Reinhart and Reinhart 2009; and Rothenberg and Warnock 2011).

Consequently, identifying episodes of nonresident capital flow surges and stops is important in undertaking macrofinancial surveillance. Knowing "how large" nonresident capital inflows and outflows should be needs consideration before assessing what policy tools or combination thereof would be best in managing capital flow surges and stops. Annex $4 \mathrm{~b}$ discusses commonly used methods in identifying capital flow stops and surges.

Applying the capital flow surge and stop definition of Forbes and Warnock (2012a and 2021) to selected Asia and Pacific economies from 2000 to 2020 reveals two noteworthy observations (Figure 4.28). First, surges and stops are rare occurrences. On average, around $10 \%$ of the Asia and Pacific sample experience extreme episodes per quarter. Second, stops and surges may occur in ripples or waves. More than a third of the sample experienced surges in 2007 and stops in 2008 and 2009, whereas occurrences of these two extreme episodes were significantly less for other periods.

Periods of large nonresident capital inflows and outflows tend to coincide with improving or deteriorating domestic macroeconomic and financial indicators, suggesting their policy relevance. Figures 4.29 a to $4.29 \mathrm{f}$ trace the patterns of several macrofinancial indicators before, during, and after years of large nonresident capital inflows (surges) and outflows or reversals (stops) for selected Asia and Pacific economies from 2000 to 2020. Using annual capital flows data sourced from the Balance of Payments data set of the International Monetary Fund (IMF) and national sources, large nonresident capital inflows or surges are defined as the largest positive nonresident capital inflow reported by each economy in the sample from 2000 to 2020. In contrast, large nonresident capital outflows or stops or reversals are distinguished as the largest negative nonresident capital flows reported by each economy in the sample from 2000 to 2020.

\section{Figure 4.28: Frequency of Capital Inflows Stops and Surges}

(a) Stops

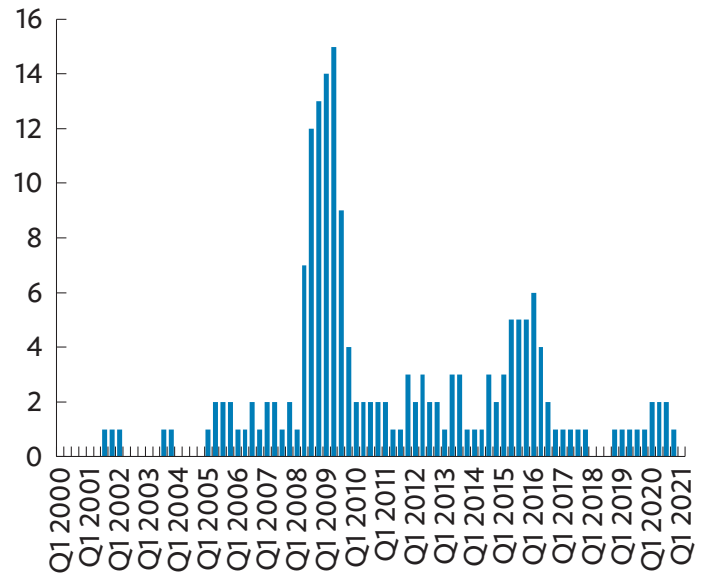

(b) Surges

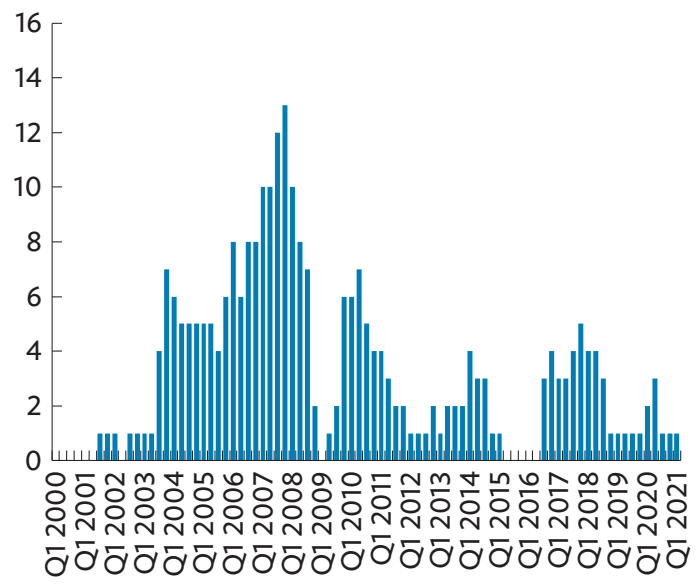

$Q=$ quarter.

Note: Asia and the Pacific includes Armenia; Australia; Azerbaijan; Bangladesh; Cambodia; Fiji; Georgia; Hong Kong, China; India; Indonesia; Japan; Kazakhstan; the Kyrgyz Republic; the Lao People's Democratic Republic; Malaysia; Mongolia; Myanmar; Nepal; New Zealand; Pakistan; Papua New Guinea; the People's Republic of China; the Philippines; the Republic of Korea; Singapore; Solomon Islands; Sri Lanka; Taipei,China; Thailand; Vanuatu; and Viet Nam.

Sources: ADB staff calculations using data from International Monetary Fund. Balance of Payments and International Investment Position Statistics. http://data.imf.org/IIP (accessed October 2021); and methodology by Forbes and Warnock (2021). 
The years with the largest nonresident inflows and outflows are noted as time ( $t$ ). Then, the median values of macrofinancial variables are taken, including GDP growth, current account balance, equity price, among others, across the sample of Asia and Pacific economies at time $t$ as well as those 3 years before and 3 years after the identified large episode of nonresident capital flows at time t, following Reinhart and Reinhart (2009).

Several key observations are noted. First, GDP growth declines during and after large nonresident capital outflows (stops or reversals), before recovering 2 years following the stop episode (red line in Figure 4.29a). Output growth is often weaker during foreign capital flow reversals as they are often associated with economic slowdowns or output drops. GDP growth also appears weaker following episodes of large nonresident capital inflows or surges (blue line in Figure 4.29a). Second, the current account balance of selected Asia and Pacific economies tends to deteriorate before and during large nonresident capital inflows (blue line in Figure 4.29b). In contrast, the current account balance improves when large nonresident capital outflows (stops) occur, due to weaker domestic demand (red line in Figure 4.29b). Third, the Asia and Pacific region accumulates official reserves during surges and decumulates reserves during stops (Figure 4.29c). Fourth, real exchange rate usually depreciates during and 1 year after large nonresident capital flow reversals (Figure 4.28d). Fifth, fiscal balance worsens during surges but slightly improves during stops (Figure 4.29e). Last, equity prices usually rise before and during surges but decrease after. They decrease during large nonresident capital flow reversals and remains depressed 1 year after (Figure 4.29f). ${ }^{37}$

\section{The Asia and Pacific economies used various policy measures to address the adverse impacts of large and volatile capital flows.}

Although capital inflows provide substantial direct and indirect benefits to emerging and developing economies, they also carry risks and pose a challenge to policy makers in the region. Specifically, the changing nature and varying significance of domestic and global factors require deeper understanding of the dynamics and evolution of nonresident capital flows. Moreover, large capital inflows and large capital flow reversals are often associated with either improving or deteriorating macroeconomic and financial conditions, thereby warranting appropriate policy responses, as shown in Figure 4.29.

In this regard, emerging and developing economies, including those in the Asia and Pacific region, have used an array of policy measures to address the adverse impacts of large and volatile capital flows, including capital flow management measures, foreign exchange measures, and macroprudential measures. Over the course of the last 2 decades most of these measures were loosened instead of tightened, as shown in Figure 4.30. For example, capital flow management measures on nonresident capital inflows were mostly loosened in line with the trend toward greater capital account liberalization. In contrast, macroprudential measures were mostly tightened, more so in the past decade, to manage systemic risks from capital flows. The survey results conducted by the IMF in 2016 on capital flows shed more light on the concerns of policy makers. Most emerging and developing economies expressed concerns about capital flows, mainly due to their volatility as well as volume (IMF 2016). Among capital flow impacts, policy makers were mostly concerned with their impact on exchange rate followed by financial stability. Among policy measures, most used greater exchange rate flexibility, while others also used foreign exchange intervention and macroprudential measures. Empirical evidence on the effectiveness of these policy measures in addressing capital flow volatilities, surges, and stops has shown their usefulness under specific conditions (Eller et al. 2021; Lepers and Mehigan 2019; Frost, Ito, and Stralen 2020; Lepers and Mercado 2021; and Carvalho, Lepers, and Mercado 2021).

37 Most of these patterns hold if the identified episodes of large nonresident inflows and outflows are restricted from 2003 to 2017 to completely capture patterns 3 years before and after the identified episode at time $t$. 
Figure 4.29: Selected Macroeconomic and Financial Variables-Asia and the Pacific

(a) GDP Growth $(\%, y-0-y)$

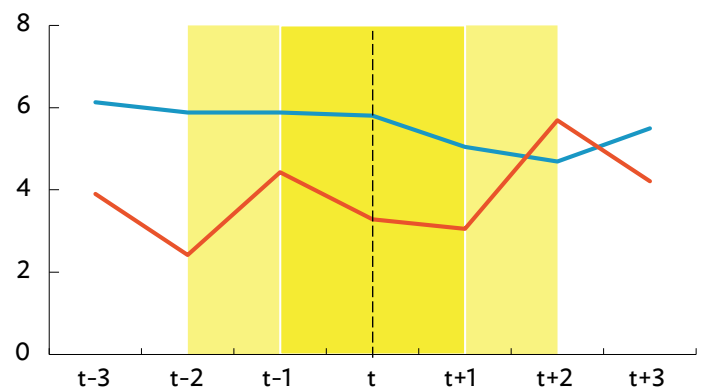

(c) Official Reserve Assets (\% of GDP)

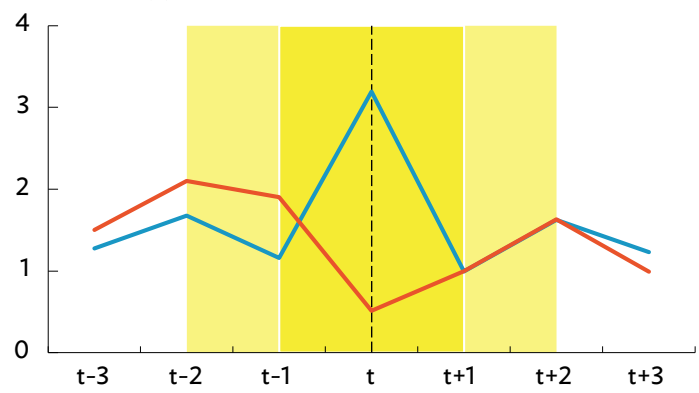

(e) Fiscal Balance (\% of GDP)

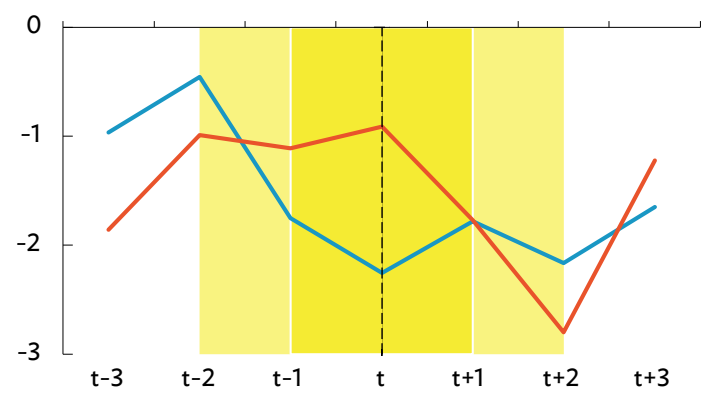

(b) Current Account Balance (\% of GDP)

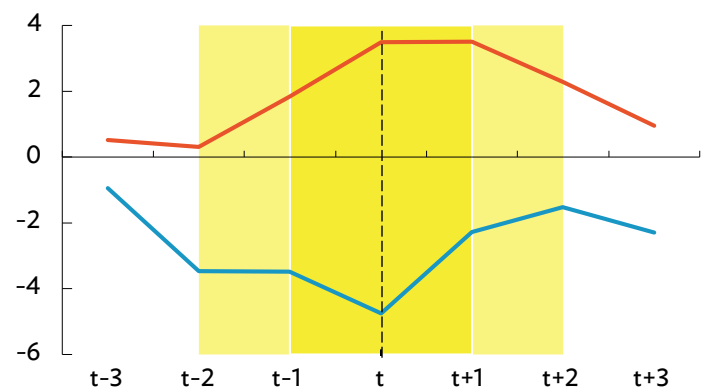

(d) Real Exchange Rate (index)

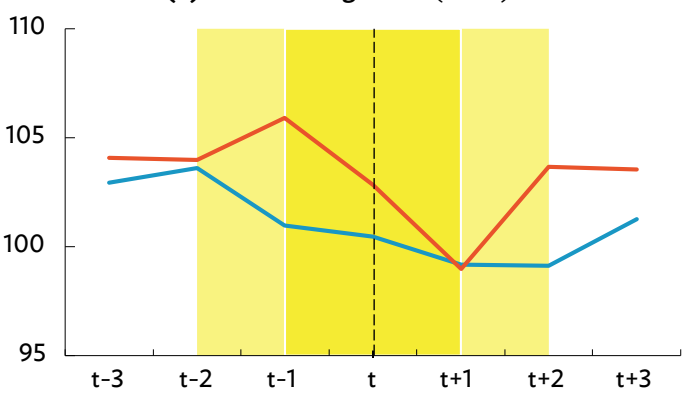

(f) Stock Price Index

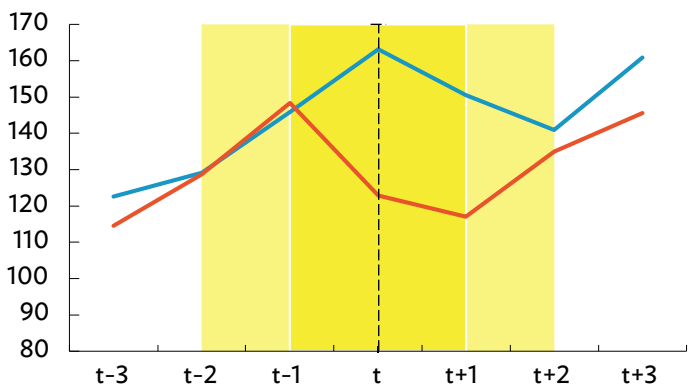

Trend during largest positive nonresident capital inflows

Trend during largest negative nonresident capital flows (reversals)

GDP = gross domestic product, $y-0-y=$ year-on-year.

Notes:

(i) The red (blue) lines in Figures 4.29a to $4.29 \mathrm{f}$ show the median values of GDP growth, current account balance, official reserve assets, real exchange rate, fiscal balance, and equity price for selected Asia and Pacific economies 3 years before $(t-3, t-2$, and $t-1)$, during $(t)$, and 3 years after $(t+1$, $t+2$, and $t+3)$ large nonresident capital outflows (inflows) are identified at time t. Time $t$ differs across sample economies, but data coverage across all economies is from 2000 to 2020 . For red lines, time t refers to the year with the largest negative nonresident capital flows for each sample of economies, while for blue lines, time $t$ refers to the year with the largest positive nonresident capital flows for each sample of economies.

(ii) Asia and the Pacific includes Afghanistan; Armenia; Australia; Azerbaijan; Bangladesh; Bhutan; Brunei Darussalam; Cambodia; the Federated States of Micronesia; Fiji; Georgia; Hong Kong, China; India; Indonesia; Japan; Kazakhstan; Kiribati; the Kyrgyz Republic; the Lao People's Democratic Republic; Malaysia; Maldives; the Marshall Islands; Mongolia; Myanmar; Nauru; Nepal; New Zealand; Pakistan; Palau; Papua New Guinea; the People's Republic of China; the Philippines, the Republic of Korea, Samoa; Singapore; Solomon Islands; Sri Lanka; Taipei,China; Tajikistan; Thailand; Timor-Leste; Tonga; Tuvalu; Uzbekistan; Vanuatu; and Viet Nam.

(iii) GDP growth refers to the year-on-year change of real GDP. Current account balance refers to all transactions other than those in financial and capital items. Official reserve assets are from the Balance of Payment Statistics in percentage of nominal GDP. Real exchange rate refers to the year-on-year change in real effective exchange rate rebased to 100 in $\mathrm{t}-4$. An increase (decrease) denotes appreciation (depreciation). Fiscal balance refers to net government lending/borrowing in percentage of nominal GDP. Values for nominal stock price index were calculated as the year-on-year change in stock price index rebased to 100 in $\mathrm{t}-4$.

Sources: ADB calculations using data from CEIC Data Company; International Monetary Fund (IMF). Balance of Payments and International Investment Position Statistics. http://data.imf.org/IIP (accessed October 2021); IMF. International Financial Statistics. http://data.imf.org/IFS; and IMF. World Economic Outlook April 2021 Database. https://www.imf.org/en/Publications/WEO/weo-database/2021/April (both accessed August 2021). 
Figure 4.30: Policy Measures of Selected Asia and Pacific Economies (count)

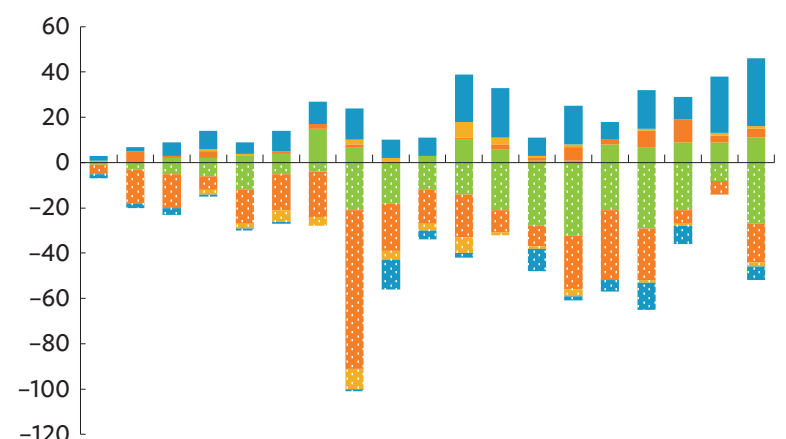

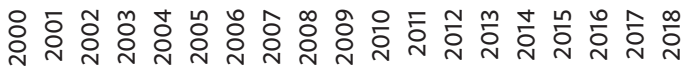

$\begin{array}{ll}\text { CC inflows: } & \text { CC outflows: } \\ \text { Tightening Easing } & \text { Tightening Easing } \\ \text { FX-M: } & \text { MPM: } \\ \text { ITightening Easing } & \text { ITightening Easing }\end{array}$

$\mathrm{CC}=$ capital controls, $\mathrm{FX}-\mathrm{M}=$ currency-based measures,

$M P M=$ traditional macroprudential measures

Note: Asia and the Pacific includes Australia, India, Indonesia, Japan, Malaysia, Mongolia, New Zealand, the People's Republic of China, the Philippines, the Republic of Korea, and Viet Nam.

Sources: International Monetary Fund. Integrated Macroprudential Policy Database. https://www.elibrary-areaer.imf.org/Macroprudential/Pages/ iMaPPDatabase.aspx (accessed 2019); and Lepers and Mehigan (2019).

\section{Given the volatile nature of capital flows and associated risks, several considerations are warranted.}

First, the pattern and composition of capital flows need to be carefully monitored, as the US is edging toward policy normalization, while emerging and developing economies are still addressing the ongoing COVID-19 pandemic. In particular, understanding cross-border financial flows along sectoral lines is needed as investment flows of nonfinancial corporations have become more complex, as emphasized in this chapter; and other financial corporates or nonbank financial institutions are now the main source of capital flows from advanced economies (Lepers and Mercado 2021). In addition, assessing the importance of domestic and global drivers, and more recently, "pipes" is required as changes in these factors will eventually determine the patterns and compositions of capital flows.

Second, large nonresident capital inflows and outflows could lead to deteriorating macroeconomic and financial conditions, and hence, can amplify risks and vulnerabilities. Moreover, earlier studies note that capital flow episodes transition from one to another, such as "surges" that are followed by "stops" (Efremidze et al. 2017; Mercado 2018a and 2019; and Sula 2010). Consequently, identifying these episodes is vital in deciding whether and when to use policy measures to help address these episodes of volatile capital flows (The SEACEN Centre 2019).

Third, the use of policy tools should be aligned with domestic situations and conditions. Yet, policy frameworks are a useful guide in deciding the appropriateness of policy tools. ${ }^{38}$

Fourth, as the patterns, compositions, and drivers of capital flows constantly evolve, the sharing of information and experiences among regional economies is helpful, specifically in identifying emerging trends as well as in the appropriateness and effectiveness of policy measures. In this regard, regional cooperation can offer a venue for sharing information and experiences in managing capital flows.

38 The IMF published its Institutional View on capital flows in 2012 and, subsequently, the Integrated Policy Framework in 2020 as guide on the appropriate use of various policy measures in addressing capital flow surges and sudden stops (IMF 2012). The Committee on Global Financial System in its 2021 report concluded that there is no "one size fits all" on how these policy measures are best combined, as it will depend on economy conditions and contexts (CGFS 2021). 


\section{Box 4.1: International Investment Position}

Figures 4.17 and 4.19 show the region's holdings of international investment assets and liabilities. The stylized facts drawn from these figures are based on underlying bilateral holdings data, where regional values are derived. Although the figures are informative and useful in understanding the proportion of external investment assets and liabilities held by regional versus non-regional economies, they do not provide the complete information as to the region's total external assets and liabilities, as bilateral source data are limited. To understand the region's external investment position, the International Investment Position is a useful statistic in tracking external adjustments and holdings. The compilation of the International Investment Position has improved over the last 2 decades, allowing policy makers more information on external debt assets and liabilities, as well as external equity investments. But information prior to 2000 is limited. Hence, longterm view of external adjustments and net international investment positions are constrained. This data gap has been addressed by Lane and Milesi-Ferretti (2007 and 2018) in their External Wealth of Nations Database.

The International Investment Position data are useful in understanding global imbalance and external adjustments (Lane and Milesi-Ferretti 2012 and 2017); as well as tracking de facto financial integration measure (Park 2013). For instance, Park (2013) noted that emerging Asia showed a steady uptrend in de facto financial integration from 1970 to 2010 despite the declines in de jure financial integration measure using the Chinn-Ito database (Chinn and Ito 2008), highlighting the substantial divergence between de facto and de jure measures of financial openness and integration. These studies show the importance and usefulness of International Investment Position data in understanding external positions and financial integration trends.

In addition, the statistic is valuable in understanding the improvement or deterioration of the net foreign asset position at the outset of the COVID-19 pandemic in 2020. Comparing the change in net foreign asset position between 2019 and 2020 for selected Asia and Pacific economies, the net foreign asset position of several economies including Armenia, Australia, Fiji, Georgia, Kazakhstan, Mongolia, and New Zealand further declined in 2020 as these economies have negative net foreign asset position in 2019, as shown in the figure. In contrast, the net foreign asset position of Bhutan, India, Indonesia, Malaysia, the Philippines, and Solomon Islands improved in 2020 despite these economies also having a negative net foreign asset position in 2019. In fact, for the latter group of economies, the improvement in net foreign asset position in 2020 coincided with the improvement of the current account balance.

\section{Change in Net Foreign Assets, 2019-2020}

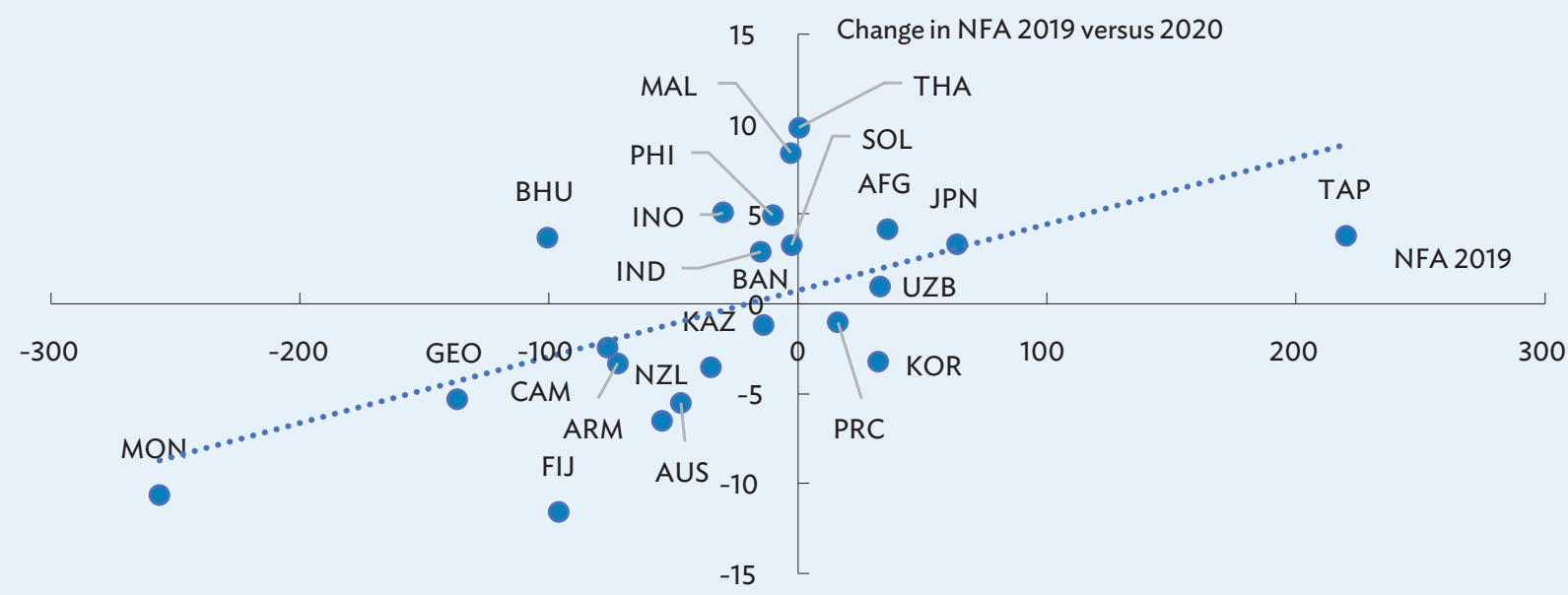

AFG = Afghanistan; ARM = Armenia; AUS = Australia; BAN = Bangladesh; BHU = Bhutan; CAM = Cambodia; FIJ = Fij; GEO = Georgia; IND = India; INO = Indonesia; $\mathrm{JPN}=$ Japan; $\mathrm{KAZ}=$ Kazakhstan; $\mathrm{KOR}=$ Republic of Korea; $\mathrm{MAL}=$ Malaysia; $\mathrm{MON}=$ Mongolia; $\mathrm{NFA}=$ net foreign asset; NZL = New Zealand; $\mathrm{PHI}=\mathrm{Philippines;}$ PRC = People's Republic of China; $\mathrm{SOL}=$ Solomon Islands; TAP = Taipei,China; THA = Thailand; UZB = Uzbekistan.

Source: ADB calculations using data from International Monetary Fund (IMF). Balance of Payments and International Investment Position Statistics. Accessed from CEIC Data Company; and IMF. World Economic Outlook April 2021 Database. https://www.imf.org/en/Publications/WEO/weodatabase/2021/April (accessed August 2021). 


\section{References}

Ahmed, S. and A. Zlate. 2014. Capital Flows to Emerging Market Economies: A Brave New World? Journal of International Money and Finance. 48. pp. 221-248.

Asian Development Bank (ADB). AsianBondsOnline. https://asianbondsonline.adb.org (accessed October 2021).

_. 2021. Asian Development Outlook (ADO) 2021 Supplement: Recovery Continues. Manila.

Avdjiev, S., M. K. Chui, and H. S. Shin. 2014. NonFinancial Corporations from Emerging Market Economies and Capital Flows. BIS Quarterly Review. December. Basel: Bank for International Settlements.

Bank for International Settlements (BIS). Global Liquidity Indicators. https:/www.bis.org/statistics/ gli.htm (accessed August 2021).

_- Locational Banking Statistics. https://www.bis.org/ statistics/bankstats.htm (accessed June 2021).

Bénétrix, A., D. Gautam, L. Juvenal, and M. Schmitz. 2019. Cross-Border Currency Exposures. Washington, DC: International Monetary Fund (IMF).

Board of Governors of the Federal Reserve System. 2021a. Federal Reserve Announces the Extension of Its Temporary US Dollar Liquidity Swap Lines with Nine Central Banks through December 31, 2021. Press Release. Washington, DC. https://www. federalreserve.gov/newsevents/pressreleases/ monetary20210616c.htm.

_ 2021b. Foreign and International Monetary Authorities (FIMA) Repo Facility. Washington, DC. https://www.federalreserve.gov/monetarypolicy/ fima-repo-facility.htm.

Byrne, J. P. and N. Fiess. 2016. International Capital Flows to Emerging Markets: National and Global Determinants. Journal of International Money and Finance. 61. pp. 82-100.
Caballero, J. 2016. Do Surges in International Capital Inflows Influence the Likelihood of Banking Crises? The Economic Journal. 126 (591). pp. 281-316.

Calderon, C. and M. Kubota. 2013. Sudden Stops: Are Global and Local Investors Alike? Journal of International Economics. 89 (1). pp. 122-142.

Calvo, G. 1998. Capital Flows and Capital-Market Crises: The Simple Economics of Sudden Stops. Journal of Applied Economics. 1. pp. 35-54.

Calvo, G., A. Izquierdo, and L. F. Mejia. 2008. Systemic Sudden Stops: The Relevance of Balance-Sheet Effects and Financial Integration. NBER Working Paper 14026. Cambridge, MA: National Bureau of Economic Research.

Calvo, G., L. Leiderman, and C. Reinhart. 1993. Capital Inflows and Real Exchange Rate Appreciation in Latin America: The Role of External Factors. IMF Staff Papers. 40 (1). pp. 108-151. Washington, DC: IMF.

1996. Inflows of Capital to Developing Countries in 1990s. Journal of Economic Perspectives. 10 (2). pp. 123-139.

Cantú, C., P. Cavallino, F. De Fiore, and J. Yetman. 2021. A Global Database on Central Banks' Monetary Responses to COVID-19. BIS Working Papers. No. 934. Basel: BIS.

Carvalho, D., E. Lepers, and R. Mercado. 2021. Taming the Capital Flows-Credit Nexus: A Sectoral Approach. Trinity Economics Paper. No. 0921.

Cavallo, E. and J. Frankel. 2008. Does Openness to Trade Make Countries More Vulnerable to Sudden Stops, or Less? Using Gravity to Establish Causality. Journal of International Money and Finance. 27. pp. 1430-1452. 
Chinn, M. D. and H. Ito. 2008. A New Measure of Financial Openness. Journal of Comparative Policy Analysis. 10 (3). pp. 309-322.

Committee on the Global Financial System (CGFS). 2021. Changing Patterns of Capital Flows. CGFS Papers. No. 66. Basel: BIS.

Efremidze, L., S. Kim, O. Sula, and T. D. Willett. 2017. The Relationships Among Capital Flow Surges, Reversals and Sudden Stops. Journal of Financial Economic Policy. 119. Article 102495.

Eller, M., N. Hauzenberger, F. Huber, H. Schuberth, and L. Vashold. 2021. The Impact of Macroprudential Policies on Capital Flows in CESEE. Journal of International Money and Finance. 9 (4). pp. 393-413.

Forbes, K. and F. Warnock. 2012a. Capital Flow Waves, Surges, Stops, Flights and Retrenchment. Journal of International Economics. 88 (2). pp. 235-251.

2012b. Debt- and Equity-Led Capital Flows Episodes. NBER Working Paper 18329. Cambridge, MA: National Bureau of Economic Research.

_ 2021. Capital Flow Waves_or Ripples? Extreme Capital Flow Movements Since the Crisis. Journal of International Money and Finance. 116. Article 102394.

Fratzscher, M. 2012. Capital Flows, Push Versus Pull Factors and the Global Financial Crisis. Journal of International Economics. 88 (2). pp. 341-356.

Frost, J., H. Ito, and R. V. Stralen. 2020. The Effectiveness of Macroprudential Policies and Capital Controls Against Volatile Capital Inflows. BIS Working Papers. No. 867. Basel: BIS.

Ghosh, A. R., M. S. Qureshi, J. I. Kim, and J. Zalduendo. 2014. Surges. Journal of International Economics. 92 (2). pp. $266-285$.

Giordani, P. E., M. Ruta, H. Weisfeld, and L. Zhu. 2017. Capital Flow Deflection. Journal of International Economics. 105. pp. 102-118.
Institute of International Finance. Global Debt Monitor November 2021. https://www.iif.com/Research/ Capital-Flows-and-Debt/Global-Debt-Monitor (accessed December 2021).

International Monetary Fund (IMF). 2012. The Liberalization and Management of Capital Flows: An Institutional View. IMF Policy Paper. Washington, DC.

. 2016. Capital Flows-Review of Experience with the Institutional View. IMF Policy Paper. Washington, DC.

_- Balance of Payments and International Investment Position Statistics. http://data.imf.org/ IIP (accessed September and October 2021).

. Coordinated Direct Investment Survey. https://data.imf.org/CDIS (accessed December 2020).

. Coordinated Portfolio Investment Survey. https://data.imf.org/CPIS (accessed September 2021).

- Integrated Macroprudential Policy Database. https://www.elibrary-areaer.imf.org/ Macroprudential/Pages/iMaPPDatabase.aspx (accessed 2019).

_- International Financial Statistics. http://data.imf. org/IFS (accessed August and October 2021).

-World Economic Outlook April 2021 Database. https://www.imf.org/en/Publications/WEO/weodatabase/2021/April (accessed August 2021).

- World Economic Outlook October 2021 Database. https:/www.imf.org/en/Publications/ WEO/weo-database/2021/October (accessed October 2021).

Knightley, J., and P. Garvey. 2022. Federal Reserve Keen to Get the Ball Rolling. ING Think. 5 January. https://think.ing.com/articles/federal-reservekeen-to-get-the-ball-rolling. 
Lane, P. R. 2020. The Market Stabilisation Role of the Pandemic Emergency Purchase Programme. The ECB Blog. 22 June. https://www.ecb. europa.eu/press/blog/date/2020/html/ecb. blog200622 14c4269b9e.en.html.

Lane, P. R. and G. M. Milesi-Ferretti. 2007. The External Wealth of Nations Mark II: Revised and Extended Estimates of Foreign Assets and Liabilities, 19702004. Journal of international Economics. 73 (2). pp. 223-250.

- 2012. External Adjustment and the Global Crisis. Journal of International Economics. 88 (2). pp. 252-265.

- 2017. International Financial Integration in the Aftermath of the Global Financial Crisis. Washington, DC: IMF.

- 2018. The External Wealth of Nations Revisited: International Financial Integration in the Aftermath of the Global Financial Crisis. IMF Economic Review. 66 (1). pp. 189-222.

Lee, J. W. and C. Y. Park. 2011. Financial Integration in Emerging Asia: Challenges and Prospects. Asian Economic Policy Review. 6 (2). pp. 176-198.

Lepers, E. and C. Mehigan. 2019. The Broad Policy Toolkit for Financial Stability: Foundations, Fences, and Fire Doors. OECD Working Paper on International Investment. Paris: Organisation for Economic Co-operation and Development.

Lepers, E., and R. Mercado. 2021. Sectoral Capital Flows: Covariates, Co-Movements, and Controls. Journal of International Financial Markets, Institutions and Money. 75. Article 101413.

Levchenko, A. and P. Mauro. 2007. Do Some Forms of Financial Flows Help Protect Against Sudden Stops? The World Bank Economic Review. 21 (3). pp. 389-411.
Li, S., J. de Haan, and B. Scholtens. 2018. Surges of International Fund Flows. Journal of International Money and Finance. 82. pp. 97-119.

Magud, N., C. Reinhart, and E. Vesperoni. 2014. Capital Inflows, Exchange Rate Flexibility, and Credit Boom. Review of Development Economics. 18 (3). pp. 415-430.

Magnus, G. 2021. End to China's Estate Market Boom Could Spell Trouble for the Economy. The Guardian. 15 October. https://www.theguardian.com/ world/2021/oct/15/chinas-booming-real-estatemarket-could-spell-trouble-for-the-economy.

McCauley, R. N., A. S. Benetrix, P. M. McGuire, and G. von Peter. 2019. Financial Deglobalisation in Banking? Journal of International Money and Finance. 94. pp. 116-131.

McQuade, P. and M. Schmitz. 2017. The Great Moderation in International Capital Flows: A Global Phenomenon? Journal of International Money and Finance. 73. pp. 188-212.

Mercado, R. 2018a. Not All Surges of Gross Capital Inflows are Alike. Journal of Economic Studies. 45 (2). pp. 326-347.

_. 2018b. Bilateral Capital Flows: Transaction Patterns and Gravity. SEACEN Working Papers. No. 2/2018. Kuala Lumpur: The South East Asian Central Banks Research and Training Centre.

2019. Capital Flow Transitions: Domestic Factors and Episodes of Gross Capital Inflows. Emerging Markets Review. 38 (1). pp. 251-264.

2020. Bilateral Capital Flows: Gravity, Push, and Pull. Irving Fisher Committee (IFC) Bulletin. No. 52. Basel: BIS.

Mercado, R. and C. Y. Park. 2011. What Drives Different Types of Capital Flows and Their Volatilities in Developing Asia? International Economic Journal. 25 (4). pp. 497-524. 
Milesi-Ferretti, G. M. and C. Tille. 2011. The Great Retrenchment: International Capital Flows During the Global Financial Crisis. Economic Policy. 26 (66). pp. 289-346.

Nikkei Asia. 2021. China Properties Defaults on Notes Worth $\$ 226 \mathrm{~m}$. 16 October. https://asia.nikkei.com/ Business/Markets/China-debt-crunch/ChinaProperties-defaults-on-notes-worth-226m.

Park, C. Y. 2013. Asian Capital Market Integration: Theory and Evidence. ADB Economics Working Paper Series. No. 351. Manila: ADB.

Park, C. Y. and R. Mercado. 2014. Determinants of Financial Stress in Emerging Market Economies. Journal of Banking and Finance. 45. pp 199-224.

Reinhart, C. and V. Reinhart. 2009. Capital Flow Bonanzas: An Encompassing View of the Past and Present. NBER International Seminar on Macroeconomics. 5 (1). pp. 9-62.

Rothenberg, A. and F. Warnock. 2011. Sudden Flight and True Sudden Stops. Review of International Economics. 19 (3). pp. 509-524.

Shin, H. S. 2013. Adapting Macro Prudential Approaches to Emerging and Developing Economies. In O. Canuto and S. Ghosh, eds. Dealing with the Challenges of Macro Financial Linkages in Emerging Markets. pp. 17-55. Washington, DC: World Bank.

The South East Asian Central Banks Research and Training Centre (The SEACEN Centre). 2019. Section II: Large Capital Flows - Some Considerations. The SEACEN Capital Flows Monitor 2019. Kuala Lumpur.
2020. SEACEN Capital Flows Monitor 2020. Kuala Lumpur.

The Straits Times. 2021. Chinese Developer Sinic Defaults Amid Evergrande Contagion. 20 October. https://www.straitstimes.com/business/ property/chinese-developer-sinic-defaults-amidevergrande-contagion.

Sula, O. 2010. Surges and Sudden Stops of Capital Flows to Emerging Markets. Open Economics Review. 21. pp. 589-605.

Tan, W. 2021. Defaults Loom Over More Property Developers as China Reassures Investors on Evergrande. CNBC. 16 October. https://www.cnbc. com/2021/10/18/china-property-defaults-risksfor-other-developers-pboc-on-evergrande.html.

Toh, M. 2021. 5 Things to Know About the Evergrande Crisis: A Simple Breakdown. CNN Business. 30 September. https://edition.cnn.com/2021/09/24/ investing/china-evergrande-group-debt-explainerintl-hnk/index.html.

Wilkins, R. C., Q. She, E. Dong, D. Ingles, A. Huang, and A. Vishnoi. 2021. Evergrande Staves Off Default With Last-Minute Bond Payment. Bloomberg. 22 October. https://www.bloomberg.com/news/ articles/2021-10-22/evergrande-pays-bondinterest-due-saturday-local-media-says. 


\section{Annex 4a: Sectoral and Subregional Decomposition of Capital Flows}

Figure 4a.1: Nonresident Capital Flows—Selected Asian Economies and Subregions, by Investment Type (\$ billion)

(a) People's Republic of China

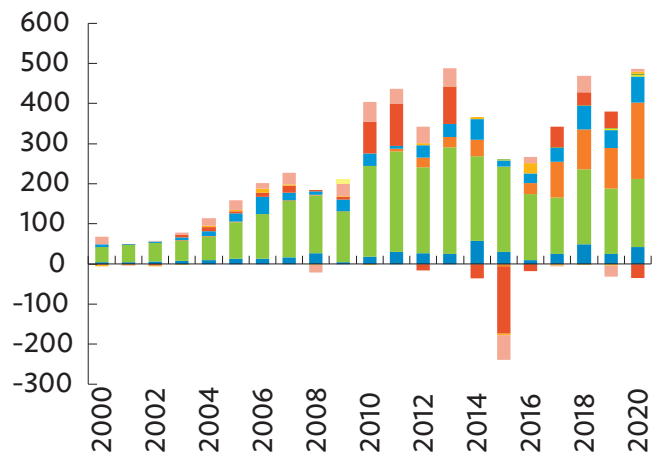

(c) Japan

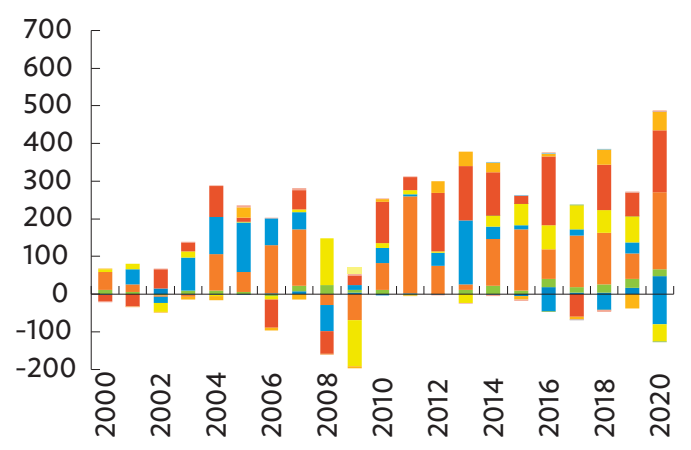

(e) ASEAN4

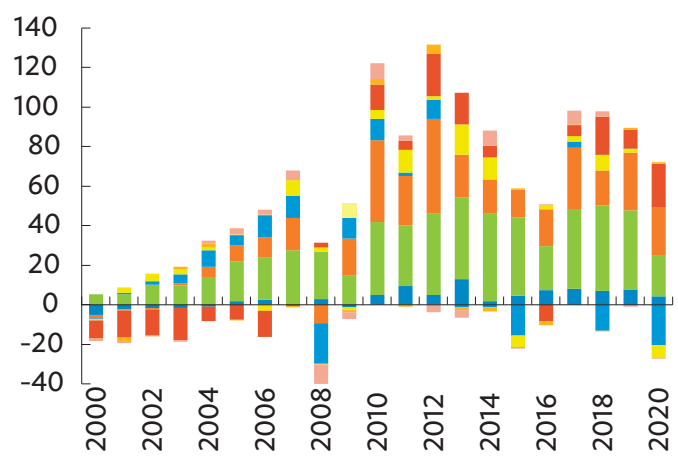

(b) India

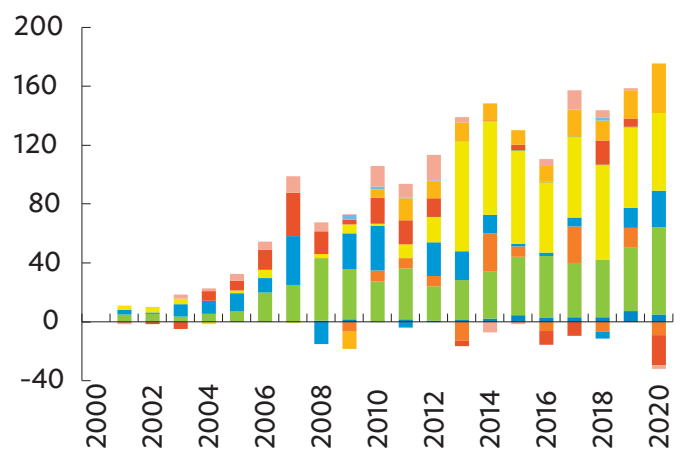

(d) Newly Industrialized Economies

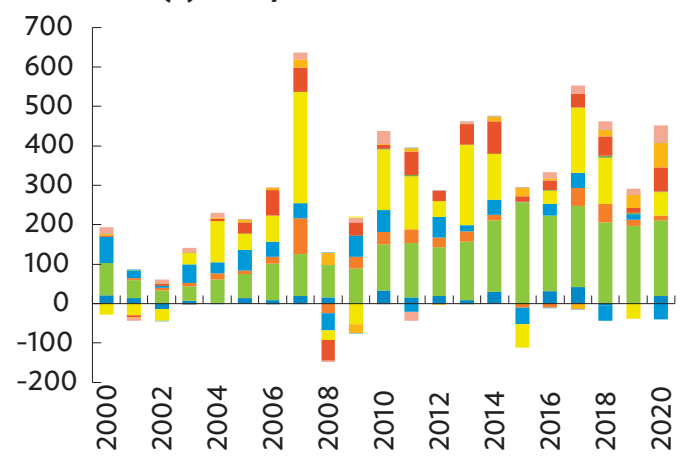

(f) Other Emerging and Developing Asia

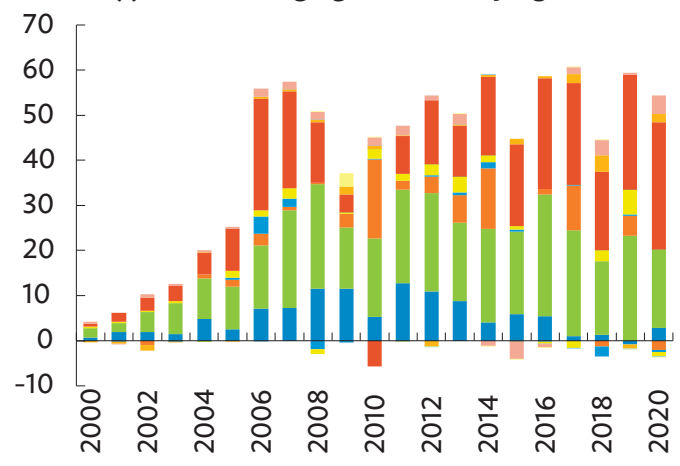

AP = accounts payable; ASEAN = Association of Southeast Asian Nations; FDI = foreign direct investment; LIPS = loans, insurance, pension, and standardized guaranteed schemes; SDR = special drawing rights.

Notes: ASEAN4 includes Indonesia, Malaysia (beginning 2002), the Philippines, and Thailand. Newly Industrialized Economies include Hong Kong, China; the Republic of Korea; Singapore; and Taipei,China. Other emerging and developing Asia includes Afghanistan (beginning 2008), Armenia, Azerbaijan (beginning 2002), Bangladesh, Bhutan (beginning 2006), Cambodia, Fiji, Georgia, Kazakhstan, Kiribati (beginning 2006), the Kyrgyz Republic, the Lao People's Democratic Republic, Maldives, Mongolia, Nepal, Pakistan, Samoa (beginning 2004), Solomon Islands, Sri Lanka, Tajikistan (beginning 2002), Timor-Leste (beginning 2006), Tonga (beginning 2003), Tuvalu, Uzbekistan (beginning 2010), and Vanuatu.

Sources: ADB calculations using data from CEIC Data Company; International Monetary Fund. Balance of Payments and International Investment Position Statistics. http://data.imf.org/IIP (accessed October 2021); and national sources. 
Figure 4a.2: Nonresident Capital Flows—Selected Asian Economies and Subregions, by Sector (\$ billion)

(a) People's Republic of China

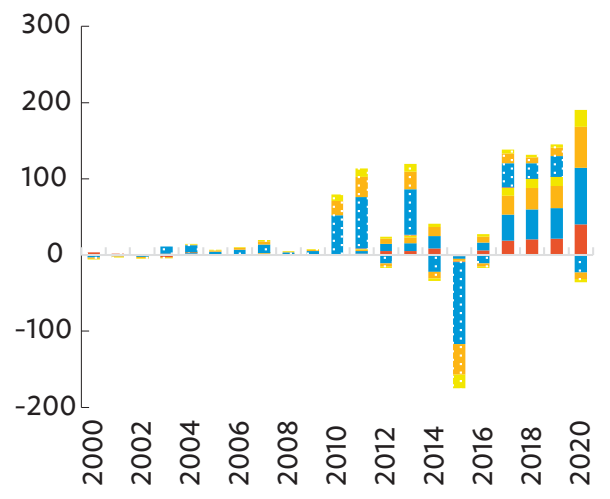

(c) Japan

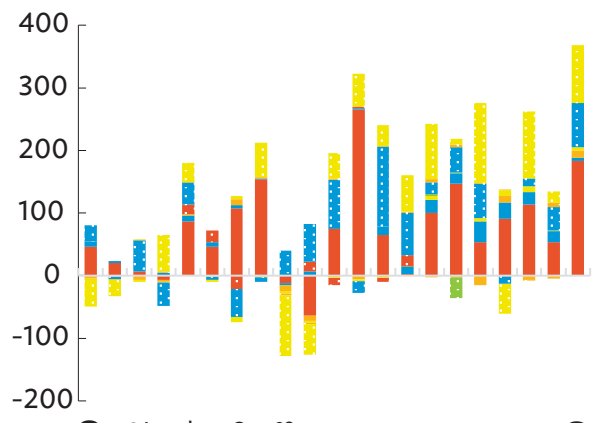

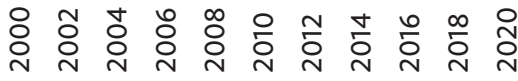

(e) Other Emerging and Developing Asia

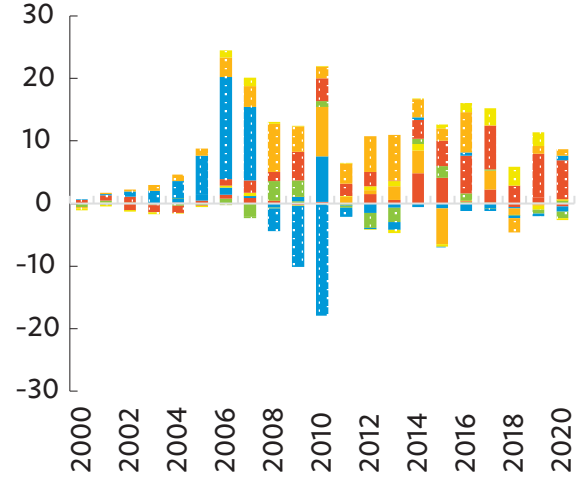

(b) India

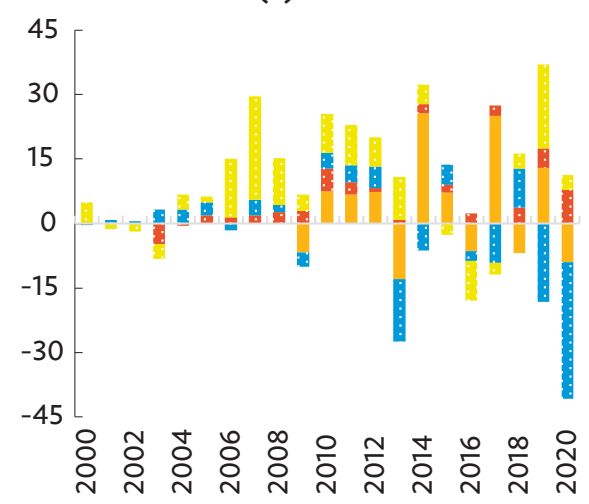

(d) ASEAN4

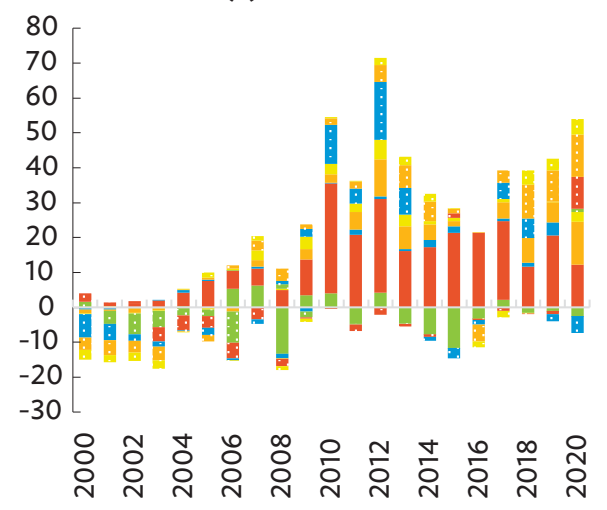

$\begin{array}{lll}\text { Central banks: } & \text { General government: } & \text { Banks: } \\ \text { Bonds } \quad \text { Loans } & \text { Bonds Loans } & \text { Bonds Loans }\end{array}$

Nonfinancial corporates: $\quad$ Other financial corporates:

Bonds Loans Bonds Loans

ASEAN = Association of Southeast Asian Nations.

Note: ASEAN4 includes Indonesia, Malaysia, the Philippines, and Thailand. Other emerging and developing Asia includes Armenia, Georgia, Kazakhstan, Mongolia, and Pakistan.

Source: ADB calculations using data from Lepers and Mercado (2021). 


\section{Annex 4b: Identifying Capital Flow Surges and Stops}

Various methods are used in the literature to identify capital inflow surges and stops. For surges, they are usually defined to imply more than the usual increase in capital inflows. However, there are various approaches in measuring "more than usual." For instance, more than usual could refer to one or two standard deviations from historic mean, filtered trend, or relative size of capital inflows. For example, Forbes and Warnock (2012a and 2021) and Mercado (2018a and 2019) used two standard deviations from historic mean. In addition, surges can also be identified based on some threshold percentile. For instance, Reinhart and Reinhart (2009) used the top 20th percentile as threshold, while Ghosh et al. (2014) used the top 30th percentile as threshold.

For "stops," Calvo, Izquierdo, and Mejia (2008) defined "sudden stops" as a sharp fall in net capital inflows. A "sharp fall" pertains to a one standard deviation drop of the year-on-year change of the 12-month moving sum of net capital inflows relative to its historic mean, provided it drops two standard deviations within the episode. In contrast, Forbes and Warnock (2012a and 2021) defined "stops" as a sharp decline in nonresident capital flows, instead of net capital inflows as used by Calvo, Izquierdo, and Mejia (2008). A sharp decline pertains to a one standard deviation drop of the year-on-year change of the 12-month moving sum of gross capital inflows relative to its 5-year rolling historic mean, provided it drops two standard deviations at some point within the episode.

In this chapter, surges and stops are derived using quarterly nonresident capital inflows sourced from the International Monetary Fund's Balance of Payments and International Investment Position Statistics. To state, "surge" is defined as an episode where nonresident capital inflows increase more than one standard deviation above its historic mean provided that (i) the entire episode lasts more than one-quarter; (ii) there are at least 5 years of data to calculate the historic mean; and (iii) it reaches at least two standard deviations above at some point within that episode. Specifically, we let $C_{t}$ be the four-quarter moving sum of gross capital inflows (GINFLOW) and derive annual year-on-year changes in $C_{t}$ :

$$
\begin{gathered}
C_{t}=\text { GINFLOW }_{t}+\text { GINFLOW }_{t-1}+\text { GINFLOW }_{t-2}+\text { GINFLOW }_{t-3}, \\
\Delta C_{t}=C_{t}-C_{t-3}
\end{gathered}
$$

Rolling average and standard deviations of $\Delta C_{t}$ are computed over the last 20 quarters. A "surge" episode is defined to start at the first month $t$ when $\Delta C_{t}$ increases more than one standard deviation above the rolling mean. But in order for an entire episode to qualify as "surge" there must be at least one quarter $t$ when $\Delta C_{t}$ increases at least two standard deviations above its mean. A "stop" episode is defined using the same approach but pertains to the opposite direction, i.e., a large decrease in nonresident capital flows. "Normal" episodes are defined as the absence of either surges or stops for a given quarter. Annex Figure 4b.1 provides an illustrative example in defining surges and stops using quarterly data for the Philippines. The figure shows that the Philippines had a surge and then stop episode before and during the global financial crisis of 2008, and a stop episode in the first quarter of 2020 at the start of the COVID-19 pandemic.

\section{Figure 4b.1: Capital Flow Surges and Stops in the Philippines}

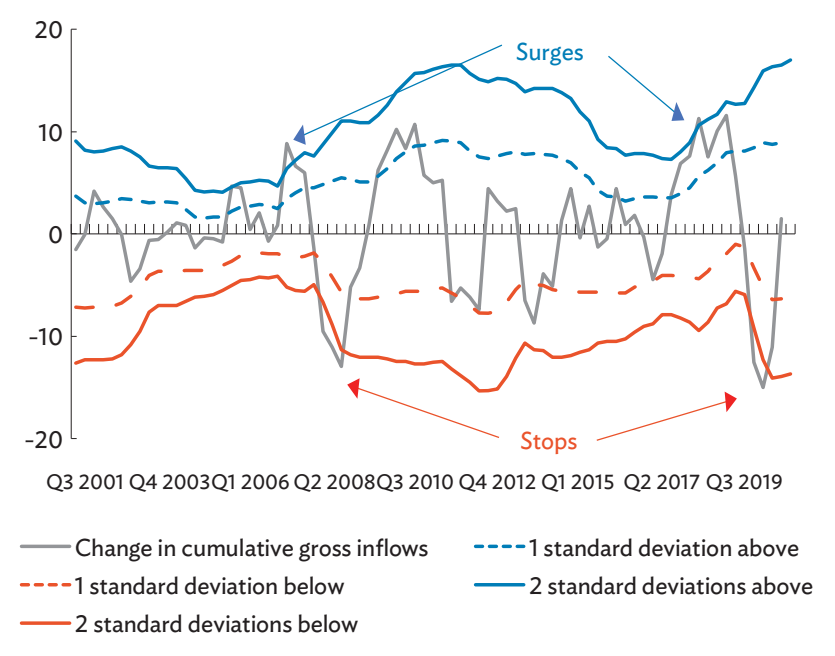

$Q=$ quarter

Sources: ADB calculations using data from International Monetary Fund. Balance of Payments and International Investment Position Statistics. http://data.imf.org/ IIP (accessed October 2021); and methodology by Forbes and Warnock (2021). 
In Asia and the Pacific, the number of female out-migrants increased to 41.3 million in 2020 from 38.2 million in 2015. Female migrants are important agents of change in the socioeconomic spheres of households and communities. They contribute to the economic development of their origin economies through remittances and poverty reducing effects and lower domestic unemployment (UN DESA 2021; Le Goff 2016; ILO 1996). Destination economies benefit through increased labor supply and its consequent impacts on employment, production, and gross domestic product (GDP) (Sijipati 2015). Female migrants were also found to be more likely to remit a higher proportion of their incomes more frequently than men (UN Women 2017). Overall, there were more male migrants (145.6 million) than female migrants ( 134.9 million) but female migrants outnumbered males in the top 10 migrant destinations in 2020, except in the United Arab Emirates, Saudi Arabia, and Germany (Figure 5.2b). The United States (US) is the destination of choice for both male and female migrants and hosted nearly 20\% (26.1 million) of global female migrants. Apart from economic drivers, female migration is influenced by factors related to social and structural gender-based inequalities, and female migrants often work in a limited range of sectors and in low-ranking jobs (Foley and Piper 2020).

The pandemic disrupted migrant flows in unprecedented ways, even though it did not alter the upward trajectory of the global stock of migrants - the 2020 global migrant stock grew 3.3\% compared with 2019 (out-migrants from Asia and the Pacific increased by 2.9\%). ${ }^{39}$

Around $91.3 \%$ of economies had no travel restrictions in January 2020 but by March, with the onset of pandemic containment measures and mobility restrictions, only about one-fifth of economies and territories allowed unencumbered international travel. ${ }^{40}$ By May 2020, an estimated $96.2 \%$ of economies had imposed total border closure (67.4\%), travel bans in some economies or regions (21.3\%), and quarantine mandate on arrivals (7.5\%). As an immediate result, hundreds of thousands of travelers, migrants, and seafarers were stranded, and

Figure 5.2: International Migrants by Origin and Destination (million)

(a) By Region of Origin

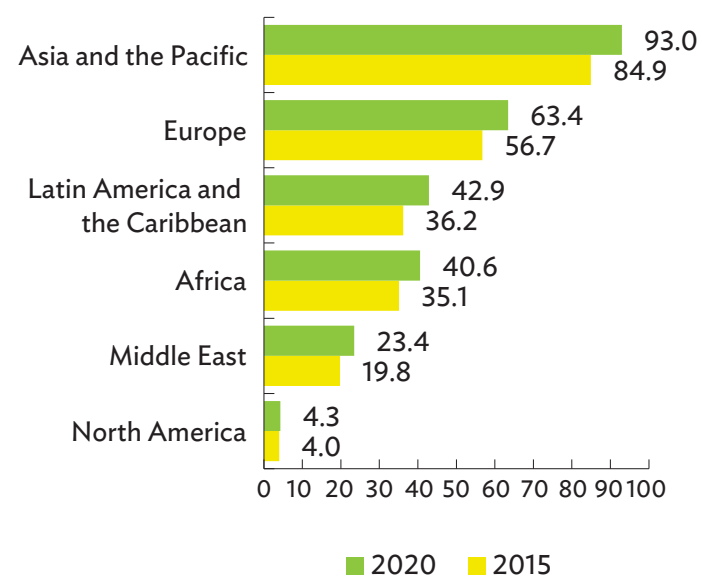

(b) In Top 10 Destinations, by Sex

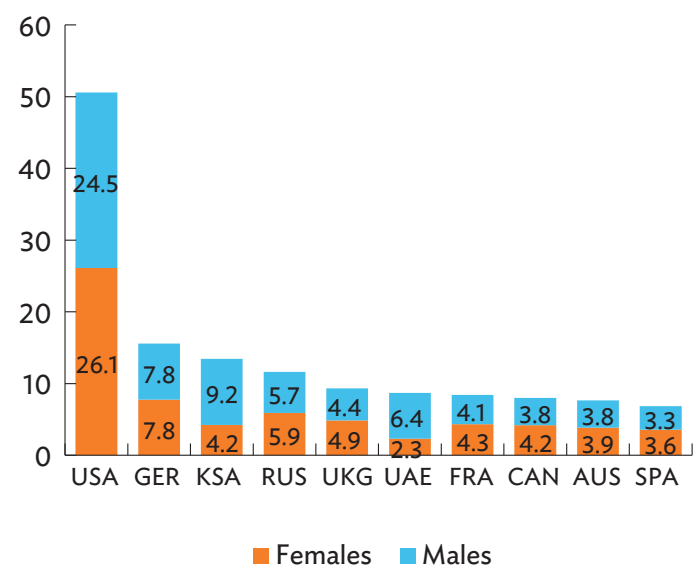

$\mathrm{AUS}=$ Australia, $\mathrm{CAN}=$ Canada, $\mathrm{FRA}=$ France, GER = Germany, $\mathrm{KSA}=$ Saudi Arabia, RUS $=$ Russian Federation, $\mathrm{SPA}=\mathrm{Spain}, \mathrm{UAE}=\mathrm{United}$ Arab Emirates, UKG = United Kingdom, and USA = United States.

Source: ADB calculations using data from United Nations Department of Economic and Social Affairs, Population Division. International Migrant Stock 2020. https://www.un.org/development/desa/pd/content/international-migrant-stock (accessed May 2021).

39 According to the United Nations Department of Economic and Social Affairs (UN DESA), early estimates assuming zero growth between 1 March and 1 July 2020 suggest a decline of 2 million international global migrants than initially expected between mid-2019 and mid-2020 (UN DESA. Migration Data Portal. https:/www.migrationdataportal.org/themes/international-migrant-stocks [accessed December 2021]).

40 ADB calculations using disaggregated international travel stringency data from Hale et al. (2021). 
international tourism went into free fall (Benton 2021). In the first 4 months of 2020 alone, international arrivals declined by $44 \%$, equivalent to a loss of 180 million arrivals relative to 2019 and tantamount to $\$ 195$ billion decline in tourism revenues. ${ }^{41}$

Governments have since shifted from restricting entry to imposing conditions for entry, requiring visa/travel/ medical documentation (Figure 5.3a). As of December 2021, such entry conditions continue to follow an upward trend, representing around $50 \%$ of travel restrictions. Gradual efforts to reopen have seen $71 \%$ of airports and $54 \%$ of water borders become fully operational (Figure $5.3 \mathrm{~b}$ ). However, $12 \%$ of land borders remained closed. Meanwhile, the portion of partially operational airports was lagging, at $14 \%$, while $24 \%$ of land borders and $30 \%$ of blue borders were partially operational.
As the pandemic constrained the movement of people, productive factors, and enterprise, the economic repercussions that followed limited opportunities for cross-border migration, some of which were caused by policy changes. The Nepali government temporarily halted sending migrant workers to the Republic of Korea under the Employment Permit System. ${ }^{42}$ Meanwhile, to ensure that the economy would have enough health workers during the pandemic, the Philippine government suspended their overseas deployment in April 2020. This measure was lifted in December 2020 and replaced by a deployment cap, which limited the number of outbound nurses to 5,000 - the cap was raised to 6,500 in June 2021 (Calonzo 2020; Baclig 2021; Punzalan 2021). The Philippines is one of the largest suppliers of nurses globally (annual pre-pandemic average was 13,000 nurses) for which demand is continuously growing, driven by the ongoing pandemic.

Figure 5.3: International Travel Restrictions

\section{(a) By Type}

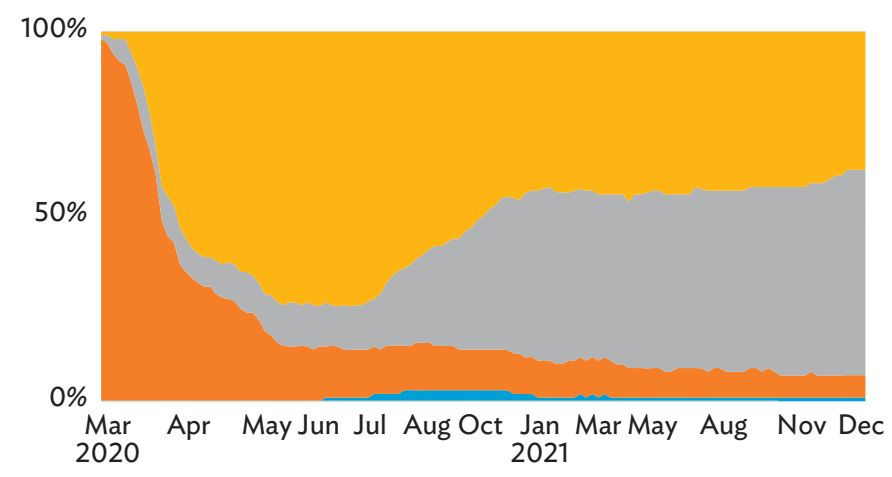

$\square$ No restrictions $\quad$ None reported Entry conditions Entry restrictions

\section{(b) By Points of Entry}

$\begin{array}{lll}\text { Airport } 6 \% \quad 14 \% & 71 \% & 9 \%\end{array}$

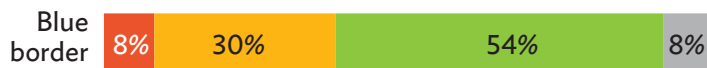

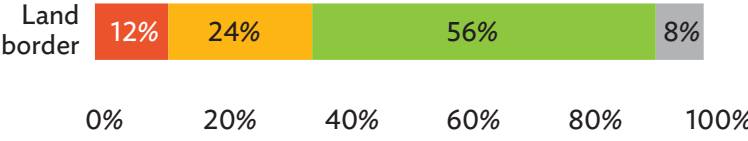

ETA = economy/territory/area.

Notes: In panel a, data refer to percentage of ETA-to-ETA travel restrictions where ETA can be an economy, territory, or area. In panel b, blue border refers to international border crossing point on sea, river, and lake ports; and land border is international border crossing point on land and includes rail. Partially operational status refers to any of the following: (i) only transport of goods is permitted and travelers are not allowed to cross; (ii) travelers cannot use the entry point to enter the economy, territory, or area; (iii) travelers cannot use the specific point to leave the economy, territory, or area; (iv) the point of entry is open to returning nationals and residents only; and (v) reduced hours of operation or closure to specific nationalities.

Source: ADB calculations using data from International Organization for Migration. Mobility Impacts. https://migration.iom.int/ (accessed January 2022).

${ }^{41}$ UNWTO. Impact Assessment of the COVID-19 Outbreak on International Tourism. https://www.unwto.org/impact-assessment-of-the-covid-19outbreak-on-international-tourism (accessed October 2021).

42 The Republic of Korea's Employment Permit System allows small and medium-sized enterprises encountering labor shortages to hire foreign workers from 16 economies in Asia and the Pacific. Government of the Republic of Korea, Ministry of Employment and Labor. Human Resources Development Service of Korea. Foreign Workforce Employment Support. https://hrdkorea.or.kr/ENG/4/2 (accessed August 2021). 


\section{Migrant workers in host economies, return migrants, and their families were disproportionately vulnerable to the pandemic shocks.}

The pandemic, which started in 2020, was estimated to have resulted in the loss of around 114 million jobs relative to 2019 and a global labor income loss equivalent to $\$ 3.7$ trillion, roughly $4.4 \%$ of global GDP (Jones, Mudaliar, and Piper 2021). The consequences of human and economic immobility plunged the global economy into a crisis, hitting international migrant workers hardest, who are generally vulnerable to major economic shocks. Among those to lose jobs first were migrants, who are overly represented in vulnerable worker groups such as younger, undocumented, low-skilled workers employed in sectors which easily succumbed to the crisis (ILO 2020a). Massive job losses among working migrants occurred in hardest-hit sectors such as accommodation and food services, arts and culture, construction, hospitality, tourism, and retail.

Amid limited financial resources and inability to return home, many of these migrants were stranded. Migrants who retained their employment faced reduced work hours; forced labor; unpaid leave; delayed, reduced, or unpaid wages; and greater exposure to physical and mental health risks. There were also instances of a resurgence of xenophobic attacks amid limited access to health services and other forms of social protection that were otherwise available to nonmigrants (Rimal 2021; IOM 2020c). In Singapore, for example, 93\% of the outbreak in COVID-19 cases occurred among migrant workers (Migration Data Portal 2021). In Qatar, where migrant workers make up $95 \%$ of the labor force, the pandemic exacerbated repeated violation of worker's right to wages - many employers used COVID-19 to not pay outstanding wages to workers who were forcibly repatriated (Human Rights Watch 2020). Government-initiated repatriation flights were used to bring significant numbers of migrants and overseas workers back to their origin economies, many of which were already reeling from the cascading impacts of the pandemic. India, the largest source of migrants globally, had repatriated around 3 million migrants by November 2020 (Migration Data Portal 2021).
Return migration and the loss of jobs was calamitous not only for remittance-sending migrants and the households they supported, but also to migrants' origin economies in general. Prior to the pandemic, many remittancedependent economies in Asia and the Pacific were transformed by leveraging the effects of remittance inflows on retail consumption, and spending on education, health, housing, and related financial investments. The sudden, massive return of migrants lowered remittance flows and risked rolling back the progress on reducing poverty and improving quality of life.

Return migration could also worsen the absorptive capacity of domestic labor markets and threaten the dwindling jobs market in the region (Weeraratne 2020). This happened in Bangladesh, Indonesia, Nepal, and the Philippines, major sources of global out-migrants with labor market challenges that the pandemic aggravated. The return of at least 327,000 overseas Filipino workers in 2020 happened as the Philippines was experiencing historically high unemployment rates and severe contractions in real output (Kang and Latoja 2022). Around 75\% of migrant workers who returned to Indonesia faced unemployment and a $60 \%$ decline in incomes (IOM 2020a). In Bangladesh, around $70 \%$ of return migrants surveyed reported difficulty in finding employment (IOM 2020b). The return of around 700,000 Nepalese migrant workers risks worsening the economy's inability to generate enough jobs for about 500,000 youth workers that the economy adds to its labor force annually (IOM 2020c). With migrants returning in droves, major migrant-sending economies in Asia and the Pacific also had to deal with mounting repatriation costs and quarantine-related expenses of return migrants. The pandemic also spotlighted the relative inadequacy of reintegration programs for return migrants (Box 5.1).

\section{Outbound migration to non-Asian destinations has steadily increased, but the COVID-19 pandemic curtailed the flow of migrant workers from Asia and the Pacific.}

Migrants from Asia and the Pacific prefer extraregional migration routes. Extraregional migration shares, which measure the relative share of Asian migrants bound for non-Asian destinations to total out-migrants from 
Box 5.1: Return and Reintegration amid the 2020 COVID-19 Crisis-The Case of Overseas Filipino Workers

Return migration is often associated with "going back to one's own culture, family and home" (ILO 2019). It occurs when migrants return to the economy of origin for a variety of voluntary and involuntary reasons. Reintegration is the re-inclusion or reincorporation of a migrant into the society of her/his economy of return (Haase and Honerath 2016). Reintegration programs in the Philippines consist of a package of interventions and mechanisms aimed at facilitating the productive return of overseas Filipino workers (OFWs) via services, which helps mitigate the economic impact and psychological costs of having to return and help returnees find paid employment or start an enterprise. These programs are overseen by the Department of Labor and Employment and are implemented primarily by the National Reintegration Center for OFWs; regional offices of the Department of Labor and Employment; and the Overseas Workers Welfare Administration.

For many OFWs impacted by the pandemic in 2020, their return was facilitated by the Department of Foreign Affair's repatriation program, the government's foremost crisis management response. While largely inevitable, this return migration has posed growing challenges in potential losses in remittances, income, and employment. More importantly, the repatriation of 327,511 OFWs in 2020 (421,676 OFWs as of September 2021) turned the spotlight on migration mechanisms facilitating the safe return of migrants and support for the reintegration of returnees into societies of origin.

OFW returnees received support through a one-time $\$ 200$ $(P 10,000)$ cash assistance. Expenses related to quarantine were also shouldered by the government and averaged around P3,000 per OFW per day. They also had access to several livelihood-oriented reintegration programs. Nevertheless, these returnees face bigger challenges, primarily due to the loss of remittance income, which constrains consumption and savings. This was particularly acute for at least $50 \%$ of OFWs who returned to households larger than the average family size, according to the results of an International Organization for Migration (IOM) survey (IOM 2021a). Finding local employment was a major hurdle as well. Many OFWs returned at a time when many regions in the Philippines were besieged by record-high double-digit unemployment rates. It came as no surprise, therefore, that $83 \%$ of return migrants were still unemployed 3 months after arrival, and that for $48 \%$ of returnees, household income had dropped by $60 \%$. The same survey also revealed that at least $50 \%$ of OFW returnees in 2020 registered for reintegration, and $58 \%$ indicated they needed financial help to support their basic needs. Many OFWs returned to communities strained by the socioeconomic costs of the pandemic and lockdown measures. Such an environment made it challenging to effectively conduct reintegration measures connecting returnees with training opportunities and livelihoods, especially with the recession crippling industries and curtailing the operations of many micro- and small enterprises.

The pandemic-induced return of OFWs offered a wealth of insights into emergency management and reception for returnees to support return migration and reintegration dynamics through reform and policy refinements. These included inculcating the value of preparedness to return for OFWs; reorienting return and reintegration mechanisms away from the one-size-fits-all approach and toward a dynamic and inclusive system that considers the diversity of migrants' needs and interests; accelerating a migrant information infrastructure; and continuing to develop skills matching programs to effectively leverage the knowledge capital brought home by returned migrants.

Sources: ADB using Haase and Honerath (2016), ILO (2019), IOM (2021a), and Kang and Latoja (2022).

Asia and the Pacific, have steadily increased since 1990 (Figure 5.4a). In 2020, 64.9\% of migrants from Asia and the Pacific emigrated to destinations outside the region but shares varied across subregions.

At least $80 \%$ of out-migrants from Central Asia goes to non-Asian destinations, most noticeably to the Russian Federation, with which the region has historical, cultural, economic, and political links. Attracted by higher wages and more employment opportunities, Central Asian migrants in the Russian Federation averaged $65.5 \%$ of total out-migrants from the subregion from 1990 to
2020. Other parts of Europe (such as Germany, Ukraine, and Belarus) and the US are also key destinations for Central Asian migrants (Figure 5.4b).

Extraregional migration shares of South Asia increased rapidly from $49.8 \% 2$ decades ago to $73.0 \%$ in 2020 , with the Middle East as the primary regional destination. During this period, the number of South Asian migrants nearly tripled. Driven by high wages and accessible employment opportunities, migrants to the Middle East steadily increased, with at least $50 \%$ of South Asian migrants in that region by 2020. The proportion of 
Figure 5.4: Out-migrants from Asian Subregions

(a) By Extraregional Migration Shares (\%)

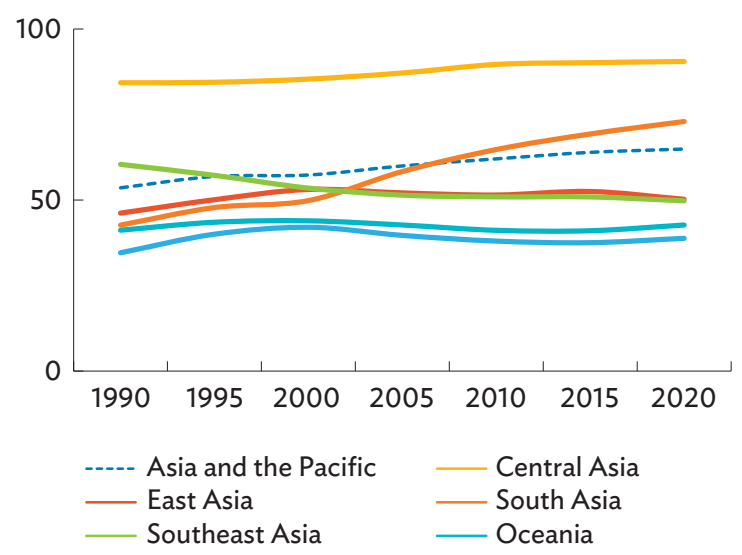

(b) By Regional Destination, 2020

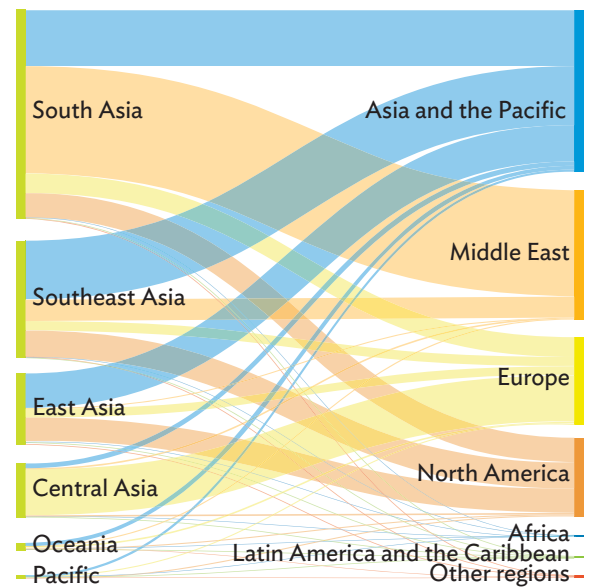

Note: In panel (a), extraregional share is computed as the share of outbound Asian migrants in extraregional destinations to the total number of Asian out-migrants. Panel (b) refers to the stock of migrants from origin Asian subregions to regional destinations.

Source: ADB calculations using data from United Nations Department of Economic and Social Affairs, Population Division. International Migrant Stock 2020. https://www.un.org/development/desa/pd/content/international-migrant-stock (accessed May 2021).

South Asian migrants of the population in the Middle East rose to $6.2 \%$ in 2020 from $3.4 \%$ in 2000 . India had the largest number of outward migrants in 2020 (17.9 million) and has been the top source of Asian out-migrants since 1995 (7.2 million). Other South Asian economies with large diaspora populations include Bangladesh (7.4 million), Pakistan (6.3 million), and Afghanistan (5.9 million) (Figure 5.5).

Figure 5.5: Top 10 Sources of Migrants from Asia and the Pacific (million)

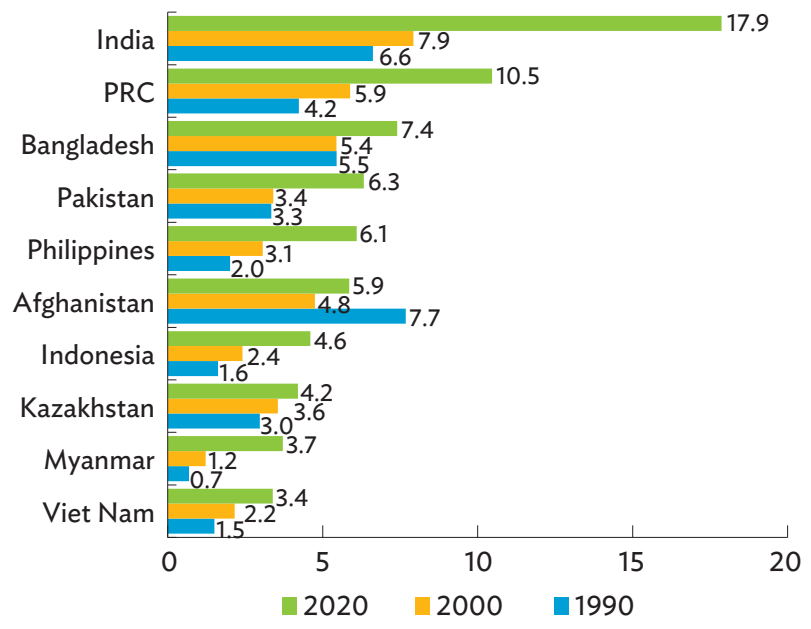

PRC $=$ People's Republic of China

Source: ADB calculations using data from United Nations Department of Economic and Social Affairs, Population Division. International Migrant Stock 2020. https://www.un.org/development/desa/pd/content/international-migrantstock (accessed May 2021).
However, the COVID-19 pandemic curtailed the flow of migrant workers from India, Bangladesh, and Pakistan to the Middle East in 2020 with some signs of recovery shown in 2021 (Table 5.1).

- Migrant flows from India in 2020 were only onefourth of the 2019 level. Significant reductions occurred in the flow of Indian workers to the United Arab Emirates (down 73.8\%); Saudi Arabia (down 46.6\%); and Qatar (down 58.3\%).

- From a pre-pandemic level of 700,159 in 2019, the flow of Bangladeshi migrants was slashed by two-thirds to 217,669 in 2020. Migrant flows declined significantly to Saudi Arabia (59.5\% lower), United Arab Emirates (67.4\%), and Qatar (92.8\%). Data for the first 5 months of 2021, however, indicated some recovery relative to 2020 outflows-year-on-year deployment to Saudi Arabia was up $7.8 \%$ while the flow of workers to the United Arab Emirates increased fourfold.

- Overall, migrant flows from Pakistan plunged $64.1 \%$ in 2020, but its major destination economies are still Saudi Arabia and the United Arab Emirates, with deployment shares of $60.7 \%$ and $23.9 \%$, respectively. Though way below the pre-pandemic average, the flow of Pakistani migrant workers in the first half of 2021 had reached at least 50\% of the 2020 level. 
Table 5.1: Migrant Flows from Bangladesh, India, and Pakistan

\begin{tabular}{|c|c|c|c|c|c|c|}
\hline \multirow[b]{2}{*}{ Destination/Origin } & \multicolumn{2}{|c|}{ Bangladesh } & \multicolumn{2}{|c|}{ India } & \multicolumn{2}{|c|}{ Pakistan } \\
\hline & 2020 & 2019 & 2020 & 2019 & 2020 & 2019 \\
\hline Bahrain & 3 & 133 & 4,175 & 5,897 & 7,843 & 8,189 \\
\hline Kuwait & 1,744 & 12,299 & 8,107 & 42,925 & 419 & 126 \\
\hline Oman & 21,071 & 72,654 & 7,206 & 26,436 & 10,336 & 28,391 \\
\hline Qatar & 3,608 & 50,292 & 8,907 & 21,381 & 7,421 & 19,327 \\
\hline Saudi Arabia & 161,726 & 399,000 & 44,316 & 83,030 & 136,339 & 332,713 \\
\hline United Arab Emirates & 1,082 & 3,318 & 17,891 & 68,203 & 53,676 & 211,216 \\
\hline Other economies & 28,428 & 162,463 & 3,543 & 120,176 & 8,671 & 25,241 \\
\hline Total outflow & 217,662 & 700,159 & 94,145 & 368,048 & 224,705 & 625,203 \\
\hline Growth in $2019-2020(\%)$ & \multicolumn{2}{|c|}{-68.9} & \multicolumn{2}{|c|}{-74.4} & \multicolumn{2}{|c|}{-64.1} \\
\hline
\end{tabular}

Sources: Government of Bangladesh, Bureau of Manpower, Employment, and Training Statistical Reports. http://www.old.bmet.gov.bd/BMET/stattisticalDataAction; Government of India, Ministry of External Affairs. Performance Smartboard. http://meadashboard.gov.in/indicators/15 (both accessed October 2021); and Government of Pakistan, Bureau of Emigration and Overseas Employment. (2020).

Meanwhile, in East Asia and Southeast Asia, the extraregional shares of out-migrants have been on a decline in recent years, as out-migration from both regions have turned toward a more intra-subregional path.

\section{Intraregional migration accounts for one- third of total migrant movement in Asia and the Pacific, varying across subregions.}

From 23 million in 1990, the stock of intraregional migrants in Asia and the Pacific had risen to $32.6 \%$ in 2020, although its share has been trending downward (Figure 5.6a). Subregionally, intraregional migration was highest in the Pacific and Oceania, followed by Southeast Asia and East Asia (Figure 5.6b). Labor agreements between the Pacific and Oceania economies, such as Australia's Pacific Labour Scheme and Seasonal Worker Programme and New Zealand's Recognized Seasonal Employer program encouraged migrant flow between these two subregions (ADB 2021). New Zealand, which had closed its international border since March 2020, excepted migrant workers from Pacific developing member countries (DMCs) and allowed their entry (through the Recognized Seasonal Employer program) in the first quarter of 2021, primarily to assist in harvest activities (Bedford 2021).

Intra-subregional migration is significant in Southeast Asia, which is a converging point of 23.6 million outbound migrants. Considerable income disparity is driving out-migrants from lower-income to higher-income economies within Southeast Asia and beyond (IOM 2019). In 2020, 11.8 million (50.2\%) of Southeast Asian migrants reside in economies within the region while 11.7 million (49.8\%) are in destinations outside Asia. Efforts of the Association of Southeast Asian Nations (ASEAN) toward greater regional integration and shared geographic borders facilitate cross-border mobility. For instance, Thailand, with a stock of 3.6 million intra-subregional migrants (of which half are from Myanmar), granted a 2-year amnesty period to regularize around 655,000 migrant workers, most of them from Cambodia, the Lao People's Democratic Republic, and Myanmar (United Nations Network on Migration 2021).

Significant demographic changes in East Asian economies, such as low fertility rates and growing aged populations have caused their governments to revise immigration policies to attract foreign workers. In general, these policies help attract more international migrants, but most of the increase in additional migrants to East Asia comes from intraregional sources. For instance, in Japan, the total number of inbound migrants increased by $24.1 \%$ to 2.8 million between 2015 and 2020, of which 2.1 million (75.1\%) were from intraregional sources. Leading the increase in the number of Japan-bound migration were migrants from the People's Republic of China (PRC), the Republic of Korea, and Viet Nam. Within the same period, the Republic of Korea also experienced a 26.1\% growth in inbound migrants, $80.7 \%$ from Asian sources, most notably Thailand, Viet Nam, and the PRC. 
Figure 5.6: Intraregional Migration in Asia and the Pacific

(a) Trend over Time

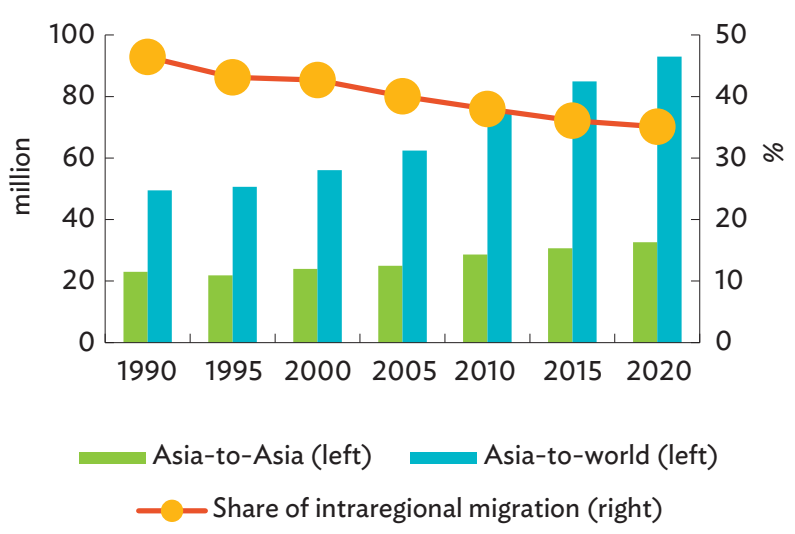

(b) By Subregion

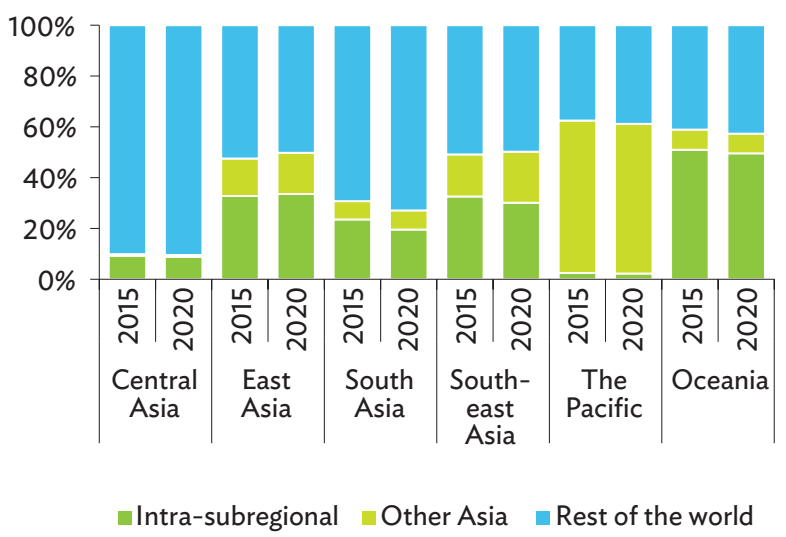

Source: ADB calculations using data from United Nations Department of Economic and Social Affairs, Population Division. International Migrant Stock 2020. https://www.un.org/development/desa/pd/content/international-migrant-stock (accessed May 2021).

Migrants from Central Asia to the Republic of Korea rose by $30.9 \%$ between 2015 and 2020, driven in part by its labor arrangements with Central Asian economies.

\section{Major host economies have been reconfiguring their approach to post- pandemic cross-border migration.}

The pandemic disrupted key processes related to the movement of migrants, including the temporary suspension of visa services, suspension of entry of certain types of immigrants, and changes in the technical coverage of certain types of visas. As a result, work permits and visas for migrant workers were drastically reduced, stalling migrant flow in major host economies. In the US, for instance, suspension of routine visa services in all consular offices from March 2020, as well as the temporary ban on the entry of certain types of nonimmigrant visa holders (such as $\mathrm{H}-1 \mathrm{~B}, \mathrm{~L}, \mathrm{~J}$, and $\mathrm{H}-2 \mathrm{~B}$ visas) from June 2020 reduced the total number of visas issued from 1.75 million in the first quarter (Q1) 2020 to 138,014 in Q2 2020. As a result, the number of workrelated US visas $(\mathrm{H}-1$ and $\mathrm{H}-2)$ issued to migrants from Asia and the Pacific, which had been increasing since 2016, fell 32.2\% in 2020 (Figure 5.7a). A similar trend was observed in other developed-economy hosts of Asian migrants (Box 5.2). Saudi Arabia, the second-largest host of migrants from Asia and the Pacific, had issued an average of 1.6 million work visas annually, from 2017 to 2019 . In 2020 , work visas issued declined by $42.5 \%$ (Figure 5.7b). Migrant flows to Saudi Arabia have since resumed-work visas in the first half of 2021 were $17.0 \%$ higher than the same period in 2020.

\section{Accelerated and inclusive vaccination programs and better disaster preparedness for migrants could improve cross-border mobility.}

There has been no change in the top economies hosting Asian migrants in 2020 relative to 2015, even with the health dangers posed by the COVID-19 pandemic. These top migrant destinations, listed in Table 5.2, hosted 61.3\% of Asian migrants based on 2020 estimates, and accounted for $38.2 \%$ of global COVID-19 cases and 31.9\% of total deaths. Among the 10 economies, COVID-19 cases per million in the top-five extraregional hosts exceeded the world average of 36,596 cases, except Saudi Arabia. Total deaths per million in Canada, Russian Federation, and the US also exceeded the world average of 690 deaths. Rapid development of the vaccine offered hope that the spread could be brought under control, but was soon dashed by supply problems, uneven access, and slow implementation of vaccine programs, especially in developing economies. High-income economies have been relatively swift in getting their populations vaccinated - in the United Arab Emirates, the vaccination rate is at least twice the world average of 117 per 100 . 
Figure 5.7: Worker Visas Issued to Asian Migrants by Selected Migrant Host Economies

(a) North America, Europe, and Oceania

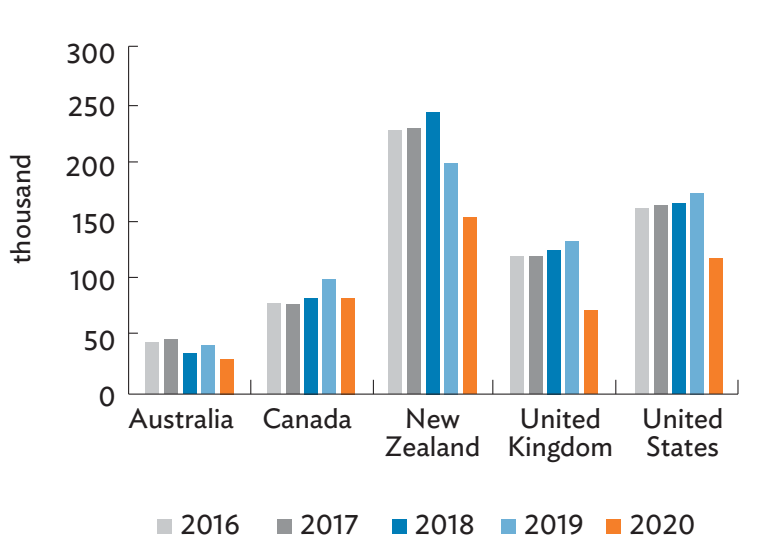

(b) Saudi Arabia

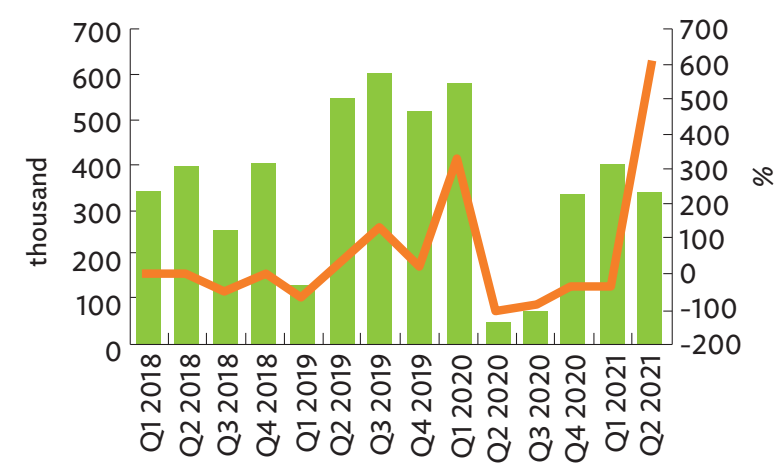

Total work visas issued (left) - Year-on-year growth (right)

Notes: Australia data refer to visas issued under the Temporary Skill Shortage and Temporary (Work) Skilled Visa programs; Canada data refer to Temporary Foreign Worker Program Work Permit holders; New Zealand data refer to work visas issued; United Kingdom data refer to work visas issued to Asian migrants; and United States data refer to total $\mathrm{H} 1$ and $\mathrm{H} 2$ visas granted to migrants from Asia and the Pacific.

Sources: ADB calculations using data from Government of Australia, Department of Home Affairs. https://www.homeaffairs.gov.au/ (accessed November 2021); Government of Canada, Employment and Social Development Canada. Quarterly Labour Market Impact Assessment Statistics. https://open.canada.ca/data/en/dataset/ e8745429-21e7-4a73-b3f5-90a779b78d1e (accessed November 2021); Government of the United States, Department of State, Bureau of Consular Affairs. https://www.state.gov/bureaus-offices/under-secretary-for-management/bureau-of-consular-affairs/ (accessed November 2021); Government of the United Kingdom, Home Office. https://www.gov.uk/government/organisations/home-office (accessed November 2021); and Kingdom of Saudi Arabia, General Authority for Statistics. https://www.stats.gov.sa/en/814 (accessed November 2021).

\section{Box 5.2: Pandemic-Induced Changes in Asian Migrant Flows to Other Major Host Economies}

Mobility disruptions caused by COVID-19 affected the cycle of temporary migration of Asian migrants as the number of visas issued by other major host economies significantly declined.

In the United Kingdom, the number of work visas issued to migrants from Asia and the Pacific dropped by $40 \%$ to 74,060 in 2020 from an average of 123,449 in 2016-2019. Changes from 2019 to 2020 were drastic for both skilled workers (-35.9\%) and temporary workers (-49.2\%).

Canada has not changed its welcoming immigration stance. It was experiencing shortages even before the pandemic happened and even introduced the Express Entry System to facilitate the migration of skilled immigrant workers. Nevertheless, the number of work permit holders under the Temporary Foreign Worker Program declined by $14.1 \%$ between 2019 and 2020. Among the top-10 source economies of Canada's migration program are India, Pakistan, the Philippines, the People's Republic of China, and the Republic of Korea, which collectively comprise $47.1 \%$ of total permanent resident visas issued in 2019.

Visas issued under Australia's Temporary Skill Shortage scheme also was down by $31.3 \%$ to 28,410 in fiscal year 2019-2020 from 41,222 in the previous fiscal year. Visas given to technicians and trade workers had the largest cut of $52.5 \%$. Visas issued to workers from India declined by $17.9 \%$ but those issued to the Philippines increased by $14.8 \%$. At the height of the pandemic, the Australian government allowed Pacific workers under both of its Pacific labor mobility initiatives (Seasonal Worker Programme and Pacific Labour Scheme) to remain working in the economy for up to 12 months. ${ }^{2}$ The impact of worker shortage on Australia's agriculture sector during the pandemic paved the way for the creation of the Australia Agriculture visa for migrant workers from Southeast Asian economies to be negotiated through bilateral agreements (Arora 2021). Although 43.1\% of migrant workers in Australia are high-skilled, the economy recently revised its Priority Migration Skilled Occupation List in a bid to attract migrants with critical skills for the continent's strong post-pandemic recovery (the box figure presents the migrant skills distribution in major host economies). Meanwhile, New Zealand is also set to replace six of its existing work visas with the Accredited Employer Work Visa to better address the economy's skilled worker shortages while providing migrants with better working conditions. The extent to which these changes in migrant flows could impact key migrant-dependent industries (such as the health sector, food processing, farming, home care, small businesses) enough to induce a pivot toward a more inclusive immigration policy has yet to be fully assessed. 


\section{Employment Distribution of Migrants by Level of Skills (\%)}

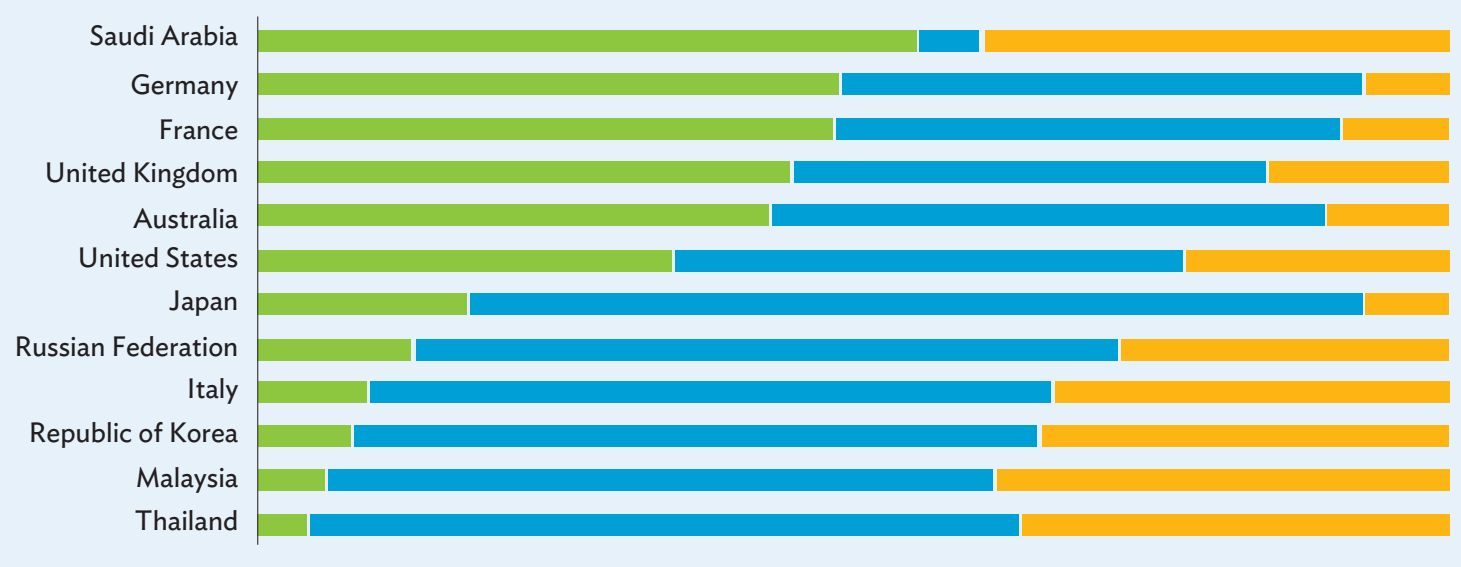

$\square$ High $\backsim$ Medium $\backsim$ Low

Notes: The International Standard Classification of Occupations defines skill level as a function of the complexity and range of tasks and duties to be performed in an occupation and is measured by considering any one of the following: (i) nature of work; (ii) level of formal education; and (iii) amount of informal on-the-job training and/or previous experience in a related occupation. High skill level refers to managers, professionals, and technicians and associate professionals. Medium skill level refers to clerical support workers, sales, and service workers, skilled agricultural, forestry, and fishery workers, crafts and related trades workers, and plant and machine operators and assemblers. Low skill level refers to elementary occupations.

Source: ADB calculations using data from International Labour Organization Statistical Database (ILOStat). https://ilostat.ilo.org/data/ (accessed 27 July 2021).

${ }^{a}$ Government of Australia, Department of Education, Skills and Employment. Seasonal Worker Programme. https://www.dese.gov.au/seasonal-worker-programme (accessed September 2021).

Source: ADB staff.

\section{Table 5.2: Top 10 Economies Hosting Asian Migrants and COVID-19 Cases}

\begin{tabular}{|c|c|c|c|c|c|}
\hline & $\begin{array}{l}\text { COVID-19 Cases } \\
\text { per Million }\end{array}$ & Deaths per Million & $\begin{array}{l}\text { Vaccination per } \\
\text { Hundred }\end{array}$ & $\begin{array}{c}\text { Stock of Asian } \\
\text { Migrants (million) }\end{array}$ & Share of Total \\
\hline United States & 164,433 & 2,480 & 153 & 12.5 & $13.5 \%$ \\
\hline Saudi Arabia & 15,739 & 251 & 144 & 9.4 & $10.1 \%$ \\
\hline Russian Federation & 70,730 & 2,074 & 100 & 6.8 & $7.3 \%$ \\
\hline United Arab Emirates & 76,262 & 217 & 224 & 6.6 & $7.1 \%$ \\
\hline India & 25,019 & 346 & 104 & 4.5 & $4.8 \%$ \\
\hline Australia & 15,625 & 87 & 165 & 3.8 & $4.1 \%$ \\
\hline Thailand & 31,786 & 310 & 147 & 3.6 & $3.9 \%$ \\
\hline Canada & 57,594 & 798 & 181 & 3.3 & $3.6 \%$ \\
\hline Malaysia & 84,149 & 961 & 176 & 3.2 & $3.5 \%$ \\
\hline Pakistan & 5,755 & 128 & 70 & 3.2 & $3.4 \%$ \\
\hline
\end{tabular}

COVID-19 = coronavirus disease.

Note: Data are as of 31 December 2021; global COVID-19 cases totaled 288,194,306.

Sources: ADB calculations using data from United Nations Department of Economic and Social Affairs, Population Division. International Migrant Stock 2020. https://www.un.org/development/desa/pd/content/international-migrant-stock (accessed May 2021); and Ritchie et al. (2020). 
Since June 2020, economies have applied various combinations of measures involving screening, testing, quarantine protocols, and (more recently) proof of vaccination, to facilitate the opening of borders and international travel to nudge migrant flow. But even the slow and cautious reopening of borders have been intermittently stalled by sudden waves of cases involving more virulent strains of the coronavirus and the uneven inclusion of migrants in national vaccination programs. Amid rising COVID-19 caseloads, which have pushed health systems in some economies in the region to near breaking point-underscoring the need for long-term health infrastructure investments-the increase in the demand for migrant workers in the field of health and medicine has not abated. For instance, the United Kingdom and Brunei Darussalam asked to be exempted from the Philippine's deployment cap of health-care workers to help fulfill its demand for additional doctors and nurses (Abuan 2021). Germany, which needs 150,000 new nurses by 2025, continued to hire Philippine nurses via its Triple Win Program (GIZ n.d.).

The COVID-19 pandemic indeed magnified the problem of lack of disaster preparedness migrants had to face. The incidences of COVID-19 are more prevalent among migrants and forcibly displaced persons than among nonmigrants. For example, the incidence rates of migrant workers who had resided in overcrowded accommodation in Singapore range from $5.64 \%$ to 21.15\% (Hintermeier et al. 2021). This is aggravated by the fact that health is frequently forgotten in migration governance and that migrants are frequently left out in preparedness and response plans (Wickramage and Annunziata 2018; Guinto et al. 2015). Previous health crises also revealed that migrants were inadequately included in crisis responses. In their study on pandemic influenza plans in the Asia and Pacific region, Wickramage and Annunziata (2018) show that only three economies (Maldives, Papua New Guinea, and Thailand) have considered noncitizens.
Migrant inclusion in COVID-19 vaccination campaigns is uneven. Globally, out of 152 economies that have submitted their National Deployment and Vaccination Plan to COVID-19 Vaccines Global Access (COVAX), only 99 have included migrants in regular situations in their plans (IOM 2021c). Other national deployment and vaccination plans, meanwhile, remain ambiguous, implying only the inclusion of migrants in their vaccination plans without explicitly mentioning them. ${ }^{43}$ Despite national efforts to include migrants in vaccination policies, a disconnect between policy and practice remains (IOM 2021c). Several obstacles emerged that have impacted migrant access to vaccines. To receive/register for vaccination, economies often require documents ranging from any form of identification to specific documents such as residence permit/national identification cards as informational barriers, mistrust (i.e., absence of reliable information for migrants), and technological requirements (i.e., internet connectivity, smartphones) for online vaccination booking also hinder migrants' access to vaccines, while clarity is lacking on costs for migrants. Yet, progress is being made. Economies where migrants may freely access COVID-19 vaccines include Australia, New Zealand, and Thailand (Bangkok Post 2021). Singapore began vaccinating its migrant workers on 8 March 2020, and Malaysia offered free vaccination to all foreigners, including undocumented migrants (Channel News Asia 2021; Latiff 2021). Meanwhile, foreign workers in the Philippines will be included in vaccination coverage as soon as the economy has procured enough supply (Geducos 2021).

\section{As economies start to rebuild, migrants can play an essential role.}

While small as a share of the global population, migration can significantly contribute to economic growth in recipient economies, as it improves overall labor productivity through the complementarity between the skills of immigrants and natives (IMF 2020). ${ }^{44}$

\footnotetext{
43 For example, the Philippine National Deployment and Vaccination Plan for COVID-19 does not specifically mention migrant workers residing in the economy in its list of priority groups. However, the Department of Health has clarified that migrants with legal residency status in the economy are part of its inoculation program (Salavierra 2021).

44 A simulation study by IMF (2020) suggests that migration could increase global GDP by about 6\% between 2020 and 2050.
} 
Migrant workers will likely play a key role in sectors badly impacted by the pandemic, particularly where migrants account for large shares in the total labor force (Box 5.3). Migrant workers boost not just their host economies but also their origin economies, through remittances, which are a lifeline for many families in low- and middleincome economies as well as a countercyclical and stabilizing macroeconomic factor.

It is crucial for host economies to leverage the power of migrants in economic recovery by including migrants in policies and plans for building back better. Australia, for instance, experienced its highest job vacancy (254,000 jobs) in the last 10 years after around 500,000 temporary visa holders left due to the pandemic (PwC 2021). Recognizing how important migrants are to the post-pandemic process, Australia has encouraged skilled migration as one of the engines for economic recovery and has been expediting visa processing to attract skilled migrants to the economy and fill critical occupations. As a majority of the world's migrants work in economies that have 75\% of the global COVID-19 cases (KNOMAD 2021b), coordinated action between and among these economies would support faster and stronger mutual recovery from the pandemic.

\section{Regional cooperation initiatives can help Asia and the Pacific navigate strategic shifts in international migration by reforging the link between migration and development.}

The COVID-19 crisis underscored the need to address key structural issues related to international migration for the long-term benefit of host and origin economies

\section{Box 5.3: Share of Migrants as a Share of Population}

The Middle East hosts the largest share of Asian migrants (7.5\%), larger than the share of non-Asian migrants (6.6\%). This is followed by North America (4.3\%) and Europe (2.3\%) (figure, panel a). Within Asia and the Pacific, with intraregional migrants accounting for less than $1 \%$ of the population, Oceania shows a significantly high share of Asian migrants (15.0\%), while Asian migrants were only a small fraction in other subregions. In regions of origin, migrants in Central Asia accounted for around $11.8 \%$ of its total population, with the Pacific (4.7\%) and Oceania (4.6\%) trailing (see figure, panel b). Central Asia (4.7\%) also remains on top in terms of remittances received as share to GDP followed closely by South Asia (4.3\%).

\section{Share of Migrants, 2020 (\%)}

(a) Population in Destination Regions

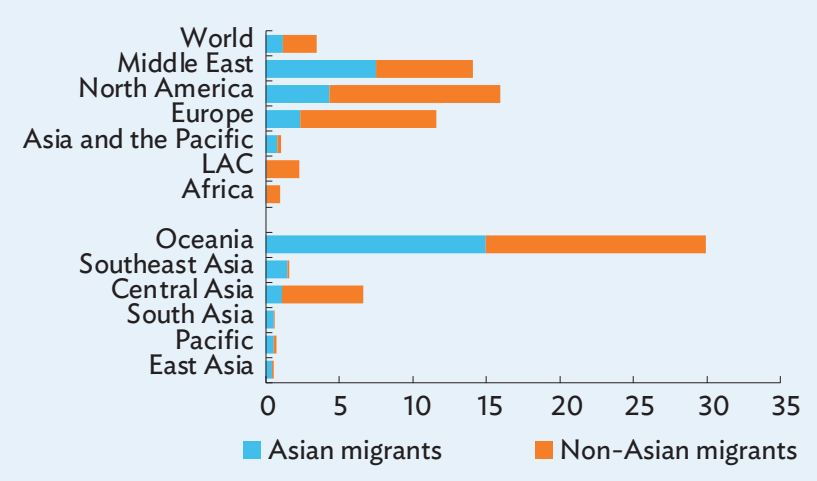

\section{(b) Population in Origin Regions}

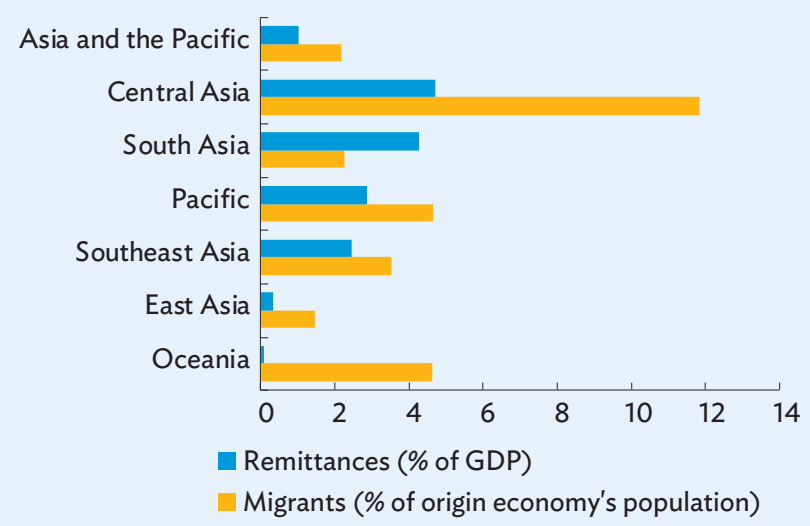

$\mathrm{GDP}=$ gross domestic product, $\mathrm{LAC}=$ Latin America and the Caribbean.

Sources: ADB calculations using data from United Nations Department of Economic and Social Affairs, Population Division. International Migrant Stock 2020. https:// www.un.org/development/desa/pd/content/international-migrant-stock (accessed May 2021); United Nations Department of Economic and Social Affairs, Population Division. World Population Prospects 2019. https://population.un.org/wpp/Download/Standard/Population/ (accessed October 2021); Global Knowledge Partnership on Migration and Development (KNOMAD). Remittances Data. http://www.knomad.org/data/remittances (accessed November 2021); and International Monetary Fund. World Economic Outlook April 2021 Database. https:/www.imf.org/en/Publications/WEO/weo-database/2021/April (accessed May 2021). 
and migrants' families. In consideration of the nature, characteristics, and drivers of migration from Asia, necessary reforms for a good recovery should be pursued at all stages of the migration process while guided by the spirit of the Global Compact for Safe, Orderly, and Regular Migration. Reinforcing the following policies is suggested:

\section{Across economies, improve migrants' access to essential infrastructure to safeguard their potential to contribute to post-COVID-19 recovery and}

beyond. Ensuring access to health services and safe accommodation facilities can contribute to migrants' physical and mental well-being and help improve their productivity. Extending migrant access to social protection coverage and integrating them into riskpooling mechanisms for social insurance will reduce overall vulnerability of migrant communities in host economies and foster social cohesion. For economies where migrant workers account for a significant share of the labor force, migrant workers can fill the labor shortages in key sectors to make economic recovery attainable. Across all economies, prioritize the vaccination for migrant workers alongside other essential workers.

\section{Leverage technology to improve migration processes} in migrant origin economies. A wide range of software applications are available to improve the recruitment system and better facilitate cross-border migration procedures, which could potentially reduce costs of migration, such as recruitment fees and placement fees. Engaging recruitment agency associations, recruitment intermediaries, placement agencies, and trade union associations to adopt or transition to technology can help governments achieve better oversight of recruitment practices. Similarly, an increasing number of online applications are available to track and monitor migrants, enable them to reach out to designated authorities during periods of distress, and/or report untoward incidents and abuse. This is especially opportune since the COVID-19 pandemic has expanded the range of uncertainties which makes migrant workers increasingly vulnerable to abuse, deceit, discrimination, and exploitation.
Accelerate efforts for secure and shareable migrant

economies. Accessible online, this type of infrastructure can speed up the facilitation of activities such as cross-border contact tracing, status verification, as well as catalyze the harmonization of standards for the issuance and use of cross-border health passports, digital vaccination certificates, skills accreditation certificates, etc. Aside from providing data-backed analysis of migration policies, migrant information systems are most useful for providing up-to-date information on migrants during periods of crises and conflicts which migration agencies, governments, and related migrant bodies may access. Migrant database systems can also help unorganized and informal migrant workers transition into the formal sector, where the ambit of the law and governance can better offer them support and protection.

\section{Reinforce commitments among migrant origin and} host economies to promote the skills profile of migrants and strengthen shared initiatives for the promotion of regular, resilient, and safe migration, particularly in major migrant corridors. This includes strengthening synergies for migrants' human capital development by expanding the mutual recognition of migrant skills between origin and destination economies, and including it in the terms of trade and investment agreements among partner economies. Exploring the portability of social insurance within the regional sphere can boost international efforts to expand social protection for migrants. Among major intraregional and intra-subregional migrant corridors, international funding initiatives such as the United Nation's Migration Multi-Partner Trust Fund, can aid regional cooperation programs, which would advance the protection of migrant workers, promote cross-border access to labor markets, and address issues to gradually eliminate irregular migration between origin and destination economies. Regional cooperation and integration initiatives on migration may also be leveraged for the design of intervention programs to promote the inflow of remittances for development, lower remittance costs, and widen financial inclusion. 


\section{Remittances}

Global remittance inflows to Asia and the Pacific totaled $\$ 314.2$ billion in 2020, a $2 \%$ decline from 2019, due to the COVID-19 pandemic. Inflows to the region are estimated to recover and grow by $2.5 \%$ in 2021 .

Over the past 2 decades, the number of migrants going abroad from Asia and the Pacific has risen, reaching 93.0 million by 2020 . Along with this increase in out-migration, the decline in the cost of remitting money, the wider use of formal remittance channels, and records of inflows to Asia and the Pacific indicated significant increases over time, reaching a peak level of $\$ 320.7$ billion in 2019. As the COVID-19 pandemic hurt the global economy-including 200 million remittancesending migrants and 800 million family recipients-it was initially estimated that remittance volume would drop as much as $7.0 \%$ globally and $7.4 \%$ in Asia and the Pacific. ${ }^{45}$ However, total remittance inflows to Asia and the Pacific declined by only $\$ 6.4$ billion in 2020 , equivalent to a $2.0 \%$ reduction over 2019 inflows (Figure 5.8). In 2021, inflows to Asia and the Pacific are estimated to have reached a new peak of $\$ 322.2$ billion as global remittances recovered a strong $6.5 \%$ from a $2.3 \%$ contraction in 2020.
Figure 5.8: Remittance Inflows to Asia and the Pacific and the World

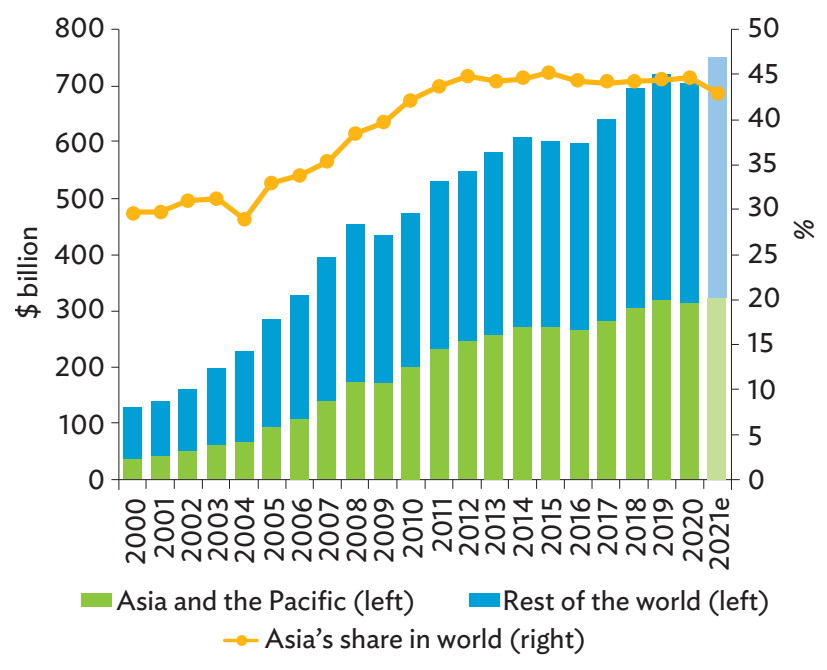

e = estimate.

Source: ADB calculations using data from Global Knowledge Partnership on Migration and Development (KNOMAD). Remittances Data. http://www. knomad.org/data/remittances (accessed November 2021).

Among regions, Asia and the Pacific continued to receive the largest share (44.6\%) of global inflows (Table 5.3). However, the combined effects of the global pandemic, weak oil prices, and movements in foreign exchange rates resulted in lower remittance inflow levels across all regions, except for Latin America and the Caribbean (KNOMAD 2021a). Relative to 2019, 2020 data reveal that Asia

Table 5.3: Remittance Inflows by Recipient Region, 2020 and 2021

\begin{tabular}{|c|c|c|c|c|c|c|c|}
\hline \multirow[b]{2}{*}{ Region } & \multirow{2}{*}{$\begin{array}{l}\text { Share of Total, } \\
2020\end{array}$} & \multicolumn{2}{|c|}{$\begin{array}{l}\text { Remittance Inflows } \\
\text { ( } \$ \text { billion) }\end{array}$} & \multicolumn{2}{|c|}{ Growth } & \multicolumn{2}{|c|}{$\begin{array}{l}\text { Level Change } \\
\text { ( } \$ \text { billion) }\end{array}$} \\
\hline & & 2020 & 2021e & 2020 & $2021 e$ & 2020 & $2021 e$ \\
\hline Asia and the Pacific & $44.6 \%$ & 314.4 & 322.2 & $-2.0 \%$ & $2.5 \%$ & -6.4 & 7.8 \\
\hline Europe & $23.9 \%$ & 168.8 & 176.9 & $-5.6 \%$ & $4.8 \%$ & -10.0 & 8.1 \\
\hline $\begin{array}{l}\text { Latin America and the } \\
\text { Caribbean }\end{array}$ & $14.8 \%$ & 104.1 & 126.4 & $6.2 \%$ & $21.4 \%$ & 6.1 & 22.3 \\
\hline Middle East & $3.3 \%$ & 23.1 & 22.9 & $-8.1 \%$ & $-0.9 \%$ & -2.0 & -0.2 \\
\hline North America & $1.0 \%$ & 7.3 & 7.0 & $13.3 \%$ & $-5.0 \%$ & -1.1 & -0.4 \\
\hline Africa & $11.8 \%$ & 83.6 & 91.7 & $-4.0 \%$ & $9.7 \%$ & -3.5 & 8.1 \\
\hline
\end{tabular}

e = estimate.

Source: ADB calculations using data from Global Knowledge Partnership on Migration and Development (KNOMAD). Remittances Data. http://www.knomad.org/data/ remittances (accessed November 2021).

45 Remittance Community Task Force Secretariat (2020) and KNOMAD. Remittances Data. https://www.knomad.org/data/remittances (accessed May 2021). 
and the Pacific had a $\$ 6.4$ billion shortfall, while flows to Europe fell by $5.6 \%$ and contracted the most in by value ( $\$ 10.0$ billion). Inflows to North America fell by $13.3 \%$, to the Middle East by $8.1 \%$, and to Africa by $4.0 \%$. Estimates suggest that global remittance inflows will grow by $6.5 \%$ to $\$ 751.2$ billion in 2021-inflows to Asia and the Pacific will recover with a $2.5 \%$ growth or additional inflows of around $\$ 7.8$ billion over 2020 (KNOMAD 2021a).

\section{Several factors including altruism, social assistance, and financial incentives to use formal channels have contributed to resilient remittances.}

Remittances to Asia and the Pacific initially slowed, especially during March to May 2020 when government mobility measures were most restrictive but rebounded thereafter. By running counter to an economy's downtrend, remittance inflows buttressed the limited fiscal space of developing economies and provided a lifeline to many households that lost jobs and incomes. ${ }^{46}$

With remittance senders eager to support their families' needs in their home countries, these "economic first responders" helped prop up recipient countries' markets through the impact of remittances on income and consumption activities of beneficiary households (Ersek 2021). This altruistic behavior by remittance senders who cut down on their consumption and drew down their savings was pointed as the primary driver of remittances in the pandemic (Ratha 2021; Kpodar et al. 2021). For instance, record inflows to South Asia could be due to their high degree of altruism relative to other middle-income economies (Mercer-Blackman and Li 2021). ${ }^{47}$ Such altruistic motivations to remit may in turn create countercyclical movements of remittances that may have mitigated the negative impacts caused by the crisis (Box 5.4). The following factors also enabled remittance inflows in 2020:
- Fiscal stimulus in developed migrant host economies, specifically cash transfers, positively impacted migrants, enabling them to remit amid the pandemic, as in the case of migrant workers in the US. ${ }^{48}$

- Mobility restrictions constrained in-person transactions from March to May 2020 and made it very prohibitive to remit via informal means. This influenced the remittance-sending behavior of migrants which accelerated the formalization of remittances, including digital channels, hence improving the capture of remittance data (Dinarte et al. 2021). For instance, remittances to Pakistan from its biggest remittance source economy, Saudi Arabia, increased by 22\% (Jamal 2021). In Nepal, the government introduced a digital wallet service to Nepali migrants abroad so they could send remittances online, which led to the sharp increase in remittance inflows in June 2020 (Ernst 2021; IOM 2021b).

- Tax and related incentives also encouraged remitting via formal channels. Pakistan incentivized banks and financial institutions to market their home remittance services, while Bangladesh and Sri Lanka offered cash and percentage incentives to their nationals abroad who remitted through authorized channels (Takenaka, Kim, and Gaspar 2021).

- The depreciation of the local currency in the recipient economy against the US dollar also raised remittance money received by recipient families, as in Bangladesh (IOM 2021b). However, an exchange rate depreciation vis-à-vis the US dollar in receiving economies could also result in lower US dollar remittances, since less US dollars can buy the same basket of goods as before the depreciation (Poghosyan 2020).

46 Unlike capital flows, remittances are unrequited transfers that do not have to be paid back and hence tend to have substantial effects on consumption stability particularly for liquidity-constrained income cohorts (ADB and World Bank 2018).

47 Altruism is captured in the World Bank's 2014 and 2017 Global Financial Inclusion (Global Findex) surveys in which respondents were asked whether they can come up with emergency funds as well as whether the source of funds are from family and friends.

48 In the US, for example, employment of migrants quickly recovered after April 2020. Combined with government cash transfers, this stimulus enabled migrants to send remittances to their origin economies. 


\section{Box 5.4: Countercyclicality of Bilateral Remittance Inflows to Asia and the Pacific}

The role of remittance inflows into developing economies has been highlighted, particularly during economic downturns, as they are more reliable sources of external financing, for example, than foreign direct investment and tourism receipts. Evidence of strong resilience in remittance inflows to developing economies during economic downturns and crises suggests that remittances may be countercyclical to the receiving economy, i.e., negative association between remittances and business cycles.

With a focus on Asian recipients, a gravity model of bilateral remittances is estimated, as remittances are influenced by the characteristics of both remittancesending and receiving economies. Annual data in the analysis cover 44 recipient economies in the region and 213 sender economies from 2010 to 2018.

Models of bilateral remittances are estimated using ordinary least squares, random-, and fixed-effects models, controlling for bilateral migrants stock, relative business cycles, economic size, income level, and time invariant variables including proximity between two economies. The relative business cycle is calculated as business cycles of receiver economy vis-à-vis its sender economy based on the standardized Christiano-Fitzgerald filtered of log of annual gross domestic product time series.
The significant, negative coefficients on relative business cycle show that bilateral remittance inflows to the region are countercyclical to the business cycles of a receiving economy relative to a sending economy (table). While various types of motives exist that lead to either countercyclical, procyclical, or acyclical remittances, such a finding suggests that motives like altruism may play a stronger role than other motives in Asia and the Pacific.

An additional analysis suggests that the degree to which remittances are countercyclical varies by subregionCentral Asia and Southeast Asia, where several economies with high economic dependence on remittances tend to show stronger countercyclicality than other subregions. Aside from the business cycles, other key determinants of bilateral remittances include exchange rate, capital account openness, and political stability. The cost of sending remittances is negatively associated with remittances, depending on the model specification.

The findings carry several policy implications and call for the attention of the policy makers and stakeholders. As remittances to Asia and the Pacific tend to be resilient during the downturn of the economy, governments can leverage these characteristics through reforming various areas of remittance policies by lowering the costs of remittances, accelerating finance sector development, introducing measures to incentivize and facilitate remittances, and maintaining a stable political climate.

\section{Estimation Results}

\begin{tabular}{|c|c|c|c|c|}
\hline Dependent variable $=$ Log $\left(\right.$ bilateral remittances $\left.\mathrm{ijt}_{\mathrm{j}}\right)$ & (1) & (2) & (3) & (4) \\
\hline \multirow[t]{2}{*}{ Log(migrant stock $\left.\mathrm{ijt}_{\mathrm{j}}\right)$} & $1.058^{* * *}$ & $0.940^{* * *}$ & $0.987^{* * *}$ & $0.754^{* * *}$ \\
\hline & $(0.008)$ & $(0.014)$ & $(0.004)$ & $(0.027)$ \\
\hline \multirow[t]{2}{*}{ Relative business cycle $_{\mathrm{ijt}}$} & $-0.135^{* * *}$ & $-0.021^{* * *}$ & $-0.061^{* * *}$ & $-0.070^{* * *}$ \\
\hline & $(0.014)$ & $(0.007)$ & $(0.010)$ & $(0.012)$ \\
\hline \multirow[t]{2}{*}{$\log \left(G D P_{i t}\right)$} & $0.123^{* * *}$ & $0.194^{* * *}$ & -0.222 & -0.468 \\
\hline & $(0.007)$ & $(0.012)$ & $(0.368)$ & $(0.453)$ \\
\hline \multirow[t]{2}{*}{$\log \left(G D P_{j t}\right)$} & $-0.069^{* * *}$ & 0.020 & -0.106 & $-0.458^{* *}$ \\
\hline & $(0.009)$ & $(0.015)$ & $(0.187)$ & $(0.214)$ \\
\hline \multirow[t]{2}{*}{$\log \left(\right.$ per capita GDP $\left.P_{\text {it }}\right)$} & $-0.054^{* * *}$ & -0.000 & $1.005^{* * *}$ & $1.308^{* * *}$ \\
\hline & $(0.014)$ & $(0.022)$ & $(0.358)$ & $(0.441)$ \\
\hline \multirow[t]{2}{*}{ Log $($ per capita GDP j $)$} & $0.115^{* * *}$ & $0.134^{* * *}$ & 0.092 & 0.299 \\
\hline & $(0.014)$ & $(0.020)$ & (0.198) & $(0.229)$ \\
\hline \multirow[t]{2}{*}{$\log \left(\right.$ distance $\left._{i j}\right)$} & $0.120^{* * *}$ & $-0.154^{* * *}$ & -0.015 & \\
\hline & $(0.027)$ & $(0.046)$ & $(0.016)$ & \\
\hline \multirow[t]{2}{*}{ Contiguity $_{i j}$} & $-0.429^{* * *}$ & $-0.397^{* *}$ & $-0.114^{* *}$ & \\
\hline & $(0.111)$ & $(0.175)$ & $(0.047)$ & \\
\hline \multirow{2}{*}{ Common language $_{i j}$} & 0.006 & $0.224^{* * *}$ & -0.011 & \\
\hline & $(0.046)$ & $(0.070)$ & $(0.028)$ & \\
\hline
\end{tabular}




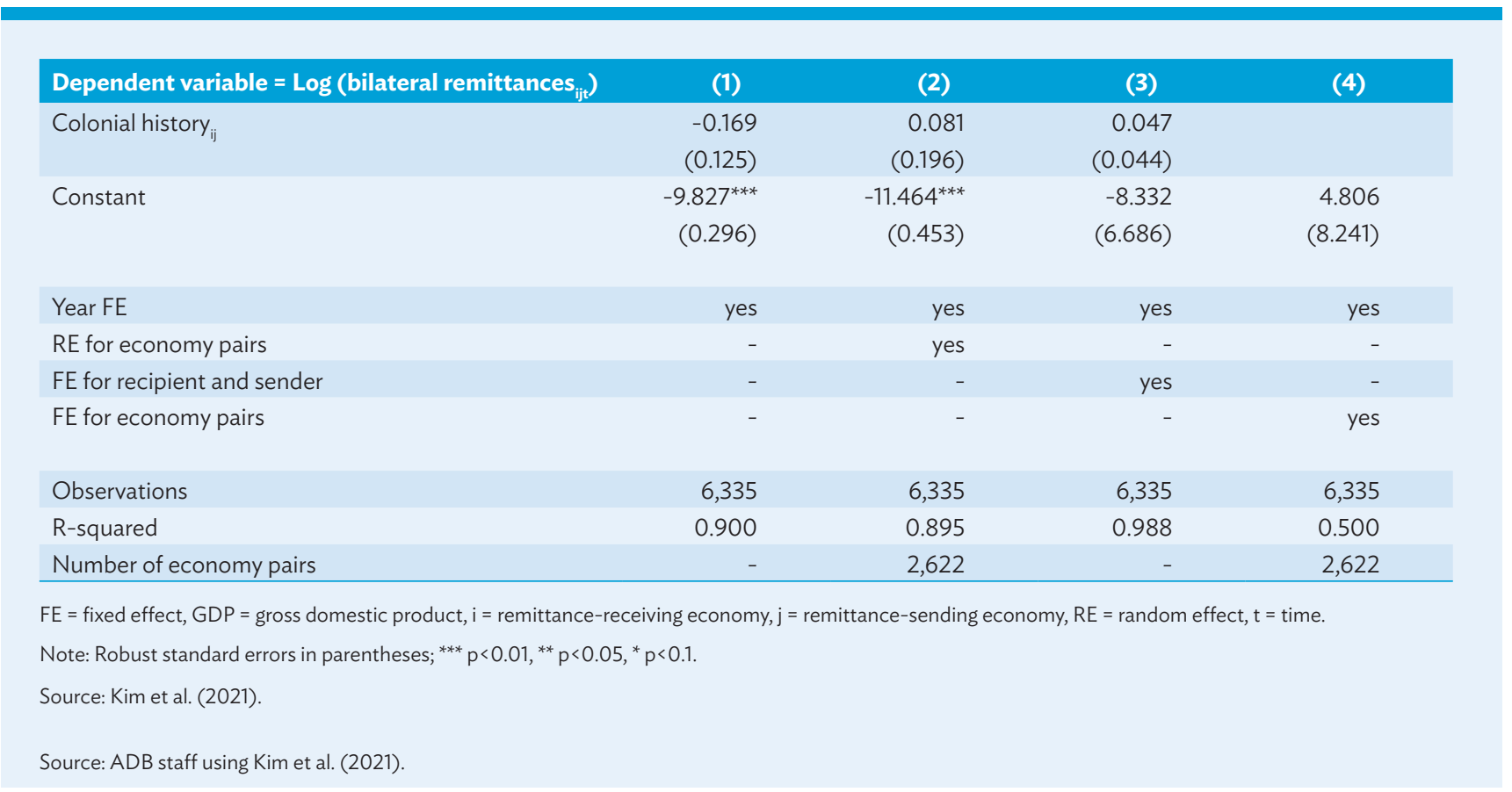

Aside from the consumption-smoothing mechanism of remittances, which serves as an important form of protection for recipient households, remittance inflows have become an increasingly important source of financial flows to Asia and the Pacific (Figure 5.9). Making up $10.3 \%$ of total inflows to the region in 2000 , the share of remittances rose to $22.3 \%$, on average, during 2015-2019. The ratio of remittances to official development assistance had gone up from a factor of 3 in 2000 to almost 13 in 2019. In the 5 years prior to the pandemic, growth in remittance inflows (average 4.2\%) was only second to tourism receipts (6.8\%) and far more robust than net foreign direct investment inflows (-3.1\%). In 20 developing economies in Asia and the Pacific, remittance inflows were proportional to around 5\% of GDP. Beyond the aggregate figures, remittances are a major source of financial support for families, especially in the rural sector (Box 5.5). Through remittances, many recipient households in Asia and the Pacific can finance transformational activities such as education and entrepreneurship, which could positively spill over to communities and the local economy (Remittance Community Task Force Secretariat 2020). As the pandemic continues, lower or no remittances could put many Asian households at risk of or even sliding back into poverty.
Figure 5.9: Financial Flows to Asia and the Pacific, by Type

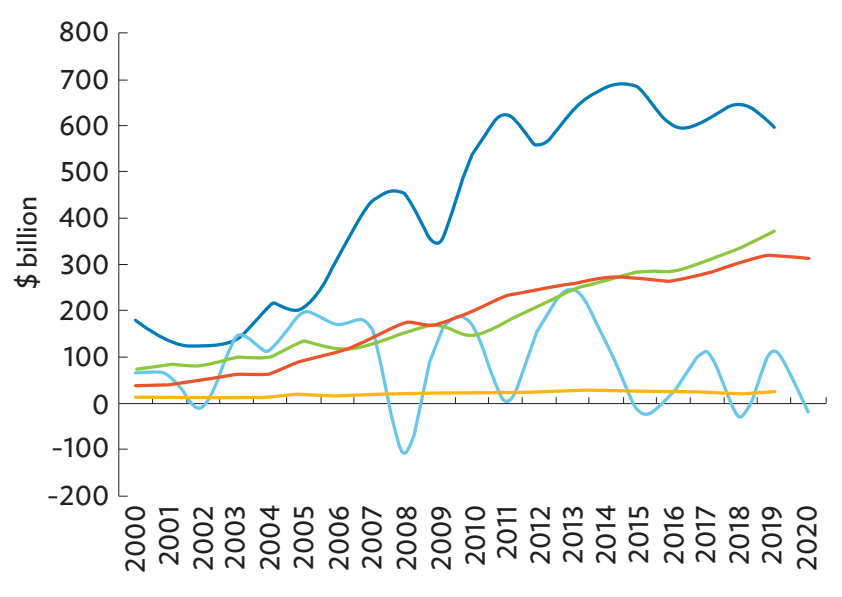

—Net FDI inflows - Net equity inflows - Tourism receipts - Remittance receipts - ODA and official aid

$\mathrm{FDI}=$ foreign direct investment, $\mathrm{ODA}$ = official development assistance.

Sources: ADB calculations using data from Global Knowledge Partnership on Migration and Development (KNOMAD). Remittances Data. http://www. knomad.org/data/remittances (accessed May 2021); and World Bank. World Development Indicators Database. https://databank.worldbank.org/source/ world-development-indicators\# (accessed December 2021). 


\section{Box 5.5: Remittance Inflows during a Pandemic-Ridden 2020: The Case of Rural Households in Bangladesh}

Bangladesh, like many other top remittance-recipient economies in the region, experienced record low remittance inflows at the onset of the COVID-19 pandemic in 2020. In March, remittance receipts fell $12.5 \%$ (equivalent to $\$ 182$ million) compared with the same month in 2019. It further dropped in April by 23.8\% (year-on-year) while it managed to post a smaller decline of $13.9 \%$ in May. Since June 2020, however, remittance inflows rebounded, offsetting earlier losses, and capping off 2020 with an annual growth of $18.6 \%$.

How was this macro-level remittance shock felt at the household level? Did remittance-recipient families experience an equivalent scale of shocks? To what extent did the fluctuations in remittance income affect their social and economic well-being?

Data from repeated tele-surveys among nationally representative rural households in Bangladesh reveal that a great majority of overseas remittance-dependent households received lower remittance money in the second quarter of 2020 , with some witnessing the unexpected return of their migrant family member/s, mainly due to pretermination of contracts. ${ }^{a}$ Major findings from the surveys reveal that:

- Among the 2,211 households surveyed, around 275 (12.4\%) reported having at least one migrant family member abroad, of which around $9.5 \%$ indicated that they did not receive any amount of remittance during the period even before the COVID-19 pandemic (i.e., December 2019 to February 2020). However, from March to May 2020, the share of migrant-sending households receiving no remittances from their migrant family member/s further increased to $40.4 \%$.

- Between March and May 2020, households only received an average of Tk6,380 (\$75) per month, a 65\% reduction from the Tk18,255 (\$215) monthly average they received 3 months prior.

- The number of migrants who returned from March to December 2020 due to permanent or temporary job loss affected a quarter (25.45\%) of migrantsending households.
While remittances significantly declined from the beginning of the pandemic, the survey data showed some recovery in the latter half of 2020. For example, the proportion of migrant-sending households with no reported remittance inflows gradually declined from $40.4 \%$ in March-May 2020 to $22.2 \%$ in the second survey wave (June to August 2020) and further to $14.5 \%$ during the survey period of September-December 2020. Accordingly, the average monthly remittances also increased from Tk6,380 in MarchMay to Tk14,605 in June-August, and further to Tk15,892 in September-December. Malek, Truong, and Sonobe (2021a, $2021 b)$ reported that the rebound of remittance inflows in the latter part of 2020 helped recipient families smooth their consumption without resorting to the sale of any of their household assets.

Although aggregate remittance inflows obtained from the telesurvey data are generally consistent with the macro data from Bangladesh Bank, the household data trend has shown greater proportionate decline and fluctuation over time, also suggesting a slower recovery. Assuming an equivalent scale of shock in the remittance-recipient economy, the extent of shock felt at the household level may have been underestimated.

In general, remittance inflows to Bangladesh remained strong in 2020 despite the many challenges induced by the pandemic. But the same may not be true for families of returned migrants who lost their jobs abroad and their remittance income. Unexpected reduction or suspension of remittances can leave recipient families particularly vulnerable. Migrant-sending households use remittances to buy essential items such as food, clothing, shelter, health, and education, some without alternative sources of income to support those needs.

Many existing government emergency social protection measures are linked to employment (e.g., unemployment benefits and minimum wage guarantee program) and these, by design, will not reach hard-hit remittance-recipient households. Financial support is deemed crucial for these families while ensuring economic reintegration of their returned migrant members. Further, it may help to expand social protection coverage to low-income remittance-recipient households who may be falling back into the poverty trap.

\footnotetext{
a A nationally representative sample involving 2,211 rural households from 62 villages in 56 districts (known as the Mahbub Hossain Survey sample) was contacted and participated in a telephone survey led by ADB Institute in three rounds, i.e., June 2020, September 2020, and January 2021.

Source: ADB staff using Malek, Truong, and Sonobe (2021a, 2021b).
}

\section{Remittance inflows to Asian subregions declined in 2020, except for South Asia and the Pacific. A strong rebound is estimated in 2021, except in East Asia.}

South Asia was the largest remittance-recipient region in 2020, followed by Southeast Asia and East Asia (Table 5.4). Driven by remittances to Bangladesh, India, and Pakistan, formal remittance flows to South Asia had been increasing 
Table 5.4: Remittance Inflows to Asian Subregions, 2020 and 2021

\begin{tabular}{|c|c|c|c|c|c|c|c|}
\hline \multirow[b]{2}{*}{ Subregions } & \multirow{2}{*}{$\begin{array}{c}\text { Share of Total, } \\
2020\end{array}$} & \multicolumn{2}{|c|}{$\begin{array}{l}\text { Remittance Inflows } \\
(\$ \text { billion })\end{array}$} & \multicolumn{2}{|c|}{ Growth } & \multicolumn{2}{|c|}{$\begin{array}{l}\text { Level Change } \\
\text { (\$ billion) }\end{array}$} \\
\hline & & 2020 & $2021 e$ & 2020 & $2021 \mathrm{e}$ & 2020 & $2021 \mathrm{e}$ \\
\hline South Asia & $46.8 \%$ & 147.1 & 158.9 & $5.2 \%$ & $8.0 \%$ & 7.3 & 11.8 \\
\hline Southeast Asia & $24.0 \%$ & 75.4 & 76.4 & $-3.5 \%$ & $1.4 \%$ & -2.7 & 1.1 \\
\hline East Asia & $23.2 \%$ & 72.8 & 66.9 & $-10.1 \%$ & $-8.1 \%$ & -8.2 & -5.9 \\
\hline Central Asia & $5.3 \%$ & 16.8 & 17.6 & $-10.8 \%$ & $4.8 \%$ & -2.0 & 0.8 \\
\hline Oceania & $0.4 \%$ & 1.3 & 1.4 & $-39.6 \%$ & $1.2 \%$ & -0.9 & 0.0 \\
\hline Pacific & $0.3 \%$ & 0.9 & 1.0 & $14.4 \%$ & $3.1 \%$ & 0.1 & 0.8 \\
\hline
\end{tabular}

$\mathrm{e}=$ estimate.

Source: ADB calculations using data from Global Knowledge Partnership on Migration and Development (KNOMAD). Remittances Data. http://www.knomad.org/data/ remittances (accessed November 2021).

at an average annual rate of $4.8 \%$ in the past decade, peaking at $\$ 147.1$ billion in 2020 . Inflows to the subregion even rose by $5.2 \%$ in 2020 despite the pandemic, which was primarily attributable to the cancellation of travel to Saudi Arabia in July 2020, allowing migrants to remit instead the funds they had set aside for the Haj pilgrimage. Flooding in Bangladesh in July 2020 also prompted greater remittances from migrant workers overseas. Tax incentives offered by Bangladesh and Pakistan also improved the use of formal remittance channels which record cross-border flow of funds. Remittances are a critical funding source for South Asian economies. In 2019, remittances to the subregion were 2.5 times the size of foreign direct investment and at least 9 times the size of official development assistance. Inflows to South Asia are estimated to have surged by $8 \%$ to reach a new high of $\$ 158.9$ billion in 2021.

In the Pacific, vibrant inflows to Fiji, Samoa, Solomon Islands, Tonga, and Vanuatu caused a $14.4 \%$ increase in remittances to the subregion in 2020 . The uptrend is forecast to continue, with $3.1 \%$ growth in 2021 as higher remittances to Fiji, Kiribati, and Tonga prevail.

Pandemic-induced mobility restrictions and the depreciation of the Russian ruble broke Central Asia's remittance growth streak in 2016-2019 as inflows plunged by $10.8 \%$ in 2020 . Inflows to all Central Asian economies declined in 2020 (except for Azerbaijan and the Kyrgyz Republic) amid the recession caused by COVID-19 and the wave of returning migrants from the Russian Federation. In
Southeast Asia, remittances were $\$ 2.7$ billion lower than in 2019-higher inflows from the US were not enough to offset the decline in remittances from migrants in the Middle East and Europe and the return of many Southeast Asian migrants. Remittance inflows to both subregions are forecast to recover in 2021 with estimates of additional inflows of $\$ 1.1$ billion and $\$ 0.8$ billion to Southeast Asia and Central Asia, respectively. Meanwhile, the decline in inflows to the PRC and Mongolia is estimated to continue to 2021, with the subregion's remittances contracting (by $8.1 \%$ ) for the second consecutive year.

\section{Remittance-Recipient Economies in Asia and the Pacific}

Quarterly data support the relative resilience manifested by remittance inflows to Asia (Figure 5.10). Although remittances to the region took a major tumble $(8.7 \%$ decline) in Q2 2020, inflows to all subregions began to recover, except Oceania. By economy, inflows grew strongly to Bangladesh (18.4\%) and Pakistan (17.3\%). The flow of Bangladeshi working migrants fell to 217,669 in 2020 from a peak of 1 million workers in 2017 and 700,159 in 2019.49 Yet remittance flows to Bangladesh were particularly robust, as monthly flows recorded double-digit year-on-year growth rates from June 2020 to May 2021. Similarly, migrant worker flows from Pakistan were lower by $64.1 \%$ in 2020 , but monthly remittance flows showed record growth rates from June to December 2020.

49 Government of Bangladesh, Bureau of Manpower, Employment, and Training Statistical Reports. http://www.old.bmet.gov.bd/BMET/ stattisticalDataAction (accessed October 2021). 
Figure 5.10: Trend of Remittance Inflows to Asia and the Pacific by Subregions (\%, year-on-year)

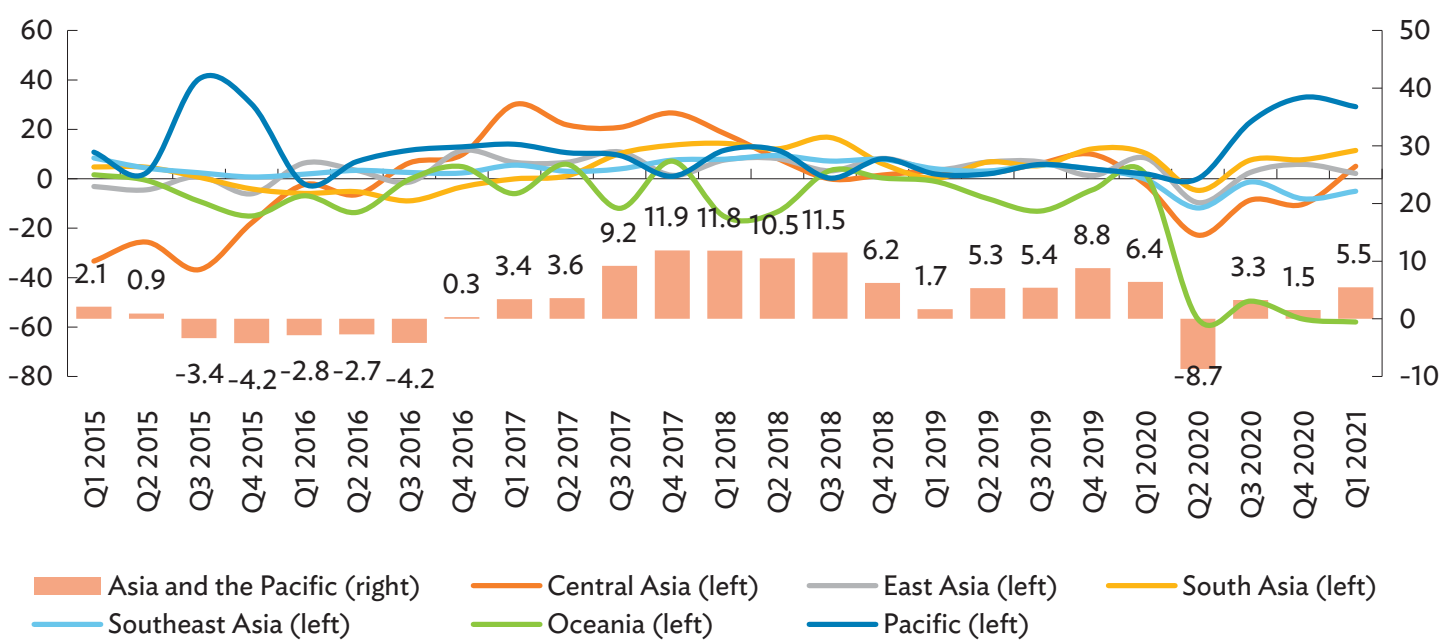

Note: Some economies with incomplete or no time series data were not included in the data set used to generate this chart.

Source: ADB calculations using data from CEIC Data Company.

The uptrend for Pakistan continues - inflows for the first half of 2021 were higher by $29.5 \%$ relative to the same period in 2020.

Bangladesh, India, Pakistan, the PRC, and the Philippines, were among the top 10 remittance-recipient economies in Asia and the Pacific, and globally. In 2020, inflows to these five economies ( $\$ 225.4$ billion) accounted for $32.0 \%$ of global inflows and $71.7 \%$ of total remittances to Asia and the Pacific (Figure 5.11a). Remittances contracted in the PRC (by 13.0\%) and, to a lesser extent, in India (by 0.2\%). In the Philippines, total remittances declined $0.7 \%$ as those 327,511 overseas Filipino workers returned home in 2020. However, major sources of cash remittances to the Philippines recorded higher year-on-year flows from the US (5.5\%), Qatar (8.2\%), Jordan (19.4\%); Singapore (12.7\%); and Taipei,China $(15.5 \%)$ in $2020 . .^{50}$

In Georgia and the Kyrgyz Republic, the ratio of remittances to GDP increased by at least 0.5 percentage points despite the lower level of remittance flows. In Uzbekistan, however, the $18.3 \%$ decline in remittances pushed the remittance-to-GDP ratio to $12.1 \%$ from
14.8\% in 2019. In some Pacific DMCs where remittances are the key source of foreign exchange inflow, higher remittance volumes were recorded by Vanuatu (up by 16.6\%) and Samoa (up by 31.5\%), driven by migrants' higher financial support inflows for their families, remittance flows from seasonal workers, and social benefits (Figure 5.11b). Inflows to Samoa in the first 6 months of 2021 were higher by $7.0 \%$ compared with the same period in 2020 and exceeded pre-pandemic flows by $11.3 \%$.

Central Asian economies which depend on remittances for at least 10\% of their GDP (Armenia, Georgia, the Kyrgyz Republic, Tajikistan, and Uzbekistan) had lower remittance inflows in 2020 with contractions in inflows ranging from 5.8\% (Tajikistan) to as much $18.3 \%$ (Uzbekistan). Although monthly inflows to Armenia in 2020 were lower than the 2019 level for most months, remittances in 2021 are showing signs of recovery. Monthly remittance inflows to Armenia, Georgia, Kazakhstan, and the Kyrgyz Republic in the first half of 2021 were higher by $29.8 \%$ relative to 2020 and by $10.9 \%$ relative to 2019 .

50 Bangko Sentral ng Pilipinas. https://www.bsp.gov.ph/SitePages/Statistics/Statistics.aspx (accessed October 2021). 
Figure 5.11: Top 10 Remittance-Recipient Economies in Asia and the Pacific, 2020

(a) \$ billion

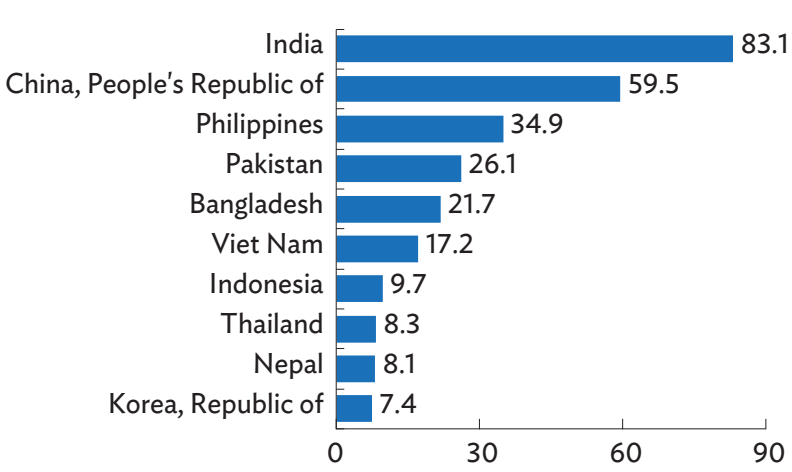

(b) \% of GDP

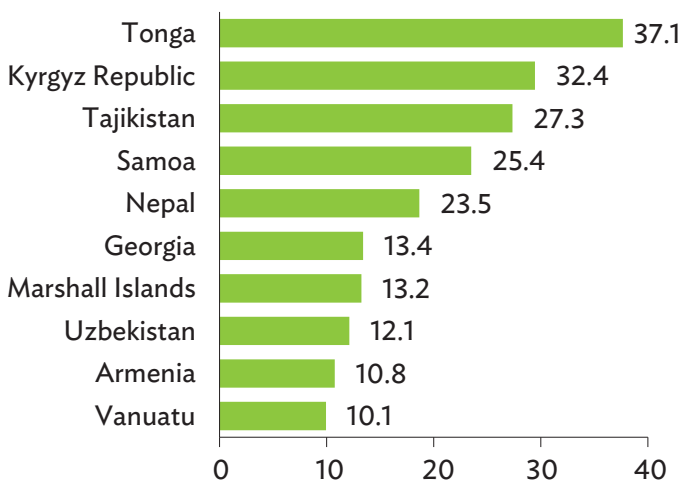

GDP = gross domestic product.

Note: Some economies with incomplete or no time series data were not included in the data set used to generate these charts.

Sources: ADB calculations using data from Global Knowledge Partnership on Migration and Development (KNOMAD). Remittances Data. http://www.knomad.org/data/ remittances (accessed May 2021); and International Monetary Fund. World Economic Outlook April 2021 Database. https://www.imf.org/en/Publications/WEO/weodatabase/2021/April (accessed November 2021).

\section{The average cost of remitting to Asia and the Pacific has been declining but remains higher than the Sustainable Development Goal target of less than $3 \%$ by 2030 .}

In the United Nation's 2030 Agenda, the average total cost of remittances is aimed to be lower than $3 \%$, and corridors with costs higher than $5 \%$ should be eliminated. As of Q1 2021, the global average total cost of remittance was $6.4 \%$ of the transaction amount $-5.9 \%$ in Asia and the Pacific. Remittance costs have been declining slowly, and existing average costs are still almost double the 3\% Sustainable Development Goal target (Figure 5.12a). Remittance costs also vary by subregion-costs in Central Asia and South Asia are lower than the Asian average while costs in the Pacific, which were at its lowest level of 8.9\% in Q1 2021, has been consistently much higher than the global average.

Lockdown measures during the initial months of the pandemic reduced the volume of transactions particularly those of nonbank remittance service providers. The remittance service providers mostly handling cash-based, in-person transfers had to close because they were tagged as nonessential business. This could explain the declines in remittance inflows in the months of March to May 2020 when mobility restrictions were most stringent.
Meanwhile, digital remittance service providers experienced an increase in transaction volumes as remittance senders who could not transact in person resorted to digital channels. Multichannel remittance service providers also deepened their digital engagement to ensure business continuity. According to AnderssonManjang and Naghavi (2021), the size of remittances through mobile money jumped $65 \%$ to $\$ 12.7$ billion in 2020. As a result, more than $\$ 1$ billion was sent and received every month via mobile money.

By payment instrument, remittances sent through mobile money globally cost much less than cash $-3.2 \%$ compared with $7.0 \%$ for cash and $4.4 \%$ for debit/credit cards (Figure 5.12b). However, cash transactions remain the dominant transaction type, accounting for around $70 \%$ of remittances sent through the three largest remittance service providers-Western Union, World Remit, and Ria (Remittance Community Task Force Secretariat 2020). Globally, cash sent through banks (12.6\%) still cost far more than through money transfer operators (6.5\%). In Asia and the Pacific, the spread between these costs have increased to 10.3 percentage points in Q4 2020 from 7.4 percentage points in Q4 2019. Advancing digitalization infrastructure will only work if accompanied by measures to develop the digital ecosystems in many migrant-sending developing economies and migrant-host economies. 
Figure 5.12: Average Total Cost of Remitting \$200 (\%)

(a) Quarterly Trend

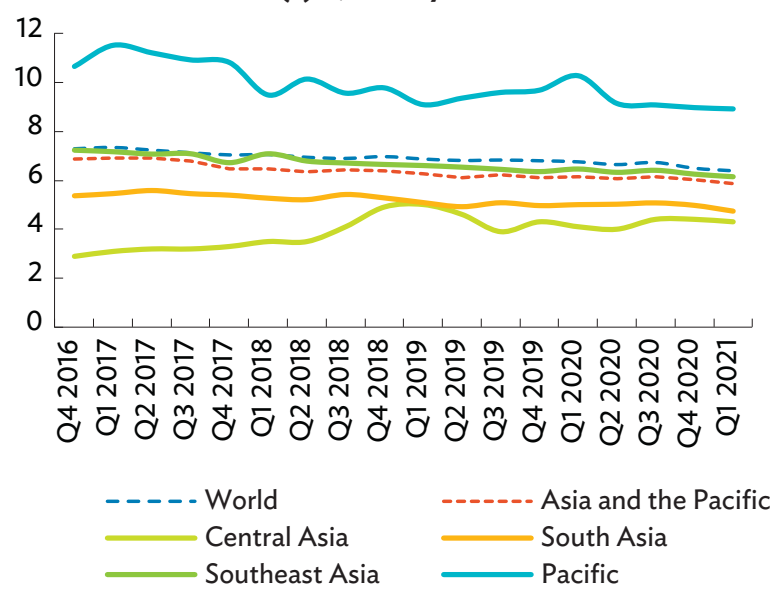

(b) By Mode of Transfer and Payment Instrument, Q1 2021

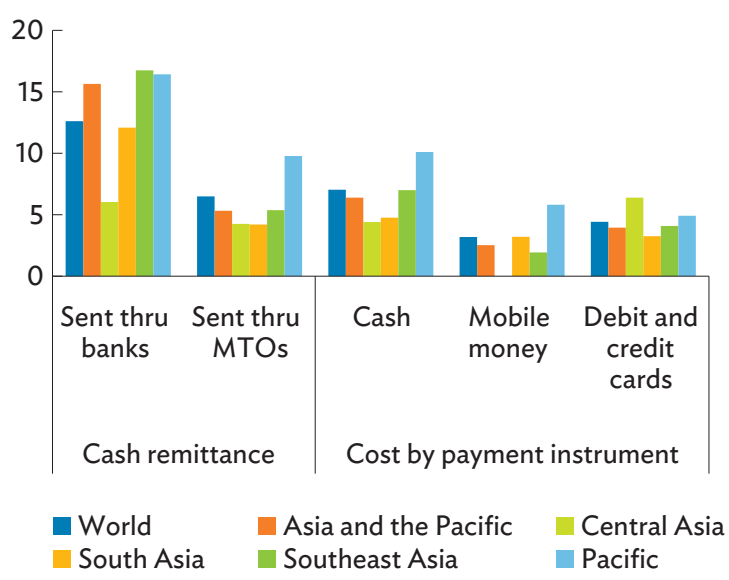

$\mathrm{MTO}=$ money transfer operator, $\mathrm{Q}=$ quarter.

Note: Central Asia data on remittance costs using mobile money are not available.

Source: ADB calculations using data from World Bank. Remittance Prices Worldwide. https://remittanceprices.worldbank.org/en (accessed October 2021).

Only $4.7 \%$ of adults aged 25 and older in the world had a mobile money account in 2017. ${ }^{.1}$

Large differences in remittance costs also exist among subregions and economies, reflecting how financial development, financial market competition, adoption of digital technology, and the state of remittance infrastructure development differ. For instance, remitting to Central Asia costs less relative to other subregions-to Azerbaijan the average cost is only $1.0 \%$, while it costs $10.1 \%$ to send money to Vanuatu. Although the average cost of remittances is highest in the Pacific (8.9\%), sending money to Southeast Asia via banks costs more (16.6\%), with rates ranging from $8.8 \%$ (Philippines) to as much as $46.0 \%$ (Thailand). Meanwhile, remittances sent to South Asia through money transfer operators cost the least, at 3.8\%. Measures to address these differences can help optimize use of digitalization technologies to reduce remittance costs and bring them closer to the desired Sustainable Development Goal target of less than 3\% by 2030.

\section{Policy Recommendations}

The resilience demonstrated by remittance inflows to Asia and the Pacific in the first year of the pandemic emphasized the magnitude and reliability of remittance inflows and their crucial role in the post-pandemic recovery. Below are some policy suggestions to improve the use of formal remittance channels.

\section{Boosting financial literacy is essential in migrant communities. Informing migrants and their families} about the basic ideas of savings, remittance channels, prices of financial services, types of investment products, risks of unregulated remittance transfers and informal remittances, and financial fraud in transparent easyto-understand language will not only expand their knowledge of basic finance but also empower them to use formal, hence safer, remittance channels. Promoting customized and gender-responsive remittance-related savings, loans, investments, and remittance-linked insurance products will promote financial inclusion of remittance-recipient families.

51 World Bank. Global Financial Inclusion Database. https://databank.worldbank.org/reports.aspx? source=global-financial-inclusion (accessed October 2021). 
Develop technology-driven payment system

infrastructure. This will facilitate international remittance flows while supporting the market entry of digital financial service providers to expand the use of digital channels. Find ways for the banking sector to have greater interoperability with other classes of remittance service providers and incentivize the growth of fast payment services where available. Elevate the degree of financial expertise among remittance service providers through capacity building and knowledgesharing activities on domestic or regional retail payment infrastructure for sending and receiving remittances.

\section{Authorize flexibility in documentary requirements} and adopt a risk-based approach that is appropriate for senders of low-volume transactions to expand the access of migrants to formal financial services.

Promote partnerships among remittance service providers and support regulations that would encourage their network expansion to poor and remote areas. In economies where remittance service providers rely on correspondent banking accounts, such as in the Pacific, improve the availability of banking services alongside guidance in complying with anti-money laundering/ combating the financing of terrorism requirements. Harmonize guidance for promoting a risk-based approach for correspondent banking and encourage dialogue to ease exceedingly conservative approaches by correspondent banks while minimizing conflicts.

\section{Incentivize informal remittance providers with} nuanced regulatory frameworks and improve the competitive environment among financial service providers. Incentives and increased competition can work together to impact the cost of remittance. Engage more female remittance senders through capacity-building modules on how to send remittances digitally and help narrow the gender gap in digital remittance uptake. Expand distribution channels among typically underserved populations, such as families in rural areas, communities with low levels of literacy, and people with disabilities.

\section{Leverage remittance-induced savings products} as medium- to long-term forms of investment.

Recipient economies could tap these funds for development-centric capital accumulation activities.

\section{Tourism}

As the devastating impacts of the COVID-19 pandemic continue to challenge Asia's international tourism, establishing recovery momentum remains elusive amid prevailing travel challenges in many economies.

The COVID-19 pandemic continues to take its toll on global tourism. The highly interconnected sector, with a multiplier effect, the global travel and tourism industry led to a loss of $\$ 4.5$ billion of GDP contribution and 62 million jobs in 2020 (WTTC 2021). Tourism's share of global GDP declined to $5.5 \%$ in 2020 from $10.4 \%$ in 2019. Measures to contain the spread of the COVID-19 virus, which nearly halted travel and tourism activity across the world, resulted in a massive $72.6 \%$ drop in global tourist arrivals in 2020 relative to 1.5 billion tourist arrivals in pre-pandemic 2019 (UNWTO 2021b). The sector continued to face travel restrictions in 2021 with the emergence of new variants of the virus and slow vaccine administration, dampening travel confidence worldwide. Tourist arrivals remain deeply stunted in Asia and the Pacific (down by 88.9\%), Africa (down by $54.3 \%$ ), and North America (down by 11.5\%) (Figure 5.13).

Figure 5.13: Tourist Arrivals, January-October

(\%, year-on-year)

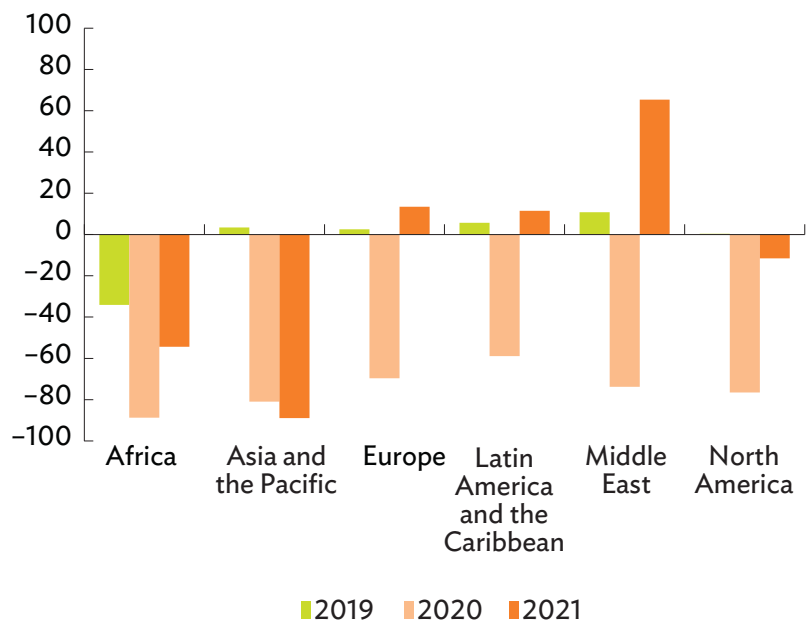

Source: ADB calculations using data from CEIC Data Company 
A study by Vanzetti and Peters (2021) estimated that a reduction in tourist arrivals by 74\% in 2021 from the 2019 level will lead to real GDP loss of $\$ 2.4$ trillion. Even under an optimistic scenario in which arrivals decline from $74 \%$ to $63 \%$ in 2021 (i.e., partial tourism rebound), will cut the loss in global GDP by $30 \%$ to $\$ 1.7$ trillion (Vanzetti and Peters 2021). Across tourism's complex supply chain, the upstream and downstream effects of a lack of tourism activities threatens 100 million-120 million jobs. As economies continue to contain the spread of the virus amid cautious efforts to reopen tourism, recovery is expected to start later than sooner and to proceed more cautiously. Experts believe a return to pre-pandemic international arrival figures will not happen until 2023 or later (UNWTO 2021a).

In Asia and the Pacific, the reinstatement of lockdowns amid the unpredictability of infection outbreaks (Figure 5.14) and the slow pace of vaccination have jeopardized plans to fully reopen borders. Although international travel has shown signs of easing globally by the last quarter of 2020, access to the region remains constrained by partial to full restrictions - as of Q4 2021, $23.8 \%$ of Asian destinations were still fully closed (versus $6.5 \%$ globally) and $20.9 \%$ continued to impose partial bans (versus $22.2 \%$ globally) (Figure 5.15). In 2020, the contribution of travel and tourism to the region's GDP fell by $53.7 \%$ to $\$ 1.4$ trillion and employment decreased by $18.4 \%$ to 151 million jobs (WTTC 2021). International spending fell by $64 \%$, depriving many tourismdependent Asian economies of foreign exchange earnings (UNWTO 2021b).

Prior to the pandemic, the dynamic performance of tourism helped carve out its role in the growth and development of many developing economies. From 2010 to 2015 , global tourist arrivals grew by $4.5 \%$ annually from 950 million to 1.2 billion (UNWTO 2016). On average, 1.3 billion international tourists traveled annually from 2015 to 2019 , only to drop to 0.5 million in 2020 (Figure 5.16). Tourist arrivals to Europe, the most visited region, fell by $64.9 \%$ to 230.1 million in 2020 from an average of 655.2 million in 2015-2019. In Asia and the Pacific, tourist arrivals fell by $82.8 \%$ to 54.4 million due to the COVID-19 crisis.
Figure 5.14: Daily COVID-19 Cases, 2021

(7-day rolling average, '000)

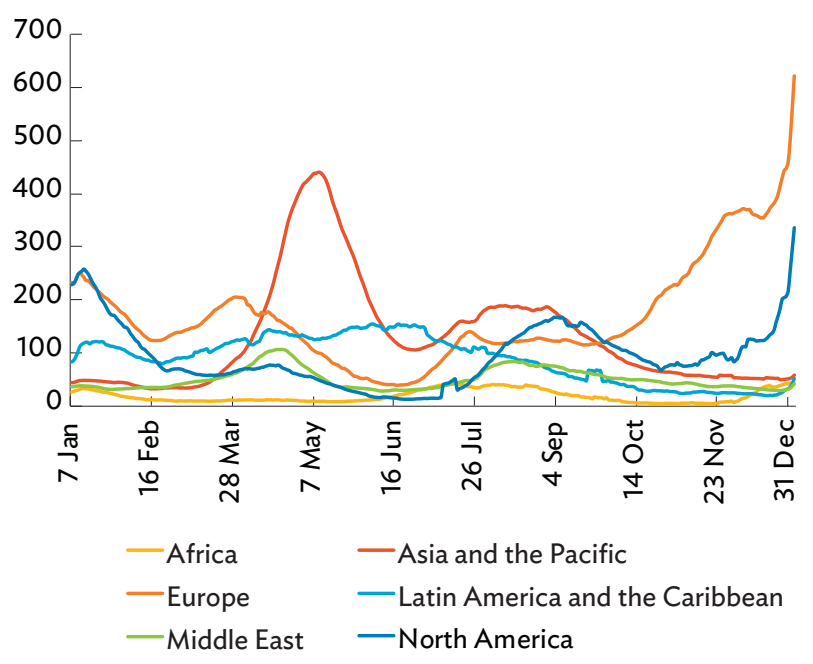

Sources: ADB calculations using data from CEIC Data Company; and World Health Organization. WHO Coronavirus (COVID-19) Dashboard. https://covid19. who.int (accessed November 2021).

\section{Figure 5.15: International Travel Restrictions} (\% of imposing economies)

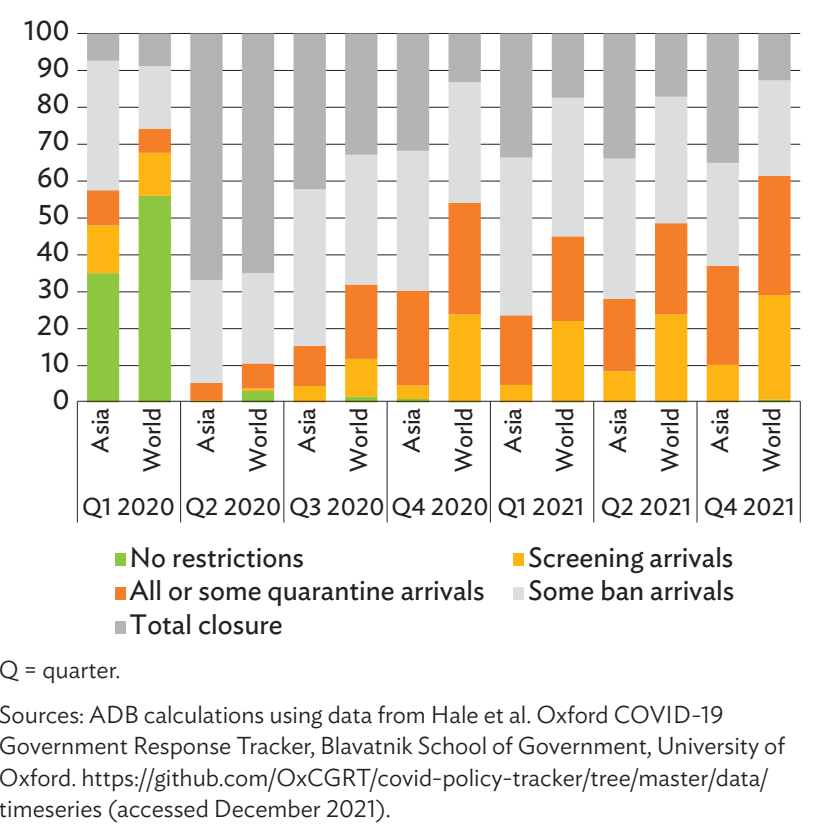

Around 316 million tourists visited Asia and the Pacific, on average, and tourist arrivals grew at $7.4 \%$ annually in 2015-2019. The phenomenal growth in tourist arrivals translated to significant tourism revenues for the region. From 2015 to 2018, Asia and the Pacific earned a cumulative $\$ 1.8$ trillion in tourism receipts, or $27.2 \%$ of the global total (Figure 5.17 a). 
Figure 5.16: International Tourist Arrivals

\section{by Region of Destination}

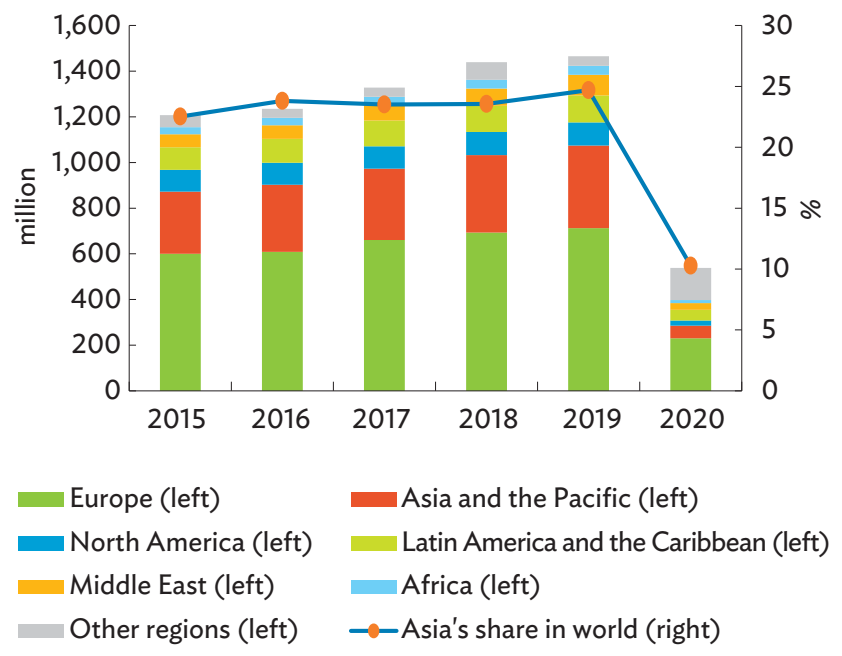

Sources: Maldives Monetary Authority. Statistics Database. https://database.mma.gov. mv/ (accessed November 2021); Pacific Tourism Organisation (2020, 2021); UNWTO. International Tourism and COVID-19. https://www.unwto.org/international-tourismand-covid-19; and UNWTO. UNWTO Tourism Data Dashboard. https://www.unwto. org/unwto-tourism-dashboard (both accessed October 2021).

In comparison, European destinations generated $\$ 2.6$ trillion (38.2\%) while North America earned $\$ 1.1$ trillion (16.4\%) from tourism. Many factors contributed to the improved performance of the Asian subregion, including a rising middle class, affordable travel costs, use of technology for tourism marketing, ease of visa policies, open skies arrangement, and others.
The impact of COVID-19 on tourism set back the industry by 3 decades (UNWTO 2020). In 2020, Asia's tourism revenues fell by $66.4 \%$ to $\$ 122.0$ billion relative to its average pre-pandemic earnings of $\$ 363.0$ billion (Figure 5.17b). The estimated decline of 1 billion tourist arrivals in 2020 relative to 2019 cost the industry $\$ 1.3$ trillion in lost tourism revenue and the global economy by over $\$ 2$ trillion in GDP.52

Among Asia's subregions, sharp declines in tourism greatly impacted East Asia and Southeast Asia, two of the region's most visited and highest grossing in terms of tourism receipts. In East Asia, the wide array of tourist destinations attracted 141.8 million international tourists annually, from 2015 to 2019, and earned for the subregion $\$ 141.0$ billion in annual tourism receipts (Table 5.5). In 2020, the pandemic slashed tourist arrivals to East Asia by $88.8 \%$ and tourism receipts by $72.7 \%$. Southeast Asia, which had $38.2 \%$ of total visitors to Asia and the Pacific and earned 34.7\% (125.8 billion) of Asia's tourism receipts in 2015-2019 saw tourist arrivals plunge by $81.9 \%$ and tourism receipts by 78.5\% because of COVID-19. The sudden and steep contraction in arrivals and tourism earnings greatly affected economies in the subregion such as Thailand where tourism impacts a network of industries both within and outside its economy (Box 5.6).

\section{Figure 5.17: International Tourist Receipts by Region of Destination}

(a) 2015-2019 (cumulative)

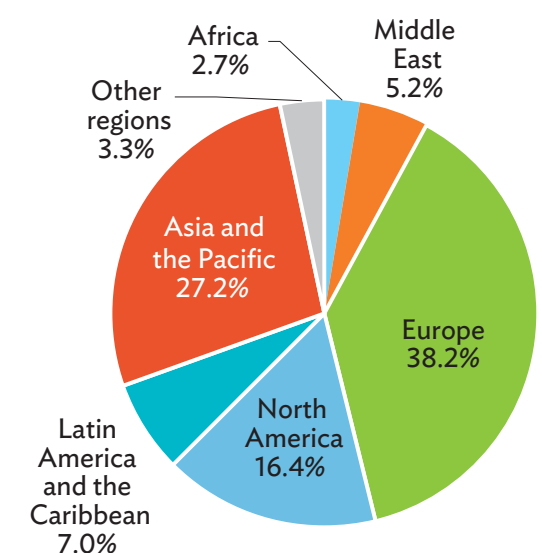

(b) 2020 (\$ billion)

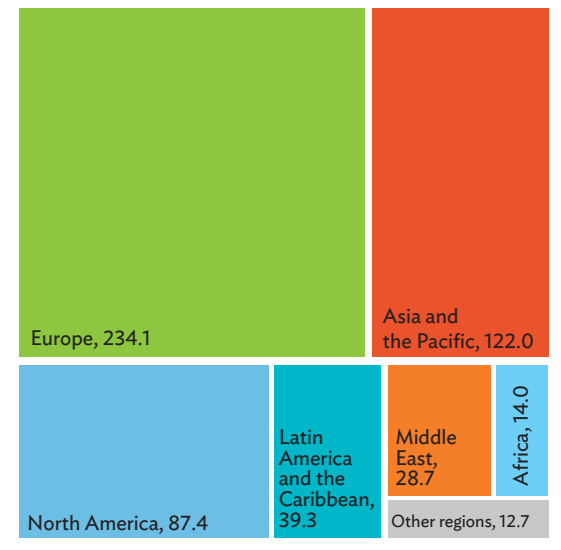

Sources: ADB calculations using data from Maldives Monetary Authority. Statistics Database. https://database.mma.gov.mv/ (accessed November 2021); Pacific Tourism Organisation (2020, 2021); UNWTO. International Tourism and COVID-19. https://www.unwto.org/international-tourism-and-covid-19; and UNWTO. UNWTO Tourism Data Dashboard. https://www.unwto.org/unwto-tourism-dashboard (both accessed October 2021).

52 According to UNWTO (2020), within the first 10 months of 2020 alone, arrivals fell by 900 million, and tourism revenues by $\$ 935$ billion-more than 10 times what the sector lost in the 2009 global financial crisis. 
Table 5.5: International Tourist Arrivals and Tourism Receipts in Asia and the Pacific, by Subregion

\begin{tabular}{|c|c|c|c|c|c|c|}
\hline \multirow[b]{2}{*}{ Subregion } & \multicolumn{3}{|c|}{ International Tourist Arrivals (million) } & \multicolumn{3}{|c|}{ International Tourism Recipients ( $\$$ billion) } \\
\hline & $\begin{array}{l}\text { 2015-2019 } \\
\text { Average }\end{array}$ & $\%$ of Asia's Total & $\begin{array}{c}2020 \\
\text { (change from 2019) }\end{array}$ & $\begin{array}{l}\text { 2015-2019 } \\
\text { Average }\end{array}$ & $\%$ of Asia's Total & $\begin{array}{c}2020 \\
\text { (change from 2019) }\end{array}$ \\
\hline Central Asia & 19.3 & $6.1 \%$ & $5.8(-82.78 \%)$ & 9.7 & $2.7 \%$ & $2.1(-81.0 \%)$ \\
\hline East Asia & 141.8 & $44.9 \%$ & $16.9(-88.8 \%)$ & 141.0 & $38.8 \%$ & $40.1(-72.7 \%)$ \\
\hline Oceania & 12.1 & $3.8 \%$ & $2.8(-78.8 \%)$ & 51.0 & $14.0 \%$ & $32.1(-42.9 \%)$ \\
\hline Pacific & 1.6 & $0.5 \%$ & $0.1(-91.6 \%)$ & 1.7 & $0.5 \%$ & $0.2(-86.1 \%)$ \\
\hline South Asia & 20.6 & $6.5 \%$ & $3.7(-84.1 \%)$ & 33.9 & $9.3 \%$ & $15.9(-59.6 \%)$ \\
\hline Southeast Asia & 120.6 & $38.2 \%$ & $25.0(-81.9 \%)$ & 125.8 & $34.7 \%$ & $31.6(-78.5 \%)$ \\
\hline $\begin{array}{l}\text { Asia and the } \\
\text { Pacific }\end{array}$ & 316.0 & $100.0 \%$ & $54.4(-85.0 \%)$ & 363.0 & $100.0 \%$ & $122.0(-69.6 \%)$ \\
\hline
\end{tabular}

Sources: ADB calculations using data from Maldives Monetary Authority. Statistics Database. https://database.mma.gov.mv/ (accessed November 2021); Pacific Tourism Organisation (2020, 2021); UNWTO. International Tourism and COVID-19. https://www.unwto.org/international-tourism-and-covid-19; and UNWTO. UNWTO Tourism Data Dashboard. https://www.unwto.org/unwto-tourism-dashboard (both accessed October 2021).

\section{Box 5.6: Thailand's Tourism Sector and Regional Economic Growth-A Global Value Chain Perspective}

A multi-regional input-output model was developed to extend the traditional input-output analysis of Thailand's tourism sector to include economies on the global value chain - the model included 62 economies and 35 industries per economy. Hotels and restaurants, air transport, and other services represented the tourism industry in Thailand.

Based on the output multiplier, the study finds that the air transport sector has the strongest spillover effect from the tourism industry to the whole economy, followed by hotels and restaurants and other service sectors. A \$1.00 increase in final demand for air transport, hotels and restaurants, and other services will stimulate the global output (within and outside Thailand) by $\$ 2.91-\$ 2.95, \$ 2.34$, and $\$ 1.79-\$ 1.88$, respectively. Extending the implications of the multiplier on employment suggests that a $\$ 100$ increase in Thai tourism's final demand can lead to an additional 12 and 12.5 employed persons, respectively.

The total intra-backward linkage slightly increased from 1.01 in 2007 to 1.03 in 2019 whereas the inter-backward linkage dropped from 0.88 to 0.73 over the same years (>1 means stronger linkage with other industries). The decrease in inter-backward linkage suggests the tourism industry in Thailand has become more independent and relied less on the upstream global market.

The Thai tourism's weak forward linkages with other industries suggest that tourism products are more likely to be consumed as final demand, rather than intermediate products for other industries. Forward linkages are on a sustained growing trend while backward linkages are on decreasing trend in 2013-2019. The Thai tourism supply chain is dominated by imports and thus the industry depends on overseas markets more than the domestic market.

Thailand's air transport sector has the greatest backward and forward global value chain participation ratio across sectors. For instance, the backward ratio in 2019 reveals that $25 \%$ of final demand in air transport sector is from intermediate imports whereas the forward ratio indicates that $39 \%$ value added produced by the air transport sector is used for intermediate exports.

Traditional revealed comparative advantage and new revealed comparative advantage of hotel and restaurants sector surged from less than 2.00 in 2007 to 8.22 and 5.19 in 2019, respectively, reflecting the rapid and sustained growth of inbound tourism in Thailand over time. Air transport, on the other hand, has low comparative advantage.

Overall, the multiplier, linkage, and leakage analyses reveal that Thailand should maintain the development of the tourism industry as one of the pillar industries, because of its strong spillover effects to other domestic industries and is well supported by the domestic economy. 
Similarly, Oceania felt the heat from the pandemic as the subregion, which attracted 12.1 million visitors during 2015-2019, saw a drop of 78.8\% in 2020. Even international tourism receipts fell by $42.9 \%$ from an annual average of $\$ 51$ billion in the pre-pandemic years. Within Oceania, Australia and New Zealand were leading the travel and tourism sector. In 2019, of the total share in Asia's international tourism earnings, Australia and New Zealand were the top recipients in absolute terms (Australia, $\$ 45.7$ billion) and in per capita terms (New Zealand, \$2,195) (Figures 5.18a and 5.18c). However, in 2020 , tourist arrivals declined by 80.7\% in Australia and $74.3 \%$ in New Zealand, causing international tourism receipts to shrink by $43 \%$ and $39 \%$, respectively. ${ }^{53}$

The Pacific subregion had less than a $1 \%$ share of both arrivals and tourism receipts prior to the pandemic. But for some economies, tourism makes up a significant share of national output in 2019, such as in Vanuatu (30.1\%), Samoa (23.6\%), and Fiji (17.5\%), as well as in per capita terms (Figures 5.18b and 5.18c). The pandemic hit hard the Pacific subregion with sharp declines in tourism arrivals (lower by $91.6 \%$ ) and international tourism receipts (down by $86.1 \%$ ) in 2020 . The pandemic also underscored major risks to the Pacific subregion's tourism sector: (i) dominance of leisure tourism products, which are vulnerable to changes in income and willingness to travel; (ii) concentration of sources markets on Oceania and the US; and (iii) limited flight connectivity, which constrains air transport, the primary means of access to Pacific destinations. Many economies in the Pacific have been closed to international tourism since March 2020 but some tourism-dependent economies are gearing up to reopen its borders (Box 5.7).

Pre-pandemic tourist arrival figures to Central Asia improved to 33.6 million in 2019 (from 22.6 million in 2018), signaling positive feedback generated by the Central Asia Regional Economic Cooperation (CAREC) program's tourism development strategy in 2019. However, the region suffered during the COVID-19 pandemic. Azerbaijan experienced a massive reduction in tourist arrivals (down by $72.6 \%$ ) and tourism receipts (down by $83.0 \%$ ).

Figure 5.18: Top-10 Recipients of International Tourism Receipts, 2019 and 2020

\section{(a) \$ billion}

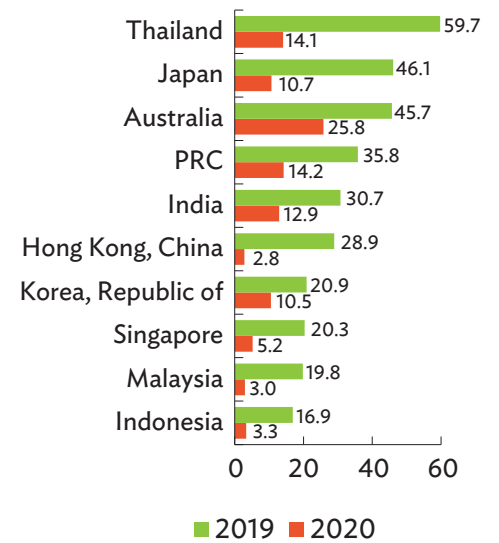

(b) $\%$ of GDP

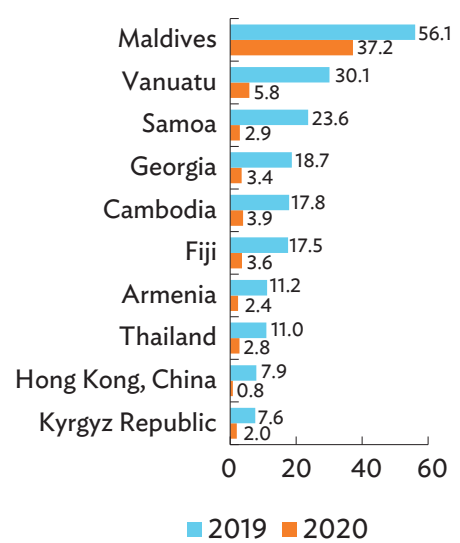

(c) \$ Per Capita

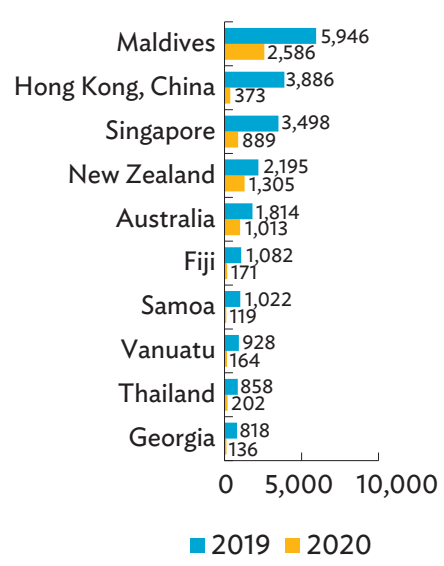

GDP = gross domestic product, PRC = People's Republic of China.

Note: Some economies with incomplete or no time-series data were not included in the data set used to generate these charts.

Sources: ADB calculations using data from International Monetary Fund. World Economic Outlook April 2021 Database. https://www.imf.org/en/Publications/WEO/weodatabase/2021/April (accessed May 2021); Maldives Monetary Authority. Statistics Database. https://database.mma.gov.mv/ (accessed November 2021); Pacific Tourism Organisation (2020, 2021); United Nations Department of Economic and Social Affairs, Population Division. World Population Prospects 2019. https://population.un.org/ wpp/Download/Standard/Population/ (accessed May 2021). UNWTO. International Tourism and COVID-19. https://www.unwto.org/international-tourism-and-covid-19; and UNWTO. UNWTO Tourism Data Dashboard. https://www.unwto.org/unwto-tourism-dashboard (both accessed October 2021).

53 Data indicated that tourist arrivals to Australia declined to 1.8 million in 2020 from 9.5 million in 2019. During the same period, the figures for New Zealand dropped to 1.0 million from 3.7 million (UNWTO Tourism Data Dashboard. https://www.unwto.org/unwto-tourism-dashboard [accessed October 2021]). 


\section{Box 5.7: Reviving Tourism in the Pacific}

Most Pacific developing member countries (DMCs) rely heavily on tourism for growth, employment, and foreign exchange. In 2019, the sector generated international tourism receipts of at least $\$ 1.5$ billion, accounted for $5 \%-40 \%$ of formal sector employment, and contributed from $9.3 \%$ to as much as $35.8 \%$ to gross domestic product (GDP). ${ }^{\text {a }}$ The sector generated as much as $87 \%$ of GDP in the Cook Islands and around $40 \%$ of GDP in Fiji and Vanuatu.

COVID-19 forced Pacific DMCs to close their borders, halting tourism activities and impacting jobs and businesses across tourism's supply chain. It brought to the fore the risks that otherwise remain less discussed due to positive economic outcomes.

With vaccination programs picking up pace in 2021, many Pacific DMCs are now gearing up to reopen. This is particularly so as the Cook Islands has achieved herd immunity with nearly all its adults fully vaccinated. After a 26.2\% decline in GDP in 2020, the Cook Islands has set its path to recovery by restarting tourism through a safe travel corridor with New Zealand. Fiji, with almost 50\% of its target adult population fully vaccinated, reopened its borders by November 2021, allowing resumption of commercial and international flights and entry to fully vaccinated travelers. Samoa, Tonga, and Vanuatu are discussing the potential of a one-way quarantinefree travel with New Zealand. Palau resumed its travel bubble arrangement with Taipei,China in August 2021 and anticipates 20,000 to 50,000 travelers. Kiribati is preparing to reopen its borders to international travelers by early 2022.
Pacific DMCs are redesigning their tourism revival strategies by incorporating tourism products that encourage tourists to stay longer and spend more in the destinations they visit. There are a number of collective initiatives in the subregion that could contribute to rebound of tourism activities. The most notable one is the mutually recognized regional health standards and protocols. The Pacific DMCs that are currently engaged in travel bubbles should adapt international travel protocols, covering most major source economies, and adhere to information- and data-sharing measures to raise confidence of international tourists and promote intraregional movement.

The Pacific DMCs should also consider recognizing skills of tourism professionals to create a bigger pool of resources to entertain more tourists in the post-COVID-19 recovery phase. In addition, the economies should engage in rebuilding and upskilling their existing tourism workforce. Learning of best practices from other small island economies will also be useful. Finally, a collective approach to rebuild airline connectivity and promote an open skies policy can improve both inter- and intraregional tourist movement across the economies. There are already some discussions happening in this direction. Palau, for example, is discussing the possibility of increased flight frequency of United Airlines between Palau and Guam. Meanwhile, the Australia Infrastructure Financing Facility for the Pacific guaranteed a loan provided to Fiji Airports to improve Fijis air infrastructure and its provision of air traffic management services to airspaces in Kiribati, New Caledonia, Tuvalu, and Vanuatu.

\footnotetext{
a ILO (2020b); UNWTO. UNWTO Tourism Data Dashboard. https://www.unwto.org/unwto-tourism-dashboard (both accessed September 2021); and World Travel and Tourism Council (2021).

Sources: ADB staff using Klyne (2021); Ngirairikl (2021); Rovoi (2021); Samoa Tourism Authority (2021); Sen and Kenny (2021).
}

Georgia's tourism sector, which hosted 5.1 million tourists and employed 150,000 people in 2019, similarly suffered declines of $78.6 \%$ in tourist arrivals and $83.4 \%$ in tourism receipts, while Uzbekistan had a combined contraction of $77.6 \%$ in tourist arrivals and $76.7 \%$ in tourism receipts.
Arrivals to South Asia also went into free fall due to the COVID-19 crisis, from a pre-pandemic average of 20.6 million tourists down to 3.7 million in 2020 . Earnings from international tourism were slashed by more than half the pre-pandemic average-from 33.9 billion to 15.9 billion in 2020-severely affecting the subregion's top 10 tourism earners, India, and Maldives. 
In many economies, domestic tourism is helping pave the way for recovery readiness. To encourage the sector to navigate despite uncertainties, governments continue to support tourism.

\section{Domestic Tourism}

Since tourist travel is primarily driven by discretionary income and tourists' confidence, the pandemic-induced global recession and high degree of uncertainty about the safety of long-haul travel could keep tourism interest and travel propensity concentrated on short-haul destinations, at best. Vanzetti and Peters (2021) reports that it may not be until 2023-2024 for arrivals to recover their 2019 level. Domestic tourism, however, could recover sooner. At nearly six times the size of international tourism ( 9 billion domestic trips in 2018 based on UNWTO data), reengaging domestic tourism demand could help in economic recovery, preserving livelihoods and income. Asian economies constituted over $50 \%$ of these domestic trips. In 2018, domestic overnight trips represented more than $80 \%$ of all tourist arrivals in India, Japan, Malaysia, the PRC, the Republic of Korea, and Thailand, highlighting the significance of domestic tourism for the national economies.

Table 5.6 below shows the impact of the pandemic on domestic tourism for selected economies. Globally, domestic visitors' spending decreased by $45 \%$ during 2019-2020 (from $\$ 4.3$ trillion to $\$ 2.4$ trillion) compared with a greater decline of $69.4 \%$ (from $\$ 1.7$ trillion to $\$ 517$ billion) for international travelers, owing to international travel restriction (WTTC 2021). Reflecting the trend, Asia and the Pacific experienced a smaller decline in domestic spending, at $48.1 \%$, raising its share in overall travel and tourism spending from $74 \%$ of the total in 2019 to $85 \%$ in 2020. Many of the economies devised policies and provided fiscal support to the tourism industry, giving a buffer to the domestic tourism industry.

Cruise tourism is being considered for its potential to boost domestic tourism. Asia's cruise tourism is viewed with immense upside for domestic tourism, given the uncertainties of international travel and the pent-up tourism appetite of residents. The PRC saw high demand for maritime tourism among its domestic travelers. In December 2020, two domestic cruise ships saw robust demand for cabin tickets and sailed from Hainan province to nearby islands over 4 days (Xinhua 2020). In November 2020, Singapore decided to work on a pilot cruise tourism program called "Cruise to Nowhere" (Box 5.8).

\section{With tourism's massive contribution in several areas of the macroeconomy, government support for one of the worst-hit economic sectors was and remains imperative.}

Initially, most of the support for tourism was part of the overall fiscal and monetary policy packages that governments had applied to alleviate the economic impact of the coronavirus pandemic. Over a year into the pandemic, policy assistance got more targeted toward the

Table 5.6: Domestic Tourism in Selected Asian Economies

\begin{tabular}{|c|c|c|c|c|}
\hline \multirow[b]{2}{*}{ Economy } & \multicolumn{2}{|c|}{ Contraction in Domestic Tourism, 2019-2020 } & \multicolumn{2}{|c|}{ Share of Domestic to Total Tourism Spending } \\
\hline & $(\%)$ & ( $\$$ billion) & in 2019 & in 2020 \\
\hline China, People's Republic of & 36.1 & 502.8 & $86 \%$ & $88 \%$ \\
\hline Japan & 30.3 & 64.4 & $81 \%$ & $95 \%$ \\
\hline Korea, Republic of & 34.0 & 9.1 & $51 \%$ & $68 \%$ \\
\hline Cambodia & 36.1 & 0.6 & $23 \%$ & $46 \%$ \\
\hline Indonesia & 35.2 & 7.6 & $55 \%$ & $78 \%$ \\
\hline Malaysia & 32.7 & 7.1 & $51 \%$ & $81 \%$ \\
\hline Philippines & 35.5 & 22.9 & $84 \%$ & $94 \%$ \\
\hline Singapore & 36.1 & 3.8 & $29 \%$ & $50 \%$ \\
\hline Thailand & 28.0 & 7.6 & $30 \%$ & $57 \%$ \\
\hline
\end{tabular}

Source: World Travel and Tourism Council (2021). 


\section{Box 5.8: Domestic Tourism in Post-COVID-19 Recovery-Reinventing Cruise Tourism}

Cruise tourism was a booming industry globally. In the 10 years to 2019 , the number of global cruise passengers grew at 5.3\% annually to 29.7 million. In 2019, the industry contributed $\$ 154.5$ billion to global output and created 1,166 jobs, on the back of demand from North America (52.0\%), Europe (26.0\%), and Asia and the Pacific (12.5\%) (CLIA 2021). Buoyed by Japan- and Singapore-bound destination demand, cruise tourism in Asia and the Pacific recorded robust growth in the period 2016-2019 in terms of the number of ships (9.6\%); number of cruises and voyages (7.1\%); operating days (9.0\%); and passenger capacity (8.0\%) (CLIA 2016, 2019). However, the COVID-19 pandemic put cruise industry operations to a halt. Many cruise lines suspended sailing, and no-sail orders were issued to help contain the spread of the virus. ${ }^{a}$ Between March and September 2020, the suspension of cruise operations resulted in an output loss of more than $\$ 77$ billion and 518,000 jobs.

Many small island economies depend on cruise tourism for its multiplier effect on local and national economies. ${ }^{\text {b }}$ As economies chart their road map for revival of the tourism industry, including cruise tourism, signs of optimism seem to emerge for the future of the domestic cruise industry. A survey in late-2020 of 4,000 vacationers in North America, the United Kingdom, Europe, and Australia highlighted that $74 \%$ were likely to cruise in the next few years. Two of the three respondents agreed to cruise in the next year (CLIA 2021). Another survey indicated willingness among $76 \%$ of 4,600 travelers for cruising as COVID-19 ends (Cruise Critic 2021). To match the positive outlook, the cruise industry implemented stricter health protocols, while cruise liners decided to work closely with public health authorities and industry associations to implement pandemic control measures. As a result, sailing resumed from July 2020, with around 200 sailings globally by the end of December 2020 (CLIA 2021).

Domestically, small economies like Singapore have slowly embarked on a cruise tourism program with $50 \%$ capacity and enhanced safety measures and infection protocols, calling it a "Cruise to Nowhere." The cruise lines depart and return to Singapore in 3-4 days without berthing anywhere else. Even bigger economies like the PRC saw high demand for maritime tourism among its domestic travelers.

As economies resume on their path to recovery, domestic cruise tourism is expected to gradually advance to revive regional cruise tourism, which was becoming popular even before the pandemic. For example, in 2018, 1.4 million New Zealanders were traveling to Australia for cruise tourism (Saraogi 2020). Leveraging their archipelagic geographies, Southeast Asian economies were working together in 2017 to attract tenfold additional cruise vacationers by 2035 (from 450,000 in 2016-2017) (Abu Baker 2017).

To maximize the potential of cruise tourism and boost the tourism sector in the short term, economies with their own coastlines need to reinvent the cruise experience to align with consumers changing behavioral pattern in post-COVID-19. Developing proximity cruise itineraries for sailing near home, promoting industry safety standards, and enhancing pandemic prevention measures can help regain vacationers' confidence, expand choices of domestic travel, and help the industry to rebound. Investing further in essential infrastructure and working with regional partners to improve regulations while carving out regional demand can nurture the cruise industry's long-term potential.

\footnotetext{
a These included Princess Cruise, Disney Cruise Line, Viking, Norwegian Cruise Line, Royal Caribbean Cruises Ltd., and others.

${ }^{b}$ For example, the industry contributes around $\$ 2$ billion to the Caribbean or around $6 \%$ of GDP of some economies.

Sources: ADB staff using Abu Baker (2017); CLIA (2016, 2021); Cruise Critic (2021); and Saraogi (2020).
}

tourism sector as the adverse impact on the sector trickled down to the connected economic activities, leading to higher losses both in terms of GDP and employment.

\section{Nationally, governments launched their respective} tourism recovery plans and initiated a combination of policies-including providing safety nets and training for workers in the sector, increasing the scope of digitalization, capacity development, improving tourism infrastructure, as well as gradually opening tourism with health and safety precautions - to support tourism's emergence from the pandemic and its gradual recovery (Table 5.7). For instance, license renewal fees in 2021 were waived in Cambodia while service quality deposits in the PRC were refunded back to travel agencies. In Georgia, the government allocated the equivalent of $\$ 330$ million for infrastructure spending and tax exemptions in tourism. Tourism workers were also given financial aid for unpaid leave and free online courses for renewed training across the region. 
Table 5.7: Key Responses to Revive Tourism in Selected Asian Economies

\begin{tabular}{|c|c|c|}
\hline \multirow[b]{2}{*}{ Economy } & \multicolumn{2}{|c|}{ Policy Responses } \\
\hline & Main Target: Domestic & International \\
\hline \multirow[t]{2}{*}{ Azerbaijan } & $\begin{array}{l}\text { - "Adventure is Near" campaign to promote } \\
\text { outdoor tourism. } \\
\text { - Support for companies engaged in domestic tourism by } \\
\text { developing and promoting digitalization. }\end{array}$ & $\begin{array}{l}\text { - Introduced a four-phased recovery plan with } \\
\text { lockdown and closed borders in phase one and } \\
\text { toward a "new normal" with international travel } \\
\text { in phase four. } \\
\text { - Launched the Regional Innovative Tourism } \\
\text { Product program to attract investments in tourism. }\end{array}$ \\
\hline & $\begin{array}{l}\text { - Launched Azerbaijan 101, an e-learning platform for trave } \\
\text { - Launched Sanitation and Hygiene Methods and Norms ( } \\
\text { safety, and hygiene standards for a post-pandemic world. }\end{array}$ & $\begin{array}{l}\text { agents and representatives. } \\
\text { AHMAN) to help transform tourism's health, }\end{array}$ \\
\hline Georgia & $\begin{array}{l}\text { - Launched these campaigns: "Explore what is yours"; } \\
\text { "Georgia - Safe Destination!"; and "Travel for Georgia." }\end{array}$ & $\begin{array}{l}\text { - "Work remotely from Georgia" campaign } \\
\text { - Resumption of flights and broadening of } \\
\text { air connectivity. }\end{array}$ \\
\hline Uzbekistan & \multicolumn{2}{|c|}{$\begin{array}{l}\text { - Granted bonus subsidies for tour operators and travel agents to encourage longer tourists to stay longer. } \\
\text { - Allocated funds to compensate hotel owners for construction and renovation expenses. }\end{array}$} \\
\hline People's Republic of China & $\begin{array}{l}\text { - Published the COVID-19 Rules for Spring Festival to better } \\
\text { manage domestic tourism during spring festival holidays. } \\
\text { - Free online training programs and digitalization projects } \\
\text { for tourism enterprises. }\end{array}$ & $\begin{array}{l}\text { - Launched a digital COVID-19 vaccination } \\
\text { certificate to enable cross-border travels. } \\
\text { - Guidelines for Reopening Tourist Attractions } \\
\text { under the Circumstance of Pandemic Control } \\
\text { and Prevention to boost safety perception. }\end{array}$ \\
\hline Japan & $\begin{array}{l}\text { - Relaxed restrictions on restaurants, bars, and } \\
\text { nightlife venues. } \\
\text { - Potential resumption of "Go to Travel" campaign to } \\
\text { shore up domestic tourism numbers. } \\
\text { - Issued subsidies to tourism businesses to help them to } \\
\text { provide discounted travel products and services or issue } \\
\text { time-limited coupons until } 31 \text { December } 2021 \text {. }\end{array}$ & $\begin{array}{l}\text { - Allocated } ¥ 9.6 \text { billion to help recover demand } \\
\text { for foreign tourism and } ¥ 10.2 \text { billion to create } \\
\text { attractive stay content for diversifying customers. } \\
\text { - Restoring airline services and campaigns once } \\
\text { deemed safe to open for foreign travel. } \\
\text { - Strengthening dissemination of accurate } \\
\text { information from Japan National Tourism } \\
\text { Administration and Japan Travel Agency } \\
\text { regarding infectious diseases. }\end{array}$ \\
\hline Republic of Korea & \multicolumn{2}{|c|}{$\begin{array}{l}\text { - Launched the "Feel the Rhythm of Korea" campaign, a series of eight music videos to promote inbound tourism. } \\
\text { - Issued } 1 \text { million discount coupons between } \$ 25 \text { and } \$ 30 \text { to stimulate tourist consumption to around } \$ 480 \text { million. } \\
\text { - Travel bubble with Saipan and Guam; "Flight to Nowhere" programs (sightseeing flights) with selected airlines. }\end{array}$} \\
\hline Cambodia & \multicolumn{2}{|c|}{$\begin{array}{l}\text { - Partnered with the World Bank to develop seven ecotourism destinations to attract domestic tourists, help } \\
\text { reopen tourism businesses, and develop infrastructure to promote community-based ecotourism. } \\
\text { - Signed a memorandum of understanding with Wonderpass Technology Company to improve digitalization in } \\
\text { the tourism sector. }\end{array}$} \\
\hline Indonesia & $\begin{array}{l}\text { - Launched the "Indonesia is Waiting" campaign. } \\
\text { - Boosting the promotion of ecotourism campaigns } \\
\text { across the economy. }\end{array}$ & $\begin{array}{l}\text { - Bali reopens to international travel from } \\
14 \text { October } 2021 . \\
\text { - The government prepared a List of Reopened } \\
\text { Tourism Spots, which is updated regularly. } \\
\text { - A certification program called Cleanliness, } \\
\text { Health, Safety, and Environmental Sustainability } \\
\text { was launched to help businesses reopen safely. }\end{array}$ \\
\hline Malaysia & $\begin{array}{l}\text { - Reopening of interstate travel in selected destinations } \\
\text { to boost domestic tourism. } \\
\text { - Domestic travel bubbles for fully vaccinated locals. } \\
\text { - "Cuti-Cuti } 1 \text { Malaysia Dekat Je" domestic promotion } \\
\text { campaign to encourage Malaysians to explore nearby } \\
\text { places for their weekend getaway. }\end{array}$ & $\begin{array}{l}\text { The hotel industry has adopted standard } \\
\text { operating procedures for safety, health, and } \\
\text { hygiene practices in relation to COVID-19. } \\
\text { - The government allocated } \$ 113 \text { million worth of } \\
\text { travel discount vouchers, personal tax relief of up to } \\
\$ 227 \text { for expenditures related to domestic tourism } \\
\text { for all Malaysians, and a matching grant (Galakan } \\
\text { Melancong Malaysia) for domestic promotion and } \\
\text { marketing activities of local tourist businesses. }\end{array}$ \\
\hline
\end{tabular}


Table 5.7 continued

\begin{tabular}{|c|c|c|}
\hline \multirow[b]{2}{*}{ Economy } & \multicolumn{2}{|c|}{ Policy Responses } \\
\hline & Main Target: Domestic & International \\
\hline Philippines & $\begin{array}{l}\text { - Issuance of Safety Seals to ensure that establishments } \\
\text { are adhering to safety protocols. } \\
\text { - Scaling up vaccination programs for workers in tourism } \\
\text { establishment to further encourage local tourists. }\end{array}$ & $\begin{array}{l}\text { - Launched the "More Fun Awaits" campaign. } \\
\text { - Launched the Tourism Response and Recovery } \\
\text { Plan to secure livelihoods, business operations, } \\
\text { infrastructure, and enhance market and product } \\
\text { development, in collaboration with private sector } \\
\text { players and related tourism stakeholders. }\end{array}$ \\
\hline Singapore & $\begin{array}{l}\text { - } \$ \$ 320 \text { million funding in the form of } \\
\text { "SingapoRediscovers Vouchers" to boost domestic } \\
\text { tourism. }\end{array}$ & $\begin{array}{l}\text { - Rolled out a } \$ 20 \text { million Marketing Partnership } \\
\text { Programme and a } \$ 2 \text { million SG Stories } \\
\text { Content Fund. } \\
\text { - Developed a CruiseSafe certification program to } \\
\text { support safety and hygiene measures for travelers. }\end{array}$ \\
\hline Thailand & $\begin{array}{l}\text { - } \$ 700 \text { million program to support domestic tourism. } \\
\text { - } \$ 3 \text { million in soft financing for tour operators. } \\
\text { activity and help tourism businesses. }\end{array}$ & $\begin{array}{l}\text { - Phuket Sandbox program was opened to fully } \\
\text { vaccinated travelers from all economies. } \\
\text { - Thailand launched its Tourism Recovery Plan, } \\
\text { which focuses around five pillars: reboot, rebuild, } \\
\text { refresh, rebound, and rebalance. } \\
\text { - Launched the Thailand Hygiene Plus Initiative to } \\
\text { promote safe and hygienic spaces for travelers. }\end{array}$ \\
\hline Viet Nam & $\begin{array}{l}\text { - Promotion of domestic tourism since May } 2020 \\
\text { through "Vietnamese People Travel in Viet Nam" and } \\
\text { "Vietnam Green Tourism" campaigns. }\end{array}$ & $\begin{array}{l}\text { - Promoted online marketing to international } \\
\text { tourists with "Stay Home with Vietnam" and } \\
\text { "Visit Vietnam from Home" campaigns. } \\
\text { - Phu Quoc City in Southern Viet Nam will be open } \\
\text { to international travelers by late November } 2021 .\end{array}$ \\
\hline
\end{tabular}

COVID-19 = coronavirus disease, $S G$ = Singapore.

Sources: ADB compilation based on Agenda.ge (2020); Firn (2021); Government of Azerbaijan. Azerbaijan Tourism Board. https://tourismboard.az/ (accessed October 2021); Government of Indonesia, Ministry of Tourism and Creative Economy/ Tourism and Creative Economy Agency (2021); Lim (2021); Pfalz (2021); Thaiembassy.com (2021); Tuoi Tre News (2021); and UNWTO. UNWTO Global Tourism Dashboard. COVID-19: Measures to Support Travel and Tourism. https://www.unwto.org/covid19-measures-to-support-travel-tourism (accessed October 2021).

India launched the Incredible India Tourist Facilitator Programme, an online program for building skills and facilitating tourist visits in destinations.

Economies in Central Asia also launched several tourism campaigns, along with their recovery plans. For example, Azerbaijan launched its four-phased tourism recovery plan and the "Adventure is Near" campaign in 2020 to encourage local tourists to rediscover the economy's range of nature and outdoor tourism. Georgia launched its safety slogan as "Georgia - Safe Destination!" and removed restrictions in July 2021, while opening its tourism information centers and businesses (such as restaurants) frequented by tourists (Agenda.ge 2020). It also launched the "Work Remotely from Georgia" program to attract long-term visitors interested in working remotely from the economy, the "Travel to Georgia" and "Explore What is Yours" to promote domestic tourism (UNWTO 2021c). Uzbekistan launched the "Uzbekistan Safe Travel Guaranteed" program in a bid to set a safe environment for tourists and help promote medical tourism in the economy (Government of Uzbekistan, Ministry of Tourism and Sports 2021). Travel agents and tour operators had subsidy support until December 2021..$^{54}$

Subregional initiatives at institutional level were also pursued to support tourism as well as broader economic recovery. Strategies and frameworks were developed in CAREC and ASEAN to guide tourism recovery in these subregions. CAREC endorsed its Tourism Strategy 2030,

54 UNWTO Tourism Data Dashboard. https://www.unwto.org/unwto-tourism-dashboard (accessed October 2021). For every foreign tourist that stays in Uzbekistan for at least 5 days, the tourism company is paid $\$ 15$ while tour operators get a 30\% subsidy on air and train tickets for every group of 10 tourists that stays at least 5 days. Funds were also allocated for expenses for hotel renovation and reconstruction until 1 June 2021. 
which acknowledges the need for health and safety, with priorities on building projects for digital connectivity and minimum standards in quality hygiene of tourism facilities. Similarly, ASEAN launched a Comprehensive Recovery Framework in November 2020, including programs for the tourism sector's recovery and resiliency, such as sharing of information, capacity building, adoption of digital technology, engaging the private sector, developing guidelines for safety and hygiene, and others.

\section{Vaccination programs, big data, and technological innovation have sparked hope for improved tourism performance in the near future.}

Economies have responded with various policies to revive domestic tourism but in most cases, domestic tourism gains cannot fill the gaps left by international tourists, especially for highly tourism-dependent destinations. Vaccination is one of the key factors that could boost traveler confidence and hasten the restoration of domestic and international travel activities. In some economies where tourism plays a significant economic role, such as in Maldives and Singapore, at least 70\% of the population has been vaccinated to kick-start international travel (Figure 5.19). But in other economies, slow pace of inoculation risks restart of tourism activities. These include many economies in Central Asia, South Asia, and the Pacific. Economies are also adhering to other models to restart their tourism activities. There are economies that have managed to achieve high vaccination rate for their popular tourist destinations, thus taking a more focused approach. For example, Thailand managed to inoculate $70 \%$ of the residents of Phuket, a popular tourist destination, before launching the Phuket Sandbox to revive the tourism industry. ${ }^{55}$ For the first 2 months since the start of the pilot scheme in July 2021, Phuket has managed to attract more than
26,000 vaccinated travelers, generating $\$ 4.9$ billion (or B1.6 billion) in tourism revenue. Of the total visitors, less than $1 \%$ tested positive for the virus during this period (Thanthong-Knight 2021). There are other economies, like in Central Asia, that are seeing a slow uptake in vaccination as the infection rate is relatively low. In Armenia, for example, only $8.9 \%$ of the population had been infected with COVID-19, leading to high degree of vaccine hesitancy among its population. This prompted the government to allow nonresident foreigners to get the vaccine in the economy, spurring "vaccine tourism" among mostly Iranian tourists (Ghazaryan 2021).

A study by ADB and UNWTO (2021) estimated the impact of vaccinations using the number of outbound travelers forecasted by the Economist Intelligence Unit. Their estimates show that international tourism in Asia and the Pacific will remain stagnant in 2021, improve significantly in 2022 (but reaching only half of 2019 levels), and recover to pre-pandemic levels in 2023 at the earliest. If vaccine delivery were delayed by 6 months, the number of outbound travelers in 2022 would reach only one-fourth the levels in 2019, while full recovery would occur in 2024 at the earliest.

Related to accelerating vaccination measures, vaccine pass - a document showing one's record of vaccination-is being considered as a tool to help restart tourism by facilitating border reopening while still protecting vulnerable groups until herd immunity is reached. Vaccine passes are expected to incentivize vaccination, as it is linked to a resumption of more normal activities. The use of vaccine passes is not new and has been in practice for many years when traveling to certain economies that present risks of contracting viral diseases. ${ }^{56}$ But for vaccine passes to work, it needs an internationally recognized standard for verification of vaccine authenticity and identity. Vaccine passes should also be supported by harmonized quarantine protocols

55 The Phuket Sandbox is a pilot project by Thailand which initially allowed tourists from low- and medium-risk economies to enter Phuket under certain conditions and allowed them to move around Thailand after staying in Phuket for 14 days. Program coverage was subsequently extended to travelers from all economies provided they have been fully vaccinated. (Thaiembassy.com 2021).

56 The "International Certificate of Vaccination or Prophylaxis" of the World Health Organization has been used for many years when traveling to economies which required vaccination against diseases such as yellow fever. 
Figure 5.19: COVID-19 Cases and People Vaccinated in Asia and the Pacific (\% of population)

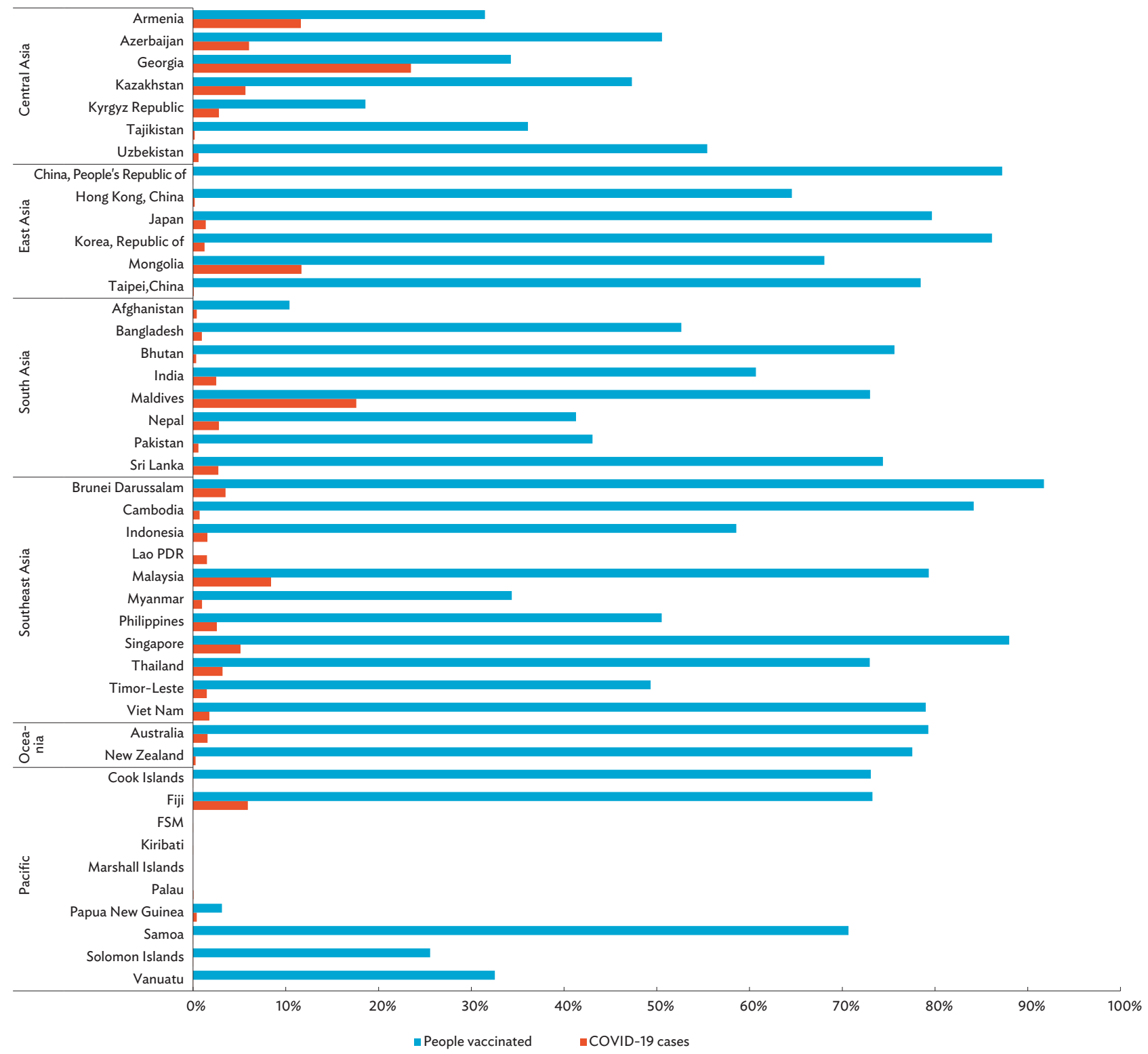

COVID-19 = coronavirus disease, FSM = Federated States of Micronesia, Lao PDR = Lao People's Democratic Republic, PRC = People's Republic of China. Note: Data as of December 2021.

Source: ADB calculations using data from Ritchie et al. (2020).

and cross-border contact tracing, which economies in Asia have yet to agree on and establish. If economies decide on adopting a digital vaccine pass, they should also ensure data security and interoperability of systems. ASEAN economies, for example, are assessing the feasibility of the ASEAN Digital COVID-19 Certificate, which can facilitate the smoother flow of intraregional travelers among ASEAN member states. However, it will require, among others, the harmonization of the verification protocols among ASEAN member economies and strong coordination between airports, airlines, and travel authorities to facilitate easier 
predeparture and arrival processes. ASEAN economies are yet to collectively achieve herd immunity, since the pace of vaccination varies widely among them.

\section{Big Data and Technology}

With the prevalence of lockdowns and movement restrictions, COVID-19 has accelerated digitalization and the use of big data by governments and private firms to aid in tourism recovery. Governments are also taking advantage of the opportunities provided by big data to formulate and implement tourism-related policies in partnerships with online travel agents, telecommunication companies, and financial services companies.

In Singapore, the Singapore Tourism Board in September 2020 partnered with financial services company VISA and digital tourism booking platform Klook to formulate policies for tourism recovery under the "SingapoRediscovers" campaign (Government of Singapore, Ministry of Trade and Industry 2021). Promotions for products and experiences, content development, and digital marketing will be curated to boost domestic spending. To support local tourism business, the government allocated $\$ \$ 320$ million ( $\$ 238.4$ million) for a tourist voucher program redeemable via five big data and tourism platforms. Similarly, the Tourism Authority of Thailand partnered with online travel agent Agoda to support the government's $\$ 482$ billion subsidized domestic tourism program using Agoda's technology-driven booking and payments process for participants (Travel and Tour World 2020). The Tourism Authority of Thailand also partnered with Alipay and Fliggy (the travel services platform of Alibaba) to market domestic tourism packages to Chinese expatriates living in Thailand (TTG Asia 2020). Tourism Malaysia also tapped "Fliggy" to promote Malaysian tourism destinations to the Chinese market (Borneo Post 2021).

Big data analysis can also be used to examine how mobility restrictions correlated to tourist flow during the pandemic. Using high frequency, mobile-driven data can yield important insights about freedom of movement, consequent changes in tourist attitude and behavior, and viable policy support for managing tourism in high-traffic destinations (Box 5.9).

\section{Policy Recommendations}

\section{Regional cooperation will be key in aiding Asia and the Pacific as it overcomes challenges in supply, coordination, and implementation of cross-border initiatives toward recovery and improved resilience in the medium term.}

The pandemic has induced the expanded role of government in tourism and highlighted the importance of public-private partnerships at the national, regional, and international spheres. It is hard to expect for the tourism sector to go back to the "business as usual" paradigm as soon as economies around the global gradually open their borders to international travelers. Evolving through and beyond the post-pandemic phase would require the sector to develop better capacity and readiness for transformation, keeping into account greater challenges of climate change, environmental sustainability, deeper community engagement for improved tourism products and services for better-value experiences for visitors. Regional cooperation is highly recommended in pursuing the following policy suggestions:

\section{Continue to develop and upgrade health, sanitation, and information and communication technology infrastructure at the economy and regional levels to boost travel confidence.}

The pandemic escalated the importance of health and safety requirements and emphasized the role of health and sanitation infrastructure in boosting travelers' confidence. Economy-level investment in these infrastructures should be given priority, along with development of national safety standards and marketing strategies for better communication between policy makers and travelers. At the regional level, economies need to work together to encourage regional and global tourist arrivals. They need to develop regional health and safety standards to restore travelers' confidence and stimulate demand. Cooperation in health and safety standards is also needed to prepare economies for similar shocks. 


\section{Box 5.9: Tourist Inflows Amid a Pandemic Environment-The Case of Seoul, Republic of Korea}

The pandemic precipitated a significant decline in the inflows of foreign tourists to Seoul. According to highfrequency population data generated from mobile phone signals in Seoul, foreign tourists nearly stopped coming into Seoul since April 2020 onward, compared with the same periods in 2019 as a baseline. The mobility (or growth) of both Seoul-residents and non-Seoul-residents visiting Seoul for tourism purposes fluctuated showing negative correlations responding to the COVID-19 cases throughout the pandemic period.

Meanwhile, local tourists exhibited a tendency to travel adjusted to the pandemic environment with increased health risks and restricted mobility.

- The number of Seoul-resident tourists often increased compared with the 2019 baseline while the changes in the number of non-Seoul-resident tourists remained in negative territory. In addition, there were a couple of periods, i.e., June-July in 2020 and 2021, when they diverged - the number of Seoul-resident-tourists further increased whereas that of non-Seoul-resident tourists declined by far. This may be attributed to the increased reluctance to travel farther distance particularly during the summer vacation months.

- As local tourists had to face with increasing public fatigue caused by the prolonged pandemic coupled with frequently changing social distancing measures, a change in tourist behaviors was also observed. When compared with 2020, the number of tourists (both Seoul- and non-Seoul-resident tourists) increased their visits to Seoul in April-May 2021 and maintained the trend somewhat despite the high-level occurrence of new cases on average (the dotted lines in the chart).

\section{Trend of Tourist Movements in Seoul, 2020 and 2021}

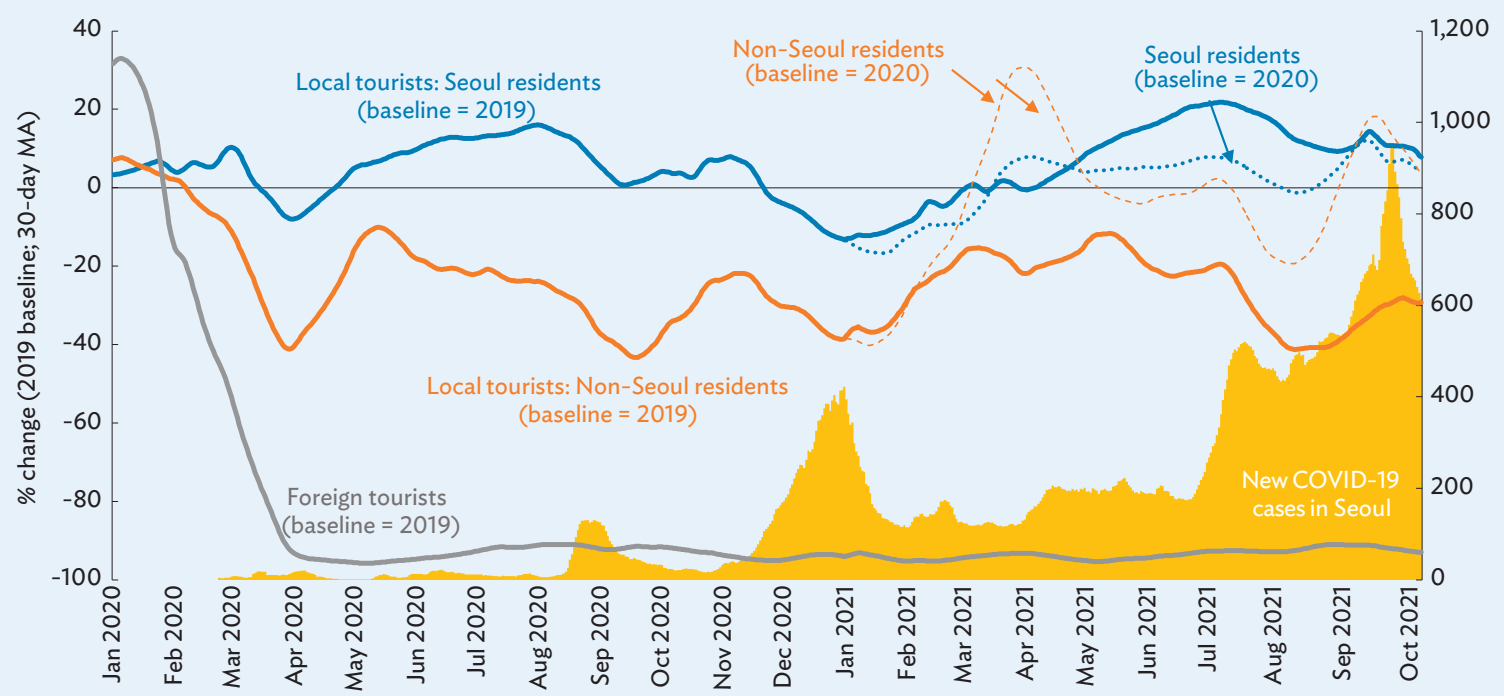

COVID-19 = coronavirus disease, $M A=$ moving average.

Notes: The data on Seoul-resident and non-Seoul-resident tourists are compiled by Korea Telecom based on their mobile phone subscribers' long-term evolution signal data. Local tourists are defined as those who (i) do not live (home or office) within the area; (ii) do not frequently or periodically visit the area; and (iii) stay in the area for the duration sufficient for sightseeing or consumption. Foreign tourists (short-term foreign visitors) are identified using Korea Telecom's roaming data.

Source: ADB staff using data from ADB (2021) and Korea Telecom.

Regional cooperation also gained importance considering the increased use of technology in all domains of economic activities during the pandemic. With greater digital adoption, economies need to take coordinated action for adopting contactless technologies, such as iris recognition as a method for biometrics identification or mobile bookings and online payment for tourism-related transactions, to ensure safe travel experience. They need to facilitate greater use of technology to track tourist traffic in popular destinations, 
increase cross-border information exchange over vaccine, testing, and tracing to safely promote tourism activities. Regional bodies should also collaborate on digital platforms to provide information on health and hygiene and implementation of like-minded safe travel protocols, building trust and flow of information across economies. The Mekong Moments platform, for example, uses a social media strategy to promote photos, videos, and write-ups of international travelers about their trips in Cambodia, the PRC, the Lao PDR, Myanmar, Thailand, and Viet Nam, which are accessed by many globally to learn about travel under the new normal. ${ }^{57}$

To enable extensive use of digital technology across borders, economies need to strengthen their information technology infrastructure and regulations, including addressing challenges around cybersecurity and interoperability of systems. Economies together also need to devise plans to be more inclusive of people that lack digital literacy.

\section{Encourage sustainable tourism to limit over-tourism and overcrowding of popular destinations.}

The outlook for post-pandemic tourism products points to the emergence of smaller travel groups with preference for outdoor or nature-type activities. However, balancing physical distancing and the allure of the outdoors is going to be a challenge for economies where tourism is concentrated in few highly popular destinations. Transforming these markets into places with controlled tourist footfalls will become important post-COVID-19 not only for limiting the spread of the virus but also to manage the adverse impact of over-tourism and environmental degradation over the long-run. Hence, cooperation among economies will become important to address the challenges from regional public goods, thereby working out a balance between the short-term gains versus long-term sustainability concerns. Regional institutions, similar to ASEAN and the Asia-Pacific Economic Cooperation, can work with their member economies on tourism strategies to develop new tourism products, such as community-based tourism, that will help to divert tourists from popular destinations while simultaneously support local communities to share their cultural experiences with visitors, thus linking the demand and expectation of both travelers and the local population.

\section{Develop better measures for capturing tourism data across its value chain activities. This could provide new insights for mapping tourism policy support.}

The tourism value chain spreads from the domestic economy, handling outbound tourists, to destination economies. While, for the domestic economies, there is the distribution network (i.e., travel agents and tour operators) and international travel (air transport), in destination economies, the tourism value chain is spread over multiple sectors, ranging from local tour guides, transport, accommodation, tourist destination, and others. Regional cooperation should enhance the capturing of data and reporting the same for these value chain activities, thereby improving greater understanding to safely facilitate cross-border flow of tourists and undertake informed policy making to benefit all participating in the sector.

\section{Continue to develop human capital across the tourism value chain to reduce livelihood vulnerability during periods of crises. Share best practices in transitioning informal tourism workers into the formal sector.}

As a labor-intensive sector, tourism is a leading source of employment and job creation especially for women, the youth, seasonal workers, part-time workers, and temporary workers. The high degree of person-to-person

57 Mekong Moments is the official travel guide of the Greater Mekong Subregion. It uses global social commerce to visually market and collaboratively promote the region as a single tourism destination. 
interaction in tourism activities also caused tourism to be one of the major sectors to be severely impacted by mobility restrictions applied to contain the spread of COVID-19. Upgrading and diversifying the skills of tourism workers can go a long way in making them less vulnerable to becoming unemployed during periods of severe macroeconomic shocks. Promoting the mutual recognition of skills among tourism professionals will help ease labor movement in the sector, and the greater cross-economy experience will improve resilience in the future. Given the high degree of informal workers in the sector, engaging economies to share their experiences in transforming workers from informal to formal sectors will give this vulnerable group access to a wider range of support schemes for jobs and skills going forward. 


\section{References}

Abuan, A. T. 2021. Brunei Wants to Hire 200 Nurses, 30 Doctors from PH. Government of the Philippines, Philippine Information Agency. 30 August. https://pia.gov.ph/news/2021/08/30/bruneiwantsto-hire-200-nurses-30-doctors-from-ph.

Abu Baker, J. 2017. ASEAN to Focus on Cruise Tourism, with 4.5 Million Passengers Expected by 2035. The Straits Times. 20 January. https://www.straitstimes. com/singapore/asean-to-focus-on-cruisetourism-with-45-million-passengers-expectedby-2035.

Agenda.ge. 2020. Rebranding Georgia's Tourism Image: Domestic Tourism Starting June 15, Int'l Tourism from July 1. 7 May. https://agenda.ge/en/ news/2020/1432.

Andersson-Manjang, S. K. and N. Naghavi. 2021. State of the Industry Report on Mobile Money. London: GSM Association.

Anyu, J. 2021. The Impact of Tourism on the Regional Economic Growth-A Global Value Chain Perspective. Manuscript.

Arora, A. 2021. Australia Announces New Pathway for Permanent Residency for Migrant Workers. SBS Punjabi. 24 August. https://www.sbs.com. au/language/english/australia-announces-newpathway-for-permanent-residency-for-migrantworkers.

Asian Development Bank (ADB). 2016. Asian Economic Integration Report 2016: What Drives Foreign Direct Investment in Asia and the Pacific. Manila.

- 2021. Asian Economic Integration Report 2021: Making Digital Platforms Work for Asia and the Pacific. Manila.

ADB and United Nations World Tourism Organization (UNWTO). 2021. Big Data for Better Tourism Policy, Management, and the Sustainable Recovery from COVID-19. Manila.
ADB and World Bank. 2018. Migration and Remittances for Development in Asia. Manila.

Baclig, C. E. 2021. PH Health Workers: A Pandemic of Big Work, Small Pay. Inquirer.net. 9 June. https://newsinfo.inquirer.net/1443920/phhealthworkers-a-pandemic-of-big-work-small-pay.

Bangkok Post. 2021. Covid Vaccinations for Everyone in Thailand. 18 February. https://www.bangkokpost.com/thailand/ general/2070455/covidvaccinations-foreveryone-in-thailand.

Bedford, C. 2021. Pacific Seasonal Workers Return for New Zealand's Summer Harvest. Devpolicy Blog. 28 January. https://devpolicy.org/pacific-seasonalworkers-return-for-new-zealands-summerharvest-20210128-2/.

Benton, M. 2021. Future Scenarios for Global Mobility in the Shadow of Pandemic. Washington, DC: Migration Policy Institute.

Borneo Post. 2021. STB to Work with Tourism Malaysia to Promote Sabah. 5 April. https://www. theborneopost.com/2021/04/05/stb-to-workwith-tourism-malaysia-to-promote-sabah/.

Calonzo, A. 2020. World's Supplier of Nurses to Limit Sending New Hires Abroad. BloombergQuint. 23 November. https://www.bloombergquint.com/ onweb/world-s-supplier-of-nurses-to-limitsending-new-hires-abroad.

Channel News Asia. 2021. Singapore to Vaccinate Migrant Workers Against COVID-19, Starting With 10,000 Dormitory Residents. 8 March. https://www.channelnewsasia.com/singapore/ covid-19-vaccination-migrant-workersdormitoriesmoh-314116.

Cruise Critic. 2021. Cruise Critic Survey: 76 Percent of Cruisers Want to Sail. 7 July. https://www. cruisecritic.com.au/articles.cfm?ID=5432. 
Cruise Lines International Association (CLIA). 2016. Asia Cruise Trends. Washington, DC.

_ 2019. Asia Cruise Deployment and Capacity Report. Washington, DC.

- 2021. State of the Cruise Industry Outlook. Washington, DC.

Dinarte, L., D. Jaume, E. Medina-Cortina, and H. Winkler. 2021. Neither by Land nor by Sea: The Rise of Electronic Remittances during COVID-19. Paper for the ACDE Seminar. Online. 13 April.

Ernst, T. M. 2021. Remittances During COVID-19 in Asia Pacific: Resilient Despite Dire Predictions. Migration Data Portal Blog. 2 June. https://www.migrationdataportal.org/blog/ covid-19-remittances-Asia-Pacific.

Ersek, H. 2021. Remittances Are Key to the Recovery in Developing Countries. Article for The Davos Agenda. Online. 25-29 January.

Firn, M. 2021. Q\&A: Sparking Ecotourism Jumpstart for Embattled Hospitality/Travel Sector. Khmer Times. 9 August. https://www.khmertimeskh.com/ 50911833/qa-sparking-ecotourism-jumpstart-forembattled-hospitality-travel-sector/.

Foley, L. and N. Piper. 2020. COVID-19 and Women Migrant Workers: Impact and Implications. Geneva: International Organization for Migration.

Geducos, A. C. 2021. IATF Policy on Vaccinating Foreign Workers Readied. Manila Bulletin. 28 May. https://mb.com.ph/2021/05/28/iatf-policy-onvaccinating-foreign-workers-readied/.

GIZ (German Agency for International Cooperation). n.d. Sustainable Recruitment of Nurses (Triple Win). https://www.giz.de/en/worldwide/41533. html.
Ghazaryan, K. 2021. Armenia Changes Vaccination Policy as Iranian Tourists Flock. Eurasianet. 12 July. https://eurasianet.org/armenia-changesvaccination-policy-as-iranian-vaccine-touristsflock.

Global Knowledge Partnership on Migration and Development (KNOMAD). 2021a. Recovery: COVID-19 Crisis Through a Migration Lens. Migration and Development Brief. No. 35. Washington, DC: World Bank.

_ 2021b. Remittance in Crises: How to Keep Them Flowing-Advancing the Development Case from the Lessons of the Pandemic. Washington, DC.

- Remittances Data. http://www.knomad.org/data/ remittances (accessed November 2021).

Government of Australia, Department of Education, Skills and Employment. Seasonal Worker Programme. https://www.dese.gov.au/ seasonal-worker-programme.

Government of Australia, Department of Home Affairs. https://www.homeaffairs.gov.au/.

Government of Azerbaijan. Azerbaijan Tourism Board. https://tourismboard.az/.

Government of Bangladesh, Bureau of Manpower, Employment, and Training. Statistical Reports. http://www.old.bmet.gov.bd/BMET/ stattisticalDataAction (accessed October 2021).

Government of Canada, Employment and Social Development Canada. Quarterly Labour Market Impact Assessment Statistics. https://open.canada. ca/data/en/dataset/e8745429-21e7-4a73-b3f590a779b78dle (accessed November 2021).

Government of India, Ministry of External Affairs. Performance Smartboard. http://meadashboard. gov.in/indicators/15 (accessed October 2021). 
Government of Indonesia, Ministry of Tourism and Creative Economy/Tourism and Creative Economy Agency. 2021. List of Reopened Tourism Spots in Regards to COVID-19 Outbreak Prevention Measurements. Wonderful Indonesia. 31 August. https://www.indonesia.travel/gb/en/news/listof-open-tourism-spots-in-regards-to-covid-19outbreak.

Government of Pakistan, Bureau of Emigration and Overseas Employment. 2020. Labour Migration Report 2020. Islamabad.

Government of the Republic of Korea, Ministry of Employment and Labor. Human Resources Development Service of Korea. Foreign Workforce Employment Support. https://hrdkorea.or.kr/ $\mathrm{ENG} / 4 / 2$.

Government of Singapore, Ministry of Trade and Industry. 2021. Singapore's Tourism Sector Emerges from 2020 With Greater Resilience and Reinvention. Media Releases. Singapore Tourism Board. 1 February. https://www.stb.gov.sg/content/ stb/en/media-centre/media-releases/SingaporeTourism-Sector-Emerges-From-2020-WithGreater-Resilience-and-Reinvention.html.

Government of the United States, Department of State, Bureau of Consular Affairs. https://www. state.gov/bureaus-offices/under-secretary-formanagement/bureau-of-consular-affairs/.

Government of the United Kingdom, Home Office. https://www.gov.uk/government/organisations/ home-office.

Government of Uzbekistan, Ministry of Tourism and Sports. 2021. COVID-19 in Uzbekistan. Uzbekistan. travel. 18 June. https://uzbekistan.travel/en/o/ covid-19-in-uzbekistan/.

Guinto, R. L. L. R., U. Z. Curran, R. Suphanchaimat, and N. S. Pocock. 2015. Universal Health Coverage in 'One ASEAN': Are Migrants Included? Global Health Action. 8 (1). p. 25749.
Haase, M. and P. Honerath. 2016. Return Migration and Reintegration Policies: A Primer. Washington, DC: German Marshall Fund of the United States and GIZ.

Hale, T., N. Angrist, R. Goldszmidt, B. Kira, A. Petherick, T. Phillips, S. Webster, E. Cameron-Blake, L. Hallas, S. Majumdar, and H. Tatlow. Oxford COVID-19 Government Response Tracker, Blavatnik School of Government, University of Oxford. https://github. com/OxCGRT/covid-policy-tracker/tree/master/ data/timeseries (accessed November 2021).

Hintermeier, M., H. Gencer, K. Kajikhina, S. Rohleder, C. Hövener, M. Tallarek, J. Spallek, and K. Bozorgmehr. 2021. SARS-CoV-2 among Migrants and Forcibly Displaced Populations: A Rapid Systematic Review. Journal of Migration and Health. 4. Article 100056.

Human Rights Watch. 2020. Qatar: Little Progress in Protecting Migrant Workers. 24 August. https:// www.hrw.org/news/2020/08/24/qatar-littleprogress-protecting-migrant-workers.

International Labour Organization (ILO). 1996. Female Asian Migrants: A Growing But Increasingly Vulnerable Workforce. Press release. 5 February. https:/www.ilo.org/global/about-the-ilo/ newsroom/news/WCMS_008072/lang--en/index. htm.

- 2019. Glossary on Migration. Geneva.

_ 2020a. Protecting Migrant Workers During the COVID-19 Pandemic: Recommendations for Policy Makers and Constituents. ILO Policy Brief. Geneva.

2020b. COVID-19 and Employment in the Tourism Sector: Impact and Response in Asia and the Pacific. Thematic Brief. Geneva.

2021. Pandemic Realities for Asia-Pacific's 48 Million International Migrants. News. 19 May. https://www.ilo.org/asia/media- centre/news/ WCMS_793027/lang-en/index.htm. 

_. ILOSTAT Database. https://ilostat.ilo.org/data/
(accessed November 2021).

International Monetary Fund (IMF). 2020. World Economic Outlook April 2020: The Great Lockdown. Washington, D.C.

- World Economic Outlook April 2021 Database. https:/www.imf.org/en/Publications/WEO/weodatabase/2021/April (accessed May 2021).

International Organization for Migration (IOM). 2019. World Migration Report 2020. Geneva.

- 2020a. Empowering Migrants is Key to COVID-19 Recovery. Joint Press Release with United Nations Development Programme. 11 June. https://www.iom.int/news/empowering-migrantskey-covid-19-recovery.

_. 2020b. IOM Reports that 70 Per Cent of Returning Migrants to Bangladesh Struggle to Find Employment. News. 12 August. https://bangladesh. iom.int/news/iom-reports-70-cent-returningmigrants-bangladesh-struggle-find-employment.

-2020c. Status of Nepali Migrant Workers in Relation to Covid-19. Kathmandu.

_. 2021a. COVID-19 Impact Assessment on Returned Overseas Filipino Workers. Manila.

_ 2021b. Remittance Inflow Trend Snapshots. Bangkok.

- 2021c. Migrant Inclusion in COVID-19 Vaccination Campaigns: IOM Country Office Review, May 2021. Geneva.

- Mobility Impacts. https://migration.iom.int/ (accessed January 2022).

Jamal, N. 2021. The Tale of Rising Remittances. Dawn. 22 February. https://www.dawn.com/ news/1608611.
Jones, K., S. Mudaliar, and N. Piper. 2021. Locked Down and in Limbo: The Global Impact of COVID-19 on Migrant Worker Rights and Recruitment. Geneva: ILO.

Kang, J. and M. C. Latoja. 2022. COVID-19 and Overseas Filipino Workers: Return Migration and Reintegration into the Home Country-The Philippine Case. ADB Southeast Asia Working Paper Series. No. 21. Manila: ADB.

Kim, K., Z. Ardaniel, A. Kikkawa, and B. Endriga. 2021. Bilateral Remittance Inflows to Asia and the Pacific: Countercyclicality and Motivations to Remit. Manuscript.

Kpodar, K., M. Mlachila, Q. Quayyum, and V. Gammadigbe. 2021. Defying the Odds: Remittances during the COVID-19 Pandemic. IMF Working Papers. No. 21/186. Washington, DC: IMF.

Klyne, S. 2021. Building Resilience in Fiji Tourism. ANZ Bluenotes. 30 July. https://bluenotes.anz.com/ posts/2021/08/anz-dfat-fiji-airport-tourisminfrastructure-development.

Latiff, R. 2021. Malaysia Offers COVID-19 Vaccinations to Foreign Residents, Undocumented Migrants. Reuters. 11 February. https://www.reuters.com/ business/healthcare-pharmaceuticals/malaysiaoffers-covid-19-vaccinations-foreign-residentsundocumented-migrants-2021-02-11/.

Le Goff, M. 2016. Feminization of Migration and Trends in Remittances. Bonn: IZA World of Labor.

Lim, J. 2021. Indonesia to Reopen Bali to Some International Travelers from Mid-October 2021. Aerotime Hub. 6 October. https://www.aerotime. aero/29100-\%20bali-indonesia-reopen-selectinternational-travelers.

Maldives Monetary Authority. Statistics Database. https://database.mma.gov.mv/ (accessed November 2021). 
Malek, M. A., H. T. Truong, and T. Sonobe. 2021a. Changes in the Rural Economy in Bangladesh under COVID-19 Lockdown Measures: Evidence from a Phone Survey of Mahbub Hossain Sample Households. ADBI Working Paper. No. 1235. Tokyo: $A D B$ Institute.

_. 2021b. Remittance Inflows Giving Resilience to Bangladesh's Rural Economy amid COVID-19. Asia Pathways. 13 July. https://www.asiapathways-adbi.org/ 2021/07/remittance-inflows-giving-resiliencebangladesh-rural-economy-covid-19/.

Mercer-Blackman, V. and Y. Li. 2021. Six Reasons Why Remittances Soared in South Asia during COVID-19. World Bank Blogs. 13 July. https://blogs. worldbank.org/endpovertyinsouthasia/six-reasonswhy-remittances-soared-south-asia-duringcovid-19.

Migration Data Portal. 2021. Migration Data Relevant for the COVID-19 Pandemic. 1 December. https://www. migrationdataportal.org/themes/migration-datarelevant-covid-19-pandemic.

Ngirairikl, O. 2021. Palau Works to Rebuild Tourism Industry. The Guam Daily Post. 27 July.

Pacific Tourism Organisation. Visitor Arrivals Snapshot. Suva (2 quarters: fourth quarter 2020 and first quarter 2021).

Pfalz, L. 2021. Indonesia To Reopen Tourism in July 2021. Travel Pulse. 2 June. https://www.travelpulse.com/ news/destinations/indonesia-to-reopen-tourismin-july-2021.html.

Poghosyan, T. 2020. Remittances in Russia and Caucasus and Central Asia: The Gravity Model. IMF Working Papers. No. 20/128. Washington, DC: IMF.

Punzalan, J. 2021. Philippines Raises Overseas Deployment Cap on Nurses, Health Care Workers. ABS-CBN News. 18 June. https://news.abs-cbn. com/news/06/18/21/overseas-deployment-capnurses-health-workers-ofw.
PwC. 2021. Australia: New Direction for Skilled Migration Post COVID-19. Insights from Global Mobility Services. 22 March. https://www.pwc.com/gx/en/ services/people-organisation/publications/assets/ australia-new-direction-for-skilled-migrationpost-covid-19.pdf.

Ratha, D. 2021. Remittances During the COVID-19 Crisis: Resilient and No Longer Small Change. World Bank Blogs. 13 May. https://blogs.worldbank. org/peoplemove/remittances-during-covid-19crisis-resilient-and-no-longer-small-change.

Remittance Community Task Force Secretariat. 2020. Remittances In Times of Crisis: Facing the Challenges of COVID-19-Blueprint for Action Final Report November 2020. Rome: International Fund for Agricultural Development.

Rimal, S. 2021. Pandemic Dramatically Alters Path of Migrant Workers. Asia Foundation. 12 May. https://asiafoundation.org/2021/05/12/ pandemicdramatically-alters-path-of-migrantworkers/.

Ritchie, H., E. Mathieu, L. Rodés-Guirao, C. Appel, C. Giattino, E. Ortiz-Ospina, J. Hasell, B. Macdonald, D. Beltekian and M. Roser. 2020. Coronavirus Pandemic (COVID-19). OurWorldlnData.org.

Rovoi, C. 2021. NZ Takes 'Cautious Approach' to Fiji's Plan to Reopen Border amid Covid-19 Crisis. Radio New Zealand. 11 September. https://www.rnz.co.nz/ international/pacific-news/451223/nz-takescautious-approach-to-fiji-s-plan-to-reopenborder-amid-covid-19-crisis.

Salavierra, L. B. 2021. Foreign Permanent Residents Also Getting Vaccinated vs COVID-19 - DOH. Inquirer. net. 30 May. https://newsinfo.inquirer.net/1438721/ doh-foreign-permanent-residents-getting-vaxtoo.

Samoa Tourism Authority. 2021. Samoa Looks to Open to NZ First. News release. 23 April. https://www.samoatourism.org/articles/295/ samoa-looks-to-open-to-nz-first. 
Saraogi, V. 2020. Setting Sail: The Rise of Australia's Domestic Cruise Industry. Analysis. Ship Technology. 11 February. https://www.shiptechnology.com/features/australia-domesticcruise-market/.

Sen, K. and T. Kenny. 2021. Pacific Islands: Economic Outlook. ANZ Bluenotes. 17 August. https://bluenotes.anz.com/posts/2021/08/anzresearch-pacific-islands-economic-forecastcovid19.

Sijipati, B. 2015. Women's Labour Migration from Asia and the Pacific. Issue in Brief. No. 12. Bangkok and Washington, DC: International Organization for Migration and Migration Policy Institute.

Takenaka, A., K. Kim, and R. Gaspar. 2021. Despite the Pandemic, Remittances Have Kept Flowing Home to Asia's Families. Asian Development Blog. 8 February. https://blogs.adb.org/blog/ despite-pandemic-remittances-have-keptflowing-home-asia-s-families.

Thaiembassy.com. 2021. "No Quarantine" Phuket Sandbox (updated 28 October). https:/www.thaiembassy.com/travel-to-thailand/ no-quarantine-phuket-sandbox-plan.

Thanthong-Knight, R. 2021. Thailand's Tourist Gateway Lines Up Booster Shots for Residents. Bloomberg. 9 September. https://www.bloomberg.com/news/ articles/2021-09-09/thailand-s-tourist-gatewaylines-up-booster-shots-for-residents.

Travel and Tour World. 2020. Agoda Joins with Thailand's Largest-Ever Subsidy Program to Boost Domestic Tourism. 14 July. https://www.travelandtourworld. com/news/article/agoda-joins-with-thailandslargest-ever-subsidy-program-to-boost-domestictourism/.

TTG Asia. 2020. TAT Targets Chinese Expats in Thailand to Boost Domestic Tourism. 20 September. https:/www.ttgasia.com/2020/09/04/tat-targetschinese-expats-in-thailand-to-boost-domestictourism/.
Tuoi Tre News. 2021. Vietnam's Phu Quoc Island to Welcome Int'l Visitors in Late November. 4 October. https://tuoitrenews.vn/news/ business/20211004/vietnams-phu-quocisland-to-welcome-intl-visitors-in-latenovember/63404.html.

United Nations Department of Economic and Social Affairs (UN DESA). 2021. International Migration 2020 Highlights. New York.

United Nations Department of Economic and Social Affairs, Population Division. International Migrant Stock. https://www.un.org/development/desa/pd/ content/international-migrant-stock (accessed May 2021).

—. World Population Prospects 2019. World Population Prospects 2019. https://population. un.org/wpp/Download/Standard/Population/ (accessed October 2021).

United Nations Network on Migration. 2021. Impact of COVID-19 on Migrants in Thailand. Situation Report. August 2021. Bangkok.

United Nations World Tourism Organization (UNWTO). 2016. World Tourism Barometer. 16 (4).

_. 2021a. Compendium of Tourism Statistics. Madrid.

—. 2021b. World Tourism Barometer. 19 (6).

. 2021c. COVID-19: Measures to Support the Travel and Tourism Sector. 10 March. https://webunwto.s3-eu-west-1.amazonaws.com/ s3fs-public/2020-06/europe.pdf.

Impact Assessment of the COVID-19 Outbreak on International Tourism. https://www.unwto.org/ impact-assessment-of-the-covid-19-outbreakon-international-tourism (accessed October 2021).

- International Tourism and COVID-19. https://www.unwto.org/international-tourism-andcovid-19 (accessed October 2021). 
. UNWTO Tourism Data Dashboard.

https://www.unwto.org/unwto-tourism-dashboard (accessed October 2021).

UN Women. 2017. Women Migrant Workers'

Contributions to Development. Policy Brief. No. 2. New York.

Vanzetti, D. and R. Peters. 2021. COVID-19 and Tourism: An Update-Assessing the Economic Consequences. Geneva: United Nations Conference on Trade and Development.

Weeraratne, B. 2020. Return and Reintegration without Assimilation: South Asian Migrant Workers in the Gulf during COVID-19. Institute of South Asian Studies Working Paper. No. 327. Singapore: Institute of South Asian Studies.

Wickramage, K. and G. Annunziata. 2018. Advancing Health in Migration Governance, and Migration in Health Governance. The Lancet. 392 (10164). pp. 2528-2530.

World Bank. Global Financial Inclusion Database. https://databank.worldbank.org/reports. aspx? source=global-financial-inclusion (accessed October 2021).
. Remittance Prices Worldwide.

https://remittanceprices.worldbank.org/en (accessed October 2021).

- World Development Indicators. https://databank. worldbank.org/source/world-developmentindicators (accessed December 2021).

World Health Organization (WHO). WHO Coronavirus (COVID-19) Dashboard. https://covid19.who.int (accessed November 2021).

World Travel and Tourism Council (WTTC). 2021. Travel \& Tourism Economic Impact 2021-Global Economic Impact \& Trends 2021. London.

Xinhuanet. 2020. Cruise Tourism Resumes in China's Xisha Islands. 9 December. http://www.xinhuanet.com/ english/2020-12/09/c_139576388.htm. 


\section{Updates on Subregional Cooperation Initiatives}

Central and West Asia: Central Asia Regional Economic Cooperation Program ${ }^{58}$

The Central Asia Regional Economic Cooperation (CAREC) Program is a partnership of 11 economies (Afghanistan, Azerbaijan, the People's Republic of China [PRC], Georgia, Kazakhstan, the Kyrgyz Republic, Mongolia, Pakistan, Tajikistan, Turkmenistan, and Uzbekistan), working together with support from development partners to accelerate growth and reduce poverty in the subregion. ${ }^{59}$ The CAREC 2030 strategy fosters an open and inclusive cooperation platform to help connect people, policies, and projects for shared and sustainable development. ${ }^{60}$ Building on 20 years of progress in transport, energy, and trade connectivity (Table 6.1), CAREC is expanding cooperation into new areas-including economic and financial stability, agriculture and water, and human development. Strengthening regional cooperation and integration ( $R C I$ ) among CAREC member economies is key to mitigating the impact of the coronavirus disease (COVID-19) pandemic, reviving economic growth, and setting the path for post-pandemic recovery.

\section{Overview}

\section{Investments continue to grow and help CAREC economies respond to the COVID-19 pandemic.}

As of 30 June 2021, CAREC investments reached $\$ 40$ billion and covered 213 regional projects, increasing from $\$ 39.3$ billion in December 2020. Of the total, about $\$ 15.0$ billion was financed by the Asian Development Bank (ADB), $\$ 16.1$ billion by other development partners, and $\$ 8.9$ billion by CAREC governments (Figure 6.1). Transport held the biggest share, with about $75 \%$, or $\$ 30$ billion; energy accounted for $22 \%$, or $\$ 8.9$ billion; and trade accounted for $3 \%$, or $\$ 1.05$ billion (Figure 6.2).

\section{Performance and Progress over the Past Year}

\section{Implementing CAREC 2030 is expected to foster economic growth for post-pandemic recovery.}

Since the COVID-19 pandemic started in 2020, CAREC economies and development partners have made huge efforts to contain the disease and maintain economic growth.

\footnotetext{
58 Contributed by Saad Abdullah Paracha, CAREC unit head, Central and West Asia Department (CWRD), Asian Development Bank (ADB); and Xinglan $\mathrm{Hu}$, principal regional cooperation specialist, CWRD, ADB.

59 ADB placed on hold its assistance in Afghanistan effective 15 August 2021. https://www.adb.org/news/adb-statement-afghanistan.

60 The CAREC 2030 strategy focuses on five operational clusters: (i) economic and financial stability; (ii) trade, tourism, and economic corridors; (iii) infrastructure and economic connectivity; (iv) agriculture and water; and (v) human development.
} 
Table 6.1: Selected Economic Indicators, 2020-CAREC

\begin{tabular}{|c|c|c|c|c|c|}
\hline & $\begin{array}{l}\text { Population } \\
\text { (million) }\end{array}$ & $\begin{array}{l}\text { Nominal GDP } \\
\quad \text { (\$ billion) }\end{array}$ & $\begin{array}{c}\text { GDP Growth } \\
\text { (2016 to 2020, } \\
\text { average, } \%)\end{array}$ & $\begin{array}{l}\text { GDP per Capita } \\
\text { (current prices, \$) }\end{array}$ & $\begin{array}{l}\text { Trade Openness } \\
\text { (total trade, } \\
\% \text { of GDP) }\end{array}$ \\
\hline Afghanistan & 38.9 & 19.1 & 1.6 & 491 & 38.2 \\
\hline Azerbaijan & 10.1 & 42.6 & -0.6 & 4,203 & 57.5 \\
\hline China, People's Republic of & $1,439.3$ & $15,269.9$ & 5.8 & 10,609 & 30.5 \\
\hline Georgia & 4.0 & 15.7 & 2.3 & 3,843 & 72.3 \\
\hline Kazakhstan & 18.8 & 164.8 & 2.2 & 8,776 & 53.4 \\
\hline Kyrgyz Republic & 6.5 & 7.5 & 1.8 & 1,145 & 75.6 \\
\hline Mongolia & 3.3 & 14.7 & 2.8 & 4,475 & 86.2 \\
\hline Pakistan & 220.9 & 262.8 & 3.3 & 1,190 & 25.9 \\
\hline Tajikistan & 9.5 & 8.0 & 6.7 & 839 & 74.3 \\
\hline Turkmenistan & 6.0 & 47.4 & 5.4 & 7,851 & 20.3 \\
\hline Uzbekistan & 33.5 & 57.7 & 4.7 & 1,724 & 57.3 \\
\hline CAREC & $1,790.9$ & $15,910.2$ & 5.7 & 8,884 & 31.0 \\
\hline
\end{tabular}

CAREC $=$ Central Asia Regional Economic Cooperation, GDP = gross domestic product.

Notes: CAREC's average GDP growth rate is weighted using nominal GDP. Total trade refers to the sum of exports and imports.

Sources: ADB calculations using data from ADB (2021a); CEIC Data Company; International Monetary Fund. Direction of Trade Statistics. https://data.imf.org/dot; and World Bank. World Development Indicators. https://databank.worldbank.org/source/world-development-indicators\# (all accessed August 2021).

\section{Figure 6.1: CAREC Investments by Funding Source, as of 30 June 2021 ( $\$$ billion)}

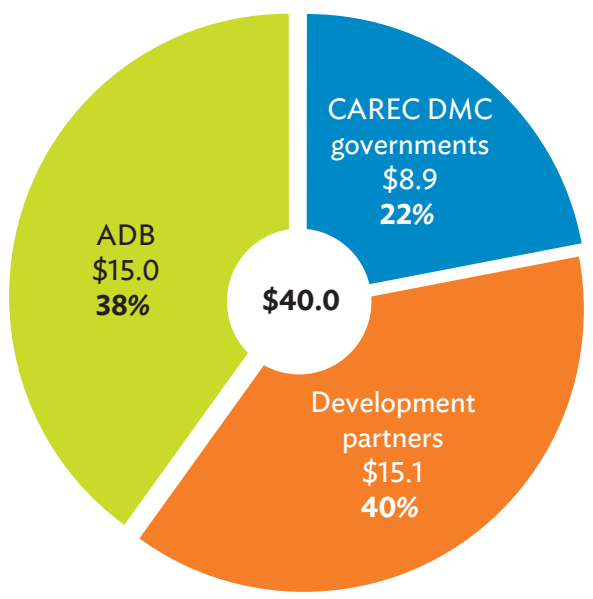

$\mathrm{ADB}=$ Asian Development Bank, $\mathrm{CAREC}=$ Central Asia Regional Economic Cooperation, $\mathrm{DMC}$ = developing member country.

Source: ADB. 2021b. CAREC Program Portfolio. Unpublished.

Among them, the budget support and emergency assistance Countercyclical Support Facility-specifically COVID-19 Pandemic Response Option (CPRO) in $A D B$, is helping CAREC economies mitigate the health, social, and economic impacts of the pandemic. Since

\section{Figure 6.2: CAREC Investments by Sector, as of 30 June 2021 ( $\$$ billion)}

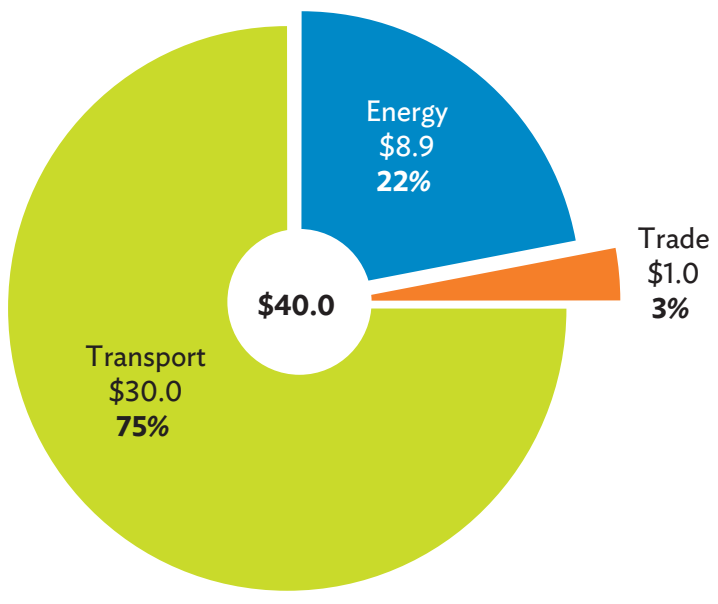

CAREC $=$ Central Asia Regional Economic Cooperation.

Source: ADB. 2021b. CAREC Program Portfolio. Unpublished.

early 2021, COVID-19 vaccination programs such as ADB's $\$ 9$ billion Asia Pacific Vaccine Access Facility (APVAX), have supported CAREC economies to roll out COVID-19 vaccination programs that create the conditions necessary for gradually relaxing restrictions 
in travel and movement, and that restore economic activities, including cross-border economic activities. Two new CAREC strategies - the CAREC Health Strategy 2030 and CAREC Digital Strategy 2030 have been adopted to complement CAREC economies' efforts in fostering growth for post-pandemic recovery. In 2021, as with other organizations during lockdowns, most CAREC activities have taken place through virtual platforms, with member economies and development partners participating in producing outputs of knowledge generation, capacity development, and project support.

Economic and Financial Stability. Activities under this cluster continue to promote policy dialogue on economic and financial stability issues important to CAREC economies, as well as regional macroeconomic policy coordination. On 1 July 2021, a CAREC High-Level Policy Dialogue on Financial Stability was organized with the International Monetary Fund and the World Bank at the sidelines of the Astana Finance Days 2021. The virtual panel discussed government policy responses to challenges on financial inclusion particularly for the poor and for micro, small, and medium-sized enterprises, and the use of fintech and innovation, as well as the role of regional cooperation platforms in promoting financial inclusion among CAREC economies, to mitigate the impact of the COVID-19 pandemic. A CAREC HighLevel Policy Dialogue on Social Spending to Tackle Rising Post-COVID-19 Inequality in CAREC was held in November 2021 and discussed social spending measures in the context of the broader COVID-19 response and macroeconomic policies. Continued progress has been achieved on implementation of technical assistance for a pilot regional disaster risk transfer facility, including economy risk profiles disseminated in CAREC regional workshops in October and November 2021, and a disaster risk modeling tool (including for infectious diseases) to measure risks and assess the costs and benefits of disaster risk reduction and disaster risk financing.

Trade, Tourism, and Economic Corridors. In the trade sector, member economies fulfilled their commitments to align with and transpose international obligations and standards into domestic practices. Notably, they continued to implement the World Trade Organization Trade Facilitation Agreement at an average implementation rate of $45.5 \%$ for mandatory provisions (Category A). At the CAREC Sanitary and Phytosanitary (SPS) Measures Week organized in April 2021, CAREC economies committed to continue modernizing SPS measures to facilitate trade while managing transboundary risks to human, animal, and plant health. Opportunities for regional and bilateral free trade agreements including the potential for a CARECwide free trade agreement are being explored. Member economies identified their research and capacity-building priorities, needs, and expectations at consultation workshops organized in May and September 2021. Digital transformation and e-commerce development have been long-standing priorities under the CAREC Integrated Trade Agenda 2030. The United Nations (UN) Framework Agreement on Facilitation of Cross-Border Paperless Trade in Asia and the Pacific (Azerbaijan and the PRC are members) entered into force in February 2021. Following Azerbaijan, Mongolia joined the UN Convention on the Use of Electronic Communications in International Contracts, which entered into force for Mongolia in July 2021. To support these efforts, ADB and the CAREC Institute completed two research studies reviewing regulatory framework and infrastructure aspects of developing e-commerce ecosystems, as well as knowledge-sharing modules on Regional Improvement of Border Services and Digital SPS Certification. In September 2021, three webinars were organized to promote knowledge sharing on e-commerce, digital trade, and innovation among CAREC economies.

In tourism, following the endorsement of the CAREC Tourism Strategy 2030 and its accompanying regional tourism investment framework 2021-2025 in 2020, several regional activities were initiated, including the development of a CAREC tourism portal as a tool for consolidating information on tourism regions and attractions in CAREC economies and promoting the services of local tourism businesses. The portal is expected to be launched by first half of 2022. As part of the implementation of the CAREC Tourism Strategy 2030, support is currently being provided to further develop the Almaty-Issyk-Kul tourism cluster through pilot projects to improve health and safety protocols and measures, enhance stakeholders' capacities, and harmonize the accommodation classification system in Kazakhstan and the Kyrgyz Republic. 
For the economic corridor development, CAREC economies have made meaningful progress in adopting the cross-border corridor concept in their national development strategies. Two CAREC economic corridor initiatives achieved tangible results. Transformative regional investment projects were conceptualized along the Almaty-Bishkek Economic Corridor (ABEC), including the Modern Agriculture Wholesale Market Development Project, the Issyk-Kul Lake Environmental Management for Sustainable Tourism Project, the ABEC Border Crossing Point Modernization Project, and the Strengthening Regional Health Security Project. Implementation of the road map for the ShymkentTashkent-Khujand Economic Corridor (STKEC) is also making good progress, with prefeasibility studies on an international center for industrial cooperation between Kazakhstan and Uzbekistan, and a trade and logistics center in Sugd oblast of Tajikistan undertaken. ADB and the International Road Transport Union conducted a joint virtual workshop on International Road Transport Digitalization for Improved Trade in September 2021, which shared experiences of international road transport digitalization projects among the STKEC economies. $A D B$ is also implementing a study supported by a small-scale technical assistance for a framework and operational guidelines that reflect wider economic benefits of economic corridor development and capture the diversity of regions in Asia and the Pacific, particularly in the Central and West Asia region, to mainstream economic corridor development operations.

\section{Infrastructure and Economic Connectivity.}

In transport, as part of efforts to implement the CAREC Transport Strategy 2030, 27 knowledge products (reports, manuals, and virtual events) and a series of virtual events were completed in 2021. These include a three-part webinar series on Aviation and Tourism between January and March 2021, a two-part series on Ports and Logistics in February 2021, and a road asset management training workshop for the Kyrgyz Republic. The sector partnered with the CAREC Institute using its e-learning platform to deliver training on road asset management and road safety, as well as with the Eastern Alliance for Safe and Sustainable Transport in developing a new e-learning course on safer road works. Other significant knowledge work completed includes the impact study of COVID-19 on CAREC Aviation and Tourism, a scoping study on CAREC Ports and Logistics (two volumes), and the CAREC Road Safety Engineering Manual 4: Pedestrian Safety, the latest addition to the series of road safety engineering manuals. Railway sector assessments were conducted and published covering all CAREC economies, and a CAREC-wide railway sector assessment is currently being finalized for publication by early 2022. ADB-financed technical assistance projects are currently supporting the implementation of the CAREC Transport Strategy 2030, the CAREC Railway Strategy 2030, and the CAREC Road Safety Strategy 2030. ADB-financed CAREC Regional Improvement of Border Services projects are supporting cross-border trade expansion in CAREC region.

The energy sector made significant progress in implementing CAREC Energy Strategy 2030. The Energy Sector Coordinating Committee (ESCC) in June 2021 endorsed the holding of the first regionwide Energy Efficiency Awareness Campaign through jointly developed TV and radio commercials; approved a preliminary concept for a new regional green financing vehicle; agreed on the main features of a new Central Asia Transmission Cooperation Association; and approved the layout and content for a new online CAREC energy reform atlas. Moreover, the ESCC committed to publishing the first 10-year CAREC Energy Outlook in 2022, an expected game changer for attracting investment in the region. All CAREC economies and development partners also endorsed a preliminary concept for the region's first Women-inEnergy Program, which includes an action plan targeted at improving employability, visibility, and education of women in the energy sector. In addition, six new energy working groups were established and became operational. Chairs of the working groups presented their deliverables under the CAREC Energy Strategy 2030 at the ESCC meeting. And a groundbreaking virtual collaboration tool (https://www.carecenergy.org) was launched as a one-stop shop and gateway to all issues of the CAREC energy program. Finally, an energy investment forum was held in December 2021 during which business opportunities in the field of energy efficiency were discussed. 
The CAREC Regional Infrastructure Projects Enabling Facility is being conceptualized with support from an ADB technical assistance approved in September 2020, to bridge infrastructure financing gaps and strengthen the project development capacities of CAREC economies. The facility will support preparation and conceptualization of infrastructure projects to provide bankable projects for investment opportunities, including catalyzing private sector and public-private partnership financing. A series of consultations with CAREC stakeholders were conducted in 2021. An ADB-supported transaction technical assistance facility has also been processed to finance preparation of ADB-supported regional infrastructure projects and improve institutional capacity in CAREC economies.

Agriculture and Water. Steady progress has been made under this new cluster. For agriculture, efforts were supported by an ongoing ADB technical assistance to strengthen institutional systems to operationalize international food safety standards, including providing advisory services for CAREC economies to harmonize domestic legislation and regulations with international norms (e.g., development of a new food safety law, national action plans, hygiene, microbiological and chemical hazard regulations, inspection checklists, and risk categorization). Training sessions were conducted on improving the food safety capacity of CAREC economies on good hygiene and manufacturing practices, and on engaging with CODEX - a collection of internationally adopted food standards and related texts, through national networks. An inspection of the Hazard Analysis Critical Control Point system was carried out in Tajikistan and Turkmenistan to improve the food safety management system.

In the water sector, a scoping study on water sector cooperation among the five Central Asian states was completed following in-depth research work and a broad range of consultations with multi-stakeholders in the five economies. The scoping study presents (i) the trajectory for water demand as the region's economies develop, and (ii) the short- to long-term impact of climate change on water supply. Three thematic papers were prepared on climate change impacts, the economic value of water, and a legal and policy analysis. The findings and proposals for the framework and content for water sector cooperation were presented at two regional consultation workshops in April and June 2021. The study was finalized which incorporated feedback and inputs from the multistakeholders in November 2021.

Human Development. In the health sector, preparation work for a CAREC health strategy toward 2030 under an ADB-supported technical assistance has been completed. A CAREC Working Group on Health was established in April 2021 to guide the formulation of the strategy and related investment framework. Regional workshops in 2021 consulted CAREC economies and development partners including the World Health Organization on the proposed framework of the new health strategy, as well as challenges and priorities in its proposed strategic areas. These include: (i) an inception workshop in March, (ii) technical review and economy consultations in July, and (iii) consultation workshops with CAREC Working Group on Health members in September. The CAREC Health Strategy 2030 was finalized which incorporated feedback and inputs from multi-stakeholders of CAREC economies and development partners.

To implement the CAREC Gender Strategy 2030 endorsed in 2020, an ADB technical assistance (\$1 million) promoting gender equality and connecting people was approved in October 2021, to help member economies strengthen the policy environment and operational mechanisms for implementing the new strategy and promote networks and people-to-people contacts, to complement CAREC investments and sustainability. Another technical assistance with $\$ 2$ million funded by the Japan Poverty Reduction Fund was also approved in 2021, to support education cooperation in skills development, including higher education and technical and vocational education development in CAREC economies.

Information and Communication Technology (ICT) is a crosscutting thematic area under CAREC 2030, which has become a crucial aspect for connectivity since the onset of the COVID-19 pandemic. There are various initiatives being implemented under the theme of ICT and connectivity in the CAREC region. First, the CAREC Digital Strategy 2030, which provides a vision, road map, and catalyst for 
digital transformation through regional cooperation, has been prepared. A combination of primary and secondary research and review and consultations were undertaken to gather data, information, and inputs for the strategy. The CAREC Program is also supporting development of the startup ecosystem in the region to mitigate the economic impact of COVID-19 pandemic and facilitate economic revival. Several initiatives are being planned under a virtual startup ecosystem hub which will engage relevant stakeholders to promote networking and knowledge exchange. Lastly, under the 'Virtual CAREC' initiative, the CAREC Secretariat has been making efforts to improve connectivity between CAREC-related agencies to improve their ability to participate in virtual events and workstreams.

To effectively manage and monitor the implementation of the CAREC Program, the first CAREC 2030 Development Effectiveness Review (DEfR) was prepared, covering 2017-2020, and based on the CAREC 2030 Program Results Framework endorsed in 2020. The DEfR, which uses relevance, process (coherence and sustainability), and progress (effectiveness) as criteria for review, reports progress against the CAREC program results framework and provides a consolidated picture of progress toward achieving the objectives of CAREC 2030. It highlights achievements in the program's five operational clusters and identifies areas for improvement. The DEfR concludes that the CAREC Program is on track to achieve its goals, and recommends efforts to continue making the Program more results-oriented, reflect and learn from past performance, and jointly develop actions to respond efficiently to the emerging needs and priorities of CAREC member economies.

\section{Prospects}

\section{New CAREC health and digital strategies will support economic growth for post- COVID-19 recovery.}

Vaccination programs and campaigns are progressing in most CAREC economies, but the COVID-19 pandemic is not yet beaten. Amid the uncertain environment, risks are tilted to the downside. The Asian Development Outlook Supplement December 2021 edition substantially revised Central Asia's growth prospects for 2021 from 4.1\% to 4.7\%, while slightly lowering overall developing Asia's growth projection from 7.3\% in April to $7.0 \%$ (ADB 2021h). The most significant threats to the economic outlook are significantly renewed COVID-19 outbreaks and delayed vaccination programs. Other risks include political turmoil, supply chain bottlenecks, and possible tightening of financial conditions.

Following the CAREC transport and energy strategies 2030 endorsed in 2019, and the tourism and gender strategies 2030 endorsed in 2020, CAREC's two new strategies endorsed in 2021-the CAREC Health Strategy 2030, and CAREC Digital Strategy 2030support CAREC economies' efforts with new policy instruments to help restore cross-border economic activities and further mitigate the COVID-19 impact.

The CAREC Health Strategy 2030 was formulated to support cooperation in addressing common health threats and challenges. The strategy promotes health cooperation in addressing communicable and noncommunicable diseases through four strategic pillars: (i) leadership and human resources capacity; (ii) technical preparedness on laboratories and surveillance; (iii) surge demands and access to supplies; and (iv) vulnerable population groups and border health. The CAREC Digital Strategy 2030 promotes the use of ICT and digital technologies for a data-driven regional digital economy across all five clusters of CAREC through three pillars, to provide (i) trusted, user-friendly digital services; (ii) secure, scalable, and interoperable digital platforms; and (iii) high-speed broadband. The strategy also promotes investment in ICT infrastructure to close the digital divide, enabling the environment for harmonizing digital and data legislature, boosting trade through reduction of barriers to cross-border trade, and contributing to job creation by developing digital skills and competencies. Both new strategies were endorsed th the 20th CAREC Ministerial Conference in November 2021. 


\section{Policy Challenges}

\section{CAREC needs to further strengthen connectivity and resilience to boost post-pandemic recovery.}

Amid renewed outbreaks of the COVID-19 pandemic including the new variants, a significant relaxation on restrictions of travel across the CAREC region has still not occurred. This has a bearing on economic recovery. It is critical for the region to remain connected through improved connectivity and resilience.

Strengthening multimodal cross-border connectivity will be key to helping CAREC economies stay connected, particularly to ensure cross-border trade during the prolonged pandemic time. Rail transport can facilitate land-based cargo transport, given that it minimizes physical contacts, partially replacing sea and air (due to the pandemic) shipment. For example, the volume of the PRC railway cargo to Europe set a record high in 2020, with a 50\% increase on 2019 including international cargoes originally set for sea and air transport. Rail transport has great potential in the CAREC region. Facilitating cross-border trade through the so-called single window and other electronic-based systems will significantly reduce the risk from physical contact of paper-based customs clearance, as well as improve the transparency and efficiency of customs procedures. In 2020, Tajikistan launched a national single window system, and Uzbekistan participated in the International Plant Protection Convention's e-Phyto certification solution. These, together with other measures facilitating e-commerce, are important to maintain trade in the CAREC region.

Tourism has been vital for most CAREC economies, and is the sector most hit by the pandemic. While fullfledged reopening will take time, facilitating resilient tourism is crucial to welcome tourists back to the region. The CAREC Tourism Strategy 2030, which promotes safe and resilient tourism, is implemented in the region. Efforts such as promoting sustainable tourism development in the Issyk-Kul lake region in the
Kyrgyz Republic and strengthening Silk Road-based regional tourism development in Uzbekistan will benefit tourism development once the pandemic is over.

\section{Southeast Asia: Greater Mekong Subregion Program ${ }^{61}$}

Cambodia, the PRC (Yunnan Province and Guangxi Zhuang Autonomous Region), the Lao People's Democratic Republic (Lao PDR), Myanmar, Thailand, and Viet Nam are the six members of the Greater Mekong Subregion (GMS) Program, while ADB houses its central secretariat. The GMS has created an interconnected subregion that continues to see improved economic growth amid enhanced connectivity and competitiveness. Since the program's 1992 launch, 109 investment projects and 230 technical assistance projects amounting to $\$ 27.7$ billion have been approved, financed by ADB, GMS governments, and multilateral and bilateral development partners. Of this, ADB contributed $\$ 12.5$ billion, GMS governments $\$ 6$ billion, and other development partners and the private sector $\$ 9$ billion.

Connectivity has been dramatically enhanced by close to 12,000 kilometers $(\mathrm{km})$ of new or upgraded roads and about $700 \mathrm{~km}$ of railway lines. Nearly 3,000 megawatts of electricity has been generated, and over 2,600 km of transmission and distribution lines now provide electricity to about 150,000 new households (ADB 2021c).

\section{Overview}

\section{GMS economies are highly interconnected through trade, tourism, and foreign direct investment, and so have been hit hard by the pandemic.}

The GMS Program supports subregional projects in agriculture, energy, environment, health, tourism, transport, transport and trade facilitation, and urban development. Their aim is to enhance the connectivity, competitiveness, and sense of community between

${ }^{61}$ Contributed by the GMS Secretariat, Southeast Asia Department. 
the six economies. Prior to COVID-19, the subregion was experiencing high growth, and interconnectedness between economies was strong with key projects in cross-border transport being completed, new crossborder power projects online, and intraregional trade and tourism on the rise. Trade among GMS economies has grown from $\$ 25.6$ billion in 2000 to $\$ 640.6$ billion in 2020. Intraregional trade was largely driven by the PRC. Trade with GMS neighbors was particularly significant for Cambodia (44\% of total trade), the Lao PDR (87\%), and Myanmar (51\%). High total trade as a share of gross domestic product (GDP), or trade openness, across the subregion was led by Cambodia, the Lao PDR, and Viet Nam (Table 6.2). The subregion was also becoming increasingly interconnected through tourism. By 2018, intra-GMS tourism accounted for nearly $23 \%$ of GMS tourism.

With the resurgence of the pandemic and extended closures of international borders and economic shutdowns to contain outbreaks, subregional growth, trade, investment, and tourism all dropped significantly in 2020. Before the pandemic, the region posted average growth of $6.1 \%$ during $2015-2019$ while growth of individual GMS economies ranged from 3.4\% to $8.8 \%$ during that period. In 2020 , the GMS as a whole recorded only $0.3 \%$ GDP growth, with modest growth only in Yunnan, PRC; Guangxi, PRC; Myanmar; and Viet Nam. Likewise, the average foreign direct investment (FDI) for the subregion dropped significantly (Table 6.2).

To support the region through the COVID-19 pandemic, ADB approved countercyclical budget support, technical assistance, and loans to GMS economies to bolster their economic and public health response measures. The GMS Program led policy dialogues and worked through sector and project areas to support the subregion to prepare for the safe resumption of open borders, trade, and tourism.

\section{Performance and Progress over the Past Year}

\section{The Ha Noi Action Plan 2018-2022 guides operational priorities, while the new GMS strategy directs medium-term efforts and broader priorities into the next decade.}

In 2019 and 2020, the GMS Program continued to implement The Ha Noi Action Plan (2018-2022), which was endorsed by GMS leaders in March 2018 to

\section{Table 6.2: Selected Economic Indicators, 2020-Greater Mekong Subregion}

\begin{tabular}{|c|c|c|c|c|c|c|}
\hline & $\begin{array}{l}\text { GDP Growth } \\
\text { (2016 to 2020, } \\
\text { average, \%) } \\
\text { and Trend }\end{array}$ & $\begin{array}{c}\text { GDP Growth } \\
(2020 \text {, average, \%) }\end{array}$ & $\begin{array}{c}\text { GDP per Capita } \\
\text { (current prices, \$) }\end{array}$ & $\begin{array}{l}\text { Trade Openness } \\
\text { (total trade, } \\
\% \text { of GDP) }\end{array}$ & $\begin{array}{l}\text { \% Change in FDI } \\
(2017 \text { to 2020) }\end{array}$ & $\begin{array}{l}\text { FDI Openness } \\
\text { (total FDI inflows, } \\
\% \text { of GDP) }\end{array}$ \\
\hline Cambodia & 5.1 & -3.1 & 1,552 & 139 & 30.1 & 14.0 \\
\hline Guangxi, PRC & 6.1 & 3.7 & 6,411 & 22 & -38.5 & 0.2 \\
\hline Yunnan, PRC & 7.8 & 4.0 & 7,534 & 11 & 9.7 & 0.3 \\
\hline Lao PDR & 4.9 & -0.5 & 2,622 & 60 & -42.6 & 5.1 \\
\hline Myanmar & 5.6 & 3.3 & 1,493 & 45 & -57.7 & 2.3 \\
\hline Thailand & 1.6 & -6.1 & 7,190 & 82 & -177.5 & -1.2 \\
\hline Viet Nam & 6.0 & 2.9 & 3,501 & 160 & 12.1 & 4.6 \\
\hline GMS & 4.9 & 0.3 & 4,801 & 70 & -45.7 & 1.1 \\
\hline
\end{tabular}

FDI = foreign direct investment, GMS = Greater Mekong Subregion, GDP = gross domestic product, Lao PDR = Lao People's Democratic Republic, PRC = People's Republic of China.

2018 for Guangxi and Yunnan, PRC.

Note: Weighted average for GMS GDP average growth rate using gross national income Atlas Method.

Sources: ADB calculations using data from CEIC Data Company; International Monetary Fund. World Economic Outlook April 2021 Database. https://www.imf.org/en/ Publications/WEO/weo-database/2021/April; and United Nations Conference on Trade and Development. World Investment Report 2021 Data Set. https://unctad.org/ system/files/non-official-document/WIR2021_tab01.xlsx (all accessed September 2021). 
set out strategic directions and operational priorities for subregional integration (ADB 2018a). The Ha Noi Action Plan is operationalized by the GMS Regional Investment Framework 2022 (RIF 2022), which is the medium-term pipeline of priority projects in the GMS that are supported by national governments, the private sector, development partners, and ADB. The GMS RIF 2022: Third Progress Report and Update presents a total of 210 investment and technical assistance projects requiring $\$ 78.3$ billion in financing (ADB 2020a). By September 2021, the RIF 2022 was updated to 204 projects requiring $\$ 78$ billion in financing. Of these needs, $76 \%$ of financing has been identified, with $63 \%$ of projects either completed or ongoing.

The 7th GMS Leaders' Summit brought together GMS economies' heads of government and the ADB President on 9 September 2021 to assess progress under the GMS Economic Cooperation Program (GMS Program) and to reaffirm the economies' commitment to advance the GMS Program. The GMS leaders endorsed the GMS Economic Cooperation Program Strategic Framework 2030 (GMS 2030), the new strategy to guide the program in the new decade. GMS 2030 sets the program's direction and priorities guided by the GMS vision of developing a more integrated, prosperous, sustainable, and inclusive subregion. Furthermore, it supports the new mission statement for the GMS Program, which aims to further expand community, connectivity, and competitiveness while promoting environmental sustainability and resilience; enhanced internal and external integration; and inclusivity. GMS leaders also endorsed the GMS COVID-19 Response and Recovery Plan 2021-2023, a supplement to GMS 2030, which supports the health and economic recovery of the subregion in the medium term.

\section{Progress and achievements in GMS sectors of cooperation were recognized at the 7th GMS Summit in September 2021 (GMS 2021).}

\section{Cross-Border Transport Connectivity and Economic Corridor Development. Transport infrastructure} remains a priority under the GMS Program. In GMS RIF 2022, 54 transport sector projects with a total value of
$\$ 50.6$ billion have been financed and are in different stages of implementation, while 11 transport projects valued at $\$ 2.0$ billion have been completed. Some key connectivity projects, which provide links between rural areas and urban economic hubs through road, rail, and border crossing facilities, are ongoing. These include the Phnom Penh Sihanoukville Expressway Project in Cambodia, Rehabilitation of the Ning'er-JiangchengLongfu road in Yunnan, PRC, the NR13 Improvement and Maintenance Project (from Vientiane to Phon Hong) in the Lao PDR, and the Aranyaprathet-Poipet New Road with Border-Crossing Facilities project connecting Thailand and Cambodia.

Moreover, in line with the Transport Sector Strategy's thrust toward multimodal transport, the Greater Mekong Railway Association (GMRA) identified and produced an initial assessment of the viability of nine priority railway links to complete GMS rail connectivity. The GMRA has also worked on a Framework Agreement on CrossBorder Railway Transport Connectivity in the GMS. A new ADB-supported technical assistance aims to strengthen GMRA and prepare a plan for developing a modern GMS railway network and updating the GMS railway strategy.

Transport and Trade Facilitation. The "Early Harvest" implementation of the GMS Cross-Border Transport Facilitation Agreement was started in August 2018, covering Cambodia, the Lao PDR, the PRC, Thailand, and Viet Nam, under which transport permits and temporary admission documents are issued and accepted along specified routes and border crossings. It is a welcome addition to trade facilitation in GMS economies, and further issuance of permits and documents is encouraged to expand benefits from these agreements. The National Trade Facilitation Committee has developed a plan to enhance and benefit from the Cross-Border Transport Facilitation Agreement further. ADB also continued to provide technical assistance for time release studies to identify ways to improve border procedures, and to support sanitary and phytosanitary standards arrangements in Cambodia and the Lao PDR.

In 2019, before the COVID-19 outbreak, cross-border trade and transport facilitation, supported by the Early 
Harvest implementation, had been progressing well. Economies' relevant officials were trained; transport operators briefed; administrative circulars, GMS transport permits and temporary admission documents issued; and national registers compiled and exchanged with other economies. To ease the heightened barrier to transport and trade caused by the pandemic, GMS economies continued to coordinate and exchange information on the status of the border crossing points and new measures applied in respective economies. The National Transportation Facilitation Committee, which leads the implementation of the GMS CrossBorder Transport Facilitation Agreement, met on 22 June 2020 to facilitate coordination and cooperation among GMS economies in ensuring safe movement of goods and passengers across GMS borders. Among the agreed immediate- to medium-term recovery measures are (i) an information platform to facilitate interagency and cross-border information exchanges between officials; (ii) a portal to keep businesses and the public informed on border crossing matters; and (iii) accelerating the publication of economy handbooks identifying host economy traffic rules (e.g., maximum permissible weights and dimensions, speed limits, vehicle markings, third party insurance providers, and the like) and specifying the permissible routes and places for (dis) embarkation of passengers and (un)loading of cargo.

Energy. Power trade has entered Stage 2 (economyto-economy power trade) and cooperation remains a priority of the Regional Power Trade Coordination Committee. Significant headway has been made in preparing a grid code and harmonized performance standards, and in formulating the regulatory framework. GMS economies have entered into bilateral and trilateral power trade agreements among themselves, including the Lao PDR-Malaysia-Thailand trilateral power trade deal, the Cambodia-Lao PDR bilateral power trade deal, and the Lao PDR-Thailand power trade deal involving part of the output of the newly operationalized Nam Ngiep 1 hydropower project in the Lao PDR (which is funded by private sector investment). The power trade between the Lao PDR, Myanmar, Viet Nam, and the PRC reached 4 terawatt-hours in 2020. An ADB technical assistance is also supporting ongoing knowledge work to lay the groundwork for a GMS regional power master plan and a clean energy transition with greater integration of renewable energy and increased private sector participation.

Tourism. The boom in tourism (80 million international tourist arrivals to the GMS in 2019 that spent about $\$ 100$ billion) collapsed due to COVID-19, with arrivals plummeting by about $80 \%$ in 2020. GMS economies, supported by the GMS Tourism Working Group and the Mekong Tourism Coordinating Office, responded to the pandemic by implementing mitigating measures that include disseminating information on travel regulations and health advisories; fiscal, monetary, and training support; social protection programs for formal and informal tourism workers; stringent health and safety regulations for key tourism subsectors; and monetary incentives to energize domestic tourism. The Mekong Tourism Recovery Communications Plan has been prepared to guide dissemination of accurate and engaging information to support a safe and sustainable GMS tourism recovery.

Although international tourism continued to be affected by COVID-19-induced border closures, various ongoing projects and initiatives under the GMS Tourism Sector Strategy (2016-2025) will contribute to the restart and recovery of the sector. The ongoing projects and initiatives include promoting secondary tourism destinations, tourism startup firms, tourism technology innovations, and strengthened tourism vocational training. Initiatives include the Second GMS Tourism Infrastructure for Inclusive Growth in Cambodia, the Lao PDR, and Viet Nam, with an estimated investment of $\$ 136.4$ million; the 2018 and 2019 Mekong Innovative Startups in Tourism initiative, where tourism technology startup firms raise investment capital from private investors (about \$1.8 million in 2017-2018); and the ADBPacific Asia Travel Association Travel Impact Lab, which was started to support pilot-scale technology innovations for tourism enterprises.

GMS economies have agreed in principle to transform and improve the status of the Mekong Tourism Coordinating Office as a formal international intergovernmental organization. The Tourism Working Group has also 
worked with destination management organizations and industry suppliers to adapt and strengthen electronic supply chains between producers and tourism end users, as well as creating social media and tourism marketing initiatives to promote a return to tourism.

\section{Urban and Border Area Development. The GMS} economies continued to focus urban development investments on planning smart and livable cities and on urban development for riverine and coastal cities and towns, as these related to healthy oceans and waterways.

The GMS Urban Development Working Group adopted a revised approach to corridor towns, focusing on the economically connected areas covering both border cities and so-called anchor cities-cities that act as natural growth poles and provide essential economic, social, and administrative support to the development of a border zone. The working group also put emphasis on capacity development for urban management and investment in local urban infrastructure.

To support these objectives, the Third and Fourth GMS Corridor Towns Development projects; the Yunnan Lincang Border Economic Cooperation Zone Development Project; and the Livable Cities Investment Project are under way.

An initiative has also been launched to expand GMS economies' efforts to promote ADB's Action Plan for Healthy Oceans and Sustainable Blue Economies, as well as recommended smart city pilots under the ASEAN Smart City Initiative. The 4th Meeting of the GMS Urban Development Working Group, convened under the theme "the enhancement of urban resilience in post-pandemic era," shared and discussed the PRC's experience in urban management and harnessing digital solutions in pandemic control, and recognized the important role of digital means in combating COVID-19.

\section{Health and other Human Resource Development.}

The GMS Health Cooperation Strategy 2019-2023 was endorsed by the GMS health ministries and launched at the 23rd GMS Ministerial Conference in October 2019. Three strategic pillars guide economies through health challenges requiring new and innovative responses and partnerships. In July 2020, a strategic results framework was endorsed by the GMS economies to evaluate the strategy's effectiveness against intended outcomes by 2023. Furthermore, the GMS Health Cooperation Working Group is preparing an action plan to operationalize the strategy and support its three pillars: (i) strengthening national health systems to address transnational health threats and health security as a regional public good, (ii) responding to the health challenges and health impacts because of connectivity and mobility, and (iii) health workforce development.

The GMS Regional Health Security Project continues to strengthen public health security mechanisms through improved regional and cross-border communicable disease control (services; disease surveillance and outbreak response; hospital infection prevention and control; and laboratory quality and biosafety). Detailed information on the GMS Program's rapid response to the COVID-19 pandemic is discussed on page 180.

To strengthen resilience against future pandemics, the GMS Healthy Border Special Economic Zones Project is developing knowledge partnerships between Thailand and its GMS neighbors, with the aim of strengthening health care for migrant workers in border areas.

The Strengthening Regional Health Cooperation in the GMS project is also funding "One Health" assessments to strengthen prevention in areas where animal and human health are interconnected, such as healthy livestock evaluation.

In the related field of labor migration, the GMS Program has initiated a GMS Task Force on Labor Migration and held the Dialogue on Labor Migration in the GMS. The forum discussed the increasingly important link between subregional cooperation in labor migration management and the overall development of the subregion as this has gained even greater relevance in light of the COVID-19 pandemic.

Agriculture. An ADB-supported regional technical assistance on the GMS Sustainable Agriculture and Food Security Program (2020-2025) approved in December 2019 continues to implement the Strategy for Promoting Safe and Environment-Friendly Agro-Based Value 
Chains and Siem Reap Action Plan for 2018-2022. The program focuses on (i) green agribusiness supply chains and agribusiness financing, (ii) crop and livestock safety and quality, and (iii) climate-adaptive agriculture in the context of water-food-energy nexus.

The GMS Working Group on Agriculture and projects are helping the GMS economies to ensure food safety and security, and boosting competitiveness of agribusiness value chains-a critical part of the response to the COVID-19 pandemic. Key themes of support include harmonization of agri-food safety and quality standards; support for livelihoods and job creation in rural areas; control of transboundary animal diseases, zoonoses, and antimicrobial resistance; support for greening and financing inclusive agribusiness supply chains; and promotion of climate-adaptive agriculture in the context of water-food-energy nexus. The Working Group on Agriculture also organized a virtual dialogue on Priorities for Post-Pandemic Food Security Response and Recovery in the GMS.

Environment. Several ADB-supported projects are assisting the GMS economies in addressing both biodiversity and climate crises, a critical part of the response to COVID-19 and the focus of two international conferences on biodiversity (COP15 in Kunming, PRC) and climate (COP26 in Glasgow, United Kingdom) in 2021. The GMS Working Group on Environment in June 2020 discussed effective ways of integrating climate and disaster resilience considerations and low carbon transitions into the GMS COVID-19 recovery efforts. It identified several areas of focus in a post-pandemic scenario: ensuring that recovery programs are green, climate-smart and resilient, and propoor; alignment with sustainable waste management; and with priorities and opportunities for biodiversity and wildlife management. The pandemic has highlighted interconnected risks and vulnerabilities, with broad humanitarian, social, economic, and environmental consequences in the GMS and is also affecting efforts to advance the Sustainable Development Goals (SDGs) and the 2030 Agenda. The GMS Working Group on Environment therefore aims to assess the opportunities in aligning post-COVID-19 recovery plans with the SDGs.
A regional technical assistance on the GMS Climate Change and Environmental Sustainability Program was approved in December 2019 to support implementation of the GMS Core Environment Program Strategic Framework for 2018-2022. The program will focus on (i) climate and disaster resilience, and lowcarbon transitions; (ii) climate-smart landscapes and environmental sustainability, including pollution control and waste management; and (iii) green technologies and climate and disaster risk financing instruments.

A technical assistance program for Thailand, Climate Change Adaptation in Agriculture for Enhanced Recovery and Sustainability of Highlands, was begun in early 2020, aiming to reduce the vulnerability of highland communities and ecosystems to cope with climate change impacts. The project will focus on (i) assessing climate change vulnerability of highland agriculture; (ii) prioritizing gender-responsive, climatesmart agriculture practices; (iii) enhancing agricultural product quality, value addition, and market linkages; and (iv) strengthening capacity of local governments and communities to tackle climate change.

\section{Prospects}

\section{Given the impact of the COVID-19 pandemic on GMS, economies' efforts in the medium term will focus on response and recovery from the effects of the crisis.}

Initially, GMS had some success in controlling the spread of COVID-19. This was largely due to the GMS economies' actions to stem the spread of the disease, including prompt travel controls; testing, contact tracing, isolation, treating, and monitoring; community quarantine policies; promoting or requiring science-based health protocols; preparing the public health and medical systems; and the rolling out of vaccines.

However, the subregion has been affected severely by the resurgence of COVID-19 in 2021. It has not been spared from the contraction of economic growth resulting mainly from disease containment efforts, which 
disrupted supply chains, impaired production capacity, and reduced demand and consumption.

In the immediate term, the GMS will continue to focus on response and recovery from the pandemic. The GMS will be guided by the COVID-19 Response and Recovery Plan 2021-2023 to help counteract and overcome the impact on public health and the economy (ADB 2021d). The plan has three pillars. Pillar 1 emphasizes protecting lives with a One Health approach to ensure the health of people, as well as animals, crops and food products, and urban environments. Pillar 2 underscores protecting the vulnerable and poor by offering opportunities in border areas and GMS corridors, as well as supporting the safe and orderly movement of labor. Pillar 3 ensures that borders remain open to accelerate inclusive, green, and resilient economic activity, to facilitate trade and transport, rebuild agriculture, and generate safe and seamless tourism opportunities.

\section{Policy Challenges}

\section{A multifaceted approach is needed to respond to the impact of the COVID-19 pandemic.}

The COVID-19 pandemic is expected to have protracted impact, and the cost to the global economy is estimated to top $\$ 35$ trillion by 2025 (Nair 2020). The main reason for the enormous impact is the highly interconnected global economy. This is especially true for GMS economies whose economies are tightly connected not just physically (many GMS economies share multiple borders with other GMS members) but also economically. Significant gains made by the subregion in reduction of inequality, alleviation of poverty, and social and economic exclusion will increase the burden on the public sector, necessitating more efforts from the private sector and the development partners.
To address the complex issues brought about by the COVID-19 pandemic, response plans must be multisector and multi-economy. Future threats of global and regional pandemics persist and will need to be planned for in parallel with economic recovery and regrowth. The GMS One Health is such an approach. It reinforces multisector cooperation (public health, animal health, wildlife, environment, agriculture) as a building block for effective response to COVID-19 and other public health threats. This implies the need for the working groups on transport and trade facilitation, tourism, agriculture, and health to coordinate activities in close collaboration. Cooperation and coordination among GMS economies to harmonize policies and regulations, especially on health security will also be critical.

\section{East Asia: Enhancing Regional Public Goods through Policy Dialogues under the CAREC and GMS Subregional Programs and Knowledge-Sharing Initiatives ${ }^{62}$}

\author{
$A D B$ through its East Asia Department (EARD) remains \\ committed to supporting regional cooperation and \\ integration with particular focus on regional public goods \\ under the new economy partnership strategies for both \\ the PRC and Mongolia. EARD is implementing a wide \\ network of cooperation and trade facilitation projects \\ traversing CAREC Corridor 4. EARD is supporting the PRC's \\ engagement under the GMS Program, including initiatives \\ to promote sustainable cooperation with its neighboring \\ border areas. EARD continues to provide opportunities for \\ cross-learning and strengthening cooperation for improved \\ resilience to transboundary threats and sustainable \\ post-pandemic recovery.
}

62 Contributed by Dorothea Lazaro, regional cooperation specialist, East Asia Department; and Loreli de Dios, ADB consultant. 


\section{Overview}

\section{The PRC and Mongolia are part (individually or jointly) of $\mathrm{RCl}$ initiatives in Asia and the Pacific, including the CAREC Program and the GMS Program.}

The PRC (specifically, Inner Mongolia Autonomous Region and Xinjiang Uygur Autonomous Region) and Mongolia are active members of the CAREC Program along with 9 of the 10 economies in ADB's Central and West Asia Department. EARD continues to support implementation of the CAREC 2030 long-term strategy, including its operational clusters and new initiatives in health cooperation and digital transformation. EARD is managing the implementation of the CAREC Integrated Trade Agenda 2030 and its 3-year Rolling Strategic Action Plan for 2021-2023. Current priorities to facilitate safe trade include modernizing SPS measures, promoting digital trade, and expanding cross-border e-commerce. EARD has also initiated the work to assess the feasibility of a CAREC free trade agreement.

EARD is implementing coordinated investments in the PRC and Mongolia to fully realize the benefits of economic corridor development along CAREC Corridor 4 These projects promote physical connectivity and policy coordination between the two economies-as with the cross-border economic cooperation zone that will link the Erenhot pilot zone in the PRC's Inner Mongolia Autonomous Region and Mongolia's ZamynUud free zone.

The ongoing Guangxi RCI Promotion Investment Program links the Guangxi Zhuang Autonomous Region with economies of the Association of Southeast Asian Nations (ASEAN), particularly those in the GMS. EARD has approved the program's third tranche-with $\$ 140$ million of ADB financing-to support small and medium-sized enterprises in border areas; develop integrated cross-border e-commerce platforms between the PRC and Viet Nam; build key infrastructure and trade-related services in border economic zones; and establish a smart tourism service system.
Besides these, EARD is implementing a technical assistance project to enhance sustainable cooperation of the PRC's Yunnan and Guizhou provinces with GMS economies. Another technical assistance project aims to strengthen GMS health cooperation, to prevent outbreaks of emerging infectious diseases and support the One Health approach, among others.

The sharing of knowledge and experience to enhance regional cooperation remains a priority for EARD, including through collaboration with the CAREC Institute and the Regional Knowledge Sharing Initiative. In addition, EARD has launched a new fund to support innovation and quality investments in developing member economies through knowledge sharing and transfer of ADB's operational experience in the PRC.

\section{Performance and Progress over the Past Year}

\section{Border zone and trade facilitation projects support economic corridor development in the PRC and Mongolia.}

In June 2019, the PRC and Mongolia signed a bilateral agreement to develop an economic cooperation zone under the framework of their bilateral strategic partnership and regional cooperation initiatives. ADB support includes a $\$ 30$ million concessional loan for Mongolia's Developing the Economic Cooperation Zone Project, which was approved in June 2020.

The project will develop the physical infrastructure and promote sustainability of the Zamyn-Uud free zone and support seamless transit to and from the Erenhot zone in the PRC's Inner Mongolia Autonomous Region.

The Inner Mongolia Sustainable Cross-Border Development Investment Program for the PRC-a $\$ 420$ million multitranche financing facility (approved by ADB in October 2020) - will install smart ports with one-stop inspection systems to improve customs clearance between the PRC and Mongolia, and establish 
a cooperation mechanism for better coordination between the two zones. Estimated at $\$ 196.3$ million, tranche 1 will upgrade key infrastructure and services in border areas; promote the use of high-level technology for ecological restoration within the cooperation zone; create income-generating opportunities by establishing inclusive agricultural value chains and improving access to finance for small and medium-sized enterprises; and improve border infrastructure in the Mandula port. The program's second tranche will be processed in 2022.

The PRC's Guangxi Regional Cooperation and Integration Promotion Investment Program Tranche 2-approved in 2018 for $\$ 180$ million—continued to strengthen small and medium-sized enterprises, develop cross-border e-commerce platforms, and upgrade infrastructure and services for border economic zones. The Yunnan Lincang Border Economic Cooperation Zone Development Project, which became effective in July 2019, is making robust headway toward building trade and logistics capacity and developing border zones. Furthermore, a technical assistance project to improve policy research and capacity building in the PRC's Yunnan and Guizhou provinces is being implemented. It will also enhance institutions and capacities for regional public goods and mobilize green finance and promote sustainable trade and investment linkages between the two provinces and the GMS.

\section{ADB is stepping up technical assistance and project support to build climate change resilience and foster environmental sustainability in the East Asia region.}

An innovative way to support responsible and sustainable finance and regional cooperation is being planned under a new technical assistance project. The technical assistance will help finance sector regulators and institutions in the PRC adopt international best practices; develop innovative finance sector products in areas such as green financing, blue financing, ${ }^{63}$ disaster risk financing, and longevity financing; and disseminate the PRC's experience in these areas including through the existing ASEAN+3's financial cooperation platforms. ${ }^{64}$ Another new technical assistance project is also supporting disaster risk management by developing frameworks, building capacity, and defining costeffective options. The technical assistance will foster partnerships among the PRC and neighboring economies for improving disaster preparedness and resilience. This will be linked to and complement the Strengthening Integrated Early Warning System project, which aims to strengthen Mongolia's climate and disaster resilience.

In Mongolia, a \$30 million Climate-Resilient and Sustainable Livestock Development Project (approved in May 2021) is supporting the improvement of livestock production systems in 20 soums (districts) of four aimags (provinces) in Central Mongolia. The project aims to enhance capacity for food safety and traceability to meet international market standards.

It is envisaged that the project outcomes and best practices will be disseminated among Mongolia's trading partners in CAREC.

\section{EARD provides opportunities for cross- learning and strengthening cooperation through knowledge-sharing initiatives.}
EARD and development partners continue to work closely to enhance cooperation through dialogue and capacity-building activities under the CAREC Integrated Trade Agenda 2030. ADB and the CAREC Institute delivered three knowledge-sharing modules on CAREC trade in the first quarter of 2021. Mongolia's experience in implementing the Regional Improvement of Border Services project underscored the importance of feasibility studies and improving capacities and cooperation among border enforcement agencies. In the same module, the PRC shared its experience

\footnotetext{
63 Blue financing refers to financing for sustainable ocean economy which involves sustainable use of ocean resources for economic growth while protecting and restoring marine ecosystems.

64 ASEAN+3 consists of the 10 ASEAN member economies and Japan, the PRC, and the Republic of Korea.
} 
in developing a national single window through a phased approach - from one-stop port formalities and regulations, followed by a platform for trade services-to interconnectivity with trading partners (CAREC 2021a). A similar module on Facilitating Trade through Digital SPS Certification (CAREC 2021b) was followed by the release of an ADB brief on Expanding Agri-Trade in Central Asia through the Use of Electronic Certificates (Lazaro et al. 2021). The CAREC SPS Measures Week on 19-22 April 2021 took the theme, Facilitating Safe and Sustainable Trade in the CAREC Region. CAREC members discussed their experiences and perspectives on cooperation in SPS measures in the post-

COVID-19 era, enhancing trade opportunities through phytosanitary measures, addressing transboundary animal diseases and food safety issues, and facilitating safe trade through risk management and digitalization. At the CAREC Trade Week in September 2021, members agreed to enhance regional cooperation and accelerate digital trade. The report on e-commerce development looking at national regulatory framework and state of infrastructure in the region was launched and provided actionable recommendations (ADB 2021e).

Similar knowledge-sharing sessions were organized for Mongolia in March and April 2021. The sessions focused on the role of special economic zones in economic development, international best practices in special economic zones, adopting water saving technology in zone operations, and exploring public-private partnerships (CAREC 2021c).

Since 2012, the PRC's Ministry of Finance and ADB have jointly implemented the Regional Knowledge Sharing Initiative to facilitate exchange of development-related knowledge among ADB's developing members. Despite the ongoing pandemic, the initiative continued to deliver timely and relevant lectures and webinars sharing the PRC's experience. This includes a collaborative effort with the PRC's Center for International Knowledge on Development series on COVID-19 experiences and lessons from the PRC and the ADB-Asia Pacific Finance and Development Institute's lecture series on international development.

\section{Prospects}

\section{Free trade and efficient movement of goods combined with green and inclusive policies will support sustainable post-COVID-19 recovery.}

Trade. Keeping trade open and movement of goods efficient will help ensure supply chain connectivity and post-pandemic recovery. In this regard, facilitating trade at borders remains crucial, and the optimal use of modern technology and active engagement in regional cooperation initiatives are essential. To complement existing $\mathrm{RCl}$ projects in Mongolia, two related technical assistance projects will be processed: one on e-government and digital transformation; and another on sustainable and inclusive integration in the regional and global economy. These will support Mongolia's 5-year Digital Nation Program and the goal to improve resilience to threats and manage risks arising from crossborder movement of goods and people. The proposed Resilient and Integrated Border Services for Safe and Fast Trade Project (for 2023) will upgrade border facilities to facilitate trade and improve detection and control of communicable diseases in border areas and support coordination among border agencies for improved responses to pandemics or similar healthrelated outbreaks.

Sustainability. Sustainable and green development are also strategic priorities under the new country partnership strategies for the PRC and Mongolia. The transition to greener future for Mongolia will be complemented by climate-resilient infrastructure to drive competitiveness and diversification. Aligned with the CAREC Tourism Strategy 2030, the proposed Sustainable Tourism Development Project will provide enabling infrastructure and promote export opportunities in tourism and related services. The proposed Aimag and Soum Center Green and Resilient Regional Development Investment Program will support a fundamental paradigm shift and transformative model to promote green territorial development and urban-rural linkages along the CAREC Corridor 4. 
The proposed Heilongjiang Green Transformation Demonstration Project aims to enhance efficiency and environmental sustainability of border economic activities while improving climate-resilient urban design and quality urban services in Heihe and Suifenhe.

\section{Policy Challenges}

\section{Expansion of services trade to promote diversification is essential to support post- pandemic recovery.}

Economic diversification is critical to sustaining economic growth in East Asia and beyond. International experience shows that the services sector can be a major driver of economic diversification, job creation, innovation, productivity growth, and development. The pandemic has made diversification an even more pressing need. However, it has also affected services production and trade profoundly. The many services associated with the trading of goods have seen demand severely contract. Transport, distribution, and traderelated financial services will take time to pick up. Tourism and other services associated with the industry have also been hit hard worldwide, while demand has surged for health-care services. Collaborating and cooperating will provide mutual benefits and lighten each economy's burden in managing the COVID-19 shock (ADB 2021f).

As economies undertake policy measures and short-term adjustments to cope with the pandemic, it is important to rebalance the economy. The pandemic hit the PRC's services sector hard, reducing its contribution to GDP growth from 63.5\% in 2019 to $47.3 \%$ in 2020. Expansion of services, through policies and investments focusing on high-value services such as information technology, health care, education, and professional services will now be critical (Qi 2021). In Mongolia, persistent challenges in education quality, skills mismatches, and the impacts of COVID-19 raise concerns about labor productivity.
Improving education services is one area critical for Mongolia's diversification efforts.

Overall, economic cooperation and integration can accelerate the development of services in the PRC and Mongolia. This requires more liberalization of trade in services and lower barriers to FDI. Regional trade agreements are one way to achieve these objectives. By continuing to engage with one another through initiatives such as the CAREC Program and other cooperation forums, members can move closer to policy coherence and commonly agreed standards (ADB 2021f).

\section{South Asia: South Asia Subregional Economic Cooperation ${ }^{65}$}

The ADB-supported South Asia Subregional Economic Cooperation (SASEC) Program continued its momentum in 2020 and 2021, despite the crippling effects of the COVID-19 pandemic in these years. ADB assistance of $\$ 2.36$ billion for $13 \mathrm{RCl}$ projects was committed during the period (annual average of $\$ 1.18$ billion is much higher than the $\$ 905$ million in 2019), consisting of five transport projects, three energy projects, and five multisector/ economic corridor projects.

As of 7 December 2021, 73 projects worth $\$ 17.43$ billion had been financed, of which ADB had extended $\$ 10.17$ billion in loan/grant assistance (ADB 2021g). SASEC membersBangladesh, Bhutan, India, Maldives, Myanmar, Nepal, and Sri Lanka-recognize the need to refocus the SASEC program to pursue more resilient multimodal corridors and supply chains through optimal blending of hard and soft interventions. The SASEC Secretariat is thus undertaking a thorough review of the progress of the SASEC Vision initiatives (ADB 2017), to be guided by the principles of enhancing ownership and commitments from the member economies, broadening multisector engagement, improving resource mobilization, and making coordination mechanisms more effective.

65 Contributed by Thiam Hee Ng, director, Regional Cooperation and Operations Coordination Division, South Asia Department (SARC); Tadateru Hayashi, principal economist, SARC; Aileen Pangilinan, senior regional cooperation officer; Esnerjames Fernandez, associate regional cooperation officer, SARC; Jesusito Tranquilino, ADB consultant, SARC; and Leticia de Leon, ADB consultant, SARC. 


\section{Overview}

\section{In 2020 and 2021, SASEC pushed ahead with its multimodal connectivity development efforts, while retooling its strategic thrusts toward achieving a more resilient and inclusive post-COVID-19 recovery.}

Bangladesh, Bhutan, India, and Nepal established SASEC in 2001 to strengthen subregional economic cooperation and tackle development challenges such as persistent poverty and demographic expansion (Table 6.3). Maldives and Sri Lanka joined in 2014 followed by Myanmar in 2017, expanding opportunities to enhance cross-border connectivity, intraregional trade, and regional cooperation and integration. ADB is lead financier, secretariat, and development partner, financing investments and technical assistance.

By 7 December 2021, 73 projects ( $\$ 17.43$ billion) had been financed (Figure 6.3), with an additional \$194.01 million in 141 technical assistance grants. Investments in infrastructure connectivity accounted for the largest share (44 projects, $\$ 12.32$ billion), with power generation, transmission, and cross-border electricity trade second (16 projects, $\$ 2.92$ billion). Investments in economic corridor development, trade facilitation, and ICT development amounted to $\$ 2.18$ billion (Figure 6.4). ADB committed about $\$ 10.17$ billion in investments ( $\$ 7.03$ billion from ordinary capital resources and $\$ 3.14$ billion in concessional finance), while SASEC members and cofinanciers contributed more than $\$ 7.25$ billion (Figure 6.5).

Figure 6.3: SASEC Investment, by Sector, 2001-2021 (\$ million)

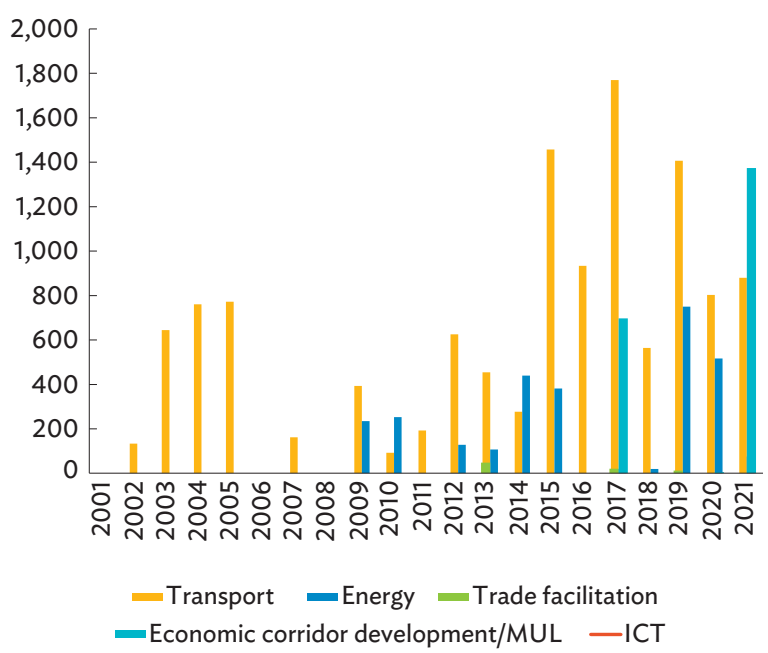

ICT = information and communication technology, MUL = Multisector, SASEC = South Asia Subregional Economic Cooperation

Note: Data are as of 7 December 2021.

Source: ADB. 2021g. SASEC Project Portfolio 2021. Unpublished.

Table 6.3: Selected Economic Indicators, 2020-SASEC

\begin{tabular}{|c|c|c|c|c|c|}
\hline Economy & $\begin{array}{l}\text { Population } \\
\text { (million) }\end{array}$ & $\begin{array}{l}\text { Nominal GDP } \\
\text { ( } \$ \text { billion })\end{array}$ & $\begin{array}{l}\text { GDP Growth } \\
(\%, 2016-2020, \\
\text { average })\end{array}$ & $\begin{array}{l}\text { GDP per Capita } \\
\text { (current prices, } \$ \text { ) }\end{array}$ & $\begin{array}{c}\text { Trade Openness } \\
\text { (total trade, } \\
\% \text { of GDP) }\end{array}$ \\
\hline Bangladesh & 164.7 & 329.1 & 7.1 & $1,998.4$ & 23.3 \\
\hline Bhutan & 0.8 & 2.5 & 4.5 & $3,243.9$ & 113.9 \\
\hline India & 1,380.0 & $2,708.8$ & 3.7 & $1,962.9$ & 23.8 \\
\hline Maldives & 0.5 & 3.8 & -0.7 & $6,946.7$ & 53.3 \\
\hline Myanmar & 54.4 & 81.3 & 4.2 & $1,493.4$ & 42.6 \\
\hline Nepal & 29.1 & 34.5 & 4.2 & $1,182.9$ & 33.3 \\
\hline Sri Lanka & 21.9 & 80.7 & 2.0 & 3.681 .7 & 33.2 \\
\hline SASEC & $1,651.5$ & $3,240.6$ & 4.0 & $1,962.2$ & 24.6 \\
\hline
\end{tabular}

GDP = gross domestic product, SASEC = South Asia Subregional Economic Cooperation.

Notes: Average GDP growth rate for Myanmar covers 2017 onward. SASEC average GDP growth rate is weighted using nominal GDP, based on International Monetary Fund staff estimates. Total trade refers to the sum of merchandise exports and imports.

Sources: ADB (2021a); International Monetary Fund (IMF). Direction of Trade Statistics. https://data.imf.org/dot; IMF. World Economic Outlook April 2021 Database. https://www.imf.org/en/Publications/WEO/weo-database/2021/April; and World Bank. World Development Indicators. https://databank.worldbank.org/source/worlddevelopment-indicators\# (all accessed August 2021). 
Figure 6.4: SASEC Projects by Sector, 2021

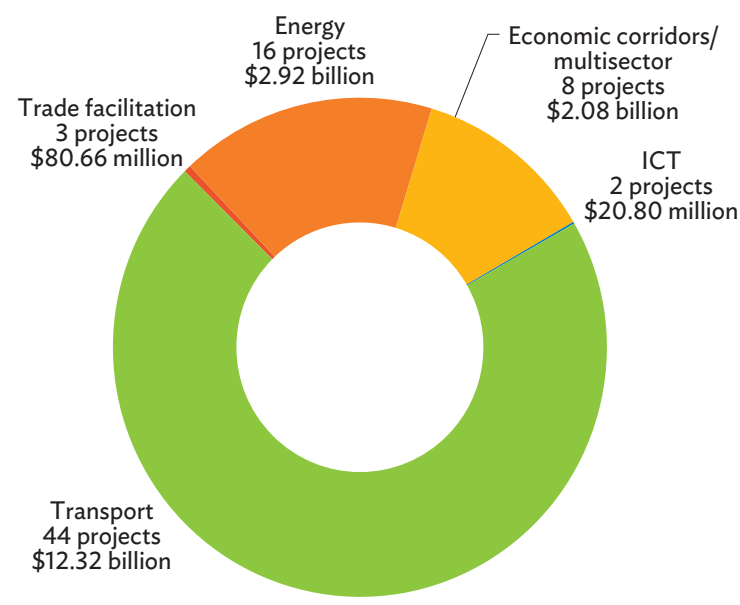

$\mathrm{ICT}=$ information and communication technology, SASEC = South Asia Subregional Economic Cooperation.

Source: ADB. 2021g. SASEC Project Portfolio 2021. Unpublished.

Figure 6.5: SASEC Investment by Volume and Financier, 2001-2021 (\$ million)

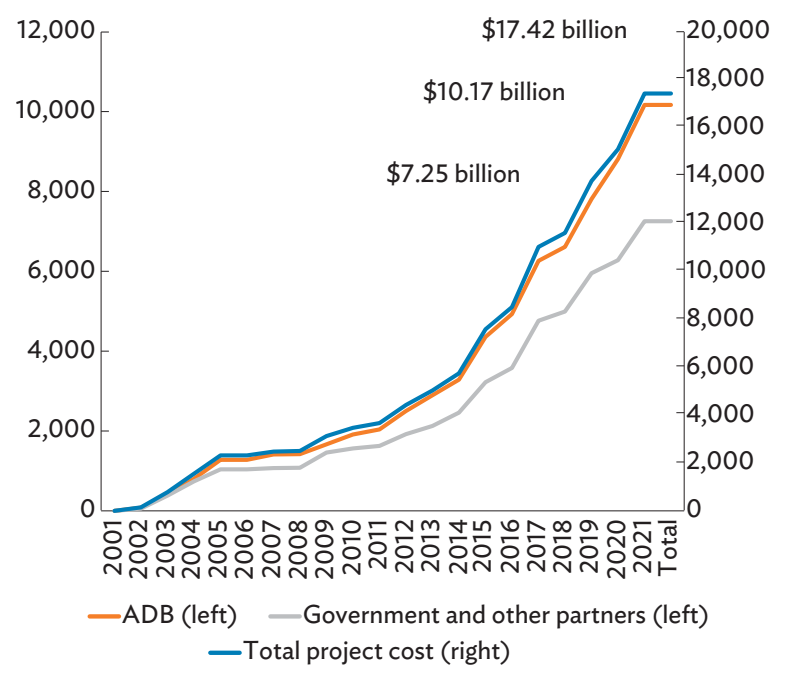

$\mathrm{ADB}=$ Asian Development Bank, SASEC = South Asia Subregional Economic Cooperation.

Note: Data are as of 7 December 2021.

Source: ADB. 2021g. SASEC Project Portfolio 2021. Unpublished.

SASEC's operational focus on enhancing multimodal transport networks (ADB 2016) took hold with airport, rail, and last mile road projects approved in 2019-2020, complemented by maritime connectivity studies which identified measures to enhance port logistics and hinterland connectivity. Following revamp of the SASEC Operational Plan 2016-2025 in 2019 (ADB 2020b), a quick stock take of the SASEC Vision's progress in 2020-2021 led to adoption of measures to improve program implementation, such as (i) formulating an Action Plan of SASEC Initiatives (APSI) for 2021-2023 to accelerate multimodal corridor development, accounting for COVID-19 pandemic challenges; and (ii) strengthening SASEC institutional mechanisms to boost economy ownership of the SASEC program, and to better align with the subregion's SDG targets. ${ }^{66}$ These enhancements are designed to better adapt SASEC economies toward a more inclusive and resilient postCOVID-19 recovery.

\section{Performance and Progress over the Past Year}

\section{Multimodal transport corridor development and measures to improve trade efficiencies have been strengthened, while green energy and subregional power transmission also remain priorities.}

The SASEC Nodal Officials and Working Groups meetings held virtually in September-October 2020 endorsed, in principle, the overall approach and directions of the proposed APSI, 2021-2023, prescribing actions for accelerating progress of multimodal corridors based on the SASEC Road Corridors in the 2019 update of the SASEC Operational Plan 2016-2025. The meeting also endorsed the proposal to strengthen the SASEC institutional arrangements, subject to further refinements based on the economy consultations that were planned to follow.

Transport. Completing key sections of multimodal transport corridors continued in 2020-2021, with upgrading of Bangladesh's Dhaka-Northwest international trade corridor and the Dhaka-Sylhet international corridor, together with financing of a facility to help Bangladesh in preparing priority projects to boost

66 Also to better align with ADB's Strategy 2030 (ADB 2018b). 
road and rail connectivity to ports, border crossings, and intermodal transshipment facilities, among others. Two airport projects in Nepal are improving capacity of two international gateways (e.g., Kathmandu and Lumbini) and supporting civil aviation reforms and improving the sector's operational efficiency. The SASEC program continues to prioritize bettering multimodal links between port gateways and landlocked Bhutan, Nepal, and India's northeast region. ADB stands ready to support consultations to enhance Nepal's transit trade access to various Indian ports, for instance. To promote maritime connectivity, ADB is supporting studies to address common port issues such as port performance, digitization, inland logistics, and environmental impacts.

Trade Facilitation. SASEC trade facilitation efforts continued to focus on expediting cargo clearance, reducing transaction costs, and ensuring efficient compliance management (ADB 2014). Support for the SASEC Customs Subgroup has advanced various national and subregional projects (e.g., electronic data exchanges, transit automation, and so on) and capacity building. ADB's completed policy-based customs lending to Nepal has led to preparation of a new Nepal Customs Act submitted to Parliament for approval. SASEC mechanisms will be leveraged for improving coordination in developing and managing border infrastructure to improve connectivity and better match capacities between border crossing pairs. After completing diagnostic studies on sanitary and phytosanitary (SPS) and technical barriers to trade (TBT), SASEC has undertaken, and will continue studies on SPS-TBT facilities and a regional framework on certification and mutual agreement on select products. As a COVID-19 pandemic response, procedural improvements were initiated to sustain trade and reduce supply interruptions particularly for critical goods, with due regard for public health and safety.

Energy. Harnessing hydropower potential and improving internal transmission and cross-border interconnections to enable regional power trading remain priorities for the power sector. ADB committed $\$ 416$ million for three power transmission projects in Nepal in 2020-2021 to build future capacity allowing surplus power to be exported. In line with developments in SASEC electricity trading, with the move toward easing restrictions on transmission corridor access and pricing of power traded, SASEC economies are finalizing the draft of the proposed intergovernmental SASEC Regional Power Trade Framework Agreement to provide a broad framework for multi-economy power trading. The SASEC Cross-Border Power Trade Working Group will oversee efforts in this area, in addition to firming up the priority transmission and generation pipeline.

\section{Prospects}

The SASEC program is leveling up across a broad range of interventions to support the economies in achieving a more inclusive and resilient post-COVID-19 recovery. This involves strategic reorientation of the program, optimally combining "soft" and "hard" interventions and institutional restructuring. Innovations will be reflected in the proposed updating of the APSI 2022-2024, covering the outcomes of completed/ ongoing knowledge initiatives, which will enable the SASEC program to respond better to new development challenges and evolving needs of the subregion.

\section{SASEC's strategic reorientation will tap into knowledge initiatives, which will enable the SASEC program to better respond to new development challenges and evolving needs of the subregion.}

The proposed updated APSI 2022-2024 will highlight the outcomes from the maritime transport cooperation study, the supply chain mapping studies (Phase 1 and Phase 2), and the study on the way forward in the SASEC tourism sector. Future maritime cooperation will focus on improving port logistics and facilities for enhanced port capacity and more efficient cargo handling, thereby boosting SASEC trade competitiveness. Supply chain mapping will aim to develop the regional supply chain within SASEC for various products, eventually moving toward identifying measures to enhance production linkages with neighboring subregions. In tourism, which is already a SASEC Vision flagship initiative, proposed future efforts will position the subregion as a prime tourism destination through joint development of tourism products, joint marketing, standardization of services and facilities, and seamless accessibility. 


\section{Policy Challenges}

\section{SASEC's institutional restructuring will need to be tailored to meet the demands of the program's strategic refocusing.}

Given the SASEC program's increasing demands, the SASEC member economies are showing stronger ownership of and commitment to it, by upgrading oversight. SASEC nodal officials, meeting in August 2020, endorsed the proposal for a regular meeting of SASEC finance ministers to guide the program's strategic directions. Additional institutional enhancements will involve strengthening national coordination mechanisms and operationalizing the SASEC Secretariat. There is also a need to create broad multisector engagement in implementing the SASEC corridor approach, given the need to carefully blend "hard" and "soft" interventions. For example, giving landlocked Nepal access to ports in India (e.g., Kolkata and Visakhapatnam) required not only developing last mile connectivity but also concluding trade protocols and transit permits between the economies.

With the SASEC Vision halfway through implementation, it is timely for APSI to be developed in response to the evolving needs of the subregion; it summarizes the key priority initiatives and actions, and will serve as the tool for monitoring progress of the SASEC operational plan. However, with the COVID-19 pandemic's added strain on fiscal resources, resource mobilization efforts need to be improved. While development partners have been regularly invited to the SASEC nodal officials meeting, it will be worth arranging development partner/private sector forums to generate wider buy-in for SASEC initiatives and promote better appreciation of their synergies and impacts. At the working level, a functioning SASEC Secretariat should be able to support existing working groups as well as form new subgroups as needed. A regional forum on SPS-TBT may be set up to deal with uniform safety standards for food and medical goods. Regional pandemic responses and disaster prevention and management may be handled by a suitable working group, supplemented by strengthening national coordination mechanism between member economies.

\section{The Pacific: Leveraging Regional Reach for Broader COVID-19 Vaccine Coverage ${ }^{67}$}

The Systems Strengthening for Effective Coverage of New Vaccines in the Pacific Project, recently expanded to include the introduction of COVID-19 vaccines, provides an ideal platform to help four developing member economies in the subregion roll out vaccines. Resource pooling and regional implementation arrangements will support procurement of COVID-19 vaccines, injection supplies, and cold chain equipment, while capacity building for health and immunization systems and community engagement under the existing project will facilitate service delivery.

\section{Overview}

\section{Existing subregional approaches will be crucial to efficiently vaccinating people of the Pacific against COVID-19.}

Most Pacific island countries have managed to avoid local transmission of COVID-19 through enacting border restrictions and quarantine measures that have depressed economic growth. Coverage of COVID-19 vaccines has been uneven: some economies have benefited from the direct support of bilateral and multilateral development partners, while others continue to struggle with uncertainties over supply and shipment of vaccines, and how to support rollouts to efficiently immunize their populations.

67 Contributed by Cara Tinio, associate economics officer; Ki-Fung Kelvin Lam, health specialist; Inez Mikkelsen-Lopez, health specialist; Remrick Patagan, economics and statistics analyst; and Rommel Rabanal, public sector economist in ADB's Pacific Department. In this section, Pacific economies include the Cook Islands, the Federated States of Micronesia, Fiji, Kiribati, the Marshall Islands, Nauru, Niue, Palau, Papua New Guinea, Samoa, Solomon Islands, Tonga, Tuvalu, and Vanuatu. 
ADB has approved supplemental financing for its regional vaccines project to help Samoa, Tonga, Tuvalu, and Vanuatu introduce COVID-19 vaccines. Mechanisms in the existing project will facilitate procurement and implementation, and complementary capacity building and community engagement will help ensure efficient vaccine delivery. The project's ongoing support to enhance routine immunization will also strengthen public health and health systems against COVID-19. These measures are key to broadening vaccine coverage in the Pacific, which will facilitate border reopening and the resumption of economic activity.

\section{The Pacific and the Pandemic}

\section{Many Pacific island countries have managed to keep COVID-19 out, but the pandemic has taken a serious socioeconomic toll.}

Most economies in the Pacific have managed to avoid local transmission of COVID-19 by quickly closing their borders and establishing quarantine protocols. However, this has taken a toll across the subregion. Travel restrictions, including border closures, have caused tourism-dependent economies to grind to a halt and stalled prospects for overseas employment. Domestic lockdowns and other restrictions on movement have dampened local business, to the detriment of small firms and informal workers. Quarantine protocols have also constrained trade, affecting both large commodity exporters and the small island economies that depend on import-intensive public investment projects to stimulate growth.

Two of ADB's largest Pacific developing member countries, Papua New Guinea and Fiji, have also experienced widespread community transmission of COVID-19, delaying prospects for their recovery. From initial expectations of recovery in 2021, ADB now estimates that the subregional economy contracted by $0.6 \%$ during the year and forecasts a return to growth of $4.7 \%$ in 2022 (Figure 6.6).
Figure 6.6: GDP Growth in the Pacific (\% per year)

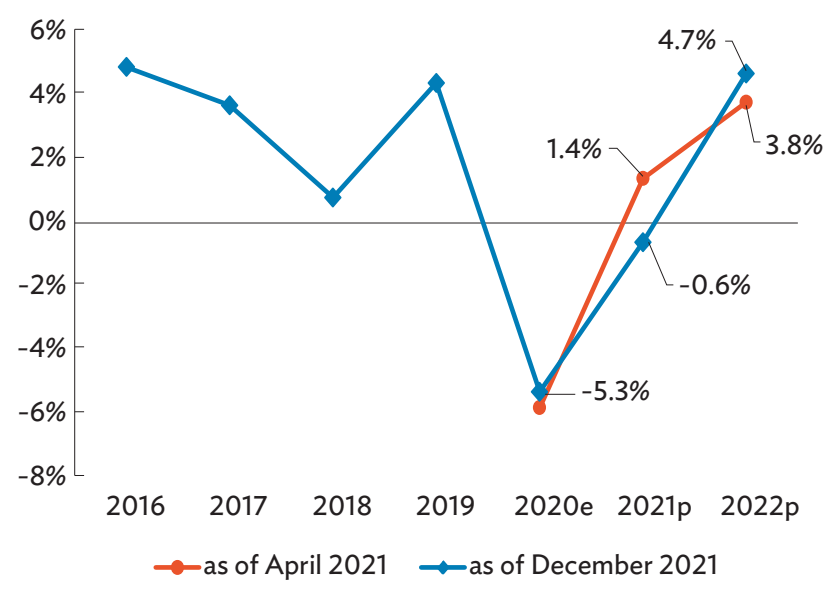

e = estimate, $G D P=$ gross domestic product, $\mathrm{p}=$ projection .

Sources: ADB (2021a, 2021h).

Costs continue to mount as Pacific island countries work to (i) strengthen the capacities of their health systems for disease surveillance and infection prevention and control, and for case management; and (ii) mitigate the pandemic's economic impact especially on vulnerable people. Development partner assistance has gone a long way in covering these additional costs, but the pressure to reopen borders and resume business activity remains.

\section{Support from bilateral partners has facilitated COVID-19 vaccination coverage in most Pacific island countries.}

Vaccination against COVID-19 is recognized as a key factor to safely reopening borders and resuming economic activity, besides protecting populations from ill health, but progress in rolling out the vaccine has been uneven across the subregion (Figure 6.7).

Several Pacific island countries introduced the vaccine with the help of bilateral partners who facilitated procurement and supported preparations for vaccine introductions, or implemented rollouts themselves through their own national vaccination programs. 
The four economies with the largest fully vaccinated populations-Palau, Nauru, the Cook Islands, and Niue-have benefited from these partnerships. Palau, together with the Federated States of Micronesia and the Marshall Islands, began vaccinations in January 2021 through the United States' Operation Warp Speed. Although the Federated States of Micronesia and the Marshall Islands face logistical challenges in rolling out the vaccine to outer island communities, by late July 2021 , Palau had fully vaccinated about $95 \%$ of its eligible adult population (Homasi, Rabanal, and Webb 2021). Nauru self-financed its vaccines with assistance from the Australian government (through the multilateral COVID-19 Vaccines Global Access [COVAX] facility) and India. The only Pacific developing member country that had self-financed its vaccines, Nauru took only a month to roll out each dose of the vaccine to its adult population (Cruz 2021). The Cook Islands received its vaccines through New Zealand, as did Niue. Niue fully immunized $97 \%$ of its population aged 16 and older in about 5 weeks, ending in early July (ADB 2021i), while $71.9 \%$ of the Cook Islands' total population was fully inoculated as of 18 January 2022.

Figure 6.7: COVID-19 Vaccination Coverage

(\% of total population)

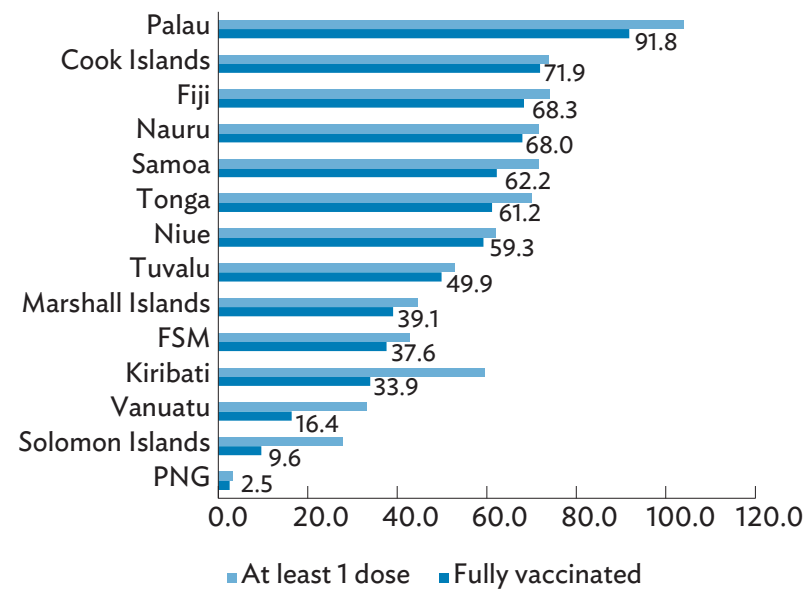

COVID-19 = coronavirus disease, FSM = Federated States of Micronesia, PNG = Papua New Guinea.

Note: Data as of 18 January 2022

Source: ADB calculations using data from Secretariat of the Pacific Community Pacific Data Hub. https://stats.pacificdata.org (accessed January 2022).

\section{The COVAX facility pools resources to support equal global access to the vaccine, but uncertainties remain.}

COVAX is consolidating assistance from development partners such as United Nations Children's Fund (UNICEF), the World Health Organization (WHO), and the World Bank, as well as the governments of Australia and New Zealand. For several economies in the subregion, COVAX's advance market commitment mechanism has been the main option for accessing initial supplies of COVID-19 vaccines for $20 \%$ of their populations but supplies through this channel are limited and deliveries have been delayed due to global production constraints (Lam et al. 2021). Further, WHO's Roadmap for Prioritizing Uses of COVID-19 Vaccines in the Context of Limited Supply prioritizes vaccinations in places with widespread transmission, suggesting further delays for Pacific island countries that are still free of COVID-19.

\section{Mechanisms established under an existing subregional project will help expand COVID-19 vaccine coverage in the Pacific.}

The Asian Economic Integration Report 2021 highlighted ADB's Systems Strengthening for Effective Coverage of New Vaccines in the Pacific Project, which aims to help Samoa, Tonga, Tuvalu, and Vanuatu strengthen vaccine procurement and local health systems, and improve community awareness about vaccination (Tinio et al. 2021). Following the emergence of the COVID-19 pandemic and its impact on their respective economies, the governments of these economies requested $\mathrm{ADB}$ assistance in introducing COVID-19 vaccines. In April 2021, ADB approved additional financing to support the following:

- Support Samoa, Tonga, Tuvalu, and Vanuatu in introducing COVID-19 vaccines together with UNICEF and other development partners.

- Further upgrade cold chain capacities to accommodate COVID-19 vaccines.

- Support deployment of COVID-19 vaccines, including incorporating it into national immunization policy and regulatory frameworks, providing added training 
for vaccinators, identifying and prioritizing target populations for the vaccine rollout, and further strengthening routine immunization programs.

- Increase, through engagement with WHO, monitoring and surveillance and contribute to global knowledge about vaccination against COVID-19, such as on adverse events following immunization.

- Strengthen community engagement, with UNICEF's support, on infection prevention and control, risk communication and perceptions, rumor tracking, and community-level engagement through faith-based or school-based campaigns to minimize possible vaccine hesitancy and improve public health awareness.

Certain aspects of the ongoing project make it ideal for introducing COVID-19 vaccines in Samoa, Tonga, Tuvalu, and Vanuatu (ADB 2021j). The pooled arrangements used to support vaccine-related supplies and logistics, training, and implementation will continue, facilitated by the partnership between the governments and UNICEF under the existing project. The project management unit will also continue to support operational implementation, building on existing roles in financial management, procurement, gender action, and monitoring and evaluations. The additional financing will enhance existing complementary measures to expand the capacity of the health-care system and build on community engagement, as well as continue promoting routine vaccination programs impacted by the COVID-19 pandemic.

\section{ADB also serves as a conduit for information and assistance.}

Besides directly supporting vaccine procurement and rollout in Samoa, Tonga, Tuvalu, and Vanuatu, $A D B$ is coordinating regional knowledge sharing on the development of vaccines against COVID-19. It is also channeling cofinancing toward Pacific island countries' responses to the immediate needs and adverse socioeconomic impacts of the pandemic. These measures complement the introduction of COVID-19 vaccines in the region, while the coordinated approach minimizes the risk of redundancy.

\section{Conclusion}

\section{Efficient regional mechanisms and networks facilitate support of development partners in vaccines supply.}

Development partners play a key role in helping Pacific island countries to supply vaccines against COVID-19 and deliver these to their populations. In cases where support from bilateral partners or the COVAX facility is limited, assistance from multilateral partners such as ADB will be crucial for securing vaccine supplies and building the capacity to safely immunize populations. Such assistance benefits from regional mechanisms and networks that can efficiently implement interventions across many economies, share important information, and pool resources toward broadening vaccine coverage and contributing to reviving economies in the subregion.

\section{Subregional Responses to COVID-19 and ADB's Support}

The Asia and Pacific region's management of the pandemic required commitment and action toward wider-scale coordination of national responses and developing and implementing activities reflecting interdisciplinary and multisector approaches.

Accordingly, CAREC, GMS, SASEC, the Pacific Islands Forum, and the Council of Regional Organisations in the Pacific, with assistance from ADB and other development partners, undertook a range of vital and innovative cross-border initiatives to respond to the COVID-19 emergency, through technical and financial assistance to supplement economies' resources and strengthen capabilities.

In April 2020, ADB announced a comprehensive $\$ 20$ billion package of support along with various measures to streamline its operations for quicker and more flexible assistance. As part of the package, ADB established a new financing modality called the COVID-19 Pandemic Response Option (CPRO). Through this, ADB has provided quick-disbursing support to help governments finance their countercyclical economic stimulus packages focusing on the poor and 
vulnerable as well as women and children. In December 2020, ADB launched its \$9 billion Asia Pacific Vaccine Access Facility (APVAX) to support developing member countries in procuring and delivering safe and effective vaccines as swiftly and equitably as possible.

As of 7 February 2022, ADB's comprehensive COVID-19 response has reached $\$ 25.8$ billion, with $40 \%$ of the package ( $\$ 10.4$ billion) going to Southeast Asia, 26\% ( $\$ 6.7$ billion) to Central and West Asia, and $26 \%$ ( $\$ 6.6$ billion) to South Asia (Figure 6.8). Of these, $55 \%$ ( $\$ 14.2$ billion) will fund public sector management projects, while $27 \%$ ( $\$ 6.9$ billion) will go to the finance sector, and 10\% ( $\$ 2.7$ billion) will finance health projects. This package includes CPRO operations totaling $\$ 10.4$ billion as of 28 January 2022 in 27 developing member countries.

Figure 6.8: ADB's COVID-19 Response Package by Region, as of 7 February 2022 ( $\$$ billion)

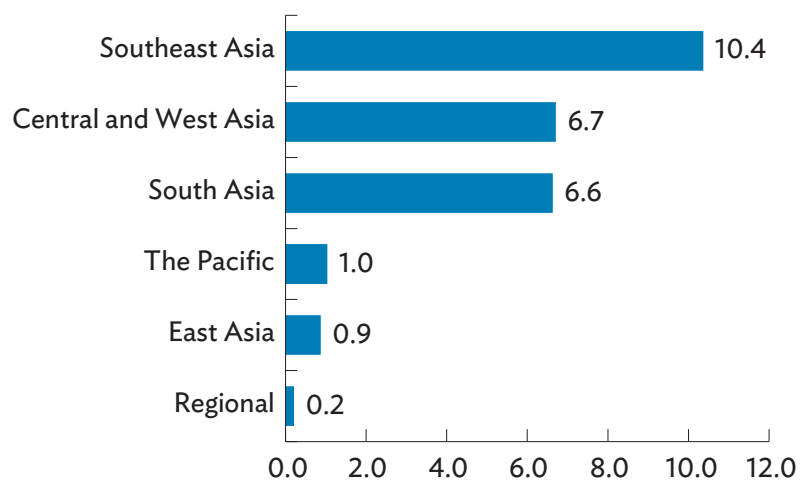

Source: COVID-19 (Coronavirus): ADB's Response. https://www.adb.org/whatwe-do/covid19-coronavirus (accessed February 2022).

Meanwhile, $45 \%$ ( $\$ 4.1$ billion) of the $\$ 9$ billion APVAX has been committed to 15 projects, with $68 \%$ of that ( $\$ 2.8$ billion) going to South Asia, $17 \%$ ( $\$ 0.7$ billion) to Southeast Asia, and 15\% ( $\$ 0.6$ billion) to Central and West Asia (Figure 6.9).

Following the Pacific section that focused on broadening COVID-19 vaccine coverage, this section discusses the other subregional responses to the COVID-19 pandemic and the corresponding support provided by ADB.
Figure 6.9: APVAX Committed Amount by Region, as of 7 February 2022 ( $\$$ billion)

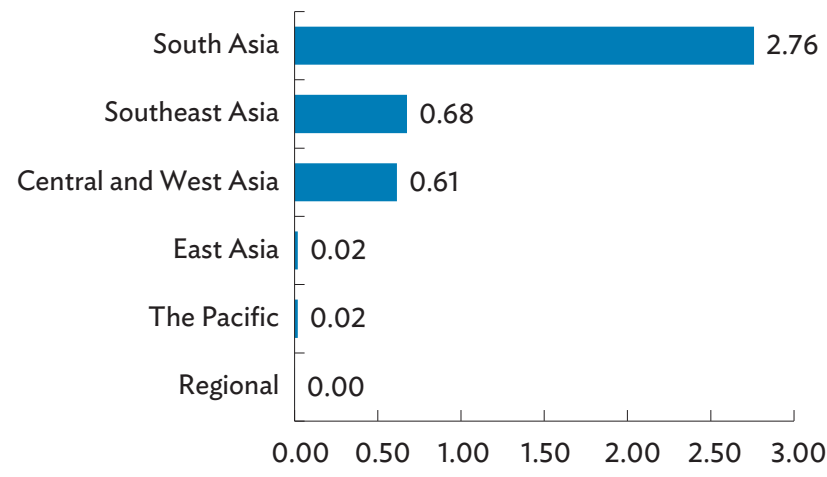

APVAX = Asia Pacific Vaccine Access Facility.

Source: COVID-19 (Coronavirus): ADB's Response. https://www.adb.org/whatwe-do/covid19-coronavirus (accessed February 2022).

\section{Central Asia Regional Economic Cooperation}

\section{Vaccinations are being scaled up in hopes of preventing further economic losses brought about by the COVID-19 pandemic.}

In the CAREC region, the continuous quarantine measures imposed by member economies to mitigate the impact of the COVID-19 pandemic in 2020 is estimated to have pushed 1.5 million people into extreme poverty (people living on less than $\$ 1.90 /$ day) and 6.6 million people into poverty (people living on less than $\$ 3.20 /$ day). Income inequality is estimated to rise by $10 \%$ to 0.38 on the Gini index in 2021. Labor market disruptions further added to economic losses, with 9.9 million full-time jobs lost in 2020, and workinghour losses were three times greater than during the global financial crisis. Returning to a healthy and safe life without restrictions has become a priority in all CAREC economies, and one of the critical instruments on the road to normalcy is access to COVID-19 vaccines aimed at building herd immunity.

Building on the progress of ADB COVID-19 response projects in CAREC economies in 2020, ADB has gradually scaled up COVID-19 vaccination programs 
in the region. Since 2021, ADB has approved APVAX projects for four CAREC economies supporting vaccination programs totaling $\$ 565$ million in Georgia, the Kyrgyz Republic, Pakistan, and Tajikistan. These projects provide the relevant CAREC governments with urgently needed and flexible financing for COVID-19 vaccine procurement and logistics, and capacitystrengthening activities, which will help the government's efforts to mitigate the health, social, and economic impacts of the pandemic. They will also generate significant regional public goods such as better health security in CAREC and complement cooperation efforts in other economies to contain the COVID-19 pandemic and foster growth in the region, through addressing pandemic risks and cross-border health threats.

In addition, under the regional technical assistance, Addressing Health Threats in Central Asia Regional Economic Cooperation Countries and the Caucasus, additional funding of $\$ 200,000$ was mobilized to support COVID-19 vaccination-related activities. These include (i) assessments and development of national operational plans/strategies including costing as needed, (ii) comprehensive reviews of the supply chain in anticipating future challenges in cold chain management and outreach, (iii) thorough analysis of national regulations of pharmaceutical products for assuring regulatory compliance of new vaccines without creating contingency measures that could further weaken national drug regulation systems, (iv) fostering public-private partnerships in the promotion and distribution of COVID-19 vaccines and boosting a market that will contribute to a sustainable response to the economic shock due to the pandemic, and (v) development and implementation of training and capacity-building activities as needed. ADB's support for COVID-19 vaccinations in CAREC is closely coordinated with $\mathrm{WHO}$ and other related agencies. These efforts have also strengthened coordination of COVID-19 vaccination programs in CAREC.

\section{Greater Mekong Subregion Economic Program}

\begin{abstract}
ADB assisted GMS economies in their response to COVID-19 through projects and technical assistance that strengthen public health security and facilitate vaccine delivery, budget support, and relief to some private companies hit hard by the pandemic.
\end{abstract}

Due to the established platform under the GMS program, the Working Group on Health Cooperation responded promptly to the COVID-19 pandemic and mobilized the GMS health community to respond rapidly to the pandemic at both subregional and local levels. As early as February 2020, additional financing of $\$ 2$ million was approved to support ADB's ongoing technical assistance project, Strengthening Regional Health Cooperation in the GMS for epidemic responses, including investigation, surveillance, and prevention of infection. Moreover, $\$ 50$ million from the ongoing Regional Health Security Project was reprogrammed for delivery of essential medical equipment, and training and capacity building. ADB released a further $\$ 10$ million for procurement of various materials and equipment for diagnosis and protection, and training and capacity building for pandemic preparedness and resilience.

ADB assistance also aimed at broader responses to both the health and economic impacts of the pandemic. Under the COVID-19 Active Response and Expenditure Support (CARES) program facility which is part of CPRO, $\$ 2$ billion went to GMS economies: $\$ 250$ million to Cambodia, $\$ 250$ million to Myanmar, and $\$ 1.5$ billion to Thailand. Other development partners' cofinancing for that program amounted to about $\$ 742$ million. ADB also topped up the assistance to Strengthening Regional Health Cooperation in the GMS by $\$ 2$ million to support GMS economies' capacity for epidemic response, provide laboratory equipment, and enhance regional cooperation on disease surveillance. 
In 2021, under the APVAX initiative, ADB has been working closely with $\mathrm{WHO}$ and other multilateral institutions to deliver safe and effective vaccines equitably and efficiently to the region's populations. Support for Cambodia under APVAX is currently set at $\$ 95$ million and is topped up in 2021 with $\$ 30$ million from the GMS Regional Health Security Project. The project will extend targeted interventions to 89 provincial and district referral hospitals not covered under the original project. It will also upgrade hospital clinical care, laboratory, infection prevention and control, and human resources capacity to respond to COVID-19 and other public health threats. Moreover, a $\$ 5$ million new technical assistance, Supporting Enhanced COVID-19 Vaccination and Post-COVID-19 Health Security Response in Southeast Asia will assist selected economies in Southeast Asia in vaccine rollout and delivery.

For nonsovereign operations, ADB's COVID-19 support include supply chain finance (Cambodia, Thailand and Viet Nam), trade finance (Cambodia and Viet Nam), pharmaceutical production (Viet Nam) and support to SMEs (Viet Nam). ${ }^{68}$

\section{East Asia}

\section{Mongolia sought a comprehensive pandemic response package from $A D B$ that includes budget support and vaccine delivery while assistance to the PRC includes a project to improve health security as well as nonsovereign support.}

As COVID-19 emerged at the start of 2020, Mongolia responded quickly to avoid the rapid spread of the disease. However, community transmission surfaced in November 2020, straining the health system's capacity. ADB mobilized a comprehensive pandemic response, including $\$ 100$ million in countercyclical budget support to Mongolia, support for the procurement of emergency medical equipment, and technical assistance for the region's pandemic response.
About $\$ 75,000$ of loan funding under the Regional Improvement of Border Services project for Mongolia has been restructured to procure personal protection equipment such as surgical masks for customs officers and inspectors working at the front lines of borders. Another technical assistance, Strengthening Institutional Capacity to Respond to COVID-19, supports capacity building for detection and surveillance of the coronavirus in Mongolia, through capacity development training and information dissemination, especially for the General Agency for Specialized Inspection. Inspectors at the borders are responsible for effectively managing cross-border control and inspection of goods at entry points.

In May 2021, ADB approved a \$19 million package support for COVID-19 Vaccine Delivery in Mongolia under the APVAX. The project will increase the availability of the APVAX-eligible vaccines to immunize at least $30 \%$ of the population. ADB is also processing a complementary $\$ 5$ million grant from the Japan Fund for Poverty Reduction to build capacity for COVID-19 vaccine delivery, including equipment for diagnostics and laboratories. It will strengthen delivery through capacity building of health workers and increase testing capacity particularly in provinces and border areas. The Technical Assistance on Regional Solutions for COVID-19 Response and Vaccine Delivery in selected developing member countries will document the PRC's pharmaceutical and non-pharmaceutical responses and disseminate this to Mongolia and Tajikistan.

The unprecedented impact of COVID-19 has led the $P R C$ to renew its interest in focused preparedness and response programs for longer-term health security. ADB is preparing the Strengthening Health Security Project for the PRC, which will upgrade public health emergency facilities, modernize disease prevention, policies, research and control systems, and improve talent and international exchange. The regional and global public goods nature of prevention and control of emerging infectious diseases is clear, and is fundamentally an issue of international security and economic development. The PRC participates in initiatives to implement the GMS One Health approach.

68 ADB. COVID-19 (Coronavirus): ADB's Response. https://www.adb.org/what-we-do/covid19-coronavirus (accessed February 2022). 
In the PRC, ADB's non-sovereign COVID-19 support include supply chain finance, improved distribution of drugs and rural health care. ${ }^{69}$

\section{South Asia}

\section{Much of SASEC members' pandemic responses took the form of budget support.}

Governments worldwide have put in place various fiscal and monetary measures to minimize the supply and trade shocks caused by the pandemic. By the end of 2020, ADB members devoted about $12.5 \%$ of their GDP to support measures, valued at about $\$ 28$ trillion. South Asia (Bangladesh, Bhutan, India, Maldives, Nepal, and Sri Lanka) registered $\$ 428.50$ billion in COVID-19 response packages, a mere $1.56 \%$ of the global total, although India was among those with the largest packages, at $\$ 412.09$ billion.

Governments' key policy responses comprised (i) liquidity support, (ii) credit creation, (iii) direct longterm lending, (iv) equity support, and ( $v$ ) health and income support. For all ADB members, credit creation and health/income support took the largest shares, at 46.9\% and 32.9\%, respectively. However, for South Asia, health/income support (46.6\%) and liquidity support (38.2\%) were most significant (ADB 2021k). India provided large direct income support, combined with subsidies for businesses and investments in the health and agriculture sectors. India also provided high liquidity support by way of increased short-term repurchase agreements and special refinance facilities for rural banks, among others.

Since the launch of ADB's $\$ 20$ billion COVID-19 response package in April 2020, ADB has committed $\$ 25.8$ billion assistance to its developing member countries (as of 7 February 2022). This includes over $\$ 10$ billion in quick-disbursing budget support for improving health-care access, direct social protection to the vulnerable, and other economic responses. Of the total $\$ 25.8$ billion ADB COVID-19 assistance, South Asia accounted for $\$ 6.63$ billion (26\%), which includes $\$ 250.07$ million (committed in April 2021) for Bangladesh for the Sustainable Economic Recovery (subprogram 1) and $\$ 500.00$ million (committed in April 2020) for India for a COVID-19 expenditure support program. Under the $\$ 9$ billion APVAX, launched in December 2020, South Asia secured total funding commitment of $\$ 2.76$ billion with $\$ 940.00$ million going to Bangladesh.

69 ADB. COVID-19 (Coronavirus): ADB's Response. https://www.adb.org/what-we-do/covid19-coronavirus (accessed February 2022). 


\section{References}

Asian Development Bank (ADB). 2014. South Asia Subregional Economic Cooperation Trade Facilitation Strategic Framework 2014-2018. Manila.

_ 2016. South Asia Subregional Economic Cooperation Operational Plan 2016-2025. Manila.

- 2017. SASEC Powering Asia in the 21st Century. Manila.

. 2018a. The Ha Noi Action Plan 2018-2022. Manila.

- 2018b. Strategy 2030: Achieving a Prosperous, Inclusive, Resilient, and Sustainable Asia and the Pacific. Manila.

- 2020a. Greater Mekong Subregion RIF 2022: Third Progress Report and Update for 2020. Report prepared for the 24th GMS Ministerial Conference. Online. 4 November.

_. 2020b. South Asia Subregional Economic Cooperation Operational Plan 2016-2025 Update. Manila.

- 2021a. Asian Development Outlook 2021: Financing a Clean and Green Recovery. Manila.

_. 2021b. CAREC Program Portfolio. Unpublished. - 2021c. The Greater Mekong Subregion Economic Cooperation Program Strategic Framework 2030. Manila.

_. 2021d. The Greater Mekong Subregion COVID-19 Response and Recovery Plan 2021-2023. Manila.

-2021e. E-Commerce in CAREC Countries: Laws and Policies. Manila.

_. 2021f. Developing the Services Sector for Economic Diversification in CAREC Countries. Manila.
—. 2021g. SASEC Project Portfolio 2021. Unpublished.

_. 2021h. Asian Development Outlook Supplement December 2021: Recovery Continues. Manila.

_. 2021i. Asian Development Outlook 2021 Update: Transforming Agriculture in Asia. Manila.

- 2021j. Report and Recommendation of the President to the Board of Directors: Proposed Grants for Additional Financing to the Independent State of Samoa, Kingdom of Tonga, Tuvalu, and Republic of Vanuatu for the Systems Strengthening for Effective Coverage of New Vaccines in the Pacific Project Under the Asia Pacific Vaccine Access Facility. Manila.

_. 2021k. One Year of Living with COVID-19: An Assessment of How ADB Members Fought the Pandemic in 2020. Manila.

- COVID-19 (Coronavirus): ADB's Response. https://www.adb.org/what-we-do/covid19coronavirus (accessed January 2022).

CAREC. 2021a. Knowledge-Sharing Modules on CAREC Trade: Regional Improvement of Border Services. Virtual meetings. 14-22 January.

_ 2021b. Knowledge-Sharing Module on CAREC Trade: Facilitating Trade through Digital SPS Certification. Virtual meeting. 24 February.

- 2021c. Knowledge-Sharing Sessions for Mongolia: Developing the Economic Cooperation Zone Project. Virtual meetings. 24 March-28 April.

Cruz, P. 2021. Three Things that Helped Nauru Achieve Full Adult Vaccination. In ADB. Pacific Economic Monitor July 2021. Manila. 
Greater Mekong Subregion (GMS). 2021. GMS: Renewed Strength to Face the Challenges of the New Decade. Report presented at the 7th GMS Summit. Phnom Penh. 9 September.

Homasi, L., R. Rabanal, and J. Webb. 2021. "Travel Bubbles of Hope" in the Cook Islands, Niue, and Palau. In ADB. Pacific Economic Monitor July 2021. Manila.

International Monetary Fund (IMF). Direction of Trade Statistics. https://data.imf.org/dot (accessed August 2021).

- World Economic Outlook April 2021 Database. https://www.imf.org/en/Publications/WEO/ weo-database/2021/April (accessed August and September 2021).

Lam, K., I. Mikkelsen-Lopez, R. Patagan, and C. Tinio. 2021. Jab Security: Broadening COVID-19 Vaccination Coverage in the Pacific. In ADB. Pacific Economic Monitor July 2021. Manila.

Lazaro, D., G. Samad, L. de Dios, and A. R. Tafgar. 2021. Expanding Agri-Trade in Central Asia through the Use of Electronic Certificates. ADB Briefs. No. 184. July. Manila: ADB.
Nair, D. 2020. COVID-19 May Cost Global Economy $\$ 35.3$ Trillion by 2025. The National News. 27 August. https://www.thenationalnews.com/ business/economy/covid-19-may-cost-globaleconomy-35-3-trillionby-2025-1.1069246.

Qi, W. 2021. Economic Recovery from COVID-19: Experience from the People's Republic of China. ADB Briefs. No. 194. October. Manila: ADB.

Secretariat of the Pacific Community. Pacific Data Hub. https://stats.pacificdata.org (accessed January 2022).

Tinio, C., R. Rabanal, I. Mikkelsen-Lopez, and K. Lam. 2021. The Pacific: Crossing "the Last Mile." In ADB. Asian Economic Integration Report 2021: Making Digital Platforms Work for Asia and the Pacific. Manila.

United Nations Conference on Trade and Development (UNCTAD). World Investment Report 2021 Data Set. https://unctad.org/system/files/nonofficialdocument/WIR2021_tab01.xlsx (accessed September 2021).

World Bank. World Development Indicators. https://databank.worldbank.org/source/worlddevelopment-indicators\# (accessed August 2021). 


\section{THEME CHAPTER Advancing Digital Services Trade in Asia and the Pacific}

\section{Introduction}

After decades of gradual opening and slow globalization of services sectors, rapid digitalization is generating new business models, which are radically cutting the costs of trade in services and offering new opportunities for international division of labor and wage arbitrage. This phenomenon, also known as the "third unbundling," may have major implications for labor markets globally (Baldwin 2019). White-collar workers in services, so far largely shielded from international competition, increasingly face the risk of job displacement.

Intensification of digitalization following the outbreak of the coronavirus disease (COVID-19) pandemic in 2020 has further accelerated the third unbundling. The pandemic led to the introduction of social distancing measures and restrictions on the movement of people within and across economies. As a result, firms revisited their business models, leveraging digital technologies, and developing new modes to produce and deliver goods and services. On the production side, an unprecedented number of jobs suddenly moved from office to home, and COVID-19 demonstrated that firms can operate in structurally different ways. ${ }^{70}$ On the consumption side, sales shifted to online solutions and e-commerce has boomed. Digital technology has also allowed disadvantaged groups to access a new range of products and services. This process may not be fully reversed after the pandemic and represents a structural shift for the Asia and Pacific region (Anson, Helble, and Rosenkranz 2021).

To fully reap the new potential benefits on offer, the Asia and Pacific region must tackle several challenges. A major obstacle is the limited access to digital technologies and telecommunications. Large parts of the region struggle to provide access to broadband internet and more than half of the region's population remains offline, one reason being the lack of affordability. ${ }^{71}$ As a result, a digital divide persists, including by gender and geographic location, potentially exacerbated by the pandemic. A second obstacle for the region is its skills stock, directly linked to the quality of education systems. While attainment and coverage have improved, education quality is mixed and contributes unevenly to workers' skill endowments. Economies often struggle to prepare their workforce for the needs of a digital economy. ${ }^{72}$ The large share of lowskilled workers in informal jobs in some service sectors and difficulties transitioning to formal employment are impediments to some developing economies offering services internationally.

70 Across multiple sectors, the pandemic has strengthened the notion that many jobs can be performed remotely. Dingel and Neiman (2020) find that $37 \%$ of jobs in the United States can be performed entirely at home, with significant variation across cities and industries. Similarly, firms estimate potential to move $44 \%$ of their workforce to remote operation (WEF 2020). The consequent emergence of "digital migrants" or "digital nomads" is symptomatic of the process inherent in the third unbundling, which calls for further research on the implications for wages, productivity, and taxation.

71 International Telecommunication Union. World Telecommunication/ICT Indicators 2020 Database 24th Edition. https://www.itu.int/en/ITU-D/ Statistics/Pages/publications/wtid.aspx (accessed July 2021).

72 The Organisation for Economic Co-operation and Development (OECD) has conducted an adult's information and communication technology (ICT) skills survey to help assess how education and skills systems impact economies' capacity for providing digitally related services. The OECD Programme for International Student Assessment round in 2022 will focus on ICT and learning outcomes. 
Regulatory barriers, including an absence of mutual recognition of qualifications, limit opportunities for services trade, as does lack of investment in human capital. While governments in developing Asia have progressively opened their economies through bilateral, regional, and multilateral trade agreements, these mostly focused on goods trade, and only later extended the commitments to services trade (Benz, Ferencz, and Nordas 2020). Sectors such as telecommunications or computer services, which underpin digital services trade, remain subject to restrictive regulatory regimes, and in many jurisdictions are becoming subject to stringent data localization requirements (Ferracane and van der Marel 2020; Ferencz 2019) and other barriers to data flows. Recent questions associated with the allocation of taxing rights in the digital economy and potential adoption of unilateral tax measures by some economies in relation to digital services may also limit their traded potential.

This theme chapter explores the implications for developing Asia of the underlying increase in services trade caused by the accelerated digitalization of the economy coupled with the third unbundling, with a particular focus on those services that can be delivered remotely across borders. ${ }^{73}$

Digitalization, or the incorporation of data and information and communication technology (ICT) into production and consumption processes, has been a driving force in the rise of digital services. Digital technologies have given firms and individuals the possibility to offer and access a wide range of services thus far only physically available. In this process, the nature of global trade is rapidly changing. As a market segment, digital services, such as publishing, audiovisual, or telecommunications, now have more of a global reach than manufacturing goods. Digital services trade has expanded thanks to the digitization of a wide range of services that can now be traded across borders with the support of ICT applications and data-driven solutions (van der Marel 2021a).
The definition of the digital economy has evolved over the years, and subject to different and coexisting approaches. Bukht and Heeks (2017) propose three levels of scope, from core (ICT-production sectors), to narrow (e.g., business process outsourcing services and platform economy services) and broad (e.g., automation, artificial intelligence). More recently, ADB (2021b) has developed a framework for measuring the digital economy that is rooted on a value-added based approach, including goods and services that comply with ADB's definition of digital products (Box 7.1). While there is still no consensus on a conceptual and measurement framework for the digital economy, these approaches provide a clearer picture today on the key features and available data sources for understanding digital services trade.

The rise of digital services trade has also been strongly linked to the growing presence of digital platforms in Asia and the Pacific. Digital platforms have been transformative in challenging established business models (ADB 2021a) and enabling consumers to become goods and service providers. Digital platforms have expanded in multiple sectors, including digital media, AdTech, and e-commerce for a wide range of goods and services. They are often associated with the provision of personal services, and government and social services such as education and health. Their emergence has raised issues around competition policy, data privacy, social protection, and income inequality.

\section{Digital Services Trade}

\section{Measurement Framework and Definitions ${ }^{74}$}

While international trade statistics are traditionally compiled around "what" is being traded, trends in digitalization are transforming the way both goods and

\footnotetext{
73 Under the WTO General Agreement on Trade in Services (GATS), this is called mode 1. A more detailed description of definitions and data sources used is contained in the conceptual framework.

74 This section is largely based on Liberatore, Avendano, and Cho (2021).
} 


\section{Box 7.1: ADB Measurement of the Digital Economy}

The ADB framework for the measurement of the digital economy is rooted on a value-added approach. The digital economy is defined as the contribution of any economic transaction involving digital products and digital industries to gross domestic product (GDP). ${ }^{\text {. Digital products }}$ are defined as goods and services with the main function of generating, processing, and/or storing digitized data, and are grouped in five main groups: (i) hardware, (ii) software publishing, (iii) web publishing, (iv) telecommunications services, and (v) specialized support services.

The distinction between digitally enabling and digitally enabled products depends on whether such products can generate, process, or store data. Digitally enabling products are captured through backward linkages with core digital products, while digitally enabled products are captured through forward linkages with core digital products. Based on this framework, estimates for the size of the digital economy are provided for 16 economies, ranging from $2 \%$ to $10 \%$ of GDP.
The framework underscores the growing role of digital sectors in international production networks and their potential impact on structural transformation and labor markets. Indeed, global value chain participation of digitaleconomy sectors has increased between 2000 and 2019 for most economies, although differences in composition across economies remain important. ${ }^{c}$ For Asian economies, employment estimates suggest an increasing share for digital sectors in India (7.6\%) and the Republic of Korea (1.7\%), and a slight decline for Japan (-0.9\%). On average, employment in digitally enabled sectors is equivalent to about one-third of the employment in digital sectors.

ADB's value-added approach to measuring the digital economy provides a new and complementary tool to the framework adopted in this chapter for measuring digital trade which, for want of up-to-date global trade in valueadded statistics, is based on gross balance of payments data. Given that the frameworks differ in definitions, concepts, methodologies, and data sources, a reconciliation is possible to link estimates between the two frameworks.

\footnotetext{
a Analog and digital products and industries are distinguished in ADB framework as follows: "analog" refers to information expressed using a continuously variable physical quantity, whereas "digital" refers to the use of discrete encoding (e.g., 0 or 1) to generate, process, or store information (ADB 2021b).

${ }^{\mathrm{b}}$ Economies included are Australia; Canada; Denmark; Fiji; Germany; India; Indonesia; Japan; Kazakhstan; Malaysia; the People's Republic of China; the Republic of Korea; Singapore; Taipei,China; Thailand; and the United States.

c In economies such as Singapore; Taipei,China; and Thailand, hardware comprises a sizable share of the digital economy, whereas software publishing is more important in Japan and the Republic of Korea. Telecommunications services account for the largest share of the digital economy in Fiji, Indonesia, and Kazakhstan
}

Source: Asian Development Bank (2021b).

services are produced, traded, and delivered. The focus has therefore shifted from "what" is traded to "how."

\section{Different approaches are emerging for improving} the measurement of the digital economy as well as international trade in services in the context of digitalization (ADB 2021b; OECD-WTO-IMF 2019; UNCTAD 2019). The OECD-WTO-IMF Handbook on Measuring Digital Trade provides a conceptual framework for digital trade, defined as "all trade that is digitally ordered and/or digitally delivered" (Figure 7.1). In this framework, digitally ordered trade comprises "the international sale or purchase of a good or service, conducted over computer networks by methods specifically designed for the purpose of receiving or placing orders. ${ }^{\prime 75}$ Digitally delivered trade is defined as "international transactions that are delivered remotely in an electronic format, using computer networks specifically designed for the purpose."

This chapter builds on the WTO-OECD-IMF framework and focuses on services that can be digitally delivered. This may involve some underestimation of trade in digital services as, in principle, digital trade in services should encompass also all internationally traded services that are either digitally ordered, or digitally delivered. 
Figure 7.1: Conceptual Framework for Digital Trade
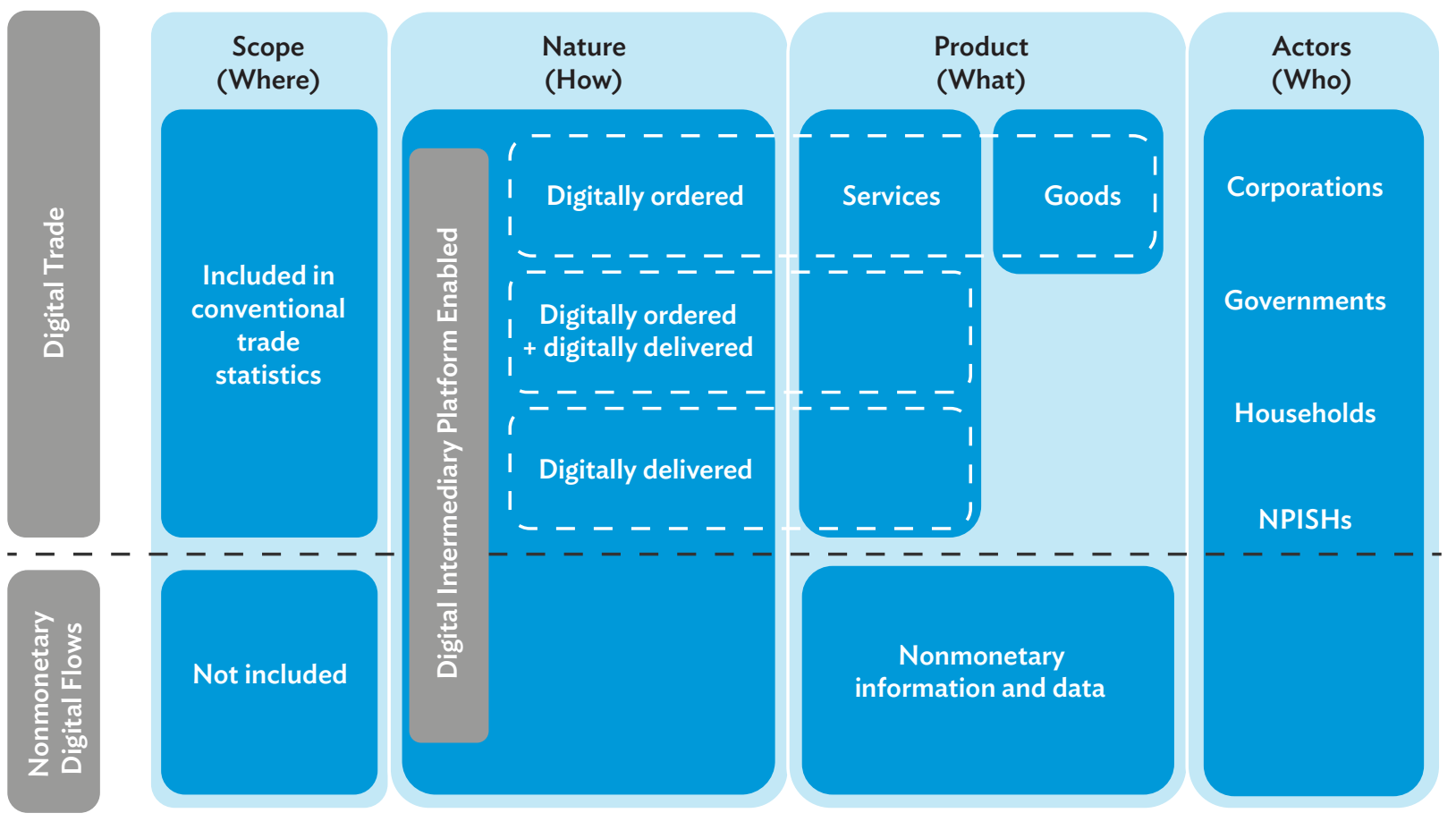

$\mathrm{NPISH}=$ nonprofit institutions serving household.

Source: OECD-WTO-IMF (2019).

Many, if not necessarily all, digitally delivered services are also digitally ordered. ${ }^{76}$

In the context of trade in services, the "how" was important long before the advent of digitalization. The General Agreement on Trade in Services (GATS) covers both services and services suppliers and identifies four modes of supply, based on jurisdictional residency of the supplier and the consumer when services are provided, and how the service is delivered (United Nations 2011). Mode 1, or cross-border supply, takes place when a service itself is supplied from the territory of one World Trade Organization (WTO) member into the territory of any other member. While the two concepts are not equivalent, mode 1 services greatly overlap with the coverage of digitally delivered services (Figure 7.2).
While digital transformation implies that more services become tradable across borders thanks to digital tools, new services business models are also created which are inherently digital (e.g., based on data analytics or cloud computing). Among those, services provided by digital intermediation platforms are particularly relevant. In the current framework, the services digital intermediation platforms provide are defined as "online, fee-based, intermediation services enabling transactions between multiple buyers and multiple sellers, without the intermediation platform taking economic ownership of the goods or rendering services that are being sold (intermediated)." Digital intermediation platforms not charging a fee, involving nonmonetary transactions, are currently out of the scope of this framework for measuring digital trade. ${ }^{77} \mathrm{~A}$ working template has been

\footnotetext{
76 However, it is also likely that many digitally delivered services transactions are not digitally ordered. For instance, roaming mobile communications charges incurred while abroad are digitally delivered but not digitally ordered; also, most large-scale transactions in services between firms, and especially intra-firm services, may also be digitally delivered but not digitally ordered (OECD-WTO-IMF 2019).

77 Some platforms provide "free" (advertising-driven) services to users. For the time being, these are excluded from the measurement framework.
} 
introduced to allow identification and harmonization of statistics on digitally ordered and delivered services including a breakdown by services category.

While some economies have produced early estimates of digitally delivered trade, reliable global estimates are not yet available. Recent initiatives do however shed light on the potential of available official statistics to capture these trends. Notably, the United Nations Conference on Trade and Development (UNCTAD)-led Partnership on Measuring ICT for Development introduced the concepts of ICT-enabled services and potentially ICTenabled services in an effort to identify the "digital" component in existing statistics (UNCTAD 2015). ${ }^{78}$
Building on the above definitions, this chapter considers the scope of services that can in principle be digitally delivered as largely overlapping with the UNCTADdeveloped list of potentially ICT-enabled services. ${ }^{79}$ The concept of potentially ICT-enabled services is therefore broadly equivalent to that of digitally deliverable services and can be used as a reasonable proxy for digitally delivered services trade.

Table 7.1 identifies in bold an initial list of services categories that are considered digitally deliverable (or potentially ICT-enabled). The list includes not only inherently digital services like telecommunications and computer services, but also services whose ability to

Table 7.1: Digitally Deliverable Services

\begin{tabular}{|c|c|c|c|}
\hline Code & Service Description & $\begin{array}{c}\text { Digitally } \\
\text { Deliverable }\end{array}$ & Parent Category \\
\hline SA & Manufacturing services on input owned by others & & Manufacturing services on input owned by others \\
\hline SB & Maintenance and repair services n.i.e. & & Maintenance and repair services n.i.e. \\
\hline SC & Transport services & & Transport services \\
\hline SD & Travel & & Travel \\
\hline SE & Construction & & Construction \\
\hline SF & Insurance and pension services & $\checkmark$ & Insurance and pension services \\
\hline SG & Financial services & $\checkmark$ & Financial services \\
\hline SH & Charges for the use of intellectual property n.i.e. & $\checkmark$ & Charges for the use of intellectual property n.i.e. \\
\hline SI1 & Telecommunication services & $\checkmark$ & Telecommunication, computer, and information services \\
\hline $\mathrm{SI2}$ & Computer services & $\checkmark$ & Telecommunication, computer, and information services \\
\hline SI3 & Information services & $\checkmark$ & Telecommunication, computer, and information services \\
\hline SJ1 & Research and development services & $\checkmark$ & Other business services \\
\hline SJ2 & Professional and management consulting services & $\checkmark$ & Other business services \\
\hline SJ3 & Technical, trade-related, and other business services & $\sqrt{a}$ & Other business services \\
\hline SK1 & Audiovisual and related services & $\checkmark$ & Personal, cultural, and recreational services \\
\hline SK2 & Other personal, cultural, and recreational services & $\sqrt{a}$ & Personal, cultural, and recreational services \\
\hline SL & Government goods and services n.i.e. & & Government goods and services n.i.e. \\
\hline
\end{tabular}

n.i.e. $=$ not identified elsewhere .

a For technical, trade-related, and other business services, subcomponents such as operational leasing services, waste treatment and depollution and trade-related services are not considered to be digitally deliverable; in other personal cultural and recreational services, other personal services (covering social services, membership dues of business associations, domestic services) are not generally considered to be yet digitally deliverable. In both cases, however, the traded values in those categories are negligible and therefore including them in the aggregate of digitally deliverable services will not affect the observed trends.

Source: Based on OECD-WTO-IMF (2019).

78 ICT-enabled services are defined as "services delivered remotely over ICT networks," while potentially ICT-enabled services refer to those that in principle can be delivered remotely over ICT networks, as opposed to those that require face-to-face contact.

79 Minor differences in coverage exist: see OECD-WTO-IMF (2019) Chapter 4 for more details. Those differences have marginal weight in total services trade. 
be traded internationally is greatly enhanced by digital tools, such as insurance and financial services, services related to intellectual property, and many types of business services. ${ }^{80}$

Existing statistics on international trade in services (on a balance of payments basis) for the service categories outlined above can provide reasonable upper bound estimates of trade in digitally delivered services. When possible, this chapter will present trends and insights on trade in digitally deliverable services for ADB members, following the definition provided in Table 7.1. When the detailed categories are not available, figures will follow a less detailed breakdown, as specified in the "parent category" column of Table 7.1.

\section{Trends in Asia and the Pacific}

\section{Global Landscape}

The global position of Asian economies' share of digitally deliverable services in total exports and their economic development suggests there is a lot of room for improvement (Figure 7.3). Overall, Figure 7.3 shows a positive relation between gross national income per capita and digitally deliverable services exports share.
High-income economies seem to have a competitive advantage on exporting digitally deliverable services, possibly attributable to them being generally endowed with more advanced technologies and better access to technological goods and services compared with lowerincome economies.

The relationship between an economy's size (measured by the gross domestic product [GDP]) and digitally deliverable exports share is less clear and shows a rough positive correlation (Box 7.2 presents the detailed empirical exercise). Most European and North American economies are in the upper right quadrant, while Asian economies are generally positioned poorly in their digitally deliverable services exports share, though better than African and Latin American economies. Even relatively advanced economies in Asia and the Pacific, such as Japan and the Republic of Korea, hover low on the scale compared with European and North American economies. On balance, it seems that economic size does not necessarily determine the competitiveness of an economy in digitally deliverable services. Some large economies such as India have relatively high digitally deliverable services export shares (22\%), as do some smaller economies such as Nepal (37\%).

\section{Figure 7.2: Measuring Trade in Digital Services: A Schematic View on Possible Proxies}
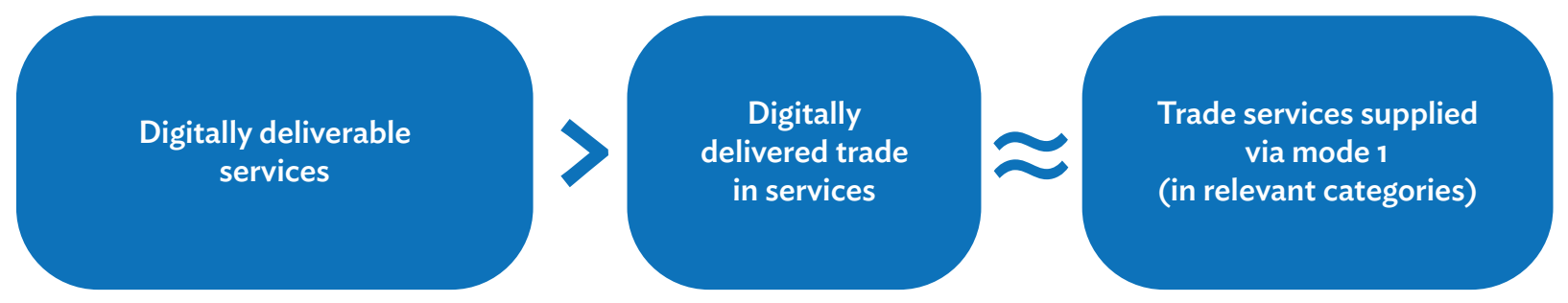

Note: Mode 1, or cross-border trade in services, takes place when a service itself is supplied from the territory of one World Trade Organization member into the territory of any other member.

Source: Asian Development Bank.

80 Available results of pilot surveys confirm that digitally deliverable services most of the time are actually digitally delivered. A survey in India, for instance, showed that $81 \%$ of exports in digitally deliverable services were actually digitally delivered, and this share climbs to $97 \%$ for Costa Rica (UNCTAD 2017a, 2018). 
Figure 7.3: Share of Digitally Deliverable Services Exports in Total Goods and Services Exports and Income Per Capita by Region, 2019

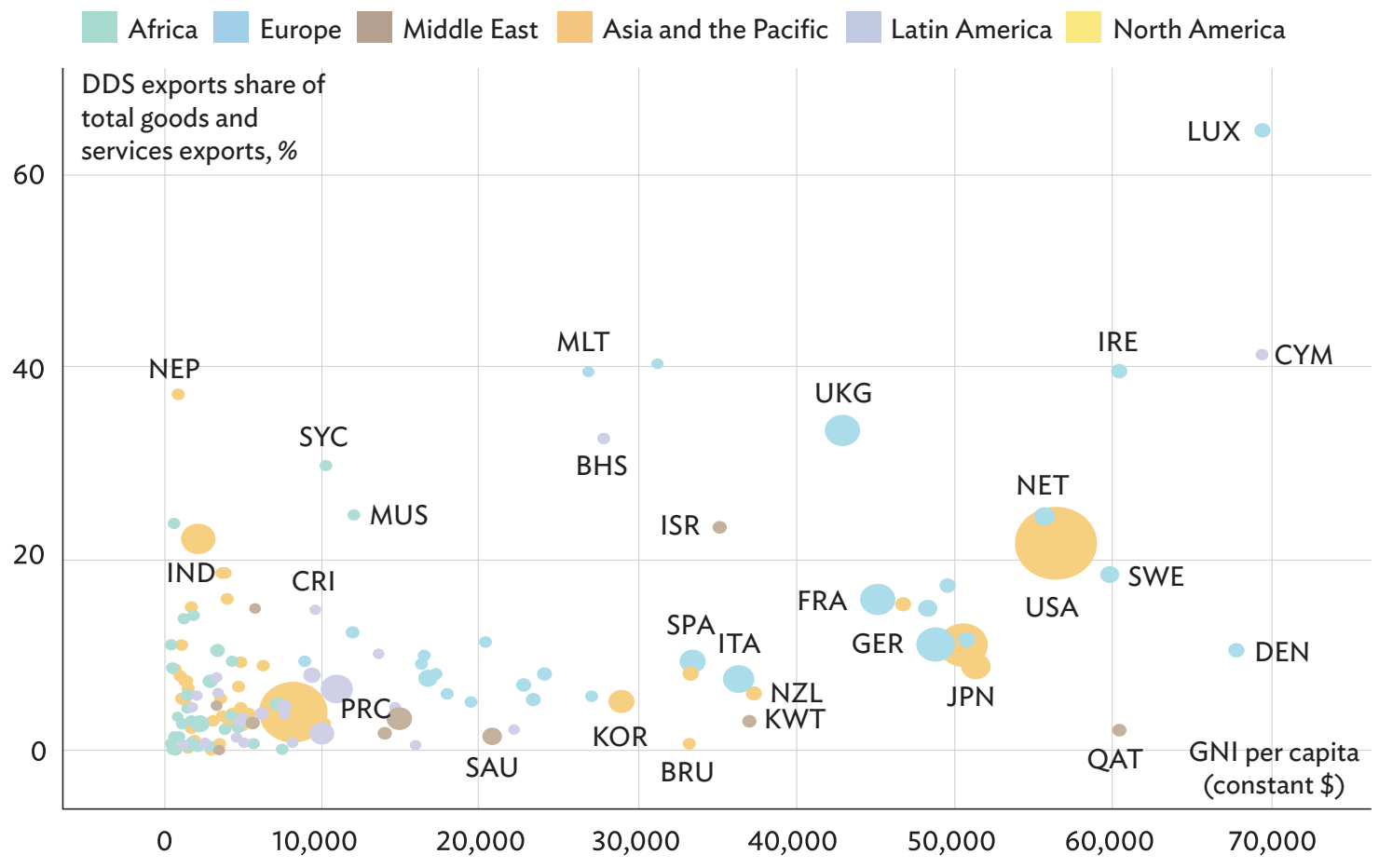

BHS $=$ The Bahamas, BRU = Brunei Darussalam, CRI = Costa Rica, CYM = Cayman Islands, DEN = Denmark, DDS = digitally deliverable services, FRA = France, $\mathrm{GER}=$ Germany, GDP = gross domestic product, GNI = gross national income, IND = India, IRE = Ireland, ISR = Israel, ITA = Italy, JPN = Japan, KOR = Republic of Korea, KWT = Kuwait, LUX = Luxembourg, MLT = Malta, MUS = Mauritius, NEP = Nepal, NET = Netherlands, NZL = New Zealand, PRC = People's Republic of China, QAT = Qatar, SAU = Saudi Arabia, SPA = Spain, SWE = Sweden, SYC = Seychelles, UKG = United Kingdom, USA = United States

Notes: The $x$-axis is gross national income per capita (constant $2010 \$$ ), while along the $y$-axis is the share of digitally deliverable services exports as percentage of total goods and services exports (log transformed). The size of the circle is determined by the GDP (constant 2010 ). The figure plots 144 economies. Only those with complete data were included. Economy groupings follow the Asian Economic Integration Report classification.

Sources: ADB calculations using WTO-OECD Balanced Trade in Services Dataset (BaTIS) - BPM6. https://www.wto.org/english/res_e/statis_e/trade_datasets_e.htm; and World Bank. World Development Indicators. https://databank.worldbank.org/source/world-development-indicators (both accessed August 2021).

Box 7.2: Digital Services Trade and Income per Capita

The relationship between international trade and economic growth or people's standard of living has been extensively studied in the literature. The analysis here adapts the framework of Frankel and Romer (1999) to investigate the impact of digitally deliverable services on output and income per capita on a longitudinal data set. Following Frankel and Romer (1999), the two-stage approach first calculates an instrument for trade share using purely geographic variables. In the second stage, the constructed trade share is used in place of actual trade share. To examine regional heterogeneity, we also include additional analysis with a regional dummy variable for Asia and the Pacific, interacted with the trade share variable as well as measures of economy size (log population and log area).
The bilateral trade equation takes the form as follows.

$$
\begin{aligned}
\operatorname{Ln}\left(\frac{\tau_{i j}}{G D P_{i}}\right)= & \beta_{0}+\beta_{1} \text { lnDist }_{i j}+\beta_{2} \operatorname{lnPop}_{i}+\beta_{3} \text { lnArea }_{i}+ \\
& \beta_{4} \text { lnPop }_{j}+\beta_{5} \text { lnArea }_{j}+\beta_{6} \text { Land }_{i j}+ \\
& \beta_{7} \text { Cont }_{i j}+\beta_{8} \text { Cont }_{i j} * \text { lnDist }_{i j}+ \\
& \beta_{9}\left(\text { Cont }_{i j} * \operatorname{lnPop}_{i}\right)+\beta_{10}\left(\text { Cont }_{i j} * \text { lnArea }_{i}\right)+ \\
& \beta_{11}\left(\text { Cont }_{i j} * \operatorname{lnPop}_{j}\right)+\beta_{12}\left(\text { Cont }_{i j} * \ln \text { Area }_{j}\right)+ \\
& \beta_{13}\left(\text { Cont }_{i j} * \text { Land }_{i j}\right)+\epsilon_{i j}
\end{aligned}
$$

where $\tau_{i j}$ is digitally deliverable services (DDS) exports as a fraction of economy $i$ 's gross domestic product (GDP),

$\operatorname{lnDist}_{i j}$ is the distance between trading partners, 
$\ln P o p_{i}$ and $\ln P o p_{j}$ refer to the population of economy $i$ and $j$, respectively,

$\operatorname{lnArea}_{i}$ and $\ln \mathrm{Area}_{j}$ are area variables,

Land $_{i j}$ is an indicator variable for landlocked economies, and

Cont $_{i j}$ is an indicator variable for contiguity.

The structural equation then takes this constructed trade share, aggregated over all the trading partners of a certain economy by year, as the instrumental variable. The constructed trade share is calculated as follows:

$$
\widehat{T}_{\imath}=\sum_{i \neq j} e^{\hat{\beta}^{T} X_{i j}}
$$

The output or income of economy $i$ then follows the basic Frankel and Romer (1999) specification, which captures both international trade and within-economy transactions. In this case, international trade is measured by the trade share, whereas within-economy transactions are a function of measures of the economy's size-area and population.
Formally:

$$
\ln \left(Y_{i}\right)=\beta_{0}+\beta_{1} T_{i}+\beta_{2} \operatorname{lnPop}_{i}+\beta_{3} \ln \text { Area }_{i}+\epsilon_{i j}
$$

where $\ln \left(Y_{i}\right)$ is the GDP or gross national income (GNI) per capita of economy $i$ and $T_{i}$ is the trade share as calculated in equation (2).

The basic random effects regression reveals a statistically significant association between DDS exports share and GDP per capita and GNI per capita. Moving to the IV estimates of the same equation, where exports share is instrumented by the constructed trade share, the results show a significant increase in the coefficients for DDS exports share for both GDP per capita and GNI per capita.

Estimating the structural equation with a dummy variable for Asia and the Pacific, as well as interactions with said dummy variable, the main effects remain similar. DDS exports share retains its positive association with both GDP per capita and GNI per capita. ${ }^{\text {a }}$ This suggests increasing the bilateral digitally deliverable services exports is associated with a rise in output and income per capita.

${ }^{a}$ More detailed regression results are presented in online Annex 1a: Regression Results-Model on Digitally Deliverable Services Exports and Income Per Capita. http://aric.adb.org/pdf/aeir2022_onlineannex1.pdf.

Source: Kang et al. (2021).

\section{Regional Trends}

Three main data sources illustrate trends in digitally deliverable services trade: (i) WTO-UNCTAD trade in services database, which provides the most recent overview of services trade trends from 2005 to 2020 , allowing to observe the effects of COVID-19,

(ii) Balanced Trade in Services (BaTIS), which provides a comprehensive picture on bilateral trade in services flows from 2005 to 2019, and (iii) the WTO's Trade in Services by Mode of Supply (TISMOS), which provides information on trade in services by mode of supply. These data sources have been reconciled to ensure consistency. ${ }^{81}$

Trends between 2005 and 2019 reveal total services and digitally deliverable services trade in Asia and the Pacific is growing. Globally, the region is the world's secondlargest trader of services, after the European Union (EU), and this ranking also holds for digital services. Asia's total services trade almost tripled over 2005-2019 to

81 The WTO-UNCTAD trade in services data set (released in July 2021) is the most comprehensive set of official economy-based information publicly available via UNCTADStat. It presents exports and imports of commercial services in conformity with the Extended Balance of Payments Services Classification (EBOPS 2010), based on the sixth edition of the International Monetary Fund Balance of Payments and International Investment Position Manual (BPM6). It is also the starting point for the WTO-OECD BaTIS (released in January 2021), an analytical data set providing a complete bilateral matrix of services trade for 2005 to 2019, covering 202 economies and the 12 main EBOPS 2010 service categories. Both WTO-UNCTAD and BaTIS cover data from balance of payments, which includes modes of supply 1, 2, and 4 in the GATS definition. Supplementary data and information-such as on data availability and differences as well as additional charts and tables on trends-for the three data sets on trade in services are presented in online Annex 1b, available at http://aric.adb.org/pdf/aeir2022_onlineannex1.pdf. 
nearly 3.3 trillion (Figure $7.4 \mathrm{a}$ ), bringing its global share in total services exports up from $19 \%$ to $25 \%$, and its share in total services imports from $25 \%$ to $29 \%$. The region's digitally deliverable services trade increased to $\$ 1.4$ trillion in 2019 from $\$ 403.4$ billion in 2005 (Figure 7.4b). Other emerging regions, including the Middle East or Latin America, experienced considerably less growth over this period.

The trend growth in global and regional services trade was drastically reversed with the offset of COVID-19 in early 2020. Global trade in total services contracted by $21 \%$ year-on-year from 2019 to 2020 . Global digitally deliverable services trade was relatively resilient, however, with a -3\% year-on-year contraction (Figure 7.4b), while non-digitally deliverable services plunged $-39 \%$ year-on-year (Figure 7.4c). Asia and the Pacific experienced a small increase (1\%) in digitally deliverable services trade in 2020 , as did North America (2\%), while other regions experienced a slowdown.
Consistent with the global decline, trade in non-digitally deliverable services in Asia and the Pacific contracted by $38 \%$ in 2020 . The region's participation in digitally deliverable services consequently increased during the pandemic.

Asia's participation in digitally deliverable services trade has increased within and outside the region (Table 7.2). From $\$ 120.8$ billion worth of digitally deliverable services trade within the region in 2005, it tripled its trade volume, achieving over $\$ 483.5$ billion in 2019 . The region is also a substantial and growing digital services trade partner with other regions, notably Europe and Northern America, where Asia's share grew to $11.9 \%$ and $26.3 \%$ in 2019, respectively.

The intraregional services trade story is a strongly positive one. Over 2005 to 2019, intraregional trade increased from just under half to $52 \%$ of the region's total services trade (Figure 7.5a).

Figure 7.4: Trade in Services by Region ( $\$$ billion)

\section{(a) Trade in Total Services}

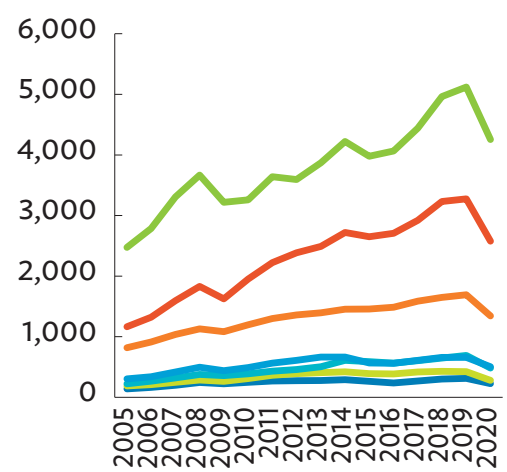

(b) Trade in Digitally Deliverable Services

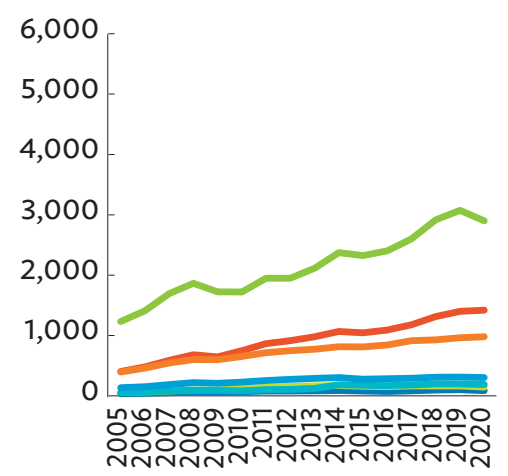

Asia and the Pacific

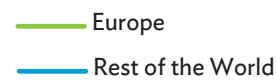

\section{(c) Trade in Non-Digitally Deliverable Services}

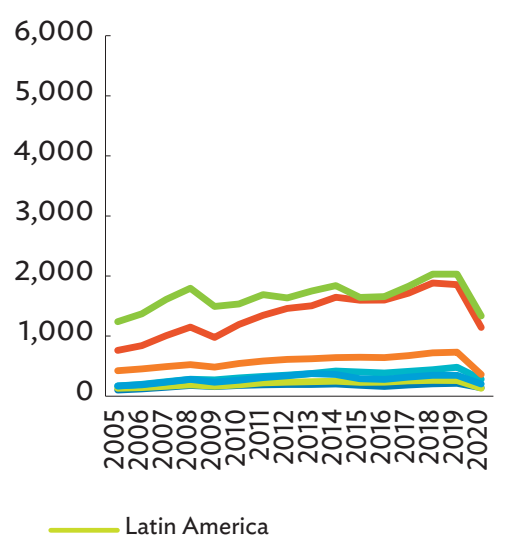

Notes:

(i) Digitally deliverable services include insurance and pension services; financial services; charges for the use of intellectual property not identified elsewhere; telecommunications, computer, and information services; other business services; and personal, cultural, and recreational services.

(ii) Non-digitally deliverable services include manufacturing services on physical inputs owned by others; maintenance and repair services not identified elsewhere; transport; travel; construction; and government goods and services not identified elsewhere.

(iii) Total services is the sum of digitally deliverable services and non-digitally deliverable services.

(iv) Economy groupings follow the Asian Economic Integration Report classification. All economies not included in the integration indicators groupings are classified as Rest of the World.

(v) Figures in conformity with the sixth edition of the International Monetary Fund Balance of Payments and International Investment Position Manual (BPM6) as well as the 2010 edition of the Manual on Statistics of International Trade in Services (MSITS 2010).

Source: United Nations Conference on Trade and Development (UNCTAD). UNCTADStat: WTO-UNCTAD (BPM6) International Trade in Services Annual Dataset. https://unctadstat.unctad.org/ (accessed July 2021). 
Table 7.2: Shares of Digitally Deliverable Services Trade, 2019 (\%)

\begin{tabular}{|c|c|c|c|c|c|c|c|}
\hline \multirow[b]{2}{*}{ REPORTER } & \multicolumn{7}{|c|}{ PARTNER } \\
\hline & Africa & $\begin{array}{l}\text { Asia and the } \\
\text { Pacific }\end{array}$ & Europe & $\begin{array}{l}\text { Latin } \\
\text { America }\end{array}$ & Middle East & $\begin{array}{c}\text { North } \\
\text { America }\end{array}$ & $\begin{array}{l}\text { Rest of the } \\
\text { World }\end{array}$ \\
\hline Africa & 3.3 & 20.7 & 45.0 & 1.8 & 4.1 & 19.6 & 5.6 \\
\hline Asia and the Pacific & 1.5 & 38.8 & 27.5 & 2.0 & 3.3 & 22.2 & 4.7 \\
\hline Europe & 1.4 & 11.9 & 58.2 & 2.2 & 2.8 & 14.2 & 9.2 \\
\hline Latin America & 0.9 & 13.1 & 33.5 & 5.3 & 1.7 & 41.0 & 4.5 \\
\hline Middle East & 2.1 & 22.6 & 44.9 & 1.7 & 5.6 & 17.2 & 5.9 \\
\hline North America & 1.7 & 26.3 & 39.1 & 7.3 & 3.0 & 12.3 & 10.2 \\
\hline Rest of the World & 1.0 & 11.6 & 56.4 & 1.7 & 2.1 & 22.6 & 4.4 \\
\hline
\end{tabular}

Notes: Orange and red indicate increased and decreased shares from 2005, respectively. The table indicates the share of bilateral trade from one region to another (extraregional) and one region to its own region (intraregional) in 2019. The bilateral trade levels are presented in online Annex 1 (Tables 1b.3 and 1b.4), available at http://aric.adb.org/pdf/aeir2022_onlineannex1.pdf.

Source: ADB calculations using WTO-OECD Balanced Trade in Services Dataset (BaTIS)—BPM6. https://www.wto.org/english/res_e/statis_e/trade_datasets_e.htm (accessed May 2021).

Figure 7.5: Intraregional and Extraregional Trade in Services in Asia and the Pacific (\$ billion)

(a) Total Services Trade

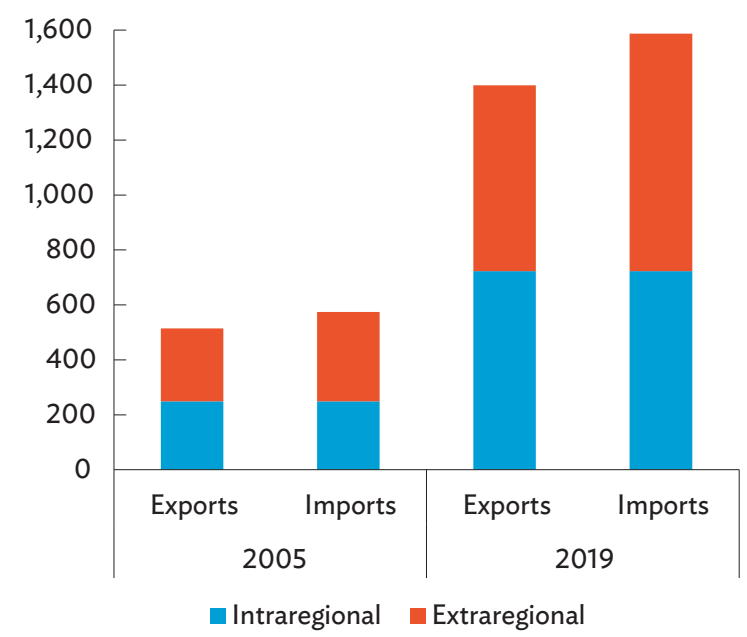

(b) Digitally Deliverable Services Trade

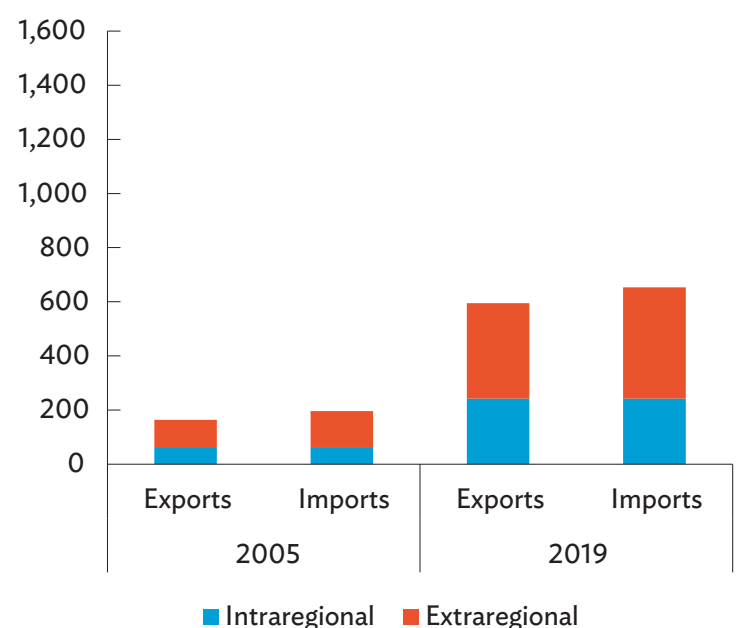

Notes: Digitally deliverable services include insurance and pension services; financial services; charges for the use of intellectual property not identified elsewhere; telecommunications, computer, and information services; other business services; and personal, cultural, and recreational services. Total services is the sum of digitally deliverable services and non-digitally deliverable services.

Source: WTO-OECD Balanced Trade in Services Dataset (BaTIS)—BPM6. https://www.wto.org/english/res_e/statis_e/trade_datasets_e.htm (accessed May 2021).

This is similar to the region's intraregional trade in goods the same year, at about $57 \%$. Intraregional trade now accounts for $39 \%$ of the region's digitally deliverable services trade, up from 33\% in 2005 (Figure 7.5b).

The data confirms a fast-growing share of digital services in Asia's total services export basket from $36 \%$ to $48 \%$ over the period, and from $34 \%$ to $39 \%$ for imports (Figure 7.6). Yet, these increments are below the increase in export shares, from $48 \%$ to $54 \%$, for the rest of the world, indicating some room for improvement in the region. The increase in the region's share of digitally deliverable services trade in 2020, from $43 \%$ to $55 \%$, was larger than the increase observed over the previous decade. 
Figure 7.6: Shares and Growth of Digitally and Non-Digitally Deliverable Services Trade (\%)

(a) Share: Asia and the Pacific

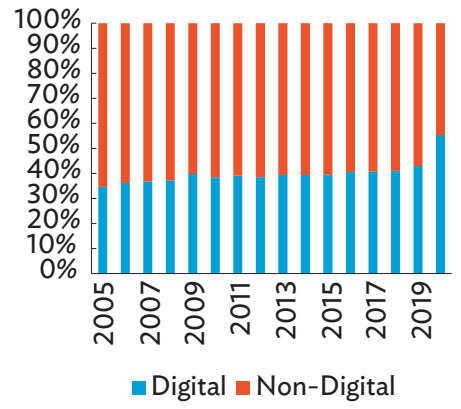

(d) Y-o-Y Growth: Asia and the Pacific

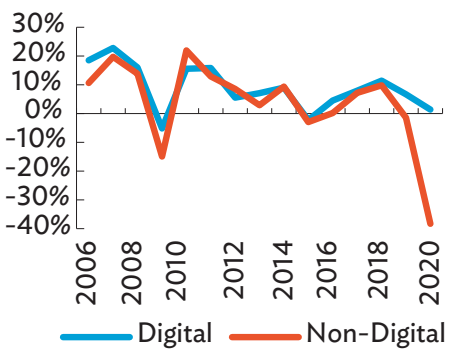

(b) Share: Rest of the World

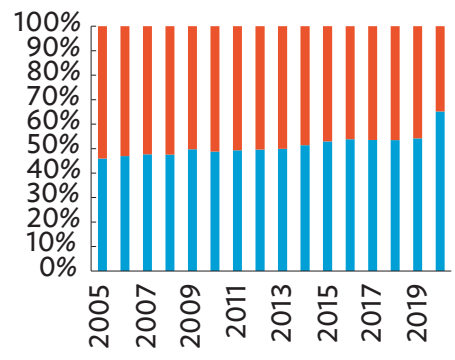

- Digital $\square$ Non-Digital

(e) Y-o-Y Growth: Rest of the World

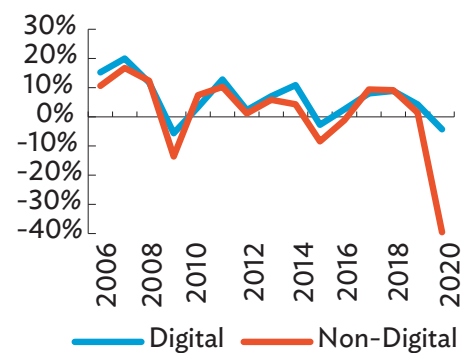

(c) Share: World

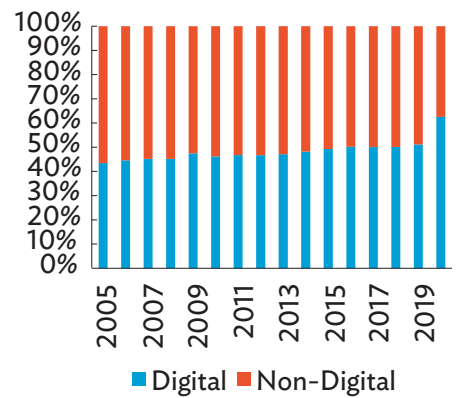

(f) Y-o-Y Growth: World

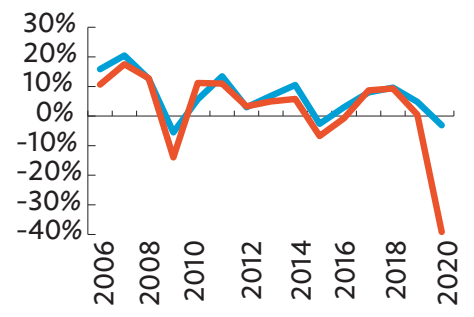

Digital Non-Digital

$y-0-y=$ year-on-year.

Notes:

(i) The values refer to the digitally and non-digitally deliverable services trade (exports plus imports) with the world.

(ii) The following groupings were used: (a) 43 economies from Asia and the Pacific, (b) 160 economies (all economies in the data set minus Asia and the Pacific), and (c) world aggregate.

(iii) Digital includes insurance and pension services; financial services; charges for the use of intellectual property not identified elsewhere (n.i.e); telecommunications, computer, and information services; other business services; and personal, cultural, and recreational services. Non-digital includes manufacturing services on physical inputs owned by others; maintenance and repair services not identified elsewhere; transport; travel; construction; and government goods and services not identified elsewhere.

(iv) The data conform with the sixth edition of the International Monetary Fund Balance of Payments and International Investment Position Manual (BPM6) as well as the 2010 edition of the Manual on Statistics of International Trade in Services (MSITS 2010).

Source: ADB calculations using United Nations Conference on Trade and Development (UNCTAD). UNCTADStat: WTO-UNCTAD (BPM6) International Trade in Services Annual Dataset. https://unctadstat.unctad.org/ (accessed July 2021).

Together with digitally deliverable services, COVID-19 has also been a driver for the significant increase in e-commerce in the region.

Services trade has grown faster in Asia and the Pacific than in other regions. Between 2005 and 2020, total annual services trade in the region increased by $6.0 \%$ on average, well above the global average of $4.5 \%$. Digitally deliverable services, on the other hand, expanded at an average $9.0 \%$ annually, compared with a $6.8 \%$ global average (Figure 7.7). However, the region started from a lower baseline than developed economies (Figure 7.8).

\section{Subregional Trends}

Largely due to the People's Republic of China (PRC), East Asia (excluding Japan) is the top exporter (50\%) and top importer (55\%) of digitally deliverable services in developing Asia (Figure 7.9). Exports grew faster than imports over 2005-2020 in most subregions, led by Southeast Asia (average annual export growth of 11.2\%), and South Asia (10.6\%) followed by East Asia (9.8\%), Central and West Asia (6.0\%), and the Pacific (4.7\%). In Southeast Asia, the rapid expansion is largely due to the Philippines, while in South Asia it is largely due to India. Digital services are now dominant sectors in both economies. 
Figure 7.7: Average Annual Growth in Services Trade, 2005-2020 (\%)

(a) Exports

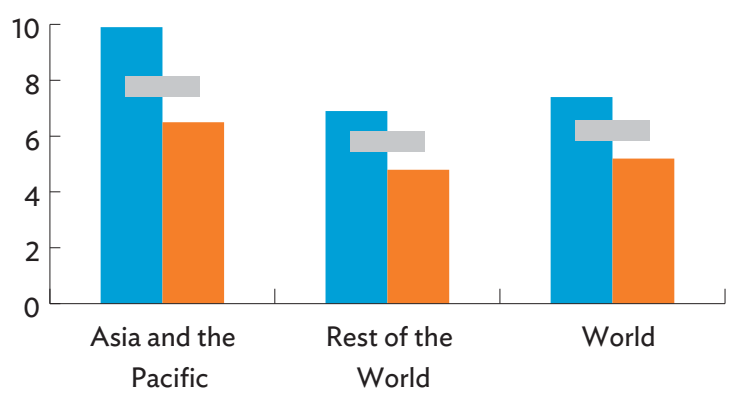

(b) Imports

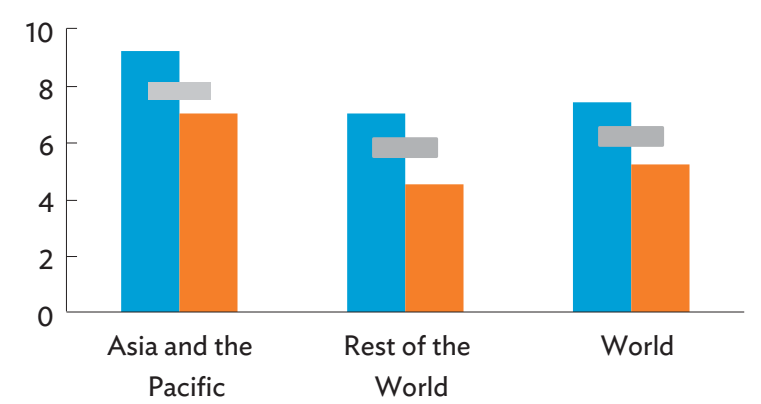

- Digitally Delivered Services

Non-Digitally Delivered Services

- Total Services

Notes:

(i) The values refer to the digitally and non-digitally deliverable services exports and imports with the world.

(ii) The following groupings were used: (a) 43 economies from Asia and the Pacific, (b) 160 economies (all economies in the data set minus Asia and the Pacific), and (c) world aggregate.

(iii) Digital includes insurance and pension services; financial services; charges for the use of intellectual property not identified elsewhere; telecommunications, computer, and information services; other business services; and personal, cultural, and recreational services. Non-digital includes manufacturing services on physical inputs owned by others; maintenance and repair services not identified elsewhere; transport; travel; construction; and government goods and services not identified elsewhere.

(iv) The data conform with the sixth edition of the International Monetary Fund Balance of Payments and International Investment Position Manual (BPM6) as well as the 2010 edition of the Manual on Statistics of International Trade in Services (MSITS 2010).

Source: ADB calculations using United Nations Conference on Trade and Development (UNCTAD). UNCTADStat: WTO-UNCTAD (BPM6) International Trade in Services Annual Dataset. https://unctadstat.unctad.org/ (accessed July 2021).

\section{Figure 7.8: Trade in Services in Asia and the Pacific} (\$ billion)

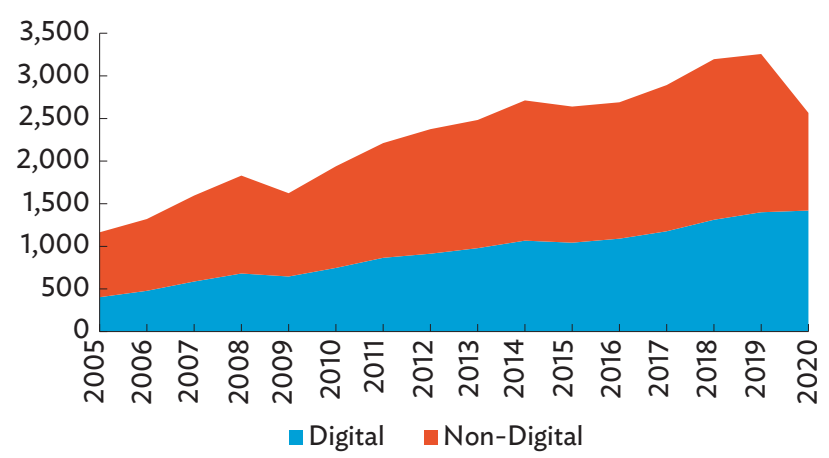

Notes:

(i) The values refer to the total services trade (exports plus imports) of Asia and the Pacific to the world.

(ii) Digital includes insurance and pension services; financial services; charges for the use of intellectual property not identified elsewhere; telecommunications, computer, and information services; other business services; and personal, cultural, and recreational services. Non-digital includes manufacturing services on physical inputs owned by others; maintenance and repair services not identified elsewhere; transport; travel; construction; and government goods and services not identified elsewhere.

(iii) The data conform with the sixth edition of the International Monetary Fund Balance of Payments and International Investment Position Manual (BPM6) as well as the 2010 edition of the Manual on Statistics of International Trade in Services (MSITS 2010).

Source: ADB calculations using United Nations Conference on Trade and Development (UNCTAD). UNCTADStat: WTO-UNCTAD (BPM6) International Trade in Services Annual Dataset. https://unctadstat.unctad.org/ (accessed July 2021).
South Asia and Southeast Asia have similarly experienced the fastest growth in imports, with annual average growth rates of $9.3 \%$ and $8.7 \%$, respectively, followed by East Asia (7.8\%), Central Asia (5.0\%), and the Pacific (3.7\%).

Figure 7.10 shows the flow of digitally deliverable services from different regions of the world to Asian subregions. Among all, East Asia accounts the highest volume of digital services imports. It received a volume worth more than $\$ 110.5$ billion in 2005 , which further increased to $\$ 351.0$ billion in 2019. Aside from intraregional trade (30.7\%), North America (31.6\%) and Europe (29.8\%) were top contributors to East Asia. Following East Asia is Southeast Asia, which received $\$ 47.8$ billion of digital services in 2005 and $\$ 173.7$ billion in 2019. Aside from interregional receipts (37.0\%), Europe (33.7\%), and North America (21.9\%) were top providers of digital services for the subregion. 
Figure 7.9: Trade in Digitally Deliverable Services of Developing Asia, by Subregion (\$ billion)

(a) Exports

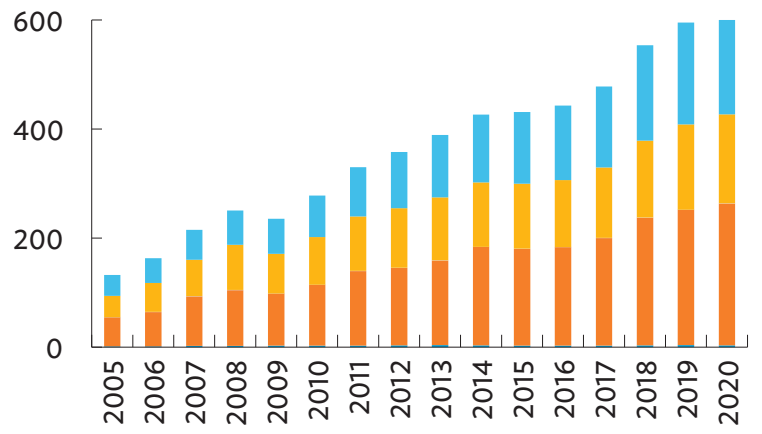

(b) Imports

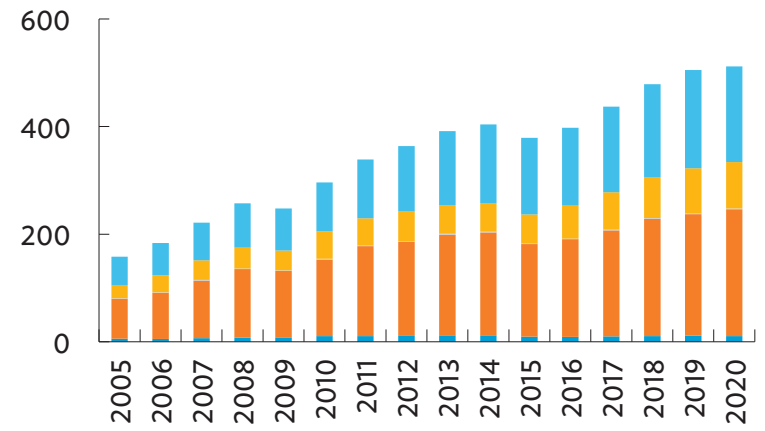

South Asia $\quad$ Southeast Asia

Notes:

(i) Central Asia consists of Armenia, Azerbaijan, Georgia, Kazakhstan, the Kyrgyz Republic, Tajikistan, Turkmenistan, and Uzbekistan. East Asia consists of Hong Kong, China; Mongolia; the People's Republic of China; the Republic of Korea; and Taipei,China. The Pacific consists of the Cook Islands, Fiji, Kiribati, Papua New Guinea, Samoa, Solomon Islands, Tonga, Tuvalu, and Vanuatu. South Asia consists of Afghanistan, Bangladesh, Bhutan, India, Maldives, Nepal, Pakistan, and Sri Lanka. Southeast Asia consists of Brunei Darussalam, Cambodia, Indonesia, the Lao People's Democratic Republic, Malaysia, Myanmar, the Philippines, Singapore, Thailand, Timor-Leste, and Viet Nam.

(ii) Digitally deliverable services include insurance and pension services; financial services; charges for the use of intellectual property not identified elsewhere; telecommunications, computer, and information services; other business services; and personal, cultural, and recreational services.

(iii) The data conform with the sixth edition of the International Monetary Fund Balance of Payments and International Investment Position Manual (BPM6) as well as the 2010 edition of the Manual on Statistics of International Trade in Services (MSITS 2010).

Source: ADB calculations using United Nations Conference on Trade and Development (UNCTAD). UNCTADStat: WTO-UNCTAD (BPM6) International Trade in Services Annual Dataset. https://unctadstat.unctad.org/ (accessed July 2021).

Figure 7.10: Digitally Deliverable Services Exports to Asia and the Pacific (\$ million)

(a) 2005

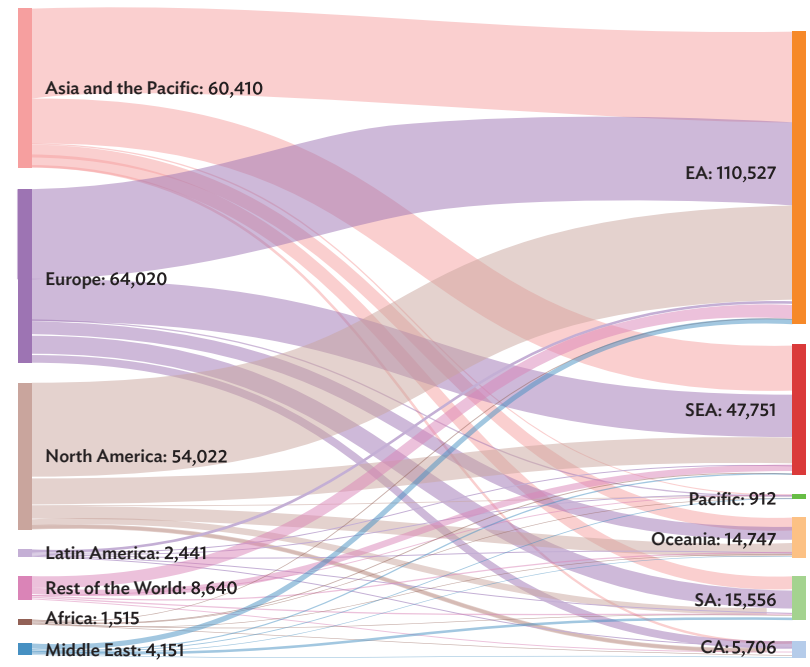

(b) 2019

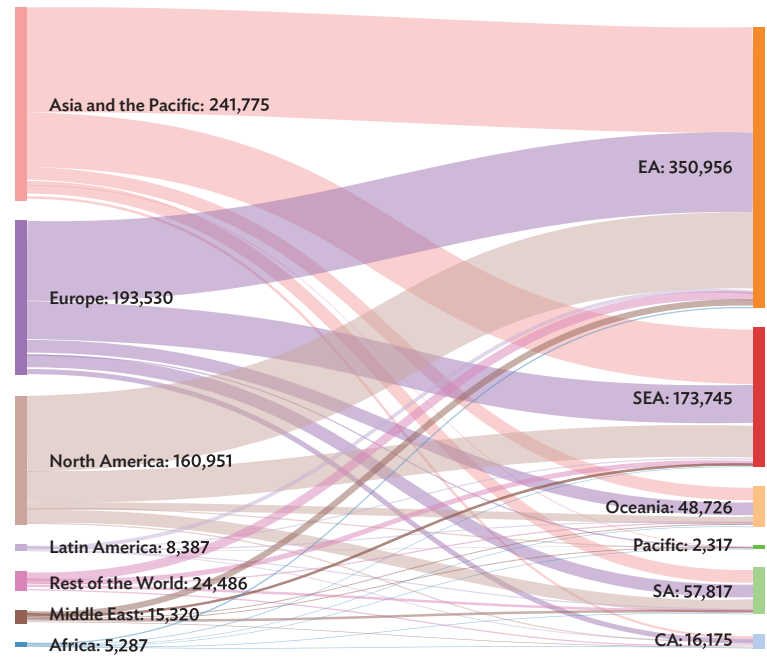

$\mathrm{CA}=$ Central Asia, $\mathrm{EA}=$ East Asia, $\mathrm{SA}=$ South Asia, $\mathrm{SEA}=$ Southeast Asia.

Notes: Bilateral trade flows from the different regions of the world to various Asian subregions in 2005 and 2019. Economy groupings follow the Asian Economic Integration Report classification. All economies not included in the integration indicators groupings are classified as Rest of the World. Digitally deliverable services include insurance and pension services; financial services; charges for the use of intellectual property not identified elsewhere; telecommunications, computer, and information services; other business services; and personal, cultural, and recreational services.

Source: WTO-OECD Balanced Trade in Services Dataset (BaTIS)—BPM6. https://www.wto.org/english/res_e/statis_e/trade_datasets_e.htm (accessed May 2021). 
Asia's top exporters and importers of digitally deliverable services point to the central role of some economies in the region's emergence as a digital services hub. In particular, India, the PRC, Singapore, Japan, and the Republic of Korea are the most dynamic economies exporting and purchasing digitally deliverable services (Figure 7.11). While not the leading economies in volume, some developing Asian economies have experienced substantial growth in digitally deliverable trade. Economies that registered a significant annual average growth in digitally deliverable services exports over 2005-2020 include Bangladesh (13.3\%), Cambodia (11.0\%), the Lao People's Democratic Republic (20.2\%), Nepal (14.0\%), and the Philippines (10.9\%).

\section{Sector Trends}

Data for services trade in Asia and the Pacific shows that overall, services trade displayed steady growth until the arrival of the pandemic. Figure 7.12 underlines the predominance of three main services sectors in the region, travel services (SD), transport (SC), and other business services (SJ).
Figure 7.12: Trade in Services in Asia and the Pacific, by Sector ( $\$$ billion)

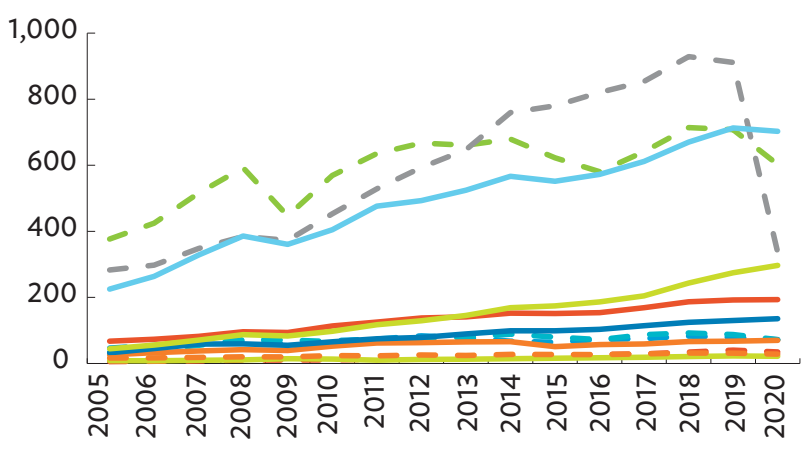

-- SA: Manufacturing services on physical inputs owned by others - - SB: Maintenance and repair services n.i.e.

$-\infty$ SC: Transport $\quad$ SJ: Other business services

-- SD: Travel $\quad$ SK:Personal, cultural, and

--- SE: Construction recreational services

_SF: Insurance and pension services _ _- SL: Government goods and

SG: Financial services services n.i.e.

SH: Charges for the use of intellectual property n.i.e.

SI: Telecommunications, computer, and information services

n.i.e. $=$ not identified elsewhere

Notes: Solid lines are digitally deliverable services, while dotted lines are nondigitally deliverable service items. The data conform with the sixth edition of the International Monetary Fund Balance of Payments and International Investment Position Manual (BPM6) as well as the 2010 edition of the Manual on Statistics of International Trade in Services (MSITS 2010).

Source: ADB calculations using United Nations Conference on Trade and Development (UNCTAD). UNCTADStat: WTO-UNCTAD (BPM6) International Trade in Services Annual Dataset. https://unctadstat.unctad.org/ (accessed July 2021).

Figure 7.11: Top Asian Exporters and Importers of Digitally Deliverable Services, 2020 (\$ billion)

(a) Top Exporters

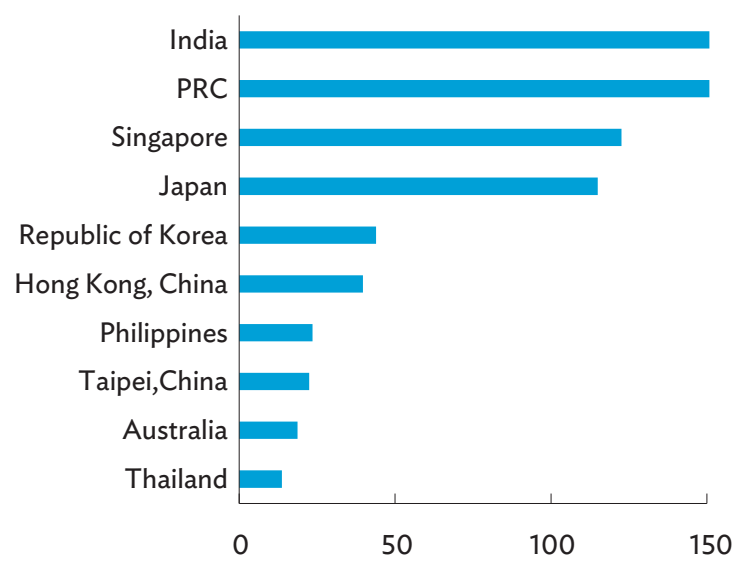

(b) Top Importers

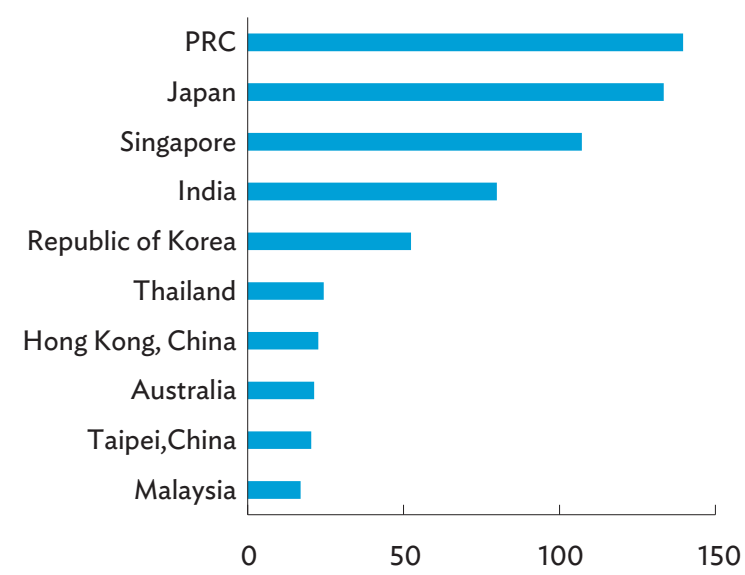

PRC = People's Republic of China

Notes: Digitally deliverable services include insurance and pension services; financial services; charges for the use of intellectual property not identified elsewhere; telecommunications, computer, and information services; other business services; and personal, cultural, and recreational services. The data conform with the sixth edition of the International Monetary Fund Balance of Payments and International Investment Position Manual (BPM6) and the 2010 edition of the Manual on Statistics of International Trade in Services (MSITS 2010)

Source: ADB calculations using United Nations Conference on Trade and Development (UNCTAD). UNCTADStat: WTO-UNCTAD (BPM6) International Trade in Services Annual Dataset. https://unctadstat.unctad.org/ (accessed July 2021). 
Travel and transport (which includes passenger transport) suffered substantial cutbacks given they require consumers' physical presence and were severely affected by tightened cross-border controls and restrictions to international travel. The contraction in other business services was considerably lower as most services grouped in this category can be digitally delivered and do not require physical proximity. Box 7.3 presents some examples of digitally deliverable services.

Figure 7.13 further dissects trends in digitally deliverable services, in particular for telecommunications, computer, and information services (SI), other business services (SJ), and personal, cultural, and recreational services (SK). Trade in computer services, including for example computer software, cloud computing, and data storage services, displayed the steepest and most continuous growth, with an eightfold increase from $\$ 31$ billion in 2005 to $\$ 256$ billion in 2020 (Figure 7.13a). In the case of trade in other business services, growth since 2005 has been steady for professional and management consulting services, including legal services, accounting, auditing, advertising, and market research services. Finally, the region's trade in personal, cultural, and recreational services, which includes health and education, expanded-though its size remains relatively modest.
These trends attest to the changing composition of the region's services trade toward digitally deliverable services (Figure 7.14). Between 2005 and 2020, digitally deliverable services trade expanded, in particular telecommunications, computer, and information services (growing $13.8 \%$ annually on average), followed by financial services (10.6\%), other business services (8.2\%), insurance and pension services (7.7\%), charges for the use of intellectual property not identified elsewhere (7.5\%), and personal, cultural, and recreational services (7.4\%). The COVID-19 shock exacerbated this trend. Indeed, most digitally deliverable service items thrived and their growth accelerated amid the pandemic. Between 2019 and 2020, the region's trade in telecommunications, computer, and information services grew by $8.1 \%$, followed by financial services (4.3\%), and insurance and pension services (3.9\%). In contrast, other business services recorded a mild (-1.4\%) contraction.

A breakdown into the six digital services subsectors illustrates some variation in digital services trade participation across Asian subregions (Figure 7.15). Other business services and telecommunications, computer, and information services are dominant, both for exports and imports, in most Asian subregions. Other business services account for almost half of digitally deliverable

Figure 7.13: Trade in Services in Asia and the Pacific, by Sector Breakdown ( $\$$ billion)

(a) Telecommunications, Computer, and Information Services

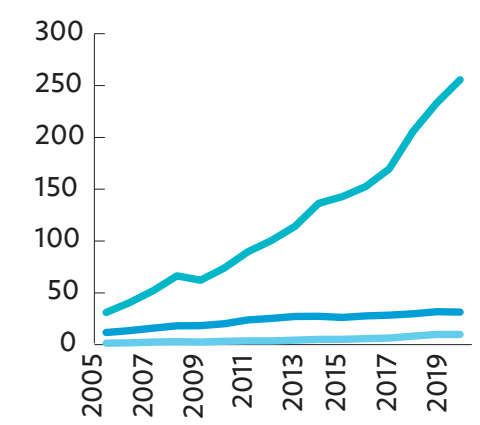

SI1: Telecommunications services

SI2: Computer services

SI3: Information services (b) Other Business Services

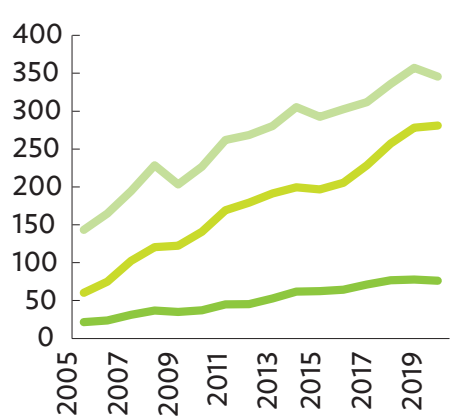

SJ1: Research and development services SJ2: Professional and management consulting services

SJ3: Technical, trade-related, and other business services (c) Personal, Cultural, and Recreational services

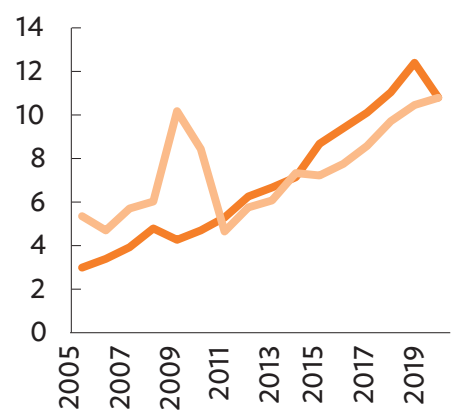

SK1: Audiovisual and related services

SK2: Health, education, and heritage and recreational

Notes: The figure shows the breakdown of total services trade (exports plus imports) in three sectors: telecommunications, computer, and information services (SI), other business services (SJ), and personal, cultural, and recreational services (SK). The data conform with the sixth edition of the International Monetary Fund Balance of Payments and International Investment Position Manual (BPM6) as well as the 2010 edition of the Manual on Statistics of International Trade in Services (MSITS 2010).

Source: ADB calculations using United Nations Conference on Trade and Development (UNCTAD). UNCTADStat: WTO-UNCTAD (BPM6) International Trade in Services Annual Dataset. https://unctadstat.unctad.org/ (accessed July 2021). 
services in most subregions, and for almost $80 \%$ of both digital service exports and imports in the Pacific in 2005. Telecommunications, computer, and information services exports are notably larger for South Asia, an effect mostly driven by India. In general, the COVID-19 pandemic disrupted to some extent the volume if not the composition of digital services trade in most subregions, with the exception of the Pacific.

Figure 7.14: Trade in Digitally Deliverable Services in Asia and the Pacific, by Service Item

\section{(a) 2005}
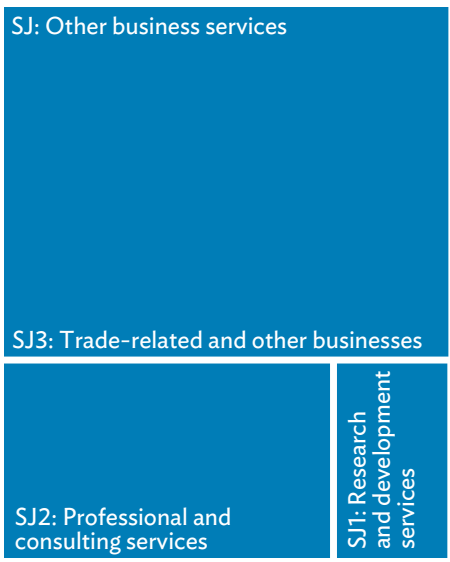
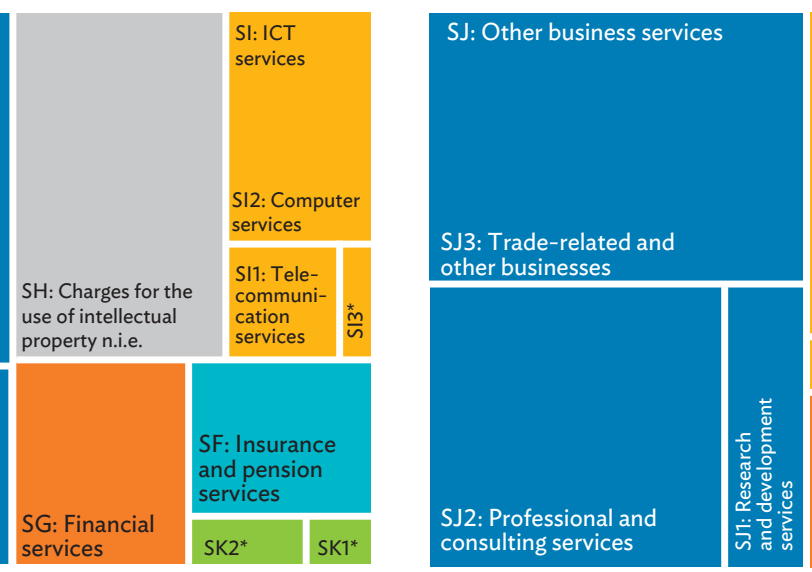

(b) 2020

$\mathrm{ICT}=$ information and communication technology; n.i.e = not identified elsewhere; $\mathrm{SI}$ = Information services; SK1 = Audiovisual and related services; SK2 = Other personal, cultural, and recreational services.

Note: The data conform with the sixth edition of the International Monetary Fund Balance of Payments and International Investment Position Manual (BPM6) as well as the 2010 edition of the Manual on Statistics of International Trade in Services (MSITS 2010).

Source: ADB illustration using United Nations Conference on Trade and Development (UNCTAD). UNCTADStat: WTO-UNCTAD (BPM6) International Trade in Services Annual Dataset. https://unctadstat.unctad.org/ (accessed July 2021).

Figure 7.15: Digitally Deliverable Services Trade in Asian Subregions (\% share)

(a) Exports

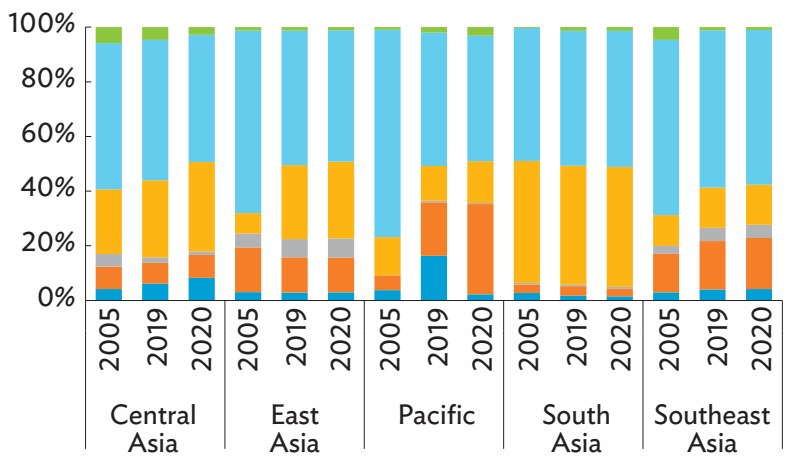

¿SK: Personal, cultural, and recreational services

SI: Telecommunications, computer, and information services

SG: Financial services (b) Imports

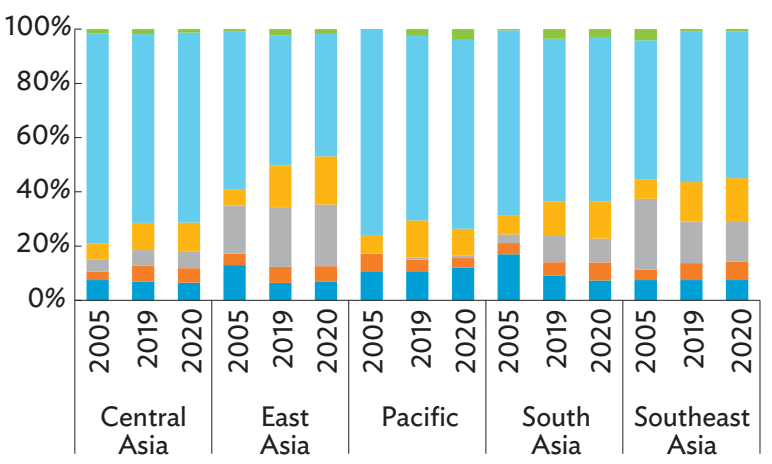

¿SJ: Other business services

$-\mathrm{SH}$ : Charges for the use of intellectual property n.i.e. -SF: Insurance and pension services

n.i.e. $=$ not identified elsewhere

Notes: The data conform with the sixth edition of the International Monetary Fund Balance of Payments and International Investment Position Manual (BPM6) as well as the 2010 edition of the Manual on Statistics of International Trade in Services (MSITS 2010).

Source: ADB calculations using United Nations Conference on Trade and Development (UNCTAD). UNCTADStat: WTO-UNCTAD (BPM6) International Trade in Services Annual Dataset. https://unctadstat.unctad.org/ (accessed July 2021). 


\section{Modes of Supply}

To complement the information provided in WTOUNCTAD and BaTIS on digitally deliverable services, the TISMOS data set provides estimates of trade in services broken down by the four modes of supply as defined in the General Agreement on Trade in Services (GATS).

By including services provided via commercial presence (besides modes 1, 2, and 4), TISMOS helps depict a more comprehensive picture of global trade in services. Indeed, mode 3 (commercial presence) is Asia's predominant mode of services supply, both for exports and for imports, mirroring the global trend. Globally, the mode 3 share decreased from $61 \%$ in 2005 to $59 \%$ in 2017, while mode 1 remained constant at 10\%. Over the same period, the share of mode 1 services in Asia's services imports increased from $13 \%$ to $14 \%$, while the share of mode 1 in services exports declined from $14 \%$ to $11 \%$.
Leaving aside commercial presence, TISMOS data reconfirm the relative importance of mode 1 within the identified cluster of digitally deliverable services and for refining the upper bound estimates of digitally deliverable services presented so far in this chapter. ${ }^{82}$ In some cases, the international supply of digitally deliverable services may still require the physical presence of the service supplier in the territory of the consumer and thus involve a non-negligible mode 4 component. Figure 7.16 highlights for the digitally deliverable services, the actual mode of supply. As expected, mode 1 is the predominant mode of supply in Asia's services exports. ${ }^{83}$

Figure 7.17 provides a further decomposition of the services grouped under other business services and telecommunications, computer, and information services, again including for each service category the breakdown by mode of supply.

Figure 7.16: Trade in Digitally Deliverable Services in Asia and the Pacific, by Mode of Supply (\$ billion)

(a) Evolution by Mode of Supply

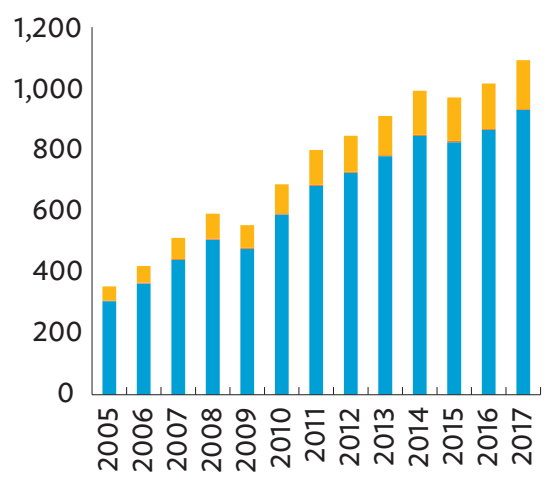

(b) By Service Item

$$
\square \text { M1 (cross-border trade) } \quad M 2 \text { (consumption abroad) } \quad M 4 \text { (presence of natural persons) }
$$

ICT = information, computer, and telecommunication; n.i.e. = not identified elsewhere; TISMOS = Trade in Services Data by Mode of Supply.

Notes: Other business services exclude trade-related services. The World Trade Organization (WTO) defines the modes of supply as: M1 (cross-border trade) - from the territory of one WTO member into the territory of any other member; M2 (consumption abroad)-in the territory of one member to the service consumer of any other member; and M4 (presence of natural persons) - by a service supplier of one member, through the presence of natural persons of a member in the territory of any other member. Data for 2017, which is the latest available year in TISMOS.

Source: WTO and Directorate-General for Trade of the European Commission. TISMOS. https://www.wto.org/english/res_e/statis_e/trade_datasets_e.htm (accessed July 2021).

82 Notwithstanding the (minor) differences between digital delivery and mode 1. See the section on the measurement framework and definitions on pages 186-190.

83 It has to be noted, however, that TISMOS includes WTO estimations. 
Figure 7.17: Asia's Largest Digitally Deliverable Services Subsectors, by Mode of Supply

(a) Other Business Services

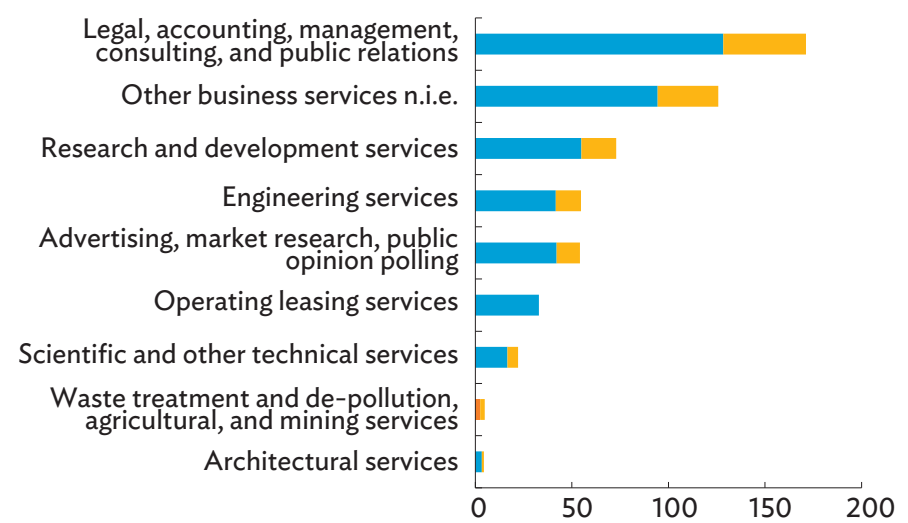

$\square \mathrm{M} 1$ (cross-border trade) $\square \mathrm{M} 2$ (consumption abroad) (b) Telecommunications, Computer, and Information Services

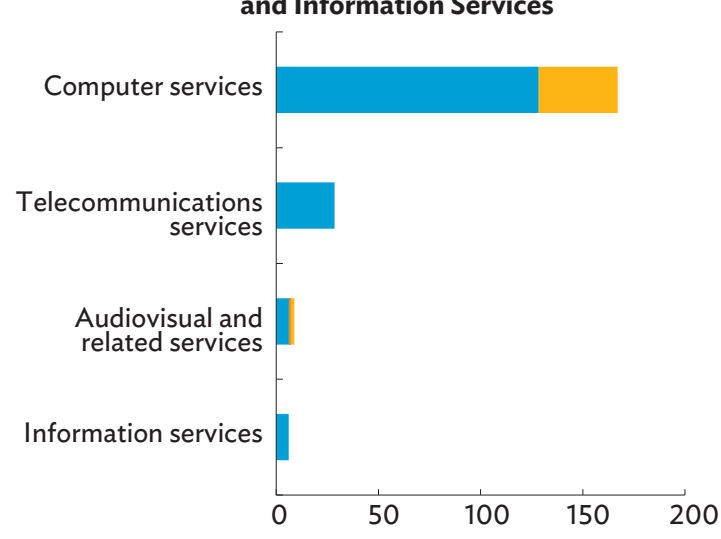

M4 (presence of natural persons)

ICT = information, computer, and telecommunications; n.i.e. = not identified elsewhere.

Notes: Other business services exclude trade-related services. The World Trade Organization (WTO) defines the modes of supply as: M1 (cross-border trade) - from the territory of one WTO member into the territory of any other member; M2 (consumption abroad) -in the territory of one member to the service consumer of any other member; and M4 (presence of natural persons) - by a service supplier of one member, through the presence of natural persons of a member in the territory of any other member.

Source: WTO and Directorate-General for Trade of the European Commission. Trade in Services Data by Mode of Supply (TISMOS). https://www.wto.org/english/res_e/ statis_e/trade_datasets_e.htm (accessed July 2021).

\section{Box 7.3: Recent Developments in Digitally Deliverable Services in Developing Asia}

Asia's expansion in digitally deliverable services exports encompasses a wide range of industries, geographic hubs, and ecosystems. Some examples from the region in the six categories defined in the conceptual framework are presented below.

Insurance and Pension Services (SF). Digital technologies are redefining how insurance services are being accessed and distributed, with big data, data analytics and artificial intelligence (AI) increasingly used for underwriting and the pricing of risk. Other digitally enabled services within the industry include claims management, data management, new insurance service offerings, marketing and distribution, platforms, and partnerships. For example, the People's Republic of China (PRC) online-only Property and Casualty insurance company ZhongAn has automatized more than $95 \%$ of claim underwriting and settlement rates, with more than $70 \%$ of customer service claims being managed through $\mathrm{Al}$.

The PRC and India dominate the regional insurance markets, housing nearly half of the 335 private InsurTechs operating in the region (Abbas 2021). Malaysia and Indonesia are also becoming prominent markets.
Indonesia's e-commerce market leader Tokopedia entered the air travel insurance market in mid-2018. Ride-hailing platform Grab and ZhongAn created an insurance marketplace for Southeast Asia in early 2019.

Financial Services (SG). Financial services driven by digital technologies_or fintech-have evolved quickly, with big data, cloud computing, and distributed ledger technology becoming ubiquitous in the sector. Fintech adoption in Asia and the Pacific has grown substantially over the past 2 years, with digital payments accounting for $86 \%$ of Asia's fintech transaction value (ADB 2021a). The increasing use of digital payments by governments to individuals (G2P) or companies (G2B) have contributed to this trend. ${ }^{\text {a }}$

Card and e-money are dominant and rising cashless payment instruments in Asia and the Pacific. Singapore's Coda Payments helps digital content providers monetize their products and operates as a platform for processing transactions for purchases online and charge them to prepaid accounts. Another payments platform, Nium, focuses on B2B transactions and supports businesses to accept and make online payments. Also, Japan's Crowd 
Credit provides debt capital to peer-to-peer lending platforms, nonbank financial institutions, microfinance institutions, and renewable energy businesses.

Charges for the use of intellectual property not identified elsewhere (SH). Services in this category include payments and receipts between residents and nonresidents for the authorized use of proprietary rights (such as patents, trademarks, copyrights, industrial processes and designs including trade secrets, and franchises), and for the use, through licensing agreements, of produced originals or prototypes and related rights.

Telecommunications, Computer, and Information Services (SI). Information and communication technology (ICT) services are the fastest growing component of the global trade in services. Services including the internet, mobile telephone, and data transmission provide the basic infrastructure for other services to be provided digitally. The provision of high-speed connectivity, $5 \mathrm{G}$, and the development of industry-specific software has accelerated this expansion. India has consolidated its position as a major exporter of information technology (IT) and computer services worldwide, only second to the European Union. India's leading IT services companies include Tata Consultancy Services (TSC), Wipro, and Tech Mahindra. Together with IT support, they provide computer services including software development, data processing, cloud computing, and data storage services, and database management.

Other Business Services (SJ). Increasing multinational activity and outsourcing has led to a considerable rise in exports of other business services, including research and development services, professional and management consulting services (such as legal, accounting, advertising, and management consulting services), architectural, engineering, scientific, and other technical services.

In professional services, India's HCL Technologies is one of the largest providers worldwide, providing services to sectors including aerospace and defense, automotive, chemicals, energy, health care, mining, and natural resources. TSC has also expanded from IT to management consulting and business process services (BPS). The Philippines is also a major hub for the services exports through business process operations (BPO) such as call centers and high-end outsourcing or knowledge process outsourcing (KPO) and business process management (BPM). Around 788 companies in the economy provide ITBPO services to domestic and international firms including Accenture, Citi, Convergys, HSBC, and JPMorgan. In legal services, PRC law firms are pursuing international strategies. FenXun Partners provides legal counseling to investors doing business in the PRC, and advises PRC firms expanding overseas.

Personal, Cultural, and Recreational Services (SK). Services included in this group include audiovisual and creative industries (audiovisual production, movies, and television programming rights to use audiovisual products), health services, education services, heritage, and recreational services. While trade in some of these sectors is still relatively small, it is growing rapidly.

Digital health services thrived during the COVID-19 pandemic to reduce patients' exposure and avoid overburdening of national health systems. Cross-border health services include shipment of laboratory samples, screening, diagnosis, and teleconsultations. In several economies, including the PRC, India, and Indonesia, digital health services grew during the pandemic. Education services were already on the rise before COVID-19, with school and university closures exacerbating this trend. While many of the virtual education initiatives during the pandemic targeted domestic demand, some economies expanded their foreign operations. The expansion of massive open online courses has opened opportunities in this regard. Malaysia, Singapore, and other economies have pursued an internationalization strategy through online learning services to become global education hubs.

a In the context of services trade, EBOPS 2010's definition of financial services include, among others, brokerage and market-seeking services, underwriting and private placement services, credit card and other related services, financial management services, and electronic funds transfers.

Sources: ADB staff based on Baur, Yew, and Xin (2021); and Osborne Clarke (2020).

Although the assumption that digitally deliverable services are indeed remotely delivered still holds in most cases, the figures suggest that for services such as computer, legal, accounting, management consulting, and research and development services, the physical presence of the supplier is still important for the service delivery.
Box 7.4 presents further examples on the role of digitalization for the shift in the delivery mode of services and implications for the region. 


\section{Box 7.4: Key Features of Digital Services Trade in Developing Asia}

Digital services have been the fastest growing area of trade in recent years. The contribution of digital services within manufacturing and non-information and communication technology (ICT) services exports has grown globally and in Asia and the Pacific, underscoring their indirect (embedded) contribution to exports. Using mode 1 data as a proxy for digital services trade, trade (exports and imports) for these economies is dominated by business, professional, and computer, and information services, followed by financial and insurance services. There is a significant shift from mode 4 toward mode 1, indicating the growing role of digital as opposed to people mobility-based services trade.

Three economy profiles among the selected economies can be identified. The first group consists of large and established exporters like India and the Philippines which are competitive in digital services exports with consistently strong performance in this area, depend on such exports, and are engaged in direct exports to varied export markets. The second group includes other middle- and upper-middle income economies. Their exports of digital services are large, growth is strong, and significance in overall services exports is high and growing. However, competitiveness essentially still lies in manufacturing and not in digital services, and performance in digital services exports seems to be linked to other parts of the economy (like manufacturing and e-commerce). The third group includes economies which have potential but are showing varied performance. They tend to have high growth in digital services exports but at a nascent stage, with limited basket and export markets. They have potential, but growth remains weak.

The economies also show characteristics distinctive of their stage as digital services exporters. They differ greatly in the scale and diversity of their export segments, from conventional call center and business process operations (BPO)-type services, to domain and skillspecific outsourcing, to higher value-added segments such as solutions based on artificial intelligence ( $\mathrm{Al})$ and predictive analytics. ${ }^{a}$ There is also a distinct difference between economies with global presence (e.g., India, the Philippines) with offshore delivery centers worldwide, and regional exporters (e.g., Fiji, Indonesia, Mongolia). Economies are different in the extent and nature of integration of digital services exports with the rest of their economies.

An examination of the digital readiness and regulatory environment for the selected economies reveals differences and help identify the scope for improvement. What emerges is an evident gap in technological infrastructure and the startup environment, followed by inadequacies in human capital and the ease of doing business. There are restrictions to trade arising from infrastructure and connectivity issues, as well as conditions on electronic transactions, data protection, and other regulatory requirements.

\section{India}

India is a leading exporter of information technology (IT) and IT-enabled services (IT-ITeS) and has seen a shift from mode 4 toward mode 1 . It is recognized as a prominent offshore outsourcing destination, accounting for $38 \%$ of global business processing outsourcing in 2018. Digital services have been a driver of these exports, accounting for an increasing share of India's global outsourcing contracts and doubling their share in total IT-ITeS exports between 2014 and 2017. According to a a survey by the Directorate General of Commercial Intelligence and Statistics of India's Ministry of Commerce and Industry and United Nations Conference on Trade and Development, an estimated 81\% of the economy's services exports were exported through ICT networks.

In terms of their composition, India's digital services exports largely comprise business-to-business (B2B) delivery of computer and telecommunications services (computer programming, data processing, consulting, database management, and so on) spanning a spectrum of skills, a wide range of professional and business support services (management, financial, engineering, research and development [R\&D], market research, design, legal process, analytics, and so on), which often require specialized and domain knowledge skills, and call centers and back-office services that are less skill and domain knowledge-intensive.

While computer and telecom services are the dominant segments, the fastest growing segment is engineering R\&D services, driven by growing global R\&D spend, digital innovations, and the emergence of startups. The shift toward startup-based exports is taking place in areas such as EdTech services, with homegrown digital enterprises acquiring overseas entities to diversify and expand their subscriber base in overseas markets. Management and back-office services in industry verticals such as banking and financial services also constitute a significant share of digital services exports. Health, retail, and utility services are the most prominent emerging verticals in the future, according to an industrial association.

Overall, there is a clear shift from call center and routine BPO services toward more applied and knowledgeintensive applications of digital services across a range of industry verticals. New technologies such as big data, Al, the Internet of Things, and machine learning and reskilling initiatives are expected to drive the further growth of digital services exports of India, with new service offerings such as predictive analytics, and digital consulting and solutions, coming to market soon. India is also witnessing growing imports of digital services such as e-mail, 
videoconferencing, VOIP, digital file sharing, and data processing, which are further enabling increased exports in both digital and non-digital sectors.

\section{Philippines}

The Philippines has a large and globally competitive IT-BPO industry. The economy currently accounts for over $12 \%$ of the global IT-BPO market and is expected to cover $15 \%$ of the global outsourcing market by 2022 (Everest Group 2020). As in India, exports are diversified spanning subsectors: contact centers, knowledge process outsourcing (KPO) and back offices, software development, animation, game development, medical transcription, and engineering design.

Contact center services are the most important segment. The industry generated $\$ 24.7$ billion in revenue in 2018 , with call centers accounting for about half of the total. Contact center services are provided to companies such as Accenture, Transcom, and Concentrix. The economy is the secondlargest offshore location for global shared services, driven by high growth areas such as data analytics, automation, and security. The Philippines is also an important player in business segments such as transcription, engineering services outsourcing, high value services for specific industry verticals, and animation and game development. According to industry experts, potential also exists in indirect digitally enabled services, Al-based KPO, construction design, and platformenabled trade. Key industry verticals and applications include financial, accounting, travel and hospitality, health care, content moderation, network services, cybersecurity, and digital customer experience management (CXM).

The Philippines shows a broad diversity in services provided and its client base. The online advertising segment, which has grown due to online video platforms, is expected to grow to $\$ 79$ million by 2030 (Hinrich Foundation 2020a). In the animation and games development segment, the Philippines provides services to international game developers and producers such as France's Ubisoft. Other clients include Walt Disney, Cartoon Network, DreamWorks, Nintendo, and Warner Brothers. The Philippines is a leading offshore-nearshore location for health services delivery in care management, medical coding, transcriptions, claims processing, telemedicine, and health analytics, given the presence of many US-registered nurses and its mix of medical knowhow and customer-servicing skills.

Several salient features emerge for developing Asia's digital services trade:

- Economies are distinctive of their stage as digital services exporters. They differ greatly in export scale and diversity, from conventional call center and BPO type services, to domain and skill-specific outsourcing, to higher value-added segments such as Al-based solutions and predictive analytics.

- Market size emerges as both an opportunity and a constraint. While large markets can support digital services solutions that are exportable or can provide the human resources needed to export a wide range of digital services, small markets can provide a laboratory to experiment with niche solutions and applications.

- Digital literacy and adoption are important. Digital transformation in key sectors such as education, banking and finance, B2B trade, and commerce has been important, and the growth of online financial transactions in particular appears an important facilitator of digital services trade.

- The role of investment (foreign direct investment and venture capital funding in unicorns) emerges as important for growth prospects in digital services exports for most economies. Thus, modalities of digital services exports may be bundled to include different modes of delivery.

- Several factors that can be leveraged to help economies export digital services include well-recognized costbased arbitrage, availability of skills, location, language, digital infrastructure, and less recognized factors such as "servicification" (increasing use, production, and supply of services by manufacturers), e-commerce, digital innovation, and domestic market-led scale economies. Several economies have potential for indirect exports of digital services in certain products (automotive, health devices).

- All the economies reflect the importance and complementarities of digital services imports alongside exports, indicating the importance of supporting twoway trade and cross-border data flows. Trade openness has a bearing on economies' ability to export.

a Some economies such as India are present in all parts of the digital services export value chain, whereas others are present in specific segments. More mature economies want to move toward higher value digital services, based on innovation and in specific domains or verticals.

b In the case of the People's Republic of China, digital services exports are linked to strengths in manufacturing, e-commerce, and the wider digital economy. For India and the Philippines, digital services exports are related to overseas demand with potential export-related spinoffs. In Indonesia, it is largely the domestic market that creates opportunities for expanding digital services exports. For Mongolia, the emergence of technology-based startups with innovative solutions is a potential source for future digital services exports.

Source: Chanda (2021). 


\section{Digital Services Trade: Drivers and Impact}

\section{Asia and the Pacific Leads the Progress}

Over the last 15 years, growth of trade in digital services has exceeded that of non-digitally deliverable services and total services. ${ }^{84}$ It has grown faster in Asia and the Pacific than in the rest of the world (Figure 7.18).

Asia's lead in digital services trade growth may not necessarily indicate increasing regional competitiveness.
Figure 7.19a reveals that the Asia and Pacific regionalong with Latin America, Africa, and the Middle Eastdoes not have revealed comparative advantage (RCA) in digital services trade. ${ }^{85}$ Europe and North America display RCA in digitally deliverable services, with RCA indexes greater than 1 for 2005 to 2019. The Middle East had the lowest RCA across all regions from 2005 to 2014 but in subsequent years overtook Asia and the Pacific, Latin America, and Africa to approach the world average. Given that the development of digital technologies and complexity of production are also correlated with an economy's development, a higher RCA for richer economies seems natural.

Figure 7.18: Average Annual Growth of Services Trade by Region, 2005-2020 (\%)

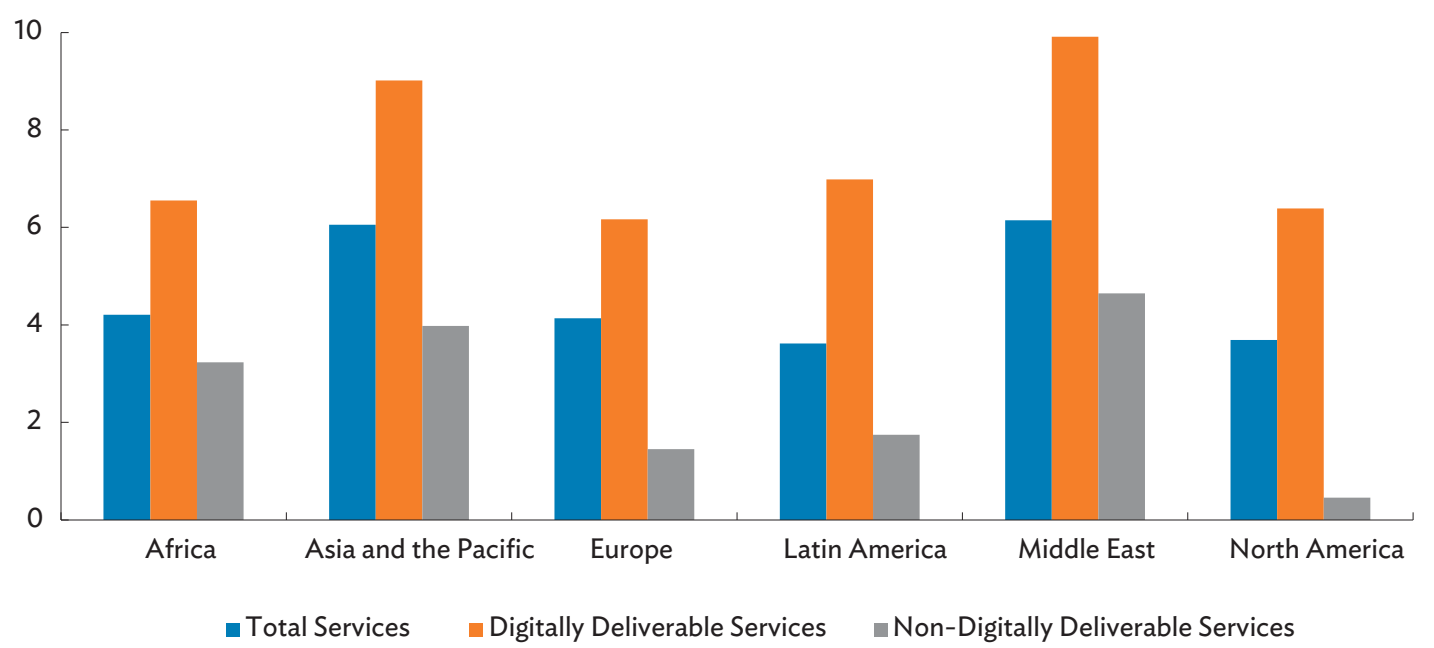

Source: ADB calculations using United Nations Conference on Trade and Development (UNCTAD). UNCTADStat: WTO-UNCTAD (BPM6) International Trade in Services Annual Dataset. https://unctadstat.unctad.org/ (accessed July 2021).

84 Insofar as sector-based analyses and descriptions are concerned, digital services trade in this part of the chapter refers to digitally deliverable services trade as defined in this chapter.

85 RCA, although having drawbacks in accurately assessing an economy's status of competitiveness, can provide a snapshot of an economy and region's trade performance relative to the world. RCA is based on the share of an economy's digitally deliverable services exports out of its total goods and services exports with respect to the share of digitally deliverable services exports out of total exports for the world. Formally, it is defined by:

$$
R C A_{i t}^{D S T}=\frac{\frac{X_{i w t}^{D S T}}{X_{i w t}}}{/ \frac{X_{w w t}^{D S T}}{X_{w w t}}}
$$

where $X_{i w t}^{D S T}$ is economy i's digitally deliverable services exports to the world at time $t$ $X_{i w t}$ is economy is total good and services exports to the world at time $t$, $X_{w w}^{D S T}$ is the world's digitally deliverable services exports at time $t$, and

$X_{w w t}$ is the world's total goods and services exports at time $t$.

An economy's share of digitally deliverable services exports is greater than the global share if its RCA index is greater than one. 
Within Asia and the Pacific, developed economies have a somewhat higher RCA than developing economies, at 0.65 compared with 0.59 (Figure 7.19b). Among the Asian subregions, South Asia emerges as the sole subregion with an RCA greater than 1 at 1.06 over the 15-year period (Figure 7.19c). As shown in Figure 7.19d, South Asian economies, such as India, Nepal, and Sri Lanka, along with Southeast Asian economy, the Philippines, lead the entire region. Of these, Nepal consistently held the highest RCA of digitally deliverable services exports. The economy specializes in services exports, which contributed $60 \%$ of the nation's GDP in 2019 (ADB 2021c), and it is very competitive in telecommunications exports (Sáez et al. 2015).

\section{Factors Affecting Competitiveness}

One metric to assess the competitiveness of digital services is their export performance, given that an economy's competitiveness is reflected into high productivity could translate into larger outputs, and further into high export performances. In explaining trade flows based on comparative advantage, literature have identified factor endowments such as human and physical capital, and institutions and policies (Chor 2011). Among the main factors affecting the competitiveness, traditional factors of production, digital infrastructure and policy environment are considered, i.e., (i) human capital, (ii) digital connectivity, (iii) ICT investment, and (iv) the policy and regulatory environment.

Figure 7.19: Revealed Comparative Advantage for Digitally Deliverable Services

(a) Region

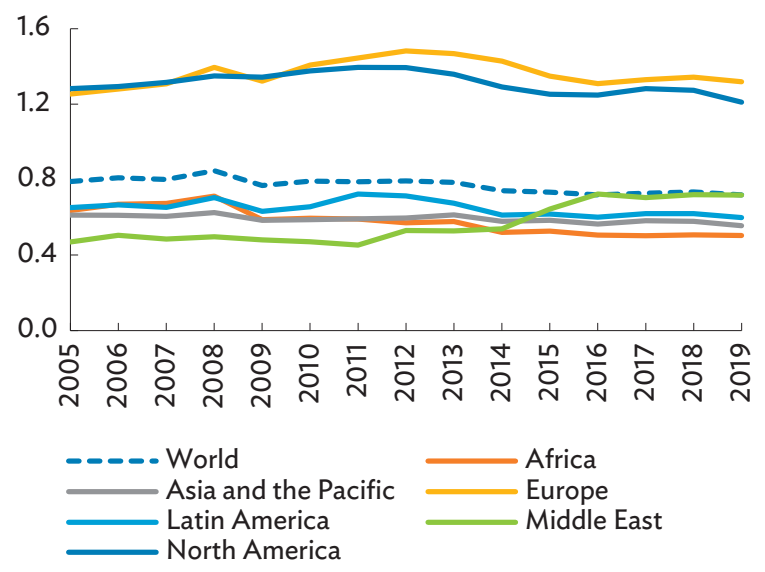

(c) Asian Subregions

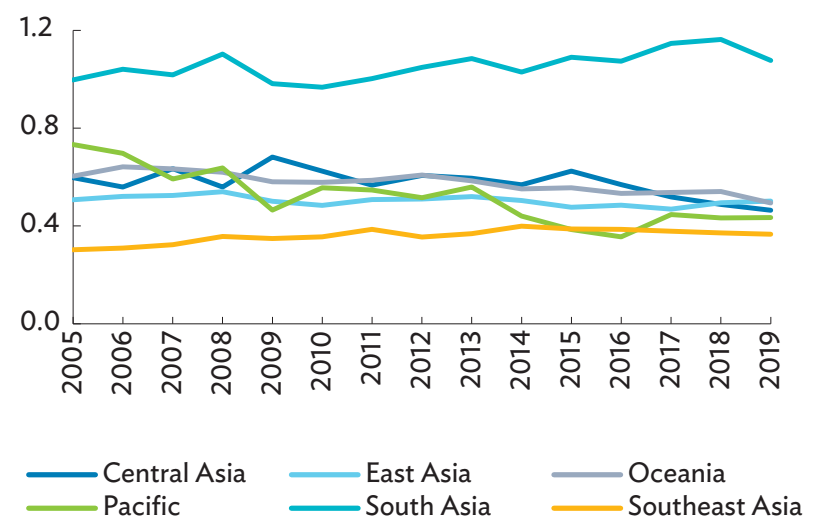

(b) Developing Asia

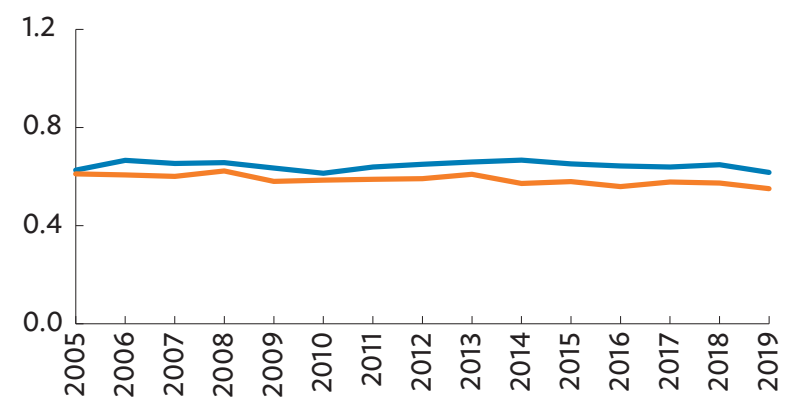

Developed Asia D Developing Asia

(d) Selected Asian Economies

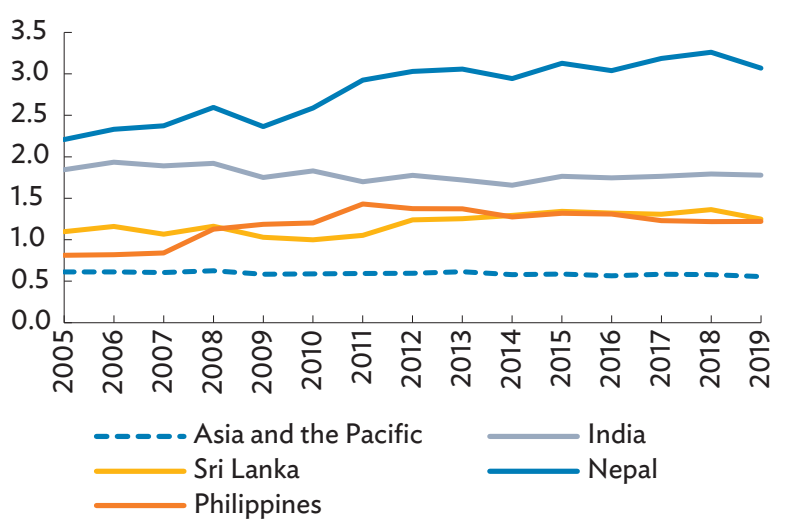

Sources: ADB calculations using WTO-OECD Balanced Trade in Services Dataset (BaTIS) -BPM6. https://www.wto.org/english/res_e/statis_e/trade_datasets_e.htm (accessed May 2021); and World Bank. World Development Indicators. https://databank.worldbank.org/source/world-development-indicators (both accessed July 2021). 
Human Capital. Digital services production requires human capital equipped with technical skills including for human-machine interaction (Grigorescu et al. 2021). Enhancing education for development of new and relevant competencies contributes to improved productivity in digital services. Educational attainment still fundamentally underpins human capital. A considerable body of literature links human capital and digital adoption. Caselli and Coleman (2001) include educational attainment as a determinant of personal computer adoption. Chinn and Fairlie (2007) find that differences in years of education explain more than a tenth of the gap in computer literacy among economies.

The availability of human capital in scale, costs, or specific expertise has been identified as important for digital services competitiveness in many economies in Asia and the Pacific. Digital services exports in India and the Philippines have been largely driven by their large, young, English-speaking population, and competitive wages. Fiji's young, literate, English-speaking labor force and Mongolia's strength in science, technology, engineering, and mathematics make them attractive destinations for developing digital applications and solutions and enabling regional exports.
International Labour Organization surveys of crowd workers in 2015 and 2017 also find that more educated people are more likely to participate in digital contract work (Berg et al. 2018). Expected years of schooling has been steadily increasing overtime in all regions of the world, posting an annual average growth rate of $0.7 \%$. For Asia and the Pacific, the annual average growth rate was $0.9 \%$, with expected years of schooling increasing from 11.8 in 2005 to 13.3 in 2019. There are large differences within the region; Australia and New Zealand are obvious outliers as global leaders with 20.4 expected years of schooling. East Asia follows with 15.4 years in 2019. South Asia records the lowest schooling years but the biggest improvement in 15 years with an annual average growth rate of $1.6 \%$, well above the $0.9 \%$ growth rate for the region as a whole. This is attributable to Pakistan, where schooling years increased from 5.7 in 2005 to 8.3 in 2019.

Figure 7.20 plots binned scatterplots for the expected years of schooling for the reporter and partner. For both entities, longer schooling years are associated with an increase of digital services exports.

It has become more important than ever to integrate digital literacy programs in the educational curriculum. Beginning digital literacy programs in grades $\mathrm{K}-12$ is considered essential, so that children can learn to use

Figure 7.20: Binned Scatterplots for Expected Years of Schooling, 2019

\section{(a) Reporter}

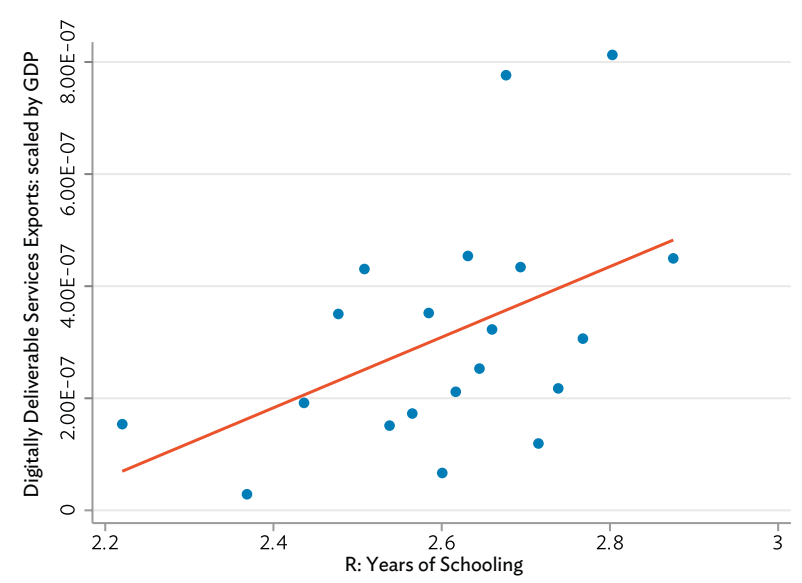

(b) Partner

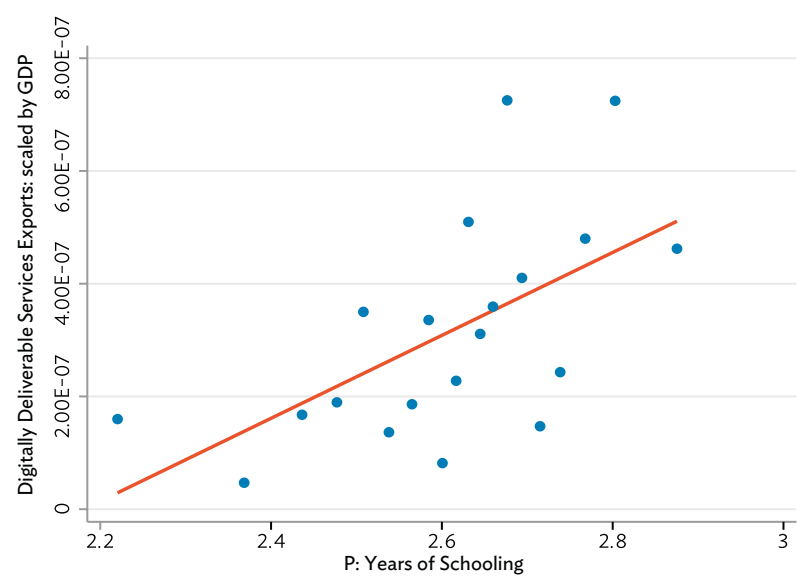

$\mathrm{GDP}=$ gross domestic product.

Sources: ADB calculations using WTO-OECD Balanced Trade in Services Dataset (BaTIS) -BPM6. https://www.wto.org/english/res_e/statis_e/trade_datasets_e.htm; and United Nations Development Programme. Human Development Index. http://hdr.undp.org/en/content/human-development-index-hdi (both accessed July 2021). 
technology responsibly and master the tools needed to thrive in an ever-changing digital world (Loveless n.d.). However, a study conducted by learning.com reveals that $75 \%$ of fifth and eighth grade students lack proficiency in technological skills (Robacker 2017).

Investing in digital skill enhancement is now a key policy tool for economic growth and competitiveness (Froy, Giguère, and Meghnagi 2012; Spante et al. 2018). A recent Asia-Pacific Economic Cooperation (APEC) report shows that in the past 3 years, Asia and the Pacific saw substantial growth in hiring of workers with digital skills. Highlighting the gap between workforce supply and demand, the report emphasizes the urgent need for economies in the region to invest in digital upskilling and reskilling of their workforces (APEC 2021).

Digital Connectivity. Enabling firms to bring services to a large number of connected customers across the globe is a prerequisite for increasing the scale, scope, and speed of digital services trade. The availability, quality, and cost of telecommunications infrastructure, internet and mobile penetration and accessibility, along with adoption of digital and mobile technologies play major roles in determining patterns of digital services trade. In some developing economies, lack of availability, high cost, and uneven quality of broadband and internet services remain significant challenges.

Figure 7.21: Broadband Subscriptions (per 100 inhabitants)

(a) Fixed Broadband
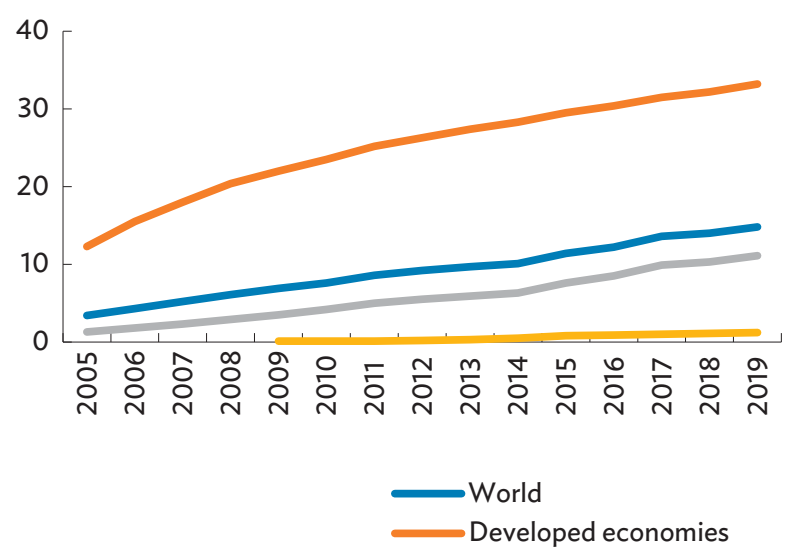

Internet penetration. The literature links broadband and internet adoption to increased productivity, as the internet provides a tool that can support businesses to flourish and hire employees (OECD 2012, 2016). Haltenhof (2019) shows internet connectivity is positively correlated with services exports; improving bilateral internet connections promotes bilateral service trade in data-intensive sectors with the greatest effects seen in financial services, computer, and information services, and other business services. Broadband subscriptions, especially for mobile broadband have been increasing steadily in recent years. The International Telecommunication Union shows fixed broadband subscriptions increased from 5.2\% in 2007 to $14 . \%$ in 2019 , while mobile broadband subscriptions grew from $4 \%$ to $74.2 \%$.

Despite this growth in subscriptions, digital divide is evident between economies (Figure 7.21). Higher levels of internet penetration are positively associated with digital services trade (Figure 7.22).

Internet speed. A reliable and higher internet speed increases firm productivity, as well as labor productivity (Dalgic and Fazlioglu 2020; Grimes, Ren, and Stevens 2012). High-speed connection is essential for business using technologies such as videoconferencing, online payments, and other e-commerce functions (DataKom 2016).

\section{(b) Mobile Broadband}

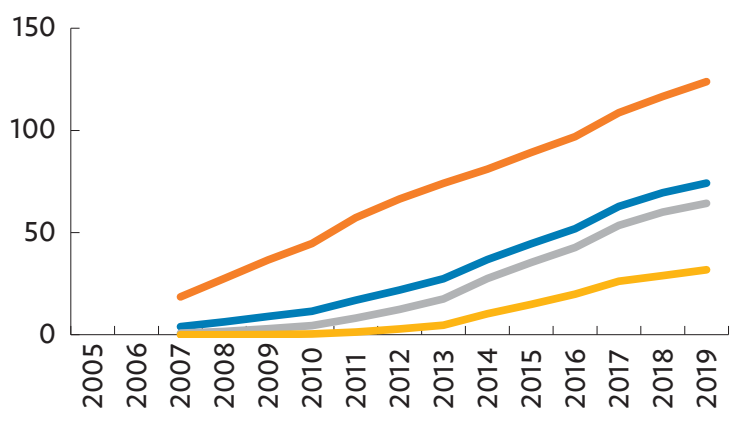


Figure 7.22: Binned Scatterplots for Mobile Broadband Subscriptions, 2019

(a) Reporter

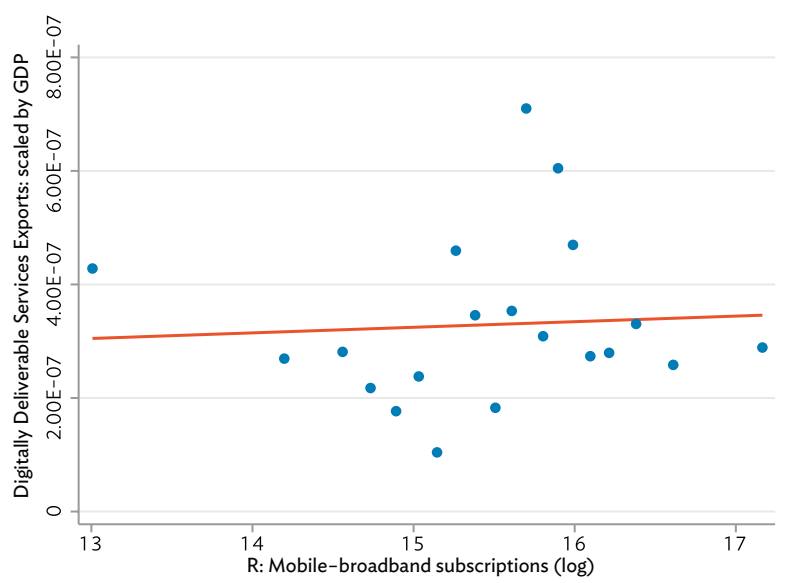

(b) Partner

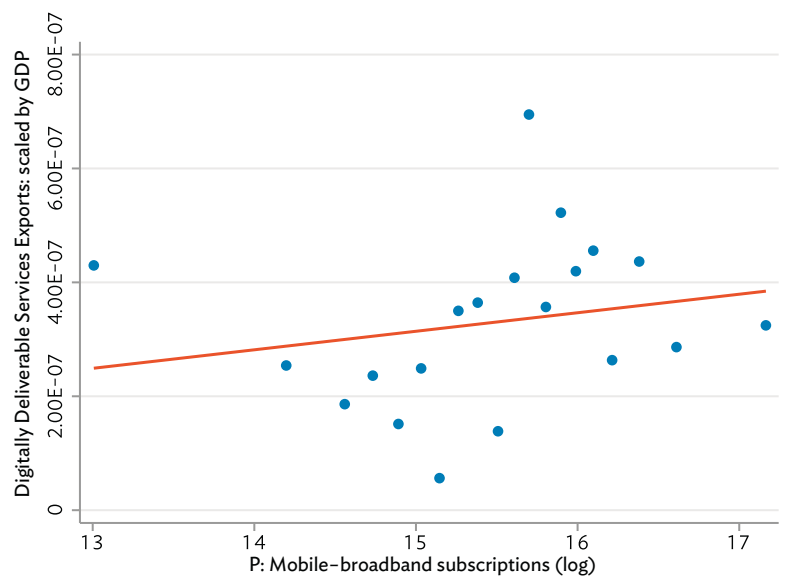

GDP = gross domestic product.

Sources: ADB calculations using WTO-OECD Balanced Trade in Services Dataset (BaTIS)—BPM6. https://www.wto.org/english/res_e/statis_e/trade_datasets_e.htm; and International Telecommunication Unit. ICT Statistics. https://www.itu.int/en/ITU-D/Statistics/Pages/stat/default.aspx (both accessed July 2021).

This is even more so for firms that depend on inputs of data flows for which a larger bandwidth is required to support productivity.

Actual internet speed and usage are also important. Some may have access to the internet but not at a usable speed. Figure 7.23 illustrates the positive relationship between digital services exports and the digital services trade and international internet bandwidth per user. It is also of note that international bandwidth capacity is more strongly related with digital services exports than with the mobile broadband subscription level. This suggests that internet speed and quality should be more important as a factor in the expansion of digital services trade than simple internet access or availability.

Investments. Firms that invest in ICT and adopt specialized digital solutions are generally in a better position to become more productive, competitive, and profitable (UNCTAD 2011). ${ }^{86} \mathrm{New}$ digital solutions are opening doors for companies of all sizes to engage in domestic and international trade (UNCTAD 2019).
Investments in telecommunications, ICT infrastructure, and digital payments enable digitally deliverable businesses to thrive. Figure 7.24 shows that investments in telecommunications infrastructure are positively associated with digital services trade.

Policy and Regulatory Environment. The ecosystem for digital services trade requires a conducive overall business and regulatory environment. ${ }^{87}$ Stakeholders typically highlight the importance of transparency in regulations, the ease of data transfers, an open trade and investment regime, and supporting incentives for innovation. Many economies are also making efforts to build trust in supporting data flows. Creating trust should come with cross-border regulatory cooperation, developing trade agreements or other arrangements that bolster privacy and consumer protection.

In classic services trade literature, Hindley and Smith (1984) propose that services trade is constrained by government control over communications, media, and broadcasting. In the digital sphere, Topornin, Pyatkina,

86 Digital solutions are defined as "other internet-based players and digital enablers, such as electronic and digital payment operators, cloud players and other service providers" (UNCTAD 2017b).

87 An important factor relevant to an enabling policy environment is entrepreneurial innovation, consisting of incubation support, funding, tax incentives, encouragement of startup clusters, promotion of higher value-added digital services, including specific segments such as e-commerce and fintech. Regulatory sandboxes are important in enabling experimentation by startups. Collaborative partnerships between industry and the academic research community are important in establishing innovation labs and mentorships. 
and Bokov (2021) characterize barriers to international data transfers, restrictions on digital payment systems, and many unique and opaque standards of filtering and blocking digital traffic as potential tools of protectionism.

Using the CATO Institute's measure of "state control over internet access," which is a component from the
Institutional Profiles Database question: "Freedom of information: Freedom of access, navigation, and publication on the internet $(0=$ no freedom of internet access; 10 = complete freedom of navigation and publication.)." Figure 7.25 shows how freedom of information positively influences digital services trade outcomes for both reporter and partner.

Figure 7.23: Binned Scatterplots for International Bandwidth per Internet User, 2019
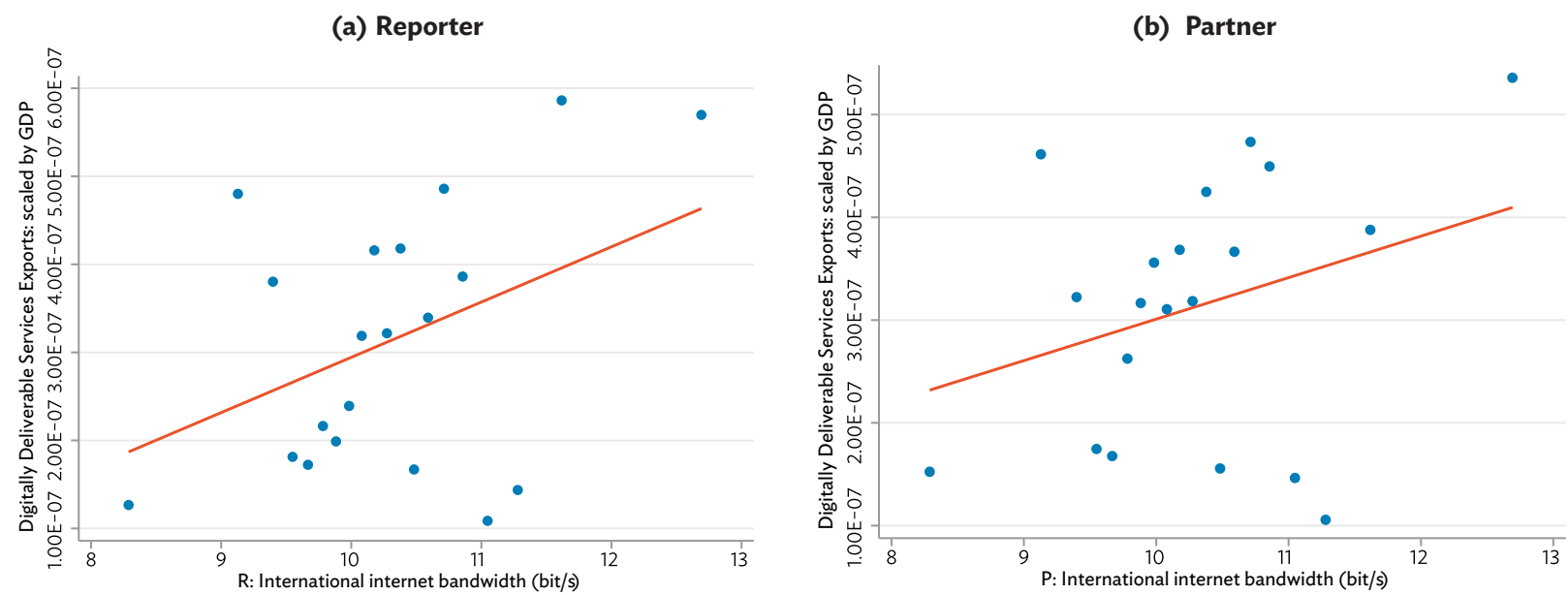

$\mathrm{bit} / \mathrm{s}=$ bits per second, GDP = gross domestic product.

Sources: ADB calculations using WTO-OECD Balanced Trade in Services Dataset (BaTIS) -BPM6. https://www.wto.org/english/res_e/statis_e/trade_datasets_e.htm; and International Telecommunication Unit. ICT Statistics. https://www.itu.int/en/ITU-D/Statistics/Pages/stat/default.aspx (both accessed July 2021).

Figure 7.24: Binned Scatterplots for Investments in Telecommunications, 2019

(a) Reporter

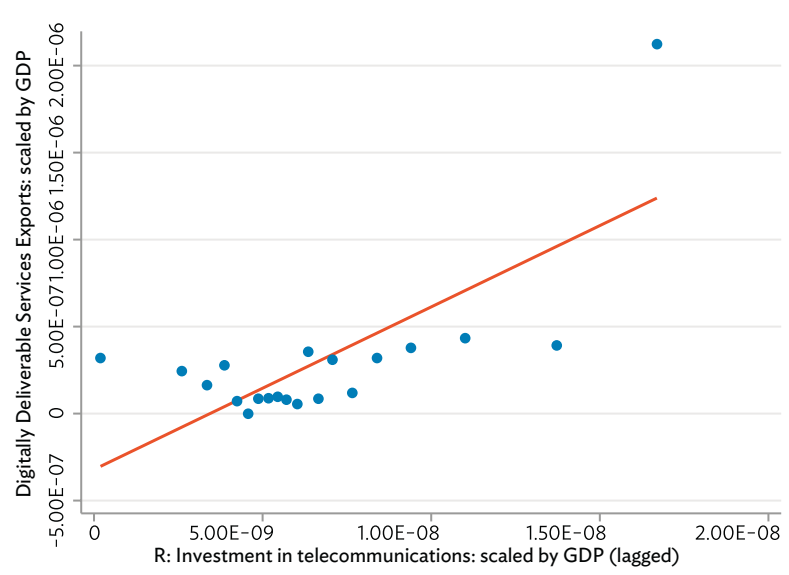

(b) Partner

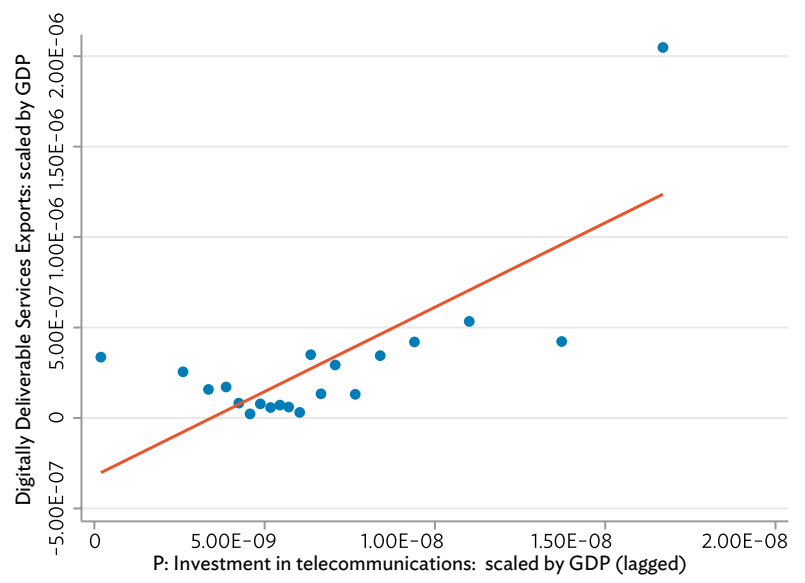

GDP = gross domestic product.

Sources: ADB calculations using WTO-OECD Balanced Trade in Services Dataset (BaTIS)—BPM6. https://www.wto.org/english/res_e/statis_e/trade_datasets_e.htm; and International Telecommunication Unit. ICT Statistics. https://www.itu.int/en/ITU-D/Statistics/Pages/stat/default.aspx (both accessed July 2021). 
Figure 7.25: Binned Scatterplots for State Control Over Internet Access, 2019

(a) Reporter

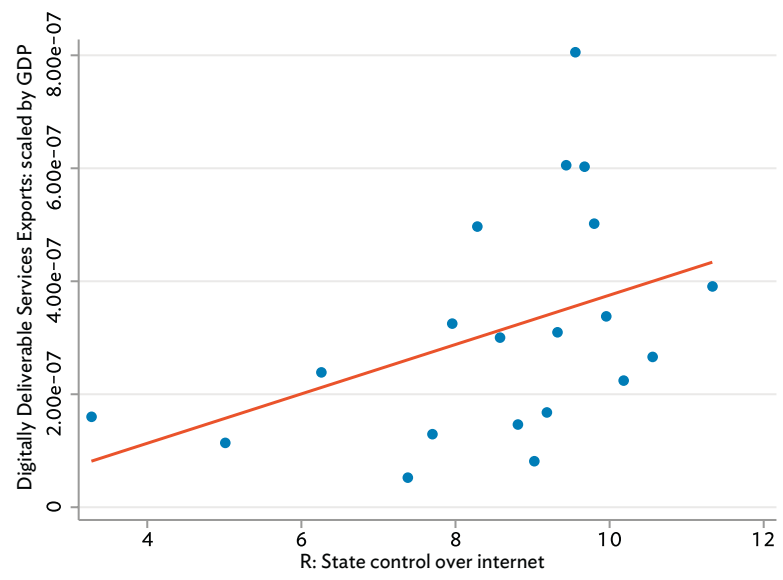

(b) Partner

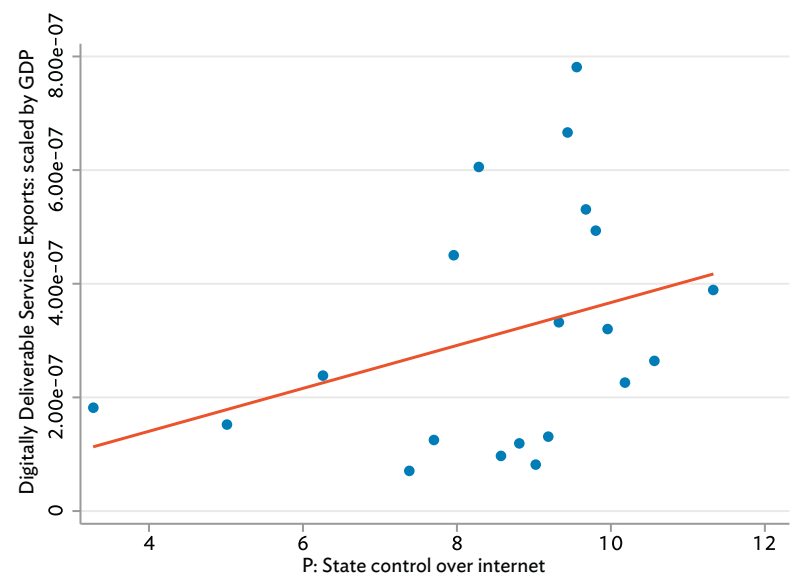

GDP = gross domestic product.

Sources: ADB calculations based on WTO-OECD Balanced Trade in Services Dataset (BaTIS)_BPM6. https://www.wto.org/english/res_e/statis_e/trade_datasets_e. htm; and CATO Institute. Human Freedom Index. https://www.cato.org/human-freedom-index/2020 (both accessed July 2021).

\section{Economic Impact of Trade Liberalization and Deregulation}

\section{Measuring the Impact through Global Value Chains}

Conceptually, digital technology seems likely to play a major role in linking the large numbers of firms that participate in global value chains (GVCs). Lead firms need to rely heavily on digital means to monitor production by suppliers and movement of goods within networked production structures. Similarly, digital payments make it possible for firms at different points in the chain to negotiate contracts and secure payments across borders, potentially at great distance.

An important policy issue is therefore the degree of linkages between the performance of goods market GVCs in sectors like electronics or apparel, as well as GVCs in services, and the policy environment governing digital services trade. If restrictive policies increase price and decrease availability for services that are provided digitally, then those services will be correspondingly less used as inputs into the production of manufactured goods and other services-potentially at a cost in trade performance and production efficiency.
This raises the question of the extent to which services provided digitally can be used as inputs for the production of exports in other sectors. These two perspectivesbackward and forward - can be employed in different contexts to better understand the role of input-output linkages, including those relating to services delivered digitally, in driving GVC performance and expansion.

To tackle these questions, digital services categories are identified based on the conceptual framework presented earlier for digitally deliverable services and ADB's MultiRegional Input-Output Tables (MRIOT) to produce consistent measures of digital services use within GVCs. The interlinkages are tracked across economies and through time, focusing on Asia and the Pacific. Second, analysis is undertaken of recently collected data on policy measures affecting digital services trade. Finally, a quantitative general equilibrium model of world trade is built, based on ADB's MRIOT for 2019. This is used to conduct counterfactual simulations based on plausible goals for policy liberalization and deregulation across economies affecting digitally delivered sectors. The model shows not only how policy changes affect trade flows and aggregate real income, but also how they influence the extent of GVC linkages. In addition, the ways in which this liberalization can promote structural change are examined through the distribution of impact by economy across primary, secondary, and tertiary sectors. 


\section{Identifying Digitally Delivered Services Trade}

The approach is to use information from surveys and external sources to construct first estimates of trade by mode. The WTO Trade in Services data by Mode of Supply (TISMOS) data currently provide the best available information.

TISMOS data make it possible to rank services sectors according to the percentage of exports delivered through GATS mode 1, which except in transportation services essentially captures service provision by digital means. A high proportion of mode 1 relative to other modes suggests a significant proportion of a sector's trade is delivered digitally, and so the sector as a whole can be regarded as "digitally delivered."

Mapping these aggregates to sectors in national accounts is not straightforward, as the classifications involved are slightly different. The following ADB's MRIOT sectors can nevertheless be considered as digitally delivered, ${ }^{88}$ on a broad reading:

- Post and telecommunications

- Financial intermediation

- Real estate activities

- Renting of machinery and equipment, and other business activities

- Other community, social, and personal services

While the analysis is necessarily approximate, given the extent of data available, this list gives us a selection of sectors where digitally delivered trade is expected to account for an important share of total trade, and where, therefore, policy reforms could be expected to have the most significant impact on digital services trade flows and input sourcing.

\section{Measuring GVC Linkages}

Wang, Wei, and Zhu (2013) provide a consistent methodology for decomposing gross value trade data into value-added components by combining them with information from input-output tables. Foreign value added as a proportion of gross exports gives a backward measure of GVC integration: the proportion of exports accounted for by imports of intermediate goods and services. To provide a measure of forward linkages, domestic value added (DVA), which Wang, Wei, and Zhu (2013) term DVA_INTRex, is used: it equates to production by domestic industries that is exported and used by other economies in the production of their own exports. Figure 7.26 shows results by sector, aggregating over all Asian economies in the database. For four of the five sectors, GVC forward linkages account for reasonably similar proportions of gross exports, around $15 \%$ to $20 \%$. The exception is other community, social, and personal services, which is considerably lower, at about $10 \%$.

\section{Figure 7.26: GVC Forward Linkages as a Percentage of Gross Exports for Digitally Delivered Services Sectors-Asian Economies (\%)}

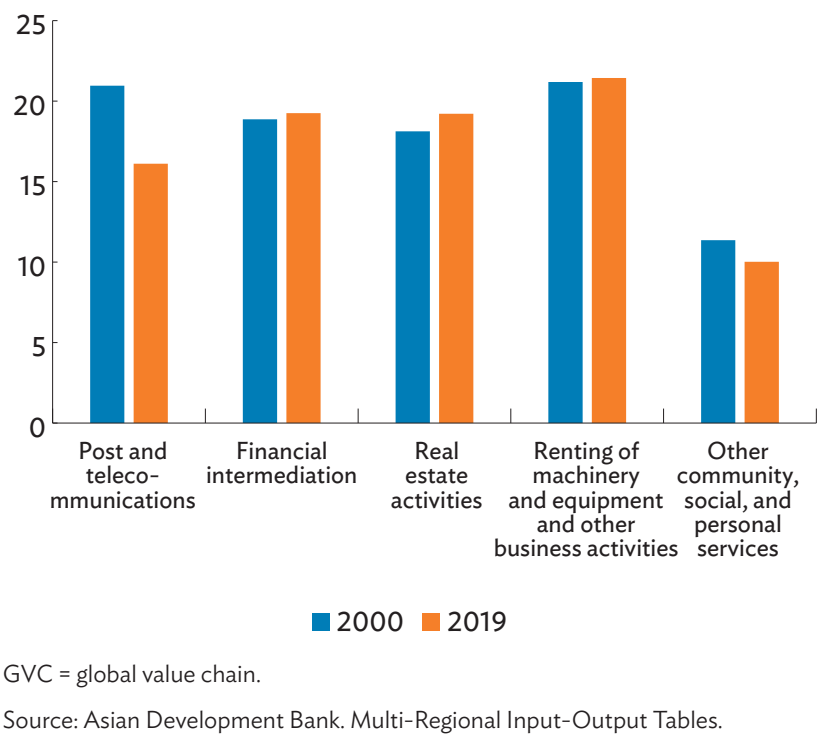

88 ADB's MRIOT sectors do not correspond exactly to TISMOS aggregates. Concordance is based on visual inspection, and matching to nearest categories, as well as information provided by the OECD Secretariat. 
Figure 7.27 shows that there is much greater growth in backward linkages than forward linkages over the sample period in post and telecommunications and for financial services. These sectors developed substantial overseas sourcing arrangements over this period, while the other sectors saw remote imports of inputs diminish or remain fairly steady. There is a clear contrast with forward linkages, where changes across all sectors were relatively small.

\section{Figure 7.27: GVC Backward Linkages as a Percentage of Gross Exports for Digitally Delivered Services Sectors-Asian Economies (\%)}

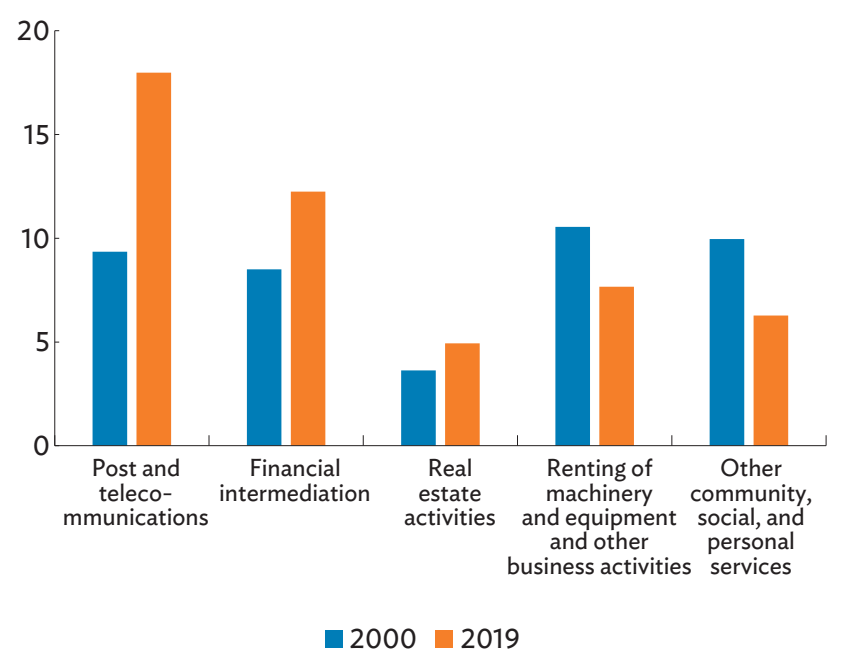

GVC = global value chain.

Source: Asian Development Bank. Multi-Regional Input-Output Tables.

Overall, the picture that emerges is that digitally delivered services sectors are an important part of the GVC landscape in Asia and the Pacific. This point is important from a policy perspective because development policy in Asia and the Pacific often focuses on manufacturing as the engine of growth, even as evidence is compelling that the economies that have seen rapid growth in recent decades have developed not only their manufacturing base but have also their services production and trade (Shepherd 2019).

\section{Quantifying Policies Affecting Digitally Delivered Trade}

Whereas tariffs in goods markets are stated in ad valorem terms, policy restrictions in services sectors- including digital services - are typically regulatory measures that affect either the ability to contest markets access or the cost of doing business once in a market and need to be quantified in a fundamentally different way from tariffs. The first step is to develop a regulatory questionnaire, typically based on consultations with experts and the private sector to identify policy measures that affect firms engaging in trade, in this case digitally. The next stage is to code restrictions quantitatively by assessing national regulations relevant to each question along a sliding scale from completely open (coded as the minimum value) to completely closed (coded as the maximum value). The third stage is to weight and aggregate the individual data points for each question in the questionnaire to produce a single summary index of economy restrictiveness. A fourth stage is to model the relationship between the restrictiveness index with some measure of economic performance, such as trade values or trade costs, generally with the objective of producing ad valorem equivalents of the bundle of policies captured by the index. The European Centre for International Political Economy (Ferracane, Makiyama, and van der Marel 2018) and the Organisation for Economic Co-operation and Development (OECD) apply variations on this general approach to produce trade restrictiveness indexes for digitally delivered trade.

The OECD Digital Services Trade Restrictiveness Index (DSTRI) is publicly available and covers all OECD members and a selection of nonmembers. For 17 Asian economies with available DSTRI data, the total number of restrictions increased from 138 in 2015 to 153 in 2020 , with barriers related to cross-border data flows accounting, on average, for around $20 \%$ over the period. The patterns of restrictiveness among Asian economies vary substantially (Figure 7.28). Based on 2020 DSTRI results, Kazakhstan is the most restrictive economy in the data set. Others are typically substantially less restrictive, with the lowest scores recorded in Australia, Japan, and Vanuatu. Compared with 2015, 5 out of 17 economies saw some improvement in reducing digital services trade restrictiveness: Cambodia, Indonesia, the Lao People's Democratic Republic, Nepal, and Vanuatu. Several economies moved in the more restrictive direction. 
Figure 7.28: Digital Services Trade Restrictiveness Index-Selected Asia and Pacific Economies

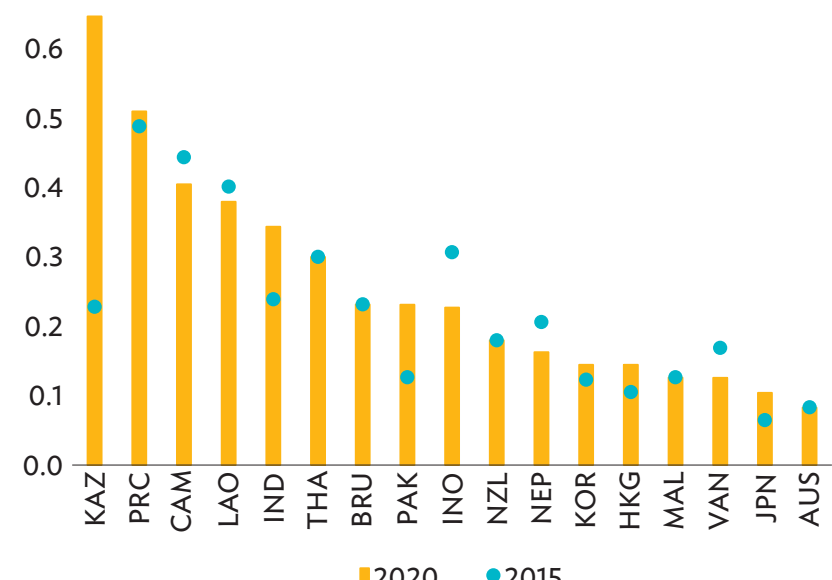

AUS = Australia; $B R U=$ Brunei Darussalam; $C A M=$ Cambodia; $\mathrm{HKG}=$ Hong Kong, China; IND = India; INO = Indonesia; JPN = Japan; KAZ = Kazakhstan; KOR = Republic of Korea; LAO = Lao People's Democratic Republic; $M A L=$ Malaysia; NEP = Nepal; NZL = New Zealand; PAK = Pakistan; PRC = People's Republic of China; THA = Thailand; VAN = Vanuatu

Notes: Given that the Digital Services Trade Restrictiveness Index is an index number, the interpretation is ordinal only, not cardinal. That is, a score of 0.2 is more restrictive than a score of 0.1 (on a range of zero to one), but it is not "twice as restrictive."

Source: Organisation for Economic Co-operation and Development (OECD). Digital Services Trade Restrictiveness Index. https://stats.oecd.org/Index. aspx?DataSetCode=STRI_DIGITAL (accessed October 2021).
From a trade and economic integration perspective, it is not only the restrictiveness of an economy's policies that matter for trade costs, but also how similar or different its policies are from those of trading partners. Data are perhaps an area, like services trade more broadly, where regulatory heterogeneity plays a significant part in determining the pattern of flows (Nordas 2016). For example, besides overall data flow restrictiveness if one economy in a trading pair has strong rules relating to data privacy and the other does not, it may be difficult or impossible to move data across the border in that direction as part of a broader economic transaction (Box 7.5).

\section{A Quantitative Trade Model with Global Value Chain Linkages}

Trade policy analysis has traditionally used computable general equilibrium (CGE) models to examine the economy-wide impacts of reform. This section takes a different approach, drawing on the literature on "new quantitative trade models” (Ottaviano 2015).

\section{Box 7.5: Impact of Data-Related Restrictions on Digital Services Trade}

Data-related policies can be categorized into (i) data localization policies, (ii) local storage requirements, and (iii) conditional flow regimes. As these policies inhibit the free flow of data across borders, they affect trade in digital services, which are reliant on transmission of data across economies. Previous research has established both theoretically and empirically the triangular relationship between cross-border data flows, international trade in digital services, and data-related policies. Manyika et al. (2016) claim that the contribution of cross-border data flows to GDP has overtaken that of flows in goods during the current wave of globalization. Goldfarb and Trefler (2018) discuss the potential theoretical implications of data-related policies, such as data localization, on international trade and how that connects to existing trade models. This analysis follows up the empirical work by Ferracane and van der Marel (2021), which studies the proportionate trade impact of data-related policies across digital services. These authors construct a composite indicator in which an index of restrictiveness in data regulation is interacted with a measure of the digital or data intensity of a sector. Asia's share of the total global number of data-related restrictions is presented in the box figure. For data localization, Asian economies account for a share of around $70 \%$ of measures.

\section{Number of Data Localization Policies, Local Storage Requirements, and Conditional Flow Regimes Imposed by Asian and Other Economies, 2019 (number of measures)}

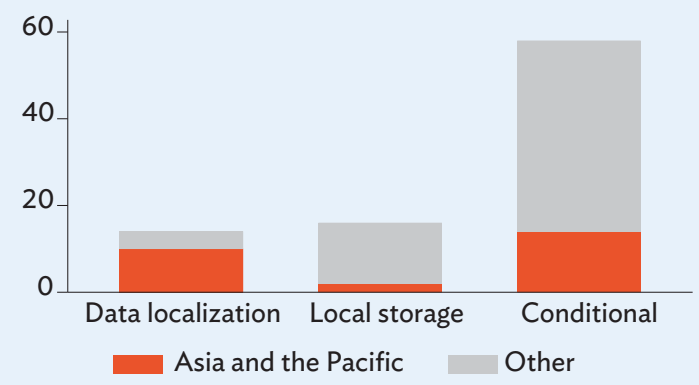

Note: Categorization of economies is performed on the basis of values assigned with an initial 0.5 , meaning that economies also apply a partial restriction in regard to the three types of data-related restrictions.

Source: van der Marel (2021b). 
The empirical strategy adopts a difference-in-differences (DID) approach in which the outcome variable is regressed against a set of dummies that separates two groups for two time periods: one group is the treatment group, the other is the control group, both before and after the time period. As is standard, the treatment group is exposed to a "treatment" in the second period, whereas the control group is not subjected to the treatment throughout the entire period of analysis. In a later stage, the treatment is applied to a third group of Asian economies.

A dummy variable is assigned to software-intense sectors starting from the year economies impose one of the three data restrictions as presented in box table 1. The control group, the non-software-intense sectors, are not exposed to this treatment and therefore given a zero during the entire period of our regressions. The DID approach is therefore composed of two levels of "differences," namely one that distinguishes between software-intense (or digital services) and non-software intense services sectors; and another one that differentiates between pre- and post-year of implementation (YIMP) in economies.

The following baseline specification is regressed:

$$
\begin{gathered}
\ln (\mathrm{SM})_{c s t}=\Phi+\theta \mathrm{D}_{c s t} \cdot \text { Software intense } \text { S }_{s} \geq \\
\text { YIMPL }_{c t-1}+\delta_{s t}+\gamma_{c t}+\varepsilon_{c s t}
\end{gathered}
$$

In equation (1), the response variable is the logarithm (In) of cross-border imports of services (SM) in economy c, for services sector $s$ in time $t$. Data is taken from both WTOUNCTAD-ITC annual trade in services data set and the WTO-OECD BaTiS data sets for robustness checks. The term $D_{\text {cst }}$ denotes the dummy variable that is of interest. It captures any difference in services imports between software-intense (box table 1) and non-software-intense services before and after the year of implementation of an economy's data restriction denoted with $\mathrm{YIMP}_{c t}$.

Fixed effects are applied, which capture all other aggregate factors that otherwise cause shifts in services trade, even in the presence of other regulatory changes. They are specified at sector-year, $\delta_{s t}$, and economy-year, $\gamma_{c t}$. The former group of fixed effects controls for sector-specific conditions, such as other sector intensities besides software. Examples are skill- and capital-intensities that affect production structures. They also cover services policy changes over the years specific to sectors. The latter set of fixed effects controls for economy-wide trends that are specific to an economy, such as macroeconomic conditions. Sector fixed effects are applied at the 2-digit aggregate given that the trade data are reported at this level. Finally, $\varepsilon_{c s t}$ is the residual term. Regressions are estimated with robust standard errors clustered by economy sector-year and performed over 2006-2019, for which policy data are available after taking a 1-year lag.
The baseline specification is extended to consider additional effects for the Asian region. The extended baseline is applied to interact the variable of interest $D_{c s t}$ with another dummy called $\mathrm{ASIA}_{c}$ which assigns unity for each of the Asia and Pacific economies. It means that these economies are interacted with the difference-in-difference dummy that signifies the group of digital sectors, starting from the policies' year of implementation. The baseline specification is augmented with a triple interaction term as follows:

$$
\begin{array}{r}
\ln (\mathrm{SM})_{c s t}=\Phi+\theta \mathrm{D}_{c s t} \cdot \text { Software intense }_{s} \geq \\
\mathrm{YIMP}_{c t-1} * \mathrm{ASIA}_{c}+\delta_{s t}+\gamma_{c t}+\varepsilon_{c s t}
\end{array}
$$

Given the interaction variable with Asian economies, a significant result on this triple interaction term confirms whether there is any differential effect for the Asian region compared with the baseline interaction term for all economy.

The coefficient results from the baseline regression presented in column (1) of box table 2 confirms that overall, any of the data-related restrictions economies have implemented are associated with lower levels of digital services imports. It implies an average negative trade effect in digital services of around $14 \%$ more for economies implementing any of these restrictions compared with non-implementing economies. In the extended regression in column (2), the differential impact for Asia and the Pacific becomes highly significant with a negative coefficient sign, whereas the control variable for the average effect remains only weakly significant, though still negative. Note that for columns (1) and (2) in box table 2 we put a score of 0 for those economies that have implemented data restrictions initially assigned 0.5 , whereas in columns (3) and (4) we give these partial restrictions a full score of 1 to check results. The size of the coefficient results could be interpreted as Asian economies exhibiting a higher-than-average effect compared with the rest of the world, given its higher value compared with column (1) and (2). Results for Asia and the Pacific retain their negative significance when fully incorporating the partial scores for the data restrictions, as reported in the last column. The average effect for the rest of the world loses its significance entirely in both columns (3) and (4). The regression results were tested with the addition of sector SK, and the results largely remain the same.

Box table 3 reports the separate results for the three specific data restrictions. They are labeled in both tables as data localization DL, local storage requirement LS, and conditional flow regimes $C F$. The average effect for data localization policies disappears but becomes highly significant for the Asian region, both when entered alone and when entered together with all the other variables in column (4). 


\section{1: Sectors Classified as Software Intensive (Over Labor)}

\begin{tabular}{llll} 
Code & \multicolumn{1}{c}{ Sector Description } & Digital & Digitally Enabled \\
SI1 & Telecommunications & \\
SI2 & Computer & & $\bullet$ \\
SI3 & Information & & $\bullet$ \\
SF & Insurance & $\bullet$ \\
SG & Financial & \\
SH & Intellectual property & $\bullet$ \\
SJ1 & Research and development & \\
SJ2 & Professional and management & \\
SJ3 & Technology, trade-related, and other & \\
SB & Maintenance and repair & \\
SD & Travel & & \\
SE & Construction & \\
SC1 & Sea transport & & \\
SC2 & Air transport & & \\
SC3 & Other transport & \\
SC4 & Postal and courier & & \\
SK1 & Audiovisual and related & & \\
SK2 & Personal, cultural, and recreation & \\
\hline
\end{tabular}

Source: van der Marel (2021b).

\section{2: Baseline and Extended Difference-in-Difference Regression for Any Data-Related Restrictions}

\begin{tabular}{|c|c|c|c|c|}
\hline & (1) & (2) & (3) & (4) \\
\hline & \multicolumn{2}{|c|}{$\begin{array}{l}\ln (S M) \\
0.5>0\end{array}$} & \multicolumn{2}{|c|}{$\begin{array}{l}\ln (S M) \\
0.5>1\end{array}$} \\
\hline$C B * D S$ & $\begin{array}{r}-0.138^{* * *} \\
(0.003)\end{array}$ & $\begin{array}{l}-0.090^{*} \\
(0.050)\end{array}$ & $\begin{array}{l}-0.097 \\
(0.115)\end{array}$ & $\begin{array}{l}-0.044 \\
(0.478)\end{array}$ \\
\hline$C B * D S * A s i a$ and the Pacific & & $\begin{array}{r}-0.614^{* * *} \\
(0.000)\end{array}$ & & $\begin{array}{r}-0.325^{* * *} \\
(0.000)\end{array}$ \\
\hline FE economy-year & Yes & Yes & Yes & Yes \\
\hline FE sector-year & Yes & Yes & Yes & Yes \\
\hline Number of observations & 11,454 & 11,454 & 11,454 & 11,454 \\
\hline Adjusted R-squared & 0.774 & 0.775 & 0.774 & 0.775 \\
\hline p-values F-stat & & 0.000 & & 0.000 \\
\hline
\end{tabular}

$\mathrm{CB}=$ cross-border data restrictions, $\mathrm{DS}=$ digital services sector, $\mathrm{FE}=$ fixed effects, $\mathrm{SM}=$ cross-border imports of services.

Notes: ${ }^{*} p<0.10 ;{ }^{* *} p<0.05 ;{ }^{* *} p<0.01$. $p$-values in parentheses.

Source: van der Marel (2021b)

In addition, the reverse seems to apply in the results for local storage requirements in column (2). This variable remains significant for the average effect across all economies but becomes insignificant when interacting with the Asia and Pacific dummy. Note that the joint significance is nearly rejected. This suggests that the trade-reducing impact of economies imposing local storage requirements may be smaller in the Asian region than elsewhere in the world. This, however, is not the case for the restrictions related to conditional flow regimes, which show negative coefficient results for the triple interaction term for Asia when entered alone and when putting together with the 
other restrictions in column (4). The average effect for conditional flow regimes stays significant, although weak, in the last column.

The last set of regressions was repeated by expanding the list of sectors with digitally enabled services. These include intellectual property, R\&D services, professional and management activities, as well as other business services. These sectors are found to have relatively high software- over-labor ratios and are to a great extent also reliant on the cross-border flows of data. The results show that again the variable measuring data localization comes out as strongly negative and significant for the Asian interaction term. This variable stays significant when entered together with all other policy measures. However, the results for both data storage requirement and conditional flow restrictions remain largely insignificant for the Asian economies.

\section{3: Extended Difference-in-Difference Regression for the Three Data-Related Restrictions Separately}

\begin{tabular}{|c|c|c|c|c|c|c|c|c|}
\hline & (1) & (2) & (3) & (4) & (5) & (6) & (7) & $(8)$ \\
\hline & \multicolumn{4}{|c|}{$\begin{array}{l}\ln (S M) \\
0.5>0\end{array}$} & \multicolumn{4}{|c|}{$\begin{array}{l}\ln (S M) \\
0.5>1\end{array}$} \\
\hline$D L^{*} \mathrm{DS}$ & $\begin{array}{r}-0.069 \\
(0.704)\end{array}$ & & & $\begin{array}{l}-0.006 \\
(0.978)\end{array}$ & $\begin{array}{r}0.128 \\
(0.115)\end{array}$ & & & $\begin{array}{r}0.104 \\
(0.202)\end{array}$ \\
\hline$D L{ }^{*} \mathrm{DS}^{*}$ Asia & $\begin{array}{r}-0.873^{* * *} \\
(0.000)\end{array}$ & & & $\begin{array}{c}-0.931^{* * *} \\
(0.000)\end{array}$ & $\begin{array}{r}-0.580^{* * *} \\
(0.000)\end{array}$ & & & $\begin{array}{r}-0.578^{* * *} \\
(0.000)\end{array}$ \\
\hline$L S * D S$ & & $\begin{array}{c}-0.213^{* *} \\
(0.013)\end{array}$ & & $\begin{array}{c}-0.239^{* *} \\
(0.015)\end{array}$ & & $\begin{array}{r}-0.099^{* *} \\
(0.024)\end{array}$ & & $\begin{array}{r}-0.157^{* * *} \\
(0.001)\end{array}$ \\
\hline $\mathrm{LS}^{*} \mathrm{DS}{ }^{*}$ Asia & & $\begin{array}{r}0.061 \\
(0.883)\end{array}$ & & $\begin{array}{r}-0.050 \\
(0.905)\end{array}$ & & $\begin{array}{r}0.047 \\
(0.704)\end{array}$ & & $\begin{array}{r}0.136 \\
(0.302)\end{array}$ \\
\hline$C F * D S$ & & & $\begin{array}{l}-0.022 \\
(0.618)\end{array}$ & $\begin{array}{l}-0.082^{*} \\
(0.075)\end{array}$ & & & $\begin{array}{r}-0.019 \\
(0.708)\end{array}$ & $\begin{array}{l}-0.080 \\
(0.148)\end{array}$ \\
\hline$C F^{*} D S^{*}$ Asia & & & $\begin{array}{r}-0.480^{* * *} \\
(0.000)\end{array}$ & $\begin{array}{r}-0.369^{* * *} \\
(0.000)\end{array}$ & & & $\begin{array}{r}-0.352^{* * *} \\
(0.000)\end{array}$ & $\begin{array}{r}-0.072 \\
(0.400)\end{array}$ \\
\hline FE country-year & Yes & Yes & Yes & Yes & Yes & Yes & Yes & Yes \\
\hline FE sector-year & Yes & Yes & Yes & Yes & Yes & Yes & Yes & Yes \\
\hline Number of observations & 11,454 & 11,454 & 11,454 & 11,454 & 11,454 & 11,454 & 11,454 & 11,454 \\
\hline Adjusted R-squared & 0.775 & 0.774 & 0.775 & 0.776 & 0.775 & 0.774 & 0.775 & 0.775 \\
\hline $\mathrm{p}$-values F-stat & 0.000 & 0.042 & 0.000 & 0.000 & 0.000 & 0.076 & 0.000 & 0.000 \\
\hline
\end{tabular}

$\mathrm{CF}=$ conditional flow regimes, $\mathrm{DL}=$ data localization, $\mathrm{DS}=$ digital services sector, $\mathrm{FE}=$ fixed effects, $\mathrm{LS}=$ local storage requirements, $\mathrm{SM}=\mathrm{cross}-\mathrm{border}$ imports of services. Notes: ${ }^{*} p<0.10 ;{ }^{* *} p<0.05 ;{ }^{* * *} p<0.01$. $p$-values in parentheses.

Source: van der Marel (2021b).

Source: van der Marel (2021b).

The new generation of models incorporates insights from standard trade theory, such as Ricardian technology differences and trade flows governed by structural gravity equations. But it incorporates the full general equilibrium approach of the earlier CGE literature, in the sense that macroeconomic constraints are respected, relative prices matter, and sectors exhibit input-output relationships. Model outputs are familiar from the CGE literature, but a key contribution of the model in this section is that it makes it possible to identify GVC 
linkages at a disaggregated level, using the same Wang, Wei, and Zhu (2013) approach as above. ${ }^{89}$

When an economy reduces its trade costs in a particular way relative to other economies, its internal trade costs remain constant. This distinction allows for a contrast between trade liberalization and deregulation, in which domestic trade costs also fall.

Taking this approach, we define two counterfactual simulations:

- Scenario 1 (Trade Liberalization): All economies reduce international iceberg trade costs in digitally delivered services by $10 \%$ but leave intranational trade costs unchanged.

- Scenario 2 (Deregulation): All economies reduce international and intranational iceberg trade costs in digitally delivered services by $10 \%$.
Using ADB's MRIOT, digitally delivered services are divided into the following: telecommunications; finance; real estate; other business services; and other community services. Table 7.3 shows how intra-Asian trade flows change by sector under the two scenarios. The impact on goods is heterogeneous. Many goods sectors contract slightly under Scenario 1: the cost-decreasing effect of liberalization of digitally delivered services, which promotes trade by reducing the cost of an input bundle, is dominated by a substitution effect that draws resources into the digitally delivered services. This intuition is confirmed by the figures for the digitally delivered sectors, which rise significantly. Nevertheless, such goods and services sectors as pulp, paper, paper products, printing, and publishing; rubber and plastics; machinery, not elsewhere classified; transport equipment; and retail trade, except of motor vehicles and motorcycles, and repair of household goods see a slight increase in their intraregional exports. The sale, maintenance, and repair of motor vehicles and motorcycles, and retail sale of fuel is expected to see the largest gains besides digital services themselves.

Table 7.3: Counterfactual Changes in Total Intra-Asian Exports, by Sector (\% over baseline)

\begin{tabular}{lcccc} 
& \multicolumn{2}{c}{ Intra-Asia } & \multicolumn{2}{c}{ Extra-Asia } \\
\cline { 2 - 5 } Sector & Scenario 1 & Scenario 2 & Scenario 1 & Scenario 2 \\
\hline Agriculture, hunting, forestry, and fishing & -1.131 & -4.301 & -0.127 & -3.627 \\
\hline Mining and quarrying & -0.045 & -3.644 & 0.453 & -3.627 \\
\hline Food, beverages, and tobacco & -0.480 & -4.752 & -0.813 & -6.627 \\
\hline Textiles and textile products & -0.335 & -5.454 & -0.178 & -6.074 \\
\hline Leather, leather products, and footwear & -0.523 & -5.715 & -0.255 & -6.621 \\
\hline Wood and products of wood and cork & -0.305 & -3.995 & 0.739 & -4.664 \\
\hline Pulp, paper, paper products, printing, and publishing & 0.319 & -1.394 & 1.817 & 0.770 \\
\hline Coke, refined petroleum, and nuclear fuel & -0.513 & -2.824 & -0.495 & -3.760 \\
\hline Chemicals and chemical products & -0.243 & -3.001 & 0.043 & -2.569 \\
\hline Rubber and plastics & 0.657 & -3.197 & 0.588 & -3.050 \\
\hline Other nonmetallic minerals & -0.507 & -3.817 & 0.075 & -3.454 \\
\hline Basic metals and fabricated metal & 0.009 & -3.767 & 0.136 & -3.562 \\
\hline Machinery, not elsewhere classified & 0.335 & -4.187 & 0.608 & -3.486 \\
\hline Electrical and optical equipment & -0.130 & -3.164 & 0.706 & -0.573 \\
\hline Transport equipment & 0.266 & -4.800 & 0.009 & -5.346 \\
\hline
\end{tabular}

89 Full details of the model are in Shepherd (2021a). 
Table 7.3 continued

\begin{tabular}{|c|c|c|c|c|}
\hline \multirow[b]{2}{*}{ Sector } & \multicolumn{2}{|c|}{ Intra-Asia } & \multicolumn{2}{|c|}{ Extra-Asia } \\
\hline & Scenario 1 & Scenario 2 & Scenario 1 & Scenario 2 \\
\hline Manufacturing, not elsewhere classified; recycling & 0.192 & -4.205 & 0.451 & -5.500 \\
\hline Electricity, gas, and water supply & -0.084 & -1.559 & -0.205 & -3.422 \\
\hline Construction & -1.877 & -4.266 & 0.744 & -2.055 \\
\hline $\begin{array}{l}\text { Sale, maintenance, and repair of motor vehicles and } \\
\text { motorcycles; retail sale of fuel }\end{array}$ & 0.627 & -0.661 & 0.531 & -2.234 \\
\hline $\begin{array}{l}\text { Wholesale trade and commission trade, except of motor vehicles } \\
\text { and motorcycles }\end{array}$ & -0.656 & -3.189 & 0.095 & -1.584 \\
\hline $\begin{array}{l}\text { Retail trade, except of motor vehicles and motorcycles; } \\
\text { repair of household goods }\end{array}$ & 0.188 & -2.163 & -0.249 & -2.448 \\
\hline Hotels and restaurants & -2.179 & -4.226 & 0.439 & -2.843 \\
\hline Inland transport & -0.883 & -2.012 & 0.838 & -3.153 \\
\hline Water transport & -0.523 & -2.873 & -0.460 & -4.374 \\
\hline Air transport & -0.342 & -4.085 & 0.575 & -2.005 \\
\hline $\begin{array}{l}\text { Other supporting and auxiliary transport activities; } \\
\text { activities of travel agencies }\end{array}$ & -1.585 & -3.769 & -0.798 & -3.942 \\
\hline Post and telecommunications & 63.769 & 9.299 & 57.027 & 17.190 \\
\hline Financial intermediation & 60.782 & 8.300 & 32.554 & -0.432 \\
\hline Real estate activities & 54.791 & 9.948 & 53.870 & $\mathbf{1 1 . 1 4 7}$ \\
\hline $\begin{array}{l}\text { Renting of machinery and equipment and } \\
\text { other business activities }\end{array}$ & 48.385 & 9.872 & 42.012 & 8.676 \\
\hline Public administration and defense; compulsory social security & -2.114 & -2.490 & 1.031 & -1.912 \\
\hline Education & 3.734 & -1.602 & -0.565 & -6.157 \\
\hline Health and social work & -0.271 & -4.428 & -0.196 & -3.578 \\
\hline Other community, social, and personal services & 57.360 & 5.644 & 67.188 & 7.056 \\
\hline Private households with employed persons & 1.786 & 8.328 & 2.696 & 12.862 \\
\hline
\end{tabular}

Notes: Boldface indicates the digitally delivered sectors, which were subject to a change in trade costs. In Scenario 1 (Trade Liberalization), all economies reduce international iceberg trade costs in digitally delivered services by 10\% but leave intranational trade costs unchanged. In Scenario 2 (Deregulation), all economies reduce international and intranational iceberg trade costs in digitally delivered services by $10 \%$. Sector definitions are based on ADB Multi-Regional Input-Output Tables.

Source: Shepherd (2021b).

In Scenario 2, by contrast, trade contracts more substantially in all goods sectors, and rises more modestly in the digitally delivered sectors. The intuition is that deregulation lowers internal and external trade costs, so given the size of the internal market, a substantial amount of sourcing switches as a consequence: the substitution effect is stronger, as the domestic market in digitally delivered sectors expand substantially. Asia's exports to markets outside the region are also affected in the same way as with the intraregional trade. Many services that are not digitally delivered generally suffer more under Scenario 2.

For most of digitally delivered services sectors, Asia's extraregional trade is less positively affected than intraregional trade under Scenario $1 .{ }^{90}$

Table 7.4 shows changes in real income. They are typically positive but modest in both scenarios; however, the real income changes are much larger in Scenario 2 than in Scenario 1, which is a standard result in the trade literature: lowering intranational trade costs creates more "trade" because of the larger internal market, and therefore results

90 For counterfactual changes in Asia's exports by economy under scenarios 1 and 2, refer to Table 1c.1 in online Annex 1c. http://aric.adb.org/pdf/ aeir2022_onlineannex1.pdf. 
in increased consumption possibilities due to stronger price falls consequent on reducing trade costs.

Except for Singapore, most Asian economies are estimated to gain less than $1 \%$ increase in real income under the trade liberalization scenario, while gaining significantly larger real income increase from the deregulation scenario. Although not presented in the table, globally European economies such as Luxembourg and Ireland are expected to gain the largest real income increase from scenarios 1 and 2 (Box 7.6 discusses the impacts on household welfare).

Figure 7.29 sets out the findings on GVC integration. As above, we first focus on forward linkages (DVA_INTRex).
Both scenarios see increases in GVC forward integration as a percentage of gross exports, but the effect is typically more pronounced in Scenario 1 than Scenario 2. The reason is that forward linkages are measured on an international basis, so the emphasis is on the effects in traded markets, not the domestic market. The five digitally delivered sectors see substantial increases in their GVC forward linkages, which means that other sectors are using them more intensively in the production of their own traded output. Even the deregulation scenario shows an increase in forward GVC integration for sectors of interest relative to the baseline, due to the changed incentives to engage in international sourcing.

Table 7.4: Counterfactual Changes in Real Income by Economy (\% change over baseline)

\begin{tabular}{|c|c|c|}
\hline Economy & Scenario 1 & Scenario 2 \\
\hline Bangladesh & 0.07 & 2.71 \\
\hline Bhutan & 0.22 & 2.04 \\
\hline Brunei Darussalam & 0.34 & 2.30 \\
\hline Cambodia & 0.28 & 2.68 \\
\hline China, People's Republic of & 0.11 & 4.64 \\
\hline Hong Kong, China & 1.07 & 8.23 \\
\hline India & 0.31 & 2.04 \\
\hline Indonesia & 0.09 & 2.44 \\
\hline Japan & 0.04 & 5.22 \\
\hline Kazakhstan & 0.21 & 4.12 \\
\hline Kyrgyz Republic & 0.40 & 3.27 \\
\hline Korea, Republic of & 0.32 & 5.81 \\
\hline Lao People's Democratic Republic & 0.23 & 2.32 \\
\hline Malaysia & 0.51 & 5.25 \\
\hline Maldives & 0.74 & 2.54 \\
\hline Mongolia & 0.65 & 3.45 \\
\hline Nepal & 0.18 & 3.37 \\
\hline Pakistan & 0.15 & 2.77 \\
\hline Philippines & 0.63 & 3.69 \\
\hline Singapore & 4.09 & 6.59 \\
\hline Sri Lanka & 0.17 & 4.63 \\
\hline Taipei,China & 0.25 & 4.33 \\
\hline Thailand & 0.40 & 3.07 \\
\hline Viet Nam & 0.57 & 2.70 \\
\hline
\end{tabular}

Notes: In Scenario 1 (Trade Liberalization), all economies reduce international iceberg trade costs in digitally delivered services by $10 \%$ but leave intranational trade costs unchanged. In Scenario 2 (Deregulation), all economies reduce international and intranational iceberg trade costs in digitally delivered services by $10 \%$.

Source: Shepherd (2021b). 


\section{Box 7.6: Impacts of Digital Services Trade on Household Welfare}

There are many channels via which trade in digital services can affect household welfare. These services have potential impacts on consumer prices, wages, and on technologies and productivity. Exports and imports of digital services can have more widespread impacts on wages, not only in services but also on manufacturing wages. This can happen if digital services are used as intermediate inputs in production.

Note that, with imperfections in labor mobility, there can be wage differentials across sectors. In particular, there is an export-service premium, which in principle can benefit both skilled and unskilled labor-even though the export sector is skill intensive. But this requires a gradual process of adjustment. Expansion of the export sector raises demand for skilled labor, increasing the skilled wage in the export sector and decreasing it in the import sector. If the digital service is imported, then lower protection and more trade may imply lower wages. The final case to consider is when digital services are not produced domestically.

However, because of the nature of the labor input required, this service may create a demand for the labor factor in the home economy. To illustrate, the service could be a digital conferencing software developed or produced abroad, which utilizes labor from different economies in, for example, writing computer codes, rendering graphics, and so on. Trade in digital services can have impacts on consumer prices. For example, enhanced trade can bring services and manufacturing prices down, directly via access to lower international prices or also indirectly via reduction in the costs of producing goods locally.
Based on the household survey data, which captures expenditure share of manufacturing goods and services as well as wages and labor incomes across different income groups, we find that increase in trade in digital services is likely to help in reducing absolute poverty in most Asian economies. This can operate both via higher wages and lower prices, though the latter mechanism is probably stronger. However, this poverty-reducing effect could also come at the cost of higher inequality. This is because digital services are more likely to generate increases in wages of urban and skilled workers, and these workers reside in initially better-off households. In addition, the prices of the goods that are likely to decline due to access to cheaper digital services inputs are goods that consumed relatively more by the richer households.

Much depends on how well governments can spread digital awareness and provide access to digital infrastructure across both urban and rural areas, income and age groups, gender and social strata and all sizes of businesses, including through public-private partnerships. For example, regulations which enable access to lower cost overseas cloud servers and cross-border data transfers can enable local enterprises to provide data-driven, affordable solutions to the poorer sections of the home market. The extent to which development benefits will be dispersed and digital divide related challenges overcome will be largely a function of how well governments understand and address the factors affecting the competitiveness of digital services trade and the enabling framework set out above in an equitable manner.

Source: Porto (2021).

From the perspective of value chains in the region, Figure 7.29 suggests that liberalizing digitally delivered services sectors can increase their breadth and depth, both in the affected sectors and elsewhere in the economy. The effect is to deepen value chain trade not only in digitally delivered services, but in goods sectors and other services sectors. ${ }^{91}$ Overall, the directional changes over baseline are the same, but the magnitudes are generally larger, particularly under Scenario 1.
Moving to backward linkages in Figure 7.30, both scenarios deliver modest increases in backward GVC integration across the board. The increases are largest for the five digital services sectors, consistent with the fact that the two scenarios only shock trade costs in those sectors. The greater impact from Scenario 1 compared with 2 is more prominent in the backward linkages. Given that backward GVC integration, like forward integration, changes only relatively slowly in

91 Table 1c.2 in online Annex 1c ( http://aric.adb.org/pdf/aeir2022_onlineannex1.pdf) also illustrates the impact on Asia's forward GVC participation with extra Asian economies. 
proportional terms, the sector results are significant in shocked sectors as well as in some other services sectors such as the sale, maintenance, and repair of motor vehicle and motorcycles; retail sale of fuel, and retail trade, except of motor vehicles and motorcycles; repair of household goods. The general picture that emerges is similar to the one for forward linkages, in the sense that value chains generally deepen in the region, and this effect extends not only to the shocked sectors but also to other parts of the economy (services value chains as well as goods).

Asia's backward GVC participation with extraregional economies are expected to be affected in a similar way under both scenarios. However, the impact will likely be smaller than for intraregional backward GVC participation, reflecting Asia's closer intraregional backward GVC linkage than extraregional. ${ }^{92}$

\section{Figure 7.29: Forward GVC Participation as a Percentage of Gross Exports by Sector-Intra-Asia and the Pacific} (\% change over baseline)

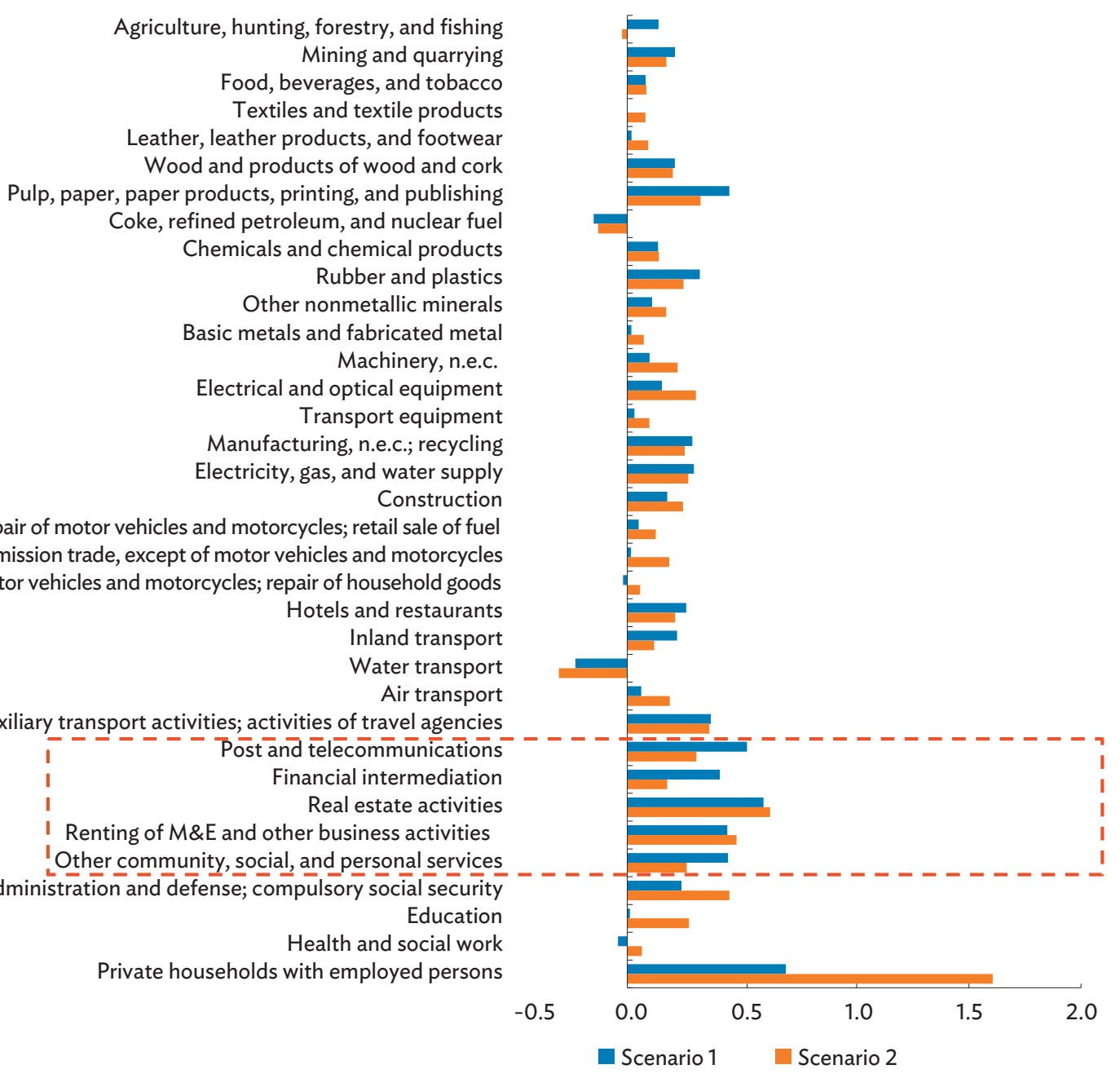

GVC = global value chain, $M \& E$ = machine and equipment, n.e.c. $=$ not elsewhere classified.

Notes: In Scenario 1 (Trade Liberalization), all economies reduce international iceberg trade costs in digitally delivered services by $10 \%$ but leave intranational trade costs unchanged. In Scenario 2 (Deregulation), all economies reduce international and intranational iceberg trade costs in digitally delivered services by $10 \%$. Sector definitions are based on ADB Multi-Regional Input-Output Tables. Sectors within the dotted outline are the digitally delivered sectors used in the analysis.

Source: Configurated based on Shepherd (2021b).

92 Table 1c.3 in online Annex 1c (http://aric.adb.org/pdf/aeir2022_onlineannex1.pdf) also illustrates the impact on Asia's forward GVC participation with extra Asian economies. 
Figure 7.30: Backward GVC Participation as a Percentage of Gross Exports by Sector-Intra-Asia and the Pacific (\% change over baseline)

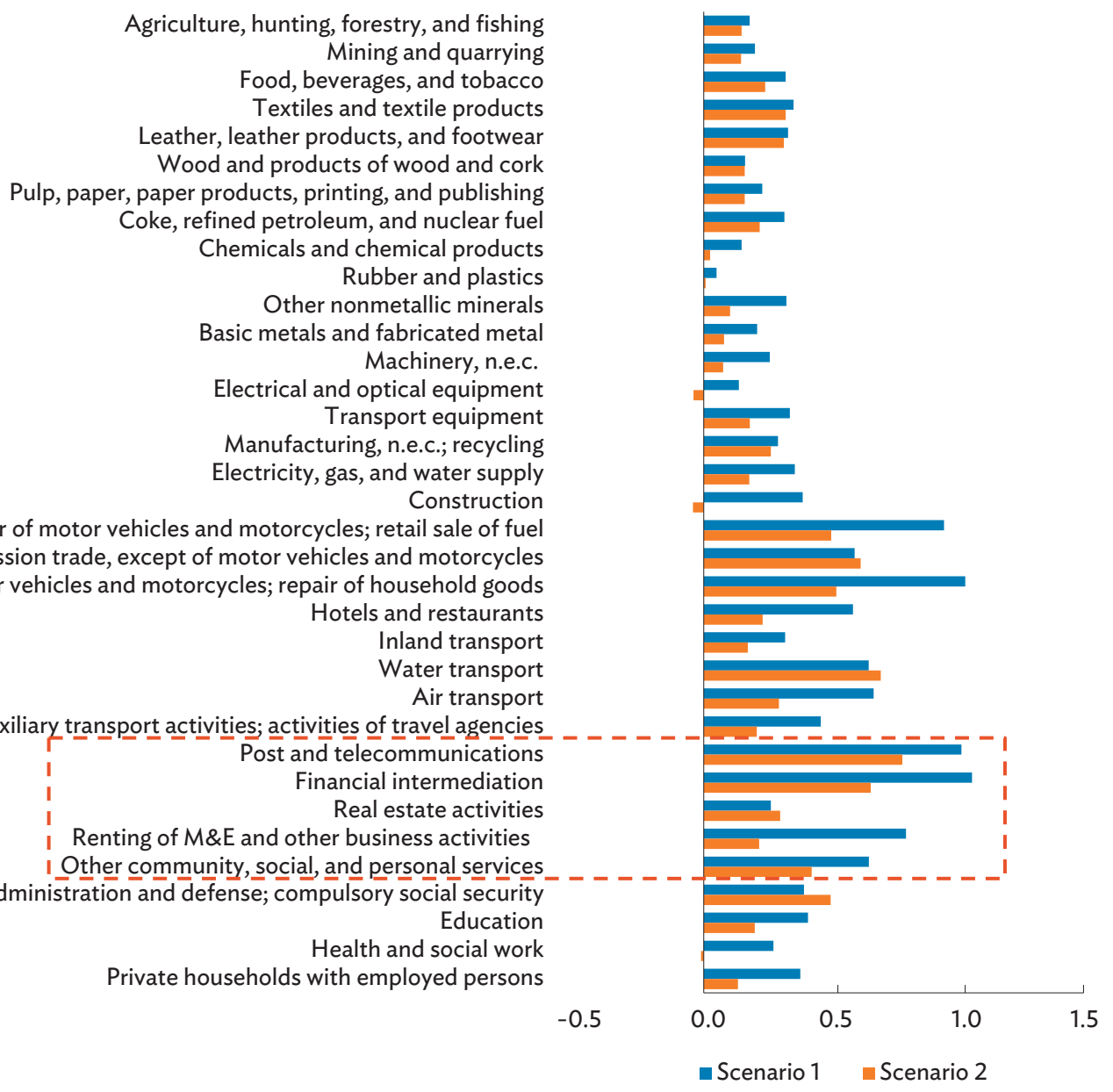

GVC = global value chain, $M \& E=$ machine and equipment, n.e.c. $=$ not elsewhere classified.

Notes: In Scenario 1 (Trade Liberalization), all economies reduce international iceberg trade costs in digitally delivered services by $10 \%$ but leave intranational trade costs unchanged. In Scenario 2 (Deregulation), all economies reduce international and intranational iceberg trade costs in digitally delivered services by $10 \%$. Sector definitions are based on ADB Multi-Regional Input-Output Tables. Sectors within the dotted outline are the digitally delivered sectors used in the analysis.

Source: Configurated based on Shepherd (2021b).

\section{Policy Recommendations}

Digitally delivered services are an important part of the trade landscape in Asia and the Pacific, and the evidence presented in this section suggests that trade costs, including those due to regulatory heterogeneity, are a significant determinant of the observed pattern of trade and GVC integration across economies. In light of these realities, it is not surprising that a "thought experiment" in which trade costs are reduced for digitally delivered services - either through trade liberalization (foreign partners only) or deregulation (all partners, including domestic trade) - typically impact the regional economy significantly. Domestic regulatory reform generally has the larger impact on real incomes while trade effects are stronger for trade liberalization.

In addition, the simulation exercise shows that a reduction in trade costs in digitally delivered services can have spillover effects to other sectors. There is clear potential for trade 
liberalization and deregulation to promote increased use of digitally delivered services as inputs for the production and export of other goods and services, which cements the already important role they play in regional GVCs.

These findings suggest three major conclusions. First, from a welfare perspective, it is important to consider nondiscriminatory policy changes in addition to trade policy reforms. While both are important from a purely trade flow perspective, changes in real income tend to be dominated by reforms that also influence domestic market conditions. This result is highly intuitive: many economies tend to source bulk of their inputs domestically and sell their outputs there, in sectors identified as digitally enabled. As a result, the price implications of policy reform are maximized when reforms are implemented in the domestic market, not just internationally. So, efforts to liberalize the policy environment should ensure that non-discriminatory measures are also addressed. Enhancing services domestic regulations should be geared toward enhancing transparency and strengthening non-discriminatory nature of qualification requirements and procedures, technical standards, and licensing requirements to the extent possible (Box 7.7).

Second, Asian economies have clear scope to conduct policy reforms from the perspective of promoting regional and international transactions. The data show substantial variation in policy stances within the region, ranging from relatively liberal to relatively restricted. Reducing trade costs can therefore help focus on moving toward policy regimes that are less restrictive and support the freer transmission of digitally deliverable services.

\section{Box 7.7: Domestic Regulations in Asia-Pacific Economic Cooperation Economies}

Services are key economic drivers in the Asia-Pacific Economic Cooperation (APEC) region. In a majority of APEC member economies, services make up more than half of their gross domestic product. However, services still have room to contribute to growth and export performance. The APEC region could do better on the export front by addressing behind-the-border regulations and barriers. The benefits for firms are manifold. It allows service provider firms to be more competitive in offering services across borders and to leverage wider markets. For service user firms, it gives them access to better services as inputs or final consumption. In the context of digital services, these include for instance, the ability to access cloud computing and data analytics services. Improving domestic regulations could reduce services trade costs in the APEC region by $7 \%$, which translates to savings in total trade cost of about $\$ 75$ billion (Benz 2021).

Recognizing the role of domestic regulations in services trade, the APEC Services Competitiveness Roadmapendorsed by APEC Leaders in 2016-identified a set of good practice principles on domestic regulations in the services sector. These are reflected in the APEC Nonbinding Principles for Domestic Regulation of the Services Sector, adopted in 2018 (APEC 2018). The principles offer best practices covering provisions such as administration of measures (including application submission and processing), independence, transparency (including information publication and enquiry points), and technical standards. Since its adoption, APEC economies have taken steps to enhance the understanding and operationalization of the principles. A recent study examined the development of domestic regulations with a focus on transparency provisions (APEC and USAID 2020a). Another showcased innovative, next-generation approaches to domestic regulation to reduce compliance costs and improve regulatory outcomes (APEC and USAID 2020b). Also, a survey was conducted to understand APEC economies' regulations of online shopping platform services and their consistency with the nonbinding principles. ${ }^{a}$ Workshops have also been organized to share best practices in applying the principles on sector-specific and crosscutting issues and to discuss ways to harmonize the principles with economies' right to regulate.

As negotiations on domestic regulations in services trade move forward, the APEC nonbinding principles could contribute to these deliberations and provide lessons for Asia and the Pacific on the most adequate design and implementation of liberalization measures.

\footnotetext{
a See Survey on Domestic Regulations in APEC Concerning Online Shopping Platform Service Providers in APEC Project Database. https://aimp2.apec.org/sites/ PDB/Lists/Proposals/DispForm.aspx?ID=2567 (accessed November 2021).

Sources: Asia-Pacific Economic Cooperation Policy Support Unit based on Benz (2020); APEC (2018, 2019); and APEC and USAID (2020a, 2020b).
} 
Finally, the evidence shows that liberalizing the policy environment for digitally delivered services can have spillover effects to other sectors, including through GVC linkages. As a result, ongoing policy discussions on GVC deepening in the region, as well as trade policy linkages more broadly, need to consider the digital dimension. Trade agreements are increasingly devoting specific text to digital issues, but a case can also be made for ensuring that schedules of specific commitments are similarly ambitious in the sectors identified as digitally delivered. New generation trade agreements involving Asian economies, such as the 11-nation Comprehensive and Progressive Agreement of Trans-Pacific Partnership (CPTPP) and the 15-nation Regional Comprehensive Economic Partnership (RCEP), will be evaluated in part based on their ability to extend GVC linkages, including through supporting the use of digital technologies. Using trade agreements to reduce regulatory heterogeneity as well as liberalizing underlying policies could be a fruitful avenue to explore for regional integration efforts.

\section{Trade Rules, Regulations, and Regional Cooperation}

\section{Regulation of Digital Services in the WTO ${ }^{93}$}

Pending eventual negotiations of new disciplines in the WTO, the main obligations for the regulation of digital trade or e-commerce under the existing WTO legal framework can be found in the General Agreement on Trade in Services (GATS) and in the GATS Reference Paper on Telecommunications. ${ }^{94}$ The reference paper sets out the basic rights of access to and use of public telecommunications transport networks and services by services suppliers, including e-commerce suppliers (WTO 1994). The general principle is that such services suppliers shall be given access to and use of public telecommunications, transport networks, and services on reasonable and non-discriminatory terms and conditions. This principle strikes a delicate balance between users' rights (para. 5 lit. b and c) and regulators' rights (para. 5 lit. e-g). ${ }^{95}$ Another key discipline has been the WTO Moratorium on Customs Duties on Electronic Transmissions (Box 7.8).

Beyond the rules in the telecom reference paper, the issues involved in the regulation of digital trade in the WTO fall largely into the following three areas.

The first is the classification issue. As stated earlier, internet activities can be classified as goods or services (Wunsch-Vincent and Hold 2012). The distinction is not merely theoretical but has profound practical implications. If they are treated as goods, they could be subject first and foremost to customs duties, as well as most favored nation (MFN), national treatment, and an entire set of nontariff disciplines such as those on rules of origin, import licensing, customs valuation, and so on. On the other hand, if they are treated as services, the members will be unable to regulate them through border measures such as tariffs, but they would have significant leeway in imposing domestic regulations. While some activities such as the online delivery of books and audiovisual products could arguably be classified as goods according to the technology-neutrality principle, ${ }^{96}$ most activities carried through the internet share more similarities with services trade. For example, many e-commerce activities such as online shopping and gaming are intangible and non-storable like services. Similarly, many e-commerce activities such as online search and e-mail involve joint inputs from suppliers and consumers - and so, as for other services, are tailored to the needs of specific consumers.

93 This section is largely based on Gao (2021b) and Chaisse, Gao, and Lo (2017).

94 E-commerce and digital trade are often used interchangeably but as noted at the outset of this chapter the OECD definition of e-commerce (which covers only digitally ordered trade) differs from the WTO definition which also covers digital delivery of services. The term e-commerce is sometimes used therefore to refer in this chapter only to e-commerce for goods. The chapter otherwise refers to e-commerce for services (e-services) or more often to digital services trade including data flows.

95 Gao (2008) presents a detailed discussion on this principle.

96 As noted by the WTO Secretariat, "the GATS is technologically neutral in the sense that it does not contain any provisions that distinguish between the different technological means through which a service may be supplied” (WTO 1999). 
Box 7.8: The Evolution of Digital Services in the World Trade Organization

At the 2nd World Trade Organization (WTO) Ministerial Conference in May 1998, WTO members adopted a Declaration on Global Electronic Commerce focusing on the establishment of a comprehensive work program on "all trade-related issues relating to global electronic commerce" and a WTO moratorium on customs duties on electronic transmissions (WTO 1998).

\section{WTO Work Programme on Electronic Commerce (WPEC)}

Under the WPEC adopted by the General Council in September 1998, "electronic commerce" covers "the production, distribution, marketing, sale or delivery of goods and services by electronic means (WTO 1998). It also includes within its scope "issues relating to the development of the infrastructure for electronic commerce." Responsibilities are divided among different WTO bodies required to report progress to the General Council regularly:

- The Council for Trade in Services is responsible for examining the treatment of e-commerce in the General Agreement on Trade in Services (GATS) legal framework, including horizontal issues such as the scope and classification of sectors, access to and use of public telecommunications transport networks and services, and the application of both core unconditional obligations (most favored nation, transparency) and discretionary negotiated commitments (market access, national treatment, domestic regulations);

- The Council for Trade in Goods is tasked with examining aspects of e-commerce relevant to the provisions of GATT 1994, the agreements covered under Annex 1A of the WTO Agreement, and the approved work program, which include tariff-related issues, and nontariff issues such as rules of origin, customs valuation, import licensing and standards;

- The Council for Trade-Related Aspects of Intellectual Property Rights deals with issues arising in connection with e-commerce (protection and enforcement of copyright and trademarks, access to technology);

- The Committee on Trade and Development reviews and reports on the development implications of e-commerce, taking into account the economic, financial, and development needs of developing economies; and

- The General Council is responsible for the review of any crosscutting trade-related issues and all aspects of the work program concerning the imposition of customs duties on electronic transmissions.

\section{Moratorium on Customs Duties}

The "practice of not imposing customs duties on electronic transmissions" has been extended repeatedly since 1998 and is due for renewal (at the time of writing) in December 2021 (WTO 2019). This moratorium nevertheless left some questions unanswered.

1. Does the term "electronic transmissions" refer only to the medium of e-commerce, or to the content of the transmission as well, i.e., the underlying product or service being transmitted?

2. If it refers to the medium of transmission only, could other digital products that are supplied via traditional mediums, such as books, music, or videos on CDs, be subject to customs duties?

3. Does the prohibition apply only to customs duties, or does it extend to other fees or charges imposed on the digital products?

4. Does the moratorium apply only to imports or to exports as well?

Although contested, the moratorium is widely cited by the global services business community as having played a fundamental role in support of innovation and growth in digital services, and some WTO members have made commitments in regional trade agreements to permanent bans on customs duties on e-transmissions.

Notwithstanding the work program's ambitious agenda, WTO members have not been able to reach any decisions on new substantive disciplines on e-commerce (WTO 2013). This changed at the 11th Ministerial Conference in December 2017, when 71 members led by three coconveners-Australia, Japan, and Singapore-issued a joint statement to "initiate exploratory work together toward future WTO negotiations" on e-commerce. The plurilateral negotiations were formally launched in January 2019 and at the time of writing, 86 members are now participating.

Sources: Gao (2021b) and Chaisse, Gao, and Lo (2017).

GATS, with its focus on services, adopts a different regulatory approach to the General Agreement on Tariffs and Trade (GATT), which applies a uniform set of rules to most products. According to the "positive listing" approach, WTO members only assume obligations with respect to sectors included in their schedule of specific 
commitments (GATS Article XVI: Market Access). Thus, to determine whether a given e-commerce activity is covered, one has to determine which sector or subsector it falls under and then examine the respective schedules.

Second, even for services covered in its schedule, a WTO member may choose among different levels of liberalization by inscribing commitments ranging from "none" (which means "no limitation" or "fully liberalized") to "unbound" (which means "no commitment") in the market access and national treatment columns (WTO 2001). Thus, determining a member's specific obligations regarding e-commerce activities requires examining the specific wording of that member's schedule.

Third, legitimate policy reasons may lead WTO members to deviate from their trade obligations. Such deviations are permitted by both GATT and GATS through the "General Exceptions" clauses (GATT 1994 Article XX and GATS Article XIV). However, as illustrated by the record of WTO disputes, the preferred exceptions under each agreement are rather different. Under GATT, the most commonly cited exceptions are the ones to protect public health and the environment. ${ }^{97}$ In contrast, the most frequently invoked GATS clause has been the public morals exception. 98

Due to its unique nature, e-commerce activities pose special challenges to the GATS regulatory framework on all three issues. While GATS, in its current form, is not well suited to the regulation of e-commerce, it can keep up with the regulatory task. However, to make this happen, appropriate solutions should be sought to deal with e-commerce activities, especially on key issues such as classifications, obligations, and exceptions.
While a number of issues involved in the regulation of digital trade in WTO are currently being addressed in the plurilateral negotiations under way through the Joint Initiative on Trade Related Aspects of E-Commerce (Box 7.9), much can be learned from the approaches taken by key players in various regional trade agreements (RTAs).

\section{International Governance ${ }^{99}$}

Any framework for digital trade regulation would need to cover cross-border data flows and hence to involve the individual, who provides the raw data and uses the processed data; the firm, which processes raw data inputs from the consumer, but may or may not control such data; and the state, which might monitor and regulate the data used by the first two groups. The different interests of these three types of players can result in conflicting priorities, with the individual advocating privacy protection, the firm promoting freedom of cross-border data flows, and the state focusing on trust and security aspects.

While all regulators would agree on the need to strike a balance between the different and possibly diverging interests of each group of stakeholders, their approaches often differ in practice. Some jurisdictions prioritize the need to safeguard the privacy of users. One example is the General Data Protection Regulation (GDPR) of the European Union (EU), which recognizes "[t]he protection of natural persons in relation to the processing of personal data" as "a fundamental right" (European Parliament and Council 2016). Other jurisdictions put commercial interests first. In the United States, this is reflected in the 1996 Telecommunication Act, which notes that it is "the policy of the United

97 GATT 1994 Article XX (b) was invoked in disputes such as the European Communities-Measures Affecting Asbestos and Asbestos-Containing Products (DS135); Brazil-Measures Affecting Imports of Retreaded Tyres (DS332); European Communities-Measures Prohibiting the Importation and Marketing of Seal Products (DS400, DS401); the United States-Measures Affecting the Production and Sale of Clove Cigarettes (DS406); Indonesia-Importation of Horticultural Products, Animals and Animal Products (DS477, DS 478). GATT 1994 Article XX (g) was invoked in disputes such as the United States-Standards for Reformulated and Conventional Gasoline (DS2); the People's Republic of China-Measures Related to the Exportation of Various Raw Materials (DS394, DS395, DS398); and the People's Republic of China-Measures Related to the Exportation of Rare Earths, Tungsten and Molybdenum (DS431, DS432, DS433).

98 GATS Article XIV(a) has been invoked in disputes such as the United States-Measures Affecting the Cross-Border Supply of Gambling and Betting Services (DS285); and the People's Republic of China-Measures Affecting Trading Rights and Distribution Services for Certain Publications and Audiovisual Entertainment Products (DS363).

99 This section is largely based on Gao (2021a, 2021b). 
States ... to preserve ... free market ... unfettered by Federal or State regulation." ${ }^{100}$ National security concerns are often cited to justify restrictions on cross-border data flows, though in varying degrees in different economies. A recent example is the PRC's 2017 Cybersecurity Law, which imposed several restrictions aiming to "safeguard cyber security, protect cyberspace sovereignty and national security."101 These divergent but not necessarily entirely incompatible approaches to building trust in the online environment are reflected in the RTAs concluded by the three main players. ${ }^{102}$

\section{United States}

The United States (US) trade agreements are pioneering the inclusion of digital trade issues with an expansive set of obligations. In particular, two provisions are now essential (sine qua non) in the digital trade chapters of US trade agreements, with the recently concluded United StatesMexico-Canada Agreement (USMCA) as the leading example: the first is the guarantee on free cross-border flow of data by stating that "no Party shall prohibit or restrict the cross-border transfer of information, including personal information, by electronic means"; and the second is the prohibition of data localization requirements by stipulating that "no Party shall require a covered person to use or locate computing facilities in that Party's territory as a condition for conducting business in that territory." ${ }^{\prime 103}$ These two provisions provide strong protection of the interests of the firm, which deem restrictions on cross-border flow of data and various localization requirements as obstacles to conducting businesses across national boundaries. The US approach essentially enables firms to have strong control on both border measures and domestic regulations.

Many other provisions in the USMCA are also designed to pave the way for the development of digital trade, either by removing regulatory barriers (e.g., the provision non-discriminatory treatment of digital products) or by providing an enabling framework (e.g., provisions covering the domestic legal framework for e-transactions, recognition of legal validity of e-signatures or e-authentication methods, acceptance of e-documents as legal equivalents of their paper versions, and open government data). One significant provision is the clause providing consumers (including business users) with freedom of access to and use of the internet for e-commerce, subject only to network management and network safety restrictions (Article 19.10 of USMCA). This provision grew out of the net neutrality principle from the domestic telecommunications' regulatory framework within the US. It is mainly designed to limit risks from market players that own or control key telecommunications infrastructure and internet services providers that could abuse their power by unreasonably denying their business users access to their infrastructure.

\section{People's Republic of China}

For the PRC, the key to data regulation is data security, which also affects national security and national sovereignty (Gao 2019). The PRC has traditionally taken a cautious approach to provisions on digital trade in trade agreements. Until recently, it did not include e-commerce chapters in its RTAs. This changed with its free trade agreements (FTAs) with the Republic of Korea and Australia, both signed in 2015. The provisions in both are modest, however, and mainly address trade facilitation issues. A major breakthrough was made in RCEP, which the PRC signed along with 14 other economies in the region in November 2020. In the chapter on e-commerce, the PRC like all other RCEP parties ${ }^{104}$ agreed to not "require a covered person to use or locate computing facilities in that Party's

100 Telecommunication Act of 1996. 47 U.S.C. 230(b) (2). See Cornell Law School. Legal Information Institute. 47 U.S.C. 230 - Protection for private blocking and screening of offensive material. https:/www.law.cornell.edu/uscode/text/47/230.

101 Cybersecurity Law of the People's Republic of China [Zhonghua Renmin Gongheguo Wangluo Anquan Fa], as adopted at the 24th Session of the Standing Committee of the 12th National People's Congress of the People's Republic of China on 7 November 2016, Article 1 (Gao 2021b).

102 Kerneis (2021) provides a recent European perspective on these three main approaches.

103 Articles 19.11 and 19.12 of the Government of the United States, Office of the United States Trade Representative. United States-Mexico-Canada Agreement (USMCA) Legal Text. USMCA 7/1/20. https://ustr.gov/trade-agreements/free-trade-agreements/united-states-mexico-canada-agreement/ agreement-between.

104 While RCEP has made a significant breakthrough in governing cross-border data flows, there remain constraints from the perspectives of essential security interests and necessity test criteria. 
territory as a condition for conducting business in that Party's territory," or "prevent cross-border transfer of information by electronic means where such activity is for the conduct of the business of a covered person." 105

Privacy protection is a relatively new concept in the PRC law. Privacy was first recognized as a civil right under the Tort Liability Law in 2009. This was incorporated into the PRC's new Civil Code in 2020, which has a separate chapter on privacy and personal information protection as part of the volume on personality rights. ${ }^{106}$ Under Art 1035 of the Civil Code, processing of personal information shall be based on the consent of the data subject, "except if there are different requirements under laws or administrative regulations." This approach is also adopted in the PRC's new Personal Information Protection Law (Article 13.3), which confirms that data processors do not need to obtain the consent of the data subject when necessary for discharging official duties and responsibilities. Some of these features are not unique to the PRC and can be found in other privacy laws such as the GDPR. ${ }^{107}$

\section{European Union}

The EU has an overriding concern for the privacy of the individual. This started with the Data Protection Directive in 1995, which prohibits the transfer of personal data to economies outside the EU unless their privacy protection standards are deemed adequate (European Parliament and Council 1995). The directive was replaced by the GDPR in 2018 (Aaronson and Leblond 2018). Despite having a name that suggests a broader reach, the GDPR applies only to personal data, which is defined as "any information relating to an identified or identifiable natural person ('data subject')" (Article 4.1). It regulates the behavior of the data controller, defined as the one who "determines the purposes and means of the processing of personal data," (Article 4.7) and the processor, who "processes personal data on behalf of the controller" (Article 4.8). Under the GDPR, processing of personal data is only allowed under certain conditions, including with the "explicit" consent of the data subject under a set of principles specifying the scope and manner of such processing (Articles 5.1 and 6.1). ${ }^{108}$ Transfer of personal data to third economies is allowed only on the basis of an adequacy decision or appropriate safeguards (Articles 45 and 46).

Following introduction of the GDPR, European Commission officials have advocated "technological sovereignty" for the EU (Burwell and Propp 2020). ${ }^{109}$ "Technological sovereignty" is a concept closely linked with "digital sovereignty," which was elaborated in the European Commission's Communication on a European Strategy for Data, unveiled in February 2020. ${ }^{110}$ Many commentators have suggested that the EU's new data strategy is designed to "counter the strong position of US and Chinese digital companies in the European market" and remedy "the key European disadvantage" of "the lack of significant European digital corporations with global influence" (Burwell and Propp 2020; Shapiro 2020). The new data strategy aims to create "a single European data space" so that "by 2030, the EU's share of the data economy-data stored, processed and put to valuable use in Europe-at least corresponds to its economic weight, not by fiat [ruling] but by choice" (European Commission 2020a).

On data flow, the EU takes a bifurcated approach. Nonpersonal data are supposed to flow freely under the EU's Framework for the Free Flow of Non-Personal Data (European Parliament and Council 1998). Crossborder flow of personal data subject to the stringent requirements of the GDPR, despite the explicit recognition under the GDPR that "[f]lows of personal data to and

105 Articles 12.14 and 12.15 of the ASEAN Secretariat. RCEP Agreement Legal Text. https://rcepsec.org/legal-text/.

106 Chapter 6, Volume 4 of The State Council of the PRC. See Civil Code of the People's Republic of China. http://english.www.gov.cn/archive/ lawsregulations/202012/31/content_WS5fedad98c6d0f72576943005.html.

107 For example, Article 6 of the GDPR.

108 See also Mattoo and Meltzer (2018).

109 Scott (2019) provides the statement by EU President Ursula von der Leyen. European Commission (2019) includes the statement by incoming EU commissioner for the internal market, Thierry Breton.

110 Burwell and Propp (2020) discusses the distinction between technological sovereignty and digital sovereignty. 
from economies outside the Union and international organizations are necessary for the expansion of international trade and international cooperation." Due to its unilateral nature and high compliance costs, the GDPR is generally considered to be "challenging especially for the small and medium-sized enterprises" (Irwin 2021; European Commission 2020b).

\section{“Digital Provisions" of Trade Agreements in Developing Asia}

The three models discussed here are not limited to the three jurisdictions. As illustrated by Ferracane and van der Marel (2021), these three models cover most economies around the world, including in Asia and the Pacific.
To assess the state of play in Asia and the Pacific, this section provides a mapping of the main RTAs in the region with chapters on e-commerce or digital trade which have been entered into by the main players since 2000 , i.e., the PRC; the Republic of Korea; Japan; India; Australia; New Zealand; ASEAN; and individual ASEAN members Singapore, Viet Nam, and Malaysia. The mapping also covers the mega RTAs in the region-i.e., RCEP, CPTPP, USMCA, and the EU-Canada Comprehensive Economic and Trade Agreement-as well as the two stand-alone digital trade agreements: the Digital Economy Partnership Agreement (DEPA) between Singapore, New Zealand, and Chile, and the Digital Economy Agreement (DEA) between Singapore and Australia. Using the CPTPP and USMCA as benchmarks, the mapping groups digital trade provisions into the four categories shown in Table 7.5.111

\section{Table 7.5: Categories of Digital Trade Provisions in Trade Agreements}

\begin{tabular}{|c|c|}
\hline Category & Provisions \\
\hline $\begin{array}{l}\text { Trade facilitation } \\
\text { Provisions designed to create a facilitating environment for digital trade. These provisions provide } \\
\text { the necessary regulatory and technological environment to enable the smooth functioning of } \\
\text { digital trade, which also forms the bedrock on which digital services trade can be conducted. }\end{array}$ & $\begin{array}{l}\text { Ban on customs duties on e-transmission } \\
\text { Non-discriminatory treatment of digital products } \\
\text { Domestic electronic transactions framework } \\
\text { Electronic authentication } \\
\text { Electronic signatures } \\
\text { Paperless trading }\end{array}$ \\
\hline $\begin{array}{l}\text { Enabling business } \\
\text { Provisions to reduce the commercial and regulatory burden for digital services trade providers } \\
\text { to a minimum. These provisions focus on the most common regulatory and commercial } \\
\text { obstacles facing digital services trade firms. By removing these obstacles, digital services will } \\
\text { flow more freely across economies, creating massive economies of scale with the data they } \\
\text { amass across different markets. }\end{array}$ & $\begin{array}{l}\text { Access to and use of the internet for electronic } \\
\text { commerce } \\
\text { Free flow of data } \\
\text { Prohibition of data localization } \\
\text { Prohibition on forced transfer of source code } \\
\text { Open government data }\end{array}$ \\
\hline $\begin{array}{l}\text { Consumer protection } \\
\text { Provisions to protect the interests of consumers. By addressing the main concerns of } \\
\text { consumers, these provisions enhance the trust of consumers in digital services trade and thus } \\
\text { indirectly boost the take-up rate of digital services among consumers. }\end{array}$ & $\begin{array}{l}\text { Online consumer protection } \\
\text { Privacy and personal information protection } \\
\text { Unsolicited commercial electronic messages }\end{array}$ \\
\hline $\begin{array}{l}\text { Regulatory autonomy } \\
\text { Preserve the regulatory autonomy of the government. These provisions help the governments } \\
\text { to reserve the space necessary to address various social policy objectives even though they } \\
\text { might ostensibly be inconsistent with various obligations under the digital trade chapter. }\end{array}$ & $\begin{array}{l}\text { Cybersecurity } \\
\text { Exceptions } \\
\text { Cooperation } \\
\text { Dispute settlement }\end{array}$ \\
\hline
\end{tabular}

Source: Gao (2021b).

${ }^{111}$ See also the annex summary table in Drake-Brockman et al. (2021). 
Agreements and digital provisions have been increasing in number (Figure 7.31). The peak in 2001 relates to the New Zealand-Singapore on Closer Economic Partnership which covers 14 kinds of digital provisions. While the two RTAs concluded in 2002 covered on average 4.5 kinds of digital provisions, the seven RTAs concluded in 2020 covered an average of 11.7 kinds. ${ }^{112}$

\section{Figure 7.31: Average Number of Digital Provisions Covered in New RTAs}

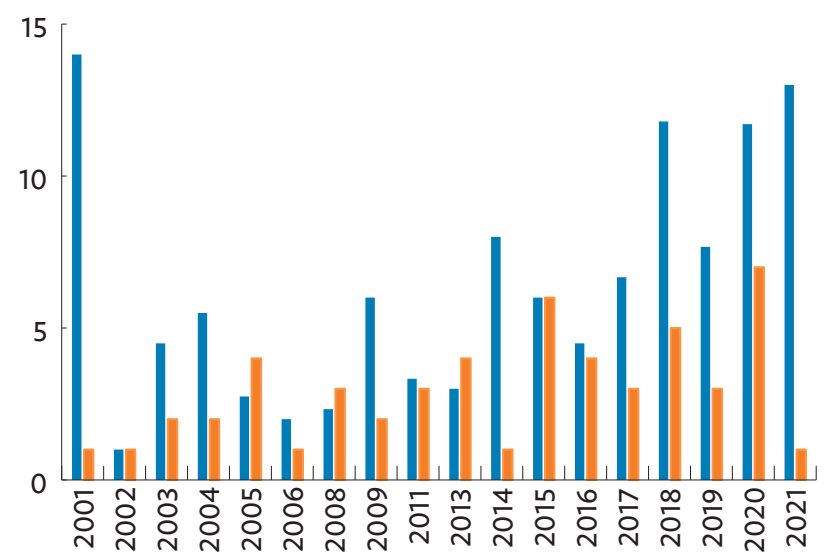

Average number of categories

Number of new agreements

$\mathrm{RTA}=$ regional trade agreement.

Source: Asian Development Bank.

Among the four categories of provisions, the first is the most common, with more than three-quarters of the RTAs surveyed including at least two provisions in this category (Figure 7.32). Many of these obligations repeat existing obligations in other international agreements, such as the United Nations Commission on International Trade Law (UNCITRAL) Model Law on Electronic Commerce 1996, the United Nations Convention on the Use of Electronic Communications in International Contracts, and the WTO Trade Facilitation Agreement. These provisions lay down the infrastructure necessary to facilitate digital trade and tend not to prescribe a specific regulatory approach on sensitive issues. Implementation of some might nevertheless require additional digital infrastructure investment, which can be a challenge for some developing economies. Moreover, putting the facilities into place might not be sufficient. Statutory requirements for documentary formalities might also need to be modified to account for new ways of contracting and approval. Many developing economies will need technical assistance for this purpose.

Figure 7.32: FTAs with at Least One Provision in Each Category (\%)

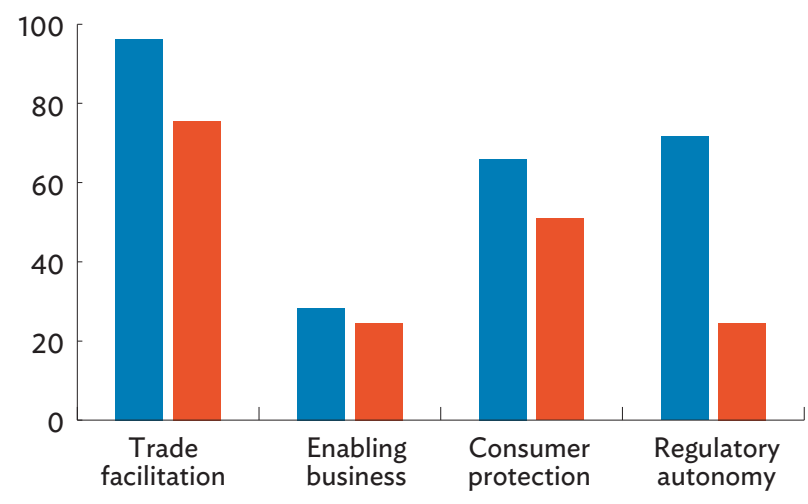

a of FTAs that have at least one provision in the category $\%$ of FTAs that have at least two provisions in the category

$\mathrm{FTA}=$ free trade agreement.

Source: Asian Development Bank.

\section{Figure 7.33: FTAs with Provisions in at Least One to All} Categories (\%)

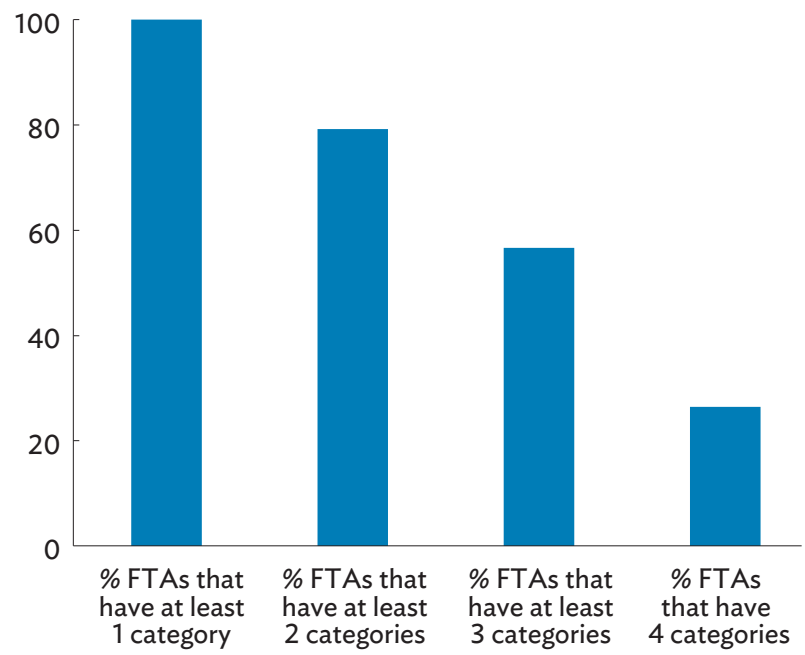

FTA = free trade agreement.

Source: Asian Development Bank.

112 The detailed results of the mapping are reported in online Annex 1d (Digital Trade Provisions in Trade Agreements-Coverage by Category). http://aric. adb.org/pdf/aeir2022_onlineannex1.pdf. 
The second category of provisions focuses on reducing regulatory barriers that block or impede digital services trade flows. As the primary beneficiaries of such measures tend to be overseas suppliers using the crossborder supply mode, these provisions can potentially affect jobs, government revenues, and development of local suppliers, and raise the hurdles for regulatory enforcement actions. As a result, many developing economies have been reluctant to adopt such provisions, and they are included in only a quarter of surveyed FTAs. Lack of regulatory capacity is one contributing factor beyond economic considerations. Many developing economies also understand the need for these provisions, if only to send a welcome signal to foreign digital firms. Without these policies, digital giants are hesitant to enter the local market because of cybersecurity risks (when data cannot flow freely) and additional costs (for building local servers).

Provisions in the third category contribute to development of digital services trade by fostering a trustworthy environment for consumers and firms. Half of the surveyed FTAs include at least two provisions in this category (Figure 7.32). Again, as many developing economies lack domestic laws and regulations covering many of these issues, this sometimes leads to laws and regulations that affect digital suppliers more severely than traditional domestic suppliers, and so could raise national treatment issues. Technical assistance is needed to help developing economies update their regulatory regimes.

The fourth category of provisions identified is designed to provide governments with discretionary policy space. The provisions do not appear to be facilitative in nature but are necessary and particularly important for developing economies where the bulk of digital services trade are provided by foreign suppliers. These provisions are relatively common. More than $70 \%$ of the surveyed RTAs adopt at least one provision of this type (Figure 7.32) and even more if the general exceptions clauses in the other chapters are included. Overall, $26 \%$ of the surveyed FTAs include provisions in each of the four categories (Figure 7.33).

\section{The Future of Digital Trade Rules-Digital Economy Agreements}

Significant advances in digital trade rules are observed in the recent DEPA between Singapore, New Zealand, and Chile, and the DEA between Singapore and Australia that entered into force, respectively, in January 2021 and December 2020. These DEAs include comprehensive upto-date provisions aimed at promoting data flow, enabling e-businesses, and ensuring confidence in the digital economy. While they generally confirm the application of e-commerce rules and principles contained in existing RTAs, some provisions go much further on digital trade facilitation issues such as e-payments, e-invoicing, e-signature, and data exchange systems.

Both of these agreements also take a soft law approach to encourage regulatory cooperation at multiple levels and across a variety of forums, in emerging areas such as artificial intelligence (Al) governance, digital identities, and financial technology (fintech).

The forms of cooperation typically involve information exchange, sharing of best practices, and digital standards development. Bilateral or international regulatory cooperation and technical cooperation are called for as regards to the many issues that both agreements cover. Transparency is stressed as a key obligation to be applied to adopting or administering domestic measures affecting digital trade. The agreements do not cover services market access issues. ${ }^{113}$

Looking back over the evolution of trade law, digital trade rulemaking has clearly intensified and become more comprehensive. At present, more concrete outcomes are being observed from regional negotiations than from multilateral discussions. Adoption of DEPA and the Singapore-Australia DEA perhaps highlight a potential regional trend toward establishing a self-contained system for the regulatory development of digital trade.

113 Honey (2021) includes a recent discussion on DEPA, including an explanation of the absence of market access outcomes. Drake-Brockman (2020) provides a summary of DEA. 


\section{Box 7.9: The Case of the Republic of Korea}

Having promoted e-commerce through over a dozen regional trade agreement (RTA) negotiations, the Republic of Korea (ROK) now seeks to go further on digital trade by concluding a digital partnership agreement with Singapore and joining the Digital Economy Partnership Agreement between Singapore, New Zealand, and Chile. This case study presents both the ROK's experience in gradually strengthening digital trade relations through free trade agreements (FTAs) and the challenges lying ahead given the gap between the conventional issue-specific e-commerce provisions in older RTAs and the crosscutting standards established in digital economy agreements.

\section{Scope of E-commerce Provisions in ROK FTAs}

Digital trade-related provisions in ROK FTAs are generally geared toward facilitating e-commerce including by avoiding unnecessary barriers. The scope and content of e-commerce chapters or provisions vary across the FTAs but most of them include a bilateral ban on customs duties on e-transmissions, personal information protection, online consumer protection, and paperless trading. In addition, promotion of e-authentication, e-signature, protection from spam messages, cooperation on cybersecurity, promotion of small and medium-sized enterprises, and transparency of domestic regulations have become increasingly prominent issues in recent FTAs.

In contrast, services delivered electronically are excluded from the legal scope of ROK FTAs' e-commerce chapters. Some of the agreements clearly state that measures affecting the supply of a service delivered or performed electronically are subject to the rules and obligations for investment and cross-border trade in services and financial services contained in other chapters of the agreements.

On the other hand, some other agreements seem to deal with the problem of regulatory overlaps more broadly, considering the overall relations between the e-commerce rules and the provisions of the other chapters. The ROK-Canada FTA, for example, explicitly recognizes that "trade conducted by electronic means" is also covered by many provisions other than for e-commerce, including those relating to national treatment and market access for goods, cross-border trade in services, financial services, telecommunications, and government procurement. ${ }^{a}$ This FTA also explicitly ensures that the e-commerce provisions do not impose obligations to allow "electronic delivery of digital products" unless other relevant chapters require so.
In other cases, such as the ROK-the People's Republic of China (PRC) FTA and ROK-Colombia FTA, similar provisions serve to clarify the boundary of the e-commerce chapter in relation to other chapters. Of note, these agreements specify that if any discrepancy between the e-commerce chapter and other chapters becomes controversial, then the latter would prevail. ${ }^{c}$ This provision fundamentally shields against excessively wide application of the e-commerce rules that might intrude into domains covered by other chapters.

Furthermore, the ROK-European Union (EU) FTA adopts e-commerce provisions not in an independent chapter but under a subsection of the chapter for Trade in Services, Establishment and Electronic Commerce. This may reflect the parties' view that trade opportunities as well as barriers and regulatory issues for e-commerce are part of the issues pertaining to cross-border trade in services. ${ }^{d}$ In that regard, the EU has long maintained in negotiations that electronic supply of digital contents and information should not be considered as new forms of services. ${ }^{e}$

Therefore, in principle, the ROK's bilateral agreements have taken an approach covering importantly what is supplied or delivered rather than how it is supplied or delivered. This means that, if it is certain that a matter is related to supply or delivery of a service, regardless of whether by electronic means, that matter is regulated by rules and commitments in services trade provisions.

\section{A Taxonomy of e-Commerce Provisions in ROK FTAs}

The ROK has concluded 17 regional agreements covering over 50 trading partners, including the Association of Southeast Asian Nations, Australia, Canada, the PRC, the EU, and the United States. Most of the agreements deal with a broad range of trade issues, including trade remedies, technical barriers to trade, sanitary and phytosanitary measures, cross-border supply of services, investment, and intellectual property protection, and have growingly embraced new issues like environmental and labor protections. These RTAs commonly include provisions to facilitate e-transmissions and to protect online users and consumers. They fall into three categories:

(i) Data flows and customs duties on e-transmissions;

(ii) Protection of personal information and consumers; and

(iii) Facilitation of e-commerce, digitalization, and cooperation. 
The Regional Comprehensive Economic Partnership (RCEP) provides for a digital trade framework that covers all the provisions ROK has adopted in other FTAs. In addition, RCEP contains an article that prohibits localization requirement on data and computing facilities.
This is the first time the ROK has undertaken FTA disciplines on this issue. In essence, not only are the e-commerce provisions in RCEP the latest but they are also considered more comprehensive than obligations in prior ROK RTAs. ${ }^{f}$

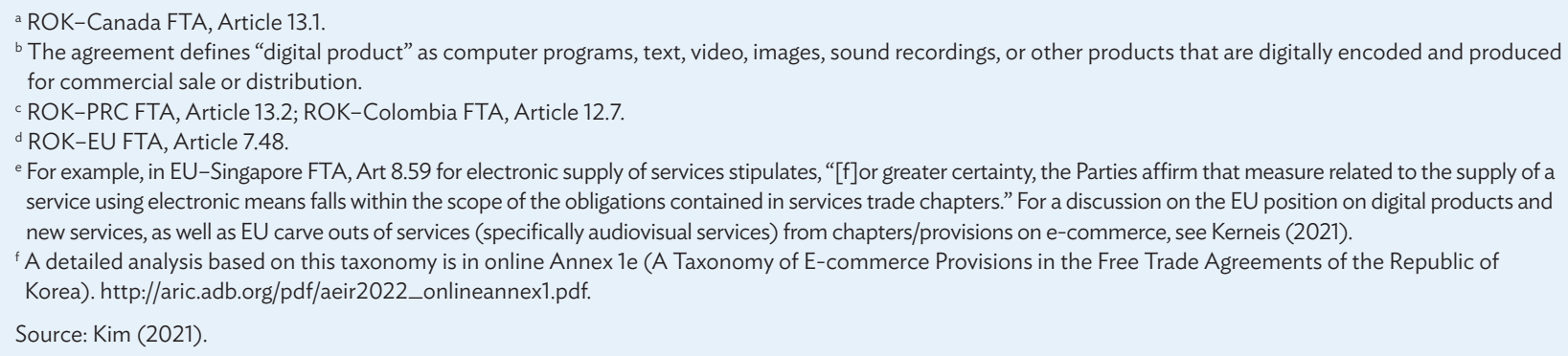

Deeper commitments and expanded coverage of RTA provisions can be crucial for fostering the development of digital trade in services. In particular, developing Asia will need to beef up such provisions focusing on enabling online business and consumer protection. To be credible and enforceable, it is recommended that these provisions be made subject to a dispute settlement procedure and with a limited number of exceptions. Of course, given the complexity of digital services trade, it would be unrealistic to assume that the mere inclusion of these provisions will boost regional trade levels. Expanded commitments in RTAs need to be accompanied by other efforts, such as building up the necessary infrastructure for digital trade and putting in place the appropriate regulatory environment striking the right balance between risk control and market liberalization. Given the low levels of services trade in many economies in developing Asia, it may be appropriate to start with market liberalization at the regional level through RTAs and/or DEAs. This could be made possible by mutual recognition agreements on services, which so far have mainly been among developed economies. For instance, economies with similar regulatory frameworks can develop recognition arrangements at the bilateral and regional levels before expanding them to a wider level.

In parallel, participation in the WTO plurilateral negotiations taking place through joint initiatives should be explored, especially on the Trade-Related Aspects of e-Commerce and Services Domestic Regulation. ${ }^{114}$

\section{Cybersecurity: Ensuring Safety of Digital Services Trade Transactions}

\section{A Regulatory Concern}

Cybercrime is a worldwide concern (Box 7.10 provides the definitions of cybersecurity and cybercrime). Cybercriminals are not only chasing money but also data. Criminologists used to say, "where there is money, there is crime" but now add "where there is data, there is crime" as cybercriminals are collecting data online for diverse purposes, including monetary gain, revenge, and political purposes. The insecurity of global

114 The Joint Initiative on Services Domestic Regulation was issued at the 11th WTO Ministerial Conference in Buenos Aires in 2017, initiated by 59 WTO members. On 2 December 2021 in Geneva, 67 members successfully concluded negotiations on new disciplines covering licensing and qualification requirements and procedures for services suppliers despite the postponement of the 12th WTO Ministerial Conference (WTO 2021a). 
cyberspace receives a lot of attention. In June 2021, Colonial Pipeline, the largest pipeline operator in the US, providing roughly $45 \%$ of the fuel supply of the nation's east coast was forced to close down its business due to cyberattacks (BBC News 2021). That same month JBS, the world's largest meat processor, paid $\$ 11$ million ransom to resolve a cyberattack (Bunge and Newman 2021). Economies in Asia and the Pacific are also suffering from serious cyberattacks. For example, AXA, one of the world's biggest cyber insurers, suffered a serious ransomware attack at its Asian offices in May 2021 when 3 terabytes of data were stolen. Kaspersky, an information security service provider, observed more than 2.7 million ransomware activities in ASEAN in the first three-quarters of 2020 (Ikeda 2021; Interpol 2021). In recent years, ransomware attacks have crippled critical infrastructure in the US and Asian economies and disrupted global supply chains. It shows that no firm is safe from insidious cyberattacks, and this is especially so for least developed economies, which do not have adequate cyber capacity and awareness.

With the broader adoption of ICT_-including various emerging technologies such as $\mathrm{Al}$, big data, cloud computing, and the Internet of Things-cyberattacks are a credible challenge facing policy makers. The risks of cyberattacks trigger different regulatory responses (or lack thereof) due to limited capacity. Insofar as regulatory intervention affects imports, exports, and foreign investment, they can raise concerns from the perspective of international trade law. Cybersecurity has emerged as a source of commercial, legal, and geopolitical conflict. It has therefore been put on the agenda of trade policy makers.

\section{Box 7.10: Defining Cybersecurity and Cybercrime}

While there is no universally agreed definition of this term, from a technical, and data-driven perspective, cybersecurity is often linked to the "CIA Triad"confidentiality, integrity, and availability of information. ${ }^{\text {a }}$ In this regard, a well-known definition comes from the International Telecommunication Union (ITU), which refers to cybersecurity as

"[a] collection of tools, policies, security concepts, security safeguards, guidelines, risk management approaches, actions, training, best practices, assurance and technologies that can be used to protect the cyber environment and organization and user's assets .... "Cybersecurity strives to ensure the attainment and maintenance of the security properties of the organization and user's assets against relevant security risks in the cyber environment."b

The National Institute of Standards and Technology of the United States further elaborates on each of these dimensions:

(i) Confidentiality-refers to "[p]reserving authorized restrictions on information access and disclosure, including means for protecting personal privacy and proprietary information." (ii) Integrity-means “[g]uarding against improper information modification or destruction and includes ensuring information nonrepudiation and authenticity. Data integrity covers data in storage, during processing, and while in transit. Typical measures include file permissions and user access controls."

(iii) Availability means "[e]nsuring timely and reliable access to and use of information. It is ensured by hardware maintenance, regular, and timely system upgrades, but also disaster recovery plans" (Kissel 2013).

Similar to cybersecurity, academics have classified cybercrime into three general forms (Grabosky 2016), noting some overlap:

(i) Crimes where the computer is used as the instrument of crime, such as phishing, or producing and disseminating child pornography;

(ii) Crimes where the computer is the target of crime, such as denial of service attack; and

(iii) Crimes where the computer is incidental to the offense, such as maintaining records of criminal transactions, such as money laundering and drug dealing.

\footnotetext{
a International Organization for Standardization. Standard ISO/IEC 27032:2012.

${ }^{b}$ ITU. Definition of Cyberspace. https://www.itu.int/en/ITU-T/studygroups/com17/Pages/cybersecurity.aspx.

Source: Chang and Liu (2021).
} 


\section{International and National Responses}

In order to tackle cybercrime and cybersecurity concerns, measures are taken nationally and internationally. Due to the "borderless" nature of cybercrime, the Council of Europe drafted the Convention on Cybercrime (the Budapest Convention) in 1989. Although this was drafted through the council, it was opened for signature by both member and nonmember states. It entered into force on 1 July 2004 after ratification by five members of the council. ${ }^{115}$ The Budapest Convention is viewed as the first international treaty focusing on combating cybercrime and has been noted by the UN General Assembly (resolution 56/121), inviting member states to become signatories (Chang 2017).

The Budapest Convention aims to pave the way for the adoption of adequate international legal instruments against cybercrime. It includes computer-related offenses relating to the confidentiality, integrity, and availability of computer data. These include (i) illegal access to a computer system; (ii) interception of nonpublic transmissions of computer data to, from, or within a computer system; (iii) interference with computer data; (iv) interference with computer systems, such as computer sabotage; and ( $v$ ) the misuse of computer-related devices (e.g., "hacker tools"), including the production, sale, procurement for use, import, or distribution of such devices. It also covers cyber-enabled crimes such as traditional fraud and forgery offenses when carried out through a computer system, child sexual exploitation using the internet, and offenses relating to copyright infringement. On the procedural part, it regulated real-time data sharing and asked its signatories to create $24 / 7$ contact points for an international computer crime assistance network. A total of 66 economies, including Australia, Japan, the Philippines, and the US, have ratified or acceded to the Budapest Convention. The Russian Federation supported by the $\mathrm{PRC}$ is proposing a separate treaty at the UN level (Chang 2017) sharing similarities with the Budapest Convention while presenting significant differences in enforcement with more autonomy given for states to start their own investigations (ADB 2021d).

Australia has promoted the Budapest Convention. In its International Cyber and Critical Technology Engagement Strategy, the government supports countries in the Indo-Pacific region to build cyber resilience and promote the convention. ${ }^{116}$ It has also become an essential component of Australia's development cooperation program, supporting developing and least developed countries in Asia and the Pacific to improve their regulations and capacity on cybersecurity.

In the past few years, while cybersecurity and cybercrime laws have been developed in Asia and the Pacific, not all are aligned with the Budapest Convention. While most countries in the region are strongly aligned with the convention, some developing economies are weakly aligned and would benefit from further developing their legal system to improve cybersecurity and combat cybercrime (Chang 2020).

Cyberattacks can cause chain reactions (Chang 2017). Although it is hard to stop an attack from happening, it is crucial to reduce the harm that an attack could cause to society. Therefore, besides the harmonization of laws on cybercrime and cybersecurity, many economies have adopted a risk-based approach to reduce the harm caused by cyberattacks, especially cyberattacks targeting critical infrastructure. For example, the US introduced the Federal Information Security Management Act, regulating computer incident information sharing in the critical infrastructure industry. Asian governments have adopted similar approaches to encourage the critical infrastructure industry to share computer incidents so that other firms might take measures in advance. In order to protect national security and prevent cyber espionage, economies also require software firms and service providers to make source codes available for review (Dou 2015).

\footnotetext{
115 Albania, Croatia, Estonia, Hungary, and Lithuania were the first five states to ratify the convention.

116 Government of Australia, International Cyber and Critical Technology Engagement Strategy. https://www.internationalcybertech.gov.au.
} 
Research has shown the need to help economies strengthen laws and regulations to combat cybercrime and maintain cybersecurity. Building cyber capacity and raising cybersecurity awareness are now essential aspects of development cooperation programs and trade negotiations. For example, the Australian government recently launched the International Cyber and Critical Technology Engagement Strategy. The key for this is to support economies in the Indo-Pacific region, especially least developed economies, to draft laws that meet the international standard, such as the Budapest Convention, and equip them with better cyber environments by building a risk-based approach to ensure cybersecurity.

The lack of cybersecurity is costly and can undermine the trust of consumers and businesses in engaging in the digital context. Protecting confidence in an online world involves cross-border collaboration between the public and private sectors, as individuals, businesses, and governments that operate through the global networks can face the same threats (Meltzer and Kerry 2019).

While Australia, the PRC, and the US take risk-based approaches by identifying "critical infrastructure" and imposing strict obligations on the relevant operators, the PRC and others have gone further by mandating local storage of data and obtaining source codes. Some developing economies, including least developed economies in ASEAN, do not yet maintain adequate schemes.

A common approach can help enhance cybersecurity and enable digital trade. Divergent, potentially protectionist approaches, can create obstacles to digital trade. Without a clear understanding of cybersecurity laws and policies, industry stakeholders can struggle to adapt to evolving restrictions. Governments need to engage each other inside of trade negotiations or otherwise manage the ramifications of restrictions. Similarly, trade policy makers need to map the issues and reconfigure the global trading system.

WTO exemptions are far from satisfactory mechanisms for managing trade conflicts arising from cybersecurity.
For one, these rules are subject to judicial interpretation case by case and there is room for WTO members to maneuver. Another, and a more crucial reason is that where a member defends itself under the security exception, WTO adjudicators may find it politically sensitive to review the disputed measures. There is significant uncertainty, as Voon (2019) remarks, around the security exception. Hence, some economies attempt to reconfigure the rules to provide greater certainty and clarity for businesses and policy makers-both within and outside the WTO context. Within the WTO, for instance, the consolidated negotiating text on e-commerce recently at least signaled the willingness of some members to tackle these recurring issues of the digital age (WTO 2020). While it remains to be seen how WTO members come up with new solutions, recent developments in RTAs serve as a good reference point for identifying the key instruments for trade policy makers to harness trade concerns around cybersecurity.

There is a consensus that cybersecurity presents significant issues across the global supply chain. However, different laws and policies introduced in the name of cybersecurity-which sometimes is framed and elevated as a national security issue - have raised trade barrier concerns in recent years. Such policies not only influence cyberspace within economies but increase transaction and communication costs for all economies by fragmenting the internet. While some of these regulatory responses may be overreacting and unnecessary to achieve their legitimate policy purposes, one should not overlook the issues around underreaction. For developing and least developed economies, it is a daunting task to grapple with the mixed opportunities of ICT. While digital technologies help accelerate social and economic development, they come with costs. Cybercrimes are borderless, as noted above. Developing economies-particularly the least developed ones lacking adequate regulatory framework and limited human capacity and financial resourcesfind it challenging to react to these threats effectively. ${ }^{117}$ It is problematic for economies to tap into the booming internet and maximize socioeconomic benefits unless there is a secure infrastructure to protect organizations' assets and resources at different levels, organizational,

${ }_{117}$ International Telecommunication Union. Enhancing Cybersecurity in Least Developed Countries. https:/www.itu.int/en/ITU-D/Cybersecurity/Pages/ CYBLDC.aspx. 
human, financial, and technical. It is also vital to prevent the clients of the digital service and digital trade from becoming victims.

To tackle the ramifications for digital trade of regulatory reactions (or lack thereof) to cybersecurity threats, a new set of rules is needed which will require cooperation among like-minded economies. It could occur within the existing multilateral trading system - as in the WTO's e-commerce negotiations or new preferential trade agreements. This new generation of trade agreements, in particular, has begun to reinvent the rules-from cybersecurity cooperation and cross-border information flow-to source code and encryption. Some new rules are "harder" than others: particularly when it comes to cybersecurity cooperation. Moreover, some offer a grace period to ease developing or least developed economies into the new setting. Such arrangements are welcome as properly acknowledging that economies have different capacities to handle cybersecurity matters. More action is needed, including through informal arrangements such as a memorandum of understanding. The gap could also be narrowed by international organizations taking a more active role in building the capacities of developing and least developed economies. Proper cooperation within and outside the WTO can therefore rebuild the trust in the online environment and facilitate the sustainable growth of global digital trade in the long term.

\section{Digital Services Trade and Taxation ${ }^{118}$}

The rise of the digital economy has offered Asia and the Pacific opportunities for expanding trade in digital services. Leading this expansion are homegrown technology firms and digital intermediation platforms that have strengthened their capacity to deliver traditional services through digital tools and to provide a new range of digitally intensive services. Because digital service providers can operate in markets without need for a physical presence, their expansion has created scope for them to artificially lower taxable income, with significant losses of revenue in the jurisdiction where profits are generated. With the rapid emergence of technology firms in Asia and the Pacific, these losses could be more important than in other developing regions.

The reforms of international tax rules under discussion will be important for Asia's prospects on digital services trade. New nexus and profit allocation rules for taxing rights beyond physical presence directly target automated digital service providers. ${ }^{119}$ As the region hosts some of the world's largest providers of digital services, a global minimum tax may likely impact the sector. Pending implementation of the multilateral tax agreement reached in October 2021, Asian economies have introduced measures to levy indirect taxes on imported digitally delivered services. Some economies have also adopted unilateral tax measures on digital services. Understanding their impact and ensuring consistency with trade rules and regional agreements is essential.

\section{Digital Services Tax Models in Asia and the Pacific}

Concerns over multinationals tax avoidance practices have been discussed in the context of the OECD/ G20 Base Erosion and Profit Shifting (BEPS) initiative since 2013, with the increasing role of digitalization underscoring the need to adapt the international tax framework. Digital services have been part of the discussion as they rely on the features bringing challenges to national tax systems: reduced need for physical presence, reliance on data and other intangible assets, and growing mobility of business processes and users.

118 This section is largely based on Da Silva and Avendano (2021). ADB (forthcoming) provides further analysis on strengthening taxes for sustainable development.

119 No consensus has been reached on what constitutes a digital service, adding complexity for implementation of tax measures. In some proposals, the definition of automated digital services is grounded on two elements: it is automated, (i.e., the provision requires minimal human involvement on the part of the service provider) and it is digital (i.e., provided over the internet or an electronic network). Efforts to identify digital and non-digital products or their digital component underline the difficulty to ringfence the digital economy for tax purposes. 
In response to these challenges, several economies have adopted unilateral measures targeting digital services to enhance tax revenues (Noonan and Plekhanova 2020, Avendano and Rosenkranz 2021). Most unilateral measures taken by Asian economies in the area of digital services can be classified into five main categories:

Digital permanent establishment. Measures to introduce amendments to domestic nexus rules to accommodate the concept of permanent establishment have been adopted in the region. These measures aim at expanding the definition of nexus by accounting for significant economic presence and allowing for the taxation of profits of a nonresident corporation regardless of the physical presence in the taxing jurisdiction. Changes to the permanent establishment model include, for example, basing economic presence on local revenue or number of users.

Indirect taxes on imported digital services. States can impose value-added taxes (VAT) or goods and services taxes (GST) on goods and services that are supplied in their territory, impacting services sectors such as internet advertising and digital intermediation services. Several Asian economies have made progress in adopting nondiscriminatory VAT/GST rules in relation to crossborder transactions (ADB-OECD-WB forthcoming).

Withholding taxes. Some economies have expanded the scope of withholding taxes and the use of sector turnover taxes. A state can use a withholding tax by classifying business profits as royalties, or by introducing a fee for online digital services. The Philippines and Malaysia, for example, have included payments for the right to use software, visual images, or sound transmissions under the scope of royalties. Nonresidents providing digital services in the local market can be required to establish a local office and be subject to income tax. This often falls outside trade agreements and double taxation agreements.

Digital services taxes. These are taxes levied on the supply of a category of e-services, charged at a fixed rate, and generally applied at the place where the services are supplied. They have gained traction among economies as they are not covered by double taxation agreements.
Digital services taxes (DSTs) can vary in scope of activities, revenue thresholds, and tax rates.

Table 7.6 provides a summary of recent unilateral measures covering digital services taken by Asian economies. Measures diverge in scope, mechanism, and sector, with some targeting e-commerce as well as a variety of digital services.

\section{Main Reforms of the International Tax Framework: Implications for Digital Services Trade}

A new taxing right without physical presence. An important component of the agreement reached by members of the OECD/G20 Inclusive Framework in October 2021 is the creation of a new taxing right to market economies which is independent from physical presence. The new taxing right allows to overcome the limitations of the permanent establishment concept and to prevent double taxation. As part of this Pillar, the multilateral solution includes three main components. First, a new taxing right on the residual profit of multinational enterprises when they meet a threshold in size and profitability. Second, a fixed return for standard marketing and distribution activities taking place physically in a market jurisdiction and following the existing arm's length principle. Third, an overall enforcement of tax certainty through innovative and effective dispute prevention and resolution mechanisms. While aspects of the agreement need to be completed, multinationals headquartered in Asia and the Pacific will likely generate a significant share of the residual profit to be reallocated among jurisdictions, with a disproportional contribution from ICT and technology firms (IMF 2021).

\section{A global minimum corporate tax for multinational enterprises. A second key component of the} multilateral agreement endorsed by 137 jurisdictions is that large multinationals, regardless of their sector and economy of operation, will pay $15 \%$ of corporate income tax. It gives economies the right to "tax back" profit that is currently taxed below the minimum agreed rate. Together with achieving a minimum taxation on income, 
Table 7.6: Recent Digital Services Tax Measures in Selected Asian Economies

\begin{tabular}{|c|c|c|c|c|}
\hline Economy & Status & Effectivity Date & Type & Description \\
\hline \multirow[t]{4}{*}{ India } & Enacted & 1 April 2022 & Digital PE & Revenue related to the digital PE \\
\hline & Enacted & 1 October 2020 & WHT & $\begin{array}{l}\text { Gross amount of sale of goods or provision of service facilitated through } \\
\text { digital or electronic facility or platform }\end{array}$ \\
\hline & Enacted & 1 June 2016 & $\begin{array}{l}\text { Equalization } \\
\text { levy }\end{array}$ & Gross amount of online advertising payments \\
\hline & Enacted & 1 April 2020 & $\begin{array}{l}\text { Equalization } \\
\text { levy }\end{array}$ & $\begin{array}{l}\text { Online sale of goods, provision of services or services facilitation } \\
\text { (when operator provides platform for others to supply service) }\end{array}$ \\
\hline \multirow[t]{2}{*}{ Indonesia } & Enacted & 31 March 2020 & Digital PE & Revenue related to the digital PE \\
\hline & Enacted & 31 March 2020 & $\begin{array}{l}\text { Electronic } \\
\text { transaction tax }\end{array}$ & $\begin{array}{l}\text { Imposed on e-commerce sales when the digital PE cannot be applied due } \\
\text { to the provision of a tax treaty }\end{array}$ \\
\hline Japan & Announced & 23 August 2021 & DST & $\begin{array}{l}\text { Currently in discussion. Tax measures the allocation of tax rights to market } \\
\text { economies (Pillar 1) for digital companies, etc. and evaluation of a DST } \\
\text { based on case studies in other economies. To be considered only if Pillar } 1 \\
\text { is delayed }\end{array}$ \\
\hline Malaysia & Enacted & 7 April 2021 & WHT & $\begin{array}{l}\text { Withholding tax for digital advertising if nonresidents do not have a PE or } \\
\text { business presence in Malaysia }\end{array}$ \\
\hline Pakistan & Enacted & 1 July 2018 & WHT & $\begin{array}{l}\text { Payments for offshore digital services (online advertising, designing, } \\
\text { creating, hosting or maintenance of websites, uploading, storing or } \\
\text { distributing digital content, etc.) performed by nonresident persons }\end{array}$ \\
\hline Taipei,China & Enacted & 24 July 2019 & WHT & $\begin{array}{l}\text { Payments for online advertisement for e-services (online games, videos, } \\
\text { audio broadcast, movie, music platform services, etc.) supplied to } \\
\text { Taipei,China customers by foreign service providers without fixed place of } \\
\text { business or business agent in Taipei,China (electronically supplied services } \\
\text { providers) }\end{array}$ \\
\hline Thailand & Proposed & 7 May 2019 & WHT & $\begin{array}{l}\text { Income from e-commerce supplies of goods and services in the economy, } \\
\text { including online advertising, gaming, shopping, and others }\end{array}$ \\
\hline Viet Nam & Enacted & 1 January 2021 & WHT & $\begin{array}{l}\text { Income derived by nonresidents from digital and e-commerce operations } \\
\text { in Viet Nam }\end{array}$ \\
\hline
\end{tabular}

DST = digital services trade, $\mathrm{PE}=$ permanent establishment, $\mathrm{WHT}=$ withholding tax.

Note: Pillar 1 of the Organisation for Economic Co-operation and Development/G20 Inclusive Framework's multilateral tax agreement entails the removal and standstill of DST and other relevant, similar measures, and the commitment to not introduce such measures in the future.

Sources: International Monetary Fund (2021); KPMG (2022); and national tax administrations.

the agreement will considerably reduce incentives of multinational enterprises to shift profits to low-tax jurisdictions and strengthen the transparency and predictability for both tax administrations and firms. ${ }^{120}$

A new provision for double taxation treaties. In parallel to the multilateral solution, a new article in double tax treaties was approved in April 2021 under the framework

\begin{abstract}
of the UN Model Tax Convention as a solution to tax income from digital services. The approach aims to take into account concerns of feasibility, administrability, and distribution of taxing rights expressed by developing economies. ${ }^{121}$ The new Article 12B allocates taxing rights to the source economy, which is entitled to levy tax on gross income-typically via a withholding tax mechanism—on payments from automated digital
\end{abstract}

120 These goals are achieved with two sets of rules. The subject to tax rule will provide a treaty-based rule designed to protect source economies against base-eroding payments, while the global minimum tax regime (GloBE) provides a systematic solution to ensure that all internationally operating businesses pay a minimum level of tax on the income in each jurisdiction in which they operate. The coordinated application of these rules is also expected to minimize risks of double taxation.

121 The UN Committee of Experts on International Cooperation in Tax Matters (UN Tax Committee) started this process in 2017 with the formation of the Subcommittee on Tax Challenges related with the Taxation of Digitalized Economy. The subcommittee considered several approaches to tax digitalized transactions from the perspective of developing economies. 
services. ${ }^{122}$ The right to tax income of digital services is granted to a contracting state from which payment originates even if the service is provided in another jurisdiction. In contrast to the OECD/G20 Inclusive Framework Agreement, it does not require a new nexus rule nor alternative to the definition of permanent establishment. ${ }^{123}$ Economies may introduce the new provision in the renegotiation of or signature of future double taxation treaties, which will need to be complemented by domestic legislation. The potential of this instrument will depend on the widespread inclusion of the provision in the existing network of double taxation treaties.

\section{Extending value-added tax to digital services. While} developing a multilateral solution, economies have made efforts toward the implementation of a framework to introduce VAT on the import of digitally delivered services and goods. An advantage of this approach is the consensus that the rules establishing the allocation of VAT taxing rights are determined by the destination principle. Under this principle, the taxing right is located at the place of consumption. Tax administrations in the region have made progress in this direction, allowing for compliance and revenue collection. Governments have also recognized that the VAT challenges of the digital economy require a globally coordinated response to ensure minimal cost and effective cooperation. International guidelines have been developed for making digital platforms liable for assessing, collecting, and remitting the VAT/GST due on the online sales they facilitate. Firm survey data also suggest VAT/GST rules for digital goods and services as their preferred alternative (WEF 2021).

As of 2021, more than 60 economies have adapted domestic legislation and undertaken reforms to capture VAT tax in digital services and low-value imported goods. Most of these have implemented the vendor collection model, in which liability for tax payment rests with the nonresident services provider.

\section{Policy Considerations}

\section{Gains from increasing tax revenues may be modest.} With implementation of the multilateral agreement starting in 2023, estimations suggest that the proposed reforms could increase global corporate income tax revenues by $6 \%$ or about $\$ 150$ billion a year (OECD 2021). ${ }^{124}$ Estimated gains from profit reallocation would be relatively modest ( $0.5 \%$ of global corporate income tax revenues) and larger among low- and middle-income economies. Revenues from a global minimum tax are estimated around $2 \%$ to $4 \%$ of global corporate income tax, with larger gains for high-income economies. Recent estimates by the IMF (2021) for Asia and the Pacific suggest a modest gain for economies in the region, with investment hubs and some economies (e.g., India; Indonesia; Hong Kong, China; Malaysia; Singapore; and Viet Nam) potentially losing some tax revenue. Considering the heterogenous type of jurisdictions in Asia and the Pacific, the revenue impact of the multilateral solution may be wide-ranging.

\section{Unilateral tax measures find favor but prompt retaliation and impact trade rules. While a multilateral} solution is adopted, unilateral tax measures involving digital services have been on the rise. These measures, however legitimate for raising tax revenue, have shown to be costly and potentially trigger retaliatory trade measures. From the perspective of businesses, they can also increase prices for consumers or result in suppliers not serving markets where measures are implemented. Estimations on the effects of trade retaliation measures to DSTs suggest a possible fall of global trade by $1 \%$ (OECD 2021). The most notable example of trade retaliation to unilateral tax measures probably comes from the US. Following the adoption of DSTs by some economies (Austria, France, India, Italy, Spain, and Turkey), the US started a Section 301 of Trade Act investigations considering that such measures would be potentially discriminatory and inconsistent. As a result, tariffs were imposed by

122 Examples of automated digital services include online advertising, supply of user data, social media platforms, cloud computing, online search engines, and online gaming.

123 The new provision does not introduce any quantitative thresholds and also applies to B2C services. While the applicable tax rate on digital services is to be negotiated bilaterally by the contracting parties in their respective double taxation treaties, a modest rate of 3\%-4\% is recommended.

124 These estimates assume that the US global intangible low-taxed income regime is replaced with a per-economy minimum tax at a higher rate, leading to a considerably higher increase in revenues. 
the US on goods imports from these economies. The measure was suspended while multilateral negotiations on international taxation at the OECD/G20 level and implementation are finalized. ${ }^{125}$

The surge in unilateral measures stresses the importance of consistency between WTO trade rules and the new international tax framework in the future. While key provisions in the General Agreement on Trade in Services (GATS) relate to nondiscrimination, international trade rules do not comprehensively encompass taxation issues (Low 2020). From the WTO perspective, most concerns on DSTs are associated with ensuring nondiscrimination, which is based on MFN and national treatment principles (Mavroidis 2020). As is the case for goods, MFN rules under GATS requires all WTO members receive the same treatment. The national treatment principle requires that service suppliers of other members are treated no less favorably than domestic suppliers. However, in contrast to goods, national treatment in services is negotiated on a sector-by-sector basis, and not all obligations apply for all services (Low 2020). GATS also includes provisions allowing exceptions to the MFN and national treatment principles. ${ }^{126}$ While DSTs differ in their scope of mechanism, they will need to be analyzed under the GATS framework to establish whether they can lead to de jure or de facto discriminatory treatment.

As RTAs gradually include more elaborate provisions for digital services trade, they will require further alignment with current proposals for international tax policy. ${ }^{127}$

\section{A global minimum tax brings investment and} competition challenges. While the adoption of a global minimum tax may overall improve tax revenue, it could also bring challenges for existing investment policy frameworks in the region. The global minimum tax may impact policies in developing Asia for attracting foreign direct investment through special investment regimes as the tax advantage provided to multinational enterprises for investing may be neutralized - at least up to the minimum agreed tax rate-in the economy where the ultimate parent of the multinational is based. To what extent tax incentives for attracting investment can be implementable or effective under the new international tax framework will require consideration by policy makers in the coming years.

Reforms in the international tax framework may also have implications for competition in digital services sectors.

As cross-border digital services expand, the compliance of foreign digital service providers to register and remit VAT/GST taxes may become a precondition for their operation. A tax framework including foreign suppliers of digital services may ensure they have the same opportunities as domestic suppliers.

\section{Compliance and implementation measures will need to be developed. From the perspective of} both governments and firms, the implementation of the OECD/G20 Inclusive Framework multilateral solution will increase compliance costs while at the same time providing tax certainty. To ensure proper implementation, efforts to upgrade the current tax framework and tax practices will be needed. Jurisdictions will need to develop domestic legislation implemented in association with a multilateral review process of the rules to be implemented. International law will need to be developed to overcome obstacles in tax treaties, in particular the development of a new multilateral convention that addresses existing treaty barriers such as Article 7 (Business Profits) of double taxation treaties. For tax administrations, an important design tool for the appropriate application of the agreement relies on the existence of a shared filing mechanism as to ensure an effective exchange of information on multinational enterprises and appropriate mechanism for dispute prevention and resolution.

\footnotetext{
125 US authorities found the introduction of a DST to be discriminatory in intent and effect. As a result, the US could levy duties up to $25 \%$ on imports from France. This measure could probably lead to more retaliatory measures.

126 These are related to the existence of a double taxation agreement in the case of MFN, or to ensure "the equitable or effective" imposition of direct taxes.

127 As of 2017 , nearly $9 \%$ of the 275 existing RTAs notified to the WTO specified a right to impose an internal tax or charge on digital products.
} 


\section{Policy Implications and Recommendations}

- Economies in the region need to consider the benefits and risks of digital services taxes and other unilateral measures. While these measures can moderately increase tax revenue, economies should assess the possible effects of their implementation. DSTs could generate trade disputes with partner economies, impose compensatory measures and cause multinational enterprises to reconsider their prospective investments. Looking forward, consistency between existing WTO rules and the international tax framework will be important. While WTO rules are not fully adaptable to the tax challenges of digital services, future negotiations on market access and national treatment commitments under GATS could contribute to a more structured approach to taxation of digital services.

- Consensus has emerged on the adequacy and feasibility of complementary measures, in particular the implementation of rules to ensure effective VAT/GST collection on imported digital services. Economies in developing Asia should continue to expand VAT to cross-border digital transactions to enhance tax revenue. Economies in the region can build on these examples to reduce administrative costs and improve compliance.

- Pending implementation of the OECD/G20 Inclusive Framework Agreement, future double tax treaties may provide a possible mechanism for granting taxing rights to digital services through the recently introduced Article 12B of the Model Tax Convention.

- Regional and international cooperation will be essential to ensure the implementation of the multilateral tax agreement. Notwithstanding the agreement, consistent efforts in developing Asia will be needed to adapt and design new domestic legislation, upgrade double tax treaties, and account for other international law amendments. Developing economies are encouraged to join the Inclusive Framework on Base Erosion and Profit Shifting (BEPS IF) and the Global Forum on Transparency and
Exchange of Information for Tax Purposes. Regional cooperation can contribute to ensuring effective exchange of information for tax purposes, developing appropriate mechanisms for dispute prevention and resolution on taxation, and technical assistance for modernization of tax administrations. ${ }^{128}$

- Should the new tax framework target specific sectors, a standardized definition and nomenclature of digital services should be agreed. ${ }^{129}$ Complementary efforts to improve the measurement of digital services trade will be welcome. The use of administrative data of digital services for tax purposes may be considered in the future.

\section{Way Forward}

\section{Policy Measures to Foster Digital Services Trade}

\section{The Evolving Landscape of Digital Services Trade in Asia and the Pacific}

Much has been discussed about international trade and investment in services in the 30 years since GATS came into force in 1995, at the end of the Uruguay round of multilateral trade negotiations. Yet services trade remains poorly understood compared with "traditional" trade in merchandise goods. A central explanation lies in the fact that many services industries-long considered "nontradable" - proved slower to globalize, and trade in services was slower to unbundle into GVCs than was the case for trade in goods. More recently, the uptake of digital technologies is launching all regions of the world into the Fourth Industrial Revolution and digital enablement has ushered in a powerful new phase of services unbundling.

The literature on GVCs had previously focused on trade in merchandise goods. Services had figured in the earlier GVC story in critical ways, but generally as support to trade in goods and rarely in their own right. Cuts in trade costs associated with telecommunications and transportation

128 In 2021, ADB launched the Asia Pacific Tax Hub as a platform to promote strategic policy dialogue, improve knowledge sharing, and coordinate action on domestic resource mobilization and international tax cooperation. The tax hub assists economies in developing medium-term revenue strategies, defining a road map for digital transformation of tax administrations and providing technical assistance for members to participate in international tax initiatives.

129 Extractive and Regulated Financial Services are currently excluded from Pillar One in the OECD/G20 tax agreement. 
services were regularly cited as contributors to the initial wave of global outsourcing of manufacturing production. And a wide variety of services, such as financial services, professional services, and logistics were regularly cited as providing the essential enabling "glue" in all merchandise goods GVCs. Rarely however has the literature or policy conversation focused on the fragmentation taking place in global services value chains (such as services outsourcing) or the ultimately digital nature of this phenomenon or its significant implications for developing economies (DrakeBrockman 2012; Drake-Brockman and Stephenson 2014).

Services trade is growing fast, not only because consumer preferences are changing as incomes rise, but also due to the "servicification" of manufacturing. While economies are endeavoring to develop domestic service industries, cross-border service transactions are growing exponentially. Digitalization is reinforcing this rapid transformation toward a services economy, by fostering easier, faster, and cheaper transaction of services for the convenience of both suppliers and consumers, lowering the intermediary costs. This "third unbundling" is likely to prevail across the world, enabling the fragmentation of jobs into individual more specialized tasks-for example, separating software engineering, data analytics, remote high-tech service providers, knowledge product providers, or web designers among others, enabling separate tasks to be performed remotely but to interact in real time. Those who are embracing this evolutionary transformation will thrive, whereas those who are clumsy will lag behind.

\section{Key Findings on Issues Underpinning Digital Services Trade}

This theme chapter is designed to shed light on the latest episode in the services globalization story; the story of transition from trade in services, through digital enablement, to trade in "digitally delivered" services or more simply trade in digital services. As such it is likely to be a first of its kind in its explicit focus on digital services trade in an integrated and holistic manner-a concept which also encapsulates cross-border commercial exchange of digitized information (more simply described as "data").
One big challenge in discussing digital services trade is its conceptual vagueness and the pursuant, blurry boundary of its current scope. This chapter attempts to provide clearer delineation based on OECD-WTO and UNCTAD frameworks, and describe the regional and sector performances of digitally deliverable services trade based on the framework.

The analysis shows that Asia and the Pacific is at the forefront of digital services trade, having demonstrated the fastest rate of growth in this sector over recent decades. The region is also showing rapid growth in the relative share of digital services trade in total services trade, although it has yet to narrow the gap in regard to the global average. Cross-economy analysis has shown that the region is far behind economies such as in the $\mathrm{EU}$ and North America in the share of digital services exports in total goods and services exports, which leads the region to having a lower revealed comparative advantage.

In closing the gap with advanced economies in international competitiveness of digital services, the region needs to focus particularly on (i) human capital development, (ii) digital connectivity, (iii) ICT investment, and (iv) an enabling policy and regulatory environment.

As demonstrated by the analysis in the section on what is driving change, the length and quality of education is associated with greater trade in digital services. The importance of upskilling and reskilling the workforce cannot be overstated, especially considering existing skill-based barriers to the uptake of digital technology. Digital technologies are also the bedrock of fostering small and medium-sized enterprises to innovate and become competitive providers of digital services. Developing digital services exports in Asia and the Pacific therefore hinges on the availability, accessibility, and affordability of broadband services. The region's rapid growth of mobile penetration bodes well. Supportive internet regulations could enable even economies with low levels of digitalization to better reap the benefits of digital services trade.

Computable general equilibrium modeling using ADB's Multi-Regional Input-Output Tables data points to clear positive impacts on digital services trade from both trade liberalization and deregulation of digital services sectors, 
with mixed impacts on other sectors. Lowering trade barriers and reforming domestic regulation both led to, however, clear gains in both backward and forward GVC participation regionally and globally across manufacturing and services sectors. Importantly, both policy shocks could garner real income impact for regional economies, with the deregulation scenario generating larger gains by far. From a welfare perspective, this reinforces the importance of implementing nondiscriminatory regulatory cost reduction measures besides trade policy reforms at the border.

Many apparent synergies exist between digital services trade and other sectors of the economy. Growth in e-commerce for merchandise goods, itself enabled by digital services platforms, creates opportunities for digital services exports such as financial services and logistics. Manufacturing growth provides opportunities for embedding digital services and applications in manufacturing exports, enabling indirect exports of digital services.

Restrictive data-related policies, on the other hand, could have significant downward impact on digital services trade. Using a unique data set that traces the development of these measures for 64 economies globally, this chapter assesses which of the restrictions on (i) data localization policies, (ii) local storage requirements, and (iii) conditional flow regimes are driving the negative result of trade in digital services for Asia and the Pacific, and the rest of the world. The baseline results show that globally, in particular, data localization and local storage requirements cause the negative trade results in digital services but that the role of conditional flow regimes is more complex. While many data flow restrictions are adopted and implemented from various legitimate policy perspectives such as protection of privacy and personal data, and protection against the threat to cybersecurity, economies need to weigh the positive effects of such restrictions against negative impact on digital trade flows.

Assessing the social and welfare impact of digital services trade requires examining household wage income and price change impact. While the overall positive labor income increases and price lowering impact of expansion in digital services trade could help poverty reduction and welfare improvement, worsening income inequality among those with different skill sets, in particular, technological and potentially yawning divergence between urban and rural households remains concern, requiring policy makers' attention.

WTO trade rules and provisions in bilateral RTAs provide an emerging international regulatory framework governing the playing field for digital services production, marketing, dissemination, and sales. While the scope of digital services is fast expanding, the governing principles and mechanisms are spread across the articles and provisions of different legal frameworks. Although more and more digital-trade-specific trade agreements are expected to emerge, heightened effort is needed to create clearer guidelines for digital services trade and digital trade at large. After 20 years of preparation through the WTO Work Programme on Electronic Commerce, members are now negotiating in the context of a plurilateral WTO Joint Initiative on Trade-Related Aspects of e-Commerce. A successful outcome to these plurilateral negotiations would constitute a significant step forward in filling some gaps in international digital services trade governance. The negotiations also offer an opportunity for progress to be made on digital services market access. WTO members in Asia and the Pacific should also consider joining the WTO's Joint Statement Initiative on Services Domestic Regulation, since a commitment to principles for good regulatory practice will help to cut trade costs including for digital services. Recent OECD estimates suggest that implementation of this agreement by the 14 regional economies in its data set would cut trade costs across all services sectors by $7 \%$ on average.

Beyond trade negotiation, it is clearly in the interests of digital services competitiveness for regional governments to participate in opportunities for digital regulatory cooperation. This can encourage interoperability of divergent digital regulatory approaches and reference to international standards. Widespread adoption of international standards in ICT has already demonstrably increased interoperability and security across technology platforms, decreased barriers to trade, ensured quality, and built greater trust in digital services. By adopting common standards, economies can avoid redundant efforts and technical duplication, achieve better interoperability, and reduce trade costs. 


\section{Box 7.11: Mutual Recognition Agreements}

Traditionally, mutual recognition agreements (MRAs) have been the key mechanism by which economies recognize each other's regulatory regimes for professional services providers as being equivalent, and so enabling market access on a reciprocal basis. Without an MRA in place, professional services providers have not been able to travel temporarily to other jurisdictions (mode 4) or establish independent commercial presence (mode 3).

Negotiation and implementation of MRAs is typically slow, including when undertaken in a plurilateral context. Unless accompanied by domestic reforms across all parties' typically closed professional services markets, the outcomes, moreover, have not necessarily facilitated growth in international trade. The Association of Southeast Asian Nations MRAs covering nurses, doctors, dentists, accountants, surveyors, architects, and engineers are big steps forward, for example, but remain a work in progress with some way to go to deliver market access gains.

Professional services have been among the slowest of the services sectors to globalize. This is partly the result of traditional client preferences for face-to-face interaction with local services providers, especially in the medical field. It is also a result of the oligopolistic nature of the professions themselves. Professional services have been among the more relatively closed sectors even to domestic competition, chiefly because of professional qualification requirements and certification processes backed by monitoring and accreditation, by the professions themselves, of tertiary education curriculums and rigorous quotas on institutions' student intake. Like most regulations, a legitimate public policy objective is involved, namely consumer protection, and in this case with good economic justification: asymmetry of information between services providers and clients. When clients are unable to check on quality before consumption of services, regulation is required for quality assurance purposes. Dental patients, for example, want to know in advance of the procedure that the dentist is both qualified and licensed to provide quality service.

Digital enablement of professional services is now profoundly changing the business environment and can be expected to push up hard against existing regulatory systems, to the point where a global rethink may be required to facilitate recognition of offshore professional services qualifications embedded in professional services software and intellectual property. Even during the pandemic, in many jurisdictions, access to remote health consultations has been the result of temporary, not yet permanent, easing of regulatory restrictions. However, it is already clear that professional services value chains are fragmenting fairly quickly. Architecture and landscape architecture are standout examples in which both B2B and $\mathrm{B} 2 \mathrm{C}$ professional services design software is now readily available online.

Meanwhile, long before the pandemic brought this to more widespread public attention, the arrival of backoffice robots in health-care diagnostics or legal services prediction and the extensive application of $3 \mathrm{D}$ imaging software in architectural and landscape architectural services - or remote monitoring and 3D printing in construction services - was already transformative for services providers. Digital enablement now allows anyone to design their own home using online architectural services software.

These questions go to the heart of Richard Baldwin's hypothesis. Baldwin envisages an emerging future for wage arbitrage in all kinds of personal and professional services that have traditionally been delivered face-to-face but will increasingly be deliverable online, not only through streaming of professional services software but, in time, by telepresence and hologram. The problem remains that customers will still require assurances that come at the present moment, through professional certification and accreditation in domestic jurisdictions. New challenges arise in Baldwin's scenarios about recognition of qualifications embedded in professional services software (intellectual property) and in due course, for telepresence and hologram, from the jurisdictions where individual services providers are accredited.

There are therefore concerns, given the ongoing relative closedness of most of these markets, that domestic professional services regulation could constitute an overwhelming barrier to mode 1 as it has been for mode 4 . In any case, the policy conclusion remains unchanged. As professional services providers shift from mode 4 to mode 1, domestic regulators that impede client access to world's best practice expertise will come under increasing pressure to improve regulatory efficiency.

For professional services, the Organisation for Economic Co-operation and Development's Digital Services Trade Restrictiveness Index generally identifies that the biggest contributors to trade restrictiveness originate in opaqueness and duplication in cumbersome domestic regulatory frameworks (Nordas 2016). Improved efficiency in services domestic regulation consequently delivers greater than average cuts in trade costs for professional services (APEC 2021; OECD 2021).

To reduce trade costs, many regional trade agreements have included provisions designed to facilitate MRAs. More 
recent ones include provisions on regulatory cooperation more broadly, including in the digital sphere. There is a discernible shift from a focus on regulatory coherence and best regulatory practice to attempts to build more deliberate mechanisms to achieve regulatory equivalence and to collaborate on development of international digital standards. For all digital services, the focus is on determinations of "adequacy," that is, whether regulations in other parties' jurisdictions are adequate enough to meet domestic public policy objectives. The key objective for the professions will be to ensure that determinations of adequacy continue to be arrived at on a mutual not a unilateral basis. For all digital services, a higher degree of regulatory convergence is becoming essential. This calls for designing MRAs in an open and transparent manner, on a potentially plurilateral basis, offering due process guarantees to any party wishing to apply to join.

New technologies are already heavily present in engineering. When the services are not seen as "like" in the eye of the regulator, regulatory discretion may continue to lead to discriminatory barriers to international trade. Future uncertainties aside, it seems clear that domestic regulatory regimes governing qualifications and licensing will have the potential to stymie the take up and use of professional services automation software-and cross-border online trade in professional services. It is important that efforts to improve professional recognition adapt rapidly to online realities. A very first step is to promote the adoption of digital credentialing for professionals.

\footnotetext{
a "In the sectors inscribed in its Schedule, and subject to any conditions and qualifications set out therein, each Member shall accord to services and service suppliers of any other Member, in respect of all measures affecting the supply of services, treatment no less favourable than that it accords to its own like services and service suppliers" (GATS Article XVII on National Treatment).

Source: Drake-Brockman (2021).
}

It is vital for the region that regional governments support the multilateral standardization systems rather than purely focusing their efforts on indigenous approaches. Recognition of regulatory outcomes, whether autonomous or by mutual arrangement, and preferably minimizing the risk of discrimination by designing mutual recognition agreements in an open and transparent manner, provides guarantees to any party wishing to join (Box 7.11 presents more details).

\section{Developing economies will need capacity-building} assistance to enhance awareness and understanding of the importance of ensuring that digital regulatory regimes satisfy international standards, principles, and guidelines, as well as support to introduce reforms aimed at developing or aligning their regulations. Technical assistance is, therefore, urgently needed for developing economies that wish to improve and upgrade data protection laws and regulations in the context of greater digitalization.

Digitalization brings in more convenience but at the same time could entail greater vulnerabilities in security and pursuant enormous costs. The importance of putting in place appropriate risk management tools against cybersecurity crimes cannot be overemphasized. As cybersecurity increasingly becomes a precondition for cross-border data flows, economies aspiring to competitiveness in digital services exports will need to strive for greater international regulatory cooperation on cybersecurity. Governments in the region should encourage the use of transparent, globally competitive and market-driven cybersecurity standards and practices and avoid adoption of domestic measures that constrain competition and innovation. The objective should be to ensure interoperability of cybersecurity frameworks while reducing the costs of regulatory friction.

Digital services are an important area in the current discussions on international tax policy. Digitization means that mode 1 is trending in the direction of taking over as the current dominant mode for services trade. The decreasing need for physical presence in the export market means the scope is increasing for service providers to implement sophisticated tax planning on tax jurisdiction nexus rules and deliberately export services from low-tax jurisdictions-entailing revenue losses on potentially taxable income in jurisdiction where profits are generated. 
In the absence of common frameworks for taxation of cross-border digital services, unilateral measures to capture tax revenue associated with cross-border delivery of digital services have proliferated in the region. Meanwhile, an international push is under way to resolve the underlying issues through international agreement on new taxation frameworks for digital services trade. Ongoing international tax cooperation could ensure fair taxation authorities across the borders.

\section{How to Promote Digital Services Trade}

The prospects for developing economies in Asia and the Pacific to take part in digital services trade are promising. In the post-pandemic period, the opportunities are likely to intensify as consumers and producers continue to embrace online purchasing, digital transactions, and remote delivery of services. These long-term shifts in behavior, production structure, and labor market needs offer all economies new opportunities to develop competitive advantages in digital services sectors.

Economies in the region are at different stages of development of digital services export-from nascent through emerging to strong players. The range of digital services traded in the region reflects this diversity. It includes traditional call-center-type services based on cost as well as location and time zone advantages; advanced Al and cloud-based services based on skills and domain competence; services linked to goods trade and manufacturing competitiveness; embedded services; and services supporting e-commerce such as fintech.

Governments can pave the way for digital services exports by adopting policies and programs that improve the economy's performance in one or more of four key dimensions discussed in this chapter as drivers of digital services competitiveness. Further efforts could include investing in digital infrastructure and skills, supporting startups by providing funding, tax incentives, and piloting opportunities, while also enacting supporting legislation on cross-border data transfers and data protection, among other measures.

Many governments already have national strategies or road maps to develop the digital economy and to expand telecom infrastructure and connectivity. Some have programs directed at developing skills for the digital economy. Some have introduced policies to support the incubation of startups and promote venture capital financing.

Below are some recommendations for supplementary policies and strategies to promote digital services trade:

- With the bulk of digital services trade currently taking place in telecommunications, computer, and information services-as well as professional and other business services, liberalizing restrictions in these services sectors will be important for driving the region's export growth prospects. The potential for digital services exports, ultimately extends, however, across all services sectors with growth already being experienced during the pandemic in health and education services as well as audiovisual and animation services.

»Economy case studies highlight the scope for digital services trade to facilitate the integration of economies into global and regional markets and to lessen the divide among them. Bilateral and regional agreements need to focus more on creating enabling conditions for digital services trade in their chapters and provisions on economic and regulatory cooperation, e-commerce, investment, and mobility of persons, as well as in their mode 1 commitments, including in sectors such as financial services.

» Governments need to weigh the pros and cons of data transfer and localization restrictions carefully. Greater international cooperation is called for on digital standards development and mechanisms for mutual recognition and interoperability. Intensified dialogue with businesses and industry associations is needed to design policies to balance national security and sovereignty concerns without undermining commercial opportunities.

» Openness to digital services imports, such as promoting the utilization of cloud services is important in enabling domestic efficiency gains, reaping socioeconomic development benefits and supporting digital services exports. 
- As the range of tradable digital services grows, there is scope to pursue cultivating digital services export markets. Niche export opportunities are on offer for a wide spectrum of economies that differ in their mix of endowments and conditions. The ability to tap digital services export opportunities depends on the capacity to leverage specific strengths and conditions, including in partnership between government and industry.

» Governments need to keep pace with emerging needs in digital services sectors, investing in ICT infrastructure and specialized skills and updating their regulatory regimes for the digital economy, including to nurture an enabling environment for businesses to have ready access to the crossborder digital services trade.

» Apart from infrastructural constraints, shortage of skills, and absence of a conducive ecosystem for digital enterprises and development of new technology-based applications and solutions, the biggest challenge for digital services trade is achieving transparency, predictability, and appropriateness of the evolving digital regulatory environment. Governments need to undertake regular regulatory review, including in consultation with services industry stakeholders, and reform domestic regulatory practices consistent with international benchmarks, principles, and frameworks. All WTO members are encouraged to join the WTO Joint Statement Initiative on Services Domestic Regulation.

» Greater preparedness for experimentation, the embrace of opportunities to pilot and test applications, and adoption of a regulatory approach that encourages risk-taking can help economies to develop digital services exports. Even if economies fall short in some areas of digital readiness, they can still be successful digital services exporters if they leverage their strengths, including first mover advantage in IT-BPO services, and fast-growing domestic demand for digital applications and solutions to develop digital services exports.
»Economies can convert disadvantages, such as geographic remoteness and a small domestic market into an opportunity, by targeting niche markets and industry segments and serving as an experimentation ground.

- To foster the development of digital trade in services, deeper commitments and expanded coverage of relevant provisions in RTAs can be crucial. In particular, developing Asia will need to strengthen such provisions, focusing on enabling business opportunities and consumer protection. Economy efforts could also be supplemented by mutual recognition agreements on services, which so far have been forged mainly among developed economies. For instance, economies with similar regulatory frameworks can develop recognition arrangements at the bilateral and regional levels first, before expanding them to a wider level.

- While unilateral measures to capture tax revenue associated with cross-border delivery of digital services have been proliferating, an international push now taking place to resolve underlying issues through international agreement on new taxation frameworks should pave the way for fair taxation on cross-border digital services transactions and associated business profits. In the meantime, governments should ensure that any tax-related measures are implemented in a nondiscriminatory manner to avoid bilateral trade friction and WTO dispute.

- Participation in digital services trade can enable social and economic convergence within and across economies by creating jobs and increasing incomes, empowering less advantaged sections of society; by supporting financial inclusion, increasing access to health and education; by improving productivity; and by lowering trade costs. To ensure that digital services trade makes such benefits possible, while avoiding aggravation of inequities as economies undergo digital transformation, it is vital that government approaches include a focus dedicated to digital access and inclusiveness. 


\section{Background Papers}

Chanda. R. 2021. Trade in Digital Services in Developing Asia. Background paper for the Asian Economic Integration Report 2022 on "Advancing Digital Services Trade in Asia and the Pacific." Manuscript.

Chang, L. and H-W. Liu. 2021. Ensuring Cybersecurity for Digital Services Trade. Background paper for the Asian Economic Integration Report 2022 on "Advancing Digital Services Trade in Asia and the Pacific." Manuscript.

Da Silva, B. and R. Avendano. 2021. Digital Services Trade and Taxation in Asia and the Pacific. Background paper for the Asian Economic Integration Report 2022 on "Advancing Digital Services Trade in Asia and the Pacific." Manuscript.

Gao, H. 2021b. Digital Services Trade and Trade Agreements. Background paper for the Asian Economic Integration Report 2022 on "Advancing Digital Services Trade in Asia and the Pacific." Manuscript.

Drake-Brockman, J. 2021. Digital Services Trade in Asia and the Pacific. Background paper for the Asian Economic Integration Report 2022 on "Advancing Digital Services Trade in Asia and the Pacific." Manuscript.

Kang, J. W., R. Avendano, P. Crivelli, D. Sy, and W. Cho. 2021. Factors Affecting the Competitiveness of Digital Services Trade. Background paper for the Asian Economic Integration Report 2022 on "Advancing Digital Services Trade in Asia and the Pacific." Manuscript.
Kim, M. 2021. Digital Trade Agreements and Services Trade: The Case of the Republic of Korea. Background paper for the Asian Economic Integration Report 2022 on "Advancing Digital Services Trade in Asia and the Pacific." Manuscript.

Liberatore, A., R. Avendano, and W. Cho. 2021. Data on Trade in Digital Services Trade. Background paper for the Asian Economic Integration Report 2022 on "Advancing Digital Services Trade in Asia and the Pacific." Manuscript.

Porto, G. 2021. Digital Services Trade: Impacts on the Welfare of Asian Households. Background paper for the Asian Economic Integration Report 2022 on "Advancing Digital Services Trade in Asia and the Pacific." Manuscript.

Shepherd, B. 2021b. Services, Digitally Delivered Trade, and Global Value Chains in Asia. Background paper for the Asian Economic Integration Report 2022 on "Advancing Digital Services Trade in Asia and the Pacific." Manuscript.

Van der Marel, E. 2021b. Data-Related Restrictions and Digital Services Trade: Comparing Asia to the Rest of the World. Background paper for the Asian Economic Integration Report 2022 on "Advancing Digital Services Trade in Asia and the Pacific." Manuscript. 


\section{Bibliography}

Aaronson, S. A. and P. Leblond. 2018. Another Digital Divide: The Rise of Data Realms and its Implications for the WTO. Journal of International Economic Law. 21 (2). pp. 245-272.

Abbas, R. 2021. Top-25 InsurTechs in Asia Revealed. Asia Insurance Review. June. https://www.asiainsurancereview.com/Magazine/ ReadMagazineArticle?aid=44573.

Access Solutions LLC. 2019. Mongolia in the Digital Age: Digital Readiness Assessment. https://artnet. unescap.org/sites/default/files/file-2019-11/ Digital\%20Readiness\%20Assessment\%20 Final\%20Draft\%20\%2009.09.pdf.

Aichele, R. and I. Heiland. 2018. Where Is the Value Added? Trade Liberalization and Production Networks. Journal of International Economics. 115. pp. 130-144.

Anson, J., M. Helble, and P. Rosenkranz. 2021. E-commerce and COVID-19: Moving to a New Equilibrium? Unpublished.

APEC. 2018. APEC Non-Binding Principles for Domestic Regulation of the Services Sector. Singapore. 13 November. https://www.apec.org/-/media/APEC/ Publications/2018/11/2018-CTI-Report-toMinisters/TOC/Appendix-13---APEC-NonbindingPrinciples-for-DR-Drafting-Group.pdf.

-2019. Survey on Domestic Regulations in APEC Concerning Online Shopping Platform Service Providers. Singapore.

_. 2021. Investing in Digital Upskilling and Reskilling of APEC's Workforce is Critical: Report. Press Release. 23 February.

APEC Project Database. https://aimp2.apec. org/sites/PDB/Lists/Proposals/DispForm. aspx?|D=2567 (accessed November 2021).
APEC and United States Agency for International Development (USAID). 2020a. Study on APEC's Non-Binding Principles for Domestic Regulation of the Services Sector. Transparency and Predictability in Rulemaking. Singapore.

_ 2020b. Next Generation Practices for Services Authorization in the Asia-Pacific Region. Singapore.

ASEAN Secretariat. RCEP Agreement Legal Text. https://rcepsec.org/legal-text/.

Asian Development Bank (ADB). 2021a. Asian Economic Integration Report 2021: Making Digital Platforms Work for Asia and the Pacific. Manila.

_ 2021b. Capturing the Digital Economy: A Proposed Measurement Framework and Its Applications. Manila.

_. 2021c. Asian Development Outlook 2021: Financing a Green and Inclusive Recovery. Manila.

- 2021d. E-Commerce in CAREC Countries: Laws and Policies. Manila.

- Forthcoming. Strengthening Taxes for Sustainable Development. Theme Chapter in ADB. Asian Development Outlook 2022. Manila.

$A D B$, Organisation for Economic Co-operation and Development (OECD), and World Bank. Forthcoming. VAT Digital Toolkit for Asia Pacific. Manila, Paris, and Washington, DC.

Asia-Pacific Centre for Security Studies. Countries of the Asia-Pacific. https://apcss.org/about/ap-countries/.

Avendano, R., and P. Rosenkranz. 2021. Digital Platforms and International Taxation in Asia. In C. Y. Park, J. Villafuerte, and J. T. Yap, eds. Managing the Development of Digital Marketplaces in Asia. Manila: ADB. 
Baldwin, R. 2011. Trade and Industrialization after Globalization's Second Unbundling: How Building and Joining a Supply Chain are Different and Why it Matters. NBER Working Paper. No. 17716. Cambridge, MA: National Bureau of Economic Research.

- 2019. The Globotics Upheaval: Globalisation, Robotics and the Future of Work. New York, NY: Oxford University Press.

Baur, A., H. Yew, and M. Xin. 2021. The Future of Healthcare in Asia: Digital Health Ecosystems. McKinsey.com. 21 July. https://www.mckinsey.com/ industries/healthcare-systems-and-services/ourinsights/the-future-of-healthcare-in-asia-digitalhealth-ecosystems.

BBC News. 2021. Colonial Pipeline Boss 'Deeply Sorry' for Cyber Attack. 8 June. https://www.bbc.com/ news/business-57403214.

Benz, S. 2021. Lowering APEC Trade Costs through Services Domestic Regulation Reform. Presentation on Translating APEC's Non-Binding Principles for Domestic Regulation of the Services Sector into Practice: A Focus on Domestic Regulations in Trade Agreements. 17 August.

Benz, S., J. Ferencz, and H. K. Nordas 2020. Regulatory Barriers to Trade in Services: A New Database and Composite Indices. The World Economy. 43 (11). pp. 2860-79.

Berg, J., M. Furrer, E. Harmon, U. Rani, and M. Six Silberman. 2018. Digital Labour Platforms and the Future of Work: Towards Decent Work in the Online World. Geneva: International Labour Organization.

Beschorner, N., S. C. Kuek, and J. Narimatsu. 2015. ICT for Jobs in the Pacific Island Countries. Washington, DC: World Bank.
Borchert, I., B. Gootiiz, J. Magdelieine, J. Marchetti, A. Mattoo, E. Rubio, and E. Shannon. 2019. Applied Services Trade Policy: A Guide to the Services Trade Policy Database and the Services Trade Restrictions Index. Staff Working Paper ERSD-2019-14. Geneva: World Trade Organization.

Bradbury, D., T. Hanappi, and A. Moore. 2018. Estimating the Fiscal Effects of Base Erosion and Profit Shifting: Data Availability and Analytical Issues. Transnational Corporations. 25 (2). pp. 91-106.

Bukht R. and R. Heeks. 2017. Defining, Conceptualising and Measuring the Digital Economy. Development Informatics Working Papers Series. No. 68. Manchester: University of Manchester.

Bunge, J. and J. Newman. 2021. Ransomware Attack Roiled Meat Giant JBS, Then Spilled Over to Farmers and Restaurants. Wall Street Journal. 11 June. https://www.wsj.com/articles/ransomwareattack-roiled-meat-giant-jbs-then-spilled-overto-farmers-and-restaurants-11623403800.

Burwell, F. and K. Propp. 2020. The European Union and the Search for Digital Sovereignty: Building 'Fortress Europe' or Preparing for a New World? Issue Brief. June 2020. Washington, DC: Atlantic Council.

Caliendo, L. and F. Parro. 2015. Estimates of the Trade and Welfare Effects of NAFTA. Review of Economic Studies. 82 (1). pp. 1-44.

Caselli, F. and W. J. Coleman. 2001. Cross-country Technology Diffusion: The Case of Computers. American Economic Review. 91 (2). pp. 328-35.

CATO Institute. Human Freedom Index. https://www.cato.org/human-freedom-index/ 2020 (accessed July 2021).

Chaisse, J., H. Gao, and C. Lo, eds. 2017. Paradigm Shift in International Economic Law Rule-Making: TPP as a New Model for Trade Agreements. Singapore: Springer. 
Chang, L. Y.-C. 2020. Legislative Frameworks Against Cybercrime: The Budapest Convention and Asia. In T. Holt and A. Bossler. The Palgrave Handbook of International Cybercrime and Cyberdeviance. London: Palgrave McMillian.

- 2017. Cybercrime and Cyber Security in ASEAN. In J. Liu, M. Travers, and L.Y.-C. Chang, eds. Comparative Criminology in Asia. New York: Springer.

Chinn, M. D. and R. W. Fairlie. 2007. The Determinants of the Global Digital Divide: A Cross-Country Analysis of Computer and Internet Penetration. Oxford Economic Papers. 59 (1). pp. 16-44.

Choi, C. 2009. The Effect of the Internet on Service Trade. Economics Letters. 109 (2010). pp. 102-04.

Chor, D. 2011. Unpacking Sources of Comparative Advantage: A Quantitative Approach. Journal of International Economics. 82 (2). pp. 152-67.

CISCO. Digital Readiness Index. https://www.cisco.com/ c/m/en_us/about/corporate-social-responsibility/ research-resources/digital-readiness-index.html\#/ (accessed July 2021).

Civil Code of the People's Republic of China. http://english.www.gov.cn/archive/ lawsregulations/202012/31/content_ WS5fedad98c6d0f72576943005.html.

Clarke, G. and S. Wallsten. 2004. Has the Internet Increased Trade? Evidence from Industrial and Developing Countries. World Bank Policy Research Working Paper. No. 3215. Washington, DC: World Bank.

Cornell Law School. Legal Information Institute. 47 U.S.C. 230 - Protection for private blocking and screening of offensive material. https://www.law.cornell.edu/ uscode/text/47/230.

Correia, S., P. Guimarães, and T. Zylkin. 2019. PPMLHDFE: Fast Poisson Estimation with High-Dimensional Fixed Effects. The Stata Journal: Promoting Communications on Statistics and Stata. 20 (1). pp. 95-115.
CUTS. 2020. Data Localisation: India's Double-Edged Sword. Jaipur.

Dalgic, B. and B. Fazlioglu. 2020. The Impact of Broadband Speed on Productivity: Findings from Turkish Firms. Applied Economics Letters. 27 (21). pp. 1764-67.

DataKom. 2016. How Slow Internet Speeds Can Impact Productivity. 22 July. https://www.datakom. co.uk/2016/07/how-slow-internet-speeds-canimpact-productivity/.

Dee, P. 2005. A Compendium of Barriers to Services Trade. Canberra: Crawford School of Economics and Government, Australian National University.

Dekle, R., J. Eaton, and S. Kortum. 2007. Unbalanced Trade. American Economic Review. 97 (2). pp. 351-355.

Dingel, J. and B. Neiman. 2020. How Many Jobs Can Be Done at Home? NBER Working Paper. No. 6948. Cambridge, MA: National Bureau of Economic Research.

Dou, E. 2015. IBM Allows Chinese Government to Review Source Code. Wall Street Journal. 16 October. https://www.wsj.com/articles/ibmallows-chinese-government-to-review-sourcecode-1444989039.

Drake-Brockman, J. 2020. Australia-Singapore Digital Trade Agreement: Setting New Benchmarks in Trade Governance. Opinion. Institute for International Trade. 24 August. https://iit.adelaide. edu.au/news/list/2020/08/24/australia-singaporedigital-trade-agreement-setting-new-benchmarksin-trade.

Drake-Brockman, J., G. Gari, S. Harbinson, B. Hoekman, H. K. Nordås, and S. Stephenson. 2021. Digital Trade and the WTO: Negotiation Priorities for Cross-Border Data Flows and Online Trade in Services. TIISA Working Paper. No. 2021-11. Adelaide: Institute for International Trade. 
Drake-Brockman, J. and S. Stephenson. 2012. Implications for 21st Century Trade and Development of The Emergence of Services Supply Chains. Geneva: International Centre for Trade and Sustainable Development.

- 2014. The Services Trade Dimension of Global Value Chains: Policy Implications for Commonwealth Developing Countries and Small States. Commonwealth Trade Policy Discussion Papers. No. 2014/04. London: Commonwealth Secretariat.

Ease of Doing Business Index. https://www. doingbusiness.org (accessed July 2021).

Eaton, J. and S. Kortum. 2002. Technology, Geography, and Trade. Econometrica. 70 (5). pp. 1741-79.

Eden, L. 2020. Winners and Losers: The OECD's Economic Impact Assessment of Pillar One. Tax Management International Journal. 49 (12). pp. 597-609.

Egger, P. and M. Larch. 2008. Interdependent Preferential Trade Agreement Memberships: An Empirical Analysis. Journal of International Economics. 76 (2). pp. 384-399.

Egger, P., M. Larch. S. Nigai, and Y. Yotov. 2018. Trade Costs in the Global Economy: Measurement, Aggregation, and Decomposition. Staff Working Paper. ERSD2021-2. Geneva: World Trade Organization.

European Commission. 2018a. Proposal for a Council Directive Laying Down Rules Relating to the Corporate Taxation of a Significant Digital Presence of 21 March 2018. Brussels.

European Commission. 2018b. Proposal for a Council Directive on the Common System of a Digital Services Tax on Revenues Resulting from the Provision of Certain Digital Services of 21 March 2018. Brussels.
European Commission. 2018c. Commission Staff Working Document Impact Assessment (Accompanying the Proposal for a Council Directive Laying Down Rules Relating to the Corporate Taxation of a Significant Digital Presence and Proposal for a Council Directive on the Common System of a Digital Services Tax on Revenues Resulting from the Provision of Certain Digital Services). 21 March. https://www.eumonitor. eu/9353000/1/j9vvik7m1c3gyxp/vk9idfnk1qrb.

-2019. Questions to the Commissioner-Designate Thierry Breton. Brussels. https://ec.europa.eu/ commission/commissioners/sites/default/ files/commissioner_ep_hearings/answers-epquestionnaire-breton.pdf.

. 2020a. Communication from the Commission to the European Parliament, The Council, The European Economic and Social Committee and the Committee of the Regions: A European Strategy for Data. COM (2020) 66 final. 19 February. https://ec.europa.eu/info/sites/info/ files/communication-european-strategy-data19feb2020_en.pdf.

2020b. Communication from the Commission to the European Parliament and the Council: Data Protection as a Pillar of Citizens' Empowerment and the EU's Approach to the Digital TransitionTwo Years of Application of the General Data Protection Regulation. COM (2020) 264 final. 24 June. https://www.eumonitor.eu/9353000/1/ j9vvik7m1c3gyxp/vl9thg3be9uy.

European Parliament and Council. 1995. Directive 95/46/ EC on the Protection of Individuals with regard to the Processing of Personal Data and on the Free Movement of such Data. OJ1995 L281. 23 November. pp. 31-50.

.1998. Framework for the Free Flow of NonPersonal Data in the European Union. Regulation 2018/1807. 14 November. https://www. europeansources.info/record/regulation-eu-20181807-on-a-framework-for-the-free-flow-of-nonpersonal-data-in-the-european-union/. 
2016. European Union Regulation 2016/679 on the Protection of Natural Persons with regard to the Processing of Personal Data and on the Free Movement of such Data and Repealing Directive 95/46/EC (General Data Protection Regulation). 27 April.

Everest Group. 2020. Recalibration of Industry Growth Forecasts 2020-22. Manila: IT and Business Process Association of the Philippines.

Ferencz, J. 2019. The OECD Digital Services Trade Restrictiveness Index. OECD Trade Policy Papers. No. 221. Paris: OECD Publishing.

Ferracane, M. F. and E. van der Marel. 2020. Digital Innovation in East Asia: Do Restrictive Data Policies Matter. Policy Research Working Paper Series. No. 9124. Washington DC: World Bank.

_2021. Regulating Personal Data: Data Models and Digital Services Trade. Policy Research Working Paper Series. No. 9596. Washington, DC: World Bank.

Ferracane, M., H. Lee Makiyama, and E. van der Marel. 2018. Digital Trade Restrictiveness Index. Brussels: ECIPE.

Fintech Philippines. Fintech Report Philippines 2020: Mapping out the Fintech Philippines Ecosystem. Manila.

Frankel, J. A. and D. H. Romer. 1999. Does Trade Cause Growth?. American Economic Review. 89 (3). pp. 379-399.

Frost \& Sullivan. 2018. Digital Market Overview: Indonesia. White Paper. Santa Clara, CA.

Froy, F., S. Giguère, and M. Meghnagi. 2012. Skills for Competitiveness: A Synthesis Report. Paris: OECD Publishing.

Gao, H. 2008. Commentary on Telecommunication Services. In R. Wolfrum and P.-T. Stoll, eds. Max Planck Commentaries on World Trade Law. Volume VI: WTO_Trade in Services. Leiden: Brill Publishers.
2019. Data Regulation with Chinese Characteristics. SMU Centre for AI \& Data Governance Research Paper. No. 2019/04. Singapore Management University.

2021a. Data Regulation in Trade Agreements: Different Models and Optios Ahead. In M. Smeets, ed. WTO Chairs Programme-Adapting to the Digital Trade Era: Challenges and Opportunities. Geneva: World Trade Organization.

Goldfarb, A. and D. Trefler. 2018. Al and International Trade. NBER Working Papers. No. 24254. Cambridge, MA: National Bureau of Economic Research.

Google, Temasek, and Bain \& Co. 2019. e-.conomy: SEA 2019. https://www.blog.google/documents/47/ SEA_Internet_Economy_Report_2019.pdf.

Government of Australia, International Cyber and Critical Technology Engagement Strategy. https://www.internationalcybertech.gov.au.

Government of India, Directorate General of Commercial Intelligence and Statistics. http://www.dgciskol.gov.in (accessed July 2021).

Government of Singapore, Ministry of Trade and Industry. 2021. Digital Economy Partnership Agreement (DEPA). https://www.mti.gov.sg/ Improving-Trade/Digital-Economy-Agreements/ The-Digital-Economy-Partnership-Agreement.

Government of the United States, International Trade Administration. Privacy Shield Framework. Mongolia Country Commercial Guide. https://www.privacyshield.gov/ article?id=Mongolia-ECommerce.

Government of the United States, United States Trade Representative. United States-Mexico-Canada Agreement (USMCA) Legal Text. USMCA 7/1/20. https://ustr.gov/trade-agreements/free-tradeagreements/united-states-mexico-canadaagreement/agreement-between. 
Grabosky, P. 2016. Cybercrime. Oxford University Press.

Grigorescu, A., E. Pelinescu, A. E. Ion, and M. F. Dutcas. 2021. Human Capital in Digital Economy:

An Empirical Analysis of Central and Eastern European Countries from the European Union. Sustainability. 13(4). Article 2020.

Grimes, A., C. Ren, and P. Stevens. 2012. The Need for Speed: Impacts of Internet Connectivity on Firm Productivity. Journal of Productivity Analysis. 37 (2). pp. 187-201.

Haltenhof, S. 2019. Services Trade and Internet Connectivity. Discussion Paper. No. 668. Ann Arbor, MI: University of Michigan.

Head, K. and T. Mayer. 2014. Gravity Equations: Workhorse, Toolkit, and Cookbook. In G. Gopinath, E. Helpman and K. Rogoff, eds. Handbook of International Economics Volume 4. Oxford: Elsevier.

Heid, B., M. Larch, and Y. Yotov. 2021. Estimating the Effects of Non-Discriminatory Trade Policies Within. Canadian Journal of Economics. 54 (1). pp. 376-409.

Hindley, B. and A. Smith. 1984. Comparative Advantage and Trade in Services. World Economy. 7 (4). pp. 369-390.

Hinrich Foundation. 2020a. The Data Revolution: How the Philippines Can Capture the Digital Trade Opportunity at Home and Abroad. Digital Trade Research Project. Scottsdale, AZ.

-2020b. The Data Opportunity: The Promise of Digital Trade for India. Scottsdale, AZ.

2020c. The Data Revolution: How China Can Capture the Digital Trade Opportunity at Home and Abroad. Centre for China and Globalization. Scottsdale, AZ.

-2020d. The Komodo Dragon: How Indonesia Can Capture the Digital Trade Opportunity at Home and Abroad. Digital Trade Research Report. Scottsdale, AZ.
Honey, S. 2021. Enabling Trust, Trade Flows and Innovation: the DEPA at Work. Hinrich Foundation. 21 July. https://www.hinrichfoundation.com/ research/article/digital/enabling-trust-trade-flowsand-innovation-depa-at-work/.

Ikeda, S. 2021. Ransomware Attack Reported at Insurance Giant AXA One Week After It Changes Cyber Insurance Policies in France. CPO Magazine. 5 May. https://www.cpomagazine.com/ cyber-security/ransomware-attack-reported-atinsurance-giant-axa-one-week-after-it-changescyber-insurance-policies-in-france/.

IMD. 2020. IMD World Digital Competitiveness Ranking 2020. New Delhi.

International Labour Organization. ILOStat Database. https://ilostat.ilo.org (accessed July 2021).

International Monetary Fund (IMF). 2021. Digitalization and Taxation in Asia. Departmental Paper. No 2021/017. Washington, DC.

International Telecommunication Union. Enhancing Cybersecurity in Least Developed Countries. https://www.itu.int/en/ITU-D/Cybersecurity/ Pages/CYBLDC.aspx.

_. Definition of Cyberspace. https://www.itu.int/en/ ITU-T/studygroups/com17/Pages/cybersecurity. aspx.

_ ICT Statistics. https://www.itu.int/en/ITU-D/ Statistics/Pages/stat/default.aspx (accessed July 2021).

—. World Telecommunication/ICT Indicators 2020 Database 24th Edition. https://www.itu.int/en/ ITU-D/Statistics/Pages/publications/wtid.aspx (accessed July 2021).

Interpol. 2021. Interpol Report Charts Top

Cyberthreats in Southeast Asia. News. 22 January. https://www.interpol.int/en/News-and-Events/ News/2021/INTERPOL-report-charts-topcyberthreats-in-Southeast-Asia. 
Irwin, L. 2021. How Much does GDPR Compliance Cost in 2021? IT Governance Blog EU. 10 June. https://www.itgovernance.eu/blog/en/how-muchdoes-gdpr-compliance-cost-in-2020.

Johnson, R. and G. Noguera. 2012. Accounting for Intermediates: Production Sharing and Trade in Value Added. Journal of International Economics. 86 (2). pp. 224-36.

Kerneis, P. 2021. The Landing Zone in Trade Agreements for Cross-Border Data Flows. TIISA Working Paper. No 2021-12. Adelaide: Institute for International Trade.

Kissel, R., ed. 2013. Glossary of Key Information Security Terms. NIST Interagency or Internal Report (NISTIR). 7298 Revision 2. Gaithersburg, MD: National Institute of Standards and Technology, US Department of Commerce.

Koopman, R., Z. Wang, and S.-J. Wei. 2014. Tracing ValueAdded and Double Counting in Gross Exports. American Economic Review. 104 (2). pp. 459-94.

KPMG. 2022. Taxation of the Digitalized Economy: Developments Summary. February.

Loveless, B. n.d. The Importance of Digital Literacy in K-12. Education Corner. https://www.educationcorner.com/importancedigital-literacy-k-12.html.

Low, P. 2020. Digital Services Taxes, Trade and Development. Working Paper. No. 2020-07. Adelaide: Institute for International Trade.

Manyika, J., S. Lund, J. Bughin, J. Woetzel, K. Stamenov, and D. Dhingra. 2016. Digital Globalization: The New Era of Global Flows. Washington, DC: McKinsey Global Institute.

Martin, A. and J. Grudziecki. 2006. DigEuLit: Concepts and Tools for Digital Literacy Development. Innovation in Teaching and Learning in Information and Computer Sciences. 5 (4). pp. 249-67.
Mattoo, A. and J. P. Meltzer. 2018. International Data Flows and Privacy: The Conflict and Its Resolution. Journal of International Economic Law. 21 (4). pp. 769-89.

Mavroidis, P. C. 2020. And You Put the Load Right on Me: Digital Taxes, Tax Discrimination and Trade in Services. Trade, Law and Development. 12 (1). pp. 75-108.

Meltzer, J. 2020. China's Digital Trade and Data Governance. How Should the United States Respond? The Brookings Institution. October. https://www.brookings.edu/articles/chinas-digitalservices-trade-and-data-governance-how-shouldthe-united-states-respond/.

Meltzer, J. P. and Kerry, C. F. 2019. Cybersecurity and Digital Trade: Getting it Right. Washington, DC: The Brookings Institution.

Noonan, C. and V. Plekhanova. 2020. Taxation of Digital Services under Trade Agreements. Journal of International Economic Law. 23. pp. 1015-39.

Nordas, H. 2016. Services Trade Restrictiveness Index (STRI): The Trade Effect of Regulatory Differences. Trade Policy Paper. No. 189. Paris: OECD Publishing.

Organisation for Economic Co-operation and Development (OECD) 2011. OECD Guide to Measuring the Information Society. Paris.

_. 2012. OECD Internet Economy Outlook 2012. Paris.

_. 2016. Skills and Jobs in the Digital Economy: A Digital Economy Toolkit. Paris.

- 2018a. Implications of the Digital Transformation for the Business Sector. Paris.

_. 2018b. Tax Challenges Arising from DigitalisationInterim Report 2018: Inclusive Framework on BEPS, OECD/G20 Base Erosion and Profit Shifting Project. Paris. 
_ 2019. The Role of Digital Platforms in the Collection of VAT/GST on Online Sales. Paris.

_. 2020. Tax Challenges Arising from DigitalisationEconomic Impact Assessment: Inclusive Framework on BEPS, OECD/G20 Base Erosion and Profit Shifting Project. Paris.

_. 2021.Lowering APEC Trade Costs through Services Domestic Regulation Reform. OECD Trade Policy Brief. June. Paris.

_. Digital Services Trade Restrictiveness Index. https://stats.oecd.org/Index. aspx?DataSetCode=STRI_DIGITAL\# (accessed October 2021).

— Digital Trade. https://www.oecd.org/trade/topics/ digital-trade/.

—. Trade in Value Added (TiVA) Database. https://stats.oecd.org/Index. aspx?datasetcode=TIVA_2018_C1\# (accessed July 2021).

OECD and World Trade Organization (WTO). 2021. The OECD-WTO Balanced Trade in Services Database (BPM6 edition). Paris: OECD Publishing.

OECD, WTO, and International Monetary Fund (IMF). 2019. Handbook on Measuring Digital Trade. Paris: OECD Publishing.

Osborne Clarke. 2020. The Future of Insurance in AsiaPacific: Navigating InsurTech Issues in the Digital Era. London.

Ottaviano, G. 2015. European Integration and the Gains from Trade. In H. Badinger and V. Nitsch, eds. Routledge Handbook of the Economics of European Integration. London: Routledge.

Reserve Bank of India. 2018. Survey on Computer Software \& IT Enabled Services Exports. Mumbai.
Robacker, T. 2017. More Than 75 Percent of Fifth and Eighth Graders are Non-Proficient in 21st Century Skills, According to Learning.com Study. Learning. com. 22 August. https://www.learning.com/morethan-75-percent-of-fifth-and-eighth-graders-arenon-proficient-in-21st-century-skills-according-tolearning-com-study/.

Sáez, S., D. Taglioni, E. Van der Marel, C. H. Hollweg, and V. Zavack. 2015. Valuing Services in Trade: A Toolkit for Competitiveness Diagnostics. Washington, DC: World Bank.

Santos Silva, J. M. C., and S. Tenreyro. 2006. The Log of Gravity. The Review of Economics and Statistics. 88 (4). pp. 641-58.

Scott, M. 2019. What's Driving Europe's New Aggressive Stance on Tech? Politico. 27 October. https://www. politico.eu/article/europe-digital-technologicalsovereignty-facebook-google-amazon-ursulavon-der-leyen/.

Serafica, R. and J. R. Albert. 2018. Issues in Digital Trade. Manila: Philippine Institute of Development Studies.

Shapiro, J. 2020. Introduction: Europe's Digital Sovereignty. In C. Hobbs, ed. Europe's Digital Sovereignty: From Rulemaker to Superpower in the Age of US-China Rivalry. Berlin: European Council on Foreign Relations.

Shepherd, B. 2019. Productivity and Trade Growth in Services: How Services Helped Power Factory Asia. In M. Helble and B. Shepherd, eds. Leveraging Services for Development: Prospects and Policies. Manila: ADB.

_ 2021a. Modeling Global Value Chains: From Trade Costs to Policy Impacts. Working Paper. DTC-2021-1. New York, NY: Developing Trade Consultants.

Spante, M., S. S. Hashemi, M. Lundin, A. Algers, and S. Wang. 2018. Digital Competence and Digital Literacy in Higher Education Research: Systematic Review of Concept Use. Cogent Education. 5 (1). Article 1519143. 
Topornin, N., D. Pyatkina, and Y. Bokov. 2021. Government Regulation of the Internet as Instrument of Digital Protectionism in Case of Developing Countries. Journal of Information Science. May 2021. doi:10.1177/01655515211014142.

United Nations (UN). 2011. Manual on Statistics of International Trade in Services 2010 (MSITS 2010). New York, NY.

- 2020. Committee of Experts on International Cooperation in Tax Matters, 20th Session. E/C.18.2020/CRP.25. 30 May. New York. https://www.un.org/development/desa/financing/ sites/www.un.org.development.desa.financing/ files/2020-06/CICTM\%2020th_CRP.25\%20 _\%20Digitalized\%20Economy.pdf.

2021. Committee of Experts on International Cooperation in Tax Matters, 22nd Session. E/C.18/2021/CRP.1 6. April. New York. https://www.un.org/development/desa/financing/ sites/www.un.org.development.desa.financing/ files/2021-04/CITCM\%2022\%20CRP.1_ Digitalization\%206\%20April\%202021.pdf.

\section{E-Government Development Index.} https://publicadministration.un.org/egovkb/en-us/ Data/Compare-Countries (accessed July 2021).

United Nations Children's Fund (UNICEF). Education Overview. https://data.unicef.org/topic/education/ overview/.

United Nations Conference on Trade and Development (UNCTAD). 2011. Information Economy Report 2011: ICTs as an Enabler for Private Sector Development. Geneva.

- 2015. International Trade in ICT Services and ICT-Enabled Services: Proposed Indicators from the Partnership on Measuring ICT for Development. Technical Notes on ICT for Development. No 3. Geneva. 2017a. UNCTAD Training to Help Launch New Pilot Survey on International Trade in ICTEnabled Services. https://unctad.org/meeting/ unctad-traininghelp-launch-new-pilot-surveyinternational-trade-ict-enabled-services.

2017b. World Investment Report 2017. Geneva.

2018. India's Digital Services Exports Hit \$83 Million Says New Survey. News. 14 November. https://unctad.org/news/indias-digital-servicesexports-hit-83-million-says-new-survey.

_ 2019. Digital Economy Report 2019: Value Creation and Capture-Implications for Developing Countries. Geneva.

. UNCTADStat: WTO-UNCTAD (BPM6) International Trade in Services Annual Dataset. https://unctadstat.unctad.org/ (accessed July 2021).

United Nations Development Programme (UNDP). Human Development Data Center. http://hdr.undp.org/ en/data (accessed July 2021).

United Nations Economic and Social Commission for Asia and the Pacific (UNESCAP). 2016. International Trade in a Digital Age. In Asia Pacific Trade and Investment Report. Bangkok.

2020. Asia-Pacific Trade and Investment Trends 2020/2021: Trade in Commercial Services Outlook in Asia and the Pacific. Bangkok.

US Trade Office of the United States Representative. 2020. https://ustr.gov/sites/default/files/ enforcement/301Investigations/DST_Initiation_ Notice_June_2020.pdf.

van der Marel, E. 2021a. Digital-Based Services Globalization and Multilateral Trade Cooperation. Global Policy. 12 (3). pp. 392-98.

Voon, T. 2019. The Security Exception in WTO Law: Entering a New Era. AJIL Unbound. 113. pp. 45-50. 
Wang, Z., S.-J. Wei, and K. Zhu. 2013 (Revised 2018). Quantifying International Production Sharing at the Bilateral and Sector Levels. NBER Working Paper. No. 19677. Cambridge, MA: National Bureau of Economic Research.

Woetzel, J., J. Seong, K. W. Wang, J. Manyika, M. Chui, and W. Wong. 2017. China's Digital Economy-A Leading Global Force. Discussion Paper. Washington, DC: McKinsey Global Institute.

World Bank. Global Competitivness Index. https://tcdata360.worldbank.org (accessed July 2021).

- World Development Indicators. https://databank. worldbank.org/source/world-developmentindicators (accessed August 2021).

World Economic Forum (WEF). 2020. The Future of Jobs Report 2020. October. Geneva.

_. 2021. Digital Trade in Services and Taxation. White Paper. October. https://www.weforum.org/ whitepapers/digital-trade-in-services-andtaxation.

World Trade Organization (WTO). 1994. Annex on Telecommunications, GATS, (1999). 15 April., Marrakesh Agreement Establishing the World Trade Organization, Annex 1B, The Legal Texts: The Results of the Uruguay Round of Multilateral Trade Negotiations 284 (1999), 1869 U.N.T.S. 183, 33 I.L.M. 1167 (1994). Geneva.

- 1998. Work Programme on Electronic Commerce (Adopted by the General Council on 25 September 1998). WT/L/274. 30 September. Geneva.

. 1999. Work Program on Electronic Commerce: Progress Report to the General Council (Adopted by the Council for Trade in Services on 19 July 1999). S/L/74. 27 July. Geneva.
2001. Guidelines for the Scheduling of Specific Commitments under the GATS (Adopted by the Council for Trade in Services on 23 March 2001). S/L/92. 28 March. Geneva.

2013. Work Programme on Electronic Commerce, Dedicated Discussion on Electronic Commerce Under the Auspices of the General Council: Report to the 21 November 2013 Meeting of the General Council. WT/GC/W/676. 11 November. Geneva.

- 2019. Work Programme on Electronic Commerce: General Council Decision (Adopted on 10 December 2019). WT/L/1079. 11 December. Geneva.

- 2020. Negotiations on E-commerce Continue, Eyeing a Consolidated Text by the End of the Year. News. 26 October. Geneva.

- 2021a. Negotiations on Services Domestic Regulation Conclude Successfully in Geneva. News. 2 December. https://www.wto.org/english/news_e/ news21_e/jssdr_02dec21_e.htm.

- 2021b. Adapting to the Digital Trade Era: Challenges and Opportunities. Geneva.

- Regional Trade Agreements Database. https://rtais.wto.org/UI/PublicMaintainRTAHome. aspx (accessed July 2021).

-WTO-OECD Balanced Trade in Services Dataset (BaTIS)-BPM 6. https://www.wto.org/english/ res_e/statis_e/trade_datasets_e.htm (accessed May and August 2021).

WTO and Directorate-General for Trade of the European Commission. Trade in Services Data by Mode of Supply (TISMOS). https://www.wto.org/ english/res_e/statis_e/trade_datasets_e.htm (accessed July 2021). 
Wunsch-Vincent, S. and A. Hold. 2012. Towards

Coherent Rules for Digital Trade: Building on

Efforts in Multilateral versus Preferential Trade

Negotiations. In M. Burri and T. Cottier, eds. Trade

Governance in the Digital Age: World Trade Forum.

Cambridge: Cambridge University Press.

Zhang, L., and S. Chen. 2019. China's Digital Economy:

Opportunities and Risks. Washington, DC:

International Monetary Fund. 


\section{Table A3: Trade Share-Asia and the Pacific (\% of total trade)}

It is calculated as $T_{i j} / T_{i w} \cdot 100$, where $T_{i j}$ is the total trade of economy "i" with economy " $j$ ", and $T_{i w}$ is the total trade of economy " $i$ " with the world. A higher share indicates a higher degree of regional trade integration.

\section{Table A4: Free Trade Agreement Status-Asia and the Pacific}

It is the number and status of bilateral and plurilateral free trade agreements (FTAs) with at least one of the Asian economies as signatory. FTAs that are only proposed are excluded. It covers FTAs with the following status: Framework agreement signed - the parties initially negotiate the contents of a framework agreement, which serves as a framework for future negotiations; Negotiations launched - the parties, through the relevant ministries, declare the official launch of negotiations or set the date for such, or start the first round of negotiations; Signed but not yet in effect-parties sign the agreement after negotiations have been completed, however, the agreement has yet to be implemented; and Signed and in effect-provisions of the FTA come into force, after legislative or executive ratification.

\section{Table A5: Cross-Border Portfolio Equity Holdings Share-Asia and the Pacific (\% of total cross-border portfolio equity holdings)}

It is calculated as $E_{i j} E_{i w} \cdot 100$ where $E_{i j}$ is portfolio equity holdings of economy "i" issued by economy " $j$ ", and $E_{i w}$ is the total global cross-border portfolio equity holdings of economy "i". Calculations are based solely on available data in the Coordinated Portfolio Investment Survey (CPIS) database of the International Monetary Fund (IMF). Rest of the world (ROW) includes equity securities issued by international organizations defined in the CPIS database and "not specified (including confidential) category." A higher share indicates a higher degree of regional integration.

\section{Table A6: Cross-Border Portfolio Debt Holdings Share-Asia and the Pacific (\% of total cross-border portfolio debt holdings)}

It is calculated as $D_{i j} / D_{i w} \cdot 100$ where $D_{i j}$ is portfolio debt holdings of economy " $i$ " issued by economy " $j$ ", and $D_{i w}$ is the total global cross-border portfolio debt holdings of economy "i". Calculations are based solely on available data in the CPIS database of the IMF. ROW includes debt securities issued by international organizations defined in the CPIS database and "not specified (including confidential) category." A higher share indicates a higher degree of regional integration.

\section{Table A7: Foreign Direct Investment Inflow Share-Asia and the Pacific (\% of total FDI inflows)}

It is calculated as $F_{i} / F_{i w} \cdot 100$ where $F_{i j}$ is the foreign direct investment (FDI) received by economy "i" from economy " $j$ ", and $F_{i w}$ is the FDI received by economy " $i$ " from the world. Figures are based on net FDI inflow data. A higher share indicates a higher degree of regional integration. The bilateral FDI database was constructed using data from the United Nations Conference on Trade and Development, ASEAN Secretariat, Eurostat, and national sources. For missing data in in the last 2 years of the inclusive period, bilateral FDI estimates derived from a gravity model are used. All bilateral data available beginning 2001 were utilized to estimate the following gravity equation:

$$
\begin{aligned}
\ln F D I_{i j t}= & \alpha+\beta 1 \ln G D P_{i t}+\beta 2 \ln G D P_{j t}+ \\
& \gamma X_{i j t}+\delta_{i} F_{i}+\delta_{j} F_{j}+\delta_{t} F_{t}+v_{i j t}
\end{aligned}
$$

where $F D I_{i j t}$ is the FDI from economy " $j$ " (home) to economy "i" (host) in year $t, G D P_{i t}$ is the gross domestic product (GDP) of economy " $i$ " in year $t, G D P_{j t}$ is the GDP of economy " $j$ " at year $t, X_{i j t}$ are the usual gravity variables (distance, contiguity, common language, colonial relationship) between economies "i" and "j", and $F_{j}, F_{i}, F_{t}$, are home, host, and year fixed effects, respectively, and $v_{i j t}$ is the error term. Data on distance, 
contiguity, common language, colonial relationship are from the Centre d'Études Prospectives et d'Informations Internationales (the French Research Center in International Economics) and data on GDP are from the World Development Indicators of the World Bank. For more details on methodology and data sources, please see Asian Economic Integration Report 2018 online Annex 1: http://aric.adb.org/pdf/aeir2018_onlineannex1. pdf.

\section{Table A8: Remittance Inflows Share-Asia and the Pacific (\% of total remittance inflows)}

It is calculated as $R_{i j} / R_{i w} \cdot 100$ where $R_{i j}$ is the remittance received by economy "i" from partner " $"$ ", and $R_{i w}$ is the remittance received by economy "i" from the world. Remittances refer to the sum of the following: (i) workers' remittances which are recorded as current transfers under the current account of the IMF's Balance of Payments (BOP); (ii) compensation of employees which includes wages, salaries, and other benefits of border, seasonal, and other nonresident workers and which are recorded under the "income" subcategory of the current account; and (iii) migrants' transfers which are reported under capital transfers in the BOP's capital account. Transfers through informal channels are excluded.

\section{Table A9: Outbound Migration}

Share-Asia and the Pacific (\% of total outbound migrants)

It is calculated as $M_{i j} / M_{i w} \cdot 100$ where $M_{i j}$ is the number of migrants of economy "i" residing in economy "j", and $M_{i w}$ is the number of all migrants of economy " $i$ " residing overseas. This definition excludes those traveling abroad on a temporary basis. A higher share indicates a higher degree of regional integration.

\section{Table A10a: Inbound Tourism Share-Asia and the Pacific (\% of total inbound tourists)}

It is calculated as $V_{i j} / V_{i w} \cdot 100$ where $V_{i j}$ is the number of nationals of economy "i" that have arrived as tourists in destination " $"$ ", and $V_{i w}$ is the total number of nationals of economy "i" that have arrived as tourists in all international destinations. A higher share indicates a higher degree of regional integration.

\section{Table A10b: Outbound Tourism Share-Asia and the Pacific (\% of total outbound tourists)}

It is calculated as $V_{i j} / V_{i w} \cdot 100$ where $V_{i j}$ is the number of nationals of economy "i" that have traveled as tourists in destination " $j$ ", and $V_{i w}$ is the total number of nationals of economy "i" that have traveled as tourists abroad. A higher share indicates a higher degree of regional integration. 
Table A1: Asia-Pacific Regional Cooperation Integration Index

a: Overall Asia-Pacific Regional Cooperation and Integration Index and Dimensional Subindexes-Asia and the Pacific

\begin{tabular}{|c|c|c|c|c|c|c|c|c|c|}
\hline \multirow[b]{2}{*}{ Year } & \multirow[b]{2}{*}{$\begin{array}{l}\text { Overall } \\
\text { Index }\end{array}$} & \multicolumn{8}{|c|}{ Dimensional Indexes } \\
\hline & & $\begin{array}{l}\text { Trade and } \\
\text { Investment } \\
\text { Integration }\end{array}$ & $\begin{array}{l}\text { Money and } \\
\text { Finance } \\
\text { Integration }\end{array}$ & $\begin{array}{l}\text { Regional } \\
\text { Value } \\
\text { Chain }\end{array}$ & $\begin{array}{l}\text { Infrastructure } \\
\text { and Connectivity }\end{array}$ & $\begin{array}{c}\text { People } \\
\text { and Social } \\
\text { Integration }\end{array}$ & $\begin{array}{l}\text { Institutional } \\
\text { Arrangements }\end{array}$ & $\begin{array}{l}\text { Technology } \\
\text { and Digital } \\
\text { Connectivity }\end{array}$ & $\begin{array}{l}\text { Environmental } \\
\text { Cooperation }\end{array}$ \\
\hline 2006 & 0.447 & 0.439 & 0.332 & 0.553 & 0.450 & 0.562 & 0.213 & 0.361 & 0.499 \\
\hline 2007 & 0.448 & 0.384 & 0.330 & 0.556 & 0.452 & 0.574 & 0.217 & 0.377 & 0.506 \\
\hline 2008 & 0.444 & 0.406 & 0.335 & 0.547 & 0.454 & 0.560 & 0.224 & 0.385 & 0.508 \\
\hline 2009 & 0.453 & 0.411 & 0.335 & 0.537 & 0.461 & 0.560 & 0.229 & 0.388 & 0.515 \\
\hline 2010 & 0.471 & 0.444 & 0.352 & 0.544 & 0.478 & 0.580 & 0.233 & 0.416 & 0.513 \\
\hline 2011 & 0.451 & 0.472 & 0.313 & 0.540 & 0.478 & 0.572 & 0.234 & 0.435 & 0.515 \\
\hline 2012 & 0.454 & 0.444 & 0.317 & 0.544 & 0.482 & 0.577 & 0.237 & 0.428 & 0.514 \\
\hline 2013 & 0.473 & 0.443 & 0.363 & 0.548 & 0.484 & 0.564 & 0.238 & 0.463 & 0.520 \\
\hline 2014 & 0.469 & 0.424 & 0.352 & 0.542 & 0.481 & 0.561 & 0.240 & 0.462 & 0.526 \\
\hline 2015 & 0.476 & 0.485 & 0.368 & 0.544 & 0.477 & 0.560 & 0.243 & 0.481 & 0.540 \\
\hline 2016 & 0.479 & 0.449 & 0.341 & 0.542 & 0.481 & 0.565 & 0.244 & 0.481 & 0.550 \\
\hline 2017 & 0.477 & 0.442 & 0.359 & 0.540 & 0.483 & 0.567 & 0.246 & 0.490 & 0.530 \\
\hline 2018 & 0.475 & 0.470 & 0.359 & 0.530 & 0.493 & 0.568 & 0.247 & 0.522 & 0.511 \\
\hline 2019 & 0.479 & 0.439 & 0.342 & 0.547 & 0.497 & 0.576 & 0.248 & 0.517 & 0.505 \\
\hline
\end{tabular}

b: Overall Asia-Pacific Regional Cooperation and Integration Index-Asian Subregions and Subregional Initiatives

\begin{tabular}{|ccccccccccc} 
& Central Asia & East Asia & $\begin{array}{c}\text { Southeast } \\
\text { Asia }\end{array}$ & South Asia & Oceania & ASEAN & CAREC & GMS & SASEC \\
\hline 2006 & 0.320 & 0.494 & 0.501 & 0.405 & 0.504 & 0.502 & 0.322 & 0.496 & 0.392 \\
\hline 2007 & 0.323 & 0.484 & 0.503 & 0.415 & 0.483 & 0.504 & 0.367 & 0.497 & 0.416 \\
\hline 2008 & 0.327 & 0.502 & 0.506 & 0.415 & 0.495 & 0.507 & 0.332 & 0.503 & 0.411 \\
\hline 2009 & 0.346 & 0.510 & 0.508 & 0.406 & 0.508 & 0.512 & 0.352 & 0.505 & 0.400 \\
\hline 2010 & 0.342 & 0.503 & 0.516 & 0.430 & 0.524 & 0.517 & 0.378 & 0.504 & 0.455 \\
\hline 2011 & 0.351 & 0.492 & 0.512 & 0.429 & 0.515 & 0.521 & 0.366 & 0.503 & 0.427 \\
\hline 2012 & 0.351 & 0.502 & 0.513 & 0.444 & 0.514 & 0.517 & 0.371 & 0.507 & 0.448 \\
\hline 2013 & 0.371 & 0.507 & 0.524 & 0.447 & 0.521 & 0.527 & 0.395 & 0.519 & 0.446 \\
\hline 2014 & 0.361 & 0.515 & 0.522 & 0.435 & 0.521 & 0.531 & 0.385 & 0.514 & 0.442 \\
\hline 2015 & 0.373 & 0.525 & 0.531 & 0.444 & 0.522 & 0.541 & 0.400 & 0.520 & 0.442 \\
\hline 2016 & 0.372 & 0.525 & 0.526 & 0.447 & 0.523 & 0.535 & 0.405 & 0.519 & 0.456 \\
\hline 2017 & 0.373 & 0.522 & 0.522 & 0.436 & 0.516 & 0.537 & 0.404 & 0.509 & 0.448 \\
\hline 2018 & 0.382 & 0.522 & 0.526 & 0.426 & 0.512 & 0.537 & 0.412 & 0.518 & 0.435 \\
\hline 2019 & 0.381 & 0.527 & 0.524 & 0.424 & 0.512 & 0.536 & 0.413 & 0.508 & 0.409 \\
\hline
\end{tabular}


c: Regional Integration Index-Asia and the Pacific and Other Regions

\begin{tabular}{|lcccccc}
\hline & $\begin{array}{c}\text { Asia and } \\
\text { the Pacific }\end{array}$ & EU+UK & Latin America & Africa & Middle East & North America \\
\hline 2006 & 0.447 & 0.619 & 0.417 & 0.347 & 0.402 & 0.541 \\
\hline 2007 & 0.448 & 0.617 & 0.409 & 0.328 & 0.401 & 0.541 \\
\hline 2008 & 0.444 & 0.612 & 0.398 & 0.329 & 0.407 & 0.559 \\
\hline 2009 & 0.453 & 0.615 & 0.397 & 0.328 & 0.401 & 0.550 \\
\hline 2010 & 0.471 & 0.614 & 0.409 & 0.351 & 0.416 & 0.558 \\
\hline 2011 & 0.451 & 0.613 & 0.399 & 0.363 & 0.423 & 0.554 \\
\hline 2012 & 0.454 & 0.611 & 0.406 & 0.363 & 0.437 & 0.562 \\
\hline 2013 & 0.473 & 0.616 & 0.411 & 0.355 & 0.428 & 0.562 \\
\hline 2014 & 0.469 & 0.615 & 0.408 & 0.374 & 0.431 & 0.563 \\
\hline 2015 & 0.476 & 0.614 & 0.418 & 0.377 & 0.429 & 0.555 \\
\hline 2016 & 0.479 & 0.622 & 0.410 & 0.378 & 0.426 & 0.552 \\
\hline 2017 & 0.477 & 0.622 & 0.409 & 0.371 & 0.427 & 0.552 \\
\hline 2018 & 0.475 & 0.617 & 0.396 & 0.379 & 0.445 & 0.542 \\
\hline 2019 & 0.479 & 0.625 & 0.402 & 0.381 & 0.451 & 0.527 \\
\hline
\end{tabular}

ASEAN = Association of Southeast Asian Nations, CAREC = Central Asia Regional Economic Cooperation,

EU = European Union, GMS = Greater Mekong Subregion, SASEC = South Asia Subregional Economic Cooperation, UK = United Kingdom

Notes:

(i) The Asia-Pacific Regional Cooperation and Integration Index (ARCII) for each subregion (subregional initiative) for each year is calculated by averaging the ARCII scores for all the economies in each subregion (member economies in each subregional initiative).

(ii) The economy coverage for subregions and subregional initiatives include Central Asia (Georgia, Kazakhstan, and the Kyrgyz Republic); East Asia (the People's Republic of China [PRC]; Hong Kong, China; Japan; the Republic of Korea; and Mongolia); Southeast Asia (Cambodia, Indonesia, the Lao People's Democratic Republic [Lao PDR], Malaysia, the Philippines, Singapore, Thailand, and Viet Nam); South Asia (Bangladesh India, Nepal, Pakistan, and Sri Lanka); Oceania (Australia and New Zealand); ASEAN (Cambodia, Indonesia, the Lao PDR, Malaysia, the Philippines, Singapore, Thailand, and Viet Nam); CAREC (the PRC, Georgia, Kazakhstan, the Kyrgyz Republic, Mongolia, and Pakistan); GMS (Cambodia, the PRC, the Lao PDR, Thailand, and Viet Nam); SASEC (Bangladesh, India, Nepal, and Sri Lanka).

(iii) The regional integration index for each region (Table A1c) is calculated in the same method as ARCII but is based on worldwide normalization, i.e., normalizing raw indicator values using global minimum and maximum values.

(iv) In the Money and Finance dimension, there was a substantial decrease in the weight of Indicator II-d (Pair-wise correlation of equity returns averaged regionally minus that averaged globally).

(v) Remittance data used in Indicator V-c (Proportion of intraregional remittances to total remittances) was changed to outward remittances.

Sources: ADB. Asia Regional Integration Center. Asia-Pacific Regional Cooperation and Integration Index Database. https:// aric.adb.org/database/arcii (accessed October 2019); methodology from C. Y. Park and R. Claveria. 2018. Constructing the Asia-Pacific Regional Integration Index: A Panel Approach. ADB Economics Working Papers. No. 544. Manila: ADB; H. Huh and C. Y. Park. 2018. Asia-Pacific Regional Integration Index: Construction, Interpretation, and Comparison. Journal of Asian Economics. 54. pp. 22-38; and H. Huh and C. Y. Park. 2017. Asia-Pacific Regional Integration Index: Construction, Interpretation, and Comparison. ADB Economics Working Papers. No. 511. Manila: ADB. 
Table A2: Regional Integration Indicators-Asia and the Pacific (\% of total)

\begin{tabular}{|c|c|c|c|c|c|c|c|c|c|c|c|c|c|c|}
\hline & \multicolumn{4}{|c|}{$\begin{array}{l}\text { Movement in Trade } \\
\text { and Investment }\end{array}$} & \multicolumn{4}{|c|}{ Movement in Capital } & \multicolumn{6}{|c|}{ People Movement } \\
\hline & \multicolumn{2}{|c|}{$\begin{array}{l}\text { Trade } \\
(\%)\end{array}$} & \multicolumn{2}{|c|}{$\begin{array}{l}\text { FDI } \\
(\%)\end{array}$} & \multicolumn{2}{|c|}{$\begin{array}{l}\text { Equity } \\
\text { Holdings } \\
(\%)\end{array}$} & \multicolumn{2}{|c|}{$\begin{array}{c}\text { Bond } \\
\text { Holdings } \\
(\%)\end{array}$} & \multicolumn{2}{|c|}{$\begin{array}{l}\text { Migration } \\
(\%) \\
\end{array}$} & \multicolumn{2}{|c|}{$\begin{array}{l}\text { Tourism } \\
(\%)\end{array}$} & \multicolumn{2}{|c|}{$\begin{array}{c}\text { Remittances } \\
(\%)\end{array}$} \\
\hline & \multicolumn{2}{|c|}{2020} & \multicolumn{2}{|c|}{2020} & \multicolumn{2}{|c|}{2020} & \multicolumn{2}{|c|}{2020} & \multicolumn{2}{|c|}{2020} & \multicolumn{2}{|c|}{2018} & \multicolumn{2}{|c|}{2019} \\
\hline \multicolumn{15}{|l|}{ Within Subregions } \\
\hline ASEAN+3 (including HKG)a & 46.7 & $\boldsymbol{\Delta}$ & 51.8 & $\nabla$ & 19.0 & $\Delta$ & 13.3 & $\boldsymbol{\Delta}$ & 36.8 & $\boldsymbol{\nabla}$ & 72.8 & $\boldsymbol{\nabla}$ & 30.2 & $\nabla$ \\
\hline Central Asia & 8.8 & $\Delta$ & 2.4 & $\Delta$ & 0.0 & $\nabla$ & 0.1 & $\Delta$ & 8.8 & $\nabla$ & 60.7 & $\Delta$ & 6.2 & $\nabla$ \\
\hline East Asia & 35.9 & $\boldsymbol{\Delta}$ & 51.1 & $\nabla$ & 15.6 & $\boldsymbol{\Delta}$ & 9.2 & $\Delta$ & 33.6 & $\Delta$ & 54.9 & $\nabla$ & 32.5 & $\nabla$ \\
\hline South Asia & 5.8 & $\Delta$ & 0.3 & $\nabla$ & 0.5 & $\Delta$ & 0.0 & - & 19.5 & $\nabla$ & 13.5 & $\boldsymbol{\nabla}$ & 7.1 & $\nabla$ \\
\hline Southeast Asia & 21.1 & $\nabla$ & 27.4 & $\Delta$ & 5.9 & $\nabla$ & 6.9 & $\Delta$ & 30.1 & $\boldsymbol{\nabla}$ & 51.8 & $\boldsymbol{\nabla}$ & 12.7 & $\nabla$ \\
\hline Oceania and the Pacific & 5.5 & $\nabla$ & 13.3 & $\Delta$ & 4.6 & $\Delta$ & 4.1 & $\Delta$ & 53.8 & $\nabla$ & 19.8 & $\nabla$ & 36.6 & $\Delta$ \\
\hline \multicolumn{15}{|l|}{ Across Subregions } \\
\hline ASEAN+3 (including HKG)a & 11.7 & $\boldsymbol{\Delta}$ & 3.5 & $\nabla$ & 3.0 & $\nabla$ & 5.7 & $\Delta$ & 13.2 & $\boldsymbol{\Delta}$ & 5.1 & $\boldsymbol{\nabla}$ & 8.7 & $\boldsymbol{\Delta}$ \\
\hline Central Asia & 28.0 & $\Delta$ & 38.9 & $\Delta$ & 7.5 & $\nabla$ & 16.0 & $\boldsymbol{\nabla}$ & 0.7 & $\Delta$ & 1.9 & $\nabla$ & 0.2 & $\nabla$ \\
\hline East Asia & 20.9 & $\nabla$ & 8.1 & $\nabla$ & 2.5 & $\nabla$ & 7.6 & $\Delta$ & 16.2 & $\boldsymbol{\Delta}$ & 18.8 & $\Delta$ & 14.7 & $\nabla$ \\
\hline South Asia & 34.7 & $\Delta$ & 34.0 & $\nabla$ & 18.3 & $\nabla$ & 5.7 & $\boldsymbol{\Delta}$ & 7.5 & $\boldsymbol{\Delta}$ & 28.3 & $\boldsymbol{\nabla}$ & 8.0 & $\boldsymbol{\Delta}$ \\
\hline Southeast Asia & 47.9 & $\boldsymbol{\Delta}$ & 17.3 & $\nabla$ & 33.5 & $\Delta$ & 23.2 & $\Delta$ & 20.2 & $\boldsymbol{\Delta}$ & 40.0 & $\boldsymbol{\Delta}$ & 17.5 & $\boldsymbol{\Delta}$ \\
\hline Oceania and the Pacific & 67.1 & $\Delta$ & 85.4 & $\Delta$ & 13.1 & $\Delta$ & 14.8 & $\boldsymbol{\nabla}$ & 4.6 & $\boldsymbol{\nabla}$ & 38.4 & $\nabla$ & 7.2 & $\nabla$ \\
\hline \multicolumn{15}{|c|}{ TOTAL (within and across subregions) } \\
\hline Asia and the Pacific & 58.5 & $\Delta$ & 53.7 & $\nabla$ & 21.4 & $\Delta$ & 18.9 & $\Delta$ & 35.2 & $\nabla$ & 73.9 & $\nabla$ & 26.9 & $\nabla$ \\
\hline ASEAN+3 (including HKG) ${ }^{a}$ & 58.4 & $\Delta$ & 55.2 & $\nabla$ & 22.0 & $\Delta$ & 19.0 & $\Delta$ & 50.0 & $\boldsymbol{\Delta}$ & 77.9 & $\nabla$ & 38.9 & $\nabla$ \\
\hline Central Asia & 36.8 & $\Delta$ & 41.3 & $\Delta$ & 7.5 & $\nabla$ & 16.0 & $\nabla$ & 9.5 & $\nabla$ & 62.7 & $\Delta$ & 6.5 & $\nabla$ \\
\hline East Asia & 56.8 & $\boldsymbol{\Delta}$ & 59.2 & $\nabla$ & 18.1 & $\Delta$ & 16.9 & $\boldsymbol{\Delta}$ & 49.8 & $\boldsymbol{\Delta}$ & 73.8 & $\boldsymbol{\nabla}$ & 47.2 & $\nabla$ \\
\hline South Asia & 40.5 & $\Delta$ & 34.4 & $\nabla$ & 18.8 & $\nabla$ & 5.7 & $\Delta$ & 27.0 & $\nabla$ & 41.9 & $\nabla$ & 15.1 & $\boldsymbol{\Delta}$ \\
\hline Southeast Asia & 69.0 & $\boldsymbol{\Delta}$ & 44.7 & $\Delta$ & 39.5 & $\boldsymbol{\Delta}$ & 30.1 & $\Delta$ & 50.2 & $\boldsymbol{\Delta}$ & 91.7 & $\boldsymbol{\nabla}$ & 30.2 & $\nabla$ \\
\hline Oceania and the Pacific & 72.6 & $\Delta$ & 98.8 & $\Delta$ & 17.7 & $\Delta$ & 18.8 & $\boldsymbol{\nabla}$ & 58.4 & $\boldsymbol{\nabla}$ & 58.1 & $\boldsymbol{\nabla}$ & 43.8 & $\boldsymbol{\Delta}$ \\
\hline \multicolumn{15}{|l|}{ With the rest of the world } \\
\hline Asia and the Pacific & 41.5 & $\nabla$ & 46.3 & $\Delta$ & 78.6 & $\nabla$ & 81.1 & $\nabla$ & 64.8 & $\Delta$ & 26.1 & $\Delta$ & 73.1 & $\Delta$ \\
\hline ASEAN+3 (including HKG) ${ }^{a}$ & 41.6 & $\nabla$ & 44.8 & $\Delta$ & 78.0 & $\boldsymbol{\nabla}$ & 81.0 & $\boldsymbol{\nabla}$ & 50.0 & $\boldsymbol{\nabla}$ & 22.1 & $\Delta$ & 61.1 & $\boldsymbol{\Delta}$ \\
\hline Central Asia & 63.2 & $\nabla$ & 58.7 & $\nabla$ & 92.5 & $\boldsymbol{\Delta}$ & 84.0 & $\Delta$ & 90.5 & $\Delta$ & 37.3 & $\nabla$ & 93.5 & $\Delta$ \\
\hline East Asia & 43.2 & $\nabla$ & 40.8 & $\Delta$ & 81.9 & $\nabla$ & 83.1 & $\boldsymbol{\nabla}$ & 50.2 & $\nabla$ & 26.2 & $\Delta$ & 52.8 & $\boldsymbol{\Delta}$ \\
\hline South Asia & 59.5 & $\nabla$ & 65.6 & $\Delta$ & 81.2 & $\Delta$ & 94.3 & $\nabla$ & 73.0 & $\Delta$ & 58.1 & $\Delta$ & 84.9 & $\nabla$ \\
\hline Southeast Asia & 31.0 & $\nabla$ & 55.3 & $\nabla$ & 60.5 & $\nabla$ & 69.9 & $\boldsymbol{\nabla}$ & 49.8 & $\nabla$ & 8.3 & $\Delta$ & 69.8 & $\boldsymbol{\Delta}$ \\
\hline Oceania and the Pacific & 27.4 & $\nabla$ & 1.2 & $\nabla$ & 82.3 & $\nabla$ & 81.2 & $\Delta$ & 41.6 & $\Delta$ & 41.9 & $\Delta$ & 56.2 & $\nabla$ \\
\hline
\end{tabular}

- = unchanged from previous period; $\boldsymbol{\Delta}=$ increase from previous period; $\boldsymbol{\nabla}=$ decrease from previous period.

ASEAN = Association of Southeast Asian Nations; FDI = foreign direct investment; HKG = Hong Kong, China.

a Includes ASEAN (Brunei Darussalam, Cambodia, Indonesia, the Lao People's Democratic Republic, Malaysia, Myanmar, the Philippines, Singapore, Thailand, and Viet Nam) plus Hong Kong, China; Japan; the People's Republic of China; and the Republic of Korea.

Trade - no data available on the Cook Islands and Niue.

Equity and Bond Holdings—based on investment from Australia; Bangladesh; Hong Kong, China; India; Indonesia; Japan; Kazakhstan; Malaysia; Mongolia; New Zealand; Pakistan; Palau; the People's Republic of China; the Philippines; the Republic of Korea; Singapore; and Thailand.

Migration - share of migrant stock to total migrants in 2020 (compared with 2015).

Tourism - share of outbound tourists to total tourists in 2018 (compared with 2017).

Remittances - share of inward remittances to total remittances in 2019 (compared with 2018).

Sources: ADB calculations using data from ASEAN Secretariat. ASEANstats Database. https://www.aseanstats.org (accessed July 2021); CEIC Data Company; Eurostat. Balance of Payments. http://ec.europa.eu/eurostat/web/balance-of-payments/data/database (accessed July 2021); Global Knowledge Partnership for Migration and Development. Bilateral Remittance staff estimates (May 2020); International Monetary Fund (IMF). Coordinated Portfolio Investment Survey. https://data.imf.org/CPIS (accessed September 2021); IMF. Direction of Trade Statistics. https://data.imf.org/DOT (accessed January 2022); United Nations Department of Economic and Social Affairs, Population Division. International Migrant Stock 2020. http://www.un.org/en/development/desa/population/migration/data/index.shtml (accessed May 2021); United Nations Conference on Trade and Development. World Investment Report. https://unctad.org/topic/investment/world-investment-report (accessed July 2021); United Nations World Tourism Organization. Tourism Satellite Accounts. http://statistics.unwto.org (accessed April 2021). 
Table A3: Trade Shares in 2020-Asia and the Pacific (\% of total trade)

\begin{tabular}{|c|c|c|c|c|c|c|}
\hline \multirow[b]{3}{*}{ Reporter } & \multicolumn{6}{|c|}{ Partner } \\
\hline & \multirow[b]{2}{*}{ Asia } & \multicolumn{2}{|c|}{ of which } & \multirow[b]{2}{*}{ EU+UK } & \multirow[b]{2}{*}{ US } & \multirow[b]{2}{*}{ ROW } \\
\hline & & PRC & Japan & & & \\
\hline Central Asia & 36.8 & 17.3 & 1.1 & 24.4 & 2.0 & 36.9 \\
\hline Armenia & 21.4 & 13.5 & 0.7 & 18.6 & 2.1 & 57.9 \\
\hline Azerbaijan & 19.1 & 7.5 & 0.8 & 38.2 & 2.7 & 40.1 \\
\hline Georgia & 31.1 & 10.4 & 1.6 & 23.2 & 5.6 & 40.2 \\
\hline Kazakhstan & 37.4 & 18.0 & 1.4 & 28.8 & 2.0 & 31.9 \\
\hline Kyrgyz Republic & 38.0 & 13.8 & 0.4 & 23.2 & 2.2 & 36.7 \\
\hline Tajikistan & 51.1 & 11.9 & 1.2 & 7.3 & 1.0 & 40.6 \\
\hline Turkmenistan & 65.0 & 49.8 & 1.2 & 9.3 & 0.5 & 25.3 \\
\hline Uzbekistan & 43.4 & 17.4 & 0.6 & 11.1 & 0.7 & 44.9 \\
\hline East Asia & 56.8 & 15.5 & 5.8 & 13.1 & 12.1 & 18.1 \\
\hline China, People's Republic of & 47.4 & & 6.8 & 16.0 & 12.6 & 24.0 \\
\hline Hong Kong, China & 79.0 & 49.4 & 4.2 & 8.0 & 5.6 & 7.5 \\
\hline Japan & 58.8 & 24.0 & & 11.6 & 15.0 & 14.6 \\
\hline Korea, Republic of & 59.3 & 24.6 & 7.3 & 11.4 & 13.5 & 15.8 \\
\hline Mongolia & 66.3 & 57.0 & 3.2 & 5.4 & 2.0 & 26.3 \\
\hline Taipei,China & 74.0 & 33.6 & 9.1 & 7.9 & 11.7 & 6.4 \\
\hline South Asia & 40.5 & 13.1 & 2.3 & 14.3 & 11.0 & 34.2 \\
\hline Afghanistan & 73.3 & 14.2 & 2.5 & 2.5 & 0.7 & 23.5 \\
\hline Bangladesh & 42.1 & 14.8 & 3.3 & 23.2 & 8.0 & 26.6 \\
\hline Bhutan & 96.5 & 0.7 & 0.2 & 2.0 & 0.1 & 1.3 \\
\hline India & 38.5 & 12.1 & 2.2 & 13.1 & 11.8 & 36.6 \\
\hline Maldives & 63.6 & 13.4 & 1.1 & 10.2 & 2.3 & 23.9 \\
\hline Nepal & 85.6 & 13.9 & 0.7 & 2.4 & 1.8 & 10.3 \\
\hline Pakistan & 40.2 & 21.1 & 1.9 & 17.7 & 9.9 & 32.2 \\
\hline Sri Lanka & 49.8 & 14.3 & 2.7 & 18.3 & 11.8 & 20.1 \\
\hline Southeast Asia & 69.0 & 19.8 & 7.8 & 9.5 & 11.7 & 9.8 \\
\hline Brunei Darussalam & 81.7 & 14.3 & 15.3 & 6.1 & 3.0 & 9.2 \\
\hline Cambodia & 65.3 & 21.8 & 4.6 & 12.7 & 14.9 & 7.1 \\
\hline Indonesia & 70.0 & 23.2 & 7.9 & 8.3 & 8.9 & 12.9 \\
\hline Lao People's Democratic Republic & 92.4 & 28.3 & 2.1 & 4.1 & 1.0 & 2.6 \\
\hline Malaysia & 72.0 & 18.5 & 6.9 & 9.0 & 10.1 & 9.0 \\
\hline Myanmar & 81.7 & 34.4 & 5.2 & 11.5 & 2.6 & 4.2 \\
\hline Philippines & 75.0 & 19.4 & 12.1 & 8.8 & 10.9 & 5.3 \\
\hline Singapore & 69.7 & 14.4 & 5.2 & 10.9 & 10.8 & 8.5 \\
\hline Thailand & 66.5 & 18.3 & 11.6 & 8.7 & 11.2 & 13.6 \\
\hline Timor-Leste & 69.5 & 11.9 & 1.5 & 1.6 & 1.2 & 27.7 \\
\hline Viet Nam & 64.1 & 24.6 & 7.3 & 10.1 & 16.8 & 9.0 \\
\hline Oceania and the Pacific & 72.6 & 32.7 & 8.8 & 12.3 & 8.2 & 6.9 \\
\hline Australia & 73.3 & 34.7 & 9.4 & 12.3 & 8.2 & 6.2 \\
\hline Cook Islands & - & - & - & - & - & - \\
\hline Fiji & 81.3 & 16.0 & 3.0 & 5.3 & 9.5 & 3.8 \\
\hline Kiribati & 44.6 & 6.5 & 2.7 & 2.2 & 0.9 & 52.3 \\
\hline Marshall Islands & 78.9 & 25.1 & 9.6 & 16.4 & 1.3 & 3.4 \\
\hline Micronesia, Federated States of & 38.8 & 4.8 & 5.2 & 0.3 & 19.4 & 41.5 \\
\hline Nauru & 92.0 & 1.1 & 2.7 & 0.9 & 2.4 & 4.7 \\
\hline Nive & - & - & - & - & - & - \\
\hline New Zealand & 65.4 & 25.3 & 5.8 & 12.8 & 10.3 & 11.5 \\
\hline Palau & 35.1 & 18.7 & 8.0 & 5.1 & 28.0 & 31.7 \\
\hline Papua New Guinea & 88.0 & 18.3 & 9.2 & 8.0 & 1.2 & 2.7 \\
\hline Samoa & 61.5 & 10.6 & 3.6 & 0.5 & 4.9 & 33.1 \\
\hline Solomon Islands & 86.6 & 45.9 & 1.9 & 8.9 & 0.9 & 3.6 \\
\hline Tonga & 82.2 & 4.7 & 8.3 & 0.4 & 13.3 & 4.0 \\
\hline Tuvalu & 75.9 & 1.6 & 9.2 & 1.5 & 7.5 & 15.1 \\
\hline Vanuatu & 58.2 & 8.6 & 1.4 & 3.4 & 3.3 & 35.2 \\
\hline Asia and the Pacific & 58.5 & 17.0 & 6.0 & 12.6 & 11.6 & 17.3 \\
\hline Developing Asia & 57.9 & 15.5 & 6.5 & 12.7 & 11.4 & 18.0 \\
\hline
\end{tabular}

- = unavailable, EU = European Union, PRC = People's Republic of China, ROW = rest of the world, UK = United Kingdom, US = United States.

Source: ADB calculations using data from International Monetary Fund. Direction of Trade Statistics. https://data.imf.org/DOT (accessed January 2022). 
Table A4: Free Trade Agreement Status-Asia and the Pacific

\begin{tabular}{|c|c|c|c|c|c|}
\hline \multirow[b]{2}{*}{ Economy } & \multicolumn{2}{|c|}{ Under Negotiation } & \multirow{2}{*}{$\begin{array}{l}\text { Signed but } \\
\text { Not Yet } \\
\text { in Effect }\end{array}$} & \multirow[b]{2}{*}{$\begin{array}{l}\text { Signed and } \\
\text { in Effect }\end{array}$} & \multirow[b]{2}{*}{ Total } \\
\hline & $\begin{array}{c}\text { Framework } \\
\text { Agreement Signed }\end{array}$ & $\begin{array}{l}\text { Negotiations } \\
\text { Launched }\end{array}$ & & & \\
\hline Afghanistan & 0 & 0 & 0 & 2 & 2 \\
\hline Armenia & 0 & 3 & 2 & 13 & 18 \\
\hline Australia & 0 & 5 & 1 & 17 & 23 \\
\hline Azerbaijan & 0 & 1 & 0 & 10 & 11 \\
\hline Bangladesh & 0 & 2 & 2 & 3 & 7 \\
\hline Bhutan & 0 & 1 & 1 & 2 & 4 \\
\hline Brunei Darussalam & 0 & 0 & 0 & 11 & 11 \\
\hline Cambodia & 0 & 0 & 2 & 8 & 10 \\
\hline China, People's Republic of & 0 & 9 & 3 & 20 & 32 \\
\hline Cook Islands & 0 & 0 & 1 & 3 & 4 \\
\hline Fiji & 0 & 0 & 1 & 4 & 5 \\
\hline Georgia & 0 & 0 & 0 & 14 & 14 \\
\hline Hong Kong, China & 0 & 1 & 0 & 8 & 9 \\
\hline India & 1 & 14 & 0 & 15 & 30 \\
\hline Indonesia & 0 & 5 & 3 & 14 & 22 \\
\hline Japan & 0 & 6 & 0 & 20 & 26 \\
\hline Kazakhstan & 0 & 5 & 2 & 13 & 20 \\
\hline Kiribati & 0 & 0 & 1 & 3 & 4 \\
\hline Korea, Republic of & 0 & 10 & 2 & 20 & 32 \\
\hline Kyrgyz Republic & 0 & 3 & 2 & 13 & 18 \\
\hline Lao People's Democratic Republic & 0 & 0 & 0 & 0 & 0 \\
\hline Malaysia & 1 & 5 & 1 & 17 & 24 \\
\hline Maldives & 0 & 1 & 2 & 1 & 4 \\
\hline Marshall Islands & 0 & 0 & 1 & 4 & 5 \\
\hline Micronesia, Federated States of & 0 & 0 & 1 & 4 & 5 \\
\hline Mongolia & 0 & 0 & 0 & 2 & 2 \\
\hline Myanmar & 1 & 1 & 0 & 8 & 10 \\
\hline Nauru & 0 & 0 & 1 & 3 & 4 \\
\hline Nepal & 0 & 1 & 0 & 2 & 3 \\
\hline New Zealand & 0 & 6 & 1 & 13 & 20 \\
\hline Niue & 0 & 0 & 0 & 0 & 0 \\
\hline Pakistan & 1 & 6 & 1 & 9 & 17 \\
\hline Palau & 0 & 0 & 1 & 3 & 4 \\
\hline Papua New Guinea & 0 & 0 & 1 & 5 & 6 \\
\hline Philippines & 0 & 2 & 0 & 10 & 12 \\
\hline Samoa & 0 & 0 & 1 & 3 & 4 \\
\hline Singapore & 0 & 6 & 1 & 27 & 34 \\
\hline Solomon Islands & 0 & 0 & 1 & 4 & 5 \\
\hline Sri Lanka & 0 & 3 & 0 & 6 & 9 \\
\hline Taipei,China & 0 & 1 & 0 & 8 & 9 \\
\hline Tajikistan & 0 & 0 & 0 & 8 & 8 \\
\hline Thailand & 1 & 8 & 0 & 15 & 24 \\
\hline Timor-Leste & 0 & 0 & 0 & 0 & 0 \\
\hline Tonga & 0 & 0 & 1 & 3 & 4 \\
\hline Turkmenistan & 0 & 0 & 0 & 5 & 5 \\
\hline Tuvalu & 0 & 0 & 1 & 3 & 4 \\
\hline Uzbekistan & 0 & 0 & 0 & 9 & 9 \\
\hline Vanuatu & 0 & 0 & 1 & 4 & 5 \\
\hline Viet Nam & 0 & 2 & 0 & 15 & 17 \\
\hline
\end{tabular}

Notes:

(i) Framework agreement signed: The parties initially negotiate the contents of a framework agreement, which serves as a framework for future negotiations.

(ii) Negotiations launched: The parties, through the relevant ministries, declare the official launch of negotiations or set the date for such, or start the first round of negotiations.

(iii) Signed but not yet in effect: Parties sign the agreement after negotiations have been completed. However, the agreement has yet to be implemented.

(iv) Signed and in effect: Provisions of free trade agreement come into force, after legislative or executive ratification.

Source: ADB. Asia Regional Integration Center. FTA Database. https//aric.adb.org/fta (accessed February 2022). 
Table A5: Cross-Border Portfolio Equity Holdings as of December 2020-Asia and the Pacific (\% of total cross-border portfolio equity holdings)

\begin{tabular}{|c|c|c|c|c|c|c|}
\hline \multirow[b]{3}{*}{ Reporter } & \multicolumn{6}{|c|}{ Partner } \\
\hline & \multirow{2}{*}{$\begin{array}{l}\text { Asia and the } \\
\text { Pacific }\end{array}$} & \multicolumn{2}{|c|}{ of which } & \multirow[b]{2}{*}{ EU+UK } & \multirow[b]{2}{*}{ US } & \multirow[b]{2}{*}{ ROW } \\
\hline & & PRC & Japan & & & \\
\hline Central Asia & 7.5 & 0.1 & 5.5 & 21.6 & 64.6 & 6.3 \\
\hline Armenia & - & - & - & - & - & - \\
\hline Azerbaijan & - & - & - & - & - & - \\
\hline Georgia & - & - & - & - & - & - \\
\hline Kazakhstan & 7.5 & 0.1 & 5.5 & 21.6 & 64.6 & 6.3 \\
\hline Kyrgyz Republic & - & - & - & - & - & - \\
\hline Tajikistan & - & - & - & - & - & - \\
\hline Turkmenistan & - & - & - & - & - & - \\
\hline Uzbekistan & - & - & - & - & - & - \\
\hline East Asia & 18.1 & 5.7 & 1.0 & 12.8 & 25.1 & 44.0 \\
\hline China, People's Republic of & 60.2 & & 1.6 & 7.3 & 18.3 & 14.2 \\
\hline Hong Kong, China & 19.7 & 15.5 & 1.1 & 8.6 & 4.3 & 67.5 \\
\hline Japan & 5.4 & 0.7 & & 15.3 & 35.9 & 43.4 \\
\hline Korea, Republic of & 15.7 & 4.0 & 4.7 & 22.1 & 51.6 & 10.6 \\
\hline Mongolia & 58.1 & 1.0 & 0.8 & 14.4 & 18.0 & 9.5 \\
\hline Taipei,China & - & - & - & - & - & - \\
\hline South Asia & 18.8 & 12.5 & 1.1 & 32.7 & 40.2 & 8.3 \\
\hline Afghanistan & - & - & - & - & - & - \\
\hline Bangladesh & 100.0 & - & - & - & - & - \\
\hline Bhutan & - & - & - & - & - & - \\
\hline India & 19.2 & 12.9 & 1.1 & 33.6 & 41.3 & 5.9 \\
\hline Maldives & - & - & - & - & - & - \\
\hline Nepal & - & - & - & - & - & - \\
\hline Pakistan & - & - & - & 6.7 & 7.4 & 85.9 \\
\hline Sri Lanka & - & - & - & - & - & - \\
\hline Southeast Asia & 39.5 & 13.6 & 5.4 & 13.4 & 21.3 & 25.8 \\
\hline Brunei Darussalam & - & - & - & - & - & - \\
\hline Cambodia & - & - & - & - & - & - \\
\hline Indonesia & 98.9 & 0.1 & 0.7 & 0.1 & 0.0 & 1.0 \\
\hline Lao People's Democratic Republic & - & - & - & - & - & - \\
\hline Malaysia & 51.2 & 6.5 & 4.8 & 18.3 & 22.2 & 8.3 \\
\hline Myanmar & - & - & - & - & - & - \\
\hline Philippines & 23.1 & 0.0 & 4.8 & 49.5 & 22.8 & 4.5 \\
\hline Singapore & 38.7 & 15.5 & 5.9 & 11.4 & 21.4 & 28.4 \\
\hline Thailand & 19.1 & 0.4 & 0.6 & 35.4 & 20.9 & 24.6 \\
\hline Timor-Leste & - & - & - & - & - & - \\
\hline Viet Nam & - & - & - & - & - & - \\
\hline Oceania and the Pacific & 17.7 & 2.0 & 4.8 & 14.8 & 47.7 & 19.8 \\
\hline Australia & 15.5 & 2.1 & 4.9 & 15.4 & 48.5 & 20.6 \\
\hline Cook Islands & - & - & - & - & - & - \\
\hline Fiji & - & - & - & - & - & - \\
\hline Kiribati & - & - & - & - & - & - \\
\hline Marshall Islands & - & - & - & - & - & - \\
\hline Micronesia, Federated States of & - & - & - & - & - & - \\
\hline Nauru & - & - & - & - & - & - \\
\hline New Zealand & 33.8 & 0.9 & 3.8 & 10.1 & 41.8 & 14.3 \\
\hline Niue & - & - & - & - & - & - \\
\hline Palau & - & - & - & - & - & - \\
\hline Papua New Guinea & - & - & - & - & - & - \\
\hline Samoa & - & - & - & - & - & - \\
\hline Solomon Islands & - & - & - & - & - & - \\
\hline Tonga & - & - & - & - & - & - \\
\hline Tuvalu & - & - & - & - & - & - \\
\hline Vanuatu & - & - & - & - & - & - \\
\hline Asia and the Pacific & 21.4 & 6.5 & 2.2 & 13.2 & 27.4 & 38.1 \\
\hline Developing Asia & 31.5 & 10.8 & 2.9 & 11.5 & 17.9 & 39.0 \\
\hline
\end{tabular}

- = unavailable, EU = European Union, PRC = People's Republic of China, ROW = rest of the world, UK = United Kingdom, US = United States.

Source: ADB calculations using data from International Monetary Fund. Coordinated Portfolio Investment Survey. https://data.imf.org/CPIS (accessed September 2021). 
Table A6: Cross-Border Portfolio Debt Holdings as of December 2020-Asia and the Pacific (\% of total cross-border portfolio debt holdings)

\begin{tabular}{|c|c|c|c|c|c|c|}
\hline \multirow[b]{3}{*}{ Reporter } & \multicolumn{6}{|c|}{ Partner } \\
\hline & \multirow{2}{*}{$\begin{array}{l}\text { Asia and the } \\
\text { Pacific }\end{array}$} & \multicolumn{2}{|c|}{ of which } & \multirow[b]{2}{*}{ EU+UK } & \multirow[b]{2}{*}{ US } & \multirow[b]{2}{*}{ ROW } \\
\hline & & PRC & Japan & & & \\
\hline Central Asia & 16.0 & 3.0 & 5.7 & 19.0 & 45.3 & 19.6 \\
\hline Armenia & - & - & - & - & - & - \\
\hline Azerbaijan & - & - & - & - & - & - \\
\hline Georgia & - & - & - & - & - & - \\
\hline Kazakhstan & 16.0 & 3.0 & 5.7 & 19.0 & 45.3 & 19.6 \\
\hline Kyrgyz Republic & - & - & - & - & - & - \\
\hline Tajikistan & - & - & - & - & - & - \\
\hline Turkmenistan & - & - & - & - & - & - \\
\hline Uzbekistan & - & - & - & - & - & - \\
\hline East Asia & 16.9 & 4.9 & 1.6 & 27.4 & 38.9 & 16.8 \\
\hline China, People's Republic of & 30.4 & & 2.2 & 11.4 & 22.9 & 35.4 \\
\hline Hong Kong, China & 45.3 & 24.4 & 7.5 & 16.2 & 22.1 & 16.4 \\
\hline Japan & 8.7 & 0.7 & & 32.0 & 44.3 & 15.0 \\
\hline Korea, Republic of & 14.2 & 2.3 & 3.0 & 24.7 & 43.6 & 17.4 \\
\hline Mongolia & 50.2 & 14.3 & - & 7.5 & 12.8 & 29.5 \\
\hline Taipei,China & - & - & - & - & - & - \\
\hline South Asia & 5.7 & - & - & 45.9 & 44.1 & 4.2 \\
\hline Afghanistan & - & - & - & - & - & - \\
\hline Bangladesh & - & - & - & - & - & - \\
\hline Bhutan & - & - & - & - & - & - \\
\hline India & 5.6 & - & - & 47.7 & 45.9 & 0.7 \\
\hline Maldives & - & - & - & - & - & - \\
\hline Nepal & - & - & - & - & - & - \\
\hline Pakistan & 8.1 & - & - & - & - & 91.9 \\
\hline Sri Lanka & - & - & - & - & - & - \\
\hline Southeast Asia & 30.1 & 8.7 & 0.6 & 9.1 & 31.4 & 29.5 \\
\hline Brunei Darussalam & - & - & - & - & - & - \\
\hline Cambodia & - & - & - & - & - & - \\
\hline Indonesia & 68.2 & 2.1 & 0.3 & 1.8 & 6.7 & 23.3 \\
\hline Lao People's Democratic Republic & - & - & - & - & - & - \\
\hline Malaysia & 40.4 & 5.8 & 2.5 & 15.4 & 15.2 & 29.1 \\
\hline Myanmar & - & - & - & - & - & - \\
\hline Philippines & 34.2 & 3.9 & 0.6 & 8.0 & 35.5 & 22.4 \\
\hline Singapore & 28.0 & 9.2 & - & 9.1 & 33.2 & 29.7 \\
\hline Thailand & 53.6 & 3.0 & 14.5 & 8.2 & 7.3 & 30.9 \\
\hline Timor-Leste & - & - & - & - & - & - \\
\hline Viet Nam & - & - & - & - & - & - \\
\hline Oceania and the Pacific & 18.8 & 1.5 & 6.8 & 27.7 & 26.2 & 27.2 \\
\hline Australia & 18.1 & 1.7 & 6.6 & 29.9 & 29.9 & 22.1 \\
\hline Cook Islands & - & - & - & - & - & - \\
\hline Fiji & - & - & - & - & - & - \\
\hline Kiribati & - & - & - & - & - & - \\
\hline Marshall Islands & - & - & - & - & - & - \\
\hline Micronesia, Federated States of & - & - & - & - & - & - \\
\hline Nauru & - & - & - & - & - & - \\
\hline New Zealand & 24.1 & - & 8.2 & 12.6 & - & 63.3 \\
\hline Niue & - & - & - & - & - & - \\
\hline Palau & - & - & - & - & 100.0 & - \\
\hline Papua New Guinea & - & - & - & - & - & - \\
\hline Samoa & - & - & - & - & - & - \\
\hline Solomon Islands & - & - & - & - & - & - \\
\hline Tonga & - & - & - & - & - & - \\
\hline Tuvalu & - & - & - & - & - & - \\
\hline Vanuatu & - & - & - & - & - & - \\
\hline Asia and the Pacific & 18.9 & 5.2 & 1.9 & 24.7 & 37.0 & 19.4 \\
\hline Developing Asia & 33.2 & 12.0 & 3.6 & 13.9 & 28.8 & 24.1 \\
\hline
\end{tabular}

- = unavailable, EU = European Union, PRC = People's Republic of China, ROW = rest of the world, UK = United Kingdom, US = United States.

Source: ADB calculations using data from International Monetary Fund. Coordinated Portfolio Investment Survey. https://data.imf.org/CPIS (accessed September 2021). 
Table A7: Foreign Direct Investment Inflow Share in 2020-Asia and the Pacific (\% of total FDI inflows)

\begin{tabular}{|c|c|c|c|c|c|c|}
\hline \multirow[b]{3}{*}{ Reporter } & \multicolumn{6}{|c|}{ Partner } \\
\hline & \multirow{2}{*}{$\begin{array}{l}\text { Asia and the } \\
\text { Pacific }\end{array}$} & \multicolumn{2}{|c|}{ of which } & \multirow[b]{2}{*}{ EU+UK } & \multirow[b]{2}{*}{ US } & \multirow[b]{2}{*}{ ROW } \\
\hline & & PRC & Japan & & & \\
\hline Central Asia & 41.3 & 14.6 & 8.4 & 152.3 & 37.1 & $(130.8)$ \\
\hline Armenia & 11.6 & 8.6 & 0.0 & $(2.3)$ & $(6.0)$ & 96.8 \\
\hline Azerbaijan & 153.6 & 1.5 & 67.8 & 414.1 & 93.7 & $(561.4)$ \\
\hline Georgia & $(4.1)$ & $(5.8)$ & 1.1 & 105.0 & 16.0 & (16.9) \\
\hline Kazakhstan & 53.6 & 24.7 & 7.5 & 223.8 & 57.8 & $(235.2)$ \\
\hline Kyrgyz Republic & $(54.4)$ & $(41.2)$ & $(0.2)$ & $(30.5)$ & $(1.9)$ & 186.8 \\
\hline Tajikistan & 39.5 & 15.2 & 0.0 & 62.4 & 15.7 & $(17.7)$ \\
\hline Turkmenistan & 3.4 & 1.5 & 0.0 & 12.0 & 2.7 & 81.9 \\
\hline Uzbekistan & 6.5 & 1.3 & 0.6 & 7.8 & 1.8 & 83.9 \\
\hline East Asia & 59.2 & 7.1 & 3.1 & 18.0 & 11.8 & 11.0 \\
\hline China, People's Republic of & 82.4 & & 2.3 & 4.5 & 1.5 & 11.6 \\
\hline Hong Kong, China & 31.6 & 14.4 & 3.8 & 9.1 & 5.5 & 53.8 \\
\hline Japan & 82.3 & 13.2 & & 323.4 & 205.4 & $(511.1)$ \\
\hline Korea, Republic of & 46.0 & 16.9 & 7.9 & 26.8 & 57.5 & $(30.3)$ \\
\hline Mongolia & 31.6 & 20.7 & 2.8 & 9.7 & 2.8 & 55.9 \\
\hline Taipei,China & 29.6 & 7.1 & 6.2 & 3.2 & 1.7 & 65.5 \\
\hline South Asia & 34.4 & 2.0 & 2.3 & 22.0 & 21.2 & 22.4 \\
\hline Afghanistan & 61.5 & 29.4 & 0.0 & 129.1 & 30.2 & $(120.9)$ \\
\hline Bangladesh & 34.6 & 3.6 & 1.4 & 37.1 & 11.6 & 16.8 \\
\hline Bhutan & 591.6 & 0.0 & 0.0 & 112.4 & 0.0 & $(604.0)$ \\
\hline India & 33.1 & 0.2 & 2.3 & 20.8 & 22.2 & 23.9 \\
\hline Maldives & 16.3 & 5.7 & 1.9 & 26.3 & 8.5 & 48.9 \\
\hline Nepal & 37.4 & 15.7 & 7.0 & 7.7 & 10.7 & 44.3 \\
\hline Pakistan & 71.3 & 53.4 & 2.8 & 37.1 & 6.0 & $(14.3)$ \\
\hline Sri Lanka & 47.6 & 7.3 & 5.4 & 41.0 & 9.4 & 2.0 \\
\hline Southeast Asia & 44.7 & 3.5 & 3.3 & 7.1 & 3.3 & 45.0 \\
\hline Brunei Darussalam & 16.7 & 1.9 & 1.7 & 5.4 & 1.7 & 76.2 \\
\hline Cambodia & 5.1 & 0.5 & 0.4 & 1.6 & 0.4 & 92.9 \\
\hline Indonesia & 89.4 & 4.4 & 11.2 & $(4.9)$ & 3.3 & 12.2 \\
\hline Lao People's Democratic Republic & 6.7 & 1.2 & 0.6 & 1.9 & 0.6 & 90.8 \\
\hline Malaysia & 235.6 & 11.2 & 4.8 & 24.1 & 5.9 & $(165.6)$ \\
\hline Myanmar & 18.3 & 3.2 & 1.6 & 7.0 & 1.9 & 72.7 \\
\hline Philippines & 14.5 & 0.8 & 10.7 & 4.9 & 2.5 & 78.1 \\
\hline Singapore & 36.8 & 3.6 & 1.6 & 9.7 & 3.6 & 49.8 \\
\hline Thailand & $(6.6)$ & $(0.9)$ & $(0.6)$ & $(2.5)$ & $(0.7)$ & 109.7 \\
\hline Timor-Leste & 0.0 & 0.0 & 0.0 & 1.3 & 0.0 & 98.7 \\
\hline Viet Nam & 3.2 & 0.7 & 0.3 & 1.1 & 0.3 & 95.5 \\
\hline Oceania and the Pacific & 98.8 & 5.6 & 60.6 & 43.1 & $(34.6)$ & (7.3) \\
\hline Australia & 97.2 & 5.5 & 70.3 & 44.7 & $(41.2)$ & $(0.6)$ \\
\hline Cook Islands & - & - & - & - & - & 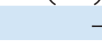 \\
\hline Fiji & 22.4 & 2.2 & 2.8 & 8.2 & 11.1 & 58.3 \\
\hline Kiribati & - & - & - & - & - & - \\
\hline Marshall Islands & - & - & - & - & - & - \\
\hline Micronesia, Federated States of & - & - & - & - & - & - \\
\hline Nauru & - & - & - & - & - & - \\
\hline New Zealand & 69.5 & 0.4 & 1.1 & 6.0 & $(1.8)$ & 26.4 \\
\hline Niue & - & - & - & - & - & - \\
\hline Palau & 45.4 & 9.7 & 25.4 & 0.0 & 37.5 & 17.0 \\
\hline Papua New Guinea & $(23.2)$ & $(2.6)$ & $(0.3)$ & (14.1) & $(7.6)$ & 144.9 \\
\hline Samoa & - & - & - & - & - & - \\
\hline Solomon Islands & 117.9 & 19.8 & 12.4 & 103.5 & 69.7 & (191.0) \\
\hline Tonga & - & - & - & - & - & - \\
\hline Tuvalu & - & - & - & - & - & - \\
\hline Vanuatu & 179.1 & 22.0 & 27.9 & 108.7 & 0.0 & $(187.8)$ \\
\hline Asia and the Pacific & 53.7 & 5.5 & 5.7 & 18.8 & 9.2 & 18.3 \\
\hline Developing Asia & 51.3 & 5.4 & 3.2 & 11.6 & 7.3 & 29.8 \\
\hline
\end{tabular}

()$=$ negative,$-=$ unavailable, $\mathrm{EU}=$ European Union, $\mathrm{FDI}=$ foreign direct investment, $\mathrm{PRC}=$ People's Republic of China, ROW = rest of the world, UK = United Kingdom, US $=$ United States.

Sources: ADB calculations using data from ASEAN Secretariat. ASEANstats Database. https://www.aseanstats.org; CEIC Data Company; Eurostat. Balance of Payments. http://ec.europa.eu/eurostat/web/balance-of-payments/data/database; and United Nations Conference on Trade and Development. World Investment Report. https:// unctad.org/topic/investment/world-investment-report (all accessed July 2021). 
Table A8: Remittance Inflows Share in 2019-Asia and the Pacific (\% of total remittance inflows)

\begin{tabular}{|c|c|c|c|c|c|}
\hline \multirow[b]{2}{*}{ Reporter } & \multicolumn{5}{|c|}{ Partner } \\
\hline & $\begin{array}{l}\text { Asia and the } \\
\text { Pacific }\end{array}$ & Middle East & EU+UK & US & ROW \\
\hline Central Asia & 6.5 & 0.9 & 9.0 & 2.5 & 81.1 \\
\hline Armenia & 17.6 & 0.4 & 9.9 & 12.2 & 60.0 \\
\hline Azerbaijan & 14.1 & 4.2 & 4.3 & 2.3 & 75.1 \\
\hline Georgia & 12.8 & 2.1 & 20.2 & 3.9 & 61.0 \\
\hline Kazakhstan & 1.5 & 0.5 & 26.8 & 0.8 & 70.3 \\
\hline Kyrgyz Republic & 3.4 & 0.7 & 14.2 & 1.2 & 80.4 \\
\hline Tajikistan & 5.4 & 0.4 & 6.4 & 1.2 & 86.7 \\
\hline Turkmenistan & - & - & - & - & 100.0 \\
\hline Uzbekistan & - & - & - & - & 100.0 \\
\hline East Asia & 47.2 & 0.2 & 9.8 & 30.2 & 12.5 \\
\hline China, People's Republic of & 49.5 & 0.2 & 9.7 & 27.5 & 13.1 \\
\hline Hong Kong, China & 40.4 & 0.0 & 13.1 & 23.9 & 22.6 \\
\hline Japan & 22.9 & 0.3 & 17.4 & 42.9 & 16.6 \\
\hline Korea, Republic of & 41.1 & 0.0 & 5.3 & 50.6 & 3.1 \\
\hline Mongolia & 42.0 & 0.3 & 24.6 & - & 33.1 \\
\hline Taipei,China & - & - & - & - & - \\
\hline South Asia & 15.1 & 59.1 & 9.5 & 12.6 & 3.7 \\
\hline Afghanistan & 21.8 & 59.2 & 13.7 & 2.6 & 2.7 \\
\hline Bangladesh & 38.3 & 51.0 & 5.9 & 3.7 & 1.1 \\
\hline Bhutan & 83.4 & 0.0 & 4.6 & - & 12.0 \\
\hline India & 8.7 & 60.7 & 8.1 & 17.3 & 5.3 \\
\hline Maldives & 69.4 & 0.5 & 18.2 & - & 11.8 \\
\hline Nepal & 43.8 & 44.6 & 4.8 & 6.0 & 0.9 \\
\hline Pakistan & 7.6 & 67.2 & 15.8 & 8.2 & 1.1 \\
\hline Sri Lanka & 19.7 & 52.9 & 20.5 & 3.4 & 3.4 \\
\hline Southeast Asia & 30.2 & 22.6 & 10.7 & 33.3 & 3.2 \\
\hline Brunei Darussalam & - & - & - & - & - \\
\hline Cambodia & 65.6 & 0.0 & 8.3 & 23.1 & 3.0 \\
\hline Indonesia & 41.1 & 51.2 & 4.1 & 2.6 & 1.0 \\
\hline Lao People's Democratic Republic & 72.7 & 0.0 & 4.5 & 21.3 & 1.5 \\
\hline Malaysia & 87.9 & 0.0 & 4.8 & 4.6 & 2.6 \\
\hline Myanmar & 84.6 & 8.9 & 0.8 & 5.2 & 0.5 \\
\hline Philippines & 17.8 & 31.5 & 9.2 & 38.8 & 2.6 \\
\hline Singapore & - & - & - & - & - \\
\hline Thailand & 84.7 & 0.0 & 14.9 & - & 0.4 \\
\hline Timor-Leste & 32.4 & 2.1 & 25.3 & 29.3 & 10.9 \\
\hline Viet Nam & 28.5 & 0.0 & 14.9 & 53.5 & 3.2 \\
\hline Oceania and the Pacific & 43.8 & 0.7 & 28.6 & 17.0 & 9.9 \\
\hline Australia & 25.4 & 1.3 & 45.9 & 17.0 & 10.5 \\
\hline Cook Islands & - & - & - & - & - \\
\hline Fiji & 60.6 & 0.0 & 3.3 & 24.2 & 11.9 \\
\hline Kiribati & 89.4 & - & 7.6 & - & 3.0 \\
\hline Marshall Islands & 1.8 & 0.0 & 0.2 & 95.8 & 2.2 \\
\hline Micronesia, Federated States of & 2.8 & - & 0.8 & 55.2 & 41.1 \\
\hline Nauru & - & - & - & - & - \\
\hline New Zealand & 82.8 & 0.1 & 10.6 & 5.0 & 1.5 \\
\hline Niue & - & - & - & - & - \\
\hline Palau & 20.3 & - & 7.0 & - & 72.7 \\
\hline Papua New Guinea & 14.5 & 0.0 & 0.8 & - & 84.8 \\
\hline Samoa & 70.9 & 0.0 & 0.8 & 18.6 & 9.7 \\
\hline Solomon Islands & 83.4 & 0.0 & 13.3 & - & 3.3 \\
\hline Tonga & 49.8 & - & 0.7 & 31.4 & 18.1 \\
\hline Tuvalu & 55.9 & 0.0 & 1.6 & - & 42.4 \\
\hline Vanuatu & 34.5 & 0.1 & 21.9 & - & 43.5 \\
\hline Asia and the Pacific & 26.9 & 31.8 & 10.0 & 21.8 & 9.4 \\
\hline Developing Asia & 26.9 & 32.5 & 9.7 & 21.6 & 9.3 \\
\hline
\end{tabular}

- = unavailable, EU = European Union, ROW = rest of the world, UK = United Kingdom, US = United States.

Source: ADB calculations using data from Global Knowledge Partnership for Migration and Development. Bilateral Remittance staff estimates (May 2020). 
Table A9: Outbound Migration Share in 2020-Asia and the Pacific (\% of total outbound migrants)

\begin{tabular}{|c|c|c|c|c|c|c|}
\hline \multirow[b]{3}{*}{ Reporter } & \multicolumn{6}{|c|}{ Partner } \\
\hline & \multirow{2}{*}{$\begin{array}{l}\text { Asia and the } \\
\text { Pacific }\end{array}$} & \multicolumn{2}{|c|}{ of which } & \multirow[b]{2}{*}{ EU+UK } & \multirow[b]{2}{*}{ US } & \multirow[b]{2}{*}{ ROW } \\
\hline & & PRC & Japan & & & \\
\hline Central Asia & 9.5 & - & - & 16.4 & 0.8 & 73.3 \\
\hline Armenia & 18.9 & - & - & 10.3 & 4.3 & 66.4 \\
\hline Azerbaijan & 14.5 & - & - & 4.5 & 0.8 & 80.3 \\
\hline Georgia & 11.0 & - & - & 20.9 & 0.8 & 67.3 \\
\hline Kazakhstan & 1.4 & - & - & 28.8 & 0.1 & 69.7 \\
\hline Kyrgyz Republic & 3.7 & - & - & 13.4 & 0.2 & 82.7 \\
\hline Tajikistan & 6.2 & - & - & 6.2 & 0.3 & 87.2 \\
\hline Turkmenistan & 2.5 & - & - & 4.6 & 0.2 & 92.7 \\
\hline Uzbekistan & 22.5 & - & - & 3.9 & 0.7 & 72.9 \\
\hline East Asia & 49.8 & 2.5 & 8.5 & 10.8 & 31.6 & 7.8 \\
\hline China, People's Republic of & 55.2 & & 7.4 & 10.9 & 27.7 & 6.2 \\
\hline Hong Kong, China & 39.2 & 20.8 & - & 12.6 & 26.7 & 21.5 \\
\hline Japan & 24.0 & 0.7 & & 19.5 & 43.4 & 13.0 \\
\hline Korea, Republic of & 38.4 & 6.6 & 20.7 & 5.6 & 49.2 & 6.8 \\
\hline Mongolia & 42.6 & - & - & 27.6 & - & 29.8 \\
\hline Taipei,China & - & - & - & - & - & - \\
\hline South Asia & 27.0 & 0.0 & 0.2 & 9.1 & 1.4 & 62.4 \\
\hline Afghanistan & 29.0 & - & - & 10.1 & 0.5 & 60.5 \\
\hline Bangladesh & 42.2 & 0.0 & 0.2 & 6.1 & 0.3 & 51.3 \\
\hline Bhutan & 86.8 & - & - & 3.5 & - & 9.7 \\
\hline India & 18.3 & 0.0 & 0.2 & 7.9 & 2.5 & 71.3 \\
\hline Maldives & 78.8 & - & - & 13.6 & - & 7.5 \\
\hline Nepal & 58.2 & - & - & 3.0 & 0.1 & 38.7 \\
\hline Pakistan & 20.5 & 0.1 & 0.3 & 14.6 & 1.5 & 63.4 \\
\hline Sri Lanka & 22.4 & 0.2 & 1.3 & 19.1 & 0.7 & 57.8 \\
\hline Southeast Asia & 50.2 & 1.7 & 3.1 & 7.5 & 8.3 & 33.9 \\
\hline Brunei Darussalam & 75.0 & - & - & 13.5 & - & 11.5 \\
\hline Cambodia & 75.8 & - & 0.4 & 7.5 & 10.8 & 5.9 \\
\hline Indonesia & 42.7 & 0.7 & 1.2 & 3.8 & 1.1 & 52.4 \\
\hline Lao People's Democratic Republic & 80.8 & - & - & 4.4 & 13.2 & 1.6 \\
\hline Malaysia & 88.0 & 0.3 & 0.6 & 5.6 & 1.8 & 4.6 \\
\hline Myanmar & 87.5 & - & - & 0.7 & 0.5 & 11.3 \\
\hline Philippines & 17.0 & 0.9 & 4.5 & 8.8 & 15.0 & 59.2 \\
\hline Singapore & 64.7 & - & 0.9 & 20.1 & 3.7 & 11.5 \\
\hline Thailand & 86.9 & - & - & 12.9 & - & 0.2 \\
\hline Timor-Leste & 43.4 & 1.1 & 4.9 & 24.6 & 9.8 & 22.2 \\
\hline Viet Nam & 38.5 & 8.9 & 9.9 & 13.1 & 16.0 & 32.4 \\
\hline Oceania and the Pacific & 55.7 & 0.2 & 0.8 & 19.8 & 5.1 & 19.4 \\
\hline Australia & 24.7 & 0.7 & 1.9 & 45.5 & 7.1 & 22.8 \\
\hline Cook Islands & 106.5 & - & - & 0.0 & - & $(6.5)$ \\
\hline Fiji & 59.0 & - & - & 3.0 & 6.8 & 31.3 \\
\hline Kiribati & 78.2 & - & - & 4.8 & - & 17.0 \\
\hline Marshall Islands & 1.3 & - & - & 0.0 & 10.0 & 88.6 \\
\hline Micronesia, Federated States of & 2.8 & - & - & 0.6 & 11.0 & 85.6 \\
\hline Nauru & 94.1 & - & - & 0.9 & - & 4.9 \\
\hline New Zealand & 77.4 & - & 0.4 & 12.4 & 1.9 & 8.3 \\
\hline Niue & 106.8 & - & - & - & - & $(6.8)$ \\
\hline Palau & 12.1 & - & - & 7.6 & - & 80.3 \\
\hline Papua New Guinea & 45.1 & - & - & 38.7 & - & 16.2 \\
\hline Samoa & 64.0 & - & - & 0.7 & 8.4 & 26.9 \\
\hline Solomon Islands & 87.1 & - & - & 11.0 & - & 1.8 \\
\hline Tonga & 51.6 & - & - & 0.7 & 14.3 & 33.4 \\
\hline Tuvalu & 70.2 & - & - & 1.6 & - & 28.1 \\
\hline Vanuatu & 26.6 & - & - & 16.1 & - & 57.3 \\
\hline Asia and the Pacific & 35.0 & 0.8 & 2.2 & 10.0 & 7.9 & 47.0 \\
\hline Developing Asia & 34.8 & 0.9 & 2.3 & 9.7 & 7.7 & 47.8 \\
\hline
\end{tabular}

$($ ) = negative,$-=$ unavailable, EU = European Union, PRC = People's Republic of China, ROW = rest of the world, UK = United Kingdom, US = United States.

Source: ADB calculations using data from United Nations Department of Economic and Social Affairs, Population Division. International Migrant Stock 2020. http://www. un.org/en/development/desa/population/migration/data/index.shtml (accessed May 2021). 
Table A10a: Inbound Tourism Share in 2018-Asia and the Pacific (\% of total inbound tourists)

\begin{tabular}{|c|c|c|c|c|c|}
\hline \multirow[b]{3}{*}{ Destination } & \multicolumn{5}{|c|}{ Origin } \\
\hline & \multirow{2}{*}{$\begin{array}{l}\text { Asia and the } \\
\text { Pacific }\end{array}$} & \multirow{2}{*}{$\begin{array}{c}\text { of which } \\
\text { PRC }\end{array}$} & \multirow[b]{2}{*}{ EU+UK } & \multirow[b]{2}{*}{ US } & \multirow[b]{2}{*}{ ROW } \\
\hline & & & & & \\
\hline Central Asia & 68.9 & 0.6 & 3.2 & 0.7 & 27.2 \\
\hline Armenia & 14.1 & 1.6 & 27.6 & 15.7 & 42.6 \\
\hline Azerbaijan & 29.2 & 0.6 & 4.0 & 0.6 & 66.2 \\
\hline Georgia & 43.6 & 0.5 & 5.7 & 0.6 & 50.0 \\
\hline Kazakhstan & 73.9 & 0.6 & 2.5 & 0.4 & 23.3 \\
\hline Kyrgyz Republic & 90.3 & 0.4 & 0.9 & 0.2 & 8.6 \\
\hline Tajikistan & 81.7 & 0.8 & 0.9 & 0.3 & 17.0 \\
\hline Turkmenistan & - & - & - & - & - \\
\hline Uzbekistan & 89.6 & 0.6 & 1.5 & 0.2 & 8.6 \\
\hline East Asia & 80.7 & 14.6 & 2.8 & 2.6 & 13.8 \\
\hline China, People's Republic of & 77.1 & & 2.0 & 1.6 & 19.3 \\
\hline Hong Kong, China & 88.6 & 67.6 & 4.2 & 3.2 & 4.0 \\
\hline Japan & 87.2 & 26.9 & 4.9 & 4.9 & 3.0 \\
\hline Korea, Republic of & 83.8 & 31.7 & 4.2 & 6.4 & 5.6 \\
\hline Mongolia & 59.7 & 31.0 & 8.7 & 3.4 & 28.2 \\
\hline Taipei,China & 90.6 & 24.7 & 2.5 & 5.3 & 1.5 \\
\hline South Asia & 49.1 & 6.4 & 25.2 & 10.9 & 14.8 \\
\hline Afghanistan & - & - & - & - & - \\
\hline Bangladesh & - & - & - & - & - \\
\hline Bhutan & 47.6 & 10.9 & 25.4 & 16.7 & 10.4 \\
\hline India & 49.0 & 2.7 & 21.4 & 13.8 & 15.7 \\
\hline Maldives & 42.2 & 19.1 & 38.6 & 2.9 & 16.3 \\
\hline Nepal & 65.3 & 15.1 & 21.1 & 9.0 & 4.6 \\
\hline Pakistan & - & - & - & - & - \\
\hline Sri Lanka & 46.8 & 11.4 & 35.7 & 3.2 & 14.3 \\
\hline Southeast Asia & 83.2 & 22.2 & 8.5 & 3.4 & 4.9 \\
\hline Brunei Darussalam & 89.4 & 23.2 & 7.0 & 1.5 & 2.1 \\
\hline Cambodia & 80.7 & 32.7 & 11.1 & 4.1 & 4.2 \\
\hline Indonesia & 80.5 & 14.2 & 11.6 & 2.6 & 5.4 \\
\hline Lao People's Democratic Republic & 94.9 & 19.4 & 3.1 & 1.2 & 0.9 \\
\hline Malaysia & 92.1 & 11.4 & 4.0 & 1.0 & 2.9 \\
\hline Myanmar & 92.7 & 27.6 & 4.7 & 1.9 & 0.8 \\
\hline Philippines & 69.5 & 17.9 & 8.7 & 14.8 & 7.0 \\
\hline Singapore & 84.6 & 19.1 & 8.7 & 3.6 & 3.0 \\
\hline Thailand & 78.5 & 28.9 & 11.0 & 3.0 & 7.5 \\
\hline Timor-Leste & 78.7 & 12.2 & 16.4 & 3.8 & 1.2 \\
\hline Viet Nam & 82.1 & 33.4 & 7.8 & 4.6 & 5.5 \\
\hline Oceania and the Pacific & 69.1 & 13.7 & 14.7 & 8.7 & 7.4 \\
\hline Australia & 66.6 & 15.5 & 16.7 & 8.5 & 8.1 \\
\hline Cook Islands & 85.7 & 0.4 & 6.4 & 4.8 & 3.1 \\
\hline Fiji & 81.3 & 6.3 & 5.5 & 10.9 & 2.2 \\
\hline Kiribati & 55.1 & - & 8.7 & 32.6 & 3.5 \\
\hline Marshall Islands & - & - & - & - & - \\
\hline Micronesia, Federated States of & - & - & - & - & - \\
\hline Nauru & - & - & - & - & - \\
\hline New Zealand & 69.5 & 11.8 & 14.0 & 9.3 & 7.3 \\
\hline Niue & - & - & - & - & - \\
\hline Palau & 88.2 & 39.2 & 3.1 & 7.6 & 1.2 \\
\hline Papua New Guinea & 88.5 & 7.0 & 4.7 & 5.2 & 1.6 \\
\hline Samoa & 79.3 & 1.8 & 1.7 & 8.7 & 10.2 \\
\hline Solomon Islands & 86.4 & 5.9 & 5.3 & 7.4 & 0.9 \\
\hline Tonga & 81.1 & 2.3 & 3.7 & 14.4 & 0.7 \\
\hline Tuvalu & - & - & - & - & - \\
\hline Vanuatu & 84.0 & 4.3 & - & - & - \\
\hline Asia and the Pacific & 79.1 & 15.5 & 5.7 & 3.2 & 11.9 \\
\hline Developing Asia & 78.9 & 14.7 & 5.5 & 2.9 & 12.8 \\
\hline
\end{tabular}

- = unavailable, EU = European Union, PRC = People's Republic of China, ROW = rest of the world, UK = United Kingdom, US = United States.

Source: ADB calculations using data from United Nations World Tourism Organization. Tourism Satellite Accounts. http://statistics.unwto.org (accessed April 2021). 
Table A10b: Outbound Tourism Share in 2018-Asia and the Pacific (\% of total outbound tourists)

\begin{tabular}{|c|c|c|c|c|c|}
\hline \multirow[b]{3}{*}{ Origin } & \multicolumn{5}{|c|}{ Destination } \\
\hline & \multirow{2}{*}{$\begin{array}{l}\text { Asia and the } \\
\text { Pacific }\end{array}$} & \multirow{2}{*}{$\begin{array}{c}\text { of which } \\
\text { PRC }\end{array}$} & \multirow[b]{2}{*}{$\mathbf{E U}+\mathbf{U K}$} & \multirow[b]{2}{*}{ US } & \multirow[b]{2}{*}{ ROW } \\
\hline & & & & & \\
\hline Central Asia & 62.7 & 1.0 & 0.9 & 0.2 & 36.2 \\
\hline Armenia & 59.1 & 0.4 & 1.1 & 0.6 & 39.2 \\
\hline Azerbaijan & 30.6 & 0.3 & 0.8 & 0.1 & 68.5 \\
\hline Georgia & 21.7 & 0.4 & 3.8 & 0.0 & 74.5 \\
\hline Kazakhstan & 55.4 & 2.0 & 1.1 & 0.3 & 43.3 \\
\hline Kyrgyz Republic & 80.7 & 1.2 & 0.1 & 0.1 & 19.1 \\
\hline Tajikistan & 84.2 & 1.3 & 0.1 & 0.1 & 15.7 \\
\hline Turkmenistan & 40.8 & 2.1 & 0.3 & 0.1 & 58.7 \\
\hline Uzbekistan & 93.5 & 0.4 & 0.3 & 0.1 & 6.0 \\
\hline East Asia & 73.8 & 33.0 & 6.2 & 3.3 & 16.7 \\
\hline China, People's Republic of & 60.0 & & 8.4 & 2.6 & 29.0 \\
\hline Hong Kong, China & 92.1 & 84.9 & 0.5 & 0.2 & 7.2 \\
\hline Japan & 59.9 & 10.9 & 15.8 & 14.2 & 10.0 \\
\hline Korea, Republic of & 72.8 & 12.8 & 9.2 & 6.8 & 11.2 \\
\hline Mongolia & 82.9 & 74.7 & 0.1 & 0.5 & 16.5 \\
\hline Taipei,China & 84.0 & 32.3 & 4.9 & 2.5 & 8.6 \\
\hline South Asia & 41.9 & 4.0 & 7.2 & 5.3 & 45.7 \\
\hline Afghanistan & 16.4 & 1.1 & 0.7 & 0.2 & 82.8 \\
\hline Bangladesh & 81.0 & 2.8 & 0.4 & 1.0 & 17.7 \\
\hline Bhutan & 87.1 & 2.7 & 1.8 & 2.0 & 9.0 \\
\hline India & 39.3 & 3.9 & 10.7 & 7.6 & 42.4 \\
\hline Maldives & 90.6 & 2.6 & 3.5 & 0.1 & 5.7 \\
\hline Nepal & 77.3 & 22.1 & 0.6 & 4.5 & 17.7 \\
\hline Pakistan & 11.8 & 3.0 & 3.1 & 2.2 & 83.0 \\
\hline Sri Lanka & 78.2 & 5.8 & 1.3 & 1.9 & 18.5 \\
\hline Southeast Asia & 91.7 & 25.9 & 1.3 & 0.9 & 6.0 \\
\hline Brunei Darussalam & 99.6 & 0.6 & 0.0 & 0.1 & 0.3 \\
\hline Cambodia & 96.7 & 6.6 & 0.0 & 0.4 & 2.9 \\
\hline Indonesia & 80.7 & 6.1 & 1.3 & 0.9 & 17.1 \\
\hline Lao People's Democratic Republic & 99.8 & 11.8 & 0.0 & 0.1 & 0.1 \\
\hline Malaysia & 90.9 & 9.2 & 2.2 & 0.6 & 6.3 \\
\hline Myanmar & 99.7 & 93.3 & 0.0 & 0.1 & 0.2 \\
\hline Philippines & 72.1 & 15.0 & 2.5 & 3.9 & 21.5 \\
\hline Singapore & 94.8 & 5.3 & 2.0 & 0.9 & 2.3 \\
\hline Thailand & 91.7 & 7.1 & 2.2 & 0.9 & 5.2 \\
\hline Timor-Leste & 99.9 & 0.0 & 0.0 & 0.0 & 0.0 \\
\hline Viet Nam & 97.8 & 57.0 & 0.2 & 0.9 & 1.1 \\
\hline Oceania and the Pacific & 58.1 & 4.3 & 22.2 & 7.9 & 11.8 \\
\hline Australia & 53.8 & 4.4 & 25.3 & 8.0 & 12.9 \\
\hline Cook Islands & 96.0 & - & 0.1 & 0.5 & 3.4 \\
\hline Fiji & 87.2 & 4.0 & 1.4 & 6.5 & 4.9 \\
\hline Kiribati & 90.5 & 28.2 & 0.2 & 2.3 & 7.0 \\
\hline Marshall Islands & 45.8 & 9.3 & 0.7 & 2.7 & 50.8 \\
\hline Micronesia, Federated States of & 11.2 & 1.2 & 0.4 & 3.5 & 84.9 \\
\hline Nauru & 92.1 & 3.1 & 1.6 & 1.5 & 4.7 \\
\hline Niue & 93.9 & - & 0.2 & 1.3 & 4.7 \\
\hline New Zealand & 73.1 & 3.8 & 11.5 & 8.0 & 7.4 \\
\hline Palau & 18.4 & 1.3 & 0.2 & 2.5 & 78.9 \\
\hline Papua New Guinea & 99.1 & 0.9 & 0.1 & 0.4 & 0.5 \\
\hline Samoa & 97.8 & 4.2 & 0.1 & - & - \\
\hline Solomon Islands & 91.0 & 6.3 & 1.1 & 1.7 & 6.3 \\
\hline Tonga & 92.0 & 3.5 & 0.2 & 6.8 & 1.0 \\
\hline Tuvalu & 78.7 & 8.5 & 1.6 & 2.7 & 16.9 \\
\hline Vanuatu & 79.1 & 2.5 & 0.2 & 0.7 & 20.0 \\
\hline Asia and the Pacific & 73.9 & 26.0 & 5.6 & 2.9 & 17.6 \\
\hline Developing Asia & 75.6 & 27.9 & 4.2 & 2.0 & 18.3 \\
\hline
\end{tabular}

- = unavailable, EU = European Union, PRC = People's Republic of China, ROW = rest of the world, UK = United Kingdom, US = United States.

Source: ADB calculations using data from United Nations World Tourism Organization. Tourism Satellite Accounts. http://statistics.unwto.org (accessed April 2021). 


\section{Asian Economic Integration Report 2022 \\ Advancing Digital Services Trade in Asia and the Pacific}

Another year into the coronavirus disease (COVID-19) pandemic, this report describes an Asia and Pacific region that has more experience in tackling pandemic hardships, better data showing positive integration trends, and greater confidence in regional cooperation to address shared concerns. As rapid digitalization and the COVID-19 pandemic are spurring growth of digital services trade in Asia and the Pacific, the theme chapter explores how the region can capitalize on greater opportunities for digital services trade through structural reforms and international cooperation.

\section{About the Asian Development Bank}

ADB is committed to achieving a prosperous, inclusive, resilient, and sustainable Asia and the Pacific, while sustaining its efforts to eradicate extreme poverty. Established in 1966, it is owned by 68 members -49 from the region. Its main instruments for helping its developing member countries are policy dialogue, loans, equity investments, guarantees, grants, and technical assistance. 